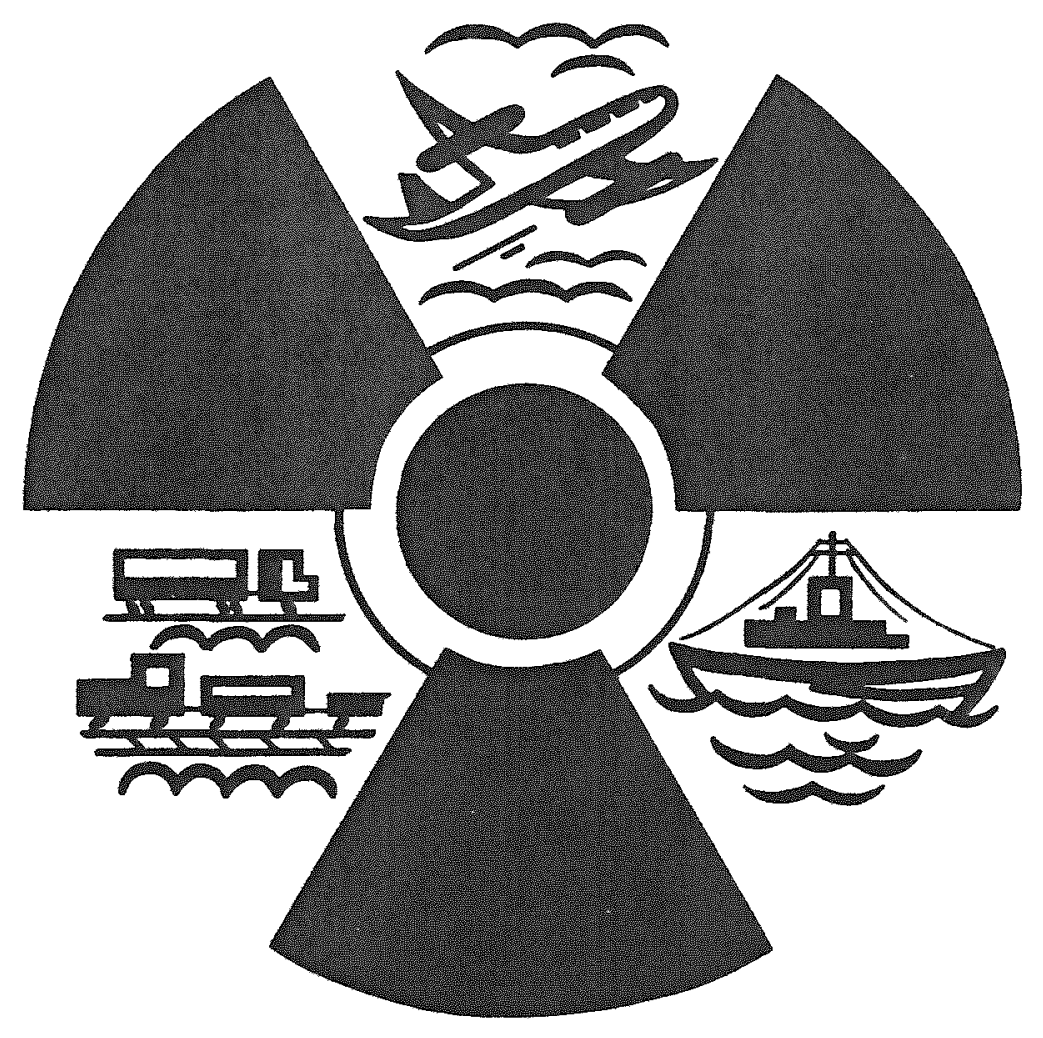

\title{
THIRD INTERNATIONAL SYMPOSIUM
}

\section{PACKAGING AND TRANSPORTATION OF RADIOACTIVE MATERIALS}

\author{
AUGUST 16-20, 1971/RICHLAND, WASHINGTON, U.S.A.
}




\section{DISCLAIMER}

This report was prepared as an account of work sponsored by an agency of the United States Government. Neither the United States Government nor any agency Thereof, nor any of their employees, makes any warranty, express or implied, or assumes any legal liability or responsibility for the accuracy, completeness, or usefulness of any information, apparatus, product, or process disclosed, or represents that its use would not infringe privately owned rights. Reference herein to any specific commercial product, process, or service by trade name, trademark, manufacturer, or otherwise does not necessarily constitute or imply its endorsement, recommendation, or favoring by the United States Government or any agency thereof. The views and opinions of authors expressed herein do not necessarily state or reflect those of the United States Government or any agency thereof. 


\section{DISCLAIMER}

Portions of this document may be illegible in electronic image products. Images are produced from the best available original document. 


\section{PROCEEDINGS OF THE \\ THIRDINTERNATIONAL SYMPOSIUM ON PACKAGING AND TRANSPORTATIONOF RADIOACTIVEMATERIALS}

This report as prepared as an acename of work sponsored by the United States Government. Neither the United Staves nor the linited States Atomic E nergy Conmision, nor ary of thate employes, nut any of their contractors. subcontracturs, or their empluvess, makes any warranty, express or imphad, or assumes any legal liability or responsibulity for the accursey, om pleteness or usefulnes, of any information, apparatus.

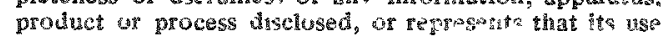

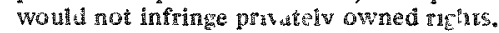

Richland, Washington

August 16-20, 1971 


\section{SYMPOSIUM COMMTTEE}

C. L. Brown

E. M. Johnston

D. R. Oden

J. S. Stoakes

D. A. Hoover

T. E. Dabrowski

E. F. Curren

A. O. Dodd

D. A. Knapp

W. A. Bevan

G. M. Dalen

G. R. Petersen

W. S. Ke11y

R. J. Bashor

A. W. DeMerschman

J. B. Edgar

G. F. Penn

R. F. Garrison

E. D. Clayton

C. N. Zangar

I. E. Dunn
Symposium Chairman

Co-chairman

Secretary
Treasurer and Registration
Program
Program
Program
Program
Transportation and Housing
Transportation and Housing
Public Relations
Public Relations
Exhibits
Proceedings
Meeting Arrangements
Meeting Arrangements
Hospitality
Tours
Banquet Arrangements
Special Assignment
Special Assignment

D. R. Swindle

W. A. Brobst

J. A. Sisler

L. B. Shappert

\section{Arrangements}

Advisory Committee

BNW*

WADCO*

BNW

BNW

ARHCO $\%$

DUN*

ARHCO

USAEC-RL

ITT\%

ITT

BNW

BNW

BNW

BNW

WADCO

WADCO

USAEC-RL

USAEC-RI

BNW

Vitro

JAJ*

USAEC-HQ

USAEC-HQ

USAEC-HQ

ORNL

Coordinators for AEC-RL

L. F. Perkins

USAEC-RL

C. F. Goodner

USAEC-RL

* ARHCO - Atlantic Richfield Hanford Company

BNW - Battelle, Pacific Northwest Laboratories

DUN - Douglas United Nuclear, Inc.

ITT - ITT/Federal Support Services, Inc.

JAJ - J. A. Jones Construction Company

Vitro - Vitro Corporation/Hanford Engineering Services

WADCO - WADCO Corporation 


\section{CONTENTS}

\section{SESSION 2 \\ U. S. Regulations}

Titre

How Abnorma 1 is Normal?

Today's Role of DOT in Regulating the Transport of Radioactive Material

Transportation Safeguards

Improving Applications for Shipping Container Approvals

A Guide to the U.S. Transportation Regulations
Author

J. A. Sisler, Transportation Branch, USAEC

A. W. Grella, Department of Transportation, Office of Hazardous

Materials, Washington, D. C.

D. L. Crowson

35

R. L. Stevenson, Div. of Materials Licensing, USAEC

A. C. Cornish \& H. Simens, Bureau of Radiological Health, Calif. Dept. of Public Health, Berkeley, Calif.; and Bechtel Corp.

SESSION 3

International Regulations

The 1970 Peviow of the IAEA Regulations for the Safe Transport of

Radioactive Materials

How Changes in the IAEA Regulations

May Affect 10 CFR Part 71

G. E. Swindel1, I.A.E.A., Vienna

R. F. Barker, Product Standards

Branch, USAEC

A. Redon \& Y. Sousselier, Commissariat a L'Energie Atomique, France

C. J. Holloway, Jr. \& J. Saltzman, Indemnity \& Export Control Branch, USAEC

\section{Isotopes and Waste Packaging}

Technology (Part 1)

The Design and Testing of a Lithium Hydroxide Shielded Cask for the Transportation of Fast Neutron-

Emitting Heat Sources

Transportation Safety of TransPlutonium Actinides

Shielded Neutron Shipping Cask

Recent Developments in Nondestructive Evaluation Applicable to Encapsulated Isotopes
R. D. Seagren, 0ak Ridge National Laboratory

C. M. Copenhaver, USAEC-ORNL

C. L. Hanson, M. S. Coops, E. D. Arnold, Lawrence Radiation Laboratory

D. R. Newman, J. C. Crowe, BattelleNorthwest 
SESSION $4 B$

Accident Experience

The AEC Accident Record and Recent Changes in AEC Manual Chapter 0529

Single Vehicle Wreck on Interstate Highway - February 1970

Enrichment Errors in Interplant Shipments

Preventing Shipping Incidents:

Two Case Studies

W. C. MCCluggage, USAEC, Div. of operational safety

166

D. F. Cronin, United Nuclear Corp.

167

D. L. Dunaway, National Lead Company of Ohio

R. C. Becker, Lawrence Radiation

Laboratory

188

SESSION $5 A$

Isotope and Waste Package

Technology (Part 2)

Shielded Transport Containers for Intermediate and High-Level Radioactive Wastes

"Celotex" Insulated Shipping

Containers

New Facility for Packaging Radio. active Liqujd Wastes

The Design of Low Cost Fire Shield for Small and Large Radioisotope Shipping Containers
W. Bechthold, J. Heil, M. C. Schuchardt, $R$. Wolf, Karlsruhe Nuclear Research Center

E. E. Lewallen, E. I. dupont deNemours, Savannah River Plant

D. E. Bloomfield, Gilbert Associates

J. D. W. de Lind van Wijngaarden \&

R. A. Harrod, Atomic Energy of

Canada, Ltd.

SESSION 5B

Shipment of UF 6

Enriching Services Transportation

B. M. Robinson, USAEC, Oak Ridge, Tenn.

W. A. Johnson, C. E. Newion,

R. G. Taylor, Union Carbide

Aspects in Transporting Uranium Hexafluoride

Engineering and Quality control Consideratjons in the Safe and

J. W. Arendt, Union Carbide

Economical Handling of Uranium

Hexafluoride Cylinders

Economics of Transportation - Uranium

G. R. Brooks, A. T. Freeman, J.A. Lamb W. R. Simpson 


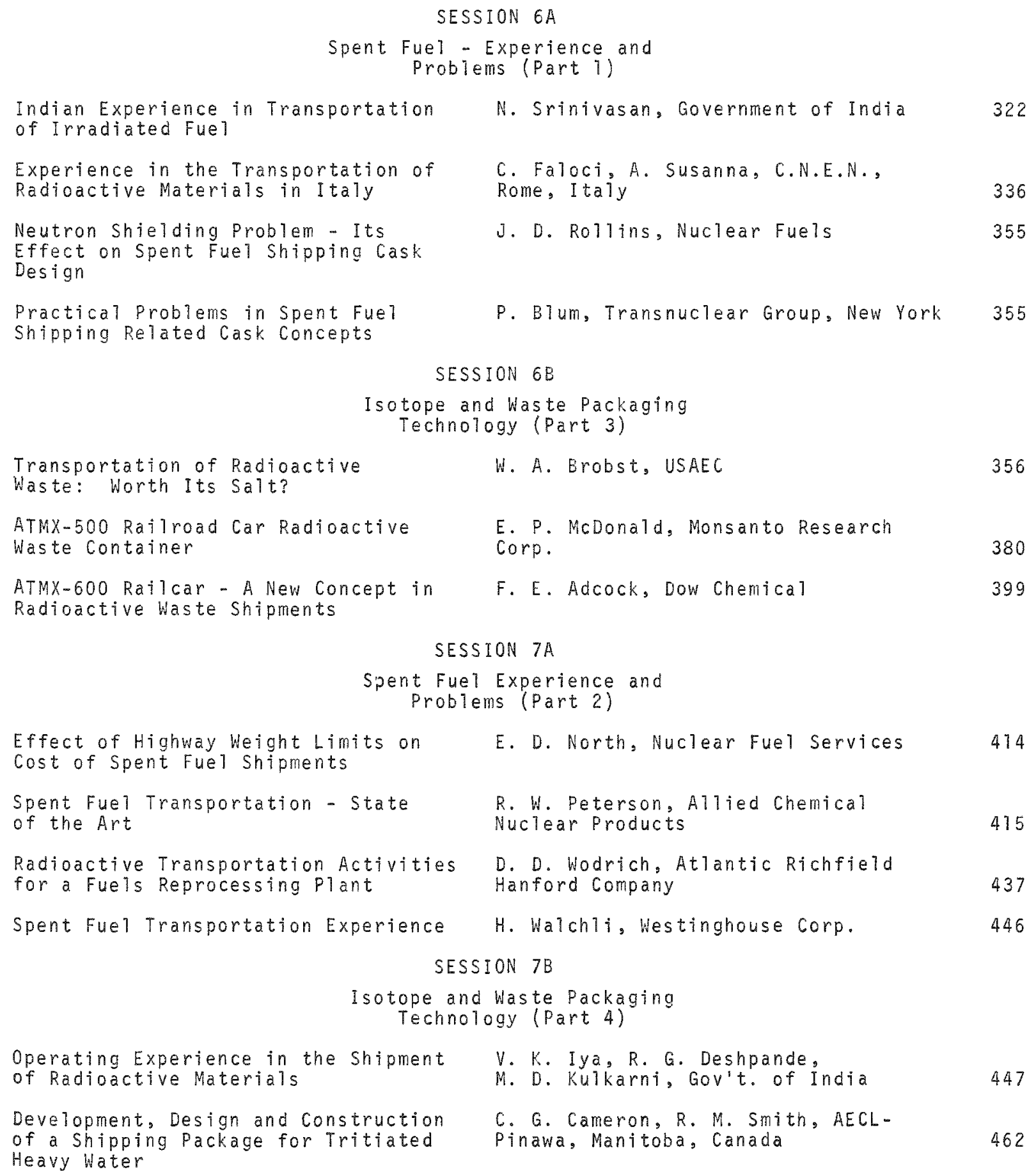
Heavy Water 
Title

Processing and Packaging of Solid Wastes from BWR's

Design Considerations for High Volume, IAEA Type B Protective overpack Shipping containers in Use with Current Transportations Systems
Author

Page

H. L. Loy, D. C. Saxena, Genera]

Electric co., San Jose, Calif.

K. Gablin, Protective Packaging, Inc. Tacoma, Wash.

PAPERS FROM SESSIONS 8 THROUGH 16

APPEAR IN VOLUME II 
SESSION 8 A

Insurance and Radiation Safety

Insurance and Indemnity Protection for Nuclear Materials in Transport

Third Party Liability Insurance and Government Indemnity Associated with the Transportation of Radioactive Material

Processing Radioactive Shipments from the standpoint of Radiation Safety

Radiation Survey of the Transportation of Radioactive Materials

A Method of Controlling Radiation Exposure of Persons in Aircraft During Transportation of Radioactive Materials
J. Saltzman \& C. J. Halloway, USAEC, Indemnity and Export Control Branch

503

L. G. Cummings, Marsh \& McLennan, Insurance, New York

C. W. Buckland Jr., Los Alamos

Scientific Laboratory

G. D. Schmidt, U.S. Public Health Service, Rockville, Maryland

P. A. Leconte, Belgian Airlines, Brussels, Belgium

\section{SESSION $8 B$}

Spent Fuel Packaging Technology

(Part 1)

Analysis of Packaging Compliance to Transport Regulations

Review of Experimental studies on the Fissle Fuel Shipping Cask in Japan

H. Lucas and M. Labrousse, Commissariat L'Energie Atomique Fontenay-Aux-Roses, France

S. Aoki, Tokyo Institute

of Technology

R. E. Latham and R. T. Brown, Gray Tool Co., Houston, Texas

SESSION $10 \mathrm{~A}$

Spent Fuel Packaging Technology

(Part 2)

Recent Developments in Lead Shields for Transport Containers in the United Kingdom

R. Smith, Lead Development

Association, London, England

B. A. Engholm, Gulf General Atomics, San Diego, Calif.

E. C. Lusk, Battelle Columbus Laboratories, Columbus, onio

J. L. Ridihalgh and R. E. Best, Battelle Columbus Laboratories

J. H. Evans, Oak Ridge National Laboratory 
SESSION 10B

Administrative Experience

Administration of the Radioactive Materials Transportation Safety Program

The Responsibilities of the

Consignor and the Consignee

Development of Documentation of the Transport of Radioactive Materials

Transportation and Handling of Radioactive Pharmaceuticals and Radioactive Chemicals
W. A. Pryor, Oak Ridge National Laboratory

689

$K$. R. Schendel, Westinghouse

Electric Corp., Pittsburgh, Pa.

708

J. Fairey, UKAEA - AWRE, Berks, England

719

S. H. Sanger, Cabs Unlimited, Mountain View, Calif.

SESSION $11 \mathrm{~A}$

Spent fuel Packaging Technology

(Part 3)

An Experimental study on the Drop Impact of Spent Fuel Shipping Cask

Impact Testing of Cask Fin Specimens

Impact Tests of Models at the Savannah River Plant

On the Prediction of Deformation and Deceleration of a Composite Cylindrical Body for the Corner Drop Case

S. Aoki, S. Nakata, S. Shimamura,

Y. Kanae, A. Muramatsu, H. Nakazawa, Tokyo Institute of Technology

F. C. Davis, Oak Ridge National Laboratory

J.W. Langhaar, E. I. duPont deNemours Co., Atomic Energy Division, Wilmington, Del.

K. Lee, ATCOR, Inc., Elmsford, N. Y.

L. Rutland, ATCOR

785

SESSION T1B

Nuclear Safety

J. T. Thomas, Union Carbide corp., Oak Ridge, Tenn.

J. K. Fox and W. G. Morrison,

Idaho Nuclear Corp., Idaho Falls, Idaho

J. D. Mccarthy, Dow Chemical Company, Golden, Colo. 
SESSION $12 \mathrm{~A}$

Spent Fuel Packaging Technology

(Part 4)

Study on Fire Resistivity for

Irradiated Fuel Shipping Casks

Heat Transfer Calculations for Spent Fuel During Hypothetical Accident Conditions

A Thermal Test Evaluation Method for Lead \& Uranium Shielded Casks

Shipping Container Design for Fire Accident Protection, Minimum Restriction to Decay Heat Removal
T. Moriya and H. Shimada, Fire

Research Institute Japan, Tokyo, Japan

C. J. Anderson, Nuclear Fuels

Services, Wheaton, Maryland

J. C. Glynn and R. H. Odegaarden, USAEC, Washington, D.C.

A. Serkiz and E. C. Lusk, Battelle Columbus Laboratories, Columbus, Ohio

SESSION T2B

Non-Irradiated

Evaluation of Plutonium form

on Safety During Transportation

Drop Tests of Shipping Containers

for PWR Type New Fuels

Shipping Package for Unirradiated

Power Reactor Fuel Assembities

A Simple Shipping system for Power Grade Plutonium oxide

Fuel Packaging Technology

L. M. Knights

860

S. Aoki, S. Nakada, S. Shimamura,

Y. Kanae, T. Koguchi, and Y Seki,

Tokyo Institute of Technology

K. E. Kropp, United Nuclear Corp., New Haven, Conn.

R. E. Giebel and R. G. Leebl, Dow Chemical Co., Golden, Colo.
SESSION $13 \mathrm{~A}$

Spent Fuel Packaging Technology

(Part 5)

Tiedown Systems for Casks

E. E. Lewallen, E. I. duPont deNumours, Aiken, South Carolina

R. J. Burian and E. C. Lusk Battelle Columbus Laboratories

J. T. Foley and M. B. Gens, Sandia Laboratories

R. A. Scaggs, E. I. duPont deNemours, Aiken, S.C. 
SESSION 138

Needs and Progress in Standardization

Future Trends in Automated Freight Handiing Systems

Quality Contral of Shipping Cask Fabrication
J. C. Wolff, Director, Drake Chelan--

Stewart Dougal1, Inc., New York, N.Y. 944

A. Short, Vitro Corp., Richland, Washington

945

\section{SESSION 15}

New Spent Fuel Cask Designs

C.M. Kershner, Allis-Chaimers, York, Pa.

C. R. Davis, Gulf General Atomic, San Diego, Calif

F. Schmiedel and R. Dietrich, Fried, Krupp GmbH, Nuclear Division, Essen, Germany

J. P. Malone, ATCOR,

Eimsford, N.Y.

SESSION 16

\section{Advanced Technology}

Contribution to the Design of Type B Packages for High Residual

Power Irradiated Fuels Elements

H. Bruel and C. Bochard,

Societetbatel SLPI, France

A. R. Irvine and L. B. Shappert, Oak Ridge National Laboratory

Concept and observations

Pertaining to Hazard Survival

Potential

Air Cushion Support for Highway

Transport of Heavy Loads

W. H. Trask, Battelle-Northwest

1015

L. H. Baker, B. J. Donham,

W. S. Gregory, and E. K. Tucker,

LASL, Los Alamos, New Mexico

1028

PAPERS NOT PRESENTED

Heat Transfer Analysis of a Cesium-137 Shipping Cask

G. R. Bray, J. J. Darby,

A Study of the Effect of Impact and $C$. E. Gruhl

L. R. Shobe and B. R. Dewey and of the Use of a Toroidal Shell

as an Energy Absorber on a

cylindrical container of Lead

and steel 
INSURANCE AND INDEMNITY PROTECTION FOR NUCLEAR MATERIALS IN TRANSPORT

\author{
Jerome Saltzman \\ C. James Holloway, Jr.
}

ABSTRACT

To provide protection to the general public and promote the growth of the nuclear industry a unique syster of liablifty coverage for nuclear operations including transportacion of nuclear materials, has been developed. The principal features of the insurance and Indemity aspects of shipments of radioactive materlals are: (a) the formation of nuclear liability insurance and nuclear property insurance pools by the casualty and property insurance companies, and (b) the establishment, through Federal legislation, of a progran of government indemity and underlying financial protection (usually nuclear liablity insurance) to cover public $11 \mathrm{ab} i 1 \mathrm{lty}$ for nuclear incidents. Liability insurance coverage for transportation is provided by means of two basic policies - the Facility Form and the Supplier's and Transporter's Form. Indemity coverage is supplled to certain licensees and contractors of the Cormission. Nuclear property insurance provides first party coverage for certain nuclear property. Some insurance coverage is available for ocean transportation and proposed legislation would extend Inderinity coverage for some aspects of ocean transportation. There are also international conventions covering third-party liability of interest to persons involved in the transport of radioactive materials. While certain problem areas remain in the insurance and indemification of transportation of radioactive materials, by cooperative efforts, these problems can be overcome.

\title{
INTRODUCTION
}

The rapid increase in the volume and scope of shipments of radioactive marials has been facllitated by a system of insurance and Indemity which recognizes the need for flexibility in providing coverage for an industry utilizing newly developed technologies. The very concepts of coverage by 
nuclear liablity and property insurance pools supplemented by government indemity is a reflection of the belief of the nuclear, eransportation, and insurance industries and the legislative and executive segments of the Government that novel insurance approaches were needed to assure protection to the general public and to promote the growth of the nuclear industry.

The principal features of the insurance and indemity aspects of shipments of radioactive materials are: (a) the formation of nuclear Lability Insurance and nuclear property insurance pools by the casualty and property Insurance companies, and (b) the establishment, through Federal legislation, of a program of government indemity and underlying financial protection (usually nuclear liability insurance) to cover public liability for nuclear Incidents.

\section{NUCLEAR INSURANCE POOLS}

Four pools were formed in 1956 by the casualty and property insurance industry to provide unprecedented amounts of liability and property insurance capacicy identified by them and the nuclear industry as required by the nuclear activities in the private sector of the economy made possible and encouraged by the Atomic Energy Act of 1954. The insurance companies owned by stock holders (the stock insurance companies) formed two pools each with an underwriting capacity of about $\$ 46.5$ milion. The Nuclear Energy Liability Insurance Association (NELIA) was established to provide liability coverage and the Nuclear Energy Property Insurance Association (NEPIA) was established to provide insurance for the purchaser's own property. The insurance companies owned by their policy holders (the mutual insurance companies) also in effect formed wo pools, each with capacity of $\$ 13.5$ million. Nuclear liability insurance was written through Mutual Atomic Energy Liability Underurlters (MAELU) and nuclear property insurance was written by Mutual Atomic Energy Reinsurance Pool (MAERP). * Thus, when the pools were formed in the mid-1950s, the combined underwriting capacity that could be written for any single nuclear liability insurance risk was $\$ 60$ million and the combined underwriting capacity that could be written for any single nuclear property risk was $\$ 60$ milion dollars. This total insurance capacity of $\$ 120$ million which could be placed against a single risk to cover 
both liability and property losses represented essentially the entire capacity that organizations constituting the world-wide insurance market could make avallable for this type of risk. Almost one-third of this capacity represented reinsurance in the foreign insurance markets (such as the Lloyds Syndicates).

The underwriting capacities for nuclear liability and property insurance have increased through the years so that today there is $\$ 82$ million in nuclear 1lability insurance avalable for each risk and $\$ 84$ million in nuclear property insurance for a total insurance coverage (liablity and property) of $\$ 166$ million for each risk. In the past year or two, major undertakings by the industries involved have attempted to pool capacity for potential catastrophic losses in such areas as the operation of jumbo aircraft and supertankers. The combined capacity of the four nuclear pools remains one of the largest amounts of insurance funds amassed for a single risk even when measured against these undertakings.

\section{PRICE-ANDERSON INDENANITY}

While the formation of the pools appeared at the time to provide adequate property coverage for nuclear installations, the capacity developed by the nuclear liab111ty pools, albeit in unprecedented amounts, was still not considered to be sufficlent to cover potential, though hardiy credible, liability claims from catastrophic nuclear accidents. Congress, through the Joint Comittee on Atomic Energy (JCAE), and the executive branch of Government through the Atonlc Energy Commission, after some two years of studies and hearings, developed the Price-Anderson system. This syster, enacted In 1957 as an amendment to the Atomic Energy Act, was designed to supplement the nuclear 1iability insurance that the pools were developing so as to best serve the dual goals of protecting the pubilc and fostering private participation in the atomic energy program by assuring that, In the event of serious accident, funds would be avallable for the payment of damages.

\section{LICENSEES OF THE COMMISSION}

Under the Act, certain licensees are required to furnish proof of financial protection (in the form of nuclear 1 lablliry insurance or as otherwise provided in the Act) to cover public liability claims up to an amount specified by the AEC. When financial protection is required, 
the AEC must provide indemity protection for up to $\$ 500$ milion for each nuclear incident over and above the amount of financial protection. In some instances, financial protection is not required and indemity is provided either fron the "first dollar" or in excess of $\$ 250,000$. The liability of all persons liable is limited to the combined sur of the financial procection and the Commission's indemnity, up to total of $\$ 560$ millon. Under the Act, the AEC requires financial protection of, and indemifies, all 11 censees for nuclear reactors and fuel reprocessing plants. Licensees authorlied to operate reactors designed with a power level of greater than 100 electrical megawats are required to provide financial protection equivalent to the maximum capacity avallable from private sources, which is currently $\$ 82$ million. The AEC Indemifies these reactor 11censees in excess of this amount up to $\$ 560$ milion.

The AEC has discretion under the Act to require financial protection of, and to indemify, nuelear terials licensees. While the Commssion has not exercised this discretionary authority to extend indemity to materials licensees to date (except for fuel in storage prior to reactor operation) it has the matter under continual study.

\section{COMISSION CONTRACTORS}

The second major group to which Price-Anderson protection is extended is the Commission's contractors. Under the Price-Anderson Act, the Conmission is achorized to indemify contractors for the construction of production or utilization facilities (such as nuelear reactors) and such other of its contractors who are engaged in activities for the benefit of the United States involving a risk of public liability for a substantial nuclear incident. The Indemification protection for Comission contractors is in the amount of $\$ 500$ milion. While the Price-Anderson Act authorimes the Commission to require its contractors to furnish private fimancial protection such as nuclear liability insurance, the Comission has chosen not to require its contractors to purchase such insurance, though sometimes insurance otherwise applicable is permitted to be maintalned (as in the case of facility in which both Comission and private work is performed).

The Comalssion has entered into indemnity agreements with all of its prime contractors who are engaged in an activity involving the risk of a substantial nuclear incident. 


\section{LIABILITY INSURANCE COVERAGE FOR TRANSPORTATION}

The two nuclear 11ability pools utilize two basic forms of liability insurance policy which provide transportation coverage for their insureds. The first form is the nuclear energy liablity policy (facility form) which has been approved by the Commission for use in meeting its requirements for underlying financial protection. This facility form is also sold by the pools to operators of nuclear installations, such as fuel fabricators, who are not subject to the Price-Anderson Act. The second form is used by pools to provide nuclear liability insurance to suppliers and transporters who are not operators of nuclear installations, and is called the nuclear energy liability policy (supplier's and transporter's form).

\section{Facility Form}

The facility form covers loss and loss expense resulting from liablitty because of bodily injury or property damage caused by "the nuclear energy hazard." Under the policy, the "nuclear energy hazard" is the radioactive, toxic, explosive, or other hazardous properties of nuclear material, when such materials are at the facility designated in the policy or, subject to specified linitations, are being transported to or from the facilicy.

One novel feature of the facility form of pollcy is that it covers the liability of any person or organization fother than the United States and its agencies) for a covered nuclear incident. (Conventional liablity policies, on the other hand ordinarily cover only the liability of the named Insured.) Another novel feature is the coverage of the of property of persons 11 able for the incident as if this off-site property had belonged to another. Also unusual is the policy's coverage for transportation.

Under the facility form, when it is certifled by the 1 icensee as evidence of financial protection, coverage is provided in the course of cransportation (Including handing and temporary storage incidental thereto) with the territorial limits of the United States, its territories. Puerto Rico and the Canal Zone. The Insured shipments covered by the policy are shipments of source material (uranium and thorium), special nuclear material 
(enciched uranium and plutonium), spent fuel or waste* that is belng transported to the facility designated in the policy from any location (except an indemified nuclear facility) or from the facility to any other location. The transportation coverage is provided until the material is removed from the transporting conveyance for any purpose other than the continuation of its transportation. While there are certain exceptions which should be reviewed by anyone transporting nuclear materials under this type of policy, in general it can be stated that where two faclity forms of nuclear liability policies apply to a single shipment, the policies are worded to assure that it is the shipper's (rather than the recelver's) policy that will provide the coverage.

The coverage is subject to vaxious exclusions in the policy, particularly the exclusion from coverage of "property damage to nuclear material in the course of transportation to or from the facility including handling or storage incldental thereto." However, in general, the Insurance policies cover liability for danage to companion cargo, and to such property as rights-of-way, roads, terminals, ports, bridges and other property used in connection with the transportation of the material, even if the person found to be 11 bble for the nuclear incident is the owner of such property.

\section{Supplier's and Transporter's Form}

The transportation coverage provided by the pools under the supplier's and transporter's form is intended among other things to supplement the transportation coverage in the facility form of policy. The supplier's and transporter's form, in addition to providing coverage for liability resulting from transportation of nuclear materials not within the scope of the facility form and not whin the scope of Price-Anderson Indemity, also provides liability coverage to a named insured (such as a transportation firm) who might be uncertain as to any other coverage or the limits of covarage for shipments it is handing. Like the facility form of policy, the supplier's and transporter's form is omnibus with respect to cransportation coverage, but

* The pools do not normally afford nuclear liability coverage under the facility form of policy to licensees for radioactive isotopes (called byproduct material) but coverage for 1iabliity from applications of radioisotopes in normal comerce is afforded by the conventional liablity insurance market. 
otherwise, unlike the facil1ty form, covers only the named insured. This form provides coverage for damage to the property of others, not the offsite property of the named insured. Like the facility form, the supplier's and transporter's form does not usualy cover liability arising out of the shipment of commercial radioisotopes; however, liability for such shipments of radloisotopes can be covered through general liability insurance policies.

\section{TRANSPORTATION COVERAGE UNDER PRICE-ANDERSON INDEMNITY}

The transportation coverage under the Comission's indemity agreements with licensees and under its agreements with its contractors is quite similar to the coverage afforded by the facility form of insurance pollcy. The Indemity agreements cover all of the "radioactive material" in the course of transportation from the indemified location and the material to the indemifled location (so long as the transportation is not "from" another indemified location). This coverage applies to material whose transportacion to or from the location is not interrupted except for continuation of the transportation or incidental temorary storage. The radioactive material covered by the policy is source, special nuclear, and byproduct material, which is used or to be used in, or produced as a result of the operation of, the indemified facility. This definition then, could Include sone byproduct naterial (radiolsotopes) which would not be covered in the faclity form or shipper's and transporter's form of liability insurance policy.*

The indemnty agreement excludes coverage for damage to the radioactive materlal being transported, as does both forms of insurance policy. How ever, in contrast to the policies, the indemity agreement also excludes coverage for damage to the container of the material and damage to the vehicle on which the container is being transported. An additional exclusion in the agreement is the workmen's compensation clatms of employees of persons indemnified whose duries involve the performance of work on the vehicle transporting the radioactive material.

often, however, the practical effect of the limitation of covergge of byproduct material to such material "used or to be used in or produced as a result of the operation of the.. . facility" in the Indemaity agreement w11 mean that the covered byproduct material is "spent fuel or waste" and within the coverage of the nuclear facility pool insurance. 


\section{NUCLEAR PROPERTY INSURANCE}

Since 1959 the standard fire and property insurance policies have contained an exclusion of damage to the insured's property and loss of revenue of the insured caused by nuclear reaction, nuclear radiation, or radioactive contamination regardless of the source of the incident or whether the incident falls within the scope of the Price-Anderson Act. We understand that the insurers consider that property danage caused by a nuclear incident would often be covered by a nuclear liability insurance and that this coverage should be excluded from the conventional fire and property policy (i.e., non-nuclear policy) to avoid duplication of insurance for the same property.

Since, however, certain property (such as the nuclear facility property, the nuclear material involved in the incident itself, and for indemity coverage also the container of the material and the transporting vehicle) is excluded from both coverage of nuclear liability insurance (and Indemity) and, in effect, conventional property insurance there was a market for coverage of excluded business property and the nuclear insurance pools established forms of property insurance to provide this coverage.

The nuclear property pools, Nuclear Energy Property Insurance Association (NEPIA) and Mutual Atomic Energy Reinsurance Pool (MAERP) currently supply a cotal of $\$ 84$ million per policy to cover damage to the property of an operator of a nuclear facility caused by an accident at the nuclear facilicy. This standard nuclear energy property insurance policy covers damage to the property (which is delineated geographically and described In the Declarations page of the pollcy) from radioactive contamination (from onsite sources) and a11 risks of direct physical loss except as provided in the policy. This pollcy then provides first-party property Insurance at the described location against conventional fire and other property risks as well as the nuclear risks. It does not provide coverage for nuclear risks where the source of the nuclear contamination is outside the location described in the agreement. Nor does this form of nuclear property Insurance provide coverage away from the location such as for meterial in cransport.

NEPIA and MAERP do provide nuclear property insurance for nuclear fuel In transport, except whlle water borne, within the continental United states 
(and Canada where the origin or destination of the transportation is in the United States) and the containers, materials, and supplies shipped with the fuel. There is one form of policy to insure the shipper for the property loss and another form to insure the carrier. The policies provide insurance coverage only to the named insured and his legal representatives.

\section{INDEMNITY AND INSURANCE FOR OCEAN TRANSPORTATION}

The Indemity protection afforded by the Price-Anderson Act applies (with certain exceptions*) only to Incidents arising within the United States. Thus, for example, irradiated fuel from an overseas reactor being sent to the united States for reprocessing at a 11censed or contractor-operated reprocessing plant would be indemified (under the licensee indemity agreement or contractor agreement) only for the portion of the trip when it is in the course of transportation within the territorial limits of the United States. If en Incident were to occur outside of the territorial limits of the United states, the person liable and the public would not receive protection for the damage suffered on the high seas, in a foreign country, or cven in the U. S. itself.

Leglelation was introduced in the $915 t$ Congress to provide PriceAnderson indemnity coverage for high seas transportation of nuclear materials in American flag vessels but was not acted upon before Congress adjourned. (As of March 31, 1971 consideration was being given to introducing similar legislation in the present Congress). The bill would have extended Price-Anderson coverage to nuclear incidents arising out of the transportation of source, special nuclear, or byproduct material on vessels of U.S. registery and which take place in the course of such transportation outside of the territorial limitations of the United States or any other nation. The person indemnified would have been limited to the 1icensee or

\footnotetext{
* See 170.d. and 170.1. of the Act. Under subsection 170.d. extraterricorial Indemity may be applicable to cover liability of persons who are contractors or subcontractors of any tier under Commission contract or other profect to which $170 . d$. Indemity has been extended, if the incident involves a facility or device owned by and used by or under contract with the United States.
} 
contractor of the AEC with whom an indemity agreement is executed and any other person: (a) who may be liable by reason of his activities within the U. S. (such as an American cask designer or manufacturer, or stevedore in a U. S. port); (b) who way be liable in connection with the ownership or operation of the vessel; (c) on board the vessel transporting the nuclear aterial while such vessel is on the high seas who may be liable (such as a seaman): (d) and any other person who has his principal place of business in the U. S. and who may be liable (such as an employee of an Armerican firm supervising loading at a foreign port). As in the case with domestic Indemity coverage, loss of the transporting vessel, and lis equipment, fuel and stores (which we understand, in some cases may be covered by hull insurance) are not covered under the proposed legislation nor are the nuclear materials befng transported and the containers used.

Liablity for covered ocean transportation would be limited to $\$ 100$ millon together with underlying insurance providing financial protection up to an aggregate liability of $\$ 115$ million. We understand that $\$ 15$ million represents the currently available maximum "protection and indemnity" coverage in the marine nuclear fleld (third-party liability). In view of this, the amount of financial protection to be required under the proposed legislation would be $\$ 15$ milion, although the Comission would be authorized to establish a greater or lesser amount of financlal protection, taking into consideration the amount of liablity insurance avallable from private sources and the cost and terms of insurance. The $\$ 100$ million in indemity for persons indennified in connection with each nuclear incldent would be reduced by the amount that financial protection required exceeds $\$ 15$ milion so that the aggregate liabliity shall remain at $\$ 115$ million even if more insurance is made avallable.

\section{INTERNATIONAL CONVENTIONS ON LIABILITY}

The Paris Convention of July 29, 1961, on Third Party Liability in the Field of Nuclear Energy, and the Vlenna Convention of Apri1 29, 1963, on Civil Libility and Nuclear Damage were drafted to cover the liability of the operator of nuclear installations for damage suffered anywhere, including during the transportation of nuclear material, except in the cerritory of 
nonadhering states. The U.S. has not signed or adhered to any of the conventions. At present, of the international conventions in the field of nuclear liability only the Paris Convention on Third-Party Liability in the Field of Nuclear Energy, has been ratified by a sufficient number of countries to bring it into force.

PROBLEMS RELATED TO INSURANCE AND INDERAITY COVERAGE FOR NUCLEAR MATERIALS IN TRANSPORTATION

International

As we describe in the preceeding section, the problem of insufficient liability protection for shipments from the United states or to the United States on the high seas should be met if proposed legislation to extend Price-Anderson protection for shipnents on U. S. flag vessels is reintroduced in Congress and becones law.

Domestic

Bridge, Tunne1, Port, and Tollroad Authorities

As was described earlier, the fire and property insurance carriers In 1959 adopted a nuclear exclusion clause in all of their policies which excluded from coverage, first-party damage and loss of revenue caused by the radioactive materials hazard. Nuclear property insurance that does not contain this exclusion was available in the U. S. only for nuclear installations, and under limited conditions, shippers and carriers of nuclear materials. Some bridge, tunnel, port and tollroad authorities were concerned that in the event of an accident that damaged their facilities or caused a loss in revenue of their facilities, they would not be able to recover against the liability pools for damage to an authority's own property without establishing the llabiliry against speciflc defendants. In view of this concern, they did not consider nuclear liabilicy insurance as an adequate substitute for the first-party coverage which would be provided to them by conventional property insurance without a nuclear exclusion.

In 1.966, Congress enacted Public Law 89-645 amending the Price-Anderson Act to provide for prompt and equitable setrlement of clalms arising out of a nuclear incident, and to provide for waivers of defenses with respect to claims arising out of an "extraordinary nuclear occurrence" as that term 
1 is defined in the Act. In accordance with the 1966 amendments to the PriceAnderson Act, In 1968 the Commission amended Part 140 of 1 ts regulations to establish criterla setting forth the basis on which the Comission would make determination as to whether or not an "extraordinary nuclear occurrence" has taken place and incorporating waivers of certain defenses in the facllity form of nuclear energy liability policy and the forms of inderanity agreement. An endorsement was added to all nuciear insurance pollcies provided as proof of financial protection for lndematy purposes, and the indemity agreements were correspondingly amended, to require that specific issues or defenses be walved by a defendant in the event of an extrardinary nuclear occurrence. A claimant might still have to proceed with an ordinary legal action involving proof of the nature, cause and amount of damages, but with the mandatory waiver of defenses his burden would be eased by the elimination of such issues as negligence, contributory negligence, assumption of risk, charitable or governmental immunity, and, to cetain extent, statute of Iimitations.

We believe that these waivers of defenses provisions go far in meeting the concern expressed by the transportation authorities with respect to having to establish negligence under the facility forms of nuclear energy liability insurance, at least in the case of extraordinary nuclear occurrences. However, in an AEC-sponsored industry conference called in 1968 to consider the (at that time) proposed amendment to the Comission's regulations providing for waivers of defenses, the representative of one of the authorities expressed some remaining reservation particularly with respect to obtaining first-parcy property insurance for those nuclear incidents that did not qualify as extraordinary nuclear occurrences.

Railroads

Although we have had no recent discussions with the railroad Industry regarding liability insurance and indemity protection for the transportation of spent fuel, the Traffic Executive Association, Eastern Railroads, did discuss with us several years ago, concerns which they had at that time. The principal problens were: (a) their uncertainty as to whether their liability under the Federal Employer's Liability Act (FELA) would be covered by government Indemity under the Price-Anderson system and nuclear liability insurance (or on the other hand, excluded as workmen's compensation claims); and (b) their concern that in particular cases they may not know whether specific shipment of nuclear reactor fuel is covered by the Price-Anderson Act. 
With regard to the first of these concerns, the rallroad representatives were advised that the FELA liability is covered by the underlying insurance policy and the government indemity is in excess thereof. We understand, however, that there may be forms of nuclear liablity insurance, other than the one approved by $\mathrm{AEC}$ as acceptable proof of financial protection under the government indemity, which do not cover FEL 11ability.

With regard to the second concern, the AEC established a procedure under which a certification can be issued by the AEC to a carrier, at the the of dellvery to the carrier of the spent fuel, which would certify that the spent fuel during specifled transportation is covered by government indemnity. Several railroads have avalled thenselves of this certification procedure and have carrled shipments of fuel as contract carriers.

\section{CONCLUSION}

Although the insurance Industry and the government have endeavored to maintain flexiblity and adapt coverage to keep pace with the growing complexity and volume of nuclear rnateril shipments, and much has been accomplished, we can see that some problem areas remain. By the cooperative efforts of all concerned, these probleas can be overcome to assure that nuclear insurance and indemity continue to provide the coverage required. 


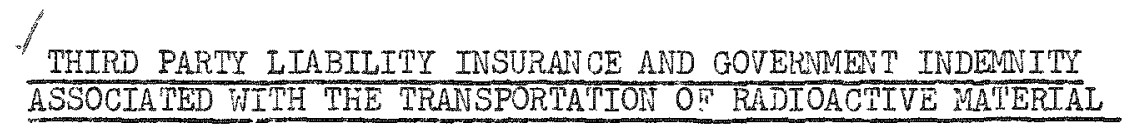

L. G. Cummings

ABSTRATI

The increasing frequency of radioactive material shipments through out the world with its potential risk of financial loss to shippers and transporters has focused considerable attention on the means to minimize or eliminate this risk. One important contribution to meet this challenge in the United States was accomplished by the formation of two nuclear liability insurance pools which make available to private industry third party nuclear liability insurance coverage up to $\$ 82,000,000$ for Bodily Injury and Property Damage arising out of a nuclear incident. In addition, the Federal Government provides, via legislation knom as the Price-Anderson Act, indemification at certain nuclear facilities including transportation up to $\$ 500,000,000$ excess of the private insurance coverage. An understanding of the interface between the conventional and nuclear liability insurance policies together with applicable government indernity is essential if the transportation risk is to be properly insured at minimum cost. Foreign nuclear material shipments also involve unique insurance questions, and certain insurance coverages are available in this field where it is determined that existing international regulations and local liability legislation do not adequately protect the shipper's or transporter's interest. This paper will provide an analysis of the above areas of interest and will include liability cost factors and loss experience data associated with the shipments of nuclear material. 
At the time the A tomic Energy Act of 1954 was enacted by the United States Congress few people would have envisioned that by March 1971 the Unitec States electric utility industry would be operating or committed to constructing over 110 nuclear reactors for commercial operation with an estimated total capacity of over $90,000 \mathrm{MJe}$. In addition there are approximately 50 commercial production facilities engaged in the nuclear fuel supply chain.

The free world, excluding the United States, is comitted to approximately 100 reactors with an estimated total capacity of nearly 50,000 MWe.

Considering the fact that only 21 United States and 40 foreign reactors are scheduled to be on line in 1971 it is obvious that the next few years will involve a very substantial growth in the broad spectrum of commercial nuclear activities. This activity will present an increasing challenge to the transportation industry to assure the safe and on-schedule delivery of maclear matexial.

Shipments of nuclear material will involve transport by truck, rail, air and water, each with its om unique problems of labor relations, overtaxed traffic lanes and terminals, equipment failures and so called "Acts of God", any of which may contribute to financial losses for the shipper and/or transporter.

It is the primary objective of this paper to examine the availability and applicability of nuclear liability insurance and government indemnity as they relate to (1) domestic shipments and (2) shipments to and from the United States. 


\section{DEVELOPMENT OF NUCLEAR LIABILITY INSURANCE AND}

GOVERNEGI INDENITY IN THE UNITED STATES

Foljowing enactment of the Atomic Energy Act of 1954 private industry expressed the need for a substantial amount of third party liability insurance to protect their financial interest against the unknown risks of nuclear energy and also indicated that the lack of adequate insurance could be a major obstacle to the commercial development of nuclear technology. A number of factors complicated the problem for the insurance industry in trying to provide for the requested high liability insurance limits with the very remote, but theoretically possible, catastrophe risk. It was recognized. that the number of nuclear facilities to be insured would be limited for several years precluding the insurers from utilizing a basic insurance requisite of spreading risks over a broad base of exposure. In addition, the lack of loss experience data and the anticipated rapid technological development in nuclear science presented additional concern to insurance underwriters.

Despite these obstacles the resources of the insurance industry were joined together in 1957 in the formation of two nuclear liability insurance pools, the stoch company pool called the Nuclear Energy Liability Insurance Association (NELIA) and the mutual company pool called the Mutual Atomic Energy Liability Underwriters (MAELU) with an initial combined insurance capaci.ty of $\$ 60,000,000$ applicable to any one nuclear incident. Subsequently, this capacity has been increased to the $\$ 82,000,000$ we have today. The NEIIA and MAELU pools issue identical liability insurance policies to cover domestic nuclear facility and transportation exposures and function on a cooperative basis with joint rating, underwriting and engineexing committees.

At the same time the nuclear insurance pools were organized it was deemed advisable by Congress to make available additional limits of coverage for certain types of facilities. This resulted in the passage of the PriceAnderson Act in 1957. This act provided govermment indermity in the maxi- 
mum amount of $\$ 500,000,000$ excess of the $\$ 50,000,000$ available from the insurance pools for a combined total of $\$ 560,000,000$. It should be noted that the available amount of government indemity is decreased by the same dollar amount whenever the nuclear insurance capacity is increased. Consequently the total combined liability limit remains at $\$ 560,000,000$ and thus today is comprised of $\$ 82,000,000$ by insurance and $\$ 478,000,000$ by indemity.

With only minor exceptions, the liability protection asforded by the insurance pools and Price-Anderson are identical minimizing administrative and loss adjustment problems.

\section{RELATIONSHIP OF CONVENTIONAL AND NUGLEA LIABILITY INSURANCE}

Several points should be commented upon prior to examining the nuclear insurance and indemity availabie to shippers and transporters.

In drafting the nuclear liability insurance policies it was decided that the conventional insurance market should continue to provide liability insurance for the non-nuclear hazard. Thus, the basic insurinz agreement in the nuclear liability policy only provides 3odily Injury and Property Damage liability coverage caused by the "nuclear energy hazard" thereby making it necessary for a policy holder to insure the non-nuclear hazarus in the conventional fashion.

An examination of the Broad Form Iuclear Energy Liability Exclusion endorsement that is attached to all United States Comprehens:-ve Automobile General Liability Policies will indicate that certain nuclear hazards continue to be insurable under the liability policy. Specifically, these deal with operations involving (I) source material (i.e. natural uranium, thorium) (2) by-product material commonly reserred to as "commercial radioactive isotopes" and (3) laboratory quantities of special nuclear material Iimited to 25 grams of Plutonium or Uranium 233 and 250 grams of Uranium 235. Conseguently we repeat, shipments of material in these three 
categories remain insurable in the conventional manner.

It is important to note that the teminology used in the above mentioned Broad Form Nuclear Exclusion and the NELIA-MAELJ policies are identical in order to avoid questions of coverage interpretation.

With regard to the availability of governinent indemnity only two types of privately omed nuclear facilities are presently eligible. These facilities, designated as indemified nuclear facilities, are (1) nuclear reactors and (2) fuel reprocessing plants. They are required to furnish financial protection pursuant to the Atomic Energy Act of 1954, as amended, and to date, have elected to satisfy this requirement by purchasing insurance from the nuclear pools. The facility operator can then enter into an indemification agreement with the Atomic Energy Comission to obtain benefits afforded by the Price-Anderson Act.

NUCE.EAR LIABILITY INSURANCE POLICY (FACILITY FORM)

Let us now examine certain features of the NELIA/MAELU Nuclear Liability Policy (Facility Form) which pertain to the liability insurance afforded during the transit of nuclear material as defined therein.

Insuring Agreement I.-- Coverage A stipulates the basic coverage afforded for the nuclear energy hazard as previously mentioned. Coverage B provides insurance for contamination to a named insureds property away from the facility. Coverage $C$ applies to the Horkmen's Compensation carrier who has paid off-site employees for injuries caused by the nuclear energy hazard. Insuring Agreement II.-- pertains to the Definition of Insured which in addition to the named insured includes anyone having legal liability for the loss, except the United States Government on its agencies. The comparable clause in the Price-Anderson Indemnity Agreement is designated "Person Indemnified" and is similarly defined.

Insuring Agreement III. -- includes a definition of "insured shipment" which deserves special attention in this paper. The "insured shipment" 


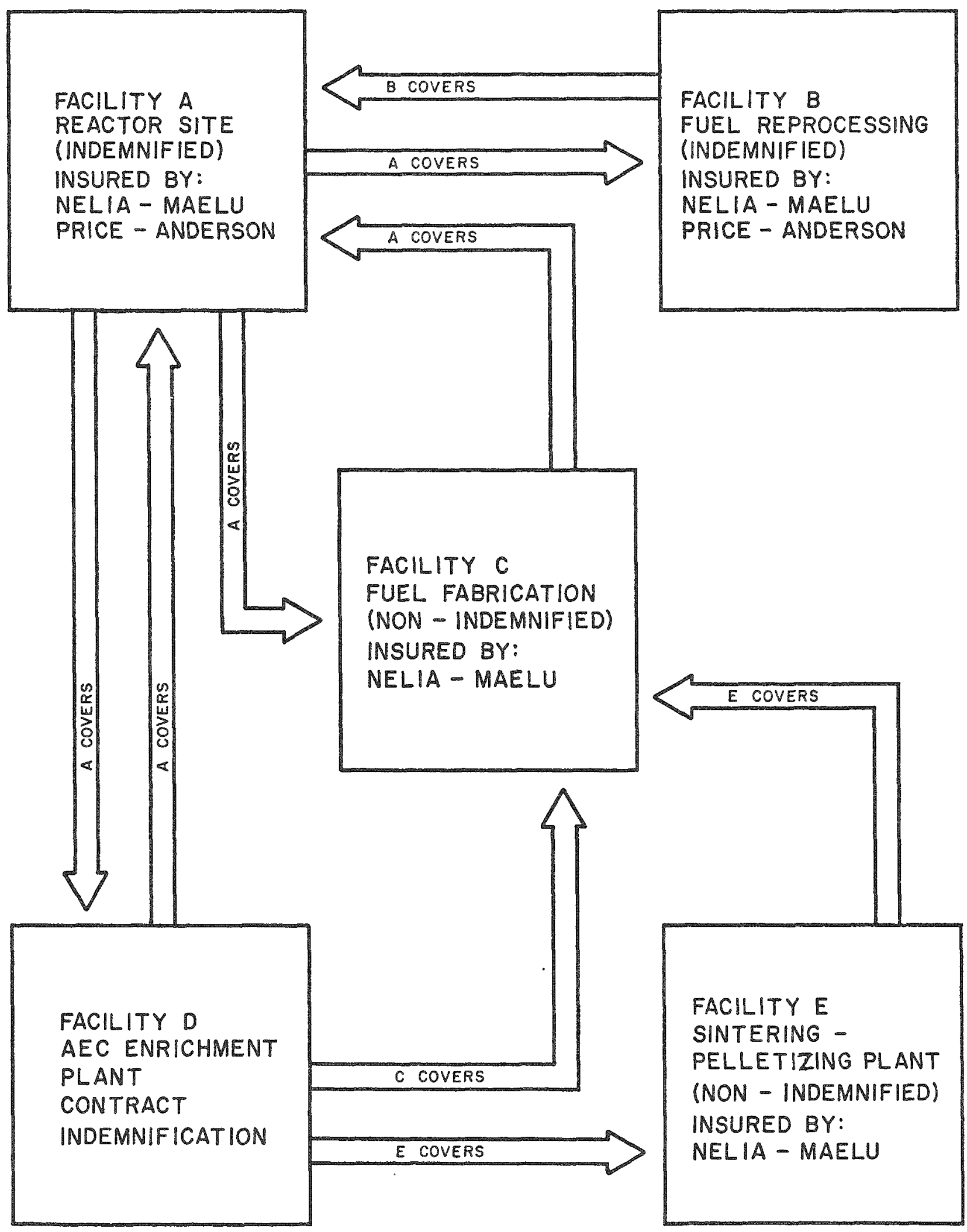

FIG. I. INSURED SHIPMENTS BETWEEN VARIOUS TYPES OF NUCLEAR FACILITIES. 
defined in the basic policy applies to an insured non-indemnified nuclear facility which reads in part as follows:

"Insured Shipment means a shipment of source material, special nuclear" material, spent fuel or waste, herein called material, (1) to the facility from a nuclear facility owned by the United States of America.. or (2) from the facility to any other location except an inderinified nuclear facility..."

The above definition is broadered by endorsement when the policy applies to an insured indemified nuclear facility and reads in part as follows:

"Insured Shipment means a shipment of source material, special nuciear material, spent fuel or waste, herein called material, (I) to the facility from any location except an indemified nuclear facility.. or (2) from the facility to any other location..."

The application of. the above Insured Shipment clauses to shipments of material be weer various types of facilities is illustrated in Figure 1 .

NUCTEAR LIABILITY INSURANCE POLICY

(SUPPLIER'S AUD TRANSPORTER'S I'CRM)

In acdition to the Facility Liability Policy NELIA/MAEU also issue a Supplier's and Transporter's Liability Policy which is generally purchased as excess insurance by manufacturers and suppliers of equipment to nuclear facilities and by shippers and transporters o: nuclear naterial.

This policy affords third party liability insurance resulting from nuclear incidents and arising out of the furnishing of equipment, supplies and services to nuclear facilities and including coverage during the course of transporting nuclear material. The basic policy covers only the named insured" except that during the course of transporting source material, spexial nuclear material, spent fuel or waste, the definition of insured has been broadened by endorsement to include anyone (other then the United States or i is agencies) with respect to his legal responsibility. 
All 1: ability policies issued by the nuclean insurance pools contain an aggregate Iimit of liability clause which in effect establishes a maximum Iimit equal to the pools capacity on any one nuclear incident irrespective of the number of policies which might apply. Consequentiy, if an insured shipment is covered by a facility policy affording the pool capacity any separate Supplier's and Transporter's polj.cy purchaced by the carrier would not provide additional limits. However, in instances where an insured. shipment is primarily covered by a facility policy with a limit less than the pool's capacity, for example, a fuel fabricator, an applicable supplier's and Transporter's policy would afford coverage excess of the existing facility policy limit.

One other important point applicable to all domestic nuclear liability policies is the territoriai limitation to insured shipments. These policies only alford coverage that is limited to the territorial limits of the United States of America, its territories or possessions, Puerto Rico or the Canal Zone. For example, ro coverage is provided between the continental linits of the United States and territorial limits of Puerto Rico even though coverage is provides within these limits in both instances.

\section{NUCLEAR LIABILITY INSURANCE FOR INSURING} SHIPMENTS OUTSIDE THE UNITED STATES

In many cases American shippers and transporters may find that their interests are not adequately protected under existing international regula. tions and should examine the availability of private insurance. In some instances the conventional liability policies specially negotiated for the airlines and steamship lines have included protection for both nuclear and non-nuclear hazarós. However there appears to be a trend anong the conventional insurance underwriters to limit or exclude protection arising from the nuclear risk. To the extent that United States firms are unsatisfied with the protection afforded above by the certain transporters they 
may consider the purchase of a Supplier's and Transporter's Foreign Liability policy designed to cover outside of the United States territorial Iimits. $\$ 10,000,000$ of this coverage is available from NELIA and $\$ 5,000,000$ from MAELU. It will be recalled that these pools operate in close cooperation with respect to domestic insurances but work independently and in competition when providing the foreign coverage. Consequently a few differences exist in the policy coverage and exclusions as well as rating procedures. In addition to the domestic pools the London Insurance Market will provide competitive coverage for nuclear liability on foreign shipments with an available capacity of approximately $\$ 15,000,000$. In sumary, United States firms may purchase a combined total of some $\$ 30,000,000$ of limits to insure their foreign transit liability at varying coverages and costs.

In addition to the above insurance the United States Congress has considered amendments to the Price-Anderson Act to provide limits up to $\$ 100,000,000$ covering foreign shipments of nuclear material via ships of United States registry. A bill was introduced during the Ninety Pirst Congress to extend this indemity for private Atomic Energy Conmission licensees and establish a financial protection requirement of $\$ 15,000,000$ from private insurance with the Price-Anderson indemnity being excess. Al though this proposed legislation did not pass it is anticipated similar legislation will be introduced again this year.

It would be appropriate for American shippers and tmasporters of nuclear material outside of the Inited States to examine the liabilities associated with shipments on intemational waters, air routes and within foreign countries. This paper cannot embrace an analysis of these areas but the following sources of information can be recommended to those interested. 1. Selected Materials on Atomic Energy Indemnity Legislation Joint Committee Print (June 1265) availabie from the U.S. Goverment Printing Office. 
2. Foreign Third Party Legal Liability - an analytical study prejared by the Secretariat of the European Nuclear Energy Agency, (1969) available from offices of the Organization of Economic Co-operation and Development.

3. Third Party Liability and Insurance in the field of Maritime Carriage of Nuclear Substances - Monaco Symposium (1968) available from the offices of the Organization of Economic Co-operation and Development. We understand another similar symposium is contemplated this year. INSURANCE COSTS

We will now examine the nuclear liability insurance costs associated with the shipments of nuclear material. As previously discussed shipments of naterial between domestic nuclear facilities are automatically included under the NELIA and MAELU Iiability facility policies. This being the case no separate premium is chargeable to shippers or transporters since they are "omibus insureds" under policies purchased by the facility owners. The annual cost of a facility policy insuring a power reactor for $\$ 82,000,000$ will develope premium in the area of $\$ 250,000$ which will vary dependine upon such rating considerations as the power level, containment and proximity to population centers and other property values. With respect to fuel reprocessing facilities, the annual facility polioy may be estimated to be $\$ 44,000$ based upon the annul separation of $1000 \mathrm{kgs}$ of fissionable material and required financial protection limits of $\$ 20,000,000$. The facility in surance for fuel fabrication plants is based upon the maximum inventory of nuclear material, plant locgtion and policy limits selected by the owner. For example, a rural location with $300 \mathrm{~kg}$. Uranium and a $\$ 10,000,000$ limit could develope an annual premium of approximately $\$ 14,000$.

Domestic Supplier's and Transporter's Liability policies are individually rated after consideration of the type and quantity of material shipped, packaging, annual number of shipments, mode of transit and desired. 
coverage. A basic rate is established for the first $\$ 1,000,000$ limit and a percentage of this rate assigned for higher limits subject to specified minimums. For example, a risk with nominal exposure might develope a premium of $\$ 750$. for the first million limit, $\$ 375$. for the second million and $\$ 250$ each million sor higher limits.

An important aspect of the domestic nuclear liability insurance is the realization of a substantial premium refund if the overall industry experience proves favorable under the Industry Credit Rating Plan. Approxmately $67 \%$ of every premium dollar is set aside for the payment of losses and loss expense and is designated as the Reserve Premium. After a ten year waiting period the total industry premiums and. losses are evaluated and a Reserve Premium ReIund determined which is shared by all policy holders for the year in a direct ratio of policy premium to total industry premiums. Accordingly, refunds were made in 1967 on those premiums paid in 1957. The four consecutive annual Industry Credit Rating Plan refunds to date have averaged $97 \%$ of the reserve premium. This is indicative of the very favorable industry operating experience to date.

A less sophisticated method is involved in developing the cost to facility owers for the Price-Anderson Indemity. The reactor facility charge is based upon a fee of $\$ 30$ per Megawatt Thermal rating of the reactor. For Fuel Reprocessing Plants, the fee is determined by the Atomic Energy Commission in consideration of the processing capacity, waste storage exposure and amount of financial protection required. The most recently proposed amnual charge for this type of facility is $\$ 4,000$.

The insurance costs associated with insuring foreign shipments are also developed on an individual risk basis after evaluating the type and quantity of the material, packaging, mode of transit, points of departure and destination and special cover required with respect to inclusion of the transporter's interest, damage to companion cargo and port facilities. The final rating 
is usually expressed by a premium per shipment for a specified limit of liability (e.g. $\$ 5,000$ per shipment for a 5,000,000 limit.)

\section{LOSS EXPERTENTE}

This paper would be incomplete with-out providing a few observations concerning the loss experience associated with the shipments of nuclear materials. Generally speaking it can be stated that the experience has been most favorable with no hom major contamination losses. However the trensportation of nuclear materials is subject to the same risks as conventional shipments.

It may be of interest to summarize certain experience data available from the United States Department of Commerce which includes reports of accidents involving USAEC shipments of radioactive material during the period 1949 through 1961. Information show in the following tables was tabulated from the above reports.

Table 1. Accident Experience by Mode or Location

\begin{tabular}{lc}
\hline Moce & No. of Accidents \\
\hline Truck Accidents & 32 \\
Rail Accidents & 13 \\
Air Accicients & 2 \\
Terminal Accidents & 15 \\
Total & 62 \\
\hline
\end{tabular}

1. A sumary of Transportation Incidents in Atomic Energy Activities 19491956 AECU-3613 (1957)

2. Health and Safety - A summary of Incidents Involving USAEC Shipments of Radioactive Material 1957-1961 by D.E. Paterson and V.P. DeFaha TID (1962) 
Table 2. Proximate Cause of Accident Irrespective of Mode

\begin{tabular}{lc}
\hline Type & No. of Accidents \\
\hline Handling (in terminals) & 15 \\
Collision & 16 \\
Fire & 6 \\
Vehicle Equipment Failure & 7 \\
Leakage of Containers & 4 \\
Derailment (Rail) & 5 \\
Tiedow Failure & 2 \\
Aerial Fispersal & 1 \\
Overturn (Vehicle) & 4 \\
Air Crash & 2 \\
Total & 62 \\
\hline
\end{tabular}

Table 3. Accident Experience by type of Naterial Involved

\begin{tabular}{lc} 
Type of Material & No. of Accidents \\
\hline Source Material & 20 \\
Radioisotopes & 11 \\
Irradiated Fuel Elements & 8 \\
Special Nuclear Material & 4 \\
Radioactive Waste & 4 \\
Emptr Containers & 3 \\
Contaminated Machinery & 3 \\
Water & 1 \\
Sand & 1 \\
Not Available & 7 \\
Total & 62 \\
\hline
\end{tabular}


The nuclear liability loss experience incurred since 1957 by NELIA MEUU for commercial operations has developed a total of sixteen reported incidents, most of them minor. of these sixteen, nine have involver transportation.

Five of the transportation incidents concerned contamination to property and incurred an average loss paymert including loss expense of $\$ 1705$, the most costly loss being \$3519. The sixth claim involved minor Uranium contamination to a warehouse and trucli weigh station which was settled without payment. A seventh report alledged bodily injury resilting from a small quantity of depleted uranium delivered to a wrong address with a final determination that the injury, if any, was covered by conventional liability insurance. The eighth and ninth reported incidents each involved alledged bodily injury to a worker in the transportation industry. Both of these cases are presently in litigation and it is qusstionable if any radiation injury is involved.

\section{CURRENT INDUSTRY PROBLEMS}

A few observations should be made relative to areas which will receive further attention for insuring the shipments of nuclear material.

You, will recall the initial concem of underwriters was the lack of loss experience data and the unknown effect of anticipated technological advances on overall loss experience. The limited number of operating reactors, the lack of operative experience with the large size units together with the relative low frequency of new and spent fuel shipments, malies it necessary to continue using considerable judgement in rating the nuclear hazard. 
There has been increasing criticism among nuclear industry opponents of the Price-Anderson Act which comes up for renewal in 1977. The critics contend that the industry should assume its own risks and are particularly vocal with respect to government indemnity being provided for certain licensees where the required financial protection is less than the available liability insurance. It is expected the upcoming hearings for Price-Anderson renewal will generate considerable public interest. Recent issues of INFO, a Public Affairs and Information Program publication by the Atomic Industrial Forum has included articles on this subject.

Several problems presently face shippers of spent fuel due to the weight and size of the transporter casks. Some railroads are refusing to haul spent fuel shipments except under very restrictive conditions. State Motor Vehicle Bureaus have become increasingly alarmed at the frequency of requests for overweight permits on their highways and many are increasingly refusing to issue them. The above rail and motor vehicle restrictions have focused attention on the possible use of barge or specially designed self-propelled vessels. This al temative appears to have merit since the majority of reactors are located on or in close proximity to navagable waterways.

One other area receiving attention involves the potential theft and hijack risk which may necessitate new safeguard and monotoring techniques to minimize loss of material during transit and the attendant liability exposure this could create. An axticle appearing in the April 26, 1971 issue of Newsweek Magazine discussed this subject. 
Both the nuclear industry and transportation industry can take pride in the excellent record of transporting nuclear materials to date. This fact should provide the industry with an additional incentive to meet the increasing challenges that will surely develope during the next several years of projected rapid growth for nuclear energy activities. 
RROCESSING RADIOACTIVE SEIPMENTS FROM THE STANDPOINT OF RADIATION SAFETY*

Carl W. Buckland Jr.

University of California, Los Alamos Scientific Laboratory

Los Alamos, IJew Mexico 87544

\section{ABSTRACT}

The complexity of current shipping regulations applied to the transport of radioactive materials justifies a procedure that minimizes the chance for human error. The procedures exercised by the Health Physics group of the Los Alamos Scientific Laboratory will be detailed in the presentation and paper.

Compliance with the regulations has been assured by developing a data sheet to be processed by the Health Physics surveyor that provides a reminder for each pertinent reguirement of the regulations. Once the surveyor has become familiar with the regulations and associates these rules with the corresponding item in the data flow sheet, the chance for overlooking sone requirement is minimal.

Radioactive shipments from a laboratory are extremely varied in nature. For this reason, the operating groups are encouraged to seek advice from traffic, criticality, health physics and engineering specialists before attempting shipment. Advisory information is provided so that the final shipment will conform to the regulations. An "Advance Information Fom" is filled in and distributed to the appropriate individuals so that all persons involved in the final shipment will be cognizant of the details. It also provides a method of pre-planning and check list to assure that no requirement has been overlooked. Tine consuning gran to curie conversions, dose rate measurements to curie determinations. Fissile class and special form declarations are among some of the items included in the form.

The operating group packages their material according to the special requirements for the package specification, Paragraph 173.396 or special permit. At the point of origin, the material packager is required to sign a package certification form for certain containers indicating his conformance with special inner packaging requirements such as ratio of hydrogen to fissile material, special inner capsules, heat load, void space, poisons, absorbers and physical form.

All radioactive shipments are indicated as such on the shipping request. upon receipt of a shipping request that includes radioactive material, the Health Physics group is notified by the shipping department to process the comprehensive data sheet after making the necessary radiation measurements, smears, label selection and double check of curie determinations.

Every effort is made by the surveyor to conscientiously examine his finished product for errors or omissions to the point of duplicating prior calculations provided in the "Advance Information Fom." He also refers to special permit reguirements for completeness of compliance.

The data sheet is then reviewed by the traffic manager for violation of any regulation and if found to be satisfactory, signs the certification for receipt by the carrier. A file copy of the data sheet is then reviewed by three supervisory personnel in the Health Physics group for possible further correction and to furnish any constructive criticism to the Health Physics surveyor for his Euture guidance in processing other radioactive shipments.

*This work was performed under the auspices of the US Atomic Energy Commission. 
The complexity of current shipping regulations applied to the transport of radioactive material justifies a procedure that minimizes the chance for human error. The procedures exercised by the Health Physics group of the Los Alamos Scientific Laboratory are detailed in this paper for the benefit of those organizations faced with comparable administrative complexities.

PRE-PIANNING

Radioactive shipments from a laboratory are extremely varied in nature. For this reason, the operating groups are encouraged to seek advice from traffic, criticality, health physics and engineering specialists before attempting shipment. Pre-planning is especially desirable when the more exotic specification containers are used or when there is a need to apply for a Department of Transportation special permit through the AEC in lieu of a specification container. Advisory information is provided so that the final shipment will conform to the regulations.

Data received from the operating group are recorded and developed in the "Advance Information Form" (Figure 1). Processing the form provides a preliminary check list to assure that no important requirement has been overlooked. Time consuming weight to curie conversions, dose rate to curie deterninations, fissile class and special fom declarations are prepared in advance. The form is distributed to the appropriate individuals so that all persons involved in the final shipment will be cognizant of the details.

\section{INITIAI PACKAGE CERTIFICATION}

The operating group packages their material according to the special requirements of the DOT specification or DOT special permit or/and DOT Paragraph 173.396. At the point of origin, the material packager is reguired to sign a package certification form for certain containers indicating his conformance with special inner packaging requirements such as the ratio of hydrogen to fissile material, special inner capsules, heat load, void space, poisons, absorbers and physical form.

Past experience indicated that operating groups were not packaging special purpose containers according to the specification or special permit requirements. There was no assurance that Iimitations on quantity, heat load and ratio of hyarogen to fissile material were not being exceeded. Once the 
RADIOACTIVE SHIPMENT

"Advance Information Form"

GROUP SEIPPING DATE

DESTINATION

MATERIAL FORM

AMOUNT

TRANSPORT GROUP A, B, Or LARGE

FISSILE CLASS TRANSPORT INDEX

CONTAINER RROVIDED

REMARKS

Fig. 1. Advance Information Form 
container was received in the shipping department there was no way to determine whether the detailed requirements had been met. It was therefore decided that "Certification of Packaging" forms would be prepared to include all of the pertinent requirements on one sheet of paper and thereby place the initial responsibility with the operating group. Forms for three DOT specification and eleven DOT Special Permit containers used most frequently were prepared for routine use. They are as follows:

$$
\begin{aligned}
& \text { DOT Specification Number } 55 \\
& \text { DOT Specification Number } 6 \mathrm{~L} \\
& \text { DOT Specification Number } 6 \mathrm{M} \\
& \text { DOT Special Permit Number } 5097 \\
& \text { DOT Special Permit Number } 5246 \\
& \text { DOT Special Permit Number } 5660 \\
& \text { DOT Special Permit Number } 5885 \\
& \text { DOT Special Permit Number } 6286 \\
& \text { DOT special Permit Number } 5915 \\
& \text { DOT Special Permit Number } 6208 \\
& \text { DOT Special Permit Number } 5645 \\
& \text { DOT Special Permit Number } 4960 \\
& \text { DOT Special Permit Number } 6000 \\
& \text { DOT Special Permit Number } 4824
\end{aligned}
$$

Additional certification forms will be prepared as dictated by need. Figure 2 illustrates a typical cextification form. No such forms are deemed necessary for most DOT specification drums or boxes.

\section{SHIPPING REQUEST FORM}

The operating group must process a shipping request form and indicate when the contents of their package are radioactive. Upon receipt of such a form by the shipping department, the Health Physics group is requested to survey the package for dose rate and removable contamination; to select the proper labels, determine curie content and process a comprehensive data sheet.

PROCEDURAL DETAIL FOR PROCESSING A COMPREHENSIVE DATA SHEET

Each Health Physics Surveyox has a working knowledge of the shipping regulations for radioactive material. By a process of association, each pertinent part of the regulation is considered with the data sheet (Figure 3) and in such an order that the information gathered clearly indicates the packaging, marking 
CERTIFICATION OF PACKAGING BY A IASL ORERATING GROUP

Covers DOT Specification Number

For Shipping Reguest Number

To assure that the container referred to above is packaged according to the DOT Specification 178.104 and DOT Paragraph 173.396, the following check 1ist has been adhered to:

1. There will be no mixture of gases or vapors in the package Initials of Packager

which could, through any credible spontaneous increase of heat or pressure, or through an explosion, significantly reduce the effectiveness of the packaging -

2. The contents are such that there will be no significant chemical or galvanic reaction among any of the materials in the package -

3. Material being shipped is solid and will not decompose at temperatures up to $250^{\circ} \mathrm{F}$ -

4. Thermal decay heat does not exceed 10 watts $\left(20 \mathrm{~g}\right.$ for ${ }^{238} \mathrm{Pu}$ and $4.5 \mathrm{~kg}$ for $\left.{ }^{239} \mathrm{Pu}\right)$ -

5. For Fissile class I quantities $\left(1.6 \mathrm{~kg}^{235} \mathrm{U}, .9 \mathrm{~kg}{ }^{239} \mathrm{Pu}\right.$, $.5 \mathrm{~kg}{ }^{23} \mathrm{U}$ or less) the maximum ratio of hyarogen to fissile material does not exceed three, all sources of hydrogen within the specification $2 \mathrm{R}$ being considered -

6. ${ }^{235} \mathrm{U}$ enrichment does not exceed $93 \%$

7. For Fissile Class II shipments the Ecllowing quantities have not been exceeded:

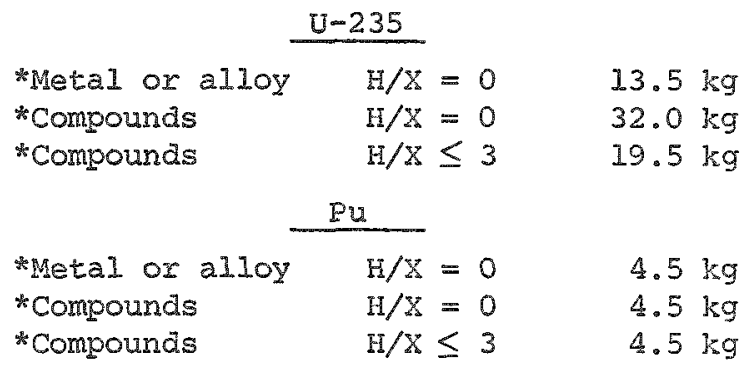

* Indicate which ratio and form on SR (or circle above) due to different Transport Index assignments!

NOTE: Only the hydrogen interspersed with the fissile material need be considered.

8. "Iarge Quantity" in "Normal Form" (both by definition) is packaged in one or more sealed and leak-tight metal cans or polyethylene bottles within the specification $2 \mathrm{R}$ containment vessel -

9. If shielding is needed, it is either inside of the $2 R$ inner vessel or protected in all directions by at least the thickness of the themal insulating material prescribed in DOT 178.104-3(a) -

Eig. 2. Certification Form 
10. Pipe threads of inner $2 R$ vessel are luted with an appropriate non-hardening compound and the cap has been tightened -

11. All of the machined discs or rings used as centering devices are in place -

12. Closure ring bolt has been secured with a lock nut or equivalent device -

13. A tamper seal has been applied -

14. The overall container has been checked for obvious structural failures from repeated handling -

The purpose of this check list is to facilitate the task of shipping radioactive materials in specialized containers. Suggestions for improving this form should be directed to the $H-1$ General Monitoring section.

This is to certify that the radioactive contents of the above described container offered for transportation have been packaged according to the Department of Transportation requirements as indicated above.

Signature of Group Leader

Packaging Date:

NOTE: Attach this completed form to Shipping Request in duplicate.

FORM-HSC-12-(12/70)

Fig. 2. Certification Form 
SR NO.

GROUP SHIPPING
DATE

DESTINATION

IOS ALAMOS SCIENTIFIC IABORATORY

RADIOACTIVE MATERIALS SHIPPING DATA SHEET

METHOD OF TRANSPORT

MATERIAL

FORM OF MATERIAL -

Liquid - Gas -

Solid - $\quad$ Powder -

Special Form* - Metal -

Normal Form - Gram Weight -

Ci.

Transport Group Type A or B quantity

"Large quantity" - Yes Fissile - Yes

$2 \mathrm{R}$ Container and properly marked

Shock or Iiquid

Absorbing Material

Secured Lead, Paraffin

Dor 55 Container

EXTERNAL CONTAINER:

Size

Type $A$ or $B$

No Significant

Removable Contamination:

Heat Load:

(Initials)

DOT and other Marking Required:

*Basis for and approved by:
Gross Weight:

Exempt per 173.391 (a) I-4

R.A. White I R.A. Yellow II

R.A. Yellow III Postal

Maximum Surface Activity on Container (gamma plus neutrons in mrem/h)

Maximum Activity $3^{\circ}$ from Container (gamma plus neutrons in $\mathrm{mrem} / \mathrm{h}$ )

Source of Criticality Evaluation and Transport Index Assignment

Transport Index Used:

Tamper Seal: Yes_ No Fissile Class I__ II__ III

Remarks : IIT

Remar

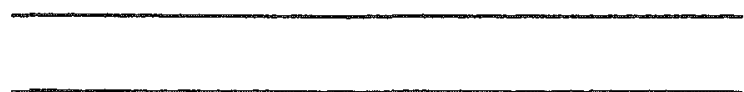


and labeling required.

Obvious items of the data sheet are not included in the discussion to follow. Because of their brevity, the not so obvious will be developed in this paper.

Method of Transport

The method of transport is taken into consideration since certain shipments are not allowed on passenger aircraft. Packages going by mail are under postal regulations rathex than the DoT. "National Security Exempt" shipments require that only one certain label be applied. Exclusive use of vehicle permits higher radiation levels; therefore, the method of shipment dictates the manner in which one evaluates his subsequent findings.

\section{Material}

It is irmortant to seek out and record the correct isotope and mass number since the curie content, heat load, fissile class, transport group, quantity designation, removable extemal contamination and ultimate package requirements are all based on this information. The word plutonium, for example, is not sufficient.

\section{Form of Material}

The physical form of the material is indicated so that judgment can be exercised concerning "Special Form" requirements. For example, ${ }^{239} \mathrm{Pu}$ as metal or oxide will pass the "Special Form" criteria when enclosed in a standard DOT 2R inner container. ${ }^{239} \mathrm{Pu}$ in solution would not pass the "Special Form" requirement, whether in an inner $2 R$ container or not. Material in liquid form requires special consideration as described in DOT $173.393(\mathrm{~g})$. Material in gaseous form requires a different method of curie determination.

\section{Curie Determination}

Most of the curie determinations are made from weight conversions. The activity-mass relationship is found with the following equation:

$$
\mathrm{Ci} / \mathrm{g}=\frac{1.308 \times 10^{8}}{\mathrm{AT}}
$$

Where $\mathrm{A}=$ atomic weight and $T=$ radioactive half life in days

For convenience, the $\mathrm{Ci} / \mathrm{g}$ value for most of the isotopes can be found in LA-4400, "Los Alamos Handbook of Radiation Monitoring 1970."

The number of curies of tritium gas is obtained by multiplying the number of cubic centimeters at STP by 2.6 .

As a rule of thumb, the curie content for fission products over $30 \mathrm{~min}$ utes of age but not greater than 200 days, is determined by measuring the 
gamma rate at one meter in $r / h$ and multiplying by 3 . If the number of fissions are known as well as the age, curies are obtained from published tables.

For radiation measurements at measured distances from known isotopes, curies can also be determined from published tables or by using commercially available isotope handling calculators (Figure 4).

Transport Group

The transport group is determined from DOT $173.390(a)$ or $(b)$ or declared as special form for each isotope and recorded since the quantity type designation is established from the curie content of a specific transport group. The correct packaging is then confirmed from this information. (Exempt, Type $A$ or Type B.) When a "large quantity" is encountered, the data sheet is indicated to this effect as a reminder to use Radioactive Yellow III labels and vehicle placards regardless of radiation levels encountered.

Fissile

For purposes of shipping, the material has to be declared fissile or nonfissile according to the DOT regulations, Paragraph 173.396 (a) (1) through (5). Small quantities of ${ }^{235} \mathrm{U}$ (16 grams total uranium with $93 \%{ }^{235} \mathrm{U}$ enrichment) are considered non-fissile since the ${ }^{235} \mathrm{U}$ content would be $<15$ grams. When the quantity of fissile material exceeds $15 \mathrm{~g}$ and there is doubt concerning an exemption based on the atomic ratio of hydrogen to fissile material, the matter is resolved by contacting a criticality expert. When the material is obviously fissile, the data sheet is identified as such as a reminder that either DOT Paragraph $173.396(b)(3)$ (i) and (ii) restrictions are imposed or that a DOT 6I, $6 \mathrm{M}$ or Special Permit container is utilized. The ultimate container is selected on the basis of type and weight of fissile material authorized.

2R Container and Properly Marked

A DOT 2R inner container is sometimes used to satisfy "Special Form." Such an arrangement permits a Type A container over a Type B thus making the shipment more economical; viz, $10 \mathrm{~g}$ of ${ }^{239} \mathrm{Pu}$ as "Special Form." This iten in the data sheet is also a reminder to see that the $2 \mathrm{R}$ has been marked as required by the specification.

Shock and Liquid Absorbing Material

This item merely records the fact that an absorber or absorbent was used as required by DOT $173.393(\mathrm{~g})(\mathrm{I})(2)$ for liquid radioactive material.

Secured Lead, Paraffin - DOT 55 Container

The purpose of this item is to remind the Health Physics Surveyor to determine if the internal lead shield plug has been secured according to 


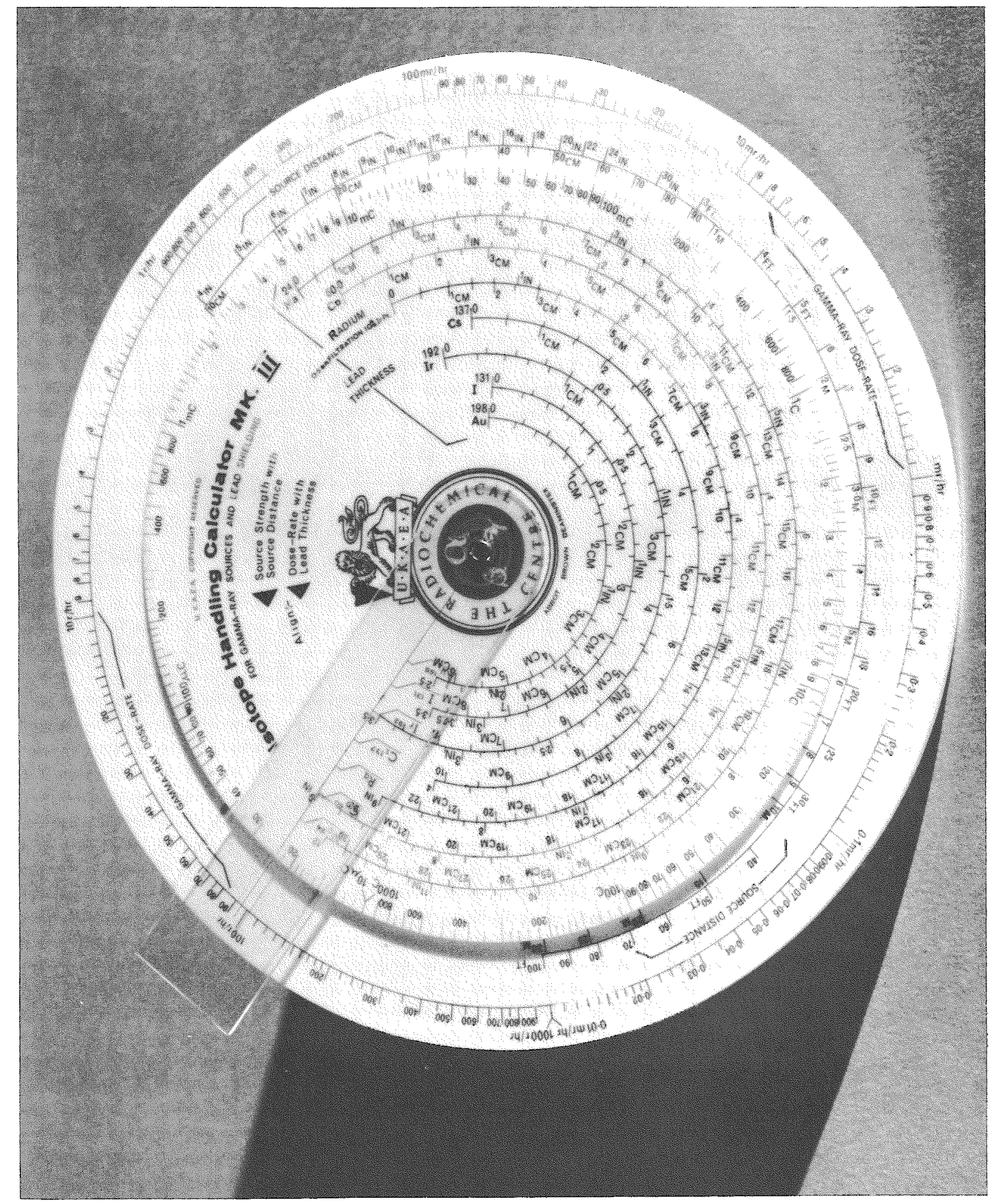

Fig. 4. Isotope Handling Calculator 
DOT $173.393(d)(1)$. The security of the shield plug should not be solely dependent upon internal wood bracing to keep in place. The mention of paraffin and a DOT 55 container provides a record as to whether either of this type of shielding was required. Other types of neutron moderator and gamma shielding may be mentioned here for informational purposes.

External Container Size

The main objective of this item is to remind the Health Physics Surveyor that no dimension of the container can be less than four inches and provide a record.

External Container Type A or B

This item is to remind us that a Type $A$ container must be used as a minimum containment for a non-exempt Type A quantity. A Type B container must be used for either a Type B or Large Quantity of material, taking into consideration the $300 \mathrm{Ci}$ limit in "Special Form" with the DOT 55 for domestic use only which is a Type B quantity. It should be noted that a DOT 6M can be used as either a Type A or Type B container. The type container declared in this latter case is usually determined by the form of the material; viz, "Normal" or "Special." DOT 173.396 (c)(I) authorizes fissile radioactive materials containing Type $\mathrm{B}$ quantities in a $6 \mathrm{~L}$; however, only $14 \mathrm{~kg}{ }^{235} \mathrm{U}$ can be shipped in a $6 \mathrm{~L}$ which is a Type A quantity even in "Normal Form." Most of the DoT Special Permit containers are Type $B$ and are used when no specification container is authorized for the contents. A check of the permit is made to be certain that the contents are authorized and that the permit has been extended to our use.

No Significant Removable Contamination

This item reminds the Health Physics surveyor to determine if the removable contamination from the external package surface by smear technique is significant according to DOT $173.397(2)(1)$ and (2). Smears are sometimes taken from numbered $100 \mathrm{~cm}^{2}$ chalked squares (4" $\mathrm{x}^{\prime \prime}$ ) so that a relationship between the count and the monitored area can be established (see Fig. 5. Smear Technique). Smears are counted with Ludlum Model 20A portable scalers (one is equipped with an end window beta-gamma probe and the other with an alpha scintillation probe) located in the offices of the shipping department. (See Fig. 6 . Counting smears.) Smear techniques can miss potentially contaninated areas. For this reason, direct instrument surveys are also accomplished when background radiation from the package permits, otherwise a general overall rough swipe is taken for the detection of loose contamination.

Heat Load

with more ${ }^{23} \mathrm{Pu}$ being shipped these days, care is taken to determine that 


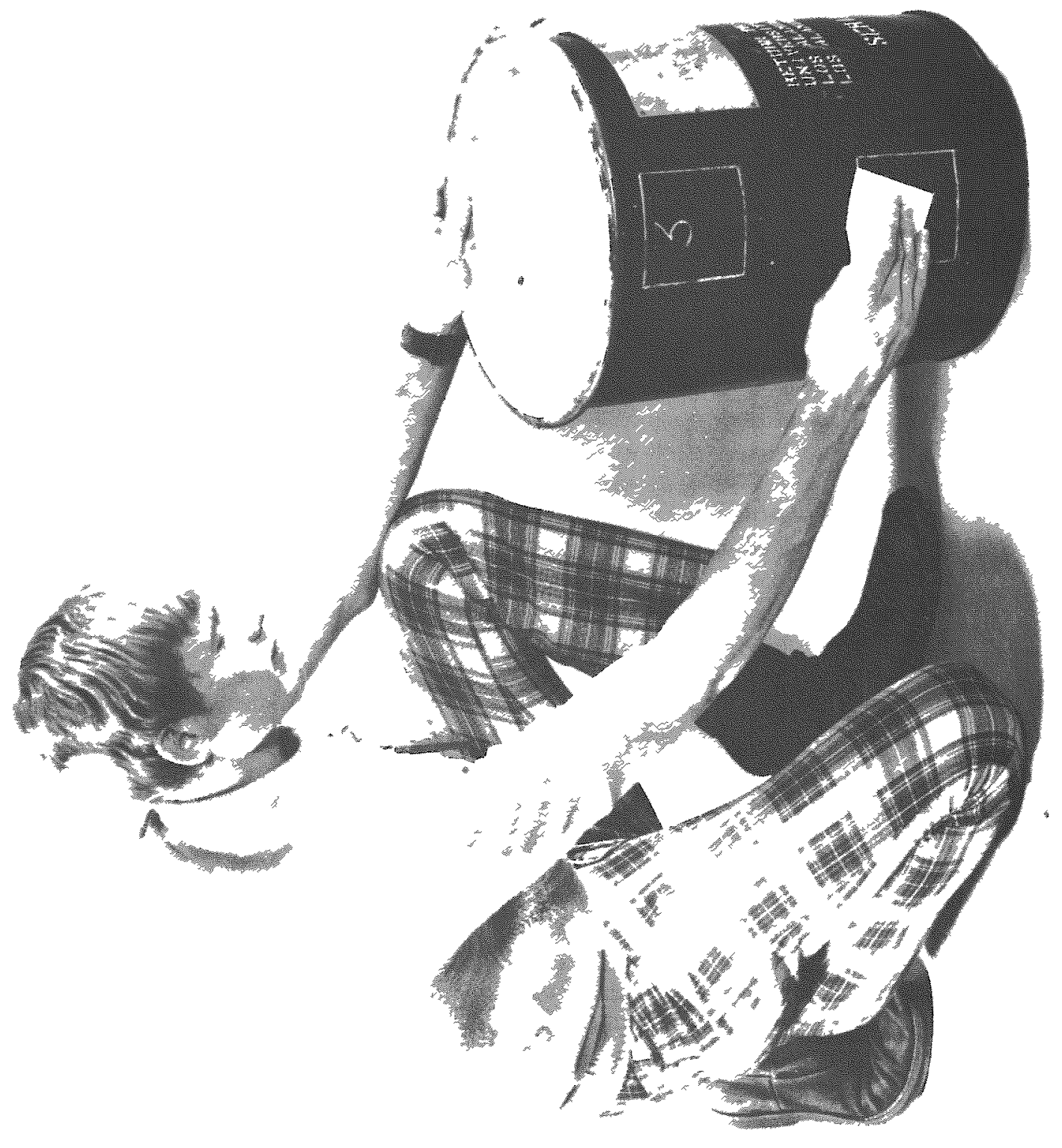

Fig. 5. Smear Pechnigue 
s

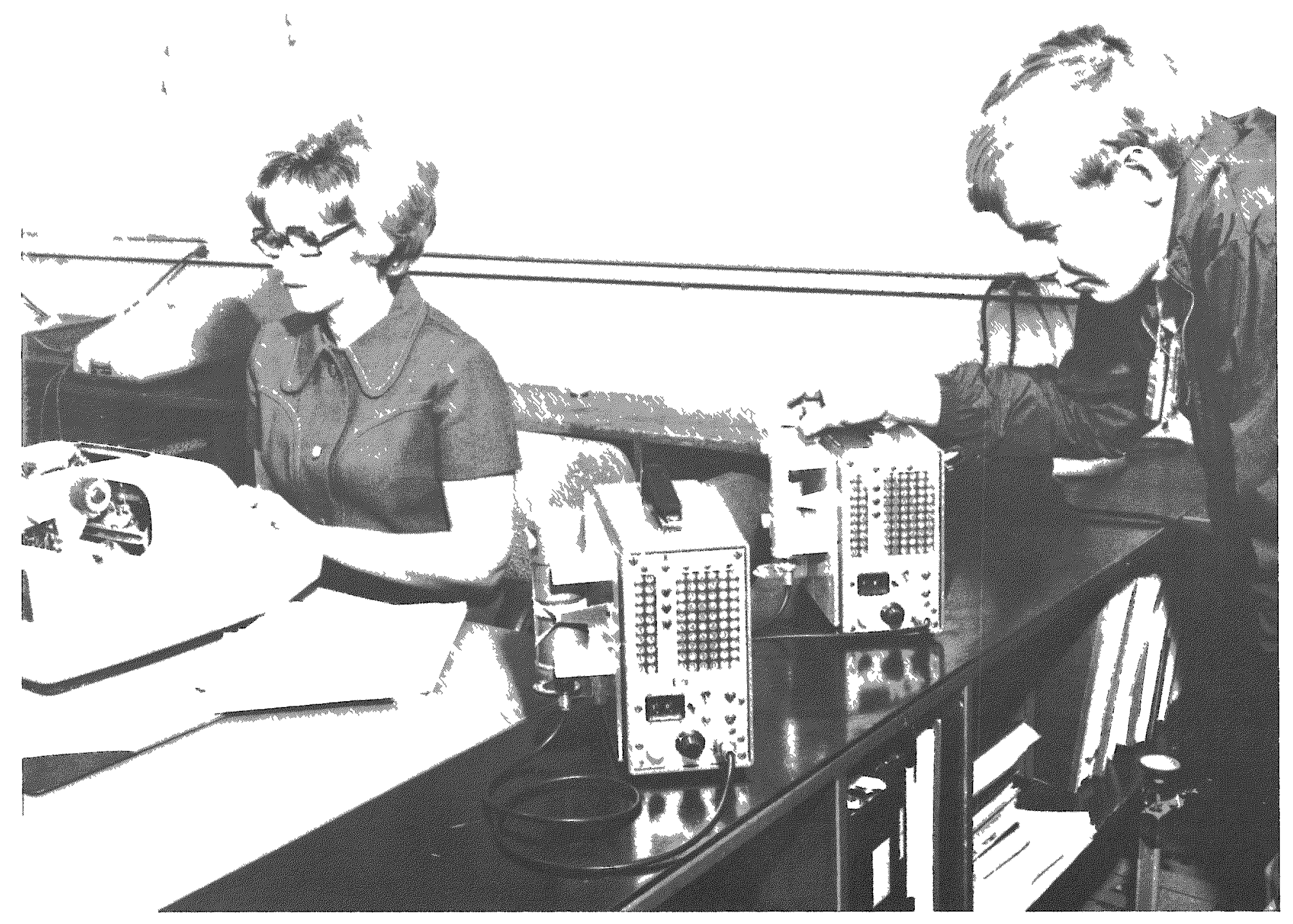

Fıg. 6. Counting Smears

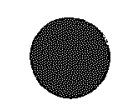


the heat load limit for the container in question is not exceeded. A heat load of .5 watts $/ g$ is assumed for ${ }^{238} \mathrm{Pu}$. Some of the old DOT Special Permit containers (such as 4960) express the content limit in kilograms of plutonium without specifying the atomic weight or heat load limit. Care is exexcised not to misinterpret the spirit and intent of the permit. It is rather obvious that Dor 4960 is not designed for 2250 watts from $4500 \mathrm{~g}$ of ${ }^{238} \mathrm{Fu}$ oxide $(4.5 \mathrm{~kg}$ of plutonium oxide is permitted in the container).

DOT and Other Marking Required

The Health Physics Surveyor determines the correct marking required for the package to be shipped from the container specifications or Special Permit. Reusable containers having permanent markings are altered when necessary. For example, the word fissile on the $6 \mathrm{M}$ is blocked out with tape when non-fissile material is enclosed. Figure 7 illustrates the typical marking required and additional optional information that may be included. The specification number and authorized gross weight of the container are required inside of a rectangle. Name of the maker is included under the rectangle as letters if registered with the Bureau of Explosives. The "Special Form" marking is not required but has been included for whom it may concern. In this instance, one would otherwise consider the shipment in violation since $.123 \mathrm{Ci}$ of ${ }^{239} \mathrm{Pu}(2$ grams as nonfissile material per DOT 173.396 (a) (1) in "Normal Form" requires a Type B container. As "Special Form" Type A quantity, the Type A, DOT $19 B$ is authorized.

Basis For and Approved By

The name of the person that authorized "Special Form" is recorded for reference purposes. This practice prevents indiscriminate use without authorization from individuals designated for this purpose. For example, only the DOT approves Special Form criteria for IAEA shipments as the competent authority.

\section{Gross Weight}

The weight is tabulated for record purposes and is a reminder to determine whether the gross weight limitation of the container specification has been exceeded. This is especially relevant when shipping heavy pieces of depleted uranium. For example, $200 \mathrm{Lbs}$. of D-38 cannot be shipped in a DOT $19 \mathrm{~B}$ even though the curie content is a Type A quantity. In the case of the DOT 55, certain weights require skids.

Exempt per 173.391 (a) $1-4$

This item is checked when the package meets all five main requirements of the referenced DOT paragraphs. On occasion, 173.391 (b) and (c) may be 


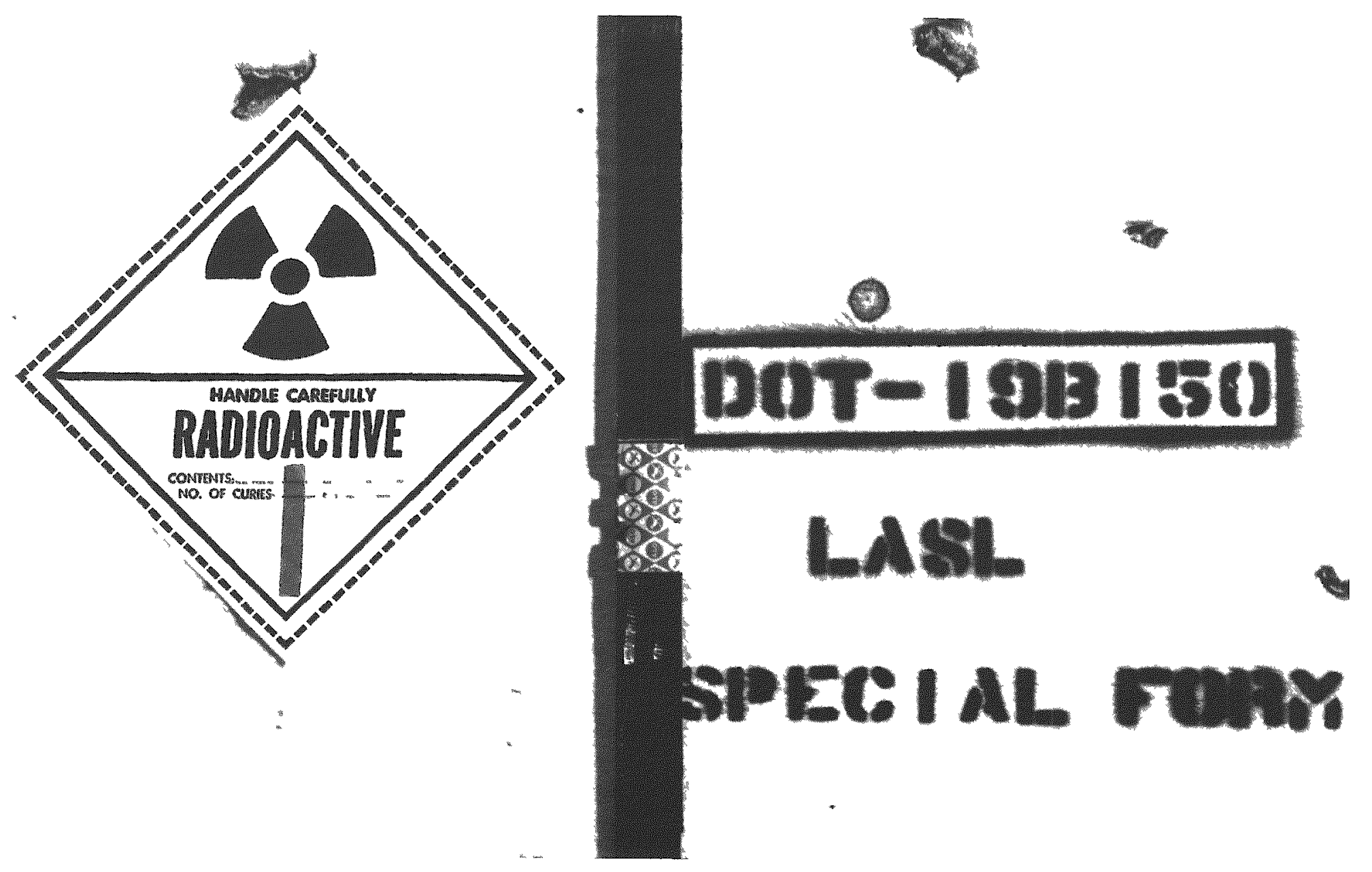

Fig. 7. Typical Marking and Tamper seal 
applicable and indicated in place of (a) $1-4$.

Labels

For the guidance of the Health Physics Surveyor, a label display with pertinent instructions is posted in the shipping department (see Figure 8). Since the label required by the regulations is not always indicative of radiation levels, abbreviated guidelines are necessary for immediate reference. For example, the Transport Index assignment for one special permit container is 1.9 for reasons of the fissile material content. A Radioactive yellow III label is required even though the radiation levels would otherwise allow a Radioactive White label. This is also the case with $173.396(b)$ (1) and (3)(i) packages. Radioactive Yellow III labels are required for National security Exempt shipments regardless of radiation levels. The same is true for "large quantities" of radioactive material and for DOT $173.393(j)$. For postal shipments, a sticker with the following statement is affixed to the package:

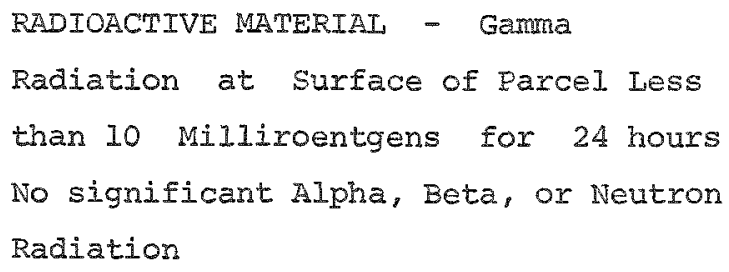

Maximum Surface Activity on Container

The external surfaces of the shipping container are surveyed with portable instruments as shown in Figure 9. Neutron measurements taken with an instrument that reads in $\mathrm{n} / \mathrm{cm}^{2}-\mathrm{sec}$ are converted to mrem/h for the energy encountered and added to the gamma reading.

Maximum Activity $3^{\prime}$ from Container

The same principle holds true for this reading as at the surface. Figure 10 illustrates a reading being taken with an enexgy independent neutron detector that reads directly in mrem $/ \mathrm{h}$.

\section{Source of Criticality Evaluation and Transport Index Assignments}

In the case of Fissile Class II shipments, the source of information providing the Transport Index is recorded for reference purposes. Such information is obtained from various DOT paragraphs, special permits and criticality experts in the case of "National security Exempt" shipments.

\section{Transport Index Used}

The larger Transport Index of the two methods for determination is recorded here and on the labels. 

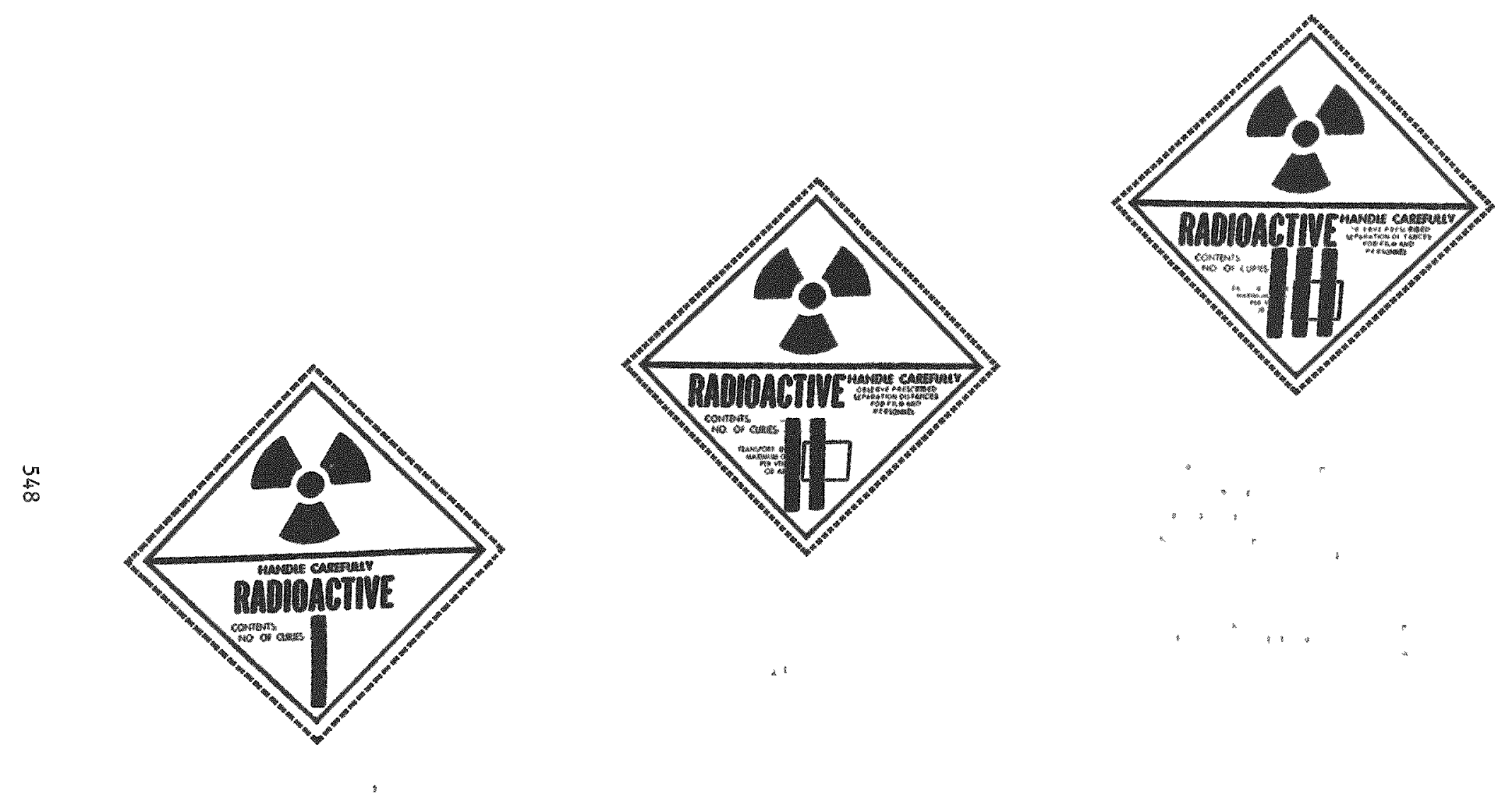

Fig. 8. Label Display 

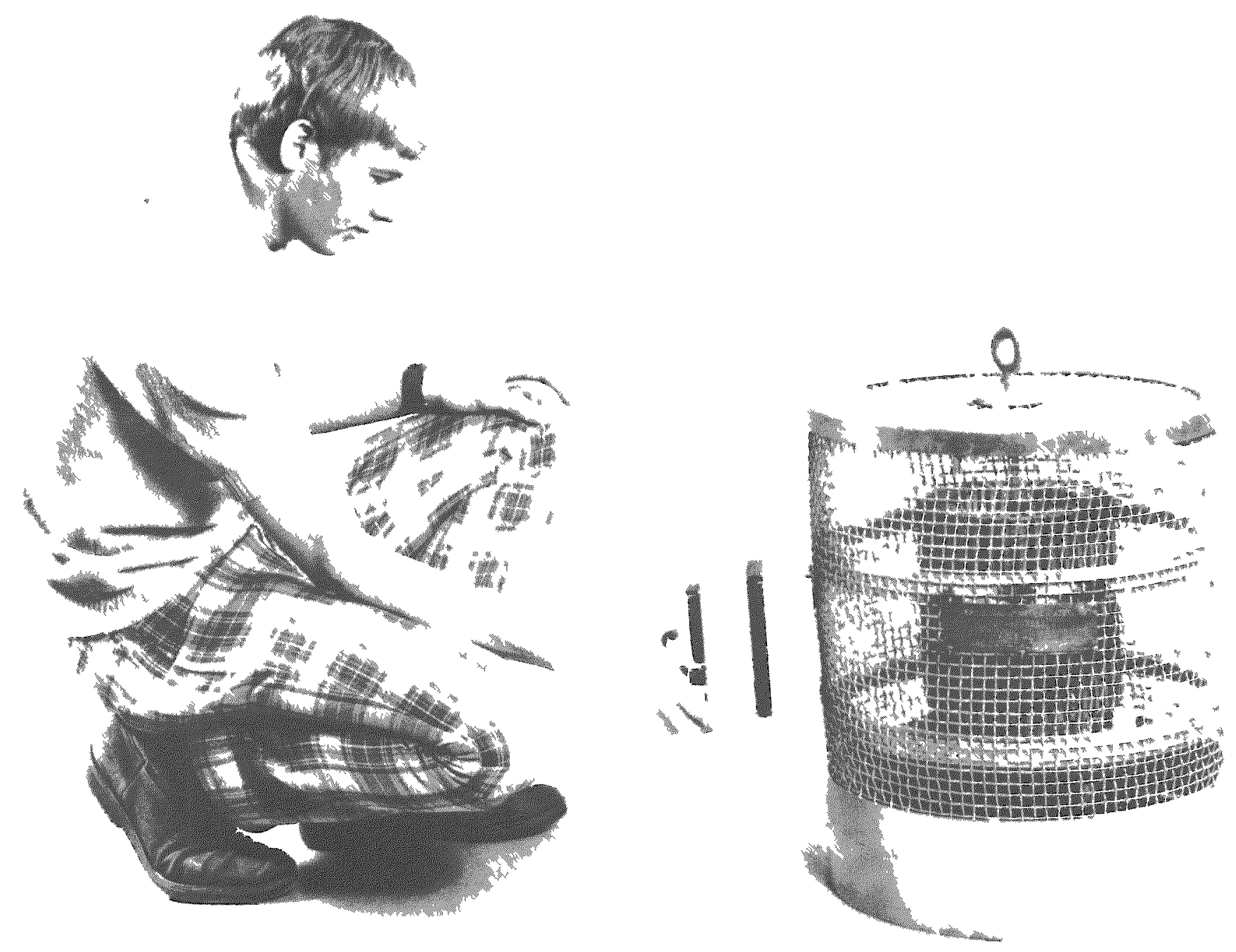

Fıg. 9. Surveyıng Package Surface 


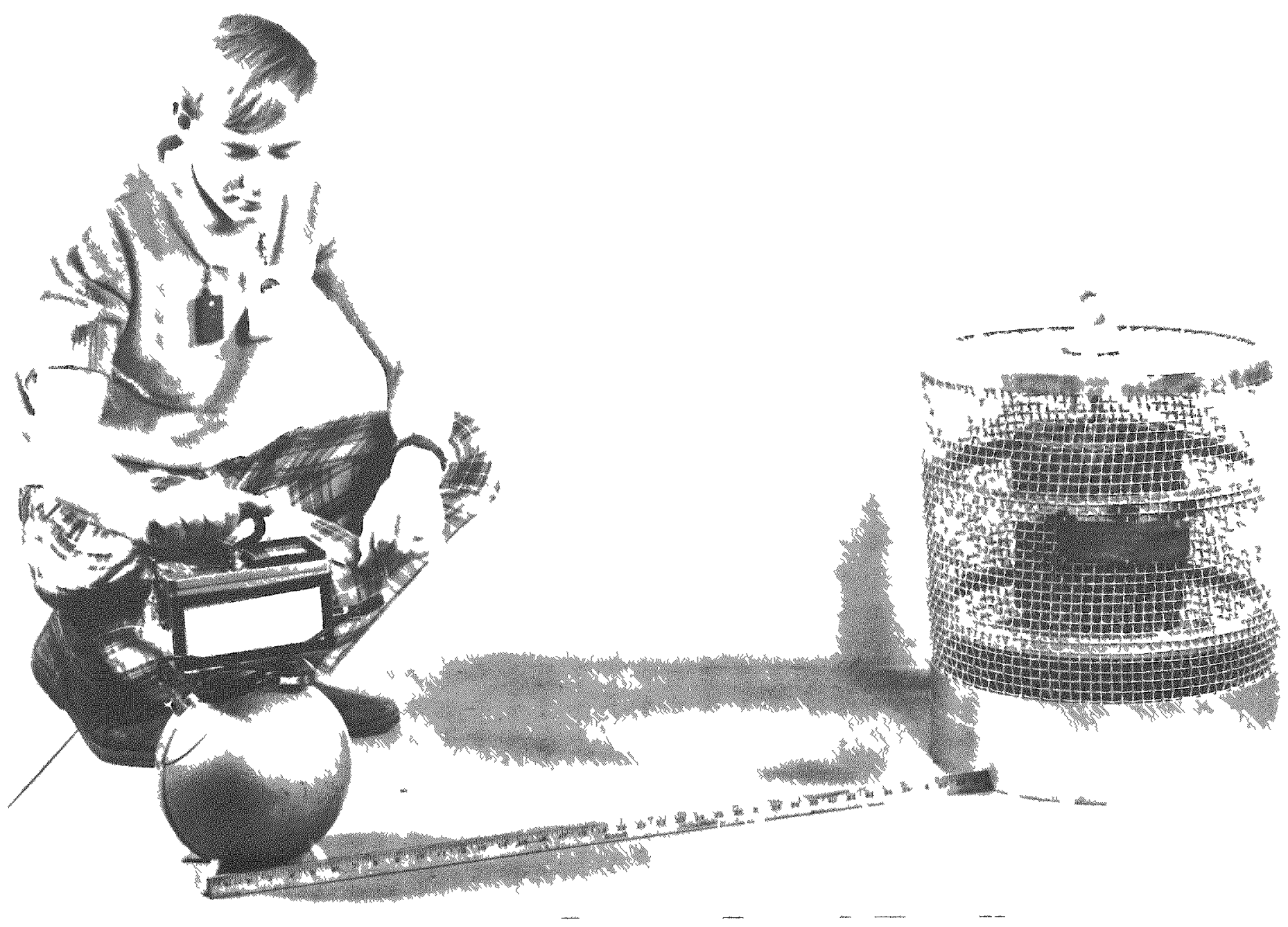

F19. 10. Surveying Package at 3 Feet 


\section{Tamper seal}

This item acts as a reminder since all non-exempt packages require a tamper seal. One type of tamper seal is shown in Figure 7.

Fissile Class I II III

The fissile class is determined from the various DOT paragraphs or DOT special permits based on quantity, form and atomic ratio of hydrogen to fissile material. The class is recorded as a reminder that the larger of the two methods of determining transport index is utilized in the case of Fissile Class II. It also acts as a double reminder concerning the proper use of labels.

The completed data sheet is then reviewed by the traffic manager for violation of any regulation. He signs the certification for receipt by the carrier if the shipment is found to be satisfactory. A file copy of the data sheet is then reviewed by three supervisory personnel of the Health Physics group for any aditional correction. 


\title{
is \\ RADIATION SURVEY OF THE TRANSPORTATION OF RADIOACTIVE MATERIALS
}

\author{
Gai1 D. Schmidt
}

\section{ABSTRACT}

The current standards for the maximum allowable radiation from packages of radioactive material in transportation were published by the Interstate Commerce Commission in 1947. The surface dose rate limitation of $200 \mathrm{mrem} / \mathrm{hr}$ was designed to prevent transportation worker from receiving more than $100 \mathrm{mrem}$ per day during package handling, while the $1 \mathrm{imit}$ of $10 \mathrm{mrem} / \mathrm{hr}$ at 3 feet was based upon considerations of exposure to photographic film. Although there has been an excellent record of safety in transporting radioactive materials there is little data available in the literature regarding radiation exposure of transportation workers and the general public or the degree of compliance of radioactive matexial shipments with the transport regulations.

Based upon these considerations the Atomic Energy Commission, Department of Transportation, and Department of Health, Education, and Welfare undertook a joint project to study the matter in greater depth. The survey conducted at 6 geographical locations (and 23 transportation terminals), included a radiation survey of about 300 packages (primarily radiopharmaceuticals). The results of the survey reported in this paper include (1) data on radiation levels from radioactive material packages, (2) an evaluation of radiation exposure to transportation workers, and (3) information on compliance by carriers and shippers with the transport regulations, including, labeling, transport. index (TI) and separation distances.

It was the conclusion of the survey that the radiation exposure of transportation workers under the conditions observed were within permissible limits. A possible exception was noted in the case of radium shipments which involved only $8.2 \%$ of the packages surveyed but represented $56 \%$ of the total exposure rate at 3 feet and $39 \%$ of the total surface exposure rate. The acceptability of radiation exposure of individuals resulted from the short transit times of packages and the low exposure rates external to the package, rather than carrier compliance with stowage/separation distance requirements. 


\section{INTRODUCTION}

Background

The several studies conducted of the occurrence of accidents and incidents during the shipment of radioactive materials have indicated that no known injuries or significant overexposures to persons have occurred. I The literature however, contains only limited data that can be used to estimate the exposure of transportation workers (or the public) and the degree of compliance with the transportation regulations. A 1958 survey of the British European Airways cargo warehouse personnel at London Airport over a two-month period indicated an average dose to transport workers of $182 \mathrm{mrem} / \mathrm{yr}$ with a maximum of $770 \mathrm{mrem} / \mathrm{yr} .^{2}$

A study by Davis et al.? using sealed sources to simulate radionuclide - shipments involved the measurement of exposure rates at various positions in commercial aircraft. The study showed maximum exposure rates for a loading of $40 \mathrm{TI}$ of about 5 to $25 \mathrm{mR} / \mathrm{hr}$ in passenger areas for most possible stowage conditions. The maximum dose rate observed in passenger areas was $400 \mathrm{mR} / \mathrm{hr}$ and the study indicated that specific cargo loading limitations might be necessary for certain of these 1960 vintage aircraft. A theoretical and practical discussion of considerations peculiar to air transport of radioactive materials packages is contained in a report by Evans. ${ }^{4}$ There is also an unpublished survey by a Field Inspector of the Bureau of Explosives, Association of American Railroads, during March 1962 at the Railroad Express Agency terminal in Knoxville, Tennessee. ${ }^{5}$ The results of this five day study of radiation levels within the terminal and from packages has not been analyzed but may be of interest to those who desire to study this subject in greater detail.

In recognition of this fact, the three Federal agencies having a regulatory or program interest in this matter, the U.S. Atomic Energy Commission, U.S. Department of Health, Education, and Welfare, and the Interstate Commerce Commission (now the Department of Transportation), began discussions in early 1967 on a proposed joint project to study the matter in greater depth. These discussions culminated in early 1969 with the approval and signature by each agency of a project plan, entitled "Joint Survey of Radioactive Materials shipments."

Purpose of the Project

The major objectives of this project were:

1. To gather factual information and data concerning radiation levels in the transportation environment from packages of radioactive materials. 
2. To obtain information on the status of compliance with the regulations for transport of radioactive materials by shippers and carriers, as related to such factors as package labeling, assignment of transport indices, and observation of prescribed separation distances.

3. To evaluate the effectiveness of the transportation regulations, with regard to the safety of the general public and transportation workers in the radioactive materials transport environment.

\section{Scope of Project}

This project involved field surveys in six selected geographical areas in the eastern part of the United States through which significant numbers of radioactive materials packages pass during normal operations. These facilities were selected after a consideration of the proximity of nuclear facilities such as radioisotope suppliers, nuclear fuel facilities, and radiographers.

\section{SURVEY METHODS}

\section{Instrumentation}

The primary instrumentation used for the survey was the Eberline E-500B beta-gamma survey meter with side-window probe which was calibrated with an NBS calibrated radium source. All measurements were made with the shield closed (i.e. gamma radiation) and as such may be lower than emitted radiation in rems where the package radiations were beta and/or low energy bremstrahlung. An alpha survey meter was also available (but used infrequently) and smear samples of packages were counted with an end-window GM counter and an alpha scintillation detector. Commercially supplied film badges and TLD finger badges were worn by the surveyors.

\section{Data Collection}

The primary data collected during the survey related to radioactive material packages and included radiation levels at contact and 3 feet, wipe tests for surface contamination, shipper compliance with regulatory requirements (such as labeling, package specification, transport indices (TI), etc.), package condition, shipper and destination. Radiation measurements were also made of terminal areas and transport vehicles and data was collected relating to storage conditions, separation of radioactive material packages from film and personnel and total txansport index of material present.

It was decided not to monitor workers with film badges nor to conduct radiation surveys inside passenger carrying aircraft. Accordingly, estimation of exposure to transportation workers had to be based upon radiation levels 
observed under working conditions. Film batges were used however in a few cases for area monitoring of terminal areas and vehicles.

SURVEY FINDINGS

\section{Package Characteristics}

Volume of Radioactive Material Packages.--During the course of this study 398 individual radioactive material packages were observed at six geographical locations and 293 of these packages were surveyed for radiation levels. Estimates based upon carriers' and suppliers' data, and observation indicated that about 1,100 radioactive material packages per day may originate at or pass through these facilities. Projections on an annual basis indicate perhaps 250,000 packages pass through these terminals which might be compared to the estimate of Patterson ${ }^{1}$ of over 300,000 packages per year in 1968 for the total U.S. traffic.

Container Types.--Most of the packages surveyed were type A cardboard boxes, only 3 were type $B$ and no "large quantity" or fissile materials" packages were observed. About $50 \%$ of the specification packages observed were DOT-7A, Type A, while the DOT-7A-55 and ICC-12B together represented about $33 \%$.

Radiation Levels. - The radiation levels at the surface and at 3 feet from the surface are summarized in Table 1 . The average radiation level per package is $56 \mathrm{mR} / \mathrm{hr}$ at the surface and $1.27 \mathrm{mR} / \mathrm{hr}$ at 3 feet.

The average ratio of the surface exposure rate to that at 3 feet as seen in Table 1 varied from 34 to 68 at different locations with the overal1 average of 44 compared to a ratio of 20 between the package limits of $200 \mathrm{mrem} / \mathrm{hr}$ at the surface and $10 \mathrm{mrem} / \mathrm{hr}$ at 3 feet. The observed ratio is consistent with the observed size of the typical package (about 1 cubic foot) and results in an activity limitation based upon surface dose rate. The optimim size to meet both limits requires a package that is about 22 inches on each side. With regard to the radiation exposure aspects, the smaller package results in a higher extremity exposure to handling personnel and a lower exposure from stored material. It was observed that a significant factor in the ratio was the number of radium packages surveyed at a given location. When the radium packages are considered separately the ratio is 31 vs. 60 for all other packages (primarily radiopharmaceuticals). 
Table 1. Package Characteristics

\begin{tabular}{|c|c|c|c|c|c|c|}
\hline Location & $\begin{array}{l}\text { No. } \\
\text { of } \\
\text { Pkgs. }\end{array}$ & $\begin{array}{l}\text { Total } \\
\text { Transport } \\
\text { Index }\end{array}$ & $\begin{array}{l}\text { Total } \\
\mathrm{mR} / \mathrm{hr} \\
3 \mathrm{Ft} .\end{array}$ & $\begin{array}{l}\text { Total } \\
\text { mR/hr } \\
\text { Surface }\end{array}$ & $\begin{array}{c}\text { Average } \\
\text { TI } \\
\text { Per Pkg. }\end{array}$ & $\begin{array}{l}\text { Ratio } \\
\text { Surface to } \\
3 \text { Ft. }\end{array}$ \\
\hline Knoxville & 38 & 33.4 & 23.7 & 1590 & 0.9 & 67 \\
\hline $\begin{array}{l}\text { Washington } \\
\text { (National) }\end{array}$ & 64 & 61.8 & 32.8 & 2012 & 0.97 & 61 \\
\hline Boston & 42 & 36.3 & 33.2 & 1596 & 0.86 & 48 \\
\hline $\begin{array}{l}\text { New York } \\
\text { (LaGuardia) }\end{array}$ & 6 & 21.0 & 22.7 & 1405 & 3.5 & 62 \\
\hline Newark & 25 & 16.7 & 25.6 & 1742 & 0.7 & 68 \\
\hline Chicago & 118 & 179.0 & 234.0 & 8059 & 1.5 & 34 \\
\hline Tota1 & 293 & 348.2 & 372.0 & 16,404 & 1.19 & 44 \\
\hline Total $\mathrm{Ra}$ & 24 & 139.0 & 207.2 & 6,465 & 5.8 & 31 \\
\hline Total other & 269 & 209.2 & 165.0 & 9,939 & 0.78 & 60 \\
\hline
\end{tabular}

It is of interest to note that radium which involved $8.2 \%$ of the packages represented $56 \%$ of the cumulative exposure rate at 3 feet and $39 \%$ of the surface exposure rate.

Ten packages exhibited radiation levels at their surfaces in excess of the allowable $200 \mathrm{mR} / \mathrm{hr}$. Only 3 packages had radiation levels at 3 feet that exceeded the allowable $10 \mathrm{mR} / \mathrm{hr}$. Maximum levels observed at the six locations were:

Location

Knoxvilie

Washington, D.C.

Newark

New York

Boston

Chicago

\section{Surface}

$(\mathrm{mR} / \mathrm{hr})$

200

175 no label

250

300

350

500
3 feet from Surface (mR/hr)

5

$4: 5$

9.0

7.0

25.0

60.0 
It should be noted that the surface levels which exceeded $200 \mathrm{mR} / \mathrm{hr}$ were measured with a detector chamber located inside the survey instrument and at a distance of about 2 inches. Thus for a typical package with dimensions of 8 to 12 inches, the actual surface levels would be higher by about a factor of two.

Transport Index.--The transport index (which is the number of $\mathrm{mrem} / \mathrm{hr}$ at 3 feet from the surface of the package) as stated on the package label is also tabulated in Table 1. Based on the totals for all packages it is observed that labelled transport index compares closely with the measured exposure rate at 3 feet while the specific locations show values that varied by up to a factor of two. The higher measured exposure rate at Chicago was due to two packages with streaming and when these are eliminated, the labelled transport index is only slightly greater than that measured, which might be expected, due to decay of short-lived radiopharmaceuticals.

There were a total of 72 packages out of 293 where the measured exposure rate at 3 feet exceeded the labelled TI value. In the case of 28 packages or 9.6 percent of the 293 packages the labelled TI was 1 ow by $0.5 \mathrm{mR} / \mathrm{hr}$ or more. Two of the three packages which exceeded $10 \mathrm{mR} / \mathrm{hr}$ at 3 feet involved streaming apparently due to poor packaging, while the third was overloaded and had a labelled TI of twenty-six (26).

Package Compliance.-- Of the 293 containers surveyed, 85 or $29 \%$ were incorrectly labelled. The most frequent error (63 packages) involves the use of a Yellow-III where a White-I or Yellow-II was adequate. Three packages or about $1 \%$ had no label and 6 packages were under labelled.

All packages examined meet the 4 inch minimum dimension requirement specified in the DOT regulations.

The requirement for a security seal (DOT regulations Sec. 173.393(b))-"a feature such as a seal, which is not readily breakable and which, while intact, will be evidence that the package has not been illicitly opened" appeared to be the single item most frequently violated or misunderstood. Most packages being cardboard were sealed with tape and/or staples and thus may be easily opened and such packages also, are frequently re-used. In most cases where a security seal was used it did not fulfill the requirement of being "not readily breakable," and only in the case of original package use was there reasonably good "evidence that the package has not been illicitly opened." In addition to the standard cardboard box closure using tape and staples, lead wires, and twisted copper wires were observed. 
It would appear that a steel security seal with the number recorded on the address label or the radioactive material label would meet the intent of the requirement although not complying completely with the "not readily breakable" provision. Such a seal is not easily applicable to cardboard boxes.

Although packages were smeared at only one geographical location all of the smears were background for both beta-gamma and alpha activity.

Personne1 Exposure

In general, ambient radiation levels in the terminals did not exceed background levels. This results from the fact that the radioactive material packages pass through air freight terminals in a pulsed stream which is geared to the user's demand. These shipments most frequently are short half-life radioisotopes for use in nuclear medicine and are shipped to arrive at the destination for an early morning use. While the transit times of packages through terminals were not timed, it was observed that a package spends about 2-4 hours on the average in a terminal. These packages are offered for shipment in the late afternoon and will have been delivered to the user about 16 hours later, i.e. by $8: 00 \mathrm{a} . \mathrm{m}$. the next day. A buildup of multiple groups of packages on a transfer dock or in a terminal for extended times was not observed at any of the sites surveyed. The highest radiation levels found for groups of packages was at Chicago in a storage cage or room called the "value room." Packages, containing radium and being briefly held in this room prior to re-shipment, gave radiation levels in the room of 5 to $20 \mathrm{mR} / \mathrm{hr}$. On this evening between the hours of 6:00 p.m. to 9:00 p.m. 12 radium packages with TI of 82 and measured exposure rate of $155.5 \mathrm{mR} / \mathrm{hr}$ at 3 feet were held temporarily in this area.

The principal radiation exposure due to radioactive material shipments appears to be the result of the physical handling of radioactive materials. Practices observed at Chicago were quite typical of those followed at the other sites where surveys were conducted. At Chicago it was observed that each package is physically handled many times during the loading, unloading, sorting, labelling, and dispatching process. At the terminal each package was handled as follows:

1. Unloaded from truck or trailer to a conveyor at loading dock (or offered over the counter for shipment).

2. Sorted at two points on the conveyor as to destination.

3. Additional labels or marking were then added to the packages, when appropriate, or where required for a signature shipment. 
4. Next, packages were segregated by destination and placed on a hand truck for carrier pickup.

5. Then carrier personnel wheeled the hand truck to the airport tractor-trailer and loaded the trailer.

It was not determined whether the airline carrier loaded directly from this trailer onto the plane or if packages went through a further sorting process at the carrier's terminal. In any case, packages were handled about 6 times at the air express terminal and at least twice more by the carrier prior to flight departure (that is unloading of the trailer onto a portable conveyor at the plane and stowage in the cargo hold).

It was also observed in the survey at Washington, D.C. that about half of the packages handled were being transferred to another flight. In these cases the radioactive material package will be handled in a least three air express (and airline) terminals and by two ground delivery services.

Although no studies were made of the actual worker exposures, two of the survey team members wore TID finger badges and film badges for whole body exposure measurement on three occasions. The results of the finger and whole body monitoring are given in Table 2. This data indicates a finger dose of 2-3 mrem per package handled.

Table 2. Summary of TLD Finger Monitor

\begin{tabular}{lccccc}
\hline Surveyor & $\begin{array}{c}\text { No. of } \\
\text { Packages }\end{array}$ & $\begin{array}{c}\text { Total } \\
\text { TI }\end{array}$ & $\begin{array}{c}\text { Measured } \\
\text { TI }\end{array}$ & $\begin{array}{c}\text { Total Surface } \\
\text { Exposure Rate }\end{array}$ & $\begin{array}{c}\text { Finger* } \\
\text { Dose (mrem) }\end{array}$ \\
\hline \#1 & 23 & 11.8 & 6.7 & $500 \mathrm{mR} / \mathrm{hr}$ & 50 \\
$\# 1$ & 56 & 60.6 & 136 & 4300 & 150 \\
$\# 2$ & 40 & 68.3 & 52 & $>2300$ & 110 \\
\hline
\end{tabular}

*Whole body doses were less than 10 mrem in all cases.

Observations of radiation exposure rates and exposure duration were made at Knoxville during handling of radioactive material packages by the ground carrier and airline personnel. Exposure during all operations at Knoxville involved in receiving, sorting, labelling, distributing and loading a package were estimated to be about 1.2 man-millirem per Transport Index and a hand exposure of 6 man-millirem. 6 The estimated whole body exposure is relatively 
higher than the experience of the surveyors (Table 2) which indicates the ratio of finger to whole body exposures to range from 5 to 15 . Unfortunately the data collected are not adequate to resolve these differences or to predict the radiation exposure of transportation workers.

\section{OTHER OBSERVATIONS AND SUMMARY}

\section{Carrier Compliance}

While only limited data was collected regarding carrier compliance with the radioactive material regulations, general observations can be made with regard to two aspects, (1) the stowage limitation of a Transport Index of 50 and (2) placarding of vehicles. In general the carriers did not appear to take precautions to meet the stowage/separation distances requirements for package aggregates. As noted earlier the radioactive material packages were not segregated, but flowed through the terminal in response to a rapid delivery to the final destination. In at least one case as noted earlier the cumulative Transport Index at a terminal exceeded 50.

With regard to placarding, two instances were observed where vehicles were not placarded and one case where the old placard format was used. During the survey about 20 vehicles carrying radioactive material were observed, however, data on placarding was not recorded in all instances.

Package Consolidation

At Washington, D.C. and Chicago it was observed that the individual packages were being combined in a plastic bag consigned to a local delivery service. A tag attached to the bag, bore one Yellow-III label, 1isted the isotopes included and the total activity, but insofar as we could determine did not state the total transport index. Where such outer containers were encountered during the survey they were not considered to be a package and the enclosed packages were examined individually.

A similar practice was observed at Newark where small packages, addressed to one receiver or destined for one terminal, were placed by the carrier into larger cardboard cartons. The appropriate labels were placed on the exterior of the large package. The total transport index was written on the new labels.

The practice of combining smaller packages into a large package for ease of handing raises questions of the standards for the outer large package and the labelling and marking requirements for the outer package. It appears that the outer container is not required to meet the packaging standards, since all the packages within the larger container meet the standards. The

labelling and marking of the outer container is the responsibility of the person, either the shipper or carrier, who puts the smaller packages into the large outer package. 
$\underline{\text { Summary }}$

1. The study examined about 300 radioactive material packages or about $1 / 1000$ th of the annual traffic. The majority of these packages involved the shipment of radiopharmaceuticals or small quantities of radioisotopes. Three type $B$ packages and no nuclear fuel shipments were surveyed.

2. The typical package had a surface exposure rate of about $50 \mathrm{mR} / \mathrm{hr}$ or $1 / 4$ of $200 \mathrm{mren} / \mathrm{hr}$ Iimit and a Transport Index of 1.0 (the maximum T.I. allowed is 10 ).

3. Packages containing radium with an average surface exposure rate of $270 \mathrm{mR} / \mathrm{hr}$ and Transport Index of 5.8 had much higher radiation levels than packages containing other radioactive materials.

4. Although, almost one-third of all packages observed were labelled incorrectly, these deficiencies did not seem to represent any significant reduction in safety. The use of a yellow-III label when not required was the most frequent infraction.

5. The requirement for a security seal which was not readily breakable and while intact presented evidence that a package had not been illicitly opened was not met in the majority of shipments.

6. No contaminated packages were observed.

7. Packages were often consolidated and overpacked in large bags or boxes. These outer containers were not completely identified in some cases with regard to the total transport index and the radioactive materials involved.

8. Carriers are generally unaware of or did not observe stowage and loading restrictions for radioactive material, and the observed total transport index in one terminal exceeded 50.

9. Radiation levels in terminal areas usually did not exceed the normal background levels except in the immediate vicinity of packages.

\section{CONCLUSIONS AND RECOMENDATIONS}

This survey of 293 radioactive material packages has indicated that in general these packages are being shipped in a safe manner and do not present an unacceptable radiation exposure to the public or transportation workers. While a significant number of packages were found that were not in strict compliance with the regulations these noncompliance items were largely administrative in nature and did not in most cases appear to affect the radiation safety of transport. 
The radiation limits at the surface and at 3 feet from the package were generally met within acceptable tolerances and radiation levels in terminal areas appeared to be acceptable. Direct monitoring of transportation workers was not undertaken, and thus estimates must be based upon observed radiation levels under working conditions. This data indicates possible cumulative doses to the ground and airline carrier personnel at one location of 1 manmrem whole body and a-hand dose of 6 man-mrem per Transport Index. With this dose shared by several individuals the radiation exposures do not appear excessive. At one terminal, however, it was observed that personnel could be exposed to levels of $5-20 \mathrm{mR} / \mathrm{hr}$ for at least 1-2 hours per day which could lead to personnel doses near the occupational limit.

Therefore, it is recommended that a detalled study be undertaken to determine actual personnel exposure of both transportation workers and the general public. Such a survey should utilize personnel monitoring devices, as well as, area monitoring.

The study also indicated several areas where compliance with the transportation regulations was deficient that should be evaluated with regard to possible modification or enforcement of the provisions. With regard to the shipment of small "radiopharmaceutical type" packages these items should be examined further:

(1) Shipping papers. Frequently a complete description was not given and the shipping paper was not carried separately by the vehicle operator but as a part of the destination label.

(2) Security seals. The gummed tape or staple closure of cardboard boxes gives some evidence that a box has not been opened but is readily breakable. There does not appear to be a major justification for this requirement.

(3) Package labels. In view of the significant mislabeling perhaps only one type label should be used for these packages (rather than the current three).

(4) Vehicle loading and stowage restrictions. The enforcement of stowage limits and separation distances in airfreight terminals would significantly affect the rapid delivery of radiopharmaceuticals which is important for short half-life radionuclides. If the exposure study recommended above shows acceptable individual doses, it is felt this requirement could be relaxed or deleted in terminals and/or vehicles. 


\section{REFERENCES}

1. PATTERSON, D.C. The accident experience of the USAEC in the shipment of radioactive material. Proceedings of the Second International Symposium on Packaging and Transportation of Radioactive Materials. Pg. 199-210, Gat1inburg, Tennessee, October 14-18, 1968.

2. A Radiological Survey of British European Airways (BEA) Cargo Warehouse and Personnel-London Airport, 1959. Regulations for the Safe Transport of Radioactive Materials--Notes on Certain Aspects of the Regulations Pg. 103105, Safety Series No. 7, International Atomic Energy Agency, Vienna, 1961.

3. DAVIS, D. M., J. C. Hart, and A. D. Warden. Radiation dose received by passengers and crew on planes carrying the maximum number of radiation units. American Industrial Hygiene Journal, Pg. 497-503, Vol. 22, No. 6, Dec. 1961.

4. EVANS, R. D. Remarks on space limitations in air transport, Chapter $\mathrm{X}$, Physical, Biological, and Administrative Problems associated with the Transportation of Radioactive Substances. Pub. No. 205, Nuclear Sciences Series, Preliminary Report No. 11, 1951.

5. Survey of Handling of Radioactive Materials at the Railway Express Agency Terminal in Knoxville, Tennessee, March 1962. Unpublished Report by R. M. Sharp, Field Inspector, Bureau of Explosives, American Association of Railroads.

6. Joint Survey of Radioactive Materials Shipments. U.S. Atomic Energy Commission, Department of Transportation, and Public Health Service, in preparation. 
A IIETHOD OF CONROLLING RADIATION EXPOSURE OF PERSONS IN AIRCRAFT DURING TRANSPORTATION OF RADIOACTIVE MATERIALS

\author{
P. A. Lecomte
}

ABSTRACT

This paper gives a method to calculate segregation distances to be observed between persons and yellow-labelled packages of radioactive materials in aircraft. The method is based on the inverse square rule applied to arrangements of spherical packages with point source located at the centre. Surface dose rate and transport index of the package are the two parameters which have been taken into account for computing the segregation distances. An IBM computer 360 was used for the method of calculation and to prepare the graphs.

\title{
INTRODUCTION
}

For the purpose of adequately protecting persons from being dangerously exposed to external radiation during air transportation of radioactive materials, the IATA Regulations ${ }^{1}$ prescribe that under any circumstances the dose rate of radiation originating from a package shall not exceed :

$200 \mathrm{mr} / \mathrm{hr}$ or equivalent at any point on the external surface; and

sn $\mathrm{mr} / \mathrm{hr}$ or equivalent at one metre ( 40 inches) from the centre of the package, or a Transport Index of 10 .

The segregation distancos prescribed in Part 2, Section 10 of the IATA Regulations are based on these limits.

However, in the latest draft revision of the IAWA Regulations ${ }^{2}$ the Transport Index of a package is broadly defined as the number expressing the maximum radiation dose-equivalent expressed in millirem per hour at one metre from the external surface of the package.

Since it is assumed that the surface measurement reference of the Transport Index will be internationally adopted in the near future, particulariy considering that this concept was already adopted in the national regulations 
of some important isotopes-producing countries, we have based our method of computing the segregation distances on the surfoce measurement reference of the Transport Index.

\section{BASIC PRINCIPLES}

The basic principles used to determine formula for calculating segregation distances between persons and yellow-labelled packages of radioactive materials in aircraft, were already set out by Aspinall, Gibson and Morley 3 in 1963. They consist of deriving a permissible mean dose rate for crew and passengers from recognized factors.

The first factor to be taken into account is the yearly maximum dose for persons. The current IAgA Basic Safety Standards ${ }^{4}$ recommend the following maximum whole body exposure doses :

- for individual members of the public: $500 \mathrm{mrem} / \mathrm{year}$

- for workers not requiring individual monitoring and special health supervision $: 1,500 \mathrm{mrem} / \mathrm{yesr}$

Therefore the value of $500 \mathrm{mrem} /$ year has been chosen for controlling radiation exposure of passengers and $1,500 \mathrm{mrem} / \mathrm{year}$ for crews.

The second factor to be considered is the maximum foreseeable annual flying period. For passengers it is assumed that 500 hours per annurn may be taken as the maximum mean llying time. For crews, in practice, 1,000 hours per annum can be taken as the maximum flying period.

The derivation of a permissible mean dose rate also depends on a third factor which has been called "radioactive traffic factor". It is used to denoto the ratio of flights made in company with yellow-labelled packages of radioactive materials to all fights when averaged over a considerable period. From statistics available some years ago for London Heathrow Airport, which is one of the intemational airports in the world where the movement of radioactive materials is the highest, it has been demonstrated that a redioactive traffic factor of one-in four is unlikely to be reached. However with the increasing movement of radioactive materials, it is considered that a radioactive traffic factor of $1: 3$ may now safely be used for air transportation throughout the world.

Multiplying the maximum poreseeable annual flying period by the radioactive traffic factor we obtain the annual mean exposure time and the permissible mean dose rate to be achieved by segregation of yellow-labelled packages of 
radioactive materials will be the quotient of the annual maximum permissible dose over the annual mean exposure time. We obtain therefore the following permissible mean dose rates:

$$
\begin{array}{ll}
\text { for passengers : } \frac{500}{500 \times \frac{1}{3}}=3 \mathrm{mrem} / \mathrm{hour} \\
\text { for crews }: \frac{1,500}{1,000 \times \frac{1}{3}}=4.5 \mathrm{mrem} / \mathrm{hour}
\end{array}
$$

Another basic principle which was also emphasized by Aspinall, Gibson and Morley ${ }^{3}$, is the fact that segregation distances for passengers have not to be calculated so that the permissible mean dose rate will never be exceeded at any passenger seat, but that they must be such that the mean dose rate along the cabin floor, i.e. within the passenger-carrying volume, does not exceed the permissible mean dose rate. As a matter of fact the mean dose received by any particular passenger over the years is considerably reduced with the assumption of his random seating within the cabin space and of the random stowage positioning of radioactive packages along the cabin in the aircraft holds.

In other words such random positioning factor must be taken into account in the method of computing the correct segregation distances for passengers. For crews however, in their fixed position in the flight deck, the random positioning factor is not available and the segregation distances must be so calcum lated that the permissible mean dose rate will never be exceeded at the flight deck boundary.

THE RHFWRENCE SOURCE

Packages of radioactive materials of the Yellow-II or Yellow-III Category are in various shapes and sizes. The dose rate at their surface will vary from 0.5 to $200 \mathrm{mrem} / \mathrm{h}$ and their transport index from 0 to 10 . Though in practice the shape of packages will never be a sphere, to facilitate the computing of segregation distances we have chosen as our reference source a package or an arrangement of packages of spherical shape, the source being ponctual and located at the centre of the sphere. In that case the radius of the spherical package, applying the simple "inverse square rule" is found according to the following formula :

$$
R=\frac{1}{\sqrt{\frac{\text { MSTRE }}{\text { TIIT }}-1}}
$$


Where

$\mathrm{R}^{*} \quad=$ radius of the package, metre,

NSURF* $=$ dose rate at the surface, mrem/h,

UNIT* = transport index of the package.

Graph $O$ shows the value of $R$ with respect to the surface dose rate for given transport indexes.

\section{Arrangement of Packages}

Since the Transport Index must not exceed 10 per package, to calculate segregation distances applicable to a sum of transport indexes above 10 , we have considered a plane arrangement of packages as our reference source. We have built two kinds of plane arrangement of packages: a compact arrangement where packages are arranged in spiral starting from the first one, and a line arrangement where packages are arranged in a single row. The appropriate arrangement for a given total number of packages shall be that one which generates the most restrictive segregation distance between the plane tangent to the external surface of the packages and the point of interest located perpendicularly to this plane from the centre of gravity of the arrangement.

\section{Compact arrangement}

Let us consider a plane spiral of spherical packages. Knowing the co-ordinates $x$ and $y$ of packages number $p$ and $n$, we have to find the co-ordinates $x_{n+1}$ and $y_{n+1}$ of packages number $n+1$

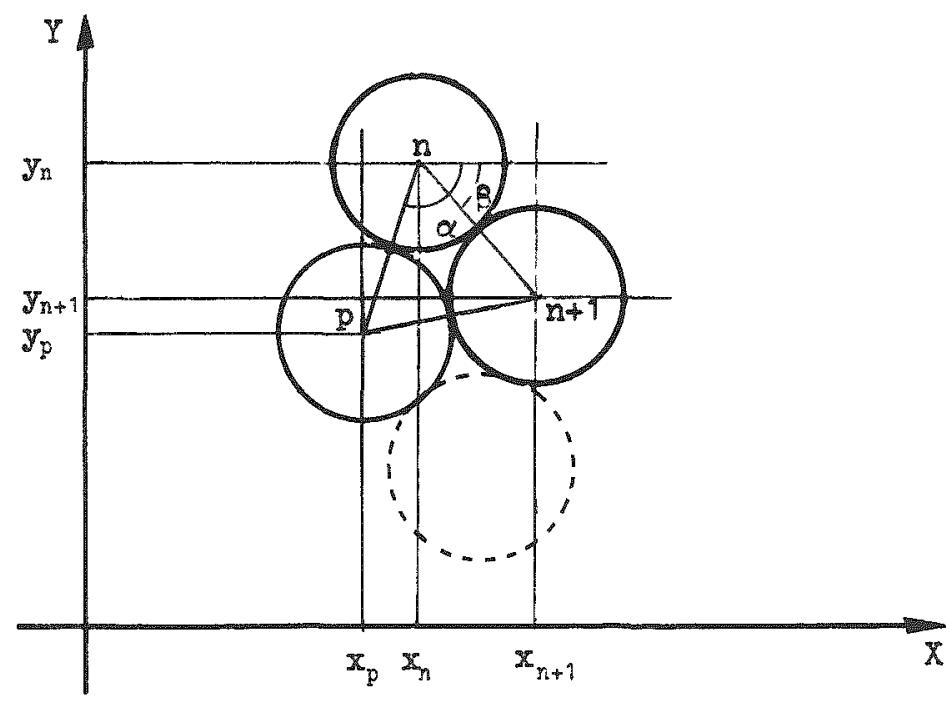

Fig. १. Compact arrangement of packages

* terms used in the computer program 
From Fig. 1 the following equations are easily found :

$$
\begin{aligned}
\cos \alpha & =\frac{x_{p}-x_{n}}{2 R} \\
\sin \alpha & =\frac{y_{n}-y_{p}}{2 R} \\
\beta & =\alpha-60^{\circ} \\
x_{n+1} & =x_{n}+2 R \cos \beta \\
y_{n+1} & =y_{n}-2 R \sin \beta
\end{aligned}
$$

where

$\alpha$ and $B$ are the angles show in the figure,

$R$ = radius of packages number $p, n, n+1$.

From Eq. (4) we can derive:

$$
\begin{aligned}
& \cos \beta=\cos \alpha \cos 60^{\circ}+\sin \alpha \sin 60^{\circ} \\
& \sin \beta=\sin \alpha \cos 60^{\circ}-\cos \alpha \sin 60^{\circ}
\end{aligned}
$$

Substituting $\frac{1}{2}$ and $\frac{\sqrt{3}}{2}$ for $\cos 60^{\circ}$ and sin $60^{\circ}$ respectively in Eq. (7) and (8), the latter two combined with $\mathrm{Eq},(5)$ and (6), we find the co-ordinates $x_{n+1}$ and $y_{n+1}$ which give us the rule to build a compact arrangement of packages :

$$
\begin{aligned}
& x_{n+1}=\frac{1}{2}\left(x_{n}+x_{p}+\sqrt{3} y_{n}-\sqrt{3} y_{p}\right) \\
& y_{n+1}=\frac{1}{2}\left(y_{n}+y_{p}+\sqrt{3} x_{p}-\sqrt{3} x_{n}\right)
\end{aligned}
$$

To start the arrangement we also have to impose that co-ordinates of packages number 1 and 2 are as follows:

$$
\begin{aligned}
& x_{1}=y_{1}=0 \\
& x_{2}=2 R \\
& y_{2}=0
\end{aligned}
$$

\section{Line arrangement}

For line arrangement of packages formulae giving the co-ordinates are very simple:

$$
\begin{aligned}
& y_{n+1}=y_{n}=0 \\
& x_{n+1}=n 2 R
\end{aligned}
$$

where

$R=$ radius of packages number $n, n+1$. 


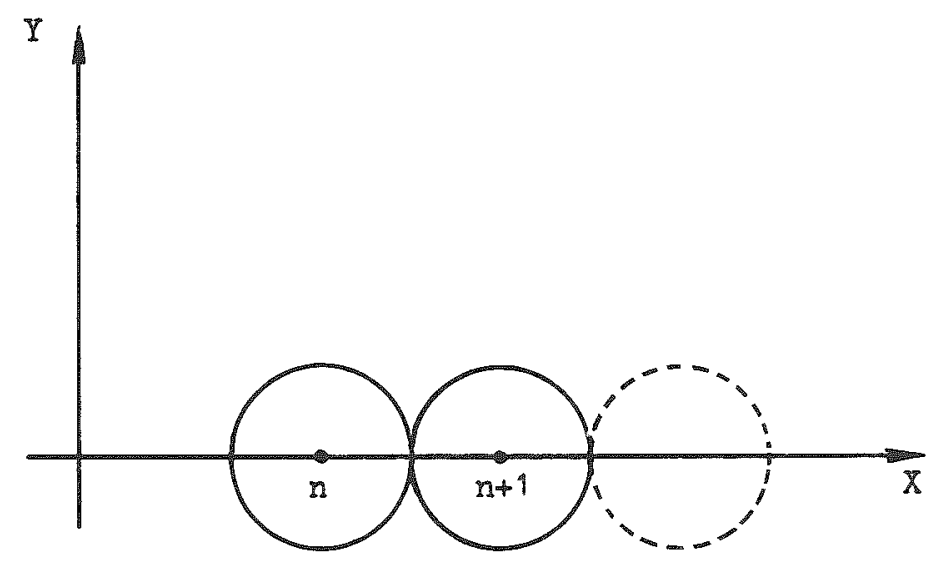

Fig.2. Line arrangement of packages

Eq. (11), (12) and (13) remain valid of course for line arrangement of packages.

\section{Centre of gravity of arrangements of packages}

Co-ordinates $x_{M}$ and $y_{M}$ of the centre of gravity of arrangements of packages will be determined by the following formulae:

$$
\begin{aligned}
& x_{M}=\frac{\sum_{n=1}^{M T S} \mathbf{x}_{n}}{\text { MTEST }} \\
& y_{M}=\frac{\sum_{n=1}^{N E S T} y_{n}}{\text { NTEST }}
\end{aligned}
$$

where

NTES $^{*}=$ total number of packages involved in the arrangement.

WHE SEGREGATION DISTANCE

Segregation distances have been calculated by a computer. Consequently general formula covering any total number of packages in the two kinds of arrangement, compact and line, for both fixed point of interest and random positioning of point of interest along the cabin floor, were needed.

For a single package, using the inverse square rule, the following formula applies when a fixed point of interest is considered :

$$
\text { DOSR }=\frac{\operatorname{UNIT}(1+R)^{2}}{(S+R)^{2}}
$$

* term used in the computer program 
for random positionine of point of interest along the cabin floor, Eq. (18) becomes :

$$
\operatorname{DOSR}=\frac{1}{L} \int_{l=0}^{l=L} \frac{\operatorname{UNIT}(1+R)^{2}}{(S+R)^{2}+I^{2}} d I
$$

where

$$
\begin{aligned}
& D_{S} R^{*}= \text { reference mean dose rate at the point of interest, mrem/h, } \\
& R^{*}= \text { radius of the package, metre, } \\
& S^{*}= \text { segregation distance between the surface of the package and } \\
& \text { the point of interest, metre, } \\
& \text { WNIT }=^{*} \text { transport index of the package, } \\
& 2 L=\text { cabin length, metre. }
\end{aligned}
$$

For an arrangement of identical packages, when the fixed point of interest is located perpendicularly above the centre of gravity of the arrangement, Eq. (18) becomes :

$$
\text { DOSR }=\sum_{n=1}^{\text {NTEST }} \frac{\text { UNIT }(1+R)^{2}}{(S+R)^{2}+\left(y_{n}-y_{M}\right)^{2}+\left(x_{n}-x_{M}\right)^{2}}
$$

For an arrangement of identical packages, when the point of interest is moving along an axis parallel to the long axis $X$ of the arrangement of packages and passing by the perpendicular to the centre of gravity of this arrangement, $\mathrm{Eq} \cdot$ (19) becomes:

$$
\text { DOSR }=\frac{1}{L} \int_{l=0}^{1=L}\left[\sum_{n=1}^{N=1 S T} \frac{\operatorname{UNIT}(1+R)^{2}}{(S+R)^{2}+\left(y_{n}-y_{N}\right)^{2}+\left(1-x_{n}+x_{M}\right)^{2}}\right] d I
$$

where

$$
\begin{aligned}
& \text { DOSR }^{*}=\text { reference mean dose rate at the point of interest, mrem } / \mathrm{h} \text {, } \\
& R^{*} \quad=\text { radius of packages, metre, } \\
& \mathrm{S}^{\text {* }} \text { = segregation distance between the plane tangent to the surface } \\
& \text { of the packages and the point of interest, or the axis passing } \\
& \text { by this point, metre, } \\
& \text { UNIT* = transport index of the packages, } \\
& \text { NTEST = total number of packages involved in the arrangement, } \\
& x_{n}, y_{n}=\text { co-ordinates of the packages, metre, } \\
& x_{M} . y_{M}=\text { co-ordinates of the centre of gravity of the arrangement, metre, } \\
& 2 L=\text { cabin length, metre. }
\end{aligned}
$$

Resolving Eq. (21) we find:

$\operatorname{DOSR}=\sum_{n=1}^{\text {MIEST }} \frac{\mathrm{UNIT}(1+R)^{2}}{L \sqrt{(S+R)^{2}+\left(y_{n}-y_{n}\right)^{2}}}\left(\tan ^{-1} \frac{L-x_{n}+x_{n}}{\sqrt{(S+R)^{2}+\left(y_{n}-y_{n}\right)^{2}}}+\tan ^{-1} \frac{x_{n}-x_{M}}{\sqrt{(S+R)^{2}+\left(y_{n}-y_{M}\right)^{2}}}\right)$

* terms used in the computer program 
Eq. (1), (9), (10), (11), (12), (13), (14), (15), (16), (17), (20) and (22) are the basic formulae which were used in the computer program to calculate the segregation distances (see attachment A). This progran permits to obtain the segregation distances applicable to any number of identical packages (of selected surface dose rate and transport index) in both compact and line arrangements, for fixed point of interest (filight deck $-4.5 \mathrm{mrem} / \mathrm{h}$ mean dose rate) and random positioning of point of interest (cabin length from 0 to 200 feet $-3 \mathrm{mrem} / \mathrm{h}$ mean dose rate).

Attachment B gives an example of a listing from the computer. Note that for fixed point of interest or short cabin length the segregation distance is more restrictive in compact arrangement than in line arrangement, but for large cabin length the distance is more restrictive in line than in compact. In this example for 45 foot cabin length the distance is about the same for both compact and line arrangement.

\section{THE INYLUENCE OF THE RADIUS}

According to selected surface dose rate and transport index various package radius can be obtained, as shown in Graph 0 . A lower limit of 0.05 metre is to be settled since the IAEA Regulations ${ }^{2}$ prescribe that the smallest overall external dimension of the packaging shall not be less than $10 \mathrm{~cm}$. On the other hand packages with external dimensions exceeding 2 metres are unlikely to from quently move in air transportation. Therefore, an upper limit of 1 metre seems to be realistic.

We fed the computer in order to get the segregation distances applicable to arrangements of packages with different radius, but with the same total sum of transport indexes. Graphs 1,2 and 3 illustrate the results for cabin lengths 0,100 and 200 feet respectively. They apply to a total sum of transport indexes 30. In other words the segregation distances corresponding to 10 transport index apply to 3 packages of 10 transport index each, whilst the distances corresponding to 0.5 transport index apply to 60 packages of 0.5 transport index each. It should be noted that the graph computer program selects the most restrictive segregation distance obtained either by compact or by line arrangement of packages.

We see from these graphs that for a given total sum of transport indexes :

(i) segregation distances are more restrictive when large packages are involved,

(ii) for short cabin lengths, limited number of packages generates the most restrictive segrogation distances, 
(iii) for large cabin lengths, the number of packages has practically no influm ence on the segregation distances.

Since no statistics about dimensions of yellow-labelled packages of radioactive materials were available to us, for the remnant of our demonstration we chose a package radius of 0.288 metre. Though this choice is arbitrary (any other radius could have been chosen), it was felt that it could represent a good average of the dimension of packages encountered in air transportation, without being too optimistic in the segregation distances. On the other hand a 0.288 metre radius corresponds to the typical Yellow-II category package ( $10 \mathrm{~m}-$ $\mathrm{rem} / \mathrm{h}$ at the surface and 0.5 transport index, or $50 \mathrm{mrem} / \mathrm{h}$ at the surface and 2.5 transport index according to the revised IAEA Regulations ${ }^{2}$ ). A package of 0.288 metre radius also corresponds to the typical Yel Low-III category (200 m$\mathrm{rem} / \mathrm{h}$ at the surface and 10 transport index).

\section{SELECTION OF THE CORRECT SEGREGATION DISTAYCES}

Graph 4, together with its listing, indicates the segregation distances applicable from yellow-labelled packages to the boundary of the passenger cabin. These distances were calculated from packages of 0.288 metre radius with the following surface dose rate and transport index in order to obtain the specified total sum of transport indexes.

Table 1. Total sum of TI. with packages characteristics

\begin{tabular}{|c|c|c|c|}
\hline $\begin{array}{c}\text { Total Sum } \\
\text { of TI. }\end{array}$ & $\begin{array}{c}\text { Total number } \\
\text { of packages }\end{array}$ & $\begin{array}{c}\text { Surface dose } \\
\text { rate, meres } / \mathrm{h}\end{array}$ & T. \\
\hline 1 & 1 & 20 & 1 \\
2 & 1 & 40 & 2 \\
5 & 1 & 100 & 5 \\
10 & 1 & 200 & 10 \\
15 & 3 & 100 & 5 \\
20 & 2 & 200 & 10 \\
25 & 5 & 100 & 5 \\
30 & 3 & 200 & 10 \\
35 & 7 & 100 & 5 \\
40 & 4 & 200 & 10 \\
45 & 9 & 100 & 5 \\
50 & 5 & 200 & 10 \\
55 & 11 & 100 & 5 \\
60 & 6 & 200 & 40 \\
\hline
\end{tabular}


If applied coxrectly these distances will always be on the safe side since no correction for intervening shielding material between packages and persons has been made. For example the attenuation of radiation by loading of dead cargo or the shielding properties of partitions or other structural items of the aircraft have not been taken into account. On the other hand, no reduction of segregation distances for the assumption that say the first foot of the cabin space will not be occupied by other than body extremities, has been allowed.

It should also be remembered that the derivation of a permissible mean dose rate depends, arnongst other factors, on the foreseoable annual flying period of the inveterate traveller. It may conceively be assumed that such a passenger is always flying first class which would considerably reduce his randon seating within the cabin space. For that reason it is felt that when selecting the appropriate segregation distance to be applied for a mixed first class/economy class cabin aircraft, the length of both types of cabin must be considered separately.

For the airline the application of the correct segregation distance will be in most cases the problem of knowing roughly the total sum of transport indexes which can be loaded in the particular holds of the aircraft located below the first class and/or the economy class cabin, since the distance available between the bottom of the hold and the cabin floor is invariable and fairly short in most instances (for the B-747 this distance is 80 inches maximum). To solve this problem Graphs 5 to 9 inclusive show, in a format directly usable by air cargo staff, the total sum of transport indexes which can be loaded in a passenger aircraft from selected available distance and cabin length.

Finally Graphs 10 and 11 show the segregation distances to be applied to the flight deck, for normal and full load conditions respectively.

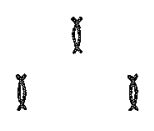

Acknowledgments

The author acknowledges the assistance he has received from M. C. L. Martin in the preparation of the computer programs. 
1. International Air Transport Asmociation (IATA) Restricted Articles Regulam tions - 14tb Edition, effective 1st June 1971.

2. IAFA Regulations for the Safe Transport of Radioactive Materials - Third. Revised Draft, November 1970.

3. K. J. Aspinall, R. Gibson, F. Morley, The Control of exposure to external radiation during the Transport of Radioactive Materials, 1963 - United Kingdom Atomic Mnergy Autbority, Report AHSB (RP) R 31.

4. IAEA Basic Safety Standards for Radiation Protection, Safety Series No. 9, 1967 Edition. 


\section{$/ /$ EXEC FFORTRAN} DHEES SION X(100), Y(100)

1 FORMAT $(I 3,1 X, I 3,1 X, F 4.1,1 X, I 1)$

2 FORMAT $/ / /, 6 x^{\prime}$ 'SEGRECATION DISTANCE COMPUTIIYG FOR', I4, PACKAGE', A $11, / 6 \mathrm{X}$, 'OF', F8.5,' METRE RADIUS', I5, SURFACE DOSE RATE', F6.1,' TR 2AISSPORT IINDEX', //)

3 FORMAT( $/ /, 1 \mathrm{X}, \mathrm{I3}$, ' FOOT CABTN IENGTH', $/ / 4 \mathrm{X}$, 'DISTARTE ',4X,' DOSE',/ $1 / 2 \mathrm{X}$, 'FEET INCHES', $/)$

4 FORAT $(2 X, I 3,3 X, 55.2,3 X, 97.4)$

5 FORMAT $\left(/ /, 1 X\right.$, , FLIGHT DECK $, F 3.1,1$ MREM/E MEAN DOSE RATE', $/ / 3 X^{\circ}, D$

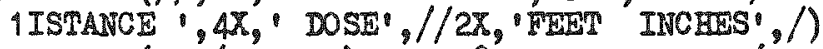

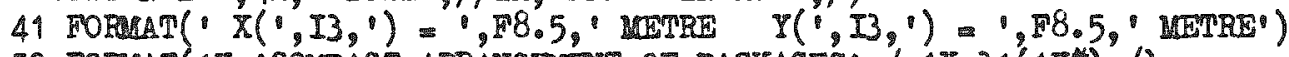

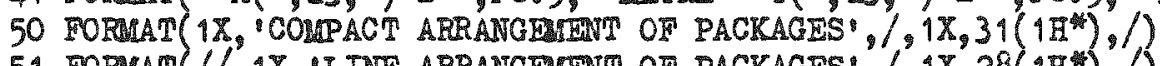

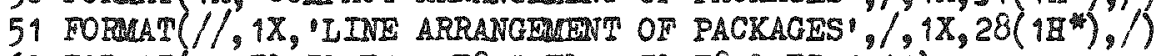

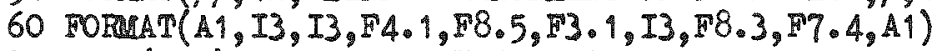

30 READ $(1,1)$ NTTEST, NSURF, UNIT, KRO

IC $=1019199424$

IF(NTESST-999)7,6,6

$7 \mathrm{R}=\mathrm{NSUR} /$ UNIT

$R=1 . /(\operatorname{SQRT}(R)=01$.

$\operatorname{IF}(R-0.05) 56,57,57$

$56 R=0.05$

57 IF(NTEST-1) $33,33,34$

$33 I=1077952576$

GO $70 \cdot 35$

$34 I=-499105728$

35 WRITE $(3,2)$ NTEST, I, R, NSURF, UNIT

$S Q=S Q R T(3$.

KOMP $=1$

IF(NTEST-2) $53,53,32$

32 MRITE(3,50)

$x(1)=0$.

$Y(1)=0$ 。

$X(2)=2$.

$Y(2)=0$.

Do $8 \mathrm{I}=3$, NTEST

$I R=I-1$

$I P=I R-1$

$I P P=I P$

$12 X N=(X(I R)+X(I P)+Y(I R) * S Q-Y(I P) * S Q) / 2$.

$\mathrm{YN}=(Y(I R)+Y(I P)+X(I P) * S Q-X(I R) * S Q) / 2$.

$\operatorname{IXN}=\mathrm{XN}^{*} \div \mathrm{1000}$

IYN $=$ IN 1000

DO $9 \mathrm{~J}=1$, IPP

IK $=$ IR $-J$

KRE $=X(I X) * 1000$

IF (IXNAKRE) $9,10,9$

$10 \mathrm{KRY}=\mathrm{Y}$ (IX) $\% 1000$

IF (IYN-KRY) 9, 11,9

$11 \mathrm{IP}=\mathrm{I}$

GO TO 12

9 CONPINUE

$X(I)=X N$

$8 \mathrm{I}(\mathrm{I})=\mathrm{MN}$

$55 \mathrm{xM}=0$.

$\mathrm{YM}=0$.

DO $13 I=1$, NTEST

$X L=X M+X(I)$ 
$13 \mathrm{Mm} \mathrm{M}+\mathrm{Y}(\mathrm{I})$

$\mathrm{XU}=\mathrm{XM} / \mathrm{NTEST}$

$\mathrm{M}=\mathrm{M} / \mathrm{MTEST}$

$\operatorname{IF}($ KRO ) $14,14,15$

15 DO $40 \mathrm{~K}=1, \mathrm{MTEST}$

$I=K+N T E S T$

40 TRITE $(3,41) \mathrm{K}, \mathrm{X}(\mathrm{K}), \mathrm{K}, \mathrm{I}(\mathrm{K})$

$14 F=(1+R)=2$

$D O S R=4.5$

$23 \mathrm{STEP}=1000$.

$N D=1$

$S I=2004$.

WRITE $(3,5)$ DOSR

19 DOSEO.

SESI 0.0254

$I$ IFT $=0$

Do $16 \quad I=1$, NTEST

$16 D O S=D O S+U N I T /\left((S+R)=2+(X(I)-M I)^{*} 2+(Y(I)-M)^{*} 2\right)$

ISI=SI

$45 \operatorname{IF}(\operatorname{ISI}-12) 43,44,44$

44 ISI $=I S I-12$

$I F T=I F T+1$

CO TO 45

43 SII $S I-12$ :IFT

IF (KRO-1)61,61,62

62 WRITE $(3,4)$ IFT, SII, DOS

61 IF (DOS-DOSR) 17, 17, 18

17 SImSI-STEP

IF(SI) $18,18,19$

18 SI SI+STHP

STEP $=$ STEP $/ 10$.

SI $=$ SI-STEP

$\mathrm{ND}=\mathrm{ND}+1$

$\operatorname{IF}(N D-6) 19,19,20$

20 WRITE $(3,4)$ IFT, SII, DOS

IFF $=-968867776$

IGRAN $=0$

SImSII+12 IFT

WRITE (2,60) IFF, NTESP, NSURF, UNIT, R, DOSR, IGRAN, SI, DOS, IC $I F(D O S R-3) 21,22,21$

21 DOSR=3.0

60 TO 23

$22 x R=2.5$

Do $24 I=1,40$

$X I=I * X R * 0.3048$

$S T E P=1000$.

$M D=1$

IGRAN $=2 \% X R^{\text {th }} I$

WRITE $(3,3)$ IGRAN

28 DOS $=0$.

$I$ INT $=0$

S.SI*0.0254

DO $25 \mathrm{~J}=1, \mathrm{NTTST}$

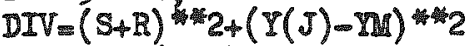

DIV SQRT (DIV)

$A R C_{\approx A T A N}((\mathrm{XI}-\mathrm{X}(\mathrm{J})+\mathrm{MM}) / \mathrm{DIV})+\operatorname{ATAN}((\mathrm{X}(\mathrm{J})-\mathrm{XI}) / \mathrm{DIV})$

$25 D O S=D O S+$ WNITHWARC/(DIV $\%$ )

ISI SI

48 IF(ISI-12) $46,47,47$

47 ISI $=I S I-12$ 
$\mathrm{T}=\mathrm{IST}+\mathrm{T}$

GO TO 48

$46 \mathrm{SII}=S I-12$ HFI

IF(KRO-1) $58,58,59$

59 WRITE $(3,4)$ IFM, SII, DOS

58 IF (DOS-DOSR $) 26,26,27$

26 SI=SI-STIPP

IN(SI) $27,27,28$

27 SI SI+STEP

$\operatorname{STEP}=\operatorname{STER} / 10$ 。

$N D=N D+1$

IN $(N D-6) 28,28,29$

$29 \operatorname{WRTTE}(3,4)$ IFT, SII, DOS

$S I=S I I+12$ IFT

24 WRITE $(2,60)$ IFF, IMTEST, NSURE, UNIT, R, DOSR, IGRAN, SI, DOS, IC - IF(KOUP-1) $30,53,30$

$53 \operatorname{WRTTE}(3,51)$

KOMP $=$ KOMPP +1

TRE 2 t

DO $54 \quad I=1$, NTEST

IN $I=1$

$\mathrm{X}(I)=0_{0}+I N$ WRE

$54 \Psi(I)=0$.

IC -750763963

CO 7055

6 CAIL BXIT

ENDD 
SEGRFGATION OISTANCE COMPUTIASG FUR 12 PAEKAGES
OF 0.28801 METKE RADIUS SO SURFACE DOSE RATE 2.5 TRANSPORT INDEX

\section{COMPACT ARRANGEMENT OF PACKAGES}
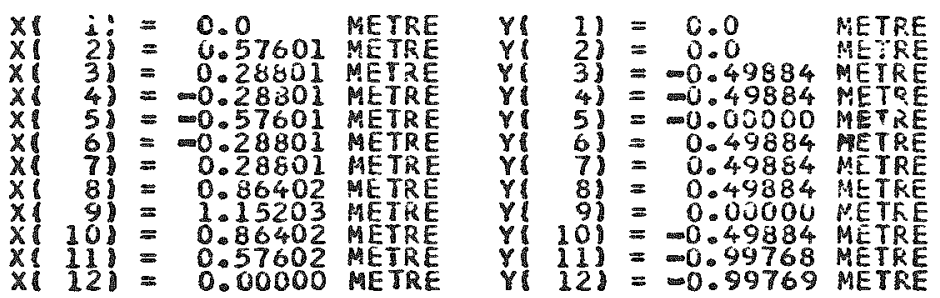

FLIGHT OECK 4.5 MREM/M MEAN DOSE RATE $\cdots$

$$
\text { DISTANCE DOSE }
$$

$\begin{array}{cc}\text { FEET INCMES } \\ 2 & 8.48\end{array}$

FL GHT DECK 3.0 MREMH MEAN COSE RATE

$$
\text { DISTANCE DOSE }
$$

FEET INCHES

$$
22.2 .48 \quad 3.0000
$$

5 FOOT CABIN LENGTH

DISTANCE DOSE

\section{FEET INCHES}

$12 \quad 1.59 \quad 3.0001$

45 FOOT CABIN LENGTM

$$
\text { DISTANCE DOSE }
$$

SEET INCMES

$2.85 \quad 3.0003$

200 FOOT CABIN LENGTM

DISTANCE DOSE

FEET INCHES

$1 \quad 4.45 \quad 3.0003$

\section{LINE ARRANGEMENT OF PACKAGES}
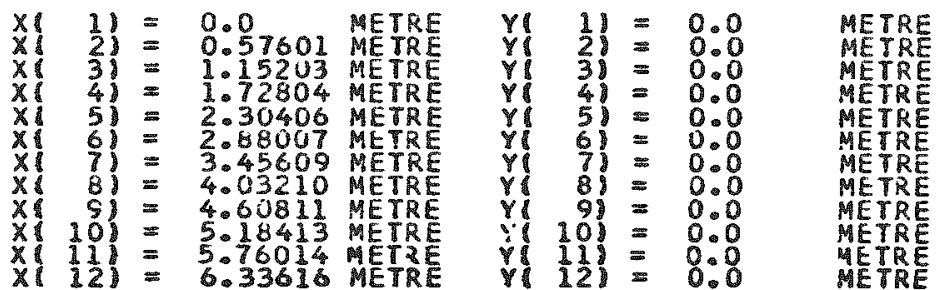

FLIGHT DECK 4.5 MREM/H MEAN DOSE RATE

$$
\text { DISTANCE DOSE }
$$

FEET... INCHES . .. .. ...

$\cdots \cdots+15 \cdots 4.5006$.

F. IGHT DECK 3.0 MREMAH MEAN DOSE RATE

$$
\text { DISTANCE DOSE }
$$

FEET TCHES

$11^{0.16^{2}} 3.0001^{\circ}$

5 FOOT CABIN LENGTH

D.ISTANCE .... DOSE ...

..FEET . INCHES ..... .....

$10 \quad 11.72 \quad 3.0002$

45 FOOT CABIN LENGTH

... DISTANCE .... DOSE...

FEET INCHES ... ......

8 $2.75 \quad 3.0000$

200 FOOT CABIN LENGTH

DISTANCE DOSE

FEET INCHES . . ...

$i^{2} \quad 9.72^{\cdots} 3.0007$ 


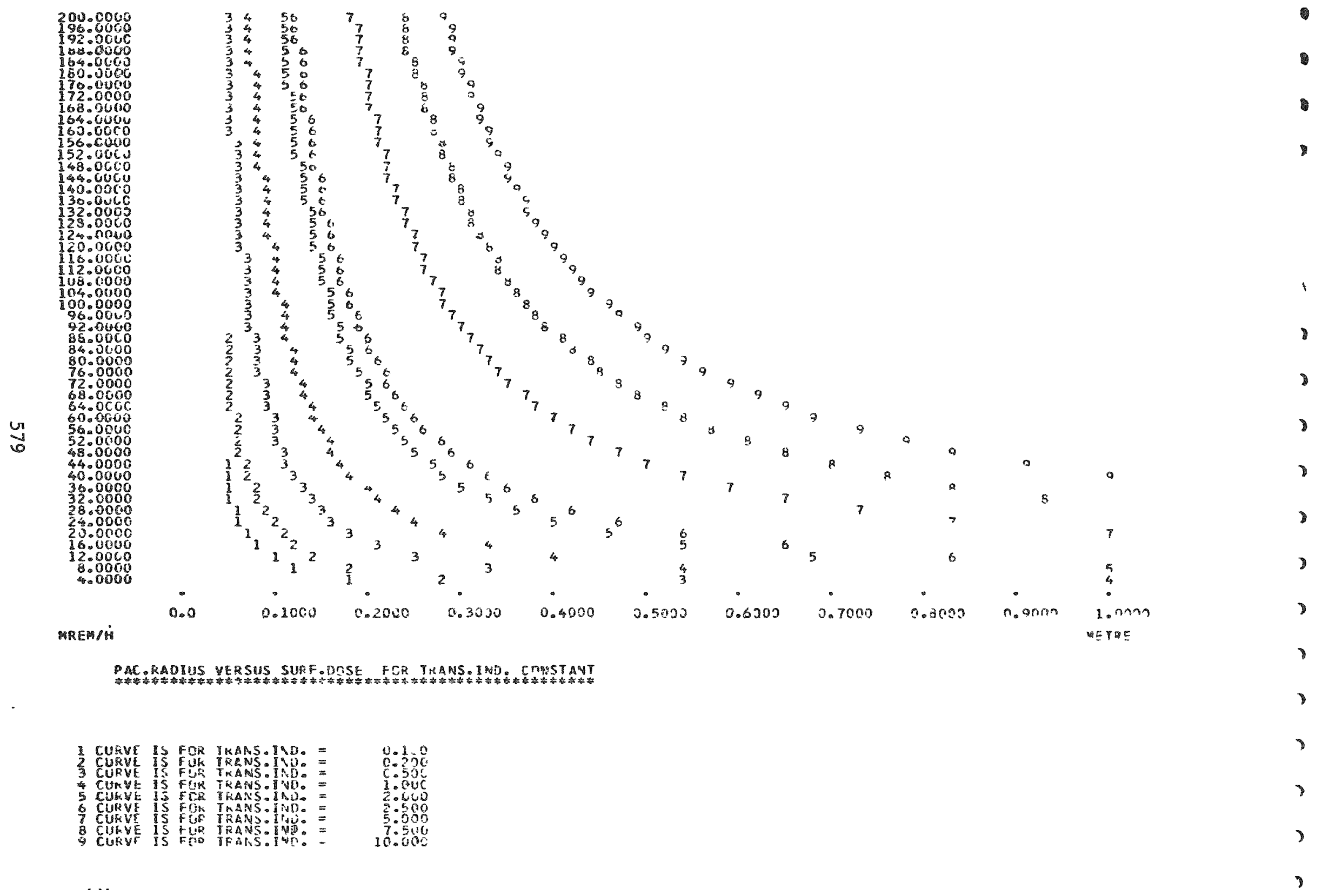




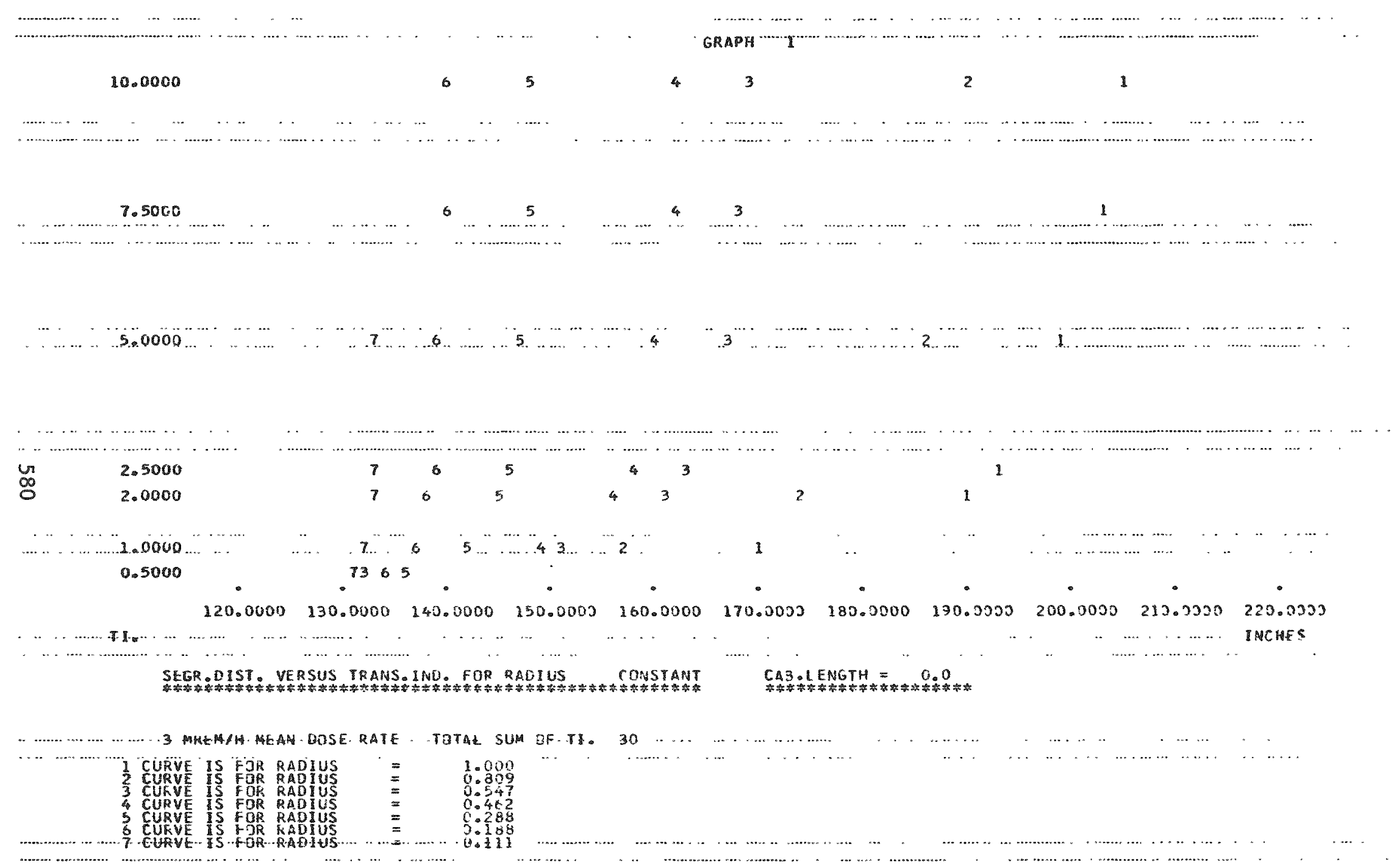




\section{-}

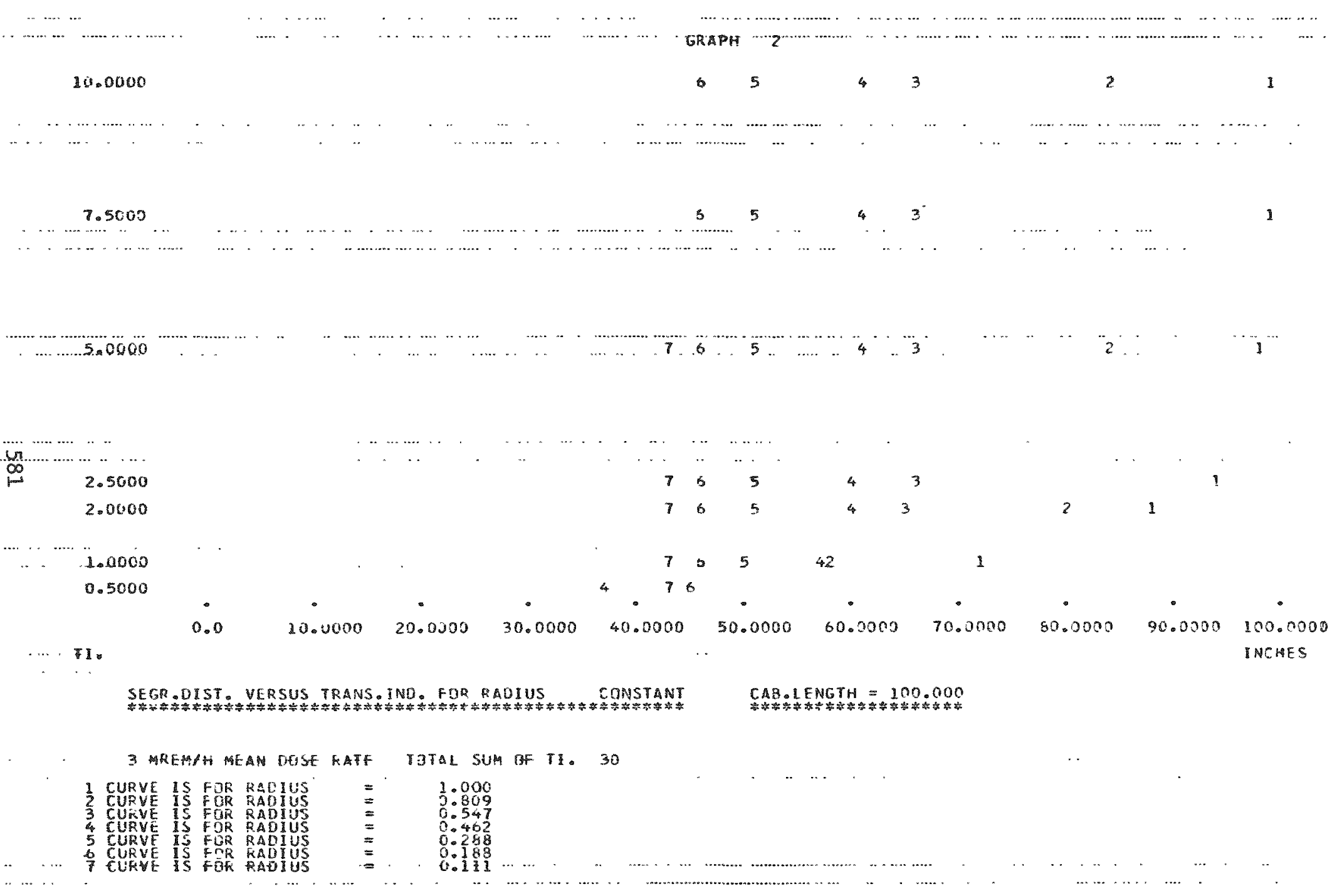


10.0000

$.5,0000$

$\ldots \ldots \cdots, \cdots \cdots$

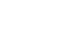

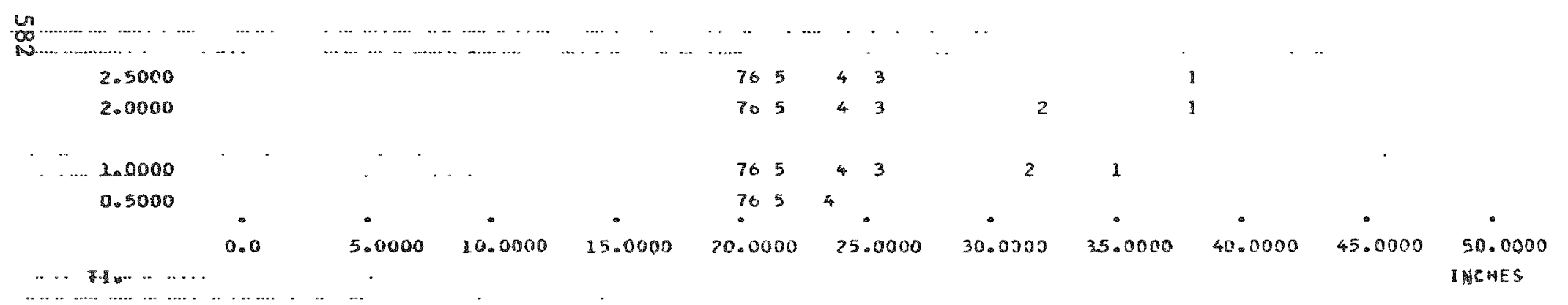

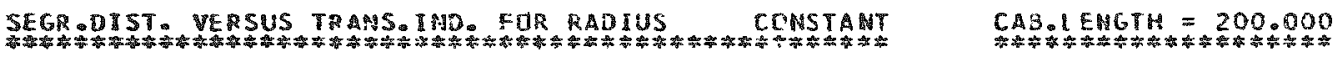

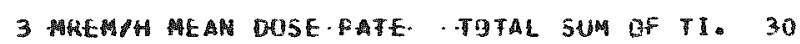

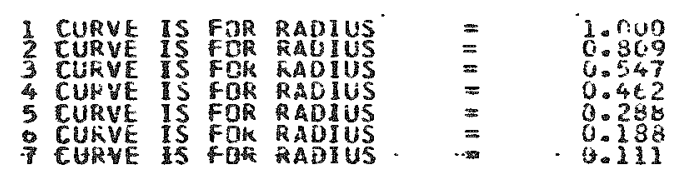




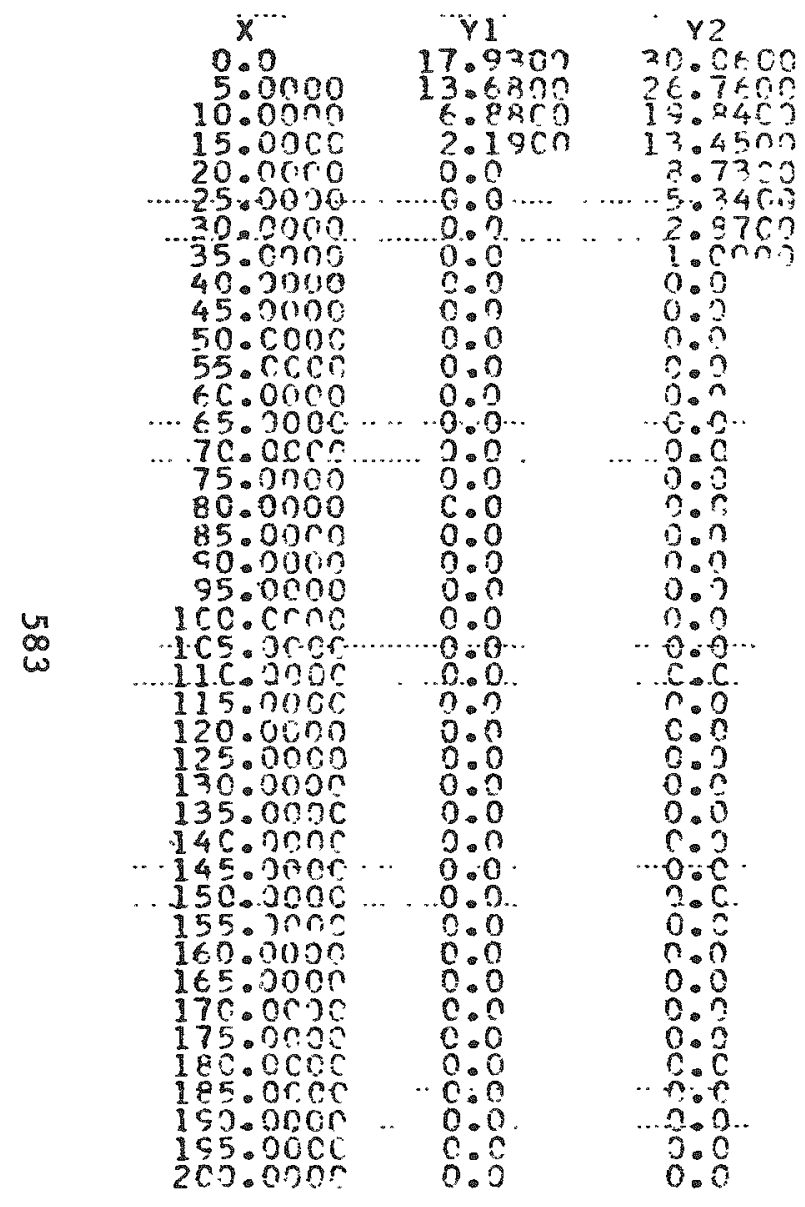

\begin{tabular}{|c|c|c|}
\hline $\begin{array}{l}4.1200 \\
1.9200 \\
6.290\end{array}$ & 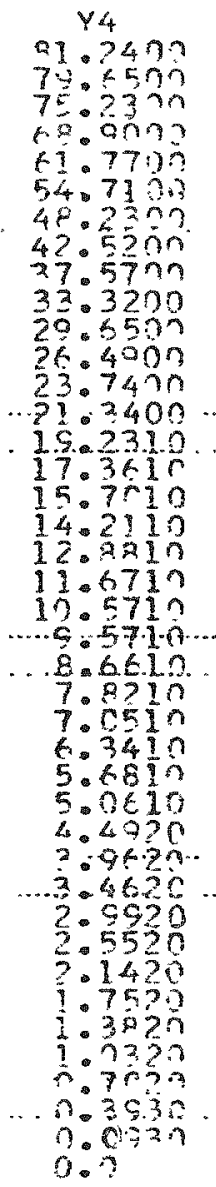 & 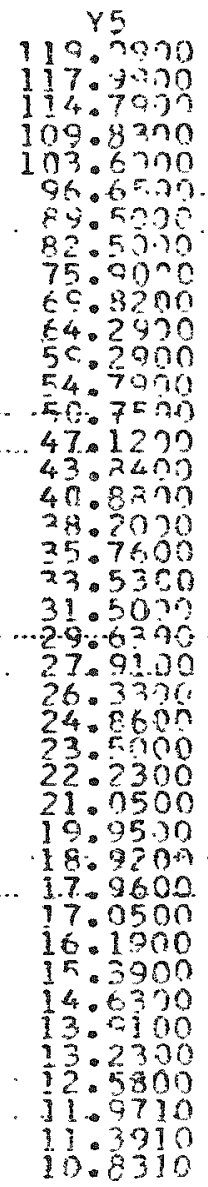 \\
\hline
\end{tabular}

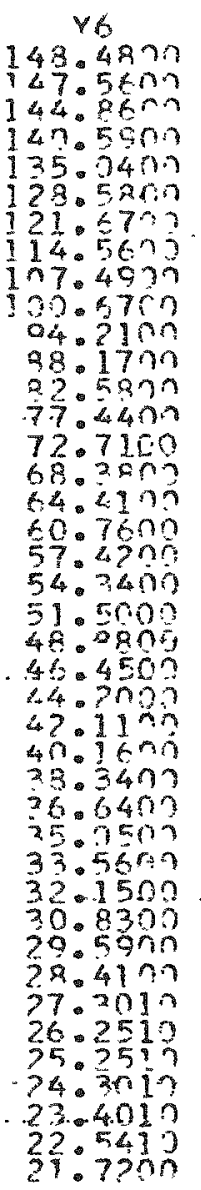

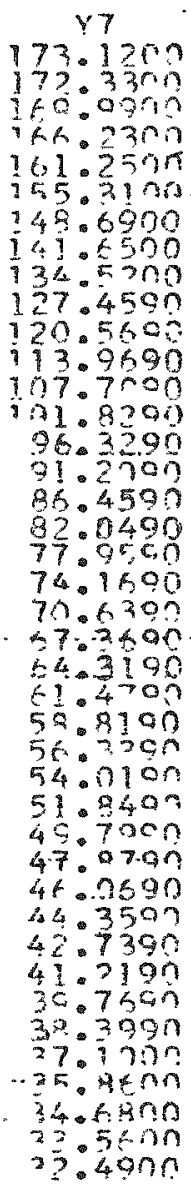

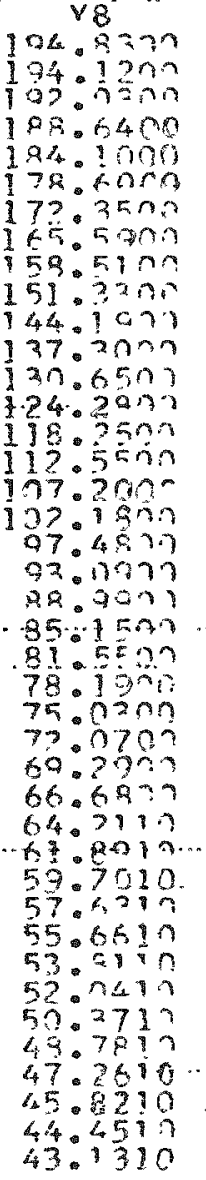

99.4100 193.4700 186.9490 172.8000 165.6910 58.3300 145.1009 139.6900 33.6900 $12607 \times n$ n 12i: 7 7ion 1 16.0800 $111.120 n$ 195.5 ann a. $34.37 n$ $30.76 n$ n 87. $370 n$ 84. 17rín 81. 1500 78. 3 nn 7.5. Rin 73.7600 70.6500 68.3500 68.1900 64. $3 n 0$ 6. 3 . 30 62.300 50.3200 5.3200 53.6500

GRAPH 4 IISTINC 


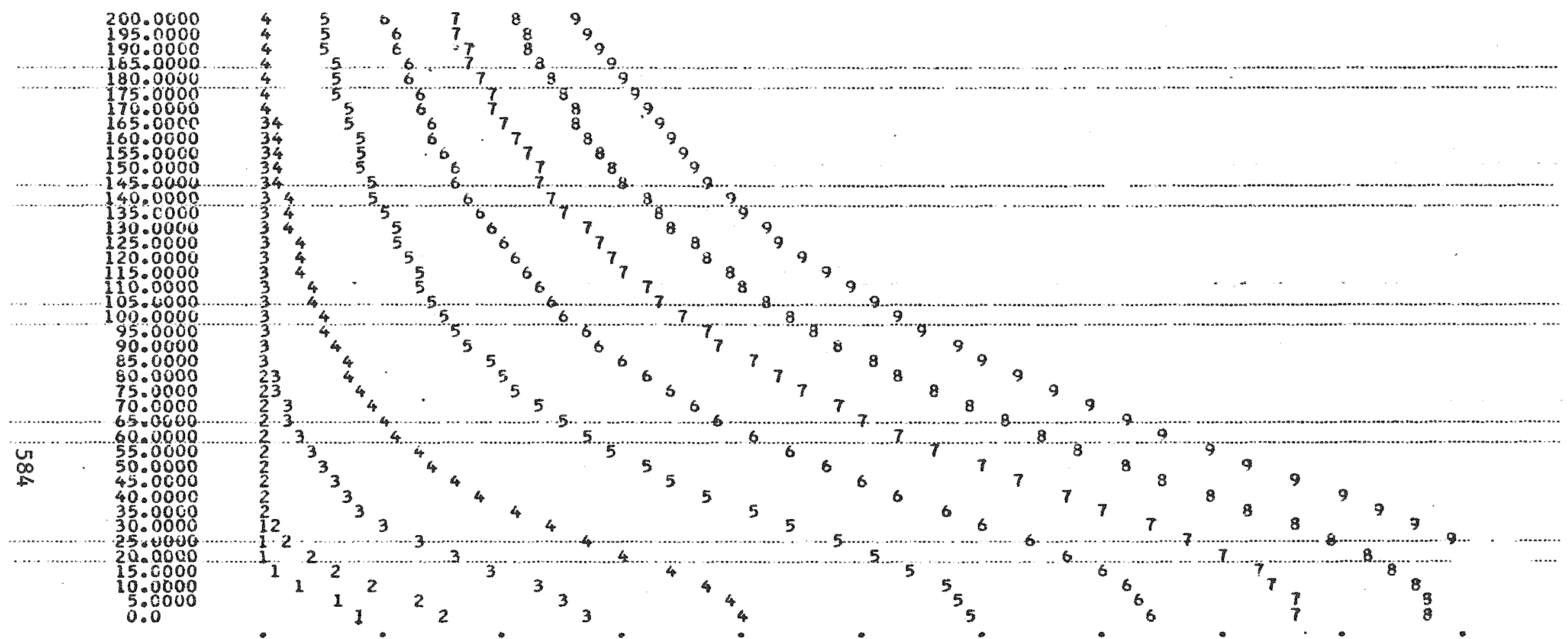

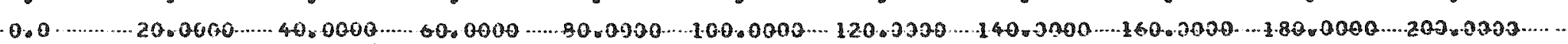

FEEI

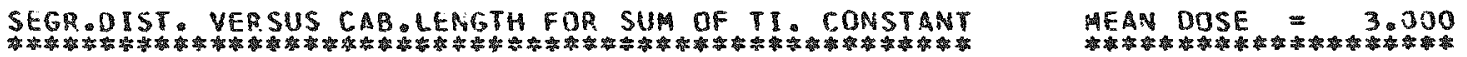

PACKAGES CF 0.288 METRE RADOUUS

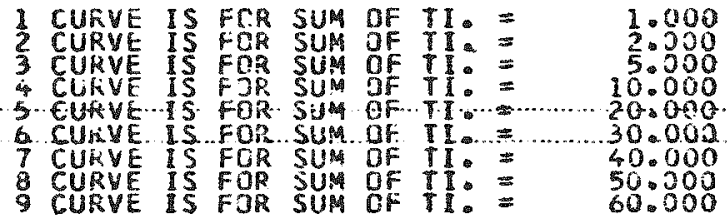


TREPQ 5

60.0000

$55.000 \mathrm{E}$

50.0000

45.0000

40.0000

35.0000

30.0000

4
$\infty$

25.0000
$<0.0000$

15.0000

10.0600

5.0000

2.0060
1.0690

I. SUM
8755432

87542

575432

3765432

97354221

87654321

8765432

4705432

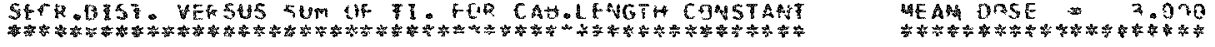

PATKAGES DF 0.2EO METHE ROALUS

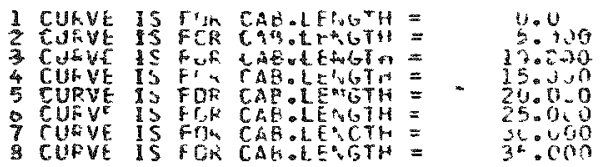


00.0000

$\$ 5.0000$

50.0000

4.50000

40.0000

35.0000

30.0000

$60.25,0000$

$\infty$

20.0000

15.0000

10.0000

87654321

$0_{0.0}^{.87 .54321}$

.................

TH. SUM

$20.0000 \quad 40.0000$

60.0000

80.0000

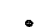

$-$

87354321

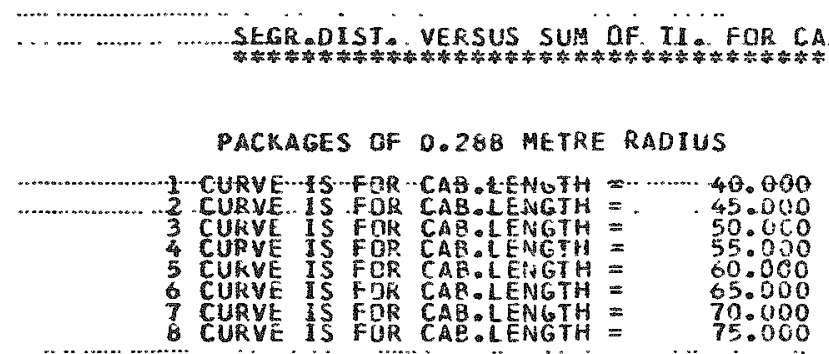

87054321

" $7054{ }^{3} 2$

7654321

.7 .6543 .2 .2

87654321

$76543 ;$ 
GRADH

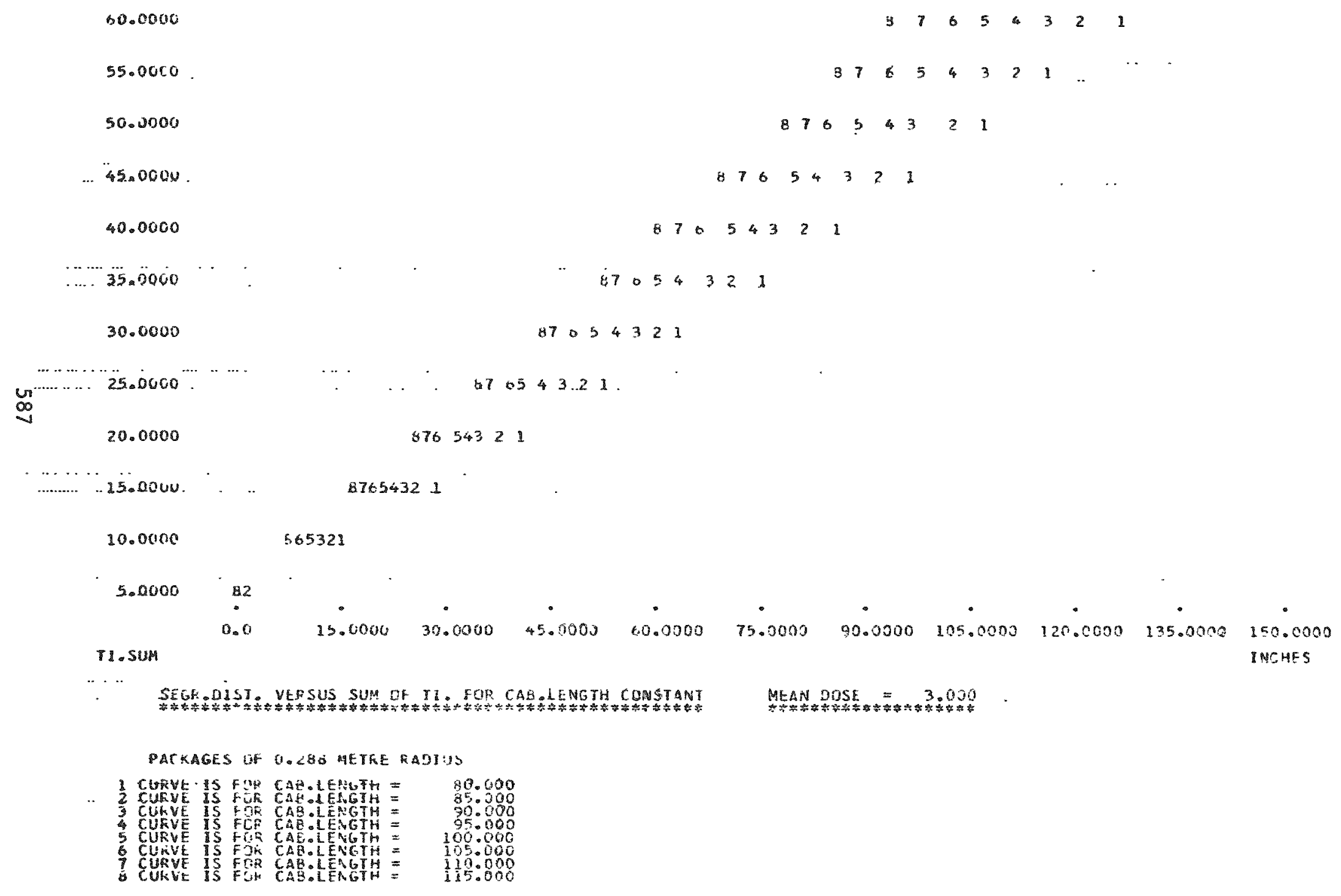




\subsection{0}

55.0000

50.0000

45.0000

40.0000

$\quad 35.0000$

30.0000

8765432

$\infty \quad 25 \cdot 0.000$

20.0000 705432.2

… $\quad \ldots . .15,0000 . .$.

$865 \quad 4321$

865431

10.0000

87542

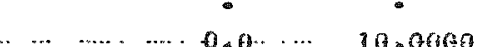

Ti.. SิUH

$.20 .0030 . .30 .0000$

40.0000 .50 .0000

60.000

70.0000

80.0030

0.0030

00.0909

IMCHES

SEGR DOIST, VERSUS SUM OF TI, FUK CAB.LENTIH CONSTANT

MEAN DOSE $=3.000$

PACKAGES OF O.2E ME

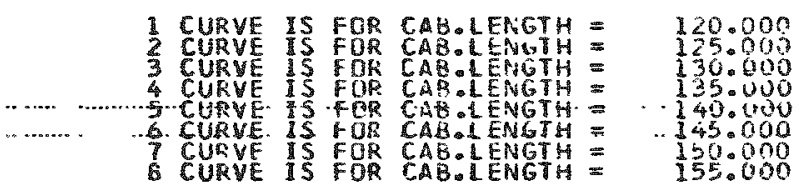

CURVE IS FOR CAB.LENGTH $=$ IST:0000 
GRAPH 9

60.0000

55.0600

50.0000

45.0000

40.0000

35.0000

30.0000

25. 0000

$\underset{6}{9}$

20.0000

15.0000

14. 6500

I. SUM
$9876 \quad 5 \quad 4321$

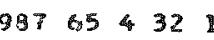

957654321

$9876 \quad 543 \quad 21$

$98765432+$

967654321

9765421

9805321

97531

952

19.0000

20.3000

30.00120

$40.0020 \quad 50.0000$

60.0095

70.0000

80.0000

90.0000

SEGR.DIST. VERSUS SUM OF TI FOR CAR IENGTH CONSTANT

MEAAS DOSE $=3.000$

PALKAGES OF 0.288 METRE RADIUS

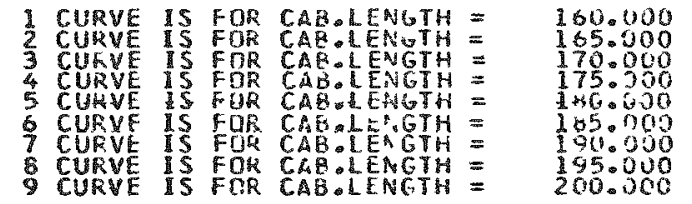


60.0000

55.0000

50.0000

45.0000

40.0000

35.0000

$\begin{array}{lll}\ldots & & \\ \ldots & \ldots & \ldots\end{array}$

30.0000

$\infty$

8....... 25.0000

20.0000

15.000

10.0000

5.0000

.00000

1日.

II. Sum

(2) 


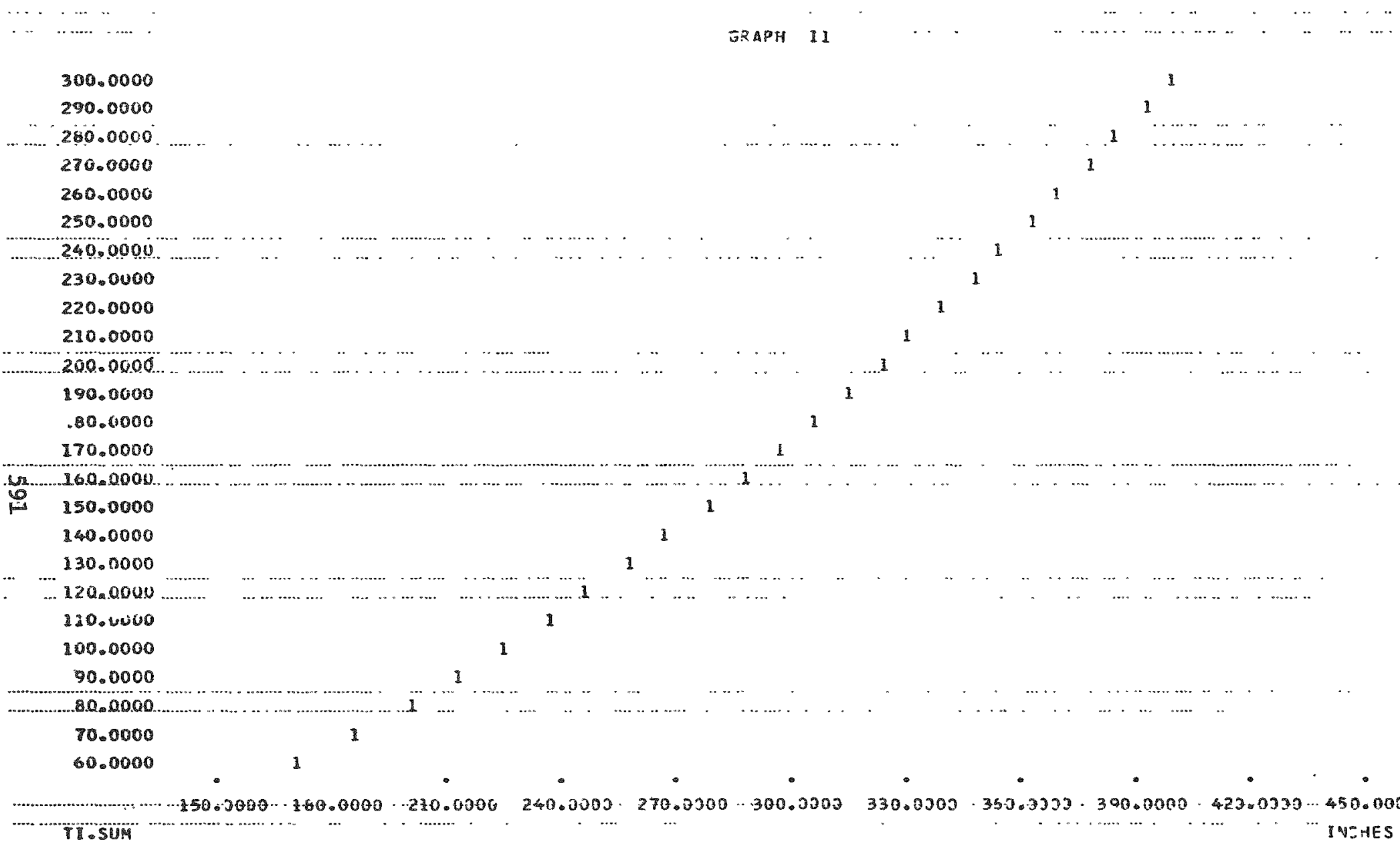


1. Labrousse

H. Lucas

ABSTRACI

This report shows the methods that can bo used to prove that a packagine complies with the Iype B drop and fire test requirenents: calculations, tests on components, tests on scale models. As regards fire resistance, besides the classical methods, an analytical method civing an approrimate solution to Fourier equation is mentioned. As regards drop test, we show how to determine the reduction of shieldins following an impact and how to determine the elongation of the screws of a closing device. The tests on components allow one to fill in gaps on some badly known particular points. The tests on scale models look promising. However, there are some difficulties in carrying them out. In conclusion, we hope for an international cooperation with a view to developing solutions to these prokloms.

\section{INTRODUCTION}

Since 1967, the shipments of radioactive materials carried out by the CEA in France have romained at a rather constant level corresponcing to about 140,000 packages weighing between 40,000 and 50,000 tons and a total distance covered of 3 million kilometers. The shipments carried out for private firms and the shipments of redionuclides manufactured by the CEA are not included in these figures, though they are increasing steadily.

A new increase of these quantities is to be expected, in particular because of the raise in power of the latest gas graphite power plants (St Laurent II, Bugey, Vande1los) and of the starting of a program of light water power plants; the increase will mainly concern the shipments of hatural and enriched UF 6 and of irradiated fuel.

The total turnover per year is presently of about 4 million dollars, of which 3 million dollars are administered by the Section des Transports Spéciaux of the CEA. The duties of the Section des Transports Spéciaux axe of two kinds and include on the one hand the execution of the transports themselves and on the other hand, studies and orders for various materials (packagings, vehicles, handline equipnents, etc.).

Though rather variable, the rean amount of the study and testing expenses involved in packagings, particularly that spent to insure that these packagings meet 
the oxisting regulations, may be assumed on an average of 100,000 per year for the last five yearse This amount will tend to increase in the coming yours, wainly vecause of the particular difficulties presented by the packasings for the fuol of the licht water or fast reactors.

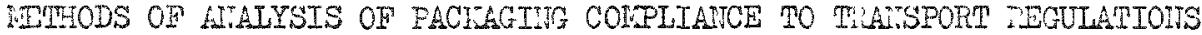

We shall study only the Type B or larce source packargings and consider only the compliance to point $\mathrm{C}-2.3$ (Amnexe IV, $\$ 1.4 .2$ and 1.4.3) of the IAEA Recomoncations, without oxamining the problems of criticity or shielding. In other vords, we shall only consider the resistance to fire and to $9 \mathrm{~m}$ drop.

Real tests porformed on one or several packagings of the saro type are evidiontly alway possible. This was the method applied at rirst. It seemed to be heyond question. We dropped the packaging from a 9 m height at a judiciously selected impact ancle; then the packaging was subitted to an open fire of $800^{\circ} \mathrm{C}$ for 30 minutes. We checked, after both tests, whether or not the pockacing met the ronvirements of $5-2.3 \%$. The designer should have been satiafied. But who can warrant that this judiciously selected angle - selected in fact on rathor subjoctive criteria - is the angle giving the meximum damage ? A difference of a few dogrees nay change the inpact surfece ano therefore the resistance of the packaging by a large amount. Who can varrant that the flames remained betwoen 0.7 and $3 \mathrm{~m}$ thick durine the 30 minutes of the test, and that the packaging was exacty in the position most damainc to it?

With moch experience and a little good faith, the designer realizes that the test performed does not offer a total gumantee. Fie also sees that the teat is exponsive. We do not montion the testine facilitios, which nay be anortized on several years, but oxcept for some coses, onch test means a pachacins damaced, and on small series the cost becomos prohibitive.

In any case, the lerge packarings that are considered for the transport of irrodiated fuel and whose weicht may reach or even exceed 100 tons are not easy to test.

There are three reasons: scientific accuracy, economics, and technical possivilities, which militate in favour of the use of other solutions.

We are poinc to examine successively three of these solutions, showing both their advantages and disedvantages.

\footnotetext{
*i.e. no loss or dispersion of the radioactive contents could happen, and the
} ohielding would reduce the dose rate at 1 meter to at most $1 \mathrm{R} / \mathrm{hr}$. 


\section{CALCULATIONSS}

\section{Resistance to fire}

The IAEA Recommendations, considering the open fire test or implicitly the oven test as a means of demonstration only, define the themal test in terms of quantities of heat brought to the packaging. Therefore, it is nomal to use this definition directly.

\section{Rough calculations}

A rough estimate, but one which is very easy to use, consists in writing an oquation of the following form:

$$
Q=M C_{p} \Delta \theta
$$

The quantity, $Q$, of heat absorbed is calculated assuming a constant temperature $T_{c}$ on the outer shell, intermediate between the initial temperature and $800^{\circ} \mathrm{C}$

$$
\mathrm{P}=23765\left(1-\left(\frac{\mathrm{T}}{1073}\right)^{4} \mathrm{Kcal} / \mathrm{hr} / \mathrm{m}^{2}\right.
$$

where

$C_{p}=$ the heat capacity of the packaging

$\Delta \theta=$ the rise in temperature of the packagine.

Thus, we obtain the mean temperature at which the packaging mass will be at the end of the test. If this temperature were to approach the acceptable limit temperature for the material employed, the packaging must very probably be rejected. If we obtain, for example, $300^{\circ} \mathrm{C}$ for a packaging with a lead shielding, a certain mass of lead will nelt. In this case, special arrangenents must be used to avoid a rupture of the shell due to melting of lead. However, this nethod, used only at the beginning, is not quite correct. The choice of the temperature of the outer shell used to calculate 2 is rather large:

for $T=273+200$, the packaging will receive (for $1 \mathrm{~m}^{2}$ surface) $22,635 \mathrm{Kcal}$ for $T=273+400$, the packaging will receive (for $1 \mathrm{~m}^{2}$ surface) 20,085 Kcal for $\mathrm{T}=273+600$, the packaging will receive (for $1 \mathrm{~m}^{2}$ surface) $13,665 \mathrm{Kcal}$

Experience shows that the mean temperature of the outer she1l is below $400^{\circ} \mathrm{C}$, but the choice remains arbitrary and the error is at least 10\% Hore important is the lack of information on the value of the gradient inside the shielding.

\section{Finite difference method}

A more elaborate method, the method of the diagram of Binder and Schmidt, allows one to ontain the distribution of the temperatures within the shielding thickness. We are not going to describe this nethod, which is well knom. It also perritis one to take into account the variation of flur versus time, since we have 
the temperature of the shell at any time. However, this method is rather tiresone to use, and the more so as we want to have a great accuracy. The numerical nethod of Dusinberre, belonging to the sane class of techniques, prosents the sane disacivantages.

\section{Use of computors}

The use of computers to solve the equations of Fourier allows one to so still furthor. For example, wo shall be able to talre into account the dilatation that can create caps between the different materials or incroase those already existins. We use currently such mothods either with analog computers or with digital computers.

\section{Analytic method}

It is vell known that the problem of fire camot be solved nathematically. But is can be fiven an approximate solution, quite astisfactory. In fact, it is a matter of defining in terms of the time $t$ :

- the temperature in any point of a hollow solid $\theta(x, t)$ and in porticular on ito surface i.e. $\theta(t)$,

- the Ilux received by this surface, i.e. $\varphi(t)$.

The relation between temperature and flus is given by Stefan's law

$$
\varphi=R(\theta)
$$

Without going into all the details, it can be shown that the Fourier equation imposes a relation of convolution between $\theta$ and $\varphi$ :

Te malse the approximation

$$
\begin{aligned}
\theta & =n * \varphi_{\theta} \theta^{\prime} \\
a^{2} & =1-\frac{\theta^{2}}{\text { (nomalized } f l u x)}
\end{aligned}
$$

Those last two equations define $\varphi(t)$ by its Laplace transform, which is the positive solution of the equation of 2nd degree

where

$$
n^{2} \Phi^{2}+\frac{a^{2}}{p} \Phi-\frac{a^{2}}{p^{2}}=0
$$

$$
\text { a = the final temperature: } a=\theta(\infty)
$$

If and $\Phi=$ the Laplace transform of $\mathrm{h}$ and $\varphi$

$$
\Phi(p, x)=\int_{0}^{\infty} \varphi(x, t) e^{-p t} d t
$$

Ilowever, all these solutions apply only to comperatively simple geonetrical shapes. The ideal would be to have spherical packacings. But this is not the conoral case; far from it. The cylinder, if it is long enough to ensble one to disregard the influence of the ends, will still be anenable to such solutions. With perallelepipeds, we are going to have difficulties on edges and particularly on comors. But their influence, which can be assessed with a certain approximation, renains local; on a large packaging, it does not much change the value of the absorbed flux. 
licthods suitable for heat barriers

The problem of fire resistanco way be rather easily solved by incorrorating a thermal insulator between an outer steel shell and the lead shiclding. If the packaging contains radioactive materials with high rosilual power, whose outrard disposal must be insured, the heat barrier must be effective in one direction only: from outside to inside. If the residual power is not too high, the use of plaster, good conductor in normal conditions when it is noist, and insulatins when heoted above $100^{\circ} \mathrm{C}$, gives the solution. A simple calculation may thon be performed. The 30 minutes are divided into two parts:

- In the first part, usins a conservative method, the outer shell is aswumed to be at a rather low constant temperature. The flux is ascumed to be absorbed only by water vaporizing. For a packaging of the dosign used for the Irradiated fuel of gas graphito reactors, including a layer, $e$, of plaster $12.5 \mathrm{~mm}$ thich vetween lead shielding and outor shell, we find a duration of 6 to 7 min. for a shell tomperature of $150^{\circ} \mathrm{C}$;

- In the second part, account is takon of the thermal conductibility of dry plaster, which decreases to $0.2 \mathrm{ncal} \mathrm{m} / \mathrm{hr} / \mathrm{m}^{2} / 0 \mathrm{C}$ (instead of 0.6 when it is noist), and the rlux going through is calculated, assuming that the maximum temperature of the outer shell is $800^{\circ} \mathrm{C}$. We introduce thereby another factor of safety, becausc the temperature is in practice below $700^{\circ} \mathrm{C}$. (If the tomporature had reached $800^{\circ} \mathrm{C}$, there would not have been any heat flux botween the fire and tire sholl).

Wo have on the one hand:

$$
d Q=i c_{p} d \theta
$$

thero

$$
I_{p}=\text { the heat capacity of the shiolding }
$$

and on the other hand:

$$
d Q=\frac{\lambda S}{e}(800-\theta)
$$

where

$$
S=\text { the external curface area }
$$

from which, we draw by integration:

$$
\log \frac{800-\theta}{300-\theta_{0}}=\frac{\lambda}{\theta} \frac{S}{\because C_{p}} T_{2}
$$

where

$$
\mathrm{T}_{2}=\text { the duration of the second part. }
$$

Conceming the irradiated fuel packagine proviously ta'kon as an example, wo find that starting from an initial temperature $\theta_{0}=1200 \mathrm{C}$, we reach $177^{\circ} \mathrm{C}$. This is of course a mean temperature. The ternperature gradient in the lead beinc low wecause of the themal protection, and the nean temrerature beine far cnough from the neltine temperature of lead, we can be sure that meltine will not occur. 


\section{Lead crushing}

In recard to cverall fracture of container, the use of lead in most of our packaging with an outer shell made of stainless steel hovine a cood ductility gives us a good degree of safety. But the problem of the lid closing device bohaviour has not bcen touched upon. It is bound up with the deceleration suffered by the packacing on crushing. Though the crushing itself is generally licht (comparatively licht, and for big packagings only), we had however to make sure that it did not roduce the whielding thickess beyond the limit of the dose rate specified by the Recomondations for accident conaitions (see \& C-2.3.1).

No tried to solve those rroblems ky a rurely mathematical approach, in the particulor case of a cylindor, startine from the assumption that drop onerey was chsorbed ontirely ky creoping of the raterial shifted on crushins.

Though this assumption is not rigorous and the value of this "creening cnorey" vories in sccordarce with a certain number of parameters: naterial quality (e.8. antimony contont of lead), matorial temporature, thicinoss and ruality of the stocl wheath surrounding the lead; it is still constant enough to sive the value of the ancle of drop involving the maximu reduction or deceleration (the most important thins to inow), even though it does not give the precise absolute value of the thiclness reduction or of the deceleration vorsus time.

We have then at our disposal curves lnom as "hull ourves", formins the family of the onvelopes of the crushins plans, plane limiting the crushed volume $V$. These curves, dowionej for a standeriized cylindor, we functions of a single paranotor: the relation $\frac{V}{V_{c}}$ of the crushed volume to the extermel volume of the pacingeine. $V$ talres into account both the height of arop and the "creepine oncrey".

\section{Analysis of lia clogure behaviour}

Calculetions of the maximum static foree pouired to rech the olastic linit of lid clowro screws eive an idea of the safoty offered by a lid closino device durine an impact. To this force will correspond a deceleration $\gamma_{L}$. ihorefore, if it can be shown that during the drop test the deceleration supported by the packacine is below $\gamma_{I}$, the lid closine device will be satiofactory. This nethod of enrocon is consorvative. In fact, this method involvos applyins the marma strength durine an infinite time, though the actual deceleration peaks are quite short (some $10^{-5}$ sece) while the natural period of the mass-sprine systen made un by the lid and the scrows is much longer (sone $10^{-3}$ seco). Therofore, the ofiect of those poales on the scrers is greatly Iessened. 
The application field of this method is limited to light packacings and to packagings provided with shock absorbing device. Fo: heavy packagings without shock absorbing device, the deceleration found by this method is much too low to be consistont with the deceloration encountered during the test.

For these latter packagings, which account for the nost problems, we use a mothod which takes into account the transient character of the shock and the elactic and plastic properties of the material. A closing device with screws may bo shom schenatically by the following figure,

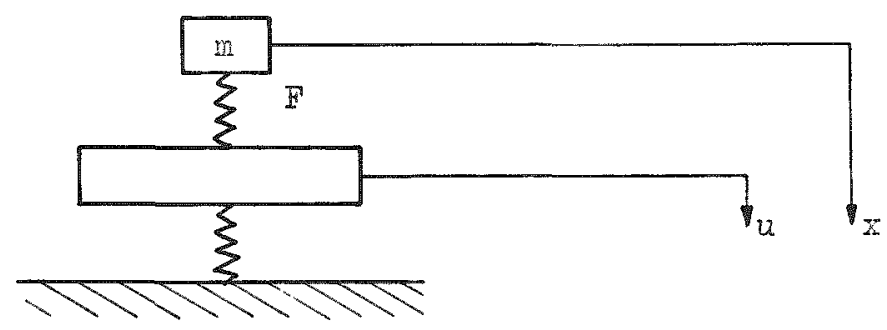

where

$\mathrm{m}=$ plue mass divided by number of screws,

$x=$ abscissa of screw head,

$u=$ abscissa of a point rigidly bound to the anchorace of the scrow and such that at the starting moment, selected just as tho shock berins, $z=u_{\text {, }}$

$F=$ binding strength of the screw.

The basic rolation of dynamics applied to the mass $n$ allows us to write:

$$
\frac{m d^{2} x}{d t^{2}}=-F+m g
$$

Disrogarding the effect of gravity and introducing the stress-strain relation of the material used, it is easy to check that this equation can be written in the following form:

$$
10 \frac{d^{2} \varepsilon}{d t^{2}}+\frac{s}{m} \quad \sigma(\varepsilon)=-\frac{d^{2} u}{d t^{2}}
$$

where

lo = free length of scrow (Iensth which can be deformed),

$S=$ cross-section of screw,

$\varepsilon \quad=$ relative elongation,

$\sigma(\varepsilon)=$ stress-strain relation of the material used.

This equation with versus $t$ is the one to be solved. 
The solution $\varepsilon(t)$ depends finally:

- on the parameters free length 10 and relation $\frac{S}{M}$,

- on the shape of the stress-strain curve of steel,

- on deceleration of the anchorage point of the screw.

Because of the term $\sigma(\mathcal{E})$, the equation is not linear. Therefore, an analog computer was used to solve this equation, and to study the effect of previously mentioned parameters. Although the study is not completed, the prominent part played by deceleration on the anchorage point may be underlined.

\section{TESTING ON CORPONENTS}

Drop test

As will be seen in Part 3, the general behaviour of a packaging during a drop test may be determined by means of scale models. However, when the effects of impact are localized, it may be interesting to study the behaviour during impact of a full size packaging component (lead, thermal insulation, shock absorber, screws, etc.).

Without losing sight of the interesting aspects of the study of lead defor mation or the adjusting of shock absorber, we turned our attention to the impact behaviour of the screws used to hold a packaging lid in position.

For this purpose, we have built a testing device reproducing the dynamic loads to which the screws of the closing devices are generally subjected. Our first concerm has been to observe the dispersion of permanent elongations of screws tested in seemingly identical conditions. We have also taken advantage of this series of tests to control the similitude laws by reproducing the testing device to $\frac{1}{2}$ scale. Without going into the details, the results of the tests have been as follows: the distribution of the elongations obtained with the first device follows fairly a Gaussian, whereas the distribution obtained with the $\frac{1}{2}$ scaled device divided into two families. This last behaviour seemed abnormal. Moreover, the comparatively large range of dispersion meant that each kind of test must be performed a great number of times, which made the continuation of the study impossible, with the means we had at our disposal. The search for the causes of these anomalies led us to think that they were due to comparatively small variations of the impact angle. Since then, the addition of a guiding system during the greater part of the drop reduced appreciably the dispersion, and we are going to proceed with this experimental study. 
Thormal test

As 2 whole, the heat transfer phenonena are vell knom. Nevertheless, some points may require particular studies, e.g. the effect of fins or the notion of the vaporization face inside a themal protection including water. The tosts on components are woll adjusted to the experimental study of this kind of problem.

\section{TESTS ON SCAIE RODELS}

The similitude laws are well known. If $1 /$ s is the scaling factor of a scale model comparod with the prototype, for a certain dropping height, the parameters such as deformation, shock duration, acceleration will be in the followine ratio:

\begin{tabular}{|l|c|c|}
\hline & inodel & Prototype \\
\hline Deformation & $d$ & $s d$ \\
\hline Acceleration & $\gamma$ & $\gamma / s$ \\
\hline Shock duration & $t$ & $s t$ \\
\hline
\end{tabular}

The method can almost be called ideal. The obvious advantace is the savings which result from the fact that the mass of the model is divided by $s^{3}$. ConseguentIy, the number of tests can be much higher than on a prototype, and by changing the impact angle, it is possible to have a rather complete idea of the resistance offered by a packging. The weight roduction also permits an easior handing: the tests can be done with a snaller number of operators.

Fowever, whon applying this procedure, some difficulties are encountered:

- in the construction of the model,

- in the carrying out of the test.

The development of the model requires theoretically the reproducins to scale of:

- plate thiclness,

- veld-seans,

- clearance betwcen Iid and body,

- pipins.

For commercially available screws, in perticular, there is no exact similarity between one screw diameter and another. Thread, pitch and diameter do not vary in the same ratios. From the foregoing, the rosult is that the exact reproduction of all the characteristics of a prototype requires a great doal of care when using quite large scalins factors. So the savings on raw materials are more or less counterbalanced by the cost of practical application. 
In free drop test, below a certain woicht, it becomes difficult to cuarantee the incidence of the angle of drop, particularly if the teats are carried out in the open. Because of this, the similiude of the deformation can he obscured. This vas the caso with the previously mentioned scrow tests. It may then be necessary to ruide the models durin; a part of thoir travel, what requires more elaborsto cquipnonto

Wo think that the experimental study of the behaviour of a mackarin arion drop tost may be roughed out by the use of a cortain nubor of molols on a rather omall scale and more thoroughly studied with a smaller number of molols on a restor scale.

Do this end, we are presently preparine a series of 9 m wop tocts that will incluäe:

- testing of five $1 / 8$ scale models of a 10 ton paclagins prototype with different ancles of drop.

- testine of three $1 / 5$ scale nodels of the ane prctotyro uith the moat destructive angles of irop followins the previous testo,

- vestine of the 10 ton prototype.

All these testa

It scens intereatine to use the scale model method for other pumposes than the simple statemont of the defomation suffered by the model.

The simplicity of the similitude law relating accoleration cnd time leads us to consider the scalo model as a "physical oporator" giving the tine-history of tho ceceleration suffered by the prototype during innact. A cherse in scale of amplitudes and times allowe us to change from the model to tho prototypo.

So, in the malor computer colution of the froblon of screw behaviour, the deceleration $-\frac{\mathrm{d}^{2} u}{\mathrm{~d} t^{2}}$ at the Ievel of the anchorage point mey we put into the coraputor starting from a signal recorded during a real test on a model.

However, this way of dealing with the data sives rise to problems of adaptation of the various matericls, and a certain specialization of the personnel is renuired.

\section{QURCLUSIOIT}

In order to establish that the packaging meets the reculation requircnents, the designer is induced on the one hand to work out "patterns" wiving the loads: stress, tempereture, etc. to which the difforent compononts of a pacharing are submitted, and on the other hand, to analyse the reactions of these components to these loads. 
Taling into sccount the increasinfly hish performances required from the paclauings, these become more and more complicated and make use of loss and Iess ordinamy materials. The problems to be solved require the use of advanced techniques involving special skills in very specialized fields. Such slills are necessarily limited and thorefore progress is slow.

Progress should be much greater if the engineers of different countries workinc at these problems were better informed of oach others work. Duplication of studies, as those appearins too clearly on each intemational meetinc, would then be aroided.

A typical example of this lack of coordination is found in the past: to dotemine the thermal test resietance, computer codes are senerally used. Each country, not to say each research department, hes worked out its om "code". AII these codes are no doubt of sare value and probably give recults that are not mach different - though this has to be confirmed - but it would have been better if a conrol conference had led to the acceptance by everyone of a unique code, which would be used in all the agreenerts using thiss "proof" of compliance.

Trancrort regulations of radioactive materials had the good fortune to cone into existence in an intemational sphere and to be common to all countries. This is a great advantase, making intemational transport easier. It rould be cood if this international cooperation were to be extended to the field of analysis of the compliance of pachagings to regulations.

Without tryine to establish "regulation standards" for the IARA Recomendations, or evon a coordinetion of the basic studies conceming safety, a better conmunication among the designers of all comtries is to be desired.

This oxchange of information could include:

(1) Erchange of physical laws applying to the phenomena under consideration, e.g. impact strongth, release of gaseous fission products fron fuel elerents whose casings are not lealproof, neutron shieldings, etc.

(2) Exchange of "standard codes", computer codes, etc. capable of boing used in the safety analyses of the agreeronts. 
REVIEK OF EXPERIMENTAL STUDIES ON THE FISSLE FUEL SHIPPING CASK IN JAPAN

S. Aoki

\section{ABSTRACT}

In order to obtain the data necessary to design spent fuel shipping cask, some experimental studies have been performed in Japan. The Research Subcommittee for Design of Spent Fuel Shipping Cask in the Japan Society of Mechanical Fngineers JSME performed the experimental study on the heat removal from lead shielding cask for the various decay heat generation rate, which was simulated by means of electric heaters loaded in the cask under steady and hypothetical accident condition. The temperature distributions in the case of "with full coolant". "with half coolant" and "without coolant" were measured and the temperature change of cask and fuel assemblies were obtained during loss of coolant also. The experimental studies on the drop impact were carried out by JSME since 1968. Assuming that the prototype cask for light-water reactor would be of horizontal cvlinder type weighing about 80 ton, the $1 / 16,1 / 8,1 / 4$, $1 / 2.5$ and $1 / 2$ scale models were fabricated and tested. In these tests deceleration at the moment of impact were measured with accelerometers and deformation of cast were also observed. The relation between drop height and deformation was analysed.

From the fire test by the Fire Institute of Japan, the coefficients of heat transmission on the surface of cask and between steel shell and lead shielding were obtained.

The orer-the-road tests of a shipping container for PWR type new fuels conducted by Mitsubishi Atomic Power Industries. Inc. (MAPI) gave some valuable data for the compatibility with road condition. The drop tests of PWR type new fuel container were also performed by MAPI, that was presented in this symposium by itself. 


\section{INTRODUCTION}

Nowadays in Japan the three 1 ight-water cooled nuclear power stations are in operation and more than ten in process of application or construction. According to the programme, the clectric output from power station will come to about $16,000 \mathrm{MW}$ in 1975 and 60,000 MW in 1985. This means that the amount of spent fuel is estimated to run into about 60,300 and 500 t,'y after 5, 10 and 15 years respectively. On the other hand the reprocessing plant will be completed in 1973. therefore the transportation of a large amount of spent fuels from light-water reactors will start at the same time. In the case of Japan al1 nuclear power stations are lorated on the seashore and consequently it seems to be most convenient to transport by ship directly from the pier of station site to the nearest harbour to the reprocessing plant and on road only in the short distance between them.

Providing for such situation. the Japanese lational Standard, "the Safety Criterion for Shipping Container of Nuclear Fissile Fuel" based on the IAEA Regulations(1967) was enacted in 1968. In this standard the shipping casks were classified as follows:

L type is equal to A type packaging for low specific activity materials in IAFA Regulations.

A type is equal to A type defined by IAEA.

$B$ type is equal to $B$ type defined by IAEA.

$H$ type corresponds to $B$ type for large radioactive source in IAEA Regulations and is very similar to $B(M)$ type proposed in the third revised draft of TAEA Regulation in 1970.

When the revision of IAEA Regulation will be finished, the Japanese National standard should be revised inevitably too.

Apart from the administrative affair. we have no experience in the test and no design data for such large cask. As a matter of course it j.s very difficult to obtain the design data from foreign countries except from few published papers. In view of such situation, we decided to perform the tests prescribed in the IAEA Regulations in order to collect the mechanical design data for shipping cask and also to investigate the reasonability of test methods. In 1967 the Japan Society of Mechanical Engineers (JSME) established the research Subcommittee for design of spent Fuel shipping Cask to carry out a series of tests supported by the Atomic Energy Bureau in the Agency of Science and Technology of Japan. The test sories consisted of following themes: 
(1) An Experimental Study on the Heat Removal from Spent Fuel Shipping Cask (1967)

(2) An Experimental Study on the Drop Impact of Spent Fuel shipping Cask

(3) An Experimental Study on the Drop Impact of Spent Fuel Shipping Cask

(4) An Experimental Study on the Drop Impact of Spent Fuel Shipping Cask

$$
\text { (III) (1970) }
$$

Separately from these programmes by JSME, some experimental and analytical studies on shipping cask have been done as follows:

(a) Fire Test of Spent Fuel Shipping Cask by the Fire Institute,

(b) Over-the-road Test of Shipping Container for PWR type New Fuel by Mitsubishi Atomic Power Industries, Inc.(MAPI),

(c) Drop Test of Shipping Container for PWR type New Fuel by MAPI. Here I would like to introduce these works briefly.

\section{AN EXPERTMENTAL STUDY ON THE HEAT REMOVAL FROM} SPENT FUEL SHIPPING CASK TX 1967

The Purpose of Experiment and Experimental Condition

The purpose of this experiment was to investigate the temperature change of lead-steel cask under loss of coolant accident.

The experiments were carried out for the various heat generation rates simulated to the decay heat of spent fuels. The experimental. condition were, (1) steady condition (a) with full coolant, (b) with half coolant and (c) without coolant, and (2) transient condition with gradually lost coolant (initially with full coolant).

\section{Cask Model and Simulated Fuel Assembly}

The cask model designed and fabricated had inside diameter $500 \mathrm{~mm}$; inside length $1.200 \mathrm{~mm}$; lead shield thickness $190 \mathrm{~mm}$; Maximum Pressure $7 \mathrm{~kg} / \mathrm{cm}^{2}$; Maximum Temperature 16500; dry height 8 ton with Longitudinal fins. Fig.l shows the cask model.

The simulated fuel assemblies were made similar to those of the actual fuel except the length. The assembly was composed of 96 sheased heaters $(10 \mathrm{~mm} x)$ and 4 structural dummy rods arranged in $10 \times 10$ square array with the dummy rods in every corners. In a cask model, four assemblies were installed. Fig.2 shows the simulated fuel assemblies. 


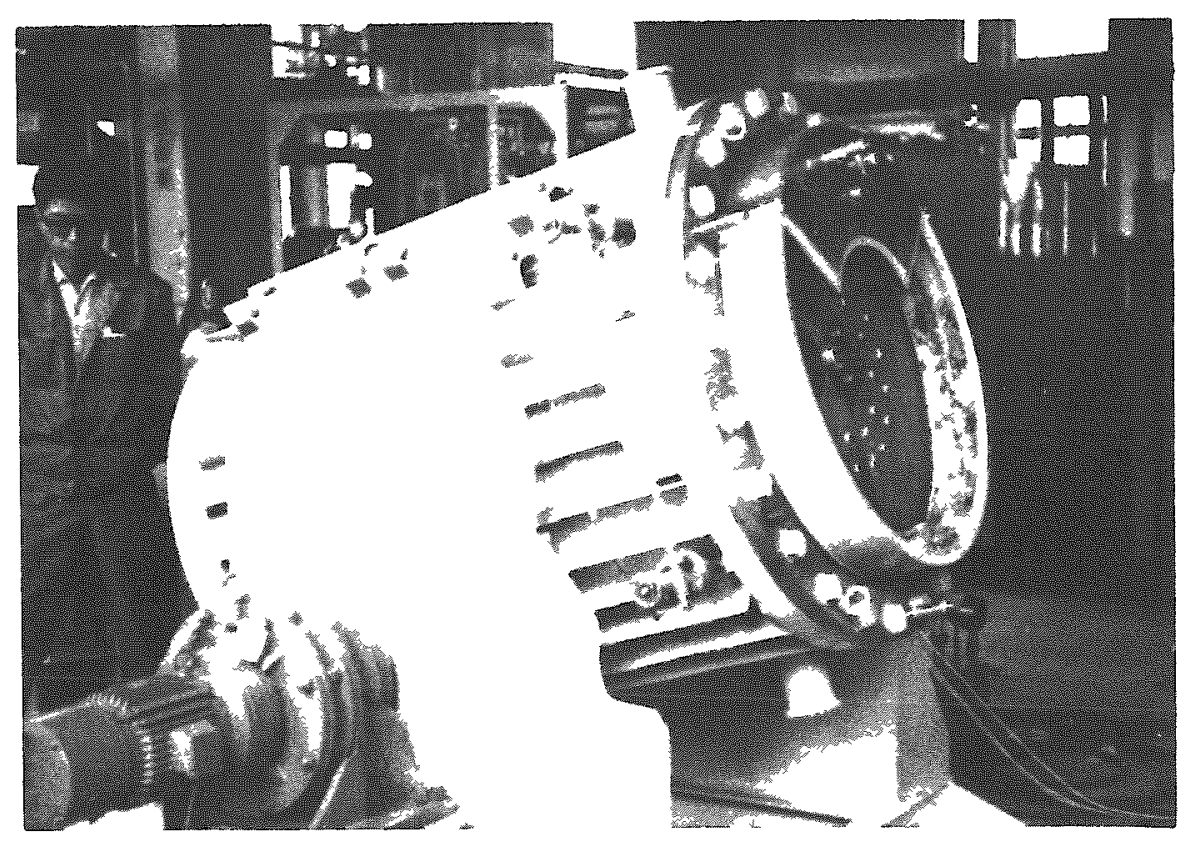

Fig. 1 Cask Model for Heat Removal Test

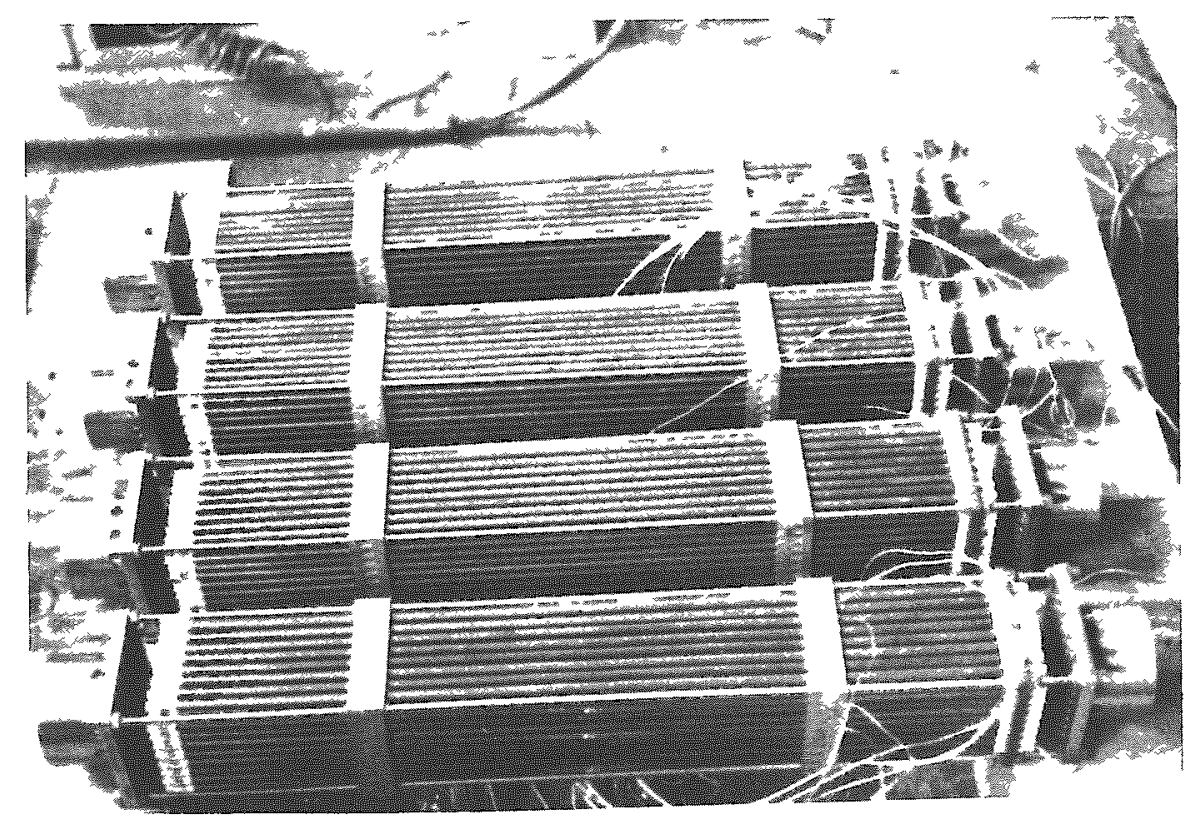

Fig. 2 Simulated Fuel Assemblies 
Considering the fact that the heat generation rate of spent fuel varied widely depending on the burn-up and cooling period, the rate was estimated to be 0.5 to $1.0 \mathrm{~kW}$ per assembly, if its length was equal to that of the simulated assembly. In order to cover this range, the test assembly was designed to generate 0.2 to $1.5 \mathrm{kl}$ per assembly. At the sevaral points the temperature were measured by sheathed Alumel

- Chromel thermocouples.

\section{Experiment}

\section{Temperature Measurement for Steady Condition}

The temperature change and maximum temperature of the cask with full coolant, with half coolant and without coolant, were measured for the various heat generation rates, as shown in Fig. 3.

Temperature Measurement for Transient Condition

First the cask filled with coolant was closed and the electric input was switched in. After the temperature and pressure became steady state, the valve at the bottom were opened quickly. Then the coolant flew out and lost. The temperature rise at several points were recorded. All these experiments were conducted with model cask laid horizontally assuming overturning accident.

Fig.4 shows the temperature change during loss of coolant.

\section{Experimental Results}

(1) The steel-lead combination has fairly high thermal resistance and particularly between the outer-sholl and lead.

(2) The maximum temperature of cank and fucl assemblies in the case of half coolant are fairly lower than that in the case of no coolant. As shown in Fig. 3. In the former case the coolant boils and generated steam cools fuel assemblies and then condensates on the inner surface of cask. Therefore, the heat transmission from fuel assemblies to cask wall may be promoted very much by boiling and cendensation. On the contrary, if there is no coolant, both convection of air and steam and radiation play a main role for heat trancmission, and it neems to be insufficient to transport the generated heat. For such case some special structure to promote heat conduction should be necessary.

(3) The record of temperature chango of cask and fuel assemblies has been obtained at loss of coolant lost. As shown in Fig.4, the temperature rise is not so rapid after having finished loss of coolant. It seems that the remaned water and stcam can remove generated heat considerably. 


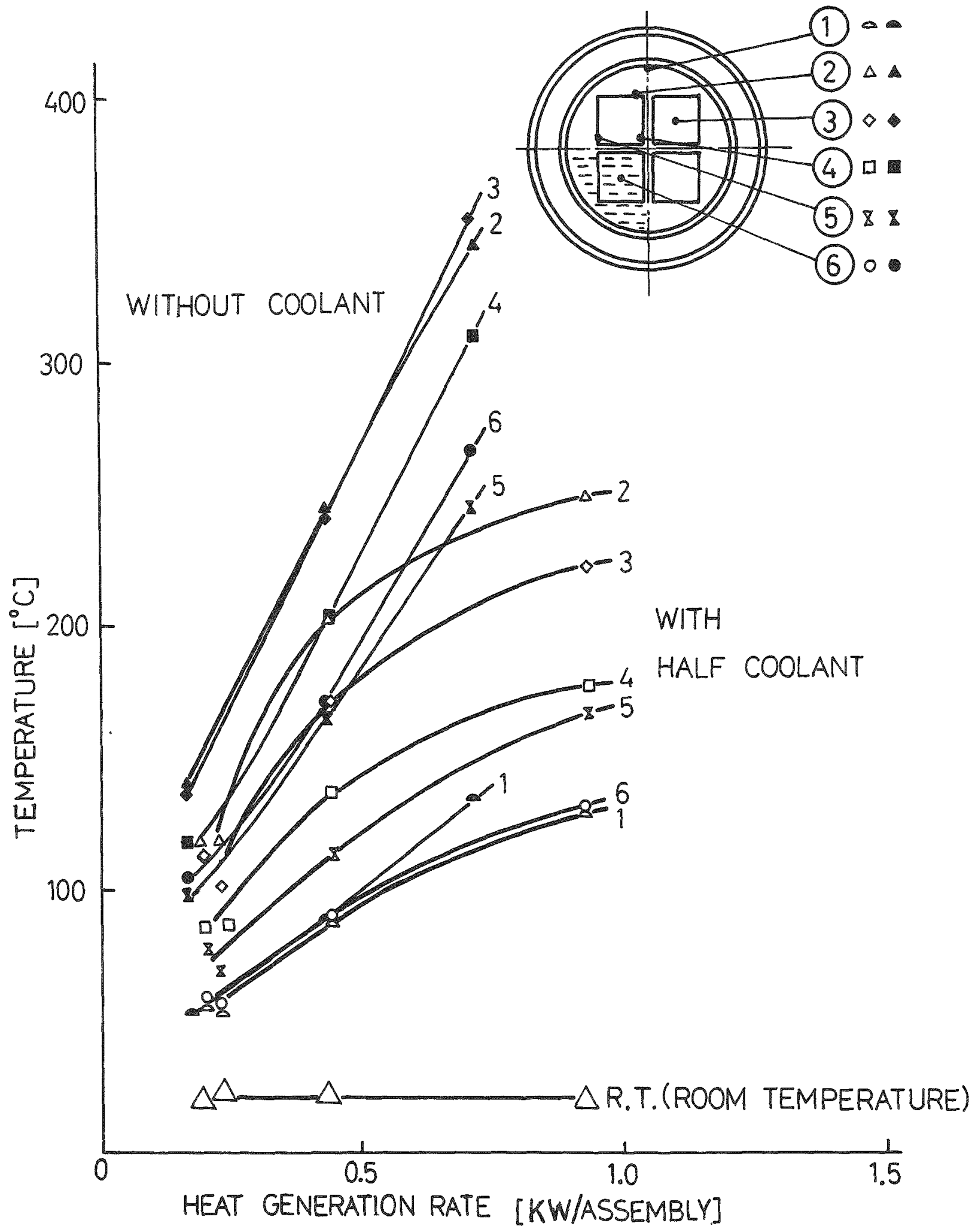

Fig. 3 Maximum Temperature for "With Full Coolant" and "With Half Coolant" 


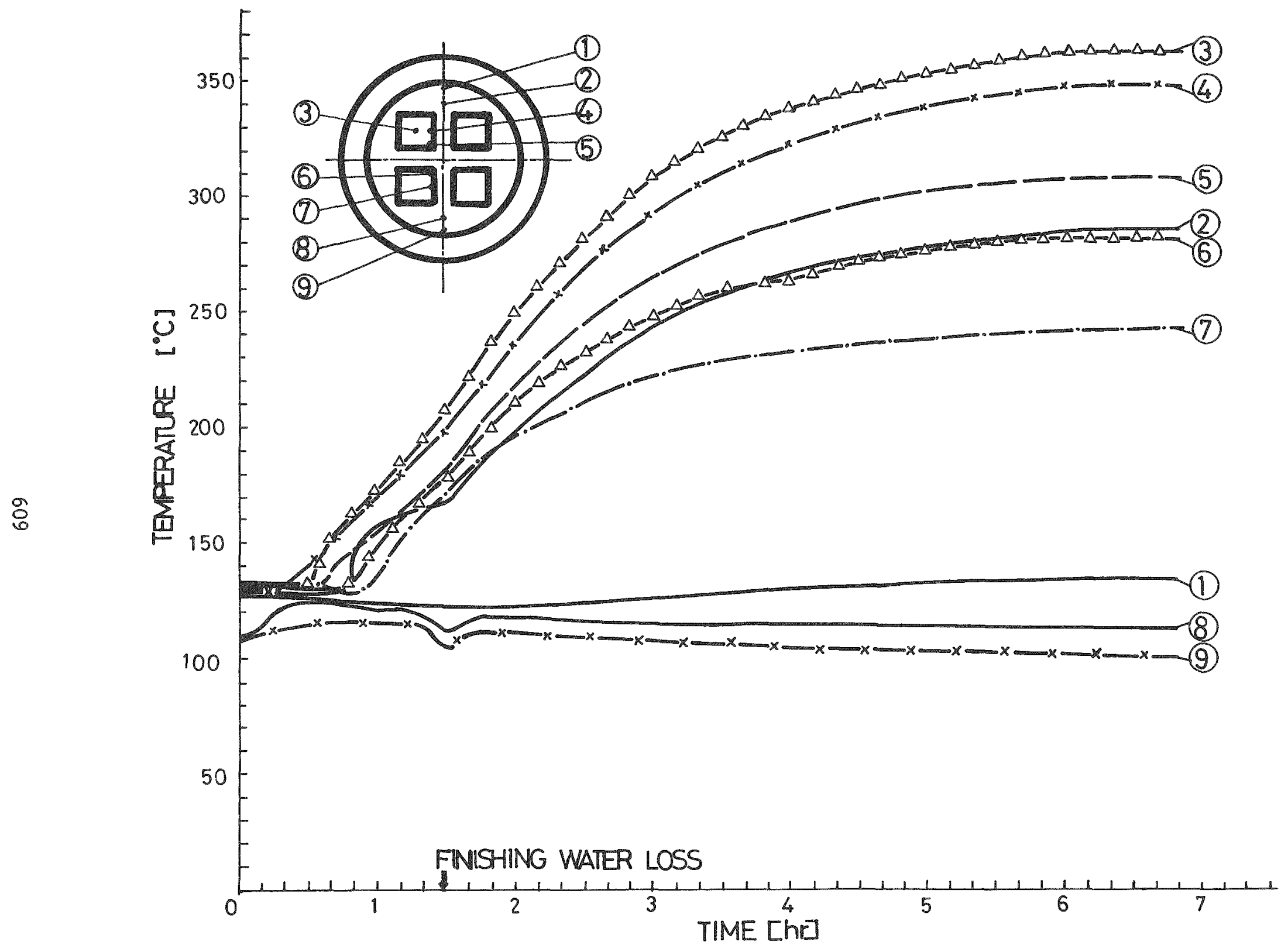

Fig. 1 Temperature Change at, "lsoss of Coolant " 


\section{AN EXPERIMFNTAL STUDY ON THE DROP IMPACT \\ OF SPENT FUTL SHIPPING CASK SINCF 1968 \\ Drop Test Facilities}

\section{Lifting and Falling Device}

The drop test facilities were constructed in the site of the Goverment Mechanical Laboratory in 1968. The main design concept was came from the IAEA Regulation as follows;

(1) the capacity of lifting device: 10 ton

(2) the maximum fall height : $\quad 9 \mathrm{~m}$

(3) the clamping device was designed to operate mechanically and also electro-magnetically.

Target

The target was made of a reinforced concrete block with a steel plate on its upper surface weighing about $210 \mathrm{t}(6 \mathrm{~m} \times 6 \mathrm{~m} \times 2.5 \mathrm{~m})$. The steel plate on the surface had the thickness $12.5 \mathrm{~mm}$ in 1968 , but $50 \mathrm{~mm}$ after 1969.

\section{Scale Model for Test}

In reference to the present situation in Japan as mentioned above, we imagined as the prototype a horizontal-type cylindrical cask, weighing about $80 \mathrm{t}$ and having steel-shells and lead shielding. The scale model was simplified in shape so that the measurement of deformation and the analysis of motion at drop impact might be made easier. The reduced scales were chosen as $1 / 16$ (about $20 \mathrm{~kg}$ ), $1 / 8.5$ (114 $\mathrm{kg}$ ) in 1968. 1/8 (about $0.15 \mathrm{t}$ ), 1/4 (about $1.25 \mathrm{t}$ ), 1/2.5 (about $5 \mathrm{t}$ ) and $1 / 2$ (10 t) in 1970, in order to confirm whether the similarity existed between the scale model and the prototype or not. In addition to these models, lead spheres and cylinders weighing $20 \mathrm{~kg}$ were prepared as the test pieces for obtaining data of lead at drop impact in 1968, and the various kinds of shock-absorber for $1 / 4$ scale model were fabricated for testing the shock-absorber performance in 1970.

\section{Experimental Results}

According to the IAEA Regulations, a shipping cask for large radioactive source must be able to pass the free drop test from $9 \mathrm{~m}$ onto a rigid target. But in 1968 we accomplished the horizontal drop test from different height, namely 3,6 and $9 \mathrm{~m}$, to examine the effect on deformation of fall height and weight. The measurement of deceleration was done by means of accelerometers mounted in the middle of 
the top surface of model in horizontal position. A high-speed cinematography was used to record and to analyse the motion of model during drop, at collision and during rebound. Deformation was measured by means of contact meter and other suitable measuring tools.

Table 1. The maximum Dereleration

\begin{tabular}{|c|c|c|c|c|c|c|}
\hline $\begin{array}{l}\text { Lead ('ylinder } \\
1046 \times 208\end{array}$ & $\begin{array}{l}10.8 \\
10.9 \\
10.10\end{array}$ & $\begin{array}{l}3 \mathrm{~m} \\
6 \\
9\end{array}$ & $\begin{array}{l}\text { drop } \\
" 1 \\
"\end{array}$ & $\begin{array}{r}347 \\
874 \\
\text { defer }\end{array}$ & $\begin{array}{l}g \\
g \\
\operatorname{tes}\end{array}$ & strain gage \\
\hline $\begin{array}{l}116 \text { scale Model } \\
1000.0 \times 325\end{array}$ & & $\begin{array}{ll}3 & m \\
6 & \\
6 & \\
9 & \end{array}$ & $\begin{array}{l}\text { drop } \\
" 1 \\
"\end{array}$ & $\begin{array}{r}860 \\
1.842 \\
1.333 \\
2.170\end{array}$ & $\begin{array}{l}\mathrm{g} \\
\mathrm{g} \\
\mathrm{g} \\
\mathrm{g}\end{array}$ & $\begin{array}{c}\text { piezo type } \\
" \\
" \\
"\end{array}$ \\
\hline $\begin{array}{l}1 / 8 \text { Scale Model } \\
185.70 .0 . \times 610\end{array}$ & & $\begin{array}{ll}3 & \mathrm{~m} \\
3 & \\
6 & \\
9 & \end{array}$ & Arop & $\begin{array}{r}760 \\
840 \\
977 \\
1.238\end{array}$ & $\begin{array}{l}\mathrm{g} \\
\mathrm{g} \\
\mathrm{g} \\
\mathrm{g}\end{array}$ & $\begin{array}{l}\text { strain gagt" } \\
\text { piezo type } \\
\text { " }\end{array}$ \\
\hline
\end{tabular}

\section{Deceleration}

The maximum deceleration in the case of almost flat collision shown in Table 1. The deceleration and the rebound behavior were strongly affected by the attitude of the model at the moment of impact Motion of Test Mode1

The motion of model during test was recorded by high-speed $16 \mathrm{~mm}$ motion pictures (film speed 3,000 - 3,500 pps) and was analysed by a motion picture analyser. An example for Model No.1, picked up from the films, is given in Fig.5. From these analrsis it was made clear that the duration time of pulse ranged from 0.3 to $3 \mathrm{msec}$.

\section{Deformation}

Fig.6 shows the deformation of model No.1 (1/8.5 scale). The theoretical analysis was applicable to reveal the relation between fall height and resulted deformation, the detail of that was presented in the paper IAEN/SM-14T/I submitted in the Seminar on Test Requirement For Packaging For The Transport of Radioactive Materials on Feb. in 1971.

\section{Experiment in 1969}

In 1969 the experimental study with $1 / 8,1 / 4,1 / 2.5$ and $1 / 2$ scale models was performed. The test was accomplished only in the case of horizontal drop from $9 \mathrm{~m}$, but both without shock-absorber and with it. The result of experiment are separately reported in this symposium. 

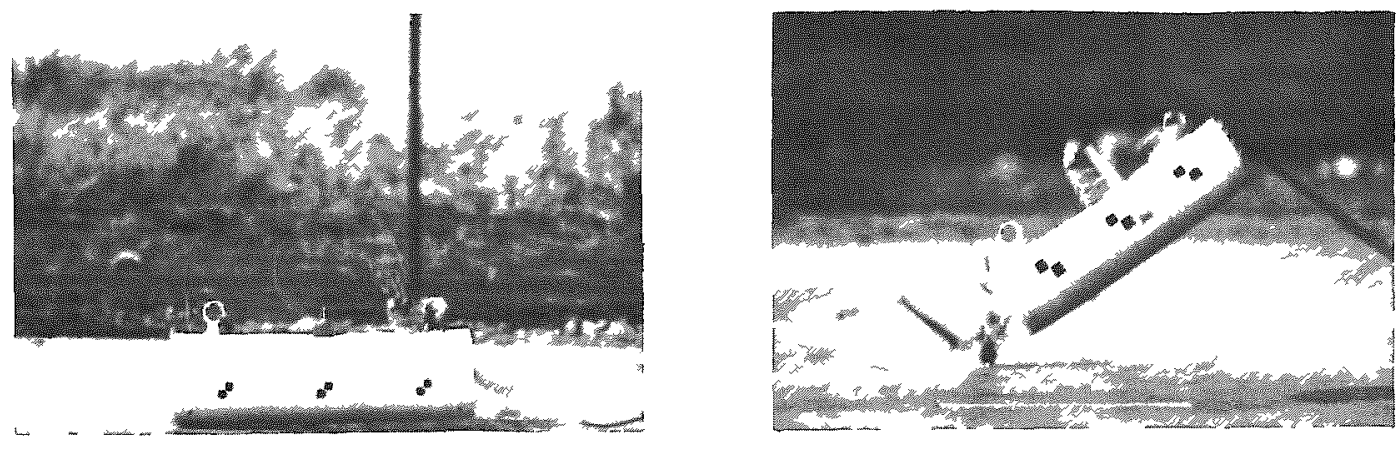

( a)

$(\mathrm{b})$

Fig. 5 Motion of Models at Drop Impact

(a) $1,8.5$ Scale Iodel, (b) 1, 16 Gcale Mode1
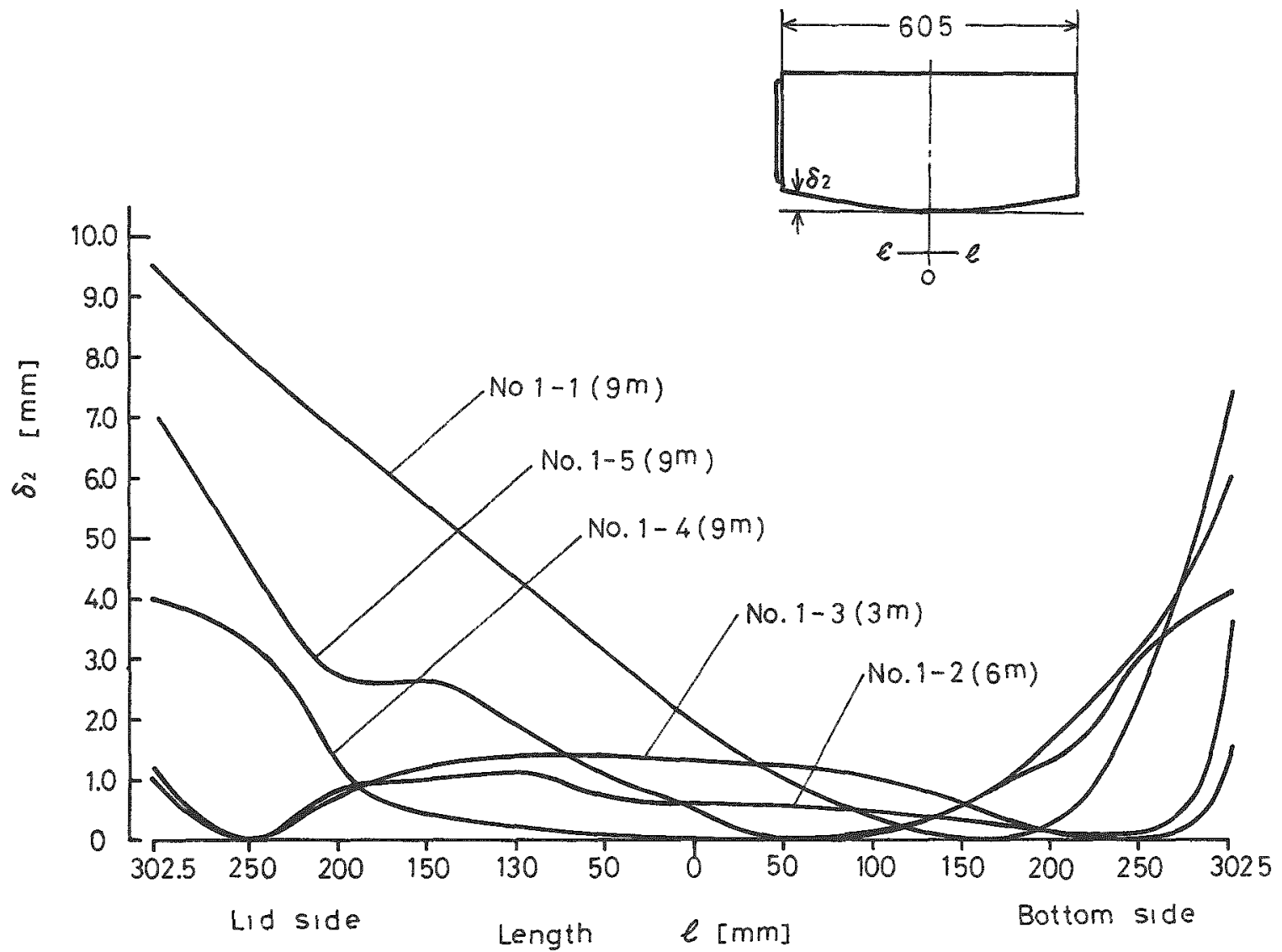

Fig. 6 Deformation of $1 / 8.5$ Scale Model 
In 1970 the corner drop tests for $1 / 4,1 / 2.5$ and $1 / 2$ scale models and the performance tests of shock-absorber for $1 / 4$ scale model were carried out. The two different sized shock-absorber for each of the four different type were disgned and fabricated. Horizontal drop and corner drop both for lid side and for bottom side were done. The fall height was always $9 \mathrm{~m}$. The deceleration and deformation at impart were measured and the motion of models was recorded.

\section{Test Programme in Future}

In 1971 the pucture test will be performed using the $1 / 2.5$ and $1 / 4$ scale models.

\section{FIRE TEST OF SPENT FUEL SHTPPTNG CASK}

The fire test has been carried out by the Fire Institute of Japan since several years ago and some of them have been reported in the 1 st and 2nd International Symposium on Packaging and Transportation of Radioactive Materials by T. Moriya. Now the heating equipment for large cask has been completed and the test are being carried out to investigate the fire resistance characteristics of spent fuel shipping sask and to obtain the fundamental data for its safoty evaluation. In this test series the four kinds of cask model have been used, which have the outer-diameter $800,400,400,200 \mathrm{~mm}$, inner-diameter 500 , $74,254,126 \mathrm{~mm}$, lead thickness 125, 150, 60, $30 \mathrm{~mm}$, length 800,600 , $600,400 \mathrm{~mm}$, and weight $3,000,636,530,85 \mathrm{~kg}$ respectively. These cask models are placed and heated in a large furnace $(1.6 \times 1.6 \times 1.6 \mathrm{~m})$ at $800^{\circ} \mathrm{C}$ during 30 minutes. The temperature in the furnace and that of outer-shell, lead-shielding and inner-shell of cask model are measured by means of Alumel-Chromel thermocouples at twenty or twentyfour points.

Based on the experimental results, the coefficients of heat transmission at the outer surface of cask and between steel and lead are obtained. And, using these results, the thermal behavior of large shipping cask for practical use will be analysed with analog-computer theoretically.

\section{OVER-THE-ROAD TESTS OF A SHIPPING CONTAINER FOR PWR TYPE NEW FUELS}

A long distance over-the-road tests of shipping container for 
PWR type new fuel assemblies were conducter by Mitsubishi Atomic Power Industries. Inc. (MAPI), in order to examine the compatibility of PWR type fuel shipping container with road condition. The container tested consisted basically of a split type cylindrical steel shell. reinforced with circumferential ribs and of a fuel assembly receptacle being capable of accommodating two PWR type fuel assemblies of $10 \mathrm{ft}$ long. In order to protect the assemblies from shocks and vibrations encountered during transportation and handing, the fuel assembly receptacle was suspended from the shell by means of shock-absorber. The container with two sets of dumy fuels, weighing about $2.5 \mathrm{t}$, was loaded and tied on an 8 t capacity truck. The tests were carried out on the route from the suburbs of Tokyo to a nuclear power station in Tsuruga, some 350 miles west of Tokyo. The road condition ranged from modern super highway tounpaved local rough roads. The wehicle speed was up to $60 \mathrm{mph}$.

From this test, the spectra of accolerations induced in the fuel shipping container due to shocks and vibrations cncounted under the test conditions over the variety of road phase were obtained. It was the most interesting result that the maximum shocks at the container shell were observed at the surface cracks and holes on the paved roads rather than on the unpaved roads. whereas the maximum deflection (derived from the acceleration) of the fuel receptacle were observed on the unpaved rough roads.

\section{DROP TESTS OF SHIPPING CONTAINER FOR PWR TYPE NEW FUEL}

This test also was accomlished by MAPI. The test procedure and test results are presented precisely in the paper titled "DROP TESTS OF SHTPPTNG CONTAINER FOR PWR NEW FUEL" in this symposium.

\section{ACKNOWLFDGMFNT}

The author wishes to express his gratitude to the Atomic Fnergy Bureau and the Japan Society of Mechanical Engineers, which supported the series of experiments. He also wishes to express his thanks to the members of the Research Subcommittee For Design of spent Fuel Shipping cask in JSMF. who conducted these experiments for a long time, and also to the Fire Institute and MAPT, who offered me their experimental informations. 


\title{
EVALUATION OF METAI SBAI CRITERIA FOR SPENT FUEI CASK CLOSURES
}

R. E. Latham*

R. T. Brown*

\author{
ABSTRACT
}

Reliability of the gasket used for sealing the end closure of fuel casks and mating appurtenances of similar fluid containing piping is of prime importance in overall system evaluation. The degree of reliability will be dependent upon the gaskets ability to respond to relative displacements of the mating seal surfaces during both operational pressure and thermal cycles and superimposed mechanical shock loads that occur during maximum credible incidents.

Basic sealing parameters for metal-tometal gasketed joints which will result in leakage rates less than $1 \mathrm{x}$ 10-6 $\mathrm{cc} / \mathrm{sec}$. helium are summarized. The mode of achieving initial minimum seal interface loading to meet this leak rate criteria is evaluated with regard to the material properties of mating connectors and gaskets.

The effects of seal geometry and mode of interface loading on the reusability of seals and seal surfaces to minimize replacement and repair is discussed. Economic considerations of manufacturing tolerances for both initial installation and rework operations are reviewed. coating and plating effects on initial sealing, reusability and reliability are considered. Overail sealing criteria are summarized for various seal types providing a guideline for designers in gasket selection.

* Chief Engineer, Gray Tool Company, Houston, Texas.

* Supervisor, General Froducts Dept., Engineering Div., Gray Tool Company, Houston, Texas. 


\section{Cask Applications}

Transportation of radioactive materials is accomplished by the use of shielded containers to protect against contamination of equipment and personnel. These containers consist of an internal vessel in which the radioactive material is placed, and an outer vessel which contains the shielding material ${ }^{2}$. The internal vessel is usually cooled by jacketing.

During nomal operating conditions, the radioactive materials are placed into the internal vessel and a lead plug is placed between this material and the end closure. A closure blind is then made up to the internal vessel, usually remotely, and the shielded cover is put in place. Pressures and temperatures remain near ambient as long as cooling system is functioning. If the cooling system fails, however, the radioactive material usually begins to heat up causing an increase in both pressure and temperature. In liquid metal fuel cells, $1,000 \mathrm{psig}$ and $1100^{\circ}-$ $1200^{\circ} \mathrm{F}$. can be reached in a matter of minutes. Not only must the internal closure seal maintain its integrity during this thermal and pressure shock loading, but its reliability during the cool down phase required to bring the system back to equilibrium.

Although failure of the cooling system can and does occur because of mechanical equipment failure, the prime credible incident occurs during transportation of these casis. Whether the transporting is being done by truck or rail, there exists the possibility of an accident which can subject the cask to a high impact load. The problem of designing a closure seal that can withstand the loads imposed by a 5,000 pound cask being thrown from a truck traveling 60 miles per hour as it rolls up 
an embaniment or into a ditch, is compounded when we must consider that this incident will, in all prorability, cause the cooling system to fail also.

Even if no catastrophic events occur, the closure seal mist be opened and its contents removed a significant number of times during the lifetime of the cask. One estimate places the num er of tull openine and closine operations at $500-600$ times. Therefore the seal should be easily adaptable to assemiz operations, reeping in mind that remote handling is at best, difficult and time consumine. Casi Closure Crizeria

Considering the applications for which the containment casks are to be used, we can estaklish certain criteria for the closure seais.

I. Seals will be required to seal relatively low pressures but must be capable of withstanding a fairly rapid pressuriation and heat up without learing or plastically deforming such that they will not seal upon depressurization. This requires that the seal be both self energized and pressure energized. and of a material and design which will impose maximum residual elasticity in the gasket. This will insure maintenance of minimum gasket loading during all phases of operation.

2. Seals must withstand severe axial and radial impact loads without deformation or loss in gasket loading. this will require a seal which is insensitive to axial unloading even to the extent of some separation of the connector faces. The seal must be of sufficient cross section to be essentially self supporting against radial or shear loading.

3. Seals must be reasonably adaptable to quick assembly and remote handling. This will require a self aligning seal or 
a seal which is confined within the connector.

4. Seals must be able to achieve a maximum number of make-break operations without damage to the seal surfaces on the cask containment vessel. This requires a seal geometry which can achieve reliable sealing with minimum gasket interface loading and a seal surface readily accessible for rework if required. Economics and availability are relatively minor considerations of the overall cost of a cask contajnment system, especially when usage of an improper seal design creates the consequences of radioactive contamination.

\section{BASIC SEAIING PARAMETERS}

\section{Sealing Interface Criteria}

The interface geometry between two metal sealing surfaces is the major factor influencins the leakage across the seal. Several conditions contribute to this factor.

1. Initial surface roughness of the two sealing surfaces.

2. Minimum contact Ioad required to obtain superficial plastic deformation at the interface and the residual load required to maintain the resulting geometry. Surfoce Finish

The resultant surfoce finish required to seal a particular fluid may be approximated from the equation for laminar flow between parallel flat plates and $D^{\prime}$ Arcy's equation for viscous flow through a permeable media?.

The required surface finishes (in microinches axithmetic average (AA)) may bo calculated for various media using this simplified method to obtain a type of sealability index. This is a relative value since the above procedure assumes uniform surface finishes and neglects compressibility effects. Figure 1 graphically depicts 


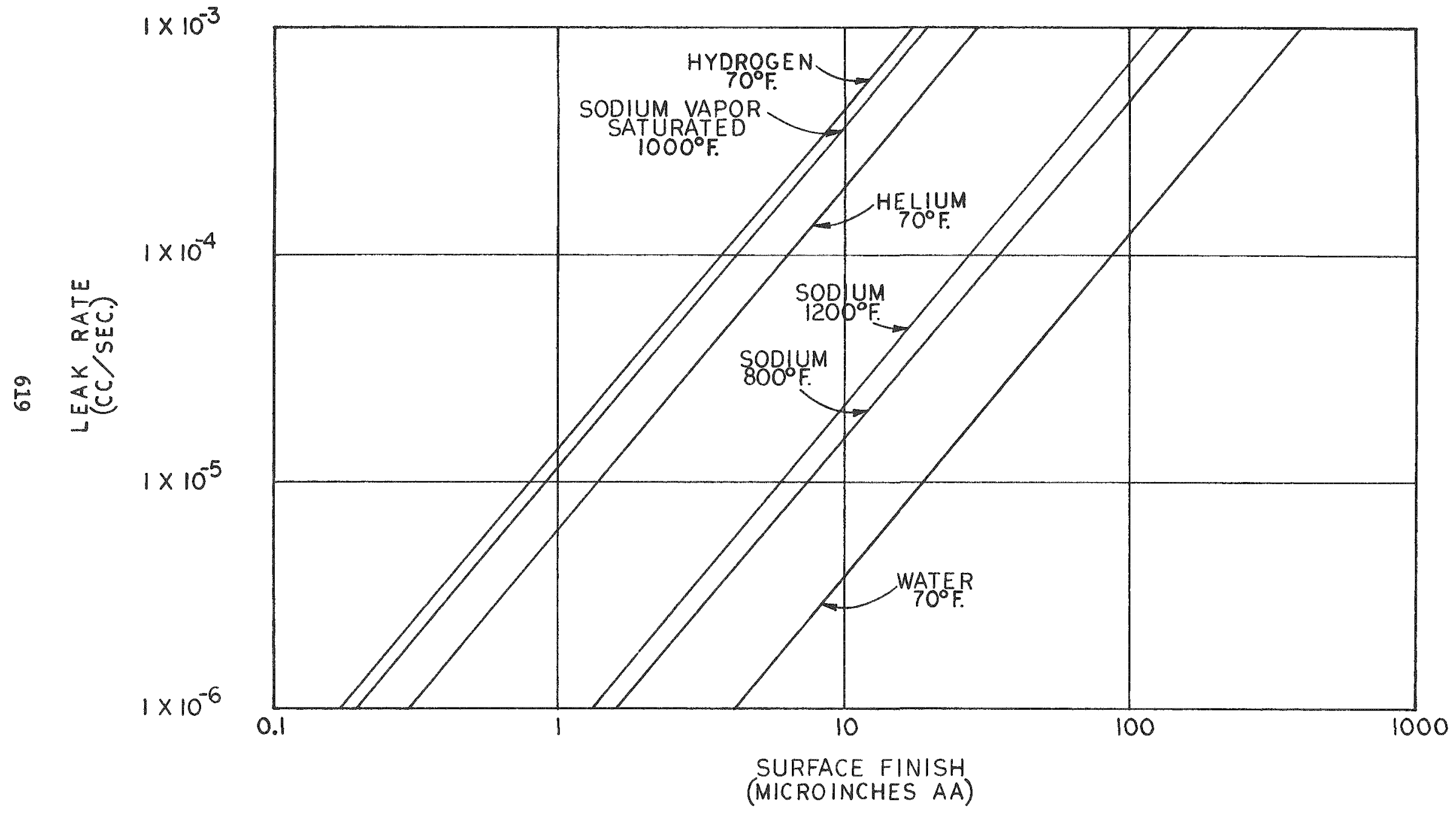

Fig. 1. Surface Finish Requirements versus Leak Rates for Various Media. 
theoretically required surface finishes for a 1,000 psi pressure differential and a 6 inch seal diameter of $1 / 2$ inch width for a I $\times 10^{-3} \mathrm{cc} / \mathrm{sec}$. leak rate, which corresponds to a kubbletight joint, and $a$ $1 \mathrm{x} 10^{-6} \mathrm{cc} / \mathrm{sec}$. Leak rate which is senerally considered a maximum leak rate for nuclear containment systems. We are normally concerned with obtaining much lower leak rates than can be economically attained by surface finish control a.lone. It is necessary to look at how this controlling characteristic can be varied, if needed, since all other sealing parameters remain constant for a given application.

It is apporent that the resultant surface finish can be created by either superfinishing techniques ${ }^{3}$, or by mechanical loading of the seal surfaces to obtain plastic flow of the matine parts Whereby the residual effective surface finish is sufficient to maintain required leak rates.

Repeatable leak rates not exceeding $1 \times 10^{-6} \mathrm{std} . \mathrm{cc} / \mathrm{sec}$. of helium have been obtained using a combinstion of superfinished seal surfaces and averae mechanical seal loading stresses below the yield of the seal material tested. However, based on past experimental work, it may be concluded that control of leak rates by superinishine alone is not the practical answer to $\operatorname{ses} 1$ design ${ }^{4}$.

\section{Initial Interface Loadine}

Since plastic deformation of one or both of the sealing surfaces is required for a reliable leaktight joint, the need for defining the magnitude and type of loadine needed to obtain this deformation recomes apparent.

There are two kasic ways to obtain plastic flow: The first by direct bearing or normal loading of the seal surfaces and, second, by a comination of nomal and shearing loadins. The 
first type of gasket loading has been investigated extensively, and minimum yield values and minimum loading constants for conventional gasket materials and geometries have been established and widely published, similar to those shown in Table UA-49.15. Normal seal loading requires contact bearing stresses over the entire gasket area from two to six times the tensile yield strength of the material used, depending upon the surface finish of the original parts and the degree to which the materials are susceptible to work hardening 3,6 .

A comprehensive description of the five modes of plastic deformation for normal loading is summarized as follows ${ }^{3}$.

1. An initia. yielding of the peaks of the surface asperities occurs at a load which produces average mean contact stresses of only a fraction of the yield strength of the seal material. The remaining deformation is essentially elastic.

2. Further yielding of the individual asperities occurs to the point that additional deformation kegins to interfere with adjacent asperities, at loading producine averase mean contact stresses equal to the yield strength of the softer material. 3. Additional loading initiates bulk flow of the softer material, resulting in a rapid increase in resistance to further deformation as the contact area increases.

4. Further loading causes bulk flow in the softer material and maximum strain hardening due to the resistance to movement imposed by containment in the harder material.

5. Additional loading will cause bulk flow in the harder material which is the final failure mode.

It should be noted that from observations made during several test programs, loadings of mode 3 or higher were required to outain reliable sealing 3,7 . Also, with mode 3 or higher loadings, a 
shearing type failure occurred at the outer and inner edges of the gasket being tested. These shearing plastic deformations resulted in a more uniform and complete seal area.

It is the shearing type of deformation that has had very little correlation to test results. However, from the previously discussed work done on a few seal materials, it can be initially concluded that this combination shearing and normal loading requires only one to three times the tensile yield strength of the material used as the seating bearing load.

Loading levels equal to and less than the bottom range of values have been observed during the design and the nanufacture of the GRAYLOC* seaI Ring, a pressure energized bore seaI used in vessel closures and piping comectors ${ }^{2}$. This gasket obtains its seal by axially drawing tapered seats together, wedging and flexing the sealing surfaces inwardly, thereby causing a shearing movenent normal to the load on the seal surfaces. From comparison of measured makeup loadings for this type of gasket over the past ten years, it is apparent that the gasket loading constants for the conventional type loading are too restrictive for this application. A new parameter (the method of loading the sealing surfaces) must therfore be considered in establishing design seal criteria. Residual Interface Loading

The next sealing criterion to be investigated is that of the minimum residual loading required to maintain sealability under operating conditions, gasket unloading due to joint separation, and seal surface rotation. Conventional gasket guidelines require unit loading up to $6-1 / 2$ times the pressure as a minimum, however,

*GRAYLOC ${ }^{R}$ is a registered trademerk owned by Gray Tool Company. 
in actual testirg, loads as low as 50 per cent and as high as five times the initial unit loading were observed to be required to maintain sealability 7,8 . Factors influencins this value are the seal material, the initial surface finish, and the degree and mode of deformation of the seal surfaces. For seal surface finishes in the range of $16 \mathrm{AA}$ to $63 \mathrm{AA}$ and plastjc deformation of the seal surface of mode 3 or greater, the required residual seal loading has been found to be only that required to prevent unloading of the seal surfaces'. This characteristic has been utilized by the manufacturers and users of pressure energized seals to reduce bolting and connector requirements. If severe cyclic movement occurs between the seal surfaces resulting from either pressure, temperature, or external mechanical loading, it is usually necessary to use soft gasket materials to prevent seal surface fretting. Seal interface loading high enough to obtain plastic flow of this softer materia.1 will a.lso be required during a.11 phases of joint loading if leakage is to be prevented.

Interface loading may be maintained by the elastic properties of the gasket itself ("springbach") and/or a pressure multiplier due to gasket geometry and location. It is recommended that higher yield strength materials be used where possible for the gasket, in order to provide a greater range of elastic movement. Platings or coatings may be required for lubrication during initial makeup to prevent seal surface microgalling. Effect of Components and operating Conditions

The relative movement of the mating flanges of a gasketed joint has a significant influence on the action of the gasket. As an example, consider the case of the closure on a vessel. Typical configurations for cask closures are shown in Figures 2 and 3 . The dimensions of the gasket and the seating surfaces for a pressure 


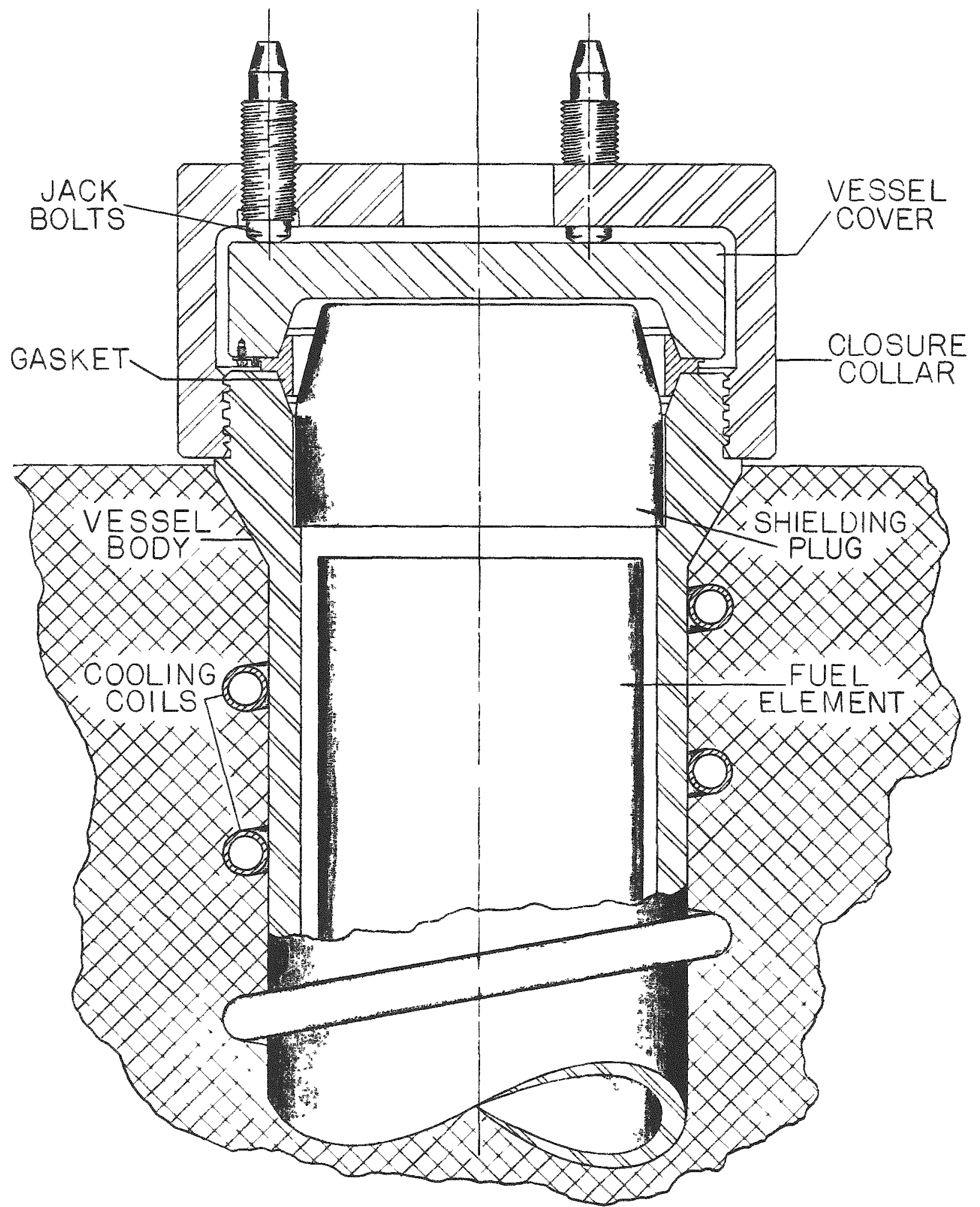

Fig. 2. Schematic of Cask Closure for semi-remote Handing. 

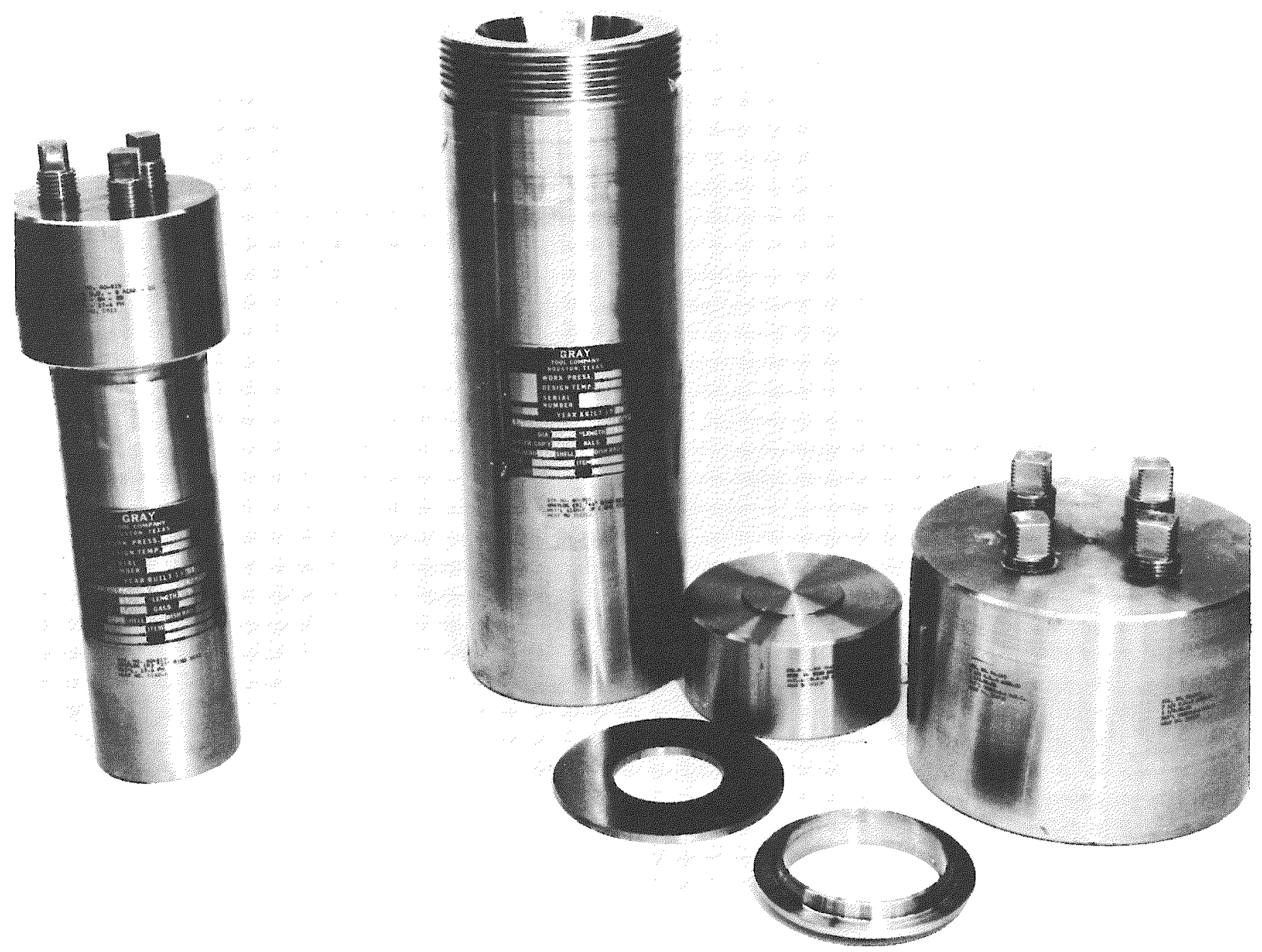

Fig. 3. Photograph of $3^{\prime \prime}$ and 4-I/2" I.D. Threaded Cap Containment Vessels. 
energizing gasket should be established to insure that the joint is tight without significant pressure application. This is necessary in order to insure a seal when the vessel is first placed. in service. However, as pressure is applied the movement of the seating surfaces requires that the gasket be deformed if the seal is to be maintained. If the operational conditions are cyclic, the deformation of the gasket must remain essentially elastic during the variations in the service conditions.

The deformation of a gasket in an assembly of identical flanges, rather than the nonsymmetric combination illustrated, would result in only translational gasket deformations. Because of the symmetric characteristics of the flange combinations, relative radial movements would not occur and therefore the gasket would not be forced to rotate ${ }^{2}$.

The influence of temperature on the elastic action of the gasket should not be neglected. The influence of differing flange and gasket materials, with different coefficients of thermal expansion, must be considered along with the effect of thermal transients which may heat or cool components of the assembly at different rates.

If the deformation of the gasket caused by the action of the cover, the flange, any differential thermal movements, and the pressure acting on the gasket itself are surficient to cause large plastic strains in the gasket, its ability to seal at lower pressures will be lost, as well as the reusability of the assembly. Therefore, it is essential in designing a gasket for a nonsymetric flange combination that recognition be given to the action of each of the components and a sufficient flexibility designed into the gasket to maintain essentially elastic action. 
A brief review of what is available, both commercially and as special designs for seals in piping systems, sharply points out that sealing problems have been prevelent for a long time. Metal seals can be catagorized as those that seal on the face of the connector and those that seal on the bore. Seals in either of these two catagories may achieve sealing by essentially crushing or ylelding the gasket; by elastically loading a flexible gasket utilizing a soft costing or plating on the seal surface; or by a combination of the above. Seals may or may not be pressure energized as dictated by their geometry and location in the connector9. Figures 4 and 5 show some of the more accepted seaI designs in use today.

The crush type face seals require either high preloading, such as the flat and ring joint gaskets, or close manufacturing tolerances, such as the solid and tubular "o" rings. Both designs dictate the use of relatively heavy, rigid connector systems to impose and maintain seal loading when suojected to interna. pressure and/or temperature fluxuations. Because of high bolt loading and high localized stresses in the connector, these seals do not lend themselves to high temperature applications, as the materials will usually creep allowing axial unloading of the seal surfaces.

The concept of the pressure energized versions of the face seals is to offer a higher degree of reliability by compensating for the reduction in the seal loading caused hy creep and bolt elongation. The gasket loading under pressure is increased by providing a larger gasket area subjected to the internal pressure than the area over which the sealing load acts. The effect of pressure energizing is dependent upon the inherent stifiness of the gasket Which, in itself, is greatly affected by the diameter of the seal. 
FACE SEALS
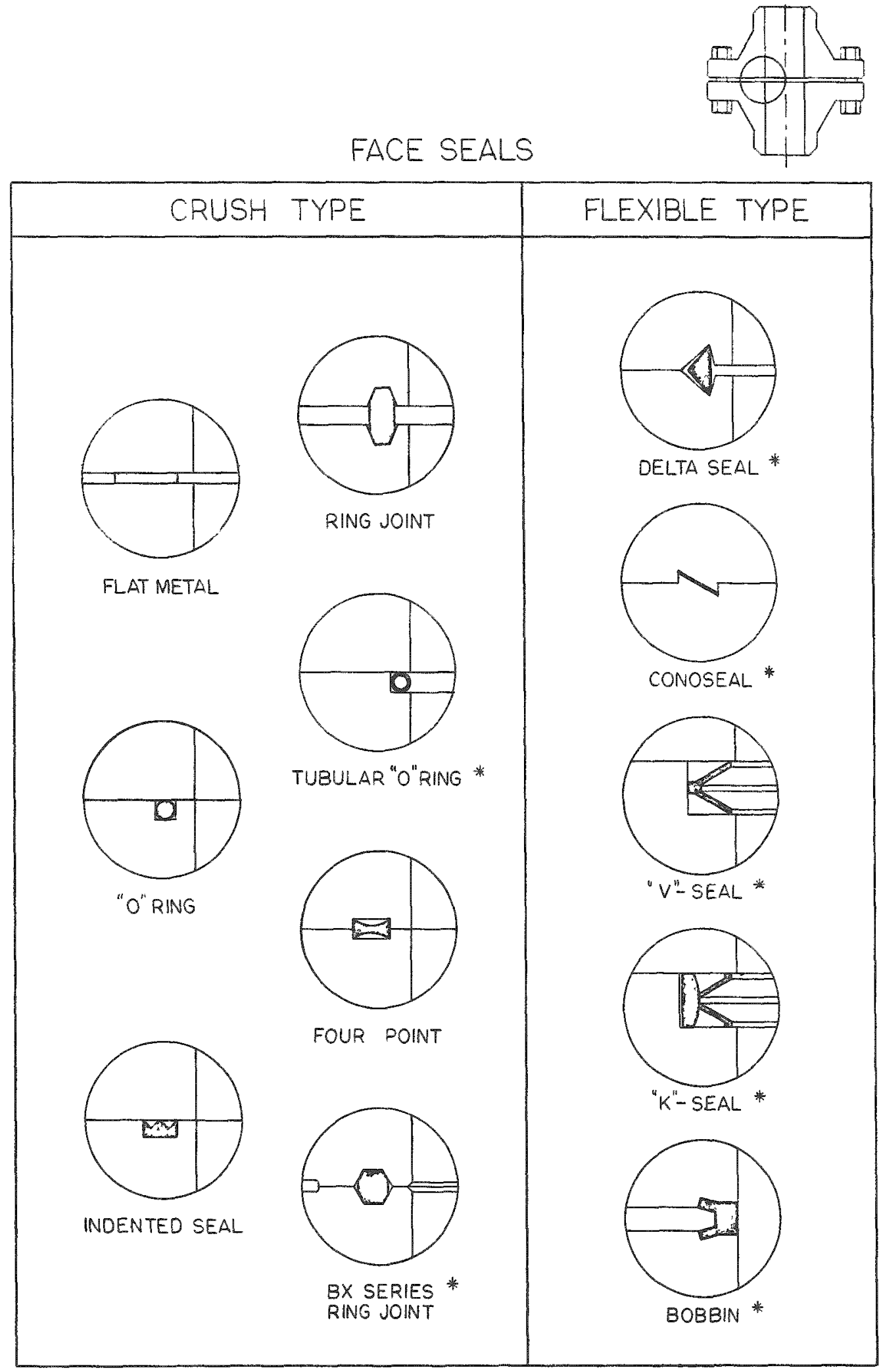

* PRESSURE energIZEO SEAL

Fig. 4. Typical Face Seal Configurations. 


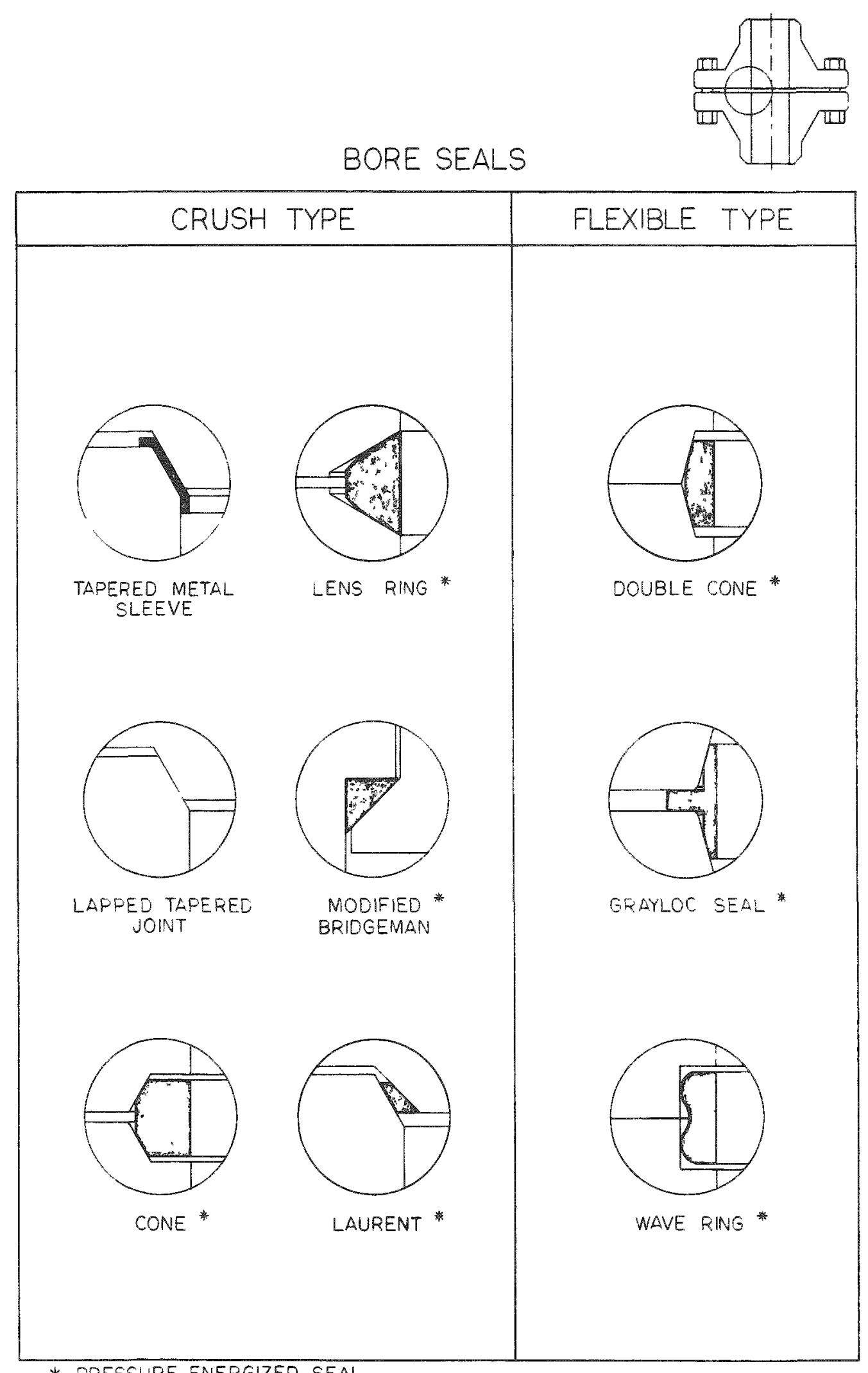

PRESSURE ENERGIZED SEAL

Fig. 5. Trpical Bore Seal Configurations. 
For liquid metal sealing applications which normally concern relatively low pressurew, the pressure energizing advantages are insignificant except to compensate for sudden pressure surges. Therefore, alI crush type face sealing gaskets can be expected to respond essenm tially the same for nuclear fuel handing applications.

The flexible face seals ditter from the crush seals in that their geometry consists of a relatively long gasket with a very small seal contact area. Since the gasket is also relatively thin, it is usually confined to prevent nonuniform gasket distortion during makeup which would prevent uniform seal interface loading. These gaskets are usually coated with a soft metallic coating to prevent damage to the connector, as seal unit contact loading is extremely high. These seals perform best when manufactured from high yield strength materials which impose maximum residual seal loading. Mary of these materials are age hardened or precipitation hardened to resist creep and prevent reduction of contact loading at high temperatures.

Because of the relatively small cross section of these gaskets, the initial seating loads are low allowing the use of a smaller connector and less bolt preload. These gaskets are, however, extremely sensitive to misalignment, and care must be taken to make up the union square and uniformly. If this is not done, the gasket will become cocked in its seat and either experience a localized failure of the seal surface or the gasket itself. Therefore, some external means must be provided to center the union and hold faces square in the made up condition. Also in high temperature appli= cations, the high unit seal loading can tend to promote pressure welding of the seal interfaces. This is especially true in the handling of liquid sodium which promotes mass transfer of elements ${ }^{10}$. All of the face type flexible gaskets require a rigid control of tolerances and surface finishes. When correctly handled, these sea.ls 
have performed with reasonable success.

The crush type bore seals have essentially the same characteristics as the crush type face seals - high preloading, rigid connectors and generally not suitable for high temperature applications. Most of the bore seals, with exception of the Bridseman, do have the advantages of being self centerins; however, only one geometry has been used extensively in mclear application, including liquid sodium systems. This is the GRAYLOC seal which uses a combination of sheering and bearing loading resulting in the lowest possible combination of seal interface loading, interface permeability, and maximum residual seal elasticity. The GRAYLOC seal is especially adaptable because it utilizes a tee shaped cross section wherein the center portion provides a centering feature and a restraint against radial displacement during preloading and operational impact loads. This allows the use of thin flexible sealing lips which, when manufactured from high yield strength material, gives maximum resistance to thermal shock. It has been experimentally shown that this type of gasket can repeatedly seal with interface loading less than the yield strength of either the gasket or the mating connector ${ }^{2}$. Therefore, the tendency to pressure weld in high temperature helium, sodium vapor, or liquid sodium is substantially reduced. Lubrication is necessary during makeup for low leak rate applications of low molucular weight gases because of the sliding action of the seal surfaces.

All of the bore seals require considerably more bolt up Iooding because of their more massive cross sections but utilize more economical manufacturing tolerancing. The flexible bore seals are readily adaptable to high temperature use because they are radially compressed during makeup with residual seal loading, a function of yield strength, and modulus of elasticity. 
CONCLUSION

In summary, only flexible seals should be considered for containment of nuclear systems where leakage cannot be tolerated. Additional considerations concerning the seal geometry to be used are, of course, economy, availability, ease of seal replacement, maintenance of sealing surfaces, to include repair of same if damage occurs during handing or seal replacement. The latter is especially important since many of the flexible seal geometries utilizing small seal areas and high contact unit loading, require hard facing of the seal seats if numerous makeups are to be a part of the design requirements. This will, of course, complicate any necessary repair as most radioactive systems require remote handling. seal materials should be as high a yield strength as seal geometry permits. For high temperature applications aged or precipitation hardened, materials will give maximum life and reli= ability. These heat treatable materials are available for temperatures ranging up to $1300^{\circ}-1350^{\circ}$. For higher temperature applications, high nickel-high colbalt or tungston alloys will provide maximum service life but will usually require a planned program of seal replacement because of their lower yield strengths. An interface of a soft material between the gasket and seal surface is desirable to provide lubrication during assembly and act as a sacrificial barrier to prevent detrimental pressure welding. This material may be a soft metallic plating, such as nickel, silver, or gold, or a high temperature coating, such as molydbenum disulphide or graphite. Coating or plating compatibility must be evaluated with system requirements. Any plating or coating process should be halogen free to prevent contamination of the system components which are usually austenitic stainless steels.

Review of all of the sealing parameters prior to the specifying of a gasket for nuclear containment systems will aid the designer in making the proper selection. 
1. Directory of Shipping Containers for Radioactive Materials, United States Atomic Energy Commission, Washington, D. C. (1969).

2. R. T. Brown and W. R. Mikesell, "Application of Primary Sealing Criteria to a SeIf Energized Gasket", 68-wiN/PVP-4, Journal of Engineering for Industry, TRANS. ASME (I969).

3. F. O. Rathbun, Jr. and R. S. White, "Superfinished Surfaces as a Means for sealing", Conference on Design of Leak-Tight Fluid Connectors, George C. Marshall Space Flight Center, Propulsion Division (1965).

4. F. O. Rathbun, Jr. "Five Regimes of Metal to Metal Sealing," Conference on Design of Leak-Tight Separable Fluid Connectors, George C. Marshall space Flight Center, Propulsion Division (1964).

5. ASME Boiler and Pressure Vessel code, Section VIII, (I965) and latest Addendum.

6. Irving Roberts, "Gaskets and Bolted Joints", Pressure Vessel and Piping Design, collected papers 1927-1959, by The American Society of Mechanical Engineers (1960).

7. F. O. Rathbun, Jr. "ExperimentaI Leakage Rate Experiments", Conference on Design of Leak-Tight Separable Fluid Connectors, George C. Marshal1 Space Flight Center, Propulsion Division (1964).

9. Bernerd Goobich, "Helium Ieak-Tight Seal; Functional Analys is and Development", Conference on Design of Leak-Tight Separable F'luid Connectors, George C. Marshall space Flight Center, Propulsion Division (1964).

10. U. S. Atomic Energy Commission, "Mass Transfer in Sodiurn", Fundamental Inclear Energy Research - 1964 (U. S. Government Printing Ofice, 1964) p. $146 \mathrm{IM}-00112$ 
RECENT DEVELOPMENTS IN LEAD SHIELDS FOR TRANSPORT CONTAINERS IN TEIE UNITED KINGDOM

R. Smith

ABSTRACT

The manufacture of the earliest transport containers in the UK suffered from lack of liaison between the various interests involved and the absence of any really satisfactory regulations and testing procedures sometimes had unfortunate results. The introduction of regulations for safe transport tended to make for improved liaison but at the same time brought new problems. While the UKAFA solved the direct problems associated with the new regulations the lead industry was busy developing new techniques of shield manufacture. The use of simple cast shields was gradually being replaced by shields fabricated from rolled lead sheet and slab. Further increases in the size and activity of sources being carried introduced new problems in that the conduction of 'source heat' through this type of shield was not very efficient and further development became necessary resulting ultimately in the production of shields made up from a number of smaller cast units thus taking advantage of the best features of both techniques. The cast units provide an efficient transfer of source heat to the outer steel where it is dissipated while the fabrication technique simplifies manufacture and handling problems. The introduction of this combination technique coincided conveniently with the introduction of the 'heat sink' theory by UKAEA eliminating the need for external packaging on the largest containers. Liaison throughout has now been improved so that designs facilitate the use of the most efficient techniques. Regulations and testing have thus become matters of guidance rather than restriction. Production efficiency is now such that the rigorous testing currently applied is almost unnecessary and is seen in light of testing for approval rather than for rejection. 
In the early days of the Nuclear Age a demand arose for lead for radiation shielding. The demand came from the nuclear scientist, who understood the ability of lead to protect him from the inherent dangers of the new scientific tool he was developing, but knew little about the production metallurgy of lead. Unfortunately the little knowledge he had became the proverbial dangerous thing; he knew that lead had a relatively low melting point, and mistakenly took this to be synonymous with ease oi casting.

As a result there seemed no need for specialist shielding companies. Anyone could make a lead shield and often did; with some unfortunate results. One large London hospital commissioned their plumber to make some small transport containers for murses to carry radioactive materials around the hospital. Fortunately, by the nature of the use made of these materials, detecting devices were in use and the inefficiency of these shields soon became obrious. Consequently expert lead companies soon entered this field, quickly learning the required nuclear knowledge to match their existing abilities in the metallurgy and handling of lead.

The transport of larger quantities of radioactive materials began in a similarly haphazard way and for similar reasons. A large shielded container was seen as an important item oi steelwork requiring - almost as an afterthought - some shielding made of lead. At the design stage the lead was considered only in terms of the space it would occupy and the weight it would add to the finished container. Most designers, being engineers were familiar with the first class steel fabricators and these companies were therefore invited to quote for the manufacture of shielded containers.

At this time there began, in the UK, what is sometimes cynically referred to as the 'Golden Egg Age'. Steel fabricators were being offered contracts to produce a steel shell and then to fill it with a relatively expensive metal which seemed to them quite simple 10 handle. For this, it appeared at the time, quite fabulous prices could be quoted and the new Nuclear Industry with seemingly unlimited finances would be happy to pay. However, the Golden Eggs soon produced chickens which equally quickly 'came home to roost'.

It soon became apparent that molten lead poured into a cold steel shell did not produce a satisfactory solid lead shield, but resulted in large voids and 
widespread porosity. These unexpected problems proved very costly to the steel fabricators.

The immediate result was two-fold. Specialist lead companies were subcontracted by the steel fabricators to undertake the lead filling. At first even this change bore little fruit. The initial design produced by the nuclear engineer was often based on the assumption that a four inch hole in the top of a large steel shell was sufficient for the introduction of several tons of molten lead. At first with all the mystery surrounding the whole subject of Atomic Energy, the lead shield maker accepted this design and tried to make the best of an almost impossible situation. In these circumstances, even the best of lead companies produced imperfect shields from time to time. Early attempts to heat the steel while the lead was being poured caused distortion of the steel.

Even the testing of shields was not as rigorous as it is today. One set of six medium sized containers crossed the Atlantic fully laden and on arrival at their destination two were found to have faulty shields and consequently to be unsafe.

Slowly but surely the lead industry began to make its voice heard. When a bad design was received for quotation, the companies spoke against it. The designer was told what was necessary to facilitate the production of a first class shield. Safety was accepted as being more important than the possibility of a lost contract - and with this acceptance it was found that the designer was only too pleased to be guided. In addition, the company which had helped him redesign one type of container often found that the next design followed the principles they had suggested so that they were in a position of some advantage over their competitors whose favoured techniques might be somewhat different.

At this point Lead Development Association, having at heart the continued and increased use of lead as a shielding material, rather than the advantage of any individual company, issued a series of publications on the use of lead for radiation shielding. The second publication in this series, 'Design and Construction of Lead Shielded Containers' outlined the problems involved in casting lead and described recommended methods for producing perfect shields either by casting or by fabrication from such semi-finished products 
as sheet and slab.

The reasons for issuing this book were two-fold. First it was felt that if designers understood the problems faced by the shield manufacturer and the techniques employed by him to overcome these problems, then future designs would tend to facilitate the use of such approved techniques. Secondly it was thought advisable to ensure that the steel fabricating companies should be made aware of the problems involved in shield manufacture so that when they decided whether to produce the shield themselves or to subcontract to a lead company, at least the decision would not have been made in ignorance of what was involved.

\section{THE EFFECT OF THE INTRODUCTION OF IAEA REGULATIONS}

At this point lead shields for transport containers were generally satisfactory as far as theix shielding duty was concexned. The established techniques of the chemical engineering industry, for bonding lead to steel were now being employed and developed to facilitate the transport of radioactive materials which emitted heat. Shields now provided a continuous metal path for the transmission of heat from the internal containment vessel to the outside shell from which it could be dissipated.

With the introduction of the first safety regulations based on the Recommendations of the International Atomic Energy Agency, came a number of new problems for both the shield and the steel shell to cope with. From the beginning the two requirements which caused the most trouble were the thermal requirement and the shock requirement.

To deal with the shock requirements; this problem has always seemed the least difficult as far as lead shields are concerned. Indeed, the ability to withstand shock is often related to the degree of 'unification' of the steel and the lead. A container whose shield completely fills its outer steel and for preference is completely bonded to it will be much less at risk than one in which the lead is free to move on impact.

Because of this apparent solubility of the shock problem it has been usual to try to solve the thermal problems first hoping that the solution to the shock problem would follow, either automatically or at least with minimal adaptations. 
In the UK some designers looked at the new requirements which specified a test at $800^{\circ} \mathrm{C}$ for 30 minutes, considered the melting point of lead $\left(327^{\circ} \mathrm{C}\right)$, and turned to steel shields as the solution to this new problem. At the same time however, they continued to designlead shielded containers for private use where it was not necessary to meet the requirements of the new regulations. This, naturally, was seen by the lead industry as an admission that the lead shielded container was acceptable as the superior type if only it could be protected from the heat generated in the fire test.

In the event the invention and development of this protection came not from the lead industry but from the UKAEA. While the lead shielding industry comprised a number of relatively small companies each with a small share in the anmual production of shields, the UKAEA was a vast organisation with a very large share in the annual purchase of shielded containers. They foresaw the need for research to ensure that their existing containers would remain in use in spite of the new regulations and to ensure that they could continue to purchase lead shielded containers which offered the advantages of minimum size and weight at a reasonable cost.

Initially the department entrusted with this work was handicapped by the lack of either a metallurgist or a lead specialist, and some of the earliest attempts to design a lead shielded container which would withstand the thermal test demonstrated this handicap.

The designers soon discovered the expansion and contraction problems likely to be encountered during melting and resolidification of the lead shield. Early tests demonstrated not only that expansion of the lead on melting could build up immense pressures causing stretching of the steel and perhaps fracture of welds, but also that resolidification would normally be accompanied by the formation of a large void either within the body of the lead or between the lead and the newly enlarged steel.

The lack of metallurgical knowledge showed in an early attempt to allow for both these problems by introducing a void of appropriate size into the original lead shield in a position where the reduction in shield thickness would cause no danger. This was done by casting in a hollow cylinder having less strength than the steel shell. It was assumed that expansion on melting would crush this cylinder and take up the space it had occupied and that on 
resolidification contraction of the lead would produce a new void in this same, harmless, position.

While the first half of this theory usually proved acceptable in practice, the second half was invariably proved wrong, and the new position of the resolidification void depended on such variables as the orientation of the shield during resolidification and the thexmal conditions, particularly the direction of maximum cooling.

The engineers involved in this programme quickly came to realise that their best chance of success was to insulate the lead shield from the external source of heat, and once this objective had been recognised, progress was rapid.

The detailed description of this progress is not a mattur for consideration in this paper and in any case it has be en fully documented by F. E. Dixon? 1,2

The result of this worl, howerex, has been to produce a whole range of standard packages, for application to lead shielded conteiners of all types and sizes, by means of which the continued use of lead shields for this purpose has been assured.

In common with all modern lesearch there has been some unexpected 'fall-out'. One development has been a series of packages which can be used with 'families' of containers. Each family is a number of close tolerance concentric cylindrical birelead containurs. By omitting the appropriate number of containers from the centre, a source of any physical size may be accommodated, while by adding additional units to the outside the required amount of shielding may be built up. Ultimately the built-up unit is placed in the appropriate protective package for tronsport safety.

Another intexesting development is the production of 'throw-away' packages. As a result of the UKAEA programme, costs have been cut to a minimum so that with the smaller sizes of lead containers, it is often cheaper to abandon them in a lar country than to accept the paperwork and transport costs of retrieving them. Cextainly the image of lead as an expensive metal has been shattered at last.

DEVELOPMENTS IN MANUFACIURING METHODS

Many of the early containers used for the transport of radioactive 
materials employed lead not merely for shiclding but for the whole container with perhaps a few minor additions such as steel supporting straps, handles etc. These tere always produced by casting and when made by experienced lead manufacturers they were perfectly satisfactory. Most small containers today are made in the same way except that some of the smallest are now produced by" a cold pressing technique. This technique, originally introduced for the mass production of shielding bricks, is, however, only economically practicable where identical containers are required in large numbers.

Of more interest here is the type of container which is mainly a steel fabrication and amploys lead for shielding purposes only. The various stages through which the casting processes progressed are now a matter of history and it is only of current interest to describe those techniques ultimately employed which are still in use today.

\section{Casting techniques}

All modern casting techniques aro based on consideration of the metallurgical processes involved in the solidification of lead. The simplest way of describing these processes is to consider a cube shaped steel box, completely filled with liquid lead, and having a closed top.

Initially cooling will eccur from all faces of the cube, and as the temperature of the lead in contact with the steel drops to $327^{\circ} \mathrm{C}$ so a thin layer of solid lead will form all round. At the four sides and the base, the pressure of the molten lead will keep this layer in contact with the steel; further cooling will take place and the solid layer will increase in thickness.

At the top surface however the state of affairs will be very different. When molten lead solidifies it contracts by $3.85 \%$. Thus even with the first small solidification there will be a decrease in the volume of lead in the box. The rery thin layer of solid laad formed at the top will fall with the surface of the contracting liquid lead since it has no strength at this thickness. Immediately this happens it loses contact with the steel top, and its cooling rate will be considerably reduced. At the same time convection within the liquid lead will tend to warm the top surface, so that further growth of solid will be retarded there.

For some time therelore the growth of the solid layers around the sides 
and the base will be more rapid than that of the top layer. Nevertheless after a time it will become thick enough to have some strength and then it will no longer fall continuously as the level of the liquid beneath it falls. At this time, when this top layer holds its position while the liquid lead level continues to fall a void will be formed. This will be small at first, but now that there is no contact between the solid lead and the top of the liquid the effect of convection will no longer keep the solid top warm; it will cool more rapidly and gain strength. At the same time further solidification on the inner faces of the solid at the sides and base will cause continuing contraction and the liquid level will fall still further, increasing the size of the cavity.

In the simplest case, the ultimate result will be a cube of solid lead with a sizeable dent in its top surface and a sizeable cavity somewhere beneath the dent.

In practical castings there will obviously be variations on this theoretical case. Nevertheless modern shield casting methods are designed to avoid the type of situation described here.

A number of techniques are applicable and all are described in detail els ewhere. ${ }^{3}$ All are designed to prevent the formation of the top solid layer of lead. It is essential in all cases that the steel shell shall have a completely open top. This ensures that whatever filling technique is used the top surface of the lead can be kept in the liquid state until the rest of the shield is completely solid. At the same time efforts are made to ensure that the direction of maximum cooling is vertically downwards to maintain a fairly flat horizontal interface on which the growth of solid lead occurs. If this is successfully achieved, the void formation described earlier is impossible since that requires a 'box' of solid with liquid lead inside, whereas this technique produces a flat layer of solid lead with a mass of liquid on top. To maintain the horizontal interface requires bottom cooling, and side and top heating, the side heating being removed upwards from the base as solidification proceeds.

The top heating may be applied with gas torches playing on the top of the whole mass of lead required to form the shield, or it may be achieved by employing very slow pouring, so that at any time there is only about two inches of liquid lead on top of the solid lead. In this way as more lead is 
added very slowly so it effectively provides the continuous top heating. This slow pouring may be continuous; or it may be intermittent, each separate pouring being sufficient to add about a six inch height to the shield and then this is allowed to solidify. With this technique where a number of 6 inch shield sections are produced successively, even if by some misfortune a void forms it cannot be of serious proportions due to the limited mass of metal from which it is formed.

\section{Fabricated shields}

Where a shielded container is of large size but relatively simple design it is often less costly, and technically more sure, to fabricate the shield from semi-finished products such as sheet and slab. Most of the casting techniques are time consuming and therefore result in high labour costs. In additicn there is always a risk of cavitation or porosity however small with the need for costly remedial action.

Fabrication of shields, by which we mean the building up of a shield from a number of pieces of solid metal, is the surest and cheapest method provided that the design is suitable. For example there should be a minimum of changes in section, and a minimum of controls, fittings etc. which have to protrude into or pass through the shield.

Given these requirements there are a number of relatively simple techniques available. Rectangular shields may be built up from flat slabs of lead. Cylindrical shields can be wrapped with a continuous sheet of lead (Fig. 1). At the time when these techniques were being developed one of the most interesting applications was in the shielding of the spent fuel container for nuclear submarines. This demonstrated the use of lead for all the best reasons. A simple cylindrical shield was required for an immense container which was to travel by rail and road on its own special vehicle, and only by using lead shielding was it possible to keep down the size and weight to within the limits which were acceptable. This was particularly so with the rail transport section of the journey where the outside diameter of the shielded container came within an inch or two of the maximum size which could be carried without danger to the traffic on neighbouring tracks.

At this time the technique of continuous wrapping with lead sheet was not new but thin sheet was always employed for ease of handling. With the 


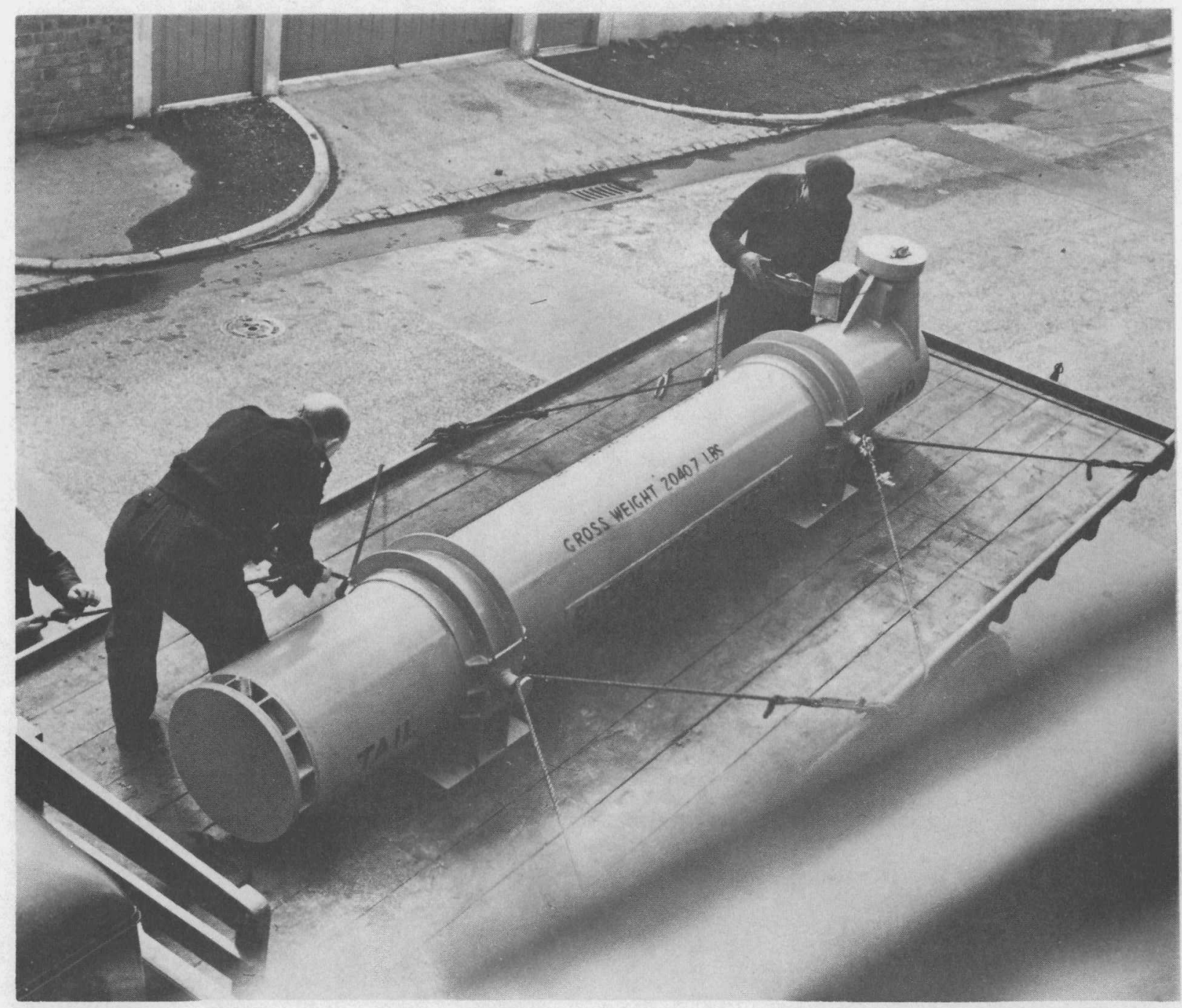

Fig. 1 One of the earliest containers to be shielded using the continuously wrapped lead sheet technique. The uniform cross section alone the whole length of the container made this technique the obvious choice.

(Photo. W. G. Jenkinson Ltd.)

size problem in this application it was necessary to rethink the whole technique.

However efficiently the wrapping is done, there will always be a slight wastage of space between lityers, and with thin sheet and many layers this can eventually add up to a significant space. It is therefore necessary to employ an outer steel shell of sufficient thickness and strength to compress 
these layers.

The design for this container was based on the idea of making the lead nearly self-supporting, and this was achieved by wrapping one-inch slabs around the central containment cylinder, and lead burning these to the steel at both ends and to each other so that the final 40 ton shicld behaved almost as a single cylinder. As a result it was only necessary to add a thin skin of steel to the outer surface of the shield to prevent accidental damage, and the size limits on the finished container were not exceeded. There was no space available for an outer package and so the container had to be transported under special conditions to eliminate any danger of an accident.

Development of this technique of shield manufacture has been so efficient that protrusions can be accommodated by cutting holes in the sheet as required and then lead burning around the protrusions when wrapping is completed, thus avoiding shine paths through the shield (Fig. 2).

\section{Thermal conductivity}

As the materials being carried have grown in size and activity a further problem has arisen. The efforts made to insulate the lead shield from external heat in an accidental fire, have also tended to prevent the dissipation of source-produced heat from the container, with the prospect of a thermal build-up inside the package.

The solution to this problem has also been devised by the UKAEA. The standard form of package for the larger containers in the UK has for some years been a timber packing case type of construction (Fig. 3). This has met all the test requirements and given ample protection from both shock and fire.

To cope with source-produced heat, experiments were tried with gaps in the timber casing near the bottom and top of each side, these allowing convection currents to be set up, by the heat emitted from the container, causing a through draught which cooled the container in normal circumstances. The discovery that, in a fire, the chimney effect caused ignition of the inside surface of the wood was in turn met by covering this surface with a thin steel sheet (Fig. 4).

The success of this design gave rise to further progress. When this 


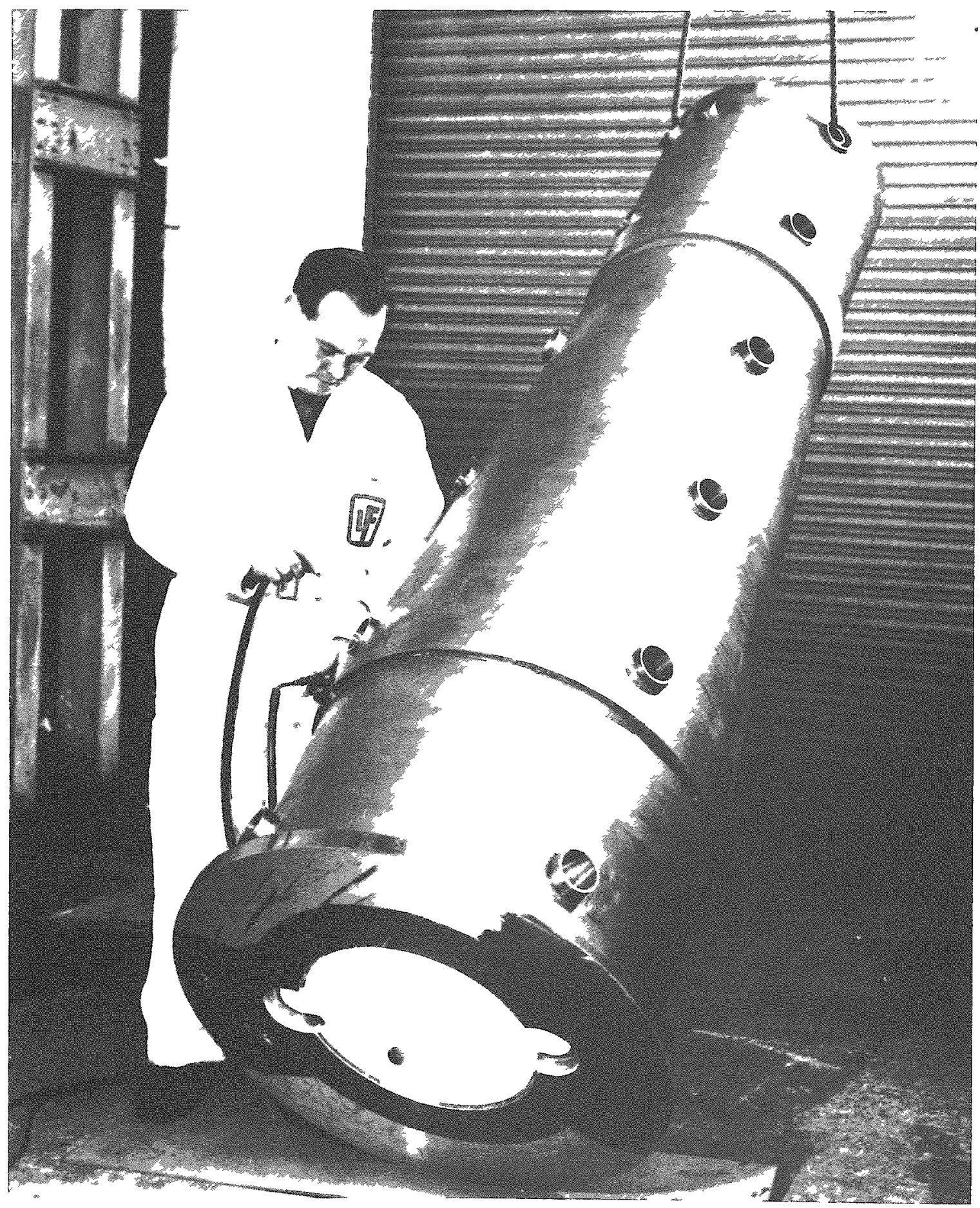

Fig. 2. A modern continuously wrapped lead sheet shield. Experience with this technique now permits change in section and protrusions to be accommodated. Shielding is lead burned around protrusions to prevent shine paths. (Photo. Lead Fabricators Ltd.) 


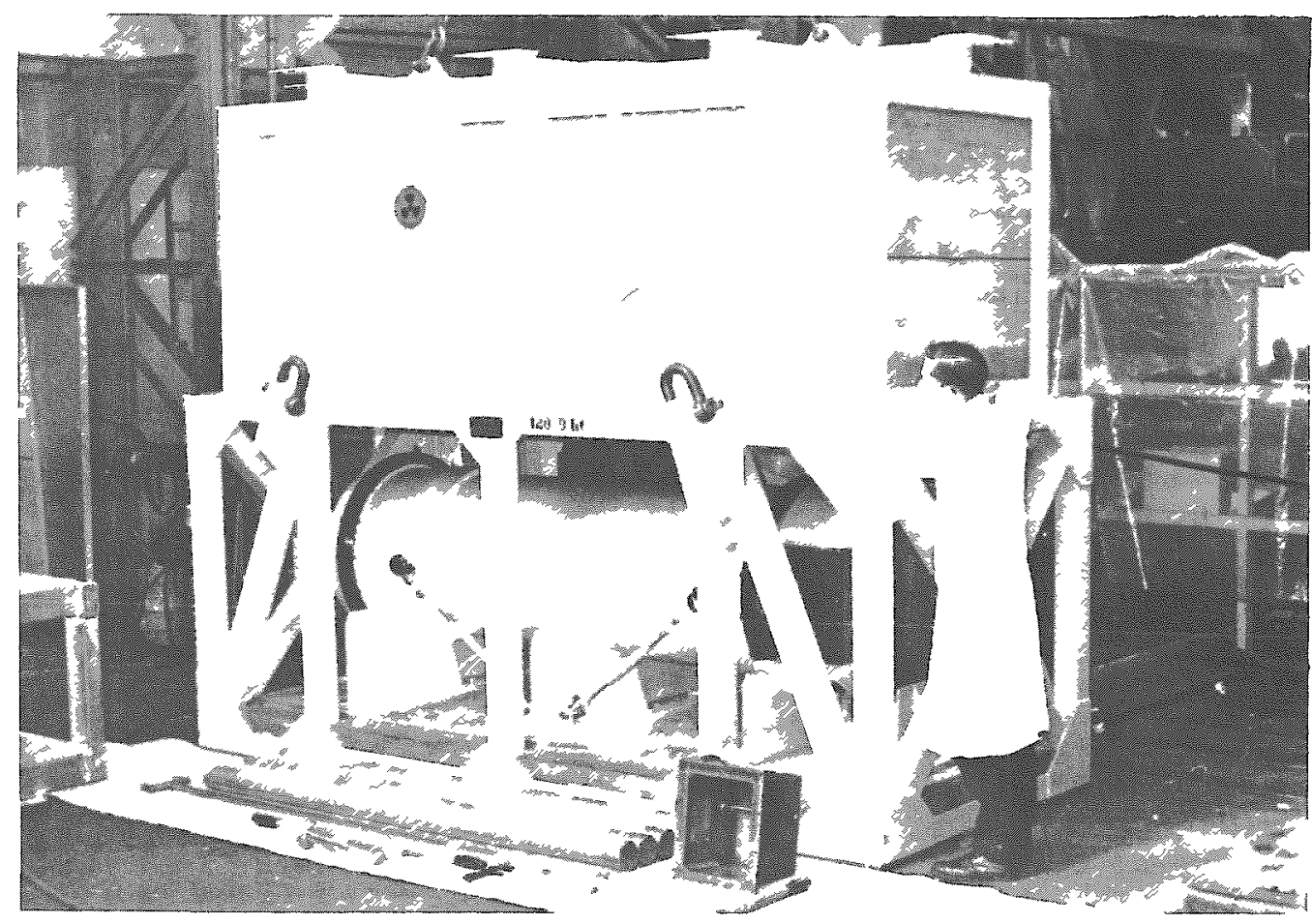

Fig. 3 Timber packing case type of protective package being assembled around lead shielded container. (Photo. Graviner Manufacturing Co. Ltd.)

design was under consideration there was a fear that the ingress of heat through the ventilating gaps would nullify the protective effect of the package durung a fire. In practical tests it was found that this was only partly true. The insulating effect of the package was only slightly reduced and it was discovered that the heat penetrating the package was not sufficient to cause damage to the shield of the large container inside. The containers had by now become so large, that the quantity of heat required to raise the container temperature to $327^{\circ} \mathrm{C}$ was approaching comparability to the quantity of heat produced in the test fire.

The next step was a matter of calculation. A sufficiently massive container could be used as a 'heat sink'. Where a source required a shield of around 1 inches of lead, it would be possible to employ, say, 10 inches of lead with an outer steel shell about 2 or 3 inches thick. The total mass would 'swallow up' the heat of the fire test whthout excessive temperature increase, the 


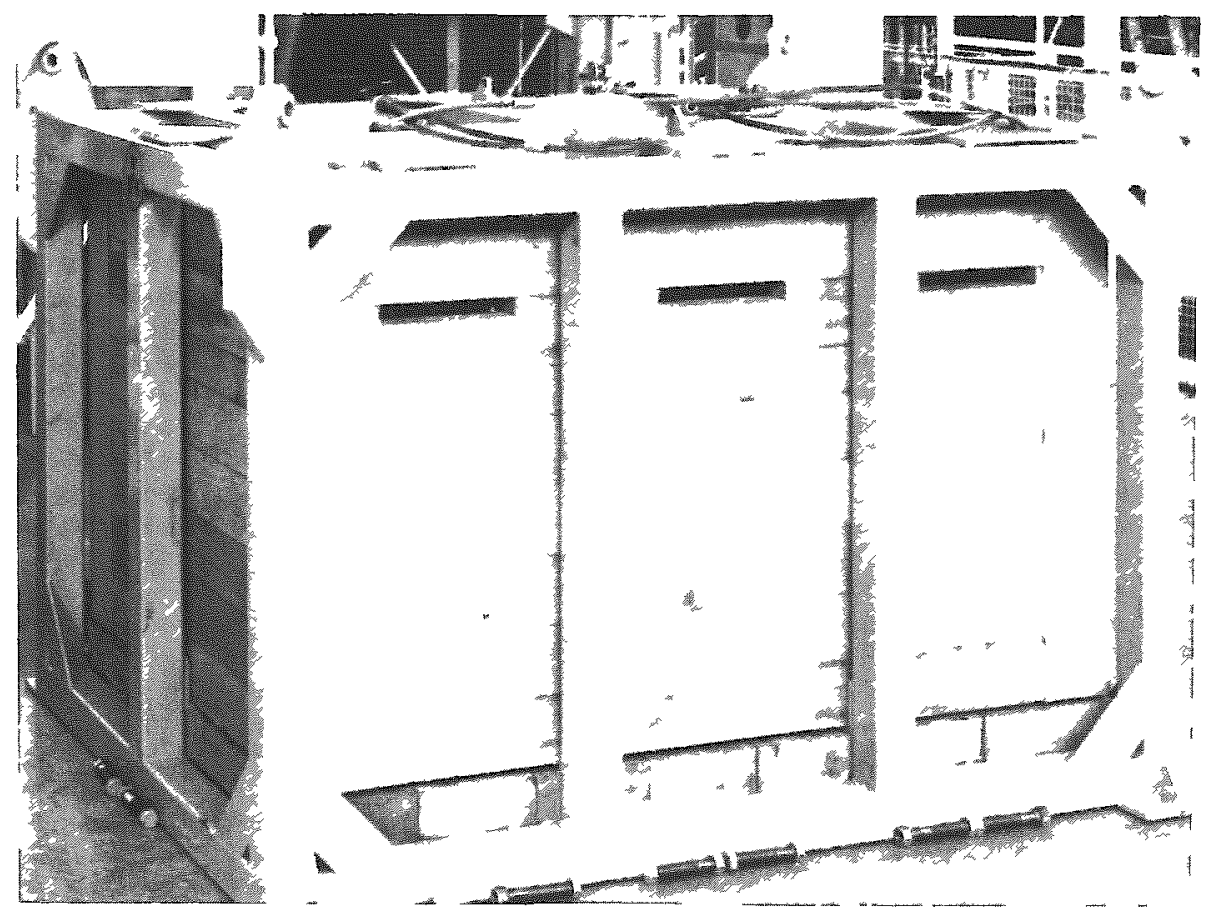

Fig. 4 Later design of packaging, showing ventilating slots for expulsion of source-produced heat. (Photo. UKAEA)

massive steel would contain the thermal expansion forces developed in the lead over the temperature increase experienced and the massive steel would withstand the shock requirements imposed by the regulations.

This has tended to halt the progress of fabricated shields of the wrapped type since the interfaces and small air gaps between layers reduce conductivity, which is now even more essential than before. In these immense containers, the sources being carried may emit large quantities of heat from which buildup at thermal barriers can be quite immense. In a fire these interfaces become even more important for what may be termed 'geographical' reasons.

Heat emitted from the sources passes through the steel inner shell to the first layer of lead. Beyond this first layer there may be a thermal barrier in the form of an interface or air gap. This will cause the first layer of lead to 
heat up, but in doing so it will expand and press against the next layer, thus reducing the effectiveness of the thermal barrier. Eventually there will be a form of dynamic equilibrium through the shield to the outer steel shell allowing the transmission of heat to this shell for dissipation.

A fire situation is 'geographically' the opposite of this. The outer steel is the first to heat up and will expand away from the outer layer of lead shielding. However the insulation of the thermal barrier between steel and lead is not pexfect and therefore the outer layer of lead will experience some increase in temperature. At first it may not be as hot as the steel, but the coefficient of thermal expansion of lead is $1 \frac{1}{2}$ to 2 times that of most steels and so eventually the lead will begin to press more closely against the steel and will accept heat from it more freely.

Unfortunately no such advantage exists between the first and second layers of lead, which have equal coefficients of expansion and will therefore move apart under the influence of external heat. At this point the 'heat sink' has been reduced to the outer steel shell and one layer of lead, and it is unlikely that the spiral path through the lead shield will provide a large enough 'heat channel' to prevent the outer layer of lead from melting.

This therefore has given rise to a return to the solid shield, but in this case it is not a simple casting manufactured in the steel shell.

\section{CURRENT PRACTICE}

In the days when fabricated shields were most widely used, one technique was occasionally employed for cylindrical shields which has not yet been described here. Where a shield was required in the form of a pure cylinder, some manufacturers would form such a cylinder from thick lead slab and then push it into the required position inside the steel shell. In doing this use was made of the softness and malleability of lead, which enabled any dimensional imperfections to be overcome by brute force.

Since that time there has been a move in the lead industry to establish lead as a recognised 'engineering material', which can be machined 4 and handled just like any other metal and one of the results of this has been the development of a technique of engineering a lead shield which suits all the current requirements. 
Cylindrical shields are now often produced as a series of shorter cylinders, made by casting, which are then machined to very accurate tolerances (Fig. 5) and fitted together around the inner steel shell by 'feeding' them on, one at a time from one end before the outer steel shell is assembled.

Thus in the radial direction the shield is a single solid casting permitting the efficient transfer outwards of heat from the source and, because of its accurate inner and outer circumferential dimensions giving good lead to steel contact. For this reason it also acts as an efficient heat sink in conjunction with the thick outer steel shell.

Because of the limited size of the cast and machined components these can be produced in a moderate sized lead works, so that the production of even the largest shields is no longer restricted to the largest companies.

The accuracy with which the mating faces of the individual units are machined ensures that even with a simple single-step interlocking between the units there will be no lack of shielding at the joints.

Finally it is now convenient for the steelwork to be manufactured in one works while the individual shielding cylinders may be cast and machined in another. Since transport of these relatively small cylinders is no great problem they are then brought to the engineering works for assembly. Radiographic testing is carried out before fitting the steel end plate and outer shell so that in the unlikely event of remedial action being necessary this can be undertaken with minimum inconvenience.

\section{SUMMARY}

Thus the problems which originally besct the lead shielding industry and the new ones arising from the safety regulations have been overcome.

Originally most designers knew nothing of lead's properties nor of the techniques of manufacture necessary to produce efficient shields. Education of design engineers has eliminated this problem, and most designers now consult shield manufacturers before finalising their designs.

Originally, many shields were cast by companies with little or no lead experience often with most unfortunate results. Currently shield manufacture is entirely in the hands of experts. 


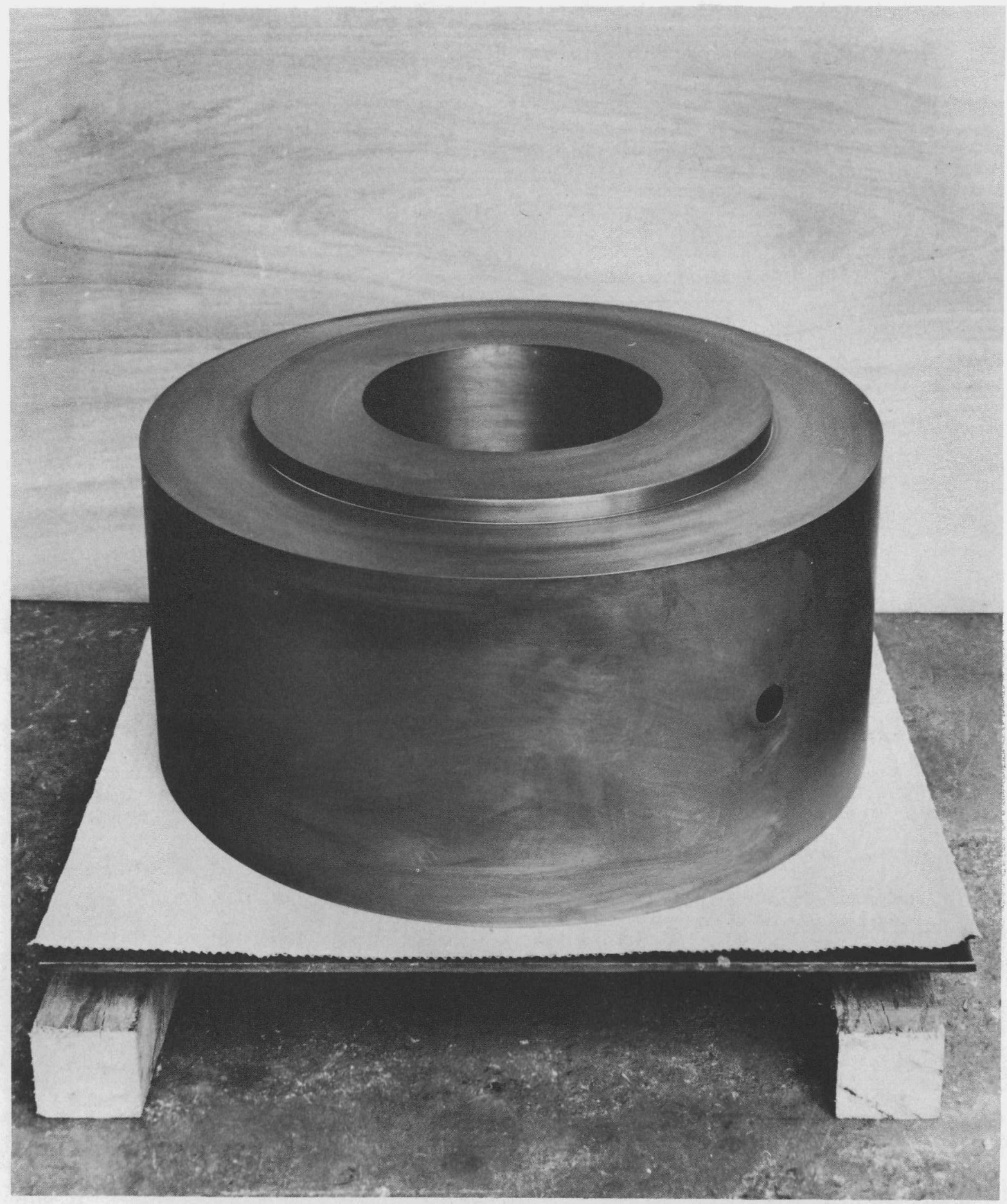

Fig. 5. Cast and machined lead cylinder ( $2 \mathrm{ft}$. deep) demonstrating high quality machined finish obtainable. Note single step interlocking design and one of two diametrically opposite holes for crane lifting. (Photo. James Girdler and Co. Ltd.) 
Originally all shields were cast. Now combination techniques prevail such as fabrication from cast and machined short cylinders.

In the early days of the IAEA recommendations, there were some doubts as to whether lead would still be the ideal material for container shields. Now even those who had no faith are returning to lead. This is due to the combined efforts of the UKAEA which has developed the techniques of protecting the container and the UK lead industry which has developed appropriate designs of shield to parallel the developments in protective packaging.

Finally, we now have rigorous radiographic and physical testing of shielded containers which by virtue of the efficiency of their design and manufacture, are less in need of testing than were the earlier somewhat hopeful products which did not always receive a detailed examination.

The overall picture of this industry is now one of modern technology at its best. Instead of regulatory bodies devising means of rejecting failures, we have complete cooperation throughout to produce an efficient product for which rigorous testing is now seen rather as a means of applying a seal of approval.

\section{REFERENCES}

1. F.E. Dixon, Thermal Shields for Lead Shielded Containers for Radioactive Materials, Proc. Lead Shielding and Nuclear Safety Conference (1969), Lead Development Association, London.

2. F.E. Dixon, Packaging for Large Lead Shielded Containers for Radioactive Material, Proc. Lead Shielding and Nuclear Safety Conference (1969), Lead Development Association, London.

3. Lead for Radiation Shielding, Lead Development Association, London (1965).

4. Lead Machining, Polishing, Etching, Lead Development Association, London. 
"

SHIELDTNG ASPECTS OF LWR SPENT-FUEI SHIPPING CASKS

B. A. Engholm

ABSTRACT

Shielding requirements for light-water-reactor spentfuel shipping casks were investigated as part of the Gulf/ Allied joint program on nuclear fuel reprocessing. Comparisons were first made with GE IF 300 cask design. The GGA PATI gamma-shielding code, which can handle three-dimensional multi-material configurations, was utilized for the gamma doserate calculations, while both transport and diffusion techniques were applied to neutron analyses. Gamma dose buildup factors for multi-laver configurations were estimated from earlier work performed by GGA for the USAEC. The important nuclide contributors to extemal dose rates were identified. Following these studies, dry casks were investigated, ranging from a single PWR element capacity to 24 BWR element capacity. Combinations of lead and depleted uranium were studied for gamna shielding, and either borated water or Uniroyal 3807 assumed for neutron shielding. Radiation levels around a dry 4-PWR cask are shown.

\section{INTRODUCTION}

In recent months Gulf General. Atomic has been engaged in the analvsis and conceptual design of several types of light-water-reactor spent-fuel shipping casks. The need for neutron shielding in such casks when carrving high-burnup fuel has complicated the overall shielding analysis and optimization. Hence, several preliminary shielding studies were performed in order to check out the available source information, GGA's calculational methods, and the effects of changing the shield configuration. The General Electric IF 300 cask design l was used as a model for some of these studies, and a concept in the ORNL "Cask Designer's Handbook" for others.

The purpose of this paper is to define the gamma and neutron source terms, to describe $G G A^{\prime}$ 's calculational methods, to present comparisons with $G^{\prime}$ 's published figures, and to show the dose rates around a dry 4-PWR cask. 


\section{Fission Product Decay Gammas}

Past experience with HTGR fuel has shown that the important shielded gamma emitters after 90 days cooling are $\mathrm{La}^{140}$ and $\mathrm{Pr}^{144}$. In the case of LWR fuel containing a substantial amount of plutonium, $\mathrm{Rh}^{106}$ also becomes important. PWR fission-product inventories ${ }^{3}$ for a burnup of 35,000 MwD/tonne, a specific power of $40 \mathrm{Kw} / \mathrm{kg}$, and a cooling time of 90 days are as follows: $\mathrm{Rh}^{106} 675,000 \mathrm{Ci} / \mathrm{MTU}, \mathrm{La}^{140} 16,460 \mathrm{Ci} / \mathrm{MTU}$, and $\operatorname{Pr}^{144} 1,078,000 \mathrm{Ci} / \mathrm{MTU}$.

The GGA PATH code $^{4}$ library contains the following hard-gamma emission data for these fission products.

Table 1. Gamma Emission Data in PATH Code (Mev/disintegration)

\begin{tabular}{lcccccccc}
\hline & \multicolumn{7}{c}{ Average Photon Energy } & (Mev) \\
Nuclide & 1.0 & 1.25 & 1.6 & 2.0 & 2.4 & 2.9 & 3.5 \\
\hline $\mathrm{Rh}^{106}$ & 0.0215 & 0.0049 & 0.0053 & 0.0018 & 0.0008 & 0.0002 & 0 \\
$\mathrm{La}^{140}$ & 0.1 & 0 & 1.58 & 0 & 0.075 & 0.001 & 0 \\
$\mathrm{Pr}^{144}$ & 0 & 0 & 0 & 0.0218 & 0 & 0 & 0 \\
\hline
\end{tabular}

An axial power peak, if present, is assumed to have a direct multiplicative effect upon these fission-product concentrations.

\section{Curium Neutrons}

The basic mechanism of curium buildup in nuclear fuel and subsequent neutron emission is well covered in the literature, and will not be repeated here except to point out that this source is unimportant in HTGR casks. The production of $\mathrm{Cm}^{242}$ plus $\mathrm{Cm}^{244}$ in HTGR fuel is only $\sim 3$ grams per tonne of metal, and the graphite fuel blocks have considerable self-shielding for neutrons. Returning to LWR fuel, in the particular case of the IF 300 cask design General Electric adopted a source term of $2 \times 10^{9}$ neutrons/sec for four PWR elements and 90 days cooling, which works out to $\sim 1.1 \times 10^{9} \mathrm{n} /$ sec-MTU. Pertinent data from Refs. 1 and 3 are listed below. 
Table 2. Curium Inventories and Emission Data for PWR Fue1, 35,000 MwD/MTU Burnup, and 90 Days Cooling

\begin{tabular}{|c|c|c|}
\hline $\mathrm{Cm}^{242}$ & $48,210 \mathrm{Ci} / \mathrm{MTU}$ & \\
\hline $\mathrm{Cm}^{244}$ & 3,856 & \\
\hline Emission Data & Yield (n/sec-g) & Yield (n/sec-Ci) \\
\hline $\mathrm{Cm}^{242}(\mathrm{SF})$ & $2.02(+7)$ & 6060. \\
\hline $\mathrm{Cm}^{242} \mathrm{O}_{2} \quad(\alpha, n)$ & $2.34(+7)$ & 7030. \\
\hline $\mathrm{Cm}^{244}$ (SF) & $1.05(+7)$ & $1.29(+5)$ \\
\hline $\mathrm{Cm}^{244} \mathrm{O}_{2} \quad(\alpha, \mathrm{n})$ & $5.05(+5)$ & 6200. \\
\hline
\end{tabular}

Ref. 5 provides neutron spectra for all four cases above. The spontaneous fission spectra for both nuclides are almost identical, as are the two $(\alpha, n)$ spectra. These are plotted in Figure I, normalized to unity. Multiplication of data in Table 2 indicates that about two-thirds of the neutrons in PWR spent fuel comes from spontaneous fission and one-third from $(\alpha, n)$ reactions. A spectrum representing this split is also shown in Figure 1. Finally, the $\mathrm{Cf}^{252}$ fission spectrum is plotted for comparison. Because of the similarity, this $\mathrm{Cf}^{252}$ spectrum was used for cross-section averaging in the GGC-4 code. 6

Axial power peaking is assumed to have no effect upon neutron source intensity.

\section{Other Source Terms}

Secondary gammas from neutron captures in hydrogen (photon energy = $2.2 \mathrm{Mev}$ ) are sometimes a problem when the neutron shield is not borated. Secondary neutrons can arise from (1) thermal fissions in the $00.2 \mathrm{w} / \mathrm{o}$ $\mathrm{U}^{235}$ present in depleted uranium (DU), (2) fast fissions in the $\mathrm{U}^{238}$ in $\mathrm{DU}$, and (3) fissions in the fuel assemblies.

$$
\text { NEUTRON CALCULATIONS - IF } 300 \text { CASK }
$$

\section{Geometry}

For purposes of the neutron calculations, the geometry of the IF 300 cask design was simplified to the one-dimensional configuration shown in Figure 2. 


\section{Materials}

For the neutron transport calculations the homogenized fuel region consisted of 0.0386 atoms $/ \mathrm{barn}-\mathrm{cm}^{*} \mathrm{H}, 0.031 \mathrm{at} / \mathrm{b}-\mathrm{cm} 0,0.012 \mathrm{at} / \mathrm{b}-\mathrm{cm} \mathrm{Zr}$, and $0.00516 \mathrm{at} / \mathrm{b}-\mathrm{cm} \mathrm{U}^{238}$, the boronated copper separators being represented by extra 0 and $\mathrm{Zr}$. In the accident case, the $\mathrm{H}$ was removed and the 0 concentration reduced to $0.0117 \mathrm{at} / \mathrm{b}-\mathrm{cm}$.

The diffusion calculations utilized $0.0386 \mathrm{at} / \mathrm{b}-\mathrm{cm} \mathrm{H}, 0.00136 \mathrm{at} / \mathrm{b}-\mathrm{cm} \mathrm{B} \mathrm{B}_{\text {nat }}$, $0.0296 \mathrm{at} / \mathrm{b}-\mathrm{cm} 0,0.012 \mathrm{at} / \mathrm{b}-\mathrm{cm} \mathrm{Zr}$, and $0.00516 \mathrm{at} / \mathrm{b}-\mathrm{cm} \mathrm{U} \mathrm{U}^{238}$. The cask water was not borated.

\section{Calculations}

Fast-neutron dose rates were calculated using the 1DF neutron-transport $\mathrm{code}^{7}$ in the $\mathrm{P}-2, \mathrm{~S}-8$ approximation with $10^{-6}$ convergence. Eight neutronenergy groups were utilized, the lowest energy boundary being 0.111 Mev. Results are shown in Figure 3.

Intermediate and thermal dose rates in the cask were computed by the GAZE diffusion code, ${ }^{8}$ using as source terms the down-scattered neutrons from the $1 D F$ runs. Four intermediate and four thermal energy groups were used. These results are also plotted in Figure 3.

Secondary neutron dose rates were estimated separately.

\section{Discussion}

Figure 3a, the normal case, shows a total surface neutron dose rate of $5.7 \mathrm{mrem} / \mathrm{hr}$, consisting of $4.5 \mathrm{mrem} / \mathrm{hr}$ fast and $1.2 \mathrm{mrem} / \mathrm{hr}$ intermediate and thermal. Secondary fission neutrons created in the DU add $0.8 \mathrm{mrem} / \mathrm{hr}$ to this surface dose rate (boration of the water would essentially eliminate this contribution). The geometrical reduction factor in moving the detector from the cask surface to $10 \mathrm{ft}$ from the centerline was found to be 0.214 for a flat power distribution. The resulting 10-ft neutron dose rate of $1.4 \mathrm{mrem} / \mathrm{hr}$ can be compared with the published ${ }^{l}$ GE value of $5.1 \mathrm{mrem} / \mathrm{hr}$, which is a factor of 3.6 higher than the GGA result.

In the accident case (Figure $3 b$ ) the surface dose rate increases to $1180 \mathrm{mrem} / \mathrm{hr}$. A geometry correction to $3 \mathrm{ft}$ from the surface - a factor of 0.41 - yields an accident neutron dose rate of $480 \mathrm{mrem} / \mathrm{hr}$, as compared

\footnotetext{
*Density in $\mathrm{g} / \mathrm{cc}=$ density in at/b-cm multiplied by $\frac{\text { atomic weight }}{0.6023}$.
} 
with the GE value of $134 \mathrm{mrem} / \mathrm{hr}$, which is a factor of 3.6 lower. Thus, GGA's studies indicate an accident neutron dose rate 340 times higher than the normal operating neutron dose rate, whereas GE finds only a factor of 26. No explanation for this large discrepancy can be offered at this time. The advantages of situating the neutron shielding outside the gamma shielding are demonstrated in Figure $3 \mathrm{c}$. Fast neutrons are inelastically scattered in the DU region, reducing their energies to the range where hydrogen has a very high scattering cross section. The primary neutron surface dose rate is thereby reduced from $5.7 \mathrm{mrem} / \mathrm{hr}$ to $1.5 \mathrm{mrem} / \mathrm{hr}$ with no change in actual material thicknesses. Furthermore, the DU weight is reduced by $35 \%$. In this altered configuration, secondary fission neutrons from thermal captures in DU would add $\sim 0.75 \mathrm{mrem} / \mathrm{hr}$ to the surface dose rate; therefore, the water should be borated. Fast fissions in the DU add only $\sim 0.13$ mrem to the surface dose rate.

\section{GAMMA CALCULATIONS - IF 300 CASK}

\section{Geometry and Materials}

The PATH gamma-shielding $\operatorname{code}^{4}$ is capable of treating three-dimensional geometries in almost any degree of complication, except where streaming dose rates would predominate over direct dose rates (such as a labyrinth). Hence, the IF 300 cask geometry did not have to be simplified for the gamma calculations. Materials were also represented accurately, except that $\mathrm{Cu}-$ not available in the PATH library - was simulated by $9-\mathrm{g} / \mathrm{cc}$ Mo.

\section{Calculations}

Gamma dose rates were calculated both at the cask surface and at $10 \mathrm{ft}$ from its centerline. Computing time was reduced by the knowledge that the remote two assemblies would contribute only $1 \%$ to the dose rate, owing to shielding by the near two assemblies.

The PATH code includes a routine for the calculation of buildup factors for any desired single material which characterizes the shield, as represented by its equivalent atomic number $z$. The GE IF 300 cask design is characterized by a DU gamna shield; therefore, the PATH calculations were performed for uranium buildup $(Z=92)$. However, as has been shown in numerous studies such as Ref. 9, following the heavy material with a lighter material can substantially increase the overall buildup of gammas. Therefore, correction factors were 
derived from the curves of Figure 4. As will be shown below, $2 \mathrm{Mev}$ is the predominant gamma source energy for purposes of this adjustment. The dose correction factor was generally about 1.8 .

\section{Results and Discussion}

The corrected gamma dose rate at dose point " $\mathrm{A}$ " in Figure 2 was found to be $13.1 \mathrm{mrem} / \mathrm{hr}$ for a flat power distribution, or 19.6 with the axial peak. At $10 \mathrm{ft}$ from the centerline along this same radius, the values were 2.81 and $3.62 \mathrm{mrem} / \mathrm{hr}$, respectively. Moving $45^{\circ}$ to this radius, so the detector is opposite a corner of the basket, PATH gives dose rates of 1.76 and $2.27 \mathrm{mrem} / \mathrm{hr}$. General Electric publishes ${ }^{1}$ a gamma dose rate of $4.24 \mathrm{mrem} / \mathrm{hr}$, in good agreement with the maximum GGA value of $3.62 \mathrm{mrem} / \mathrm{hr}$.

It is of interest to determine which source energies and isotopes contribute the most to these dose rates. Study of the PATH results shows that among the photon energies listed in Table 1, the 2-Mev source group contributes $60 \%$ of the dose rate, the $1.6-\mathrm{Mev}$ group $22 \%$, and the $2.4-\mathrm{Mev}$ group $15 \%$. By isotope, one finds that $\operatorname{Pr}^{144}$ contributes $61 \%$ of the dose rate, $\mathrm{La}^{140} 29 \%$, and $\mathrm{Rh}^{106} 10 \%$.

Under accident conditions, some gamma attenuation provided by water is lost. It is estimated that the accident gamma dose rate $3 \mathrm{ft}$ from the cask surface would then be $11.2 \mathrm{mrem} / \mathrm{hr}$ without the axial peak or $15.2 \mathrm{mrem} / \mathrm{hr}$ with the axial peak. GE's value is $7.0 \mathrm{mrem} / \mathrm{hr}$, which seems somewhat low.

\section{DOSE RATE CALCULATIONS - DRY 4-PWR CASK}

Typical of the many cask designs investigated by GGA following the IF 300 comparison studies is the National Lead concept shown in Ref. 2, and redrawn with some modifications in Figure 5 of this paper. The configuration merely illustrates the type of complicated geometries which can be handled by the PATH gamma-shielding code, and should by no means be considered as engineered design.

Neutron calculations were performed as described before, after simplification of the geometry to equivalent cylindrical regions. For a neutron source strength of $1.1 \times 10^{9} \mathrm{n} / \mathrm{sec}-\mathrm{MTU}$, a neutron shield of 6 inches of Uniroyal 3807 or borated paraffin, or 7 inches of borated water, will be adequate to keep the neutron dose rate at 6 feet from the cask surface well below $5 \mathrm{mrem} / \mathrm{hr}$. 
Gamma calculations involved buildup corrections for lead/iron as well as uranium/iron, using curves similar to those in Figure 4. Shielding was arranged so that the gamma dose rate six feet from the cask surface, on the midplane, was about $5 \mathrm{mrem} / \mathrm{hr}$ at any polar angle. The shell diameter is determined by the gamma shielding thickness needed at the corners, in this case 3 inches of DU plus 1 inch of lead. If only DU were used, the thickness would be 3.6 inches.

\section{ACKNOWLEDGEMENT}

The author gratefully acknowledges the participation of C. R. Davis, W. C. Finch, and D. E. Hurd in this work.

\section{REFERENCES}

1. Design and Analysis Report - IF 300 Shipping Cask, General Electric Company (September 26, 1969).

2. L. B. Shappert, Cask Designers Guide, Figure 8.3, ORNL-NSIC-68, (February, 1970).

3. Barnwell Nuclear Fuel Plant Safety Analysis Report, Table III-1, Part 4, Section III, Vol. I (August 15, 1969).

4. S. S. Clark and B. A. Engholm, PATH, A Highly Flexible, General Purpose Gamma Shielding Program, GA-9908 (December 10, 1969).

5. S. J. Rimshaw and E. E. Ketchen, Curium Data Sheets, ORNL-4187 (December, 1967).

6. J. Adir and K. D. Lathrop, Theory of Methods Used in the GGC-4 Multigroup Cross Section Code, GA-9021 (October 1, 1968).

7. K. D. Lathrop, DTF-IV, A FORTRAN-IV Program for Solving the Multigroup Transport Equation with Anisotropic Scattering, LA-3267 (Apri1 23, 1965).

8. S. R. Lenihan, GAZE-2, A One-Dimensional, Multigroup, Neutron Diffusion Theory Code for the IBM-7090, GA-7156 (August 3, 1962).

9. B. A. Engholm, Gamma Buildup in Heterogeneous Media, GA-8741

(September 16,1968 ). 


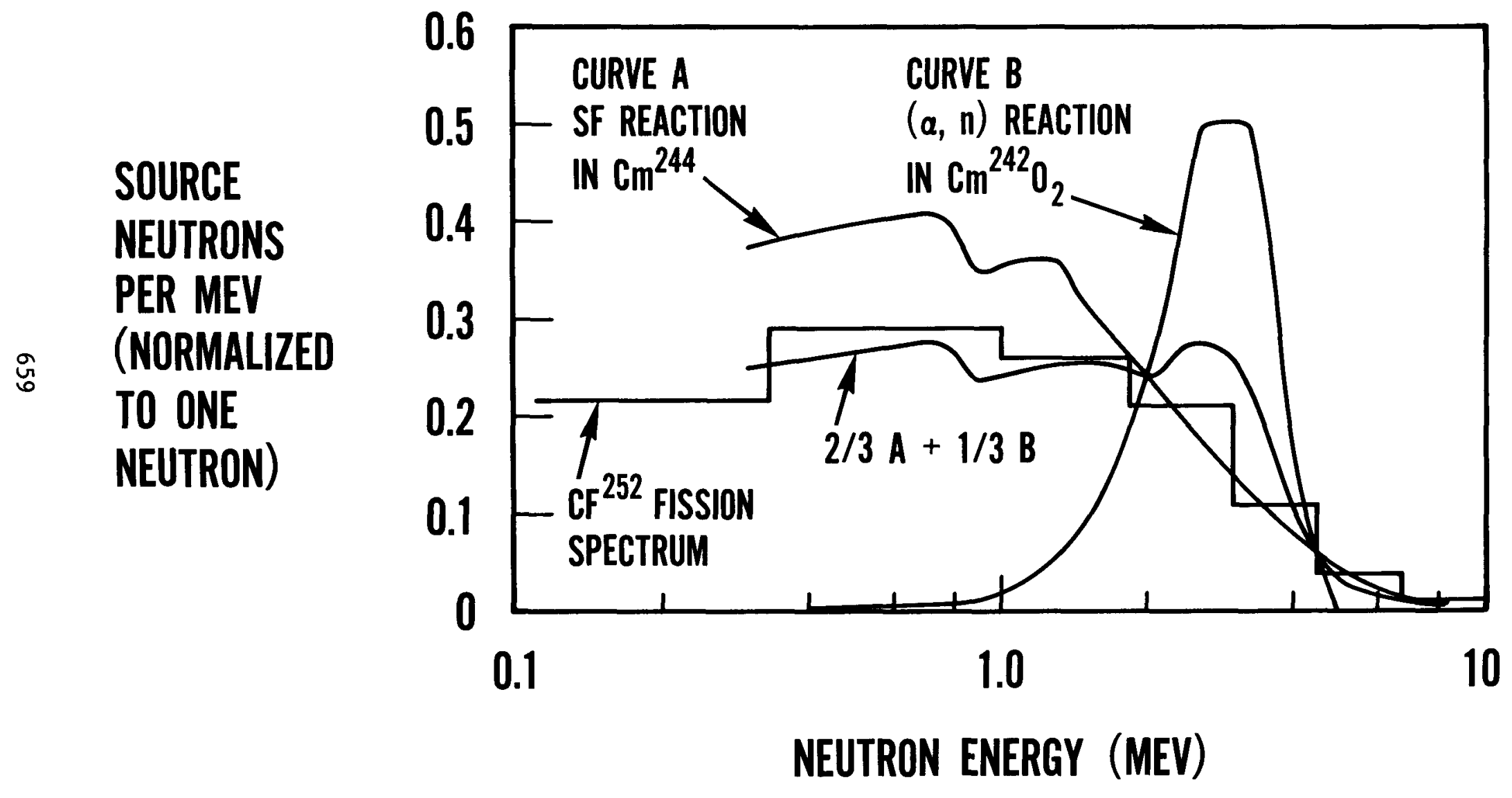



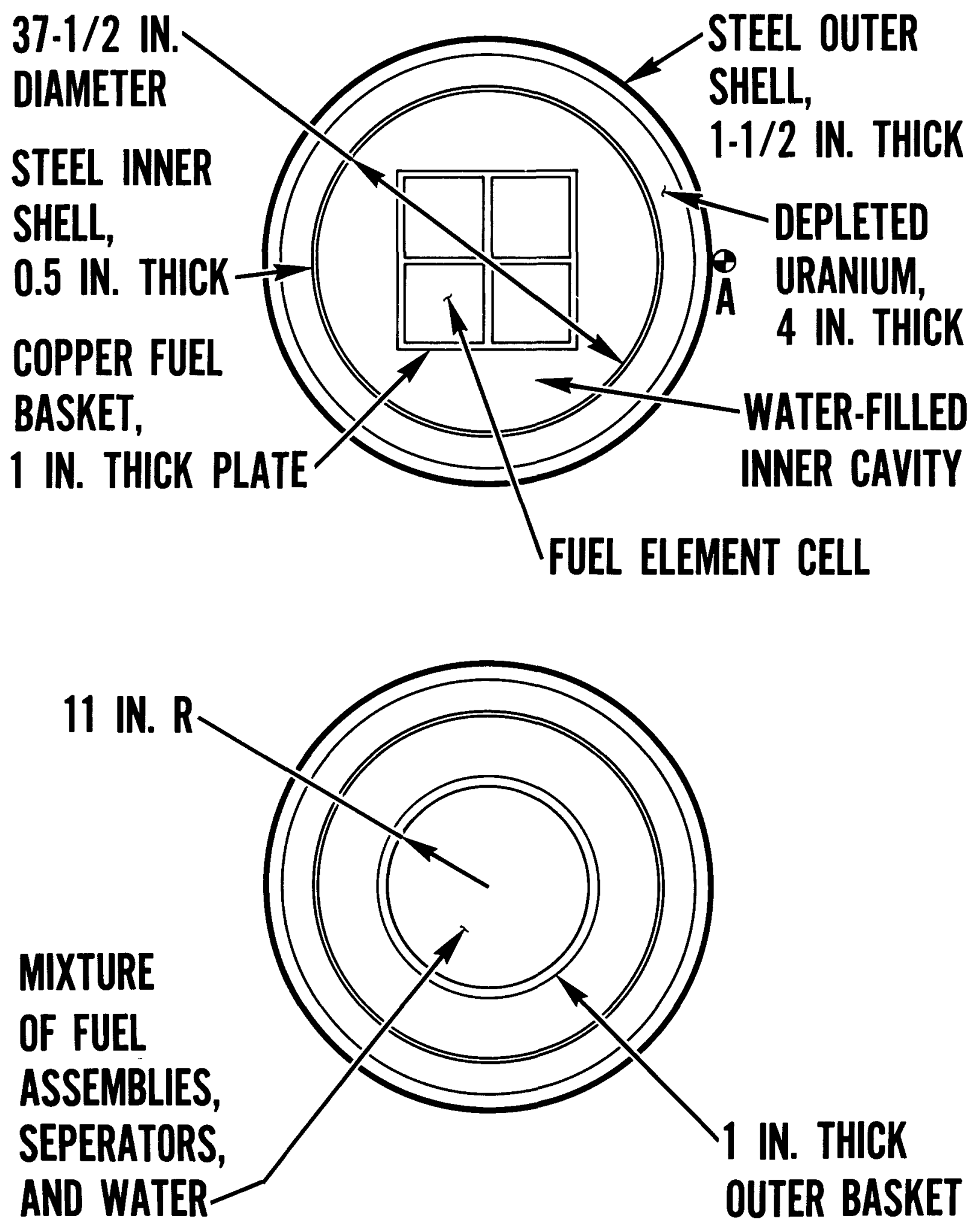

LC-88333-A

Fig. 2. Original IF 300 Cross Section (top), and Idealized IF 300 Cross Section for Neutron Calculations (bottom). 


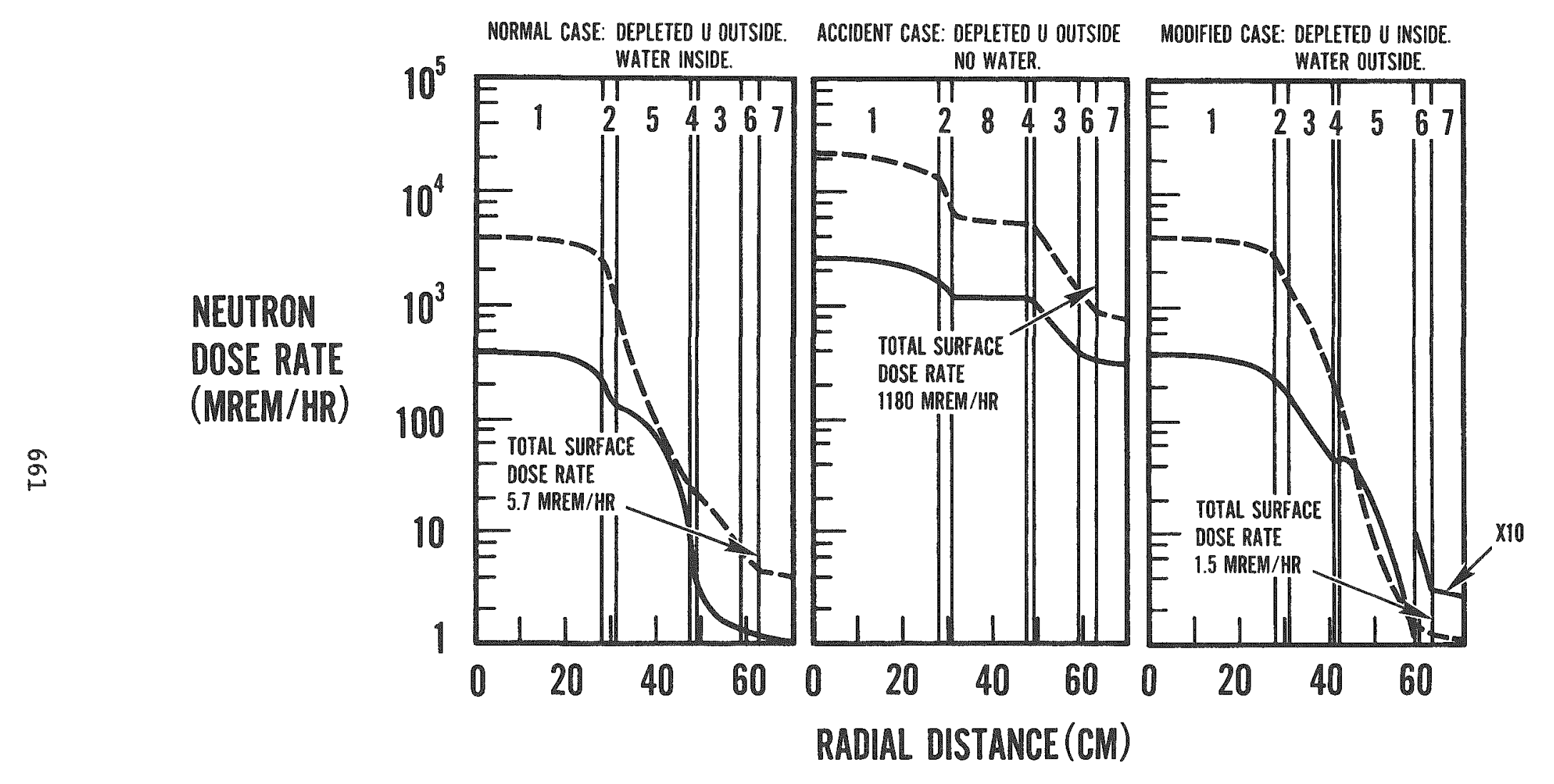

1 FUEL ASSEMBLIES 3 DU 5 WATER 7 OUTSIDE ATMOSPHERE INTERMEDIATE \& THERMAL NEUTRONS 2 OUTER BASKET 4 STEEL CLAD 6 STEEL. SHELL 8 AIR $\quad-$ - FAST NEUTRONS(E $>0.111$ MEV) 


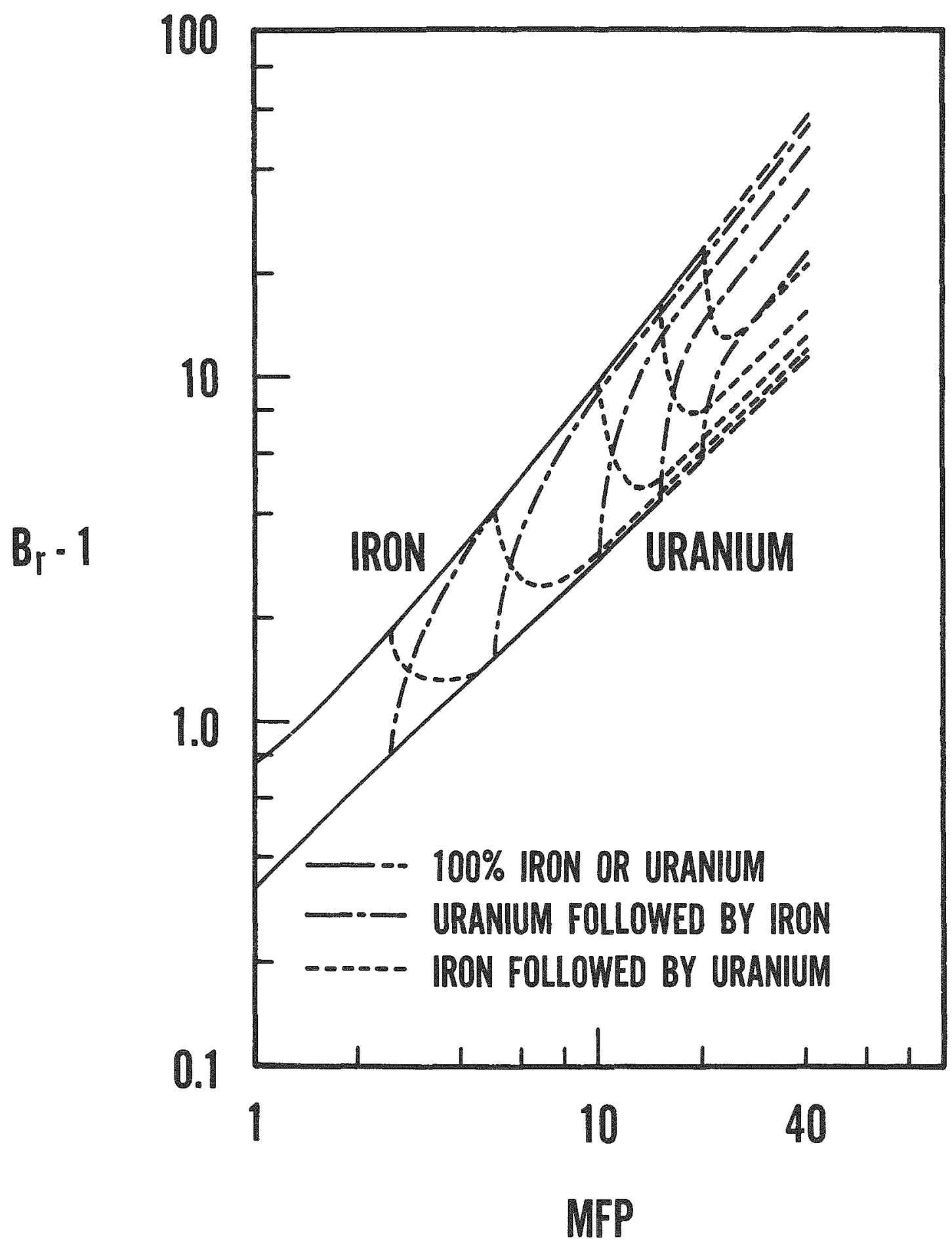




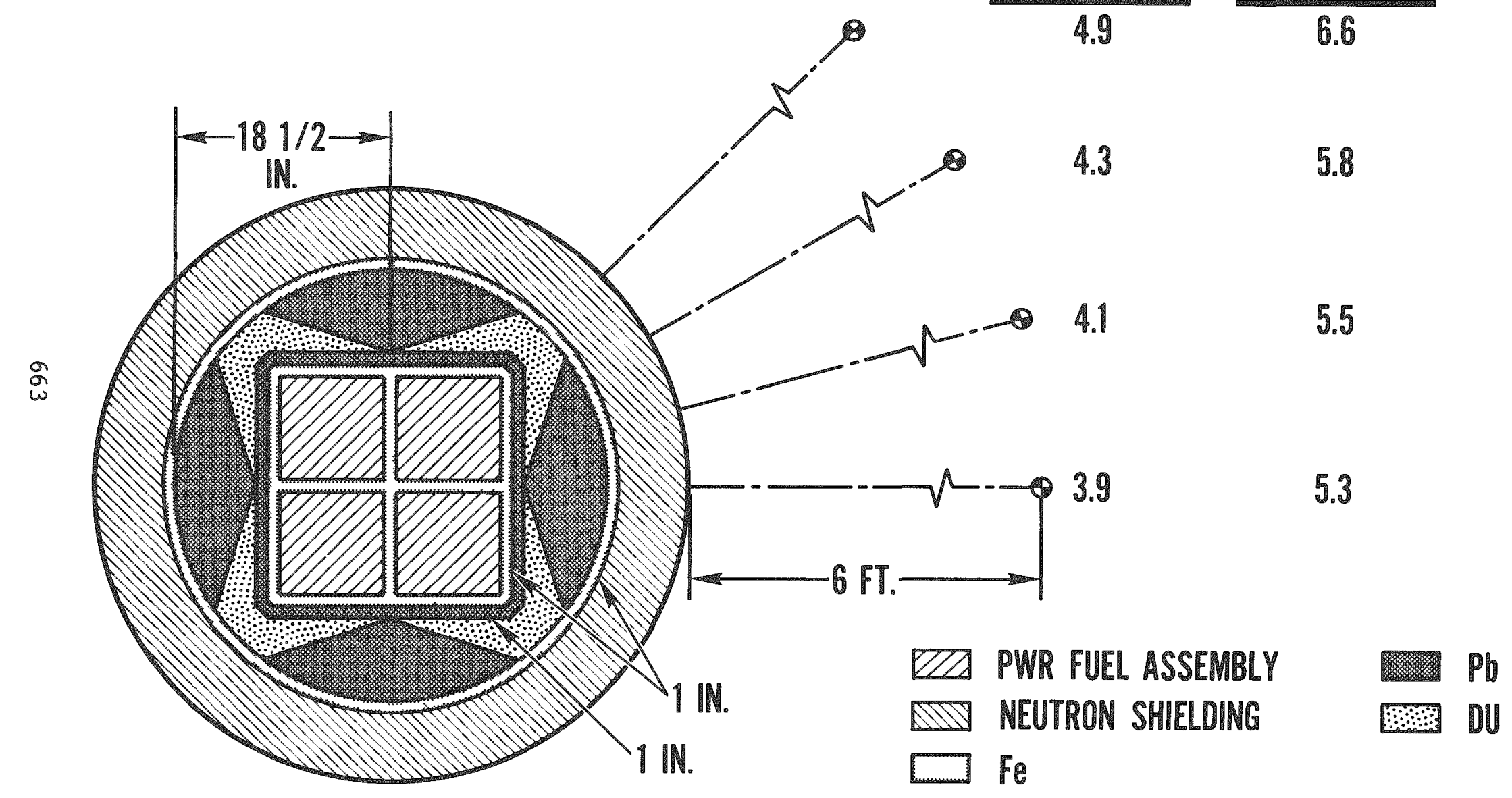

LC-88336-A

Fig. 5. Typical Dry 4-PWR Cask Design Investigated by GCA. 


\section{$\checkmark$ LEAD REMELT EXPERIENCE WITH 60-TON CASK}

E. C. Lusk

BATTELLE

Columbus Laboratories

\section{ABSTRACT}

The fabrication of large-size spent fuel shipping containers can result in a variety of unanticipated crises. During the fabrication cycle of the NFS-100 cask, (a 60-ton gross weight cask) there was a failure of the lead pouring equipment which necessitated the remelting of 80,000 $1 \mathrm{~b}$ of lead. Since the "lead pour" phase is near the end of a cask fabrication cycle, it was necessary to quickly establish a guaranteed success remelt operation which would result in a nonporous gamma shield. The size of this particular cask and a large number of heat rejection fins necessitated the set up of shroud-type furnace within the metal fabrication shop which would bring the entire cask up to the desired lead remelt temperature of approximately $680 \mathrm{~F}$. Five 750,000 Btu rated liquid propane burners (oriented so the flame was directed tangential to the cask finned exterior) were positioned at several vertical levels and a successful remelt operation was carried out. This paper presents the details of that operation, as well as the temperature history of the cask. Temperatures were recorded by means of both external thermocouples welded to the cask and dip-type thermocouples employed within the lead volume to establish the liquid/solidus interface and its movement with time. The remelt operation required 27 hours to complete, was completed on site, and resulted in a void-free gamma shield. Specifics of this operation and associated temperature data are detailed in this paper. 


\section{CASK DESCRIPTION}

The spent fuel shipping cask discussed in this paper is the NFS-M100 cask system which is shown mounted on a rail car in Figure 1 . This cask is a multipurpose shipping cask designed and licensed by BCL, and which is capable of shipping either 12 Big Rock Point, 18 Pathfinder, or 18 Humboldt Bay spent fuel assemblies. Figure 2 provides an exploded view of the NFS-M100 cask and illustrates the major components. The cask weight, exclusive of the skid, is 60 tons and has an external diametric envelope of 70 inches (as established by the heat rejection fins) and an overall length of 130 inches. The biological lead shield weighs approximately 40 tons and has a radial thickness of 8.75 inches.

The heat rejection fins, which are required to dissipate an anticipated decay heat load of approximately $28 \mathrm{kw}$ therma 1 , increase the cask surface area by more than a factor of three and were fabricated from a continuous strip of four-inch wide $x$ 1/4-inch thick stainless steel. Attachment of the fins to the outer shell was accomplished by a continuous welding operation which resulted in 1/4-inch fillet welds on both sides. The fins are four inches high and are set on 1.75-inch axial centers. The outer shell of the cask is a composite plate comprised of a 1.75-inch thickness mild steel plate to which a roll bond clad 1/4-inch thickness Type 304 stainless steel plate has been joined. The interior fuel cavity has a 40 inch ID and is 103 inches deep. Eighteen square type permanent fuel assembly cavities are established by a means of the inner basket which is comprised of $1 / 2$-inch thick copper plates which are bonded to themselves as well as to the walls of the inner cavity.

\section{Lead Melt Background}

The lead fill procedure utilized called for setting the cask in a vertical attitude and then positioning a lead kettle plus furnace apparatus at a higher level to effect a gravity feed of molten lead. During the first lead filling operation, a flow control valve on the lead fill line between the lead source kettle and the furnace froze in the closed position. During the time required to replace the stuck valve, the auxiliary heating equipment (which normally would maintain the overall cask system at the desired casting temperature) was unable to supply sufficient heat to hold the lead (which had already been cast) in a molten condition. Upon resumption of the lead filling (after the defective valve had been replaced) the cooling rate of the lead was too rapid and a void was formed at approximately 24 inches from the 
bottom of the cask surface. Information obtained from the the rmocouples which were placed on the cask to monitor the lead pour operation, indicated that the heat rejection fins were being too effective in shadow shielding the cask surface from the flame being produced by the liquid propane burners (as oriented for this initial casting operation). Since the cask would require extensive rework if the situation were not remedied quickly, the decision was made to set up an on-site remelt furnace. This is described in the next section.

\section{Description of Remelt Equipment}

A shroud-type furnace composed of 0.187 -inch thick mild steel plates was erected on-site for the remelt operation. Scheduling and cost requirements precluded moving the cask. The furnace arrangement is shown in Figure 3 , and since the cask fins increase the cask envelope by 8 inches resulted In a chimney diameter of approximately 80 inches. The cask was positioned vertically with the open end of the fuel cavity facing downward to permit heating of the cavity interior. A cover employing a controllable vent was provided for the top of the furnace shroud and the entire furnace assembly was then supported by steel legs resting on the floor of the fabrication shop. Ten burner openings were provided for in the sides of the furnace shell and were equally spaced circumferentially and vertically to permit desired burner placement for the purpose of heating up zones in a uniform fashion. These burner ports were also provided with a controlled air inlet vent and provision was made to direct the burner flame at a tangential angle with respect to the outer shell of the cask, thus utilizing the circumferential fins to, in effect, direct the flame front (see Figure 3). Baffle-type deflection plates were provided for the burner flame to impinge upon and to then provide for a swirling motion around the cask.

\section{Details of Remelt Operation}

Five 750,000 Btu rated propane burners were positioned within the furnace shroud to commence a uniform remelt heating cycle. In addition, a ring burner was positioned beneath the cask to heat the fuel assembly cavity and a standard "blast" burner was positioned at the top to heat the lead pour port. In addition, eight chromel-alumel thermocouples were welded to the outer shell of the cask between the fins for purposes of temperature monitoring during the heatup and cooldown cycles since the preceeding experience had shown the fins shadow shield the flame. These couples were positioned such 
that there would not be direct burner flame impingement and were located at approximately one foot axial increments from bottom to top. A portable diptype thermocouple was utilized to monitor temperatures within the lead cavity after the lead remelt had begun. As another backup, a portable contact pyrometer with a range of 0 to $1,200 \mathrm{~F}$ was utilized to check available surface temperatures of the furnace and cask. The pyrometer employed was a compensated, direct reading type pyrometer which had been calibrated prior to the operation against a bureau of standards related instrument.

The burners were lit at approximately $7 \mathrm{a} \cdot \mathrm{m}$. and commencement of temperature data recordings were initiated at $8 \mathrm{a} . \mathrm{m}$. Burners were adjusted for maximum heat output and within a short time period were capable of maintaining the flame baffle plates and the outer edges of the cask fins in the area of the flame impingement at a cherry red color, which was measured via a thermocouple to read approximately 1,400 F. The operation proceeded quite smoothly with very little burner adjustment being required. The vent opening at the top of the furnace configuration was adjusted upward to provide for a blast burner to be directed down at the center of the vent opening onto the lead pour hole. Despite all of this deliberate heating, lead melt temperatures did not occur until approximately $9-1 / 2$ hours after starting the heatup. The first indication of lead melting on the top was some 30 minutes later, or at $5 \mathrm{p} . \mathrm{m}$. At six o'clock p.m. the internal "dip" thermocouple indicated molten lead at a depth of four feet. At this time, the top burners were cut back and at $12: 15 \mathrm{a} . \mathrm{m} .$, or 17 hours after starting, all of the lead within the NFS cask was assessed to be in a molten condition.

The solidification process which followed required approximately ten hours. This operation was accomplished by opening the top vent, turning the burners down, and removing vertical sections of the furnace wall commencing at the bottom and proceeding upward. Following the cooldown period, a complete gamma scan of the cask surface was made on a three-inch grid. The results of this test proved that a solid condition of remelted lead gamma shielding existed. The detailed thermal history is summarized in Table 1. 
Postmelt Evaluations and Comments

The preceding sections have described the successful remelting of a large volume of lead at a fabricator's shop. However, some additional insight as to the severity of postulated industrial fires, and their effect on a cask system, can be gleaned from this experience.

First of all, the remelting process took 17 hours, with the cask outer shell temperature reaching $620 \mathrm{~F}$ after ten hours. In addition, this heat up took place in a specially erected furnace which directed propane gases to sweep between the fins, with the gases having a very high energy content. This can be illustrated by the fact that 800 gallons of liquid propane (heating value of propane is $91,690 \mathrm{Btu} / \mathrm{gal}$ ) were burned over a 17-hour period for a potential heat load of $73.4 \times 10^{6} \mathrm{Btu} / \mathrm{hr}$.

The hypothetical fire which is defined in 10-CFR-Part 71 as a 1475 $F$ radiant source having an effective emissivity of 0.9 , and which regulation also stipulates that the receiver surface has an effective absorptivity of 0.8 , permits utilization of the Stefan-Boltzmann equation to describe the heat transfer coupling, or

$$
\mathbf{q}_{\text {Fire }}=\left(\Sigma F_{G} A\right)\left(F_{\varepsilon}\right)\left(\sigma T_{\text {Fire }}^{4}-\sigma T_{\text {surface }}^{4}\right)
$$

where $F_{G}=$ geometric view factor

$$
\begin{aligned}
A & =\text { area receiving radiation energy } \\
\mathrm{F}_{\varepsilon} & =\text { emissivity factor }=\frac{1}{\frac{1}{\varepsilon_{\text {fire }}}+\frac{1}{\varepsilon_{\text {surface }}}-1}
\end{aligned}
$$

If we neglect the countering effect of an increasing surface temperature, and utilize Equation (1) to calculate a "cold wall" heat input, we obtain the following heat inputs resulting from the hypothetical fire:

$$
\begin{aligned}
\mathrm{q}_{\mathrm{RAD}} & =2.12 \times 10^{6} \mathrm{Btu} / \mathrm{hr} \text { at } \varepsilon_{\text {surface }}=0.8 \\
& =0.54 \times 10^{6} \mathrm{Btu} / \mathrm{hr} \text { at } \varepsilon_{\text {surface }}=0.2 \\
& =0.4 \times 10^{6} \mathrm{Btu} / \mathrm{hr} \text { at } \varepsilon_{\text {surface }}=0.15 .
\end{aligned}
$$

The results shown in Equation (2a) when compared to $4.3 \times 10^{6} \mathrm{Btu} / \mathrm{hr}$, as calculated from the heating value of liquid propane, would permit me to say that the remelt fire was more severe than the prescribed fire test. The latter two values illustrate the effect of a lower emissivity and since the cask fins and shell had already been polished to a $63 \mathrm{G}$ micro finish, the lower values are justifiable for 304 stainless steel. More will be said regarding these lower values below. 
Consideration of the thermal capacitance of the NFS-100 cask itself leads to the following tabulation and resulting thermal capacitance values:

$$
\begin{aligned}
80,0001 \mathrm{~b} \text { of lead } \times 0.031 \mathrm{Btu} / 1 \mathrm{~b}-\mathrm{F} & =2480 \mathrm{Btu} / \mathrm{F} \\
27,000 \mathrm{lb} \text { of steel } \times 0.11 \mathrm{Btu} / 1 \mathrm{~b}-\mathrm{F} & =2970 \mathrm{Btu} / \mathrm{F} \\
4,0001 \mathrm{~b} \text { of copper } \times 0.0915 \mathrm{Btu} / \mathrm{F} & =366 \mathrm{Btu} / \mathrm{F} \\
(\rho \mathrm{VC})_{\text {total }} & =5816 \mathrm{Btu} / \mathrm{F} .
\end{aligned}
$$

Exclusive of the heat of fusion of lead, the total heat required to raise this cask to $600 \mathrm{~F}$ above room temperature is then

$$
Q=\rho V C p \Delta T=5816 \mathrm{Btu} / \mathrm{F} \times 600 \mathrm{~F}=3.48 \times 10^{6} \mathrm{Btu} .
$$

In addition, the heat of fusion of lead $(10.5 \mathrm{Btu} / \mathrm{lb})$ raises the total heat to $4.32 \times 10^{6} \mathrm{Btu}$, which is significantly lower than the $73.4 \times 10^{6}$ Btu cited for the propane previously. The logical question is where did this heat go? However, before we go on, if the capacitance calculated via Equation (4) is averaged over a ten-hour period (time lead melt temperature is reached, see Table 1), and a 17-hour period, heat transfer levels of $0.35 \times 10^{6} \mathrm{Btu} / \mathrm{hr}$ and $0.25 \times 10^{6} \mathrm{Btu} / \mathrm{hr}$, respectively, are calculated. These latter numbers should be compared with the results shown in Equations (2b) and (2c), and the next questions is - how realistic is the absorptivity value of 0.8 (to be held constant through the 30-minute fire) stipulated by the regulations? It took ten hours in a specially designed furnace to reach melt temperatures, and another seven hours to complete melting of the lead. On the other hand, Serkiz ${ }^{(1)}$ shows melt temperatures being approached in approximately 30 minutes with the fins "blocking" and lead melt occurring if the fins are removed. There would appear to be an inconsistency.

In an attempt to consolidate the above remarks, consider the following tabulation:

Heat load required to raise cask temperature $600 \mathrm{~F}$ and melt lead

Heat load contained in 800 gal of propane

$$
\begin{aligned}
& =4.32 \times 10^{6} \mathrm{Btu} \\
& =73 \times 10^{6} \mathrm{Btu} \\
& =18.5 \times 10^{6} \mathrm{Btu} \\
\Delta & =54.5 \times 10^{6} \mathrm{Btu} .
\end{aligned}
$$$$
\text { Heat load dumped to external environment }
$$$$
\text { by } 200 \mathrm{ft}^{2} \text { of furnace shell at } 900 \mathrm{~F} *
$$

With $54.5 \times 10^{6}$ Btu of heat energy being potentially available to heat up the cask (and it is recognized that the burner gases took considerable energy out through the stack opening) why did it take ten hours to reach the lead

* Radiative coupling to the ambient environment only. 
melting temperature, and then another seven hours to melt the $40,000 \mathrm{lb}$ of lead? The hypothetical 30-minute fire heat level* (in comparison) calculated to be $0.27 \leftrightarrow 1.06 \times 10^{6}$ Btu. Obviously, convective coupling was not as effective as had been hoped for in a special furnace. Further speculation is left to the reader, but this remelt experience does raise some questions as to the actual interpretation of the effect of the fire test conditions on a shipping container. Needless to say, our analytical approaches appear to be quite conservative.

\section{ACKNOWLEDGMENTS}

Acknowledgment is extended to the Edward Lead Company, Scientific Advances, Inc., and Nuclear Fuel Services, Inc., for permission to use in this paper the information generated on this project.

\section{REFERENCES}

(1) Serkiz, A.W., "Safety Analysis Report NFS-M-100 Cask", Battelle's Columbus Laboratories.

(2) Perry, R., "Log of Lead Pour Operation NFS-M-100", Edward Lead Company.

(3) Jones, S., Pictures and Drawings and NFS-M-100 Cask, Scientific Advances, Inc. 
Table 1. Thermal History of Remelt Operation (Temperature, F)

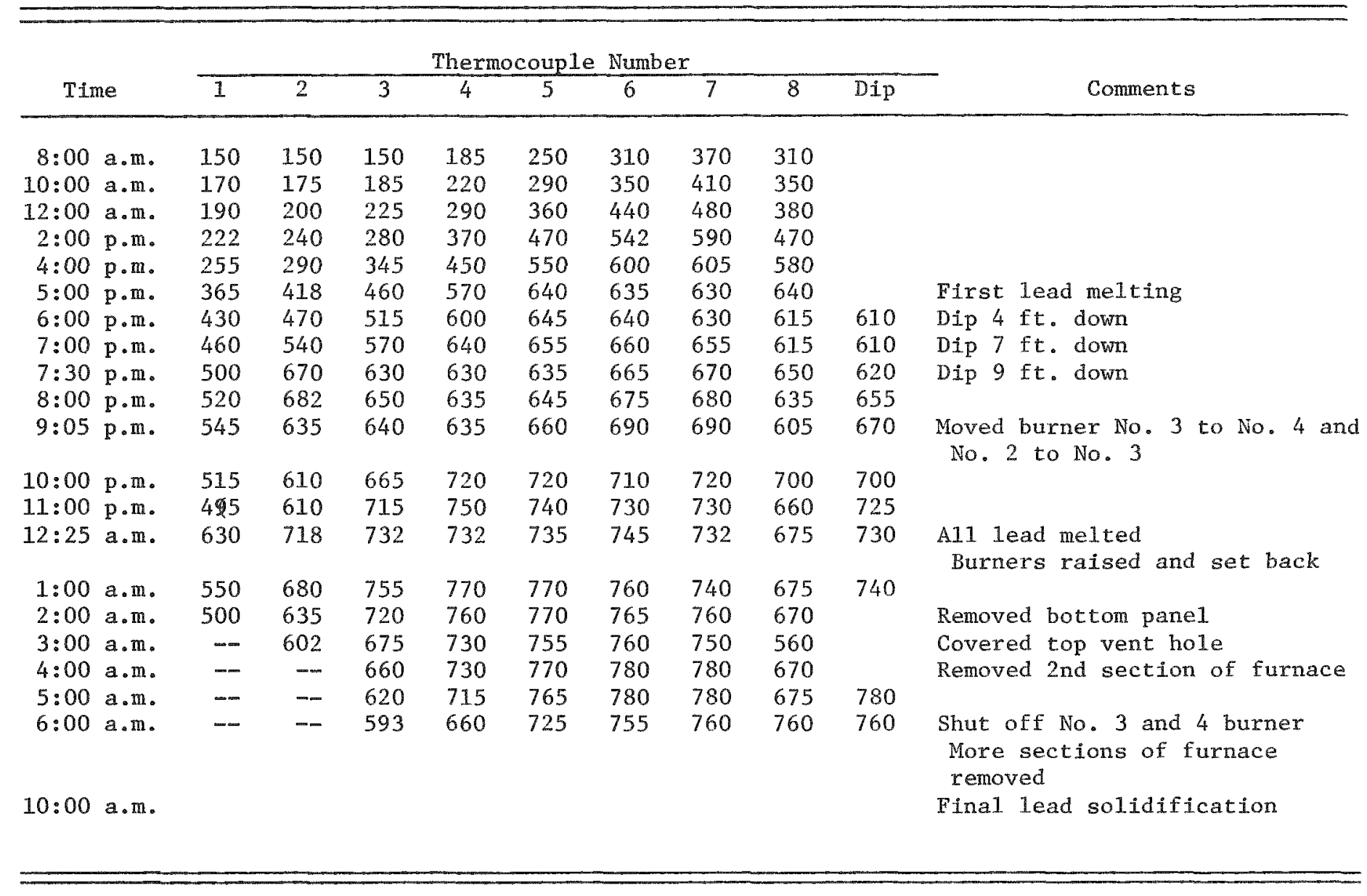




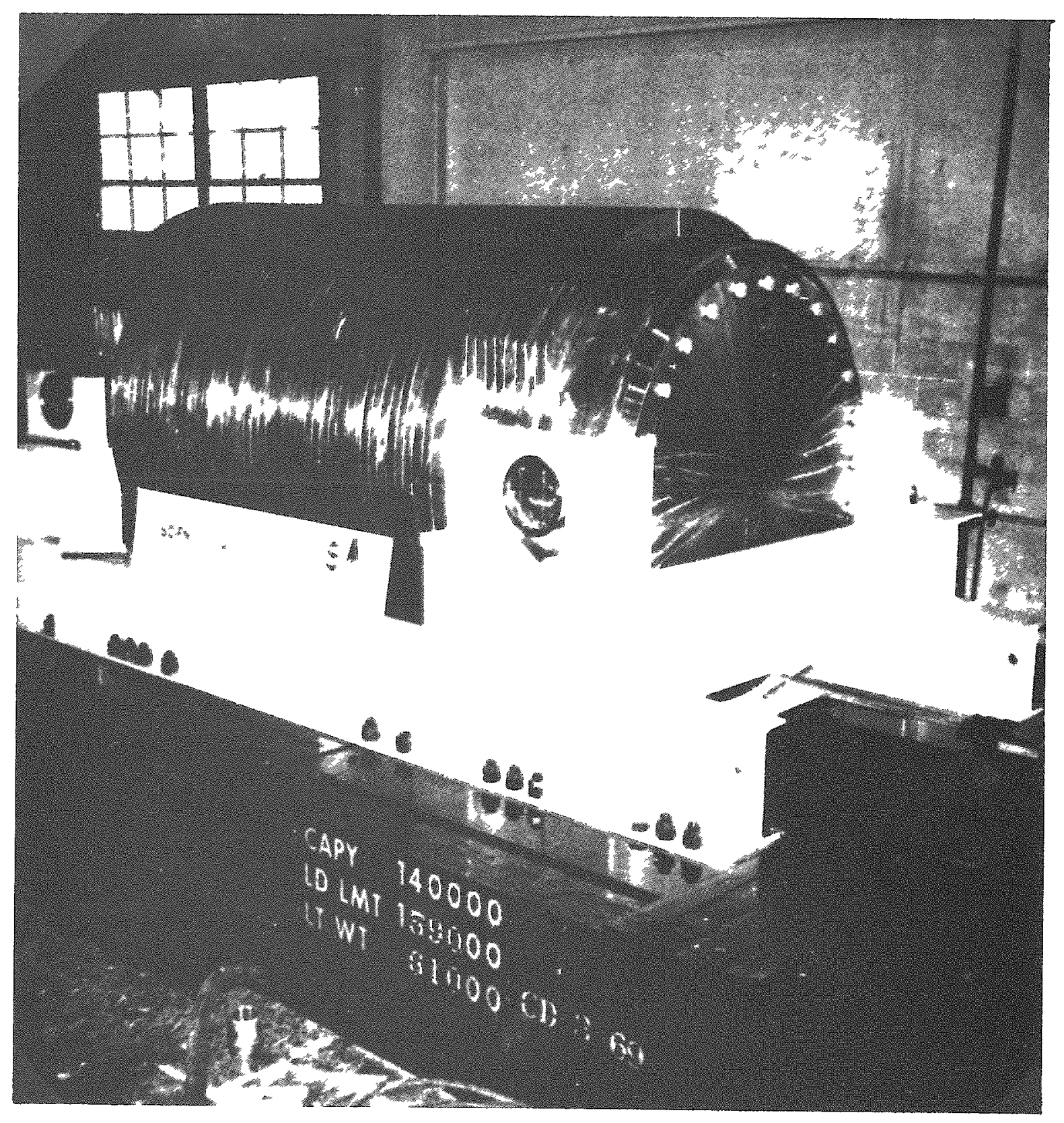

Fig. 1. NFS-M100 Cask System 


\section{0}

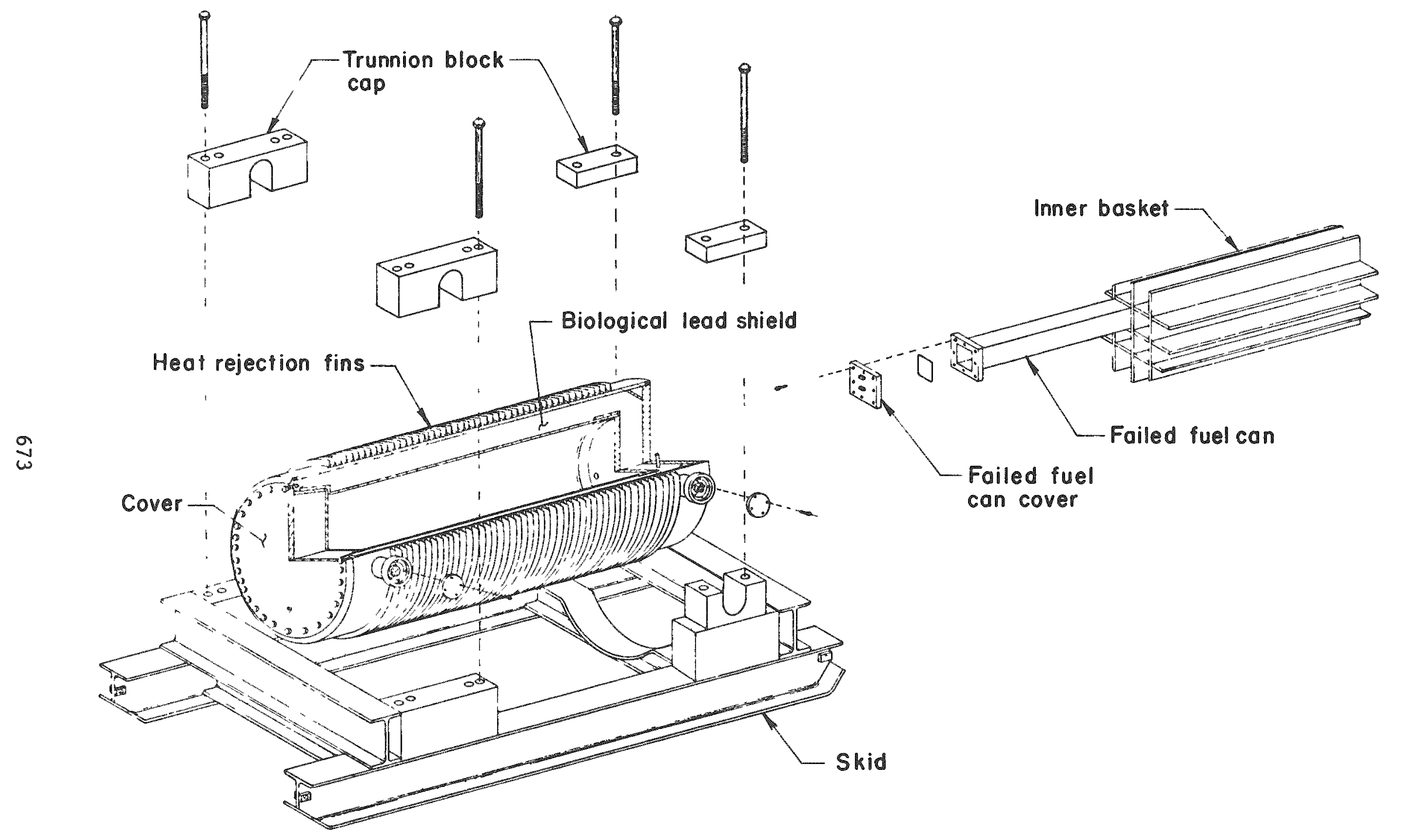

Fig. 2. Exploded View of NFS-M100 Cask System 


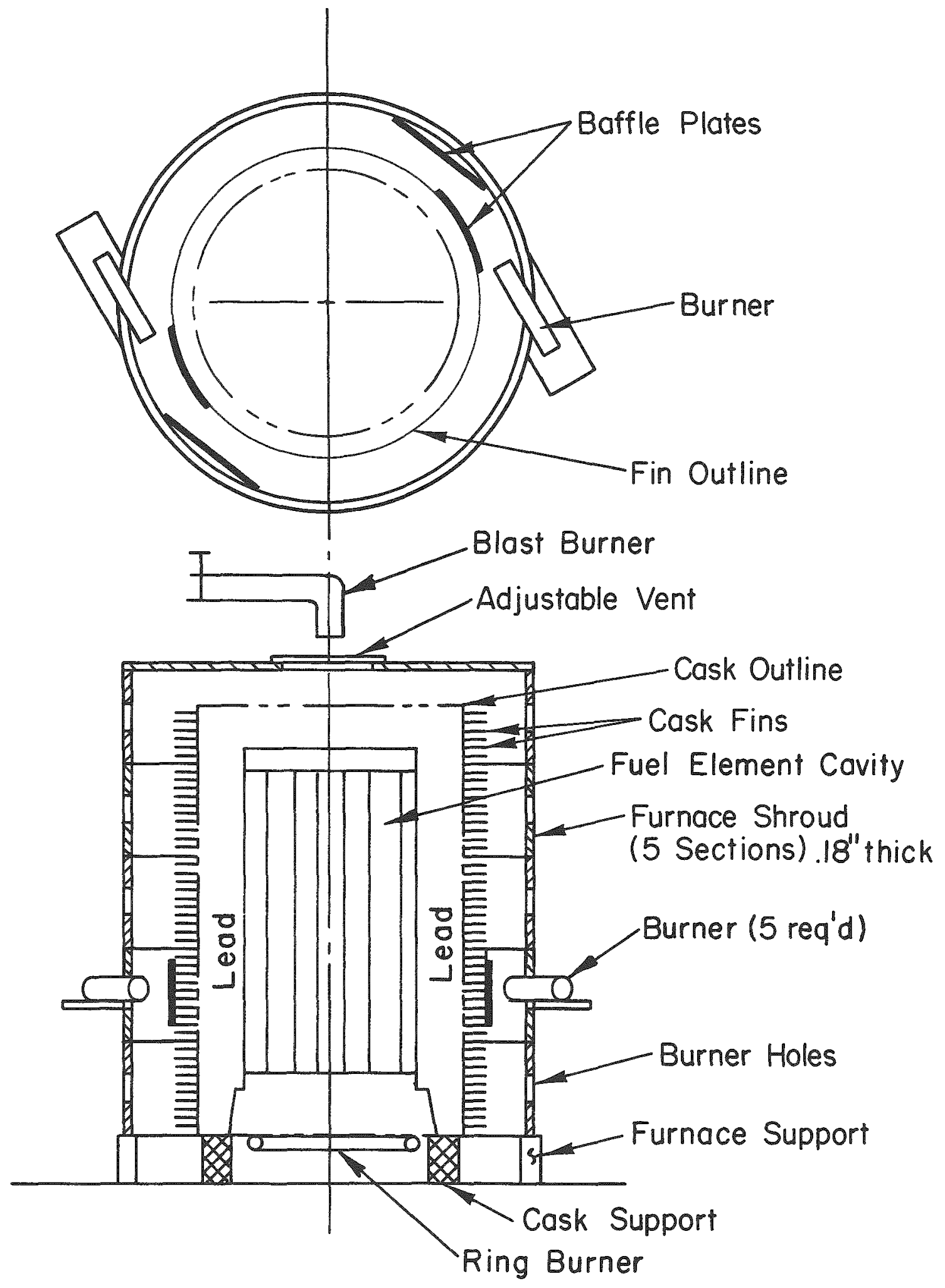

Fig. 3. Furnace Arrangement. 
WEIGHT MINIMIZATION OF CASKS FOR SHIPMENT OF HIGH

BURNUP AND RECYCLE LWR FUELS

J. L. Ridihalgh

R. E. Best

This paper was not available at the time of printing. It has subsequently been issued as BNWL-SA-3906, available from NTIS, 5285 Port Royal Road, Springfield, Virginia 22151. 
IMPACT TESTING OF CHEMICAL LEAD, CASK MODELS, AND AN ENERGY ABSORBING DEVICE

\author{
J. H. Evans
}

Oak Ridge National Laboratory*

Oak Ridge, Tennessee

ABSTRACT

Several impact test programs have been conducted at oak Ridge National Laboratory, and three recent programs directed toward the development of design and computational data relevant to the $30-f t$ free drop hypothetical accident condition specified in regulations governing the design and performance of containers in which radioactive materials are shipped are discussed herein. Chemical lead specimens were impact tested, and the stress-strain properties of lead undergoing gross impact-produced deformation at the strain levels and strainrate ranges experienced by lead-shielded casks as a result of the 30-ft free drop and impact were determined. Models of a new energy absorbing device, the tubes-in-pipe absorber, were impact tested; and the data and techniques required to predict the behavior of full-size casks equipped with this device were developed. Scale models of the proposed steel-shielded LMFBR shipping cask were impact tested, and the data and techniques necessary to predict the response of the full-size cask were developed and the feasibility of using metal-to-metal seals in such a cask was demonstrated.

\title{
INTRODUCIION
}

A series of impact testing programs directed toward answering some of the many perplexing and complex questions associated with the potential damage to shipping casks (Type-B containers) and their contents that might result from the free-drop condition of the hypothetical accident specified in current regulations governing the design and performance of containers in which radioactive materials are shipped have been conducted at Oak Ridge National Laboratory (ORNL). The results of two investigations ${ }^{3,2}$ that essentially solved the problem of predicting cladding puncture in lead-shielded casks were reported ${ }^{3}$ at the Second International Symposium held in Gatlinburg, Tennessee, in 1968. Since that time, four distinct impact testing programs have been completed and a fifth is under way. Three of these programs are discussed herein.

roak Ridge National Laboratory is operated by Union Carbide Corporation under contract with the United States Atomic Energy Commission. 
The first of the programs discussed herein involved an experimental study ${ }^{4}$ of the stress-strain properties of lead undergoing gross impact-produced deformation of the magnitude experienced by lead-shielded casks during the impact resulting from a 30-ft free drop that was successfully concluded in the spring of 1970. Models of an energy absorbing device, the tubes-in-pipe absorber devised by A. R. Irvine of ORNL, were tested ${ }^{5}$ to verify the applicability of the device and to develop the data and analytical relationships necessary to calculate the response of casks equipped with this device during an impact resulting from the $30-\mathrm{ft}$ free drop. The third program discussed herein was concluded in the spring of 1971, and it consisted of impact testing scale models of the proposed LMFBR shipping cask, ${ }^{6}$ which employs steel as the biological shielding material. The data and analytical relationships required to calculate the response of full-size casks and their contents and the potential damage resulting from the $30-\mathrm{ft}$-free-drop impact were developed during this program. The ability of a metal-to-metal seal to withstand the impact resulting from a $30-\mathrm{ft}$ free drop was also demonstrated.

An in-depth study ${ }^{7}$ of the dynamic energy absorption properties of cask heat transfer fins conducted at ORNL was completed in the fall of 1970, and this program is discussed by F. C. Davis elsewhere in these proceedings. An experimental investigation of the energy absorption properties, dynamic load capacity, and elongation properties of threaded stainless steel fasteners is now being conducted by D. D. Cannon of ORNL.

TEST FACILITIES, INSTRUMENTATION, AND DATA TRANSFORMATION TECHNIQUES

The physical impact testing reported here was conducted at the ORNL Drop Tower, which is a steel structure $40 \mathrm{ft}$ tall that has a free-drop load capacity of about $5000 \mathrm{lb}$. The tower drop pad is essentially the unyielding surface specified in the regulations by virtue of its mass, support from bedrock, and the hardness and toughness of the armor-plate impact surface. The free-drop passage down the center of the tower is square, with each side being about $5 \mathrm{ft}$ 1ong. An angle-iron track installed at the rear of this passage was used for controlledorientation specimen drops and to impact specimens with free-falling drop hammers (weights). The operating range of this system is from 25 to $500 \mathrm{lb}$. A lowcapacity system installed on one side of the free-drop passage was used to impact specimens with 2 -in.-diameter cylinders whose weights did not exceed $25 \mathrm{lb}$.

A totally automatic ball-detent release mechanism was used to release freefalling weights and specimens at specific heights. Load cells or accelerometers or both were used to measure forces or accelerations associated with the impacts. Load cells with capacities of up to $2,500,000 \mathrm{lb}$ of force were designed, 
fabricated, instrumented, and calibrated at ORNL. The output of the load ce11 during each impact was amplified, and filtered where accelerometers were used, and fed to a dual-beam cathode-ray oscilloscope. A schematic diagram of the instrumentation system is illustrated in Fig. 1. A Polaroid camera was used to photograph the trace resulting from each impact, and a typical photograph made during an impact test is show in Fig. 2.

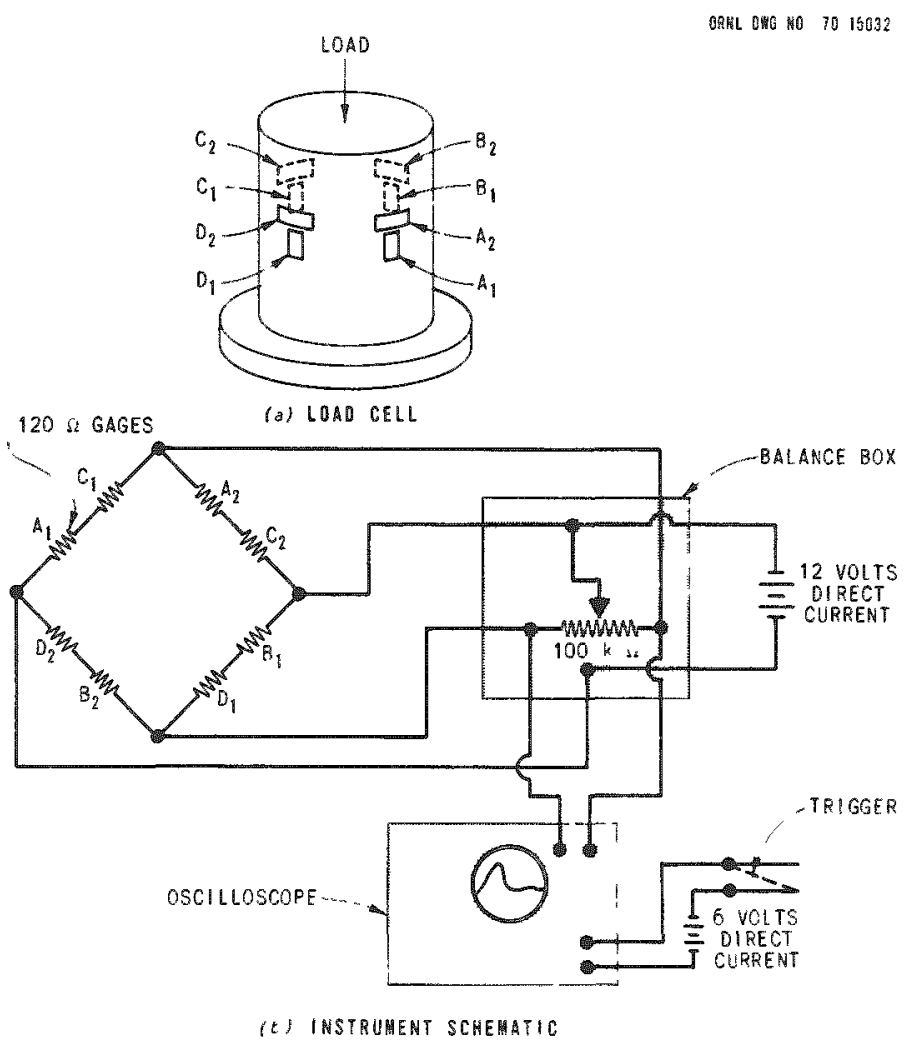

Fig. 1. Typical Load Cell and Schematic Diagram of Instrumentation Used to Measure Force-Time Relationships During the Impact Tests

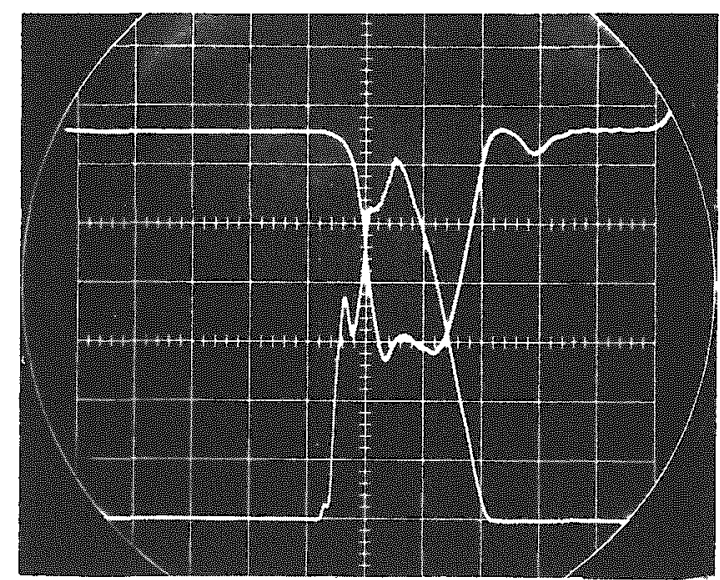

Fig. 2. Typica1 Force-Time and Acceleration-Time Photograph Recorded During An Impact Test. 
A Fortran program for cask impact data reduction (CIDR) applicable to the IBM 360 computer was used to transform the force-time data into force-deflection data. The values of force were scaled from the photographs made during the impact tests. These values were transferred to computer data cards as were data for other such test parameters as the drop height, weight of specimen or hammer dropped, initial diameter and/or length of specimen, and the final deformed length of the specimen. Force was converted to acceleration by using Newton's second $l a w$, and the impact velucity $\left(V_{0}\right)$ was computed from the wel1-known expression for the velocity of a free-falling weight.

The CIDR computer program utilizes a numerical integration technique to convert the acceleration-time data to velocity-time and deflection-time data. That is,

$$
V=V_{0}-\int_{0}^{t} a d t
$$

and

$$
x=\int_{0}^{t} V d t,
$$

where

$V=$ velocity at any time and

$\mathrm{X}=$ displacement of the model or specimen.

Since the value of the acceleration at specific points in time can be obtained from the oscilloscope readings, both of the time integrals can be evaluated by numerical integration techniques. An energy balance effected by using test data and computed values that compared the potential or kinetic energy of the system with the work done in plastically deforming the model or specimen was used as a measure of the accuracy of the data acquisition and reduction syster. Additions were made to this basic computer program to obtain data in a nore usable form and to calculate other parameters by using the laws and theories of engineering mechanics as dictated by the requirements of the individual testing programs.

\section{IMPACT TESTING OF CHEMICAL LEAD}

Analyses of lead shielded containers have generally resulted in ultraconservative designs in that most of these analyses have been based on material properties determined by static tests. However, the impact properties of many materials vary significantly from their static properties. Generally, the stress for a given strain will be higher for the higher strain rates that occur under 
impact conditions. Since lead is frequently used as the biological shielding material in many shipping containers for radioactive materials, the determination of its stress-strain properties under impact conditions is of importance.

A survey of the technical literature revealed that a considerable amount of work has been done by several investigators $8-14$ to determine the impact properties of lead. However, the published results of this work did not fill the needs of the cask designer because of the wide variation in these results, the lack of documentation of the material tested in some cases, and because the strain rates were generally out of the range of those applicable to the free-drop accident condition and the maximum strains were generally low.

Sixty-eight specimens made from chemical lead, ASTM B 29 , were impact tested by using the low-capacity system at the ORNL Drop Tower. Cylindrical specimens with nominal diameters of 1.0 and 1.25 in.; length-to-diameter ratios of $1,1.5$, and 2.0 ; and weights of $6.94,8.69$, and $10.56 \mathrm{lb}$ were dropped from heights ranging from 10 to $36 \mathrm{ft}$. Specimens before and after impact testing are shown in Fig. 3 for visual comparison. Force-time data for each impact were measured and photographically recorded with the equipment previously described. The forcetime data were reduced through the use of the CIDR computer program, which was enlarged to effect such basic calculations as area with respect to time, engineering stress, true stress, strain rate, etc., and to perform certain grouping operations to simplify evaluation of the output.
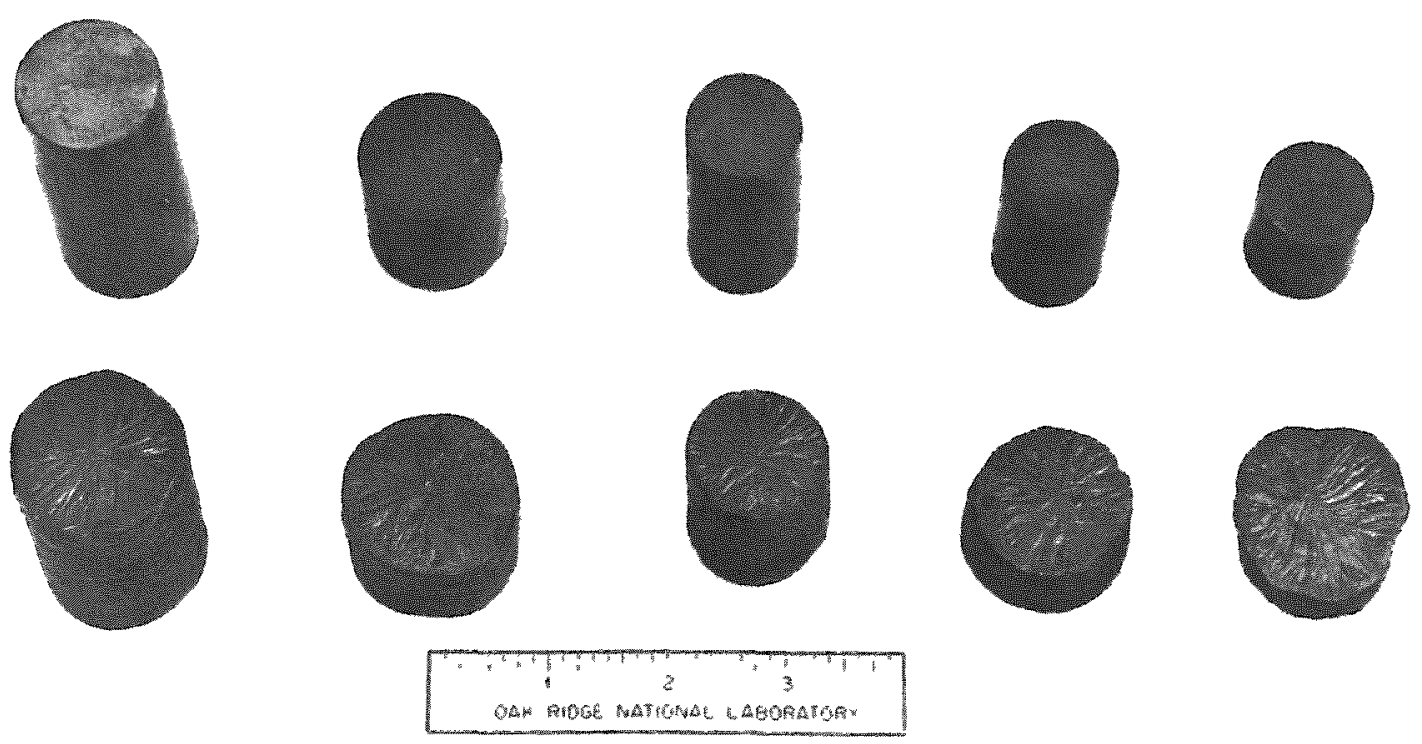

Fig. 3. Typical Lead Specimens Before and After Impact Testing. 
A least squares method was used to derive the equation

$$
\sigma_{t}=20,900-14,250 e^{-0.093} \text {, }
$$

where

$$
\begin{aligned}
\sigma_{t} & =\text { true stress and } \\
\epsilon & =\text { strain }(0.03 \leq \epsilon \leq 0.5),
\end{aligned}
$$

which describes the experimentally measured true stress for all measured strain rates with an average error of less than 267 psi. The relationship between the engineering stress and strain for a constant volume specimen is given by the expression

$$
\sigma_{e}=\frac{20,900-14250 \epsilon^{-0.203}}{1-\epsilon}
$$

where $\sigma_{e}=$ engineering or apparent stress = force/original area. Equation 4 is nonlinear and can result in awkward mathematical manipulations. When a lower level of computational accuracy can be tolerated, the following linear equation can be used.

$$
\sigma_{e}=17,470 \varepsilon+1914
$$

The effect that the strain rate had on the stress-strain relationship was investigated and found to be negligible in the test strain rate range of 100 to $800 \mathrm{in./in.-sec.} \mathrm{However,} \mathrm{when} \mathrm{the} \mathrm{dynamic} \mathrm{stress-strain} \mathrm{properties} \mathrm{are} \mathrm{compared}$ with static and quasi-static properties determined from specimens of identical material, chemical lead exhibits a significant degree of rate sensitivity.

\section{IMPACT TESTING OF TUBES-IN-PIPE ENERGY ABSORBER SPECIMENS}

Shipping casks can frequently be designed to meet the requirements of the hypothetical accident without the addition of a structure or device whose sole purpose is the storage of energy or the reduction of acceleration forces. However, the addition of such a device is sometimes necessary, and this is the case when the mass of the closure is large when compared with the total mass of the cask. This situation can be further aggravated when the contents of the cask bear directly on the closure or when significant operating pressures are encountered. Since there is a practical limit to the level of integrity that can be built into a shipping cask, particularly in the closure and seal areas, protective devices will probably receive more widespread use in future designs.

Various protective devices have been proposed and used to protect shipping casks during impact, but most of these are bulky and massive. However, one such device, the tubes-in-pipe energy absorber, is compact, efficient, and insensitive to the direction of load application. As the name implies, this device consists of several sma11-diameter tubes held in close proximity within a pipe. The tubes 
in-pipe absorber was devised primarily as a protective device for the seal and closure area of a specific shipping cask, but the unique characteristics of the device were recognized and the principle of the device was investigated to determine its applicability to the protection of shipping casks in general.

Prior to actual specimen testing, a literature search was conducted and some preliminary tests were made to determine the readily available optimum material of fabrication from the standpoint of energy absorption efficiency. Dynamic stress-strain curves presented by $\mathrm{Clark}^{15}$ indicated that 300 -series stainless steel was probably the proper material, and a series of uninstrumented impact tests was made on single-tube specimens to verify this. A second series of tests was made to determine a feasible geometric relationship between the tubes and the outer pipe of the energy absorber. The results of these preliminary tests showed that an arrangement consisting of tubing with an outside diameter of $3 / 8$ in. and a wall thickness of $0.065 \mathrm{in}$. contained within a Sch. -4.0 pipe was feasible.

Thirty tubes-in-pipe absorber specimens were impact tested, and the forcetime data for each impact were measured and photographically recorded with the equipment previously described. A specimen length of $4 \mathrm{in}$. was selected since this was the maximum length which could be accomnodated by existing test equipment. Specimens of four different geometries were impact tested with weights ranging from 126 to $498 \mathrm{lb}$ dropped from a height of $30 \mathrm{ft}$. The size of the tubes (3/8 in. with a wall thickness of $0.065 \mathrm{in.}$ ) used was the same for each specimen, but the outside diameter of the 4-in.-long schedule-40 pipe and the number of tubes contained within the pipe were varied. The pipe sizes tested were $11 / 4$, 2, 2 1/2, and $3 \mathrm{in.} \mathrm{OD;} \mathrm{and} \mathrm{the} \mathrm{tubes} \mathrm{used} \mathrm{in} \mathrm{each} \mathrm{size} \mathrm{pipe} \mathrm{were} \mathrm{9,} \mathrm{22,} \mathrm{33,} \mathrm{and}$ 51, respectively. Typical specimens before and after impact testing are shown in Fig. 4 .

The CIDR computer program was used to reduce the force-time data, but the force, energy, and deflection data developed were usable only for the particular pipe sizes tested. Scaling or modeling theory was applied to the data to develop relationships that would be valid for all reasonable pipe sizes that might be used for tubes-in-pipe energy absorbers. The force and energy data obtained from the impact tests on the 4-in.-long specimens were converted to unit force and energy or force per inch of length and energy per inch of length. Deflection was converted to a dimensionless parameter, percent deflection, by dividing its value by the actual outside diameter of the pipe. Force per linear inch was converted to a scalable quantity, defined as specific force, by dividing it by the outside diameter of the pipe. Energy per linear inch was converted to a scalable quantity, defined as specific energy, by dividing it by the number of tubes contained within the pipe. An existing graphical plotting computer program, XYPLOT, ${ }^{16}$ was used to plot curves of the specific force versus percent deflection and the 


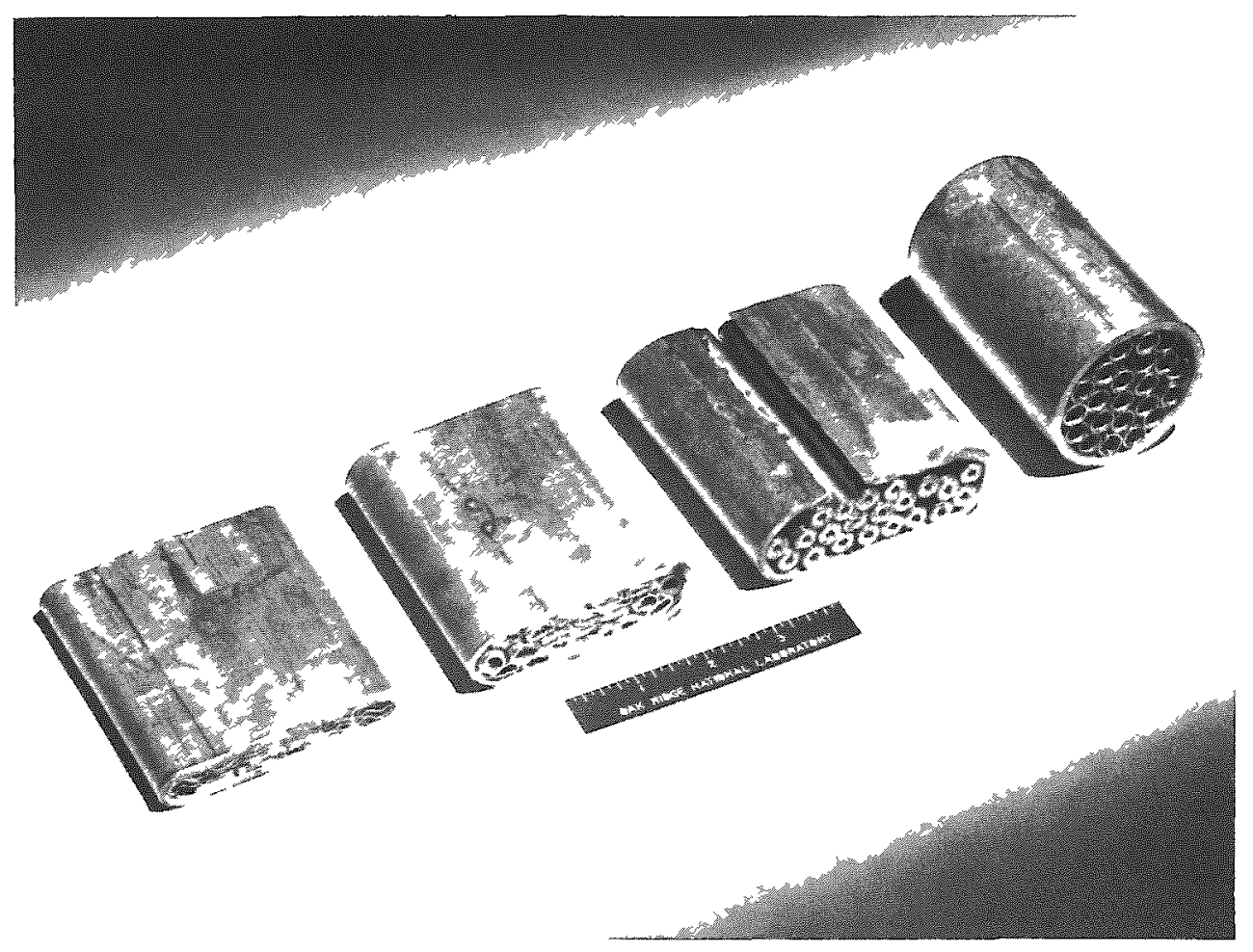

Fig. 4. Typical Tubes-in-Pipe Energy Absorber Specimens Before and After Impact Testing.

specific energy versus percent deflection. The curves shown in Fig. 5 are an example of this plotting technique.

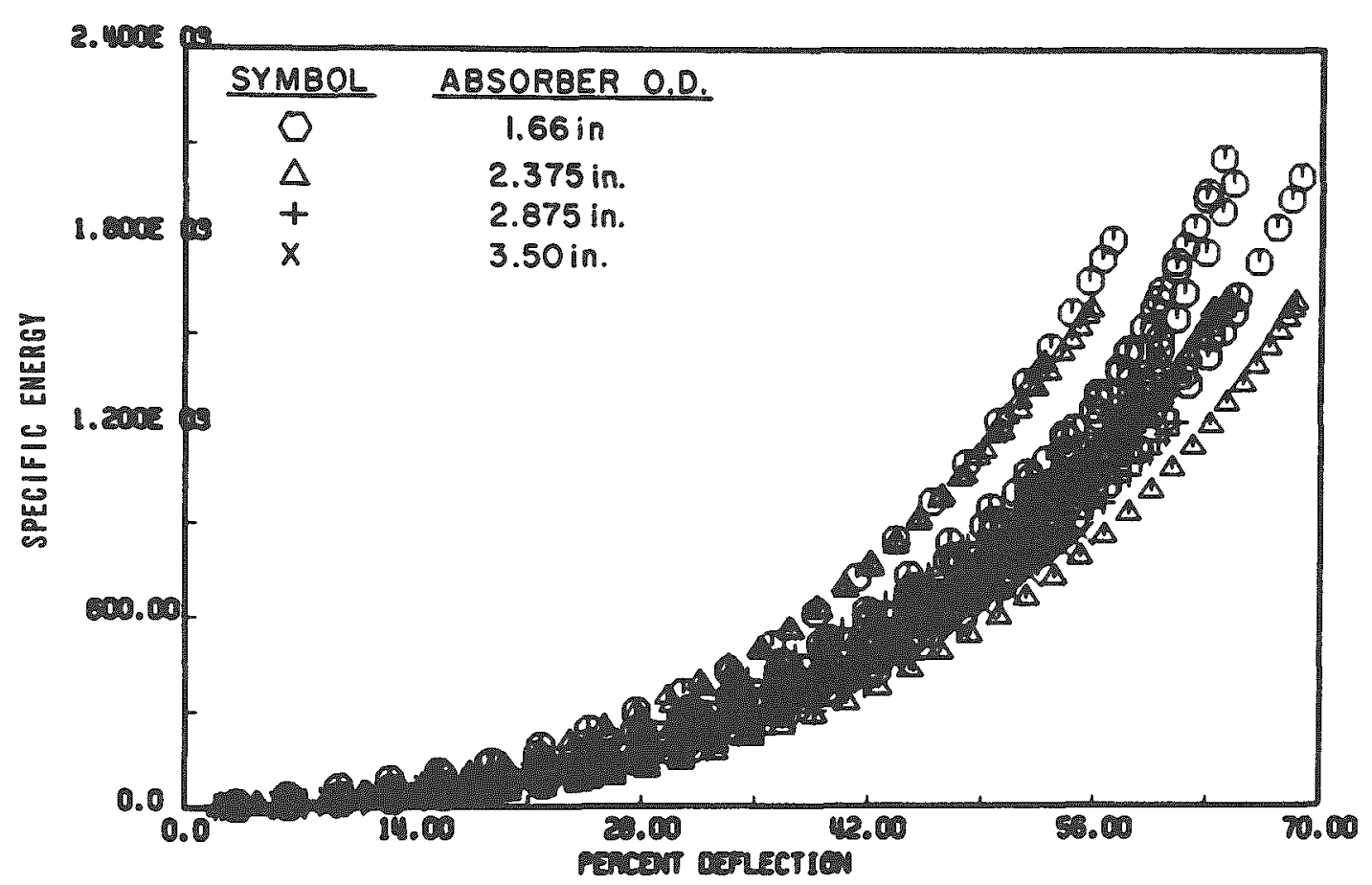

Fig. 5. XY Plot of Specific Energy Versus Percent Deflection From Impact Test Data for Tubes-in-Pipe Energy Absorber. 
Equations which adequately describe the mean of these plots were written.

These are

$$
U^{\prime}=0.121 \lambda^{2 \cdot 25}
$$

and

$$
F^{\prime}=18 \cdot 7 \lambda^{1 \cdot 73}+600
$$

where

$U^{\prime}=$ specific energy = energy per linear inch/number of tubes contained within pipe,

$\lambda=$ percent deflection $=$ deflection/outside diameter of pipe, and

$F^{8}=$ specific force $=$ force per linear inch/outside diameter of pipe.

Equations 6 and 7 may be converted to the equations

$$
U=0.121\left|\frac{X}{D} \times 100\right| 2 \cdot 25 \text { LN }
$$

and

$$
F=\left[18.7\left(\frac{\mathrm{X}}{\mathrm{D}} \times 100\right) 1 \cdot 78+600\right] \mathrm{LD}
$$

by using the definitions

and

$$
\begin{gathered}
U^{\prime}=\frac{U}{L N}, \\
3=\frac{X}{D}(100), \\
F^{\prime}=\frac{F}{L D}
\end{gathered}
$$

where

$\mathrm{U}=$ energy stored in full-size tubes-in-pipe energy absorber,

$\mathrm{I}=$ length of pipe,

$N=$ number of tubes contained within pipe,

$\mathrm{X}=$ actual deflection of full-size tubes-in-pipe energy absorber,

$\mathrm{D}=$ outside diameter of pipe, and

$F=$ force applied to ful1-size tubes-in-pipe energy absorber.

Equations 8 and 9 are valid for predictions of the energy stored and the Force applied to a tubes-in-pipe energy absorber of a particular geometry for a known or assumed deflection experienced as the result of an impact normal to the longitudinal axis of the outer pipe. When the impact is not normal to the longitudinal axis of the outer pipe of the energy absorber, the solution is more complez and is best accomplished by using computer methods. Examples of simple programs that may be used to accomplish this type of computation are given in Ref. 5 . 
Twenty-two all-steel models of the proposed LMFBR shipping cask with the geometries shown in Fig. 6 were free dropped from a height of $30 \mathrm{ft}$ in a controlled orientation so that the cask model impacted on a comer with the plane containing the corner and the center of gravity vertical. Three models were dropped in an end impact orientation. Force-time histories of the impacts were recorded with the load cel1, oscilloscope, and camera equipment described previously. Acceleration-time histories were also recorded by using the accelerometer system for three of the 6-to-1 models dropped in the corner impact orientation and for the three 6-to-1 models dropped in the end impact orientation.

ORNL DWG $71-3593$

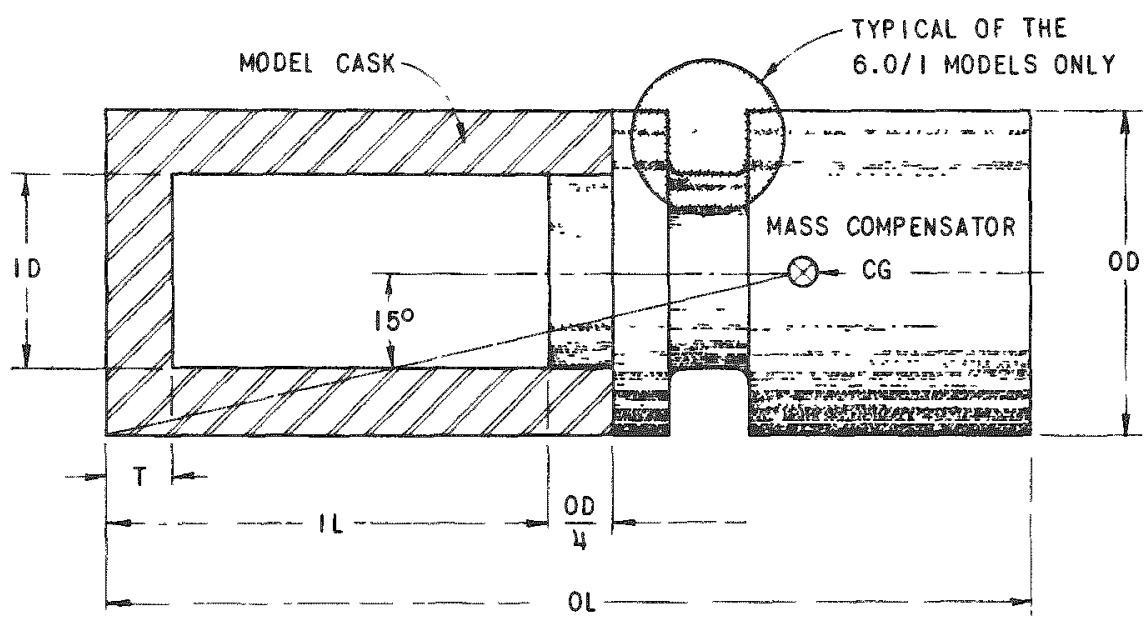

\begin{tabular}{|c|c|c|c|c|c|c|c|c|}
\hline \multirow{2}{*}{$\begin{array}{c}\text { IMPACT } \\
\text { ORIENTATION }\end{array}$} & \multirow{2}{*}{$\begin{array}{l}\text { SCALE } \\
\text { FACTOR }\end{array}$} & \multirow{2}{*}{$\begin{array}{c}\text { MEIGHT } \\
\text { (LB) }\end{array}$} & \multirow{2}{*}{$\begin{array}{l}\text { MO. OF } \\
\text { TESTS }\end{array}$} & \multicolumn{5}{|c|}{ DINENSIONS IN INCHES } \\
\hline & & & & 00 & 10 & OL & IL & $\mathrm{T}$ \\
\hline CORNER & $18.75 / 1$ & 37.9 & $\theta$ & 4.00 & 2.83 & 13.24 & 6.49 & 0.85 \\
\hline CORNER & $9.375 / 1$ & 295 & 5 & 8.00 & 5.65 & 26.50 & 13.00 & 1.71 \\
\hline CORNER & $8.34 / 1$ & 425 & 1 & 9.00 & 4.75 & $32^{\mathrm{a}}$ & $32^{a}$ & 2.0 \\
\hline CORNER & $6.0 / 1$ & 1195 & 7 & 12.5 & 8.83 & 41.67 & 14.67 & 2.67 \\
\hline END & $6.0 / 1$ & 1195 & 3 & 12.5 & 8.83 & 41.67 & 14.67 & 2.67 \\
\hline
\end{tabular}

THE 8.34/I MODEL WAS A CYLINDER WITH ONE CLOSED EMD, ONE OPEN END, AND NO MASS COMPENSATOR.

Fig. 6. Geometry of Steel Cask Models Impact Tested.

The CIDR computer program was used in conjunction with model theory to reduce the impact test data to scalable relationships, and the XYPLOT computer program $^{16}$ was used to plot these relationships for the corner impacts, as illum strated in Fig. 7. The spread of the data is significant in that it is approximate $1 \mathrm{y}+20 \%$ in the area where all the energy possessed by a large cask would be absorbed. However, these data are still the most valid tool the designer has at 


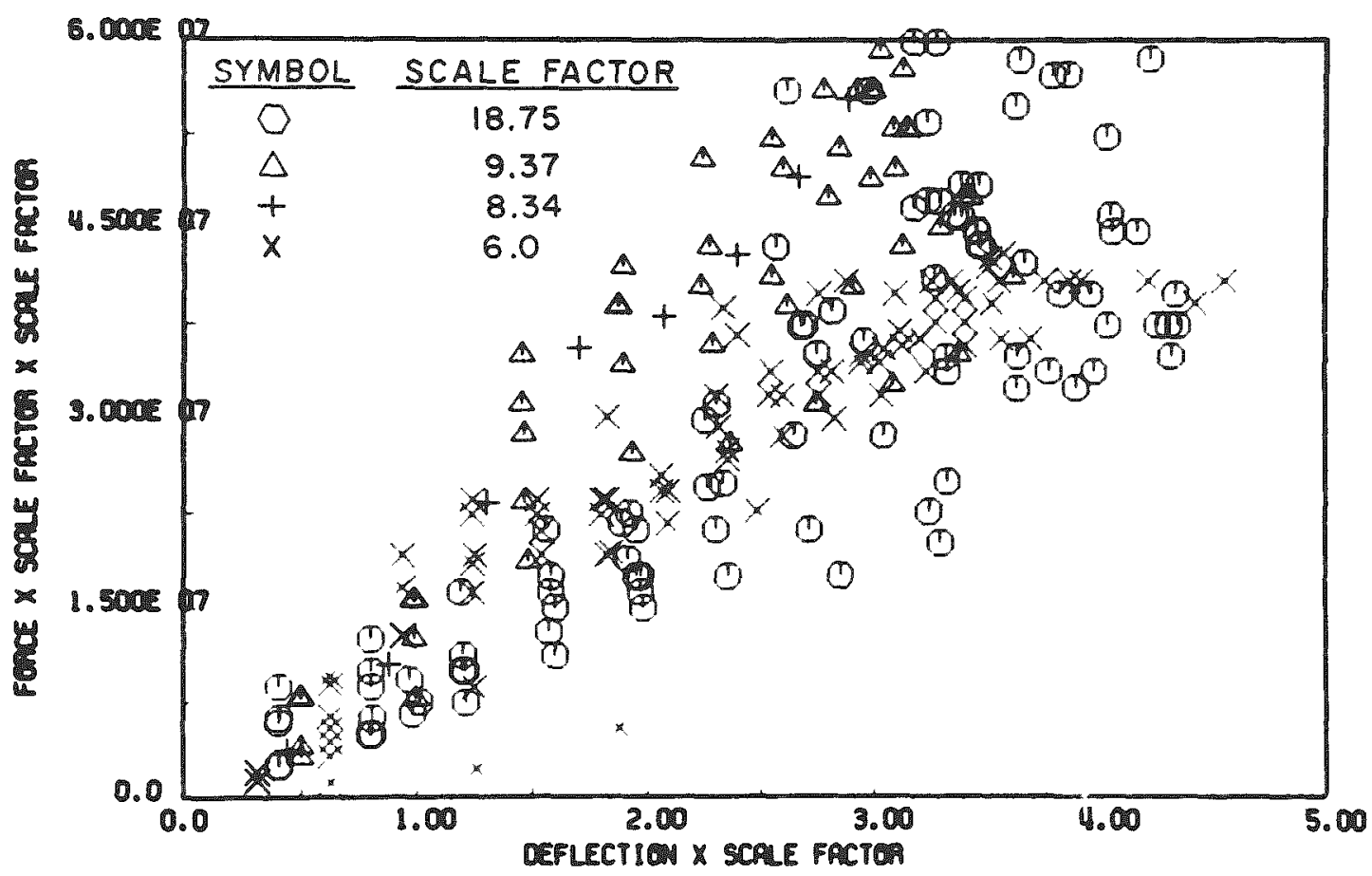

Fig. 7. XY Plot of Force Versus Deflection for Steel Casks in CornerOriented Impacts.

his disposal for predicting the behavior of steel casks with geometries similar to those of the test models.

Observation of the plot shown in Fig. 7 indicates that a reasonable approximation of the data would be a straight line through the origin and the point $\mathrm{F}=53.0 \times 10^{6} \mathrm{Ib}, \hat{\Delta}=3.6 \mathrm{in}$. An energy balance obtained by using the expression

$$
-U=-W h=W=f \int F d \triangle \simeq \frac{1}{2} f F \Delta_{\max } \simeq \frac{\mathrm{FF}^{2}}{2 \mathrm{~m}}
$$

where

$$
\begin{aligned}
& \mathrm{U}=\text { energy stored in cask, } \\
& \mathrm{W}=\text { weight of cask, } \\
& \mathrm{h}=\text { height or elevation from which cask was dropped }=360 \mathrm{in} . \\
& \mathrm{W}=\text { work required to decelerate cask, } \\
& \mathrm{f}=\text { scale factor }=\mathrm{W} / 248,000, \\
& \mathrm{~F}=\text { maximum applied force, } \\
& \Delta=\text { maximum deformation, and } \\
& \mathrm{m}=\text { slope of approximate curve }=\mathrm{F} / \mathrm{i}=\left(53 \times 10^{3}\right) / 3.6=14.7 \times 10^{6} ;
\end{aligned}
$$

may be used to estimate the forces and deflections experienced by casks with configurations similar to those of the models tested.

The cask models that were dropped in an end impact orientation failed to achieve a perfect end impact, and the test data obtained are not valid for a true end impact. A calculation based on the dimensions of the deformed area 
indicated that the axis of the model was inclined approximate $1 \mathrm{y} 3^{\circ}$. A basis for estimating the maximum forces involved in an end impact was formulated by computing the average force per unit area based on the measured final deformed area and the acceleration at the time the computer solution indicated that the velocity was zero. The resulting average force per unit area experienced by the three models dropped in the end impact orientation was $98,400 \mathrm{lb} / \mathrm{in} .{ }^{2}$ A similar calculation made for the models dropped in the corner impact orientation revealed that the average force per unit area for the 22 models was $90,530 \mathrm{lb} / \mathrm{in.}$. Until better data are available, an estimate of the maximum force applied in a perfect end impact can be obtained by multiplying values such as these by the cross-sectional area of the cask. For the proposed LMFBR shipping cask with a scale factor of 1 , the maximum acceleration computed in this manner would be $1781 \mathrm{G}^{8} \mathrm{~s}$.

\section{CONCLUSIONS}

Impact testing, particularly when conducted in conjunction with adequate instrumentation, computer data reduction techniques, and modeling theory, has been an invaluable tool. In providing the answers to some of the complex questions associated with the free-drop portions of the regulations governing the design and performance of shipping casks. The empirical equations developed to describe the dynamic stress-strain properties of lead can be used to calculate the deformation of the lead shielding in a cask and the energy stored in the lead with accuracy levels superior to those previously possible. Tubes-in-pipe energy absorbers may be installed on ful1-size casks, and the energy stored and force applied to the absorber for a known or assumed deflection experienced as the result of an impact nomal to the longitudinal axis of the outer pipe can be calculated within the bounds of engineering accuracy by using the relationships developed in conjunction with the impact testing program. The response of steel casks to the impact resulting from the 30-ft free drop can be deternined by using modeling theory and the model test data.

It is anticipated that impact testing of models and casl components directed toward answering specific questions and developing empirical relationships will be continued during the next several years. A large portion of this testing will probably be directed toward denonstrating the adequacy of primary containment and the response of various neutron shielding schemes. 
1. A. E. Spaller, "Structural Analysis of Shipping Casks, Vo1. 2: Resistance to Puncture," USAEC Report ORNL TM-1312, Vol. 2, Dak Ridge National Laboratory, September 1966.

2. H. A. Nelms, "Structural Analysis of Shipping Casks, Vo1. 3: Effects of Jacket Physical Properties and Curvature on Puncture Resistance," USAEC Report ORNL TM-1312, Vol. 3, Oak Ridge National Laboratory, June 1968.

3. J. H. Evans, H. A. NeIns, and W. C. Stoddart, "Experimental and Analytical Developments at Oak Ridge National Laboratory for Demonstrating Shipping Cask Compliance With Federal Regulations," Proceedings of the Second International Symposium on Packaging and Transportation of Radioactive Materials, USAEC Report CONF 681001, October 1968.

4. J. H. Evans, "Structural Analysis of Shipping Casks, Vo1. 8: Experimental Study of the Stress-Strain Properties of Lead Under Specified Impact Conditions," USAEC Report ORNL TM-1312, Vo1. 8, Oak Ridge National Laboratory, August 1970 .

5. J. H. Evans, "Structural Analysis of Shipping Casks, Vo1. 10: An Experimenta1 and Analytical Evaluation of the Tubes-in-Pipe Energy Absorber, "USAEC Report ORNL TM-1312, Vol. 10, Oak Ridge National Laboratory, 1971.

6. J. H. Evans, "Structural Analysis of Shipping Casks, Vol. 11: An Experimental and Analytical Evaluation of the Impact Properties of Mild-Steel Cask Mode1s," USAEC Report ORNL TM-1312, Vol. 11, Oak Ridge National Laboratory (to be published).

7. F. C. Davis, "Structural Analysis of Shipping Casks, Vol. 9: Energy Absorption Capabilities of Plastically Deformed Struts Under Specified Impact Loading Conditions," USAEC Report ORNL TM-1312, VoI. 9, Oak Ridge Nationa1 Laboratory, February 1971.

8. J. H. Vincent, "Experiments on Impact," Proceedings of the Cambridge PhiloSophical Society, Vol. X, p. 332, 1898-1900.

9. D. Tabor, pp. 120-138 in The Hardness of Metals, Oxford University Press, London, 1951.

10. A. W. Crook, "A Study of Some Impacts Between Metal Bodies By a Piezo Electrical Method," Proceedings of the Royal Society, Vo1. A212, p. 377, 1952.

11. C. H. Mok and J. Duffy, "The Behavior of Metals at Elevated Temperatures Under Impact With a Bouncing Ball, "International Journal of Mechanical Science, Vol. 6, pp. 161-175, 1963.

12. C. H. Mok and J. Duffy, "The Dynamic Stress-Strain Relation of Metals as Determined From Impact Tests with a Hard Bal1," International Journal of Mechanical Science, Vol. 7, pp. 355-371, 1964.

13. J. M. Gondusky and J. Duffy, "The Dynamic Stress-Strain Relationship of Lead and Its Dependence on Grain Structure," Division of Engineering Technical Report 53, Brown University, Providence, Rhode Island, May 1967.

14. R. A. C. Slater, W. Johnson, and S. Y. Aku, "Experiments in the Fast Upsetting of Short Pure Lead Cylinders and a Tentative Analysis, "International Journal of Mechanical Science, Vol. 10, pp. 169-186, 1968.

15. D. S. Clark, "The Influence of Impact Velocity on the Tensile Characteristics of Some Aircraft Metals and Alloys," Vational Advisory Committee for Aeronautics Technical Note No. 868, October 1942.

16. M. Tobias and L. Jung, "XYPT.OT, An Elementary Graphical Preparation Routine for the CRT Plotters," USAEC Report ORNL TM-2867, Oak Ridge National Laboratory, January 1970 . 
X ADMINISTRATION OF THE RADIOACIIVE MATERIALS TRANSFORTATION

W. A. Pryor

ABSTRACM

\begin{abstract}
Transportation safety administration within the Oak Ridge Operations Office is concerned with the implementation of domestic and international regulations. The progress and versatility in shipping container design and utilization is discussed. An accunt of the planning and experience of shipping irradiated fuel and cortrol rods from a decomissioned reactor is presented.
\end{abstract}

The Cak Kidge operations Office (ORC) is a major silld office of the U.S. Atomic Energy Commission. Figure I shows the locations of the principal installations reporting to Oak Ridge, which have significant shipments of radioactive material. There are three gasecus diffusion plants producing enriched uranium located at Oak Ridge, Tennessee, and Paducah, Kentucky, which are operated by Union Caritide Corporation and at Portsmouth, Onic, which is operated by Goodyear Atomic Corporation. The Feed Viaterials Production Plant which produces fuel elements for the Hanford and Savannah River production reactors is Iocated at Femald, Onio, and is operated by the National Lead Company of Ohio. Also tied to this fuel element production chain is the Extrusion Plant located at Ashtabula, Ohio. The other major installations located in Oaz Ridge include the $\mathrm{Y}-\mathrm{In}$ Plant, which is a weapons production facility, and the Oak Hiige National Laboratory, which is a major radioisotope producer, a reactor research ano development facility and holds the national stockpile of U-233. These installations are operated by Union Carbide Corporation. Also under ORO are the AEC operated New Brunswicl Jaboratory in New Brunswick, Niew Jersey, and the Puerto Rico Nuciear Center in Rio Piedras, Puerto Rico, which is operated by the University of Puerto Rico. The second major installation in Puerto Rico was the Boiling Nuclear Superheater Reactor (BONUS), a joint venture of the AIC and the Puerto Rico Water Resources Authority, which was shut down in 1966. ORO is concemed with the administration of radioactive materials transport from these instalations.

In the few years that we have had our upgraned radioactive materials transport regulations, considerable change has cccurred in transport safety administration. Initially, the orincipal concern was the "tooling up" period 
Where new containers had to be designed, tested against the accident test series, approved under A.EM-0529 anci permitted by the Department of Transportation. After those first containers were approved and permitted, most of the difficulty and confusion had been eliminated.

From September 1967 through April 1971, the prime contractors under Oak Ridge Operations have compiled en impressive number of approved shipping containers. Table l summarizes the Oak Ridge experience:

Table 1. Summary of Containers Approved by ORO

\begin{tabular}{|c|c|c|c|c|c|c|c|c|}
\hline \multirow{3}{*}{$\begin{array}{l}\text { Type of } \\
\text { Radioactive } \\
\text { Naterial }\end{array}$} & \multirow{3}{*}{$\begin{array}{l}\text { FY }{ }^{168} \\
\text { Initial }\end{array}$} & \multicolumn{7}{|c|}{ No. AECM-0529 Approvals } \\
\hline & & & FEI 169 & & FY 170 & & FI 171 & $4 / 71$ \\
\hline & & Ret. & Initial & Rev. & Initial & Rev. & Inttial & Rev. \\
\hline $\begin{array}{l}\text { Fissile - } \\
\text { unshielded }\end{array}$ & 5 & - & 6 & 6 & 3 & $I$ & 2 & 4 \\
\hline $\begin{array}{l}\text { Fissile - } \\
\text { shielded }\end{array}$ & 3 & - & 4 & 3 & 5 & - & - & - \\
\hline $\begin{array}{l}\text { Non-Fissile - } \\
\text { shielded }\end{array}$ & 8 & - & 4 & 4 & 2 & - & 1 & 2 \\
\hline Subtotals & 16 & - & 14 & 13 & 70 & 1 & 3 & 6 \\
\hline Totals & Initian & $I-43$ & Revisi & ons - & 20 & & & \\
\hline
\end{tabular}

We were also concerned with the upgrading of old containers and/or the building of new containers in order to meet the requirements of the then new regulations. Gradually, we are broadening the approvals so that our shipping containers are now quite versatile. Four overpacks and shipping containers approved by ORO under AECM-0529 will illustrate some of this versatility. Table 2 sumaries the initially approved usage and the subsequent applications:

Our progress in improved transportation safety can also be measured by the accident experience of the industry. For Type B containers, the number of accidents overall in a transportation environment has been sma11. A "before" and an "after" implementation of our current regulations will demonstrate how lar we have moved. Figure 3 shows a "before." This is an empty birdcage, which was received prior to 1968 at the Portsmouth Gaseous Diffusion Plant to be loaded with a 5-inch diameter cylinder of $\mathrm{JF}_{6}$. The cylinder was held under pressure between the two cups. The birdcage was junked.

Figure 4 shows the "after" sequence. It involves an Oak Ridge Gaseous Diffusion Plant tyce protective package, containing an empty 30-inch diameter UF' cylinder during an actual fire at a Knorvilie, Tennessee, motor carrier 
Table 2. ORO Broad Usage Shipping Containers

\begin{tabular}{|c|c|c|c|}
\hline $\begin{array}{l}\text { DOT SP } \\
\text { No. }\end{array}$ & $\begin{array}{l}\text { Design } \\
\text { Instal. }\end{array}$ & $\begin{array}{l}\text { Part A - Over } \\
\text { Initial } \\
\text { Usage }\end{array}$ & $\begin{array}{l}\text { rpacks } \\
\text { Subsequent Applications }\end{array}$ \\
\hline $4909^{a}$ & ORGDP & $\begin{array}{l}\text { Overpack for } \\
\text { family of } 5 \text {-in. } \\
\text { 8-in., } 22-\text { in., } \\
\text { and } 30 \text {-in. } \\
\text { cylinders of UH6 }\end{array}$ & $\begin{array}{l}\text { 1. } 50,000 \text { Ci of Tritium and all } \\
\text { Noble gases. } \\
\text { 2. Highly enriched U-metal scrap } \\
\text { 3. Scrap Fuel Element } \\
\text { 4. Unirradiated BonUS fuel Elements } \\
\text { 5. Slightly enriched U-metal for } \\
\text { critical experiments } \\
\text { 6. UF paraffin blocks used in } \\
\text { critical experiments }\end{array}$ \\
\hline $5752^{\mathrm{a}}$ & ORNI & $\begin{array}{l}\text { Overpack for } \\
\text { Sugarman Radio- } \\
\text { isotope Casi } \\
\text { Part B - Shipping }\end{array}$ & $\begin{array}{l}\text { 1. New Sugarman Cask } \\
\text { 2. Gamma Field Irradiator - } 137 \mathrm{Cs} \\
\text { 3. Thermoelectric Generator }-90 \mathrm{Sr} \\
\text { 4. NBI Hot Sample Cask } \\
\text { 5. FRIC Irradiator }-{ }^{37} \mathrm{Cs} \\
\text { Containers }\end{array}$ \\
\hline 5765 & $\begin{array}{l}\text { ORNL } \\
Y-12 \\
\text { ORGDP }\end{array}$ & $\begin{array}{l}\text { Vermiculite con- } \\
\text { tainer for highly } \\
\text { enriched uranium } \\
\text { metal and com- } \\
\text { pounds-unmoderated }\end{array}$ & $\begin{array}{l}\text { 1. Unmoderated } \mathrm{Fu} \\
\text { 2. Unmoderated } 233_{\mathrm{U}} \\
\text { 3. Uranium Moderated to } \mathrm{H} / 23 \mathrm{~S}_{\mathrm{U}} \mathrm{U}-\mathrm{IS} \\
\text { 4. U up to } 10 \% 235_{\mathrm{U}} \text { (proposed) } \\
\text { a }\end{array}$ \\
\hline 5795 & ORVL & $\begin{array}{l}\text { Foamglas container } \\
\text { for } 233_{U} \text { solution }\end{array}$ & $\begin{array}{l}\text { 1. Unmoderated Fu, } 235 \mathrm{U} \text { and } \\
233_{\mathrm{U}} \\
\text { 2. Moderated Pu and } 235_{\mathrm{U}}\end{array}$ \\
\hline
\end{tabular}

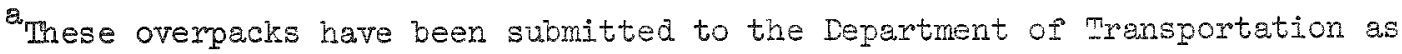
specification containers.

bigure 2 shows the INBL Hot Sample Cask, which was specially designed by ORII. in a Sugermain type overpack. 2 
terminal in March 1969. There were two protective packages in the truck. This incident was not highly publicized with the photograph being printed on Page 5 of the rewstaper. The $\$ 20,000$ statue had more descriptive words than the protective packages.

Figure; slows the more damaged protective package and its undamaged cylinder. Note the burned gasket. This one was cleaned and regasketed prior to the shipment. The other required only superficial cleaning and was shipped out immediately with a filled cylinder.

One of the most interesting situations involving transportation safety was the movement of irradiated elements and control rods from a reactor, which was being decommissioned. The basic problem was to ship from the Bollus Reactor at Rincon, Puerto Rico, 64 boiler $(2.4 \% 235 \mathrm{U})$ elements, 36 superheater $(3.25 \%$ $235 \mathrm{U}$ ) elements, 148 shim rods and 10 control rods, to the U.S. The fuel elements were to be shipped to Juclear Fuel Services at West Valley, New York, for recovery, and the control rods were to be shipped to ORNL for burial. Figure 7 indicates part of the rather cumplicated and involved logistics. At least two modes of transport would be required to make the move. In addition, the fuel and control rod removal wovld intimately affect the overall schedule for deconmissioning. The Laboratory and University Division, ORO, coordinated the entire operation. Staff assistance was provided by the ORO Safety and Mnvironmental Control and the Supply Divisions, while engineering support was provided by the ORGDP Wngineering Division.

The overall problem was divided into five basic tasks:

1. Cask Selection - criteria included:

a. ability to be approved under AECM-0529

b. economics

c. Logistics

2. Preparation of Cask and Equipment - criteria inciuded:

g. Engineering Design

b. Procurement

c. Fabrication of fuel baskets, control rod basket, cask modification, tools and handling equipment.

3. Transportation Arrangements

Axrangements with commercial carriers

4. Documentation

a. Safety Anelysis

b. AFCM-05e9 Review and Certirication

c. DOT Special Permit 
5. Shipment Execution - audit for:

a. Safety

b. Transportation Management

c. Accountability

Tasks 2 through 4 were completed concurrently.

The two casks which were considerea were the HITPF Six-Element Irradiated Fuel Casks (Hallam) and the ATCOR Vandenberg Cask. Table 3 shows some of their characteristics.

Table 3. Cask Characteristics

\begin{tabular}{|c|c|c|}
\hline & ENDPF & ATCOR-VIPDB \\
\hline Shield Thickness & $\begin{array}{l}\text { Lead EquivaIent - } \\
8-1 / 2 \text { in. }\end{array}$ & $7-3 / 4$ in. Lead \\
\hline Cavity & $\begin{array}{l}18-1 / 2 \text { in. dia. } x \\
197-1 / 2 \text { in. Iong }\end{array}$ & $\begin{array}{l}36 \text { in. dia. } x \\
117 \text { in. Iong }\end{array}$ \\
\hline Tare Weight & $71,000 \mathrm{lb}$ & $57,000 \mathrm{Ib}$ \\
\hline Loading & Top & Bottom \\
\hline Authorized Transport & Rail & $\begin{array}{l}\text { Motor Freight } \\
\text { and Rail }\end{array}$ \\
\hline
\end{tabular}

"The ATCOR Cask with its trailer could be used in the "drive on - drive off" service available by sea to Fuerto Rico.

During the cask selection period, the ATCOR Cask was physically located at the Dresden, Illinois, Reactor. A team from ORO visited the site to see the cask and to see how the Dresden crew handed the cask. We learned several very important lessons that alleviated problems later at the BONUS. Figure 7 shows such a lesson where the cask lifiting yoke would not fit on the crane hook. While this could have been a minor problem at Dresden, it would have been a major problem at BONUS. Specific checks were mace to asssure that the yoke would fit on the BONJUS crane hooks. In this particular case, the opening in the yoke was enlarged; however, this necessitated verification that the yoke had not been weakened.

From the standpoint of both time and economics, it became fairly obvious that the ATCOR Cask was the prime candidate for the job. The Hallam Cask would require adaitional modifications and significantly more trips to complete the move. Thus, the ATCOR Cask was formally selected.

The Chicago Operations Office had a current contract with ATCOR for use of the cask, and the contract was extended to ORO to cover the BONUS move. The sarety analysis was also under review and was expected shortly. Since 
there was some question in regard to the structural integrity of cask under accident conditions, ORO sent a team of structural engineers to work with the Chicago Operations office, Battelle Memorial Institute and Franklin Institute, and ATCOR, Inc., in resolving any questions.

The Lngineering Division of ORGDP provided technical support to design, evaluate, and fabricate both a fuel basket and a control rod basket. 3.4 As a part of the evaluation, a critical experiment was conducted at the $Y-12$ Critical Experiments Laboratory with unirradiated fuel. The fuel elements were spares which were shipped from BONUS before the irradiated fuel was shipped. Figure 8 shows the fuel elements at the Laboratory. Figure 9 shows the cask covered with a sunshade on its heavy duty trailer prior to leaving oak Ridge. Auxiliary equipment included the lifting yoke, the turning fixture, and a spreader base. The spreader base was used to spread the weight of the cask over a larger area of the reactor pool floor. Figure 10 shows the fuel basket sitting in the storage pool at the BONJS site. The grid in the basket containec BORAI, a neutron absorber, so that the actual shipment was mace as Fissile Class $I$.

The control rods were to be buried at ORIL in a disposable basket. Dry runs were conducted to minimize problems with both the fuel basket and the control rod basket. Figure 11 shows the empty cask and the control rod besket at the burial site during a dry run. The basket was lowered by a crane into a deep hole and covered. The robot was brought to the site and included in the dry run. This unit is operated from a control panel, which in this case was approximately 1,000 feet away. Note the two television cameras. In the actual burial operation, its services were not required, although it was on standby. This unit, which is operated by the Y-12 Plant, is part of the emergency equipment maintained by ORC.

Table 4 lists the shipments from Puerto Rico and the material shipped.

During the period of the move, there were several "roadblocks" which affected the schedule. A threatened, and subsequently an actual, longshoremen's strike required obtaining clearence for temporary storage of the loaded cask at the U.尺. IJaval Base in San Juar. The actual strike lasted about 2-1/2 months which accounted for most of the delays involved. A breakdown at sea rem quired the ship to be towed in once. This necessitated a changeover to a second steamship line.

The rove was made with no significant radiation and nucleax safety problems. It logged over 30,000 miles and transportation costs were about $\$ 38,000$. 
Table 4. Borvs shipments

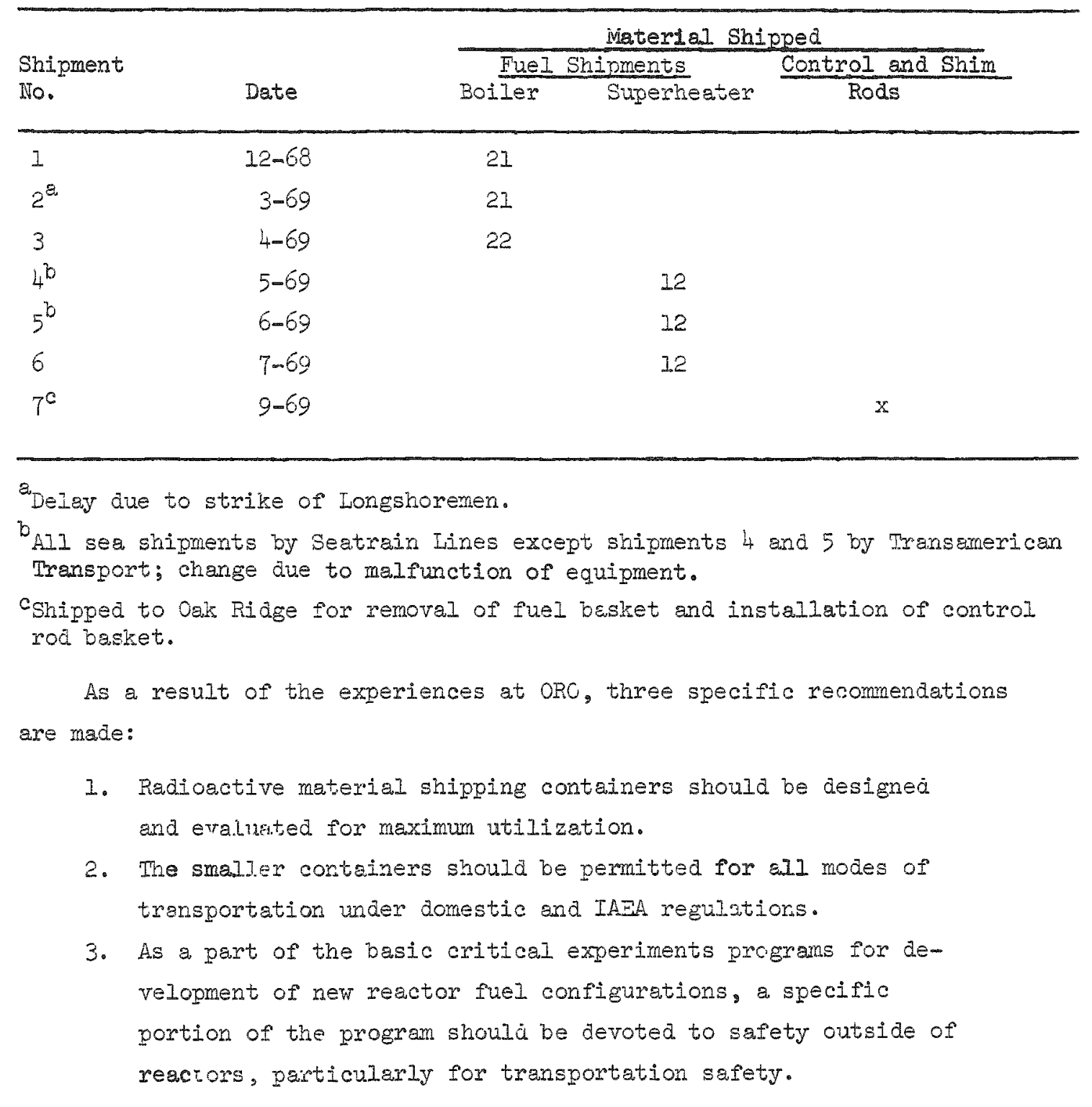

\section{ACKNOWLEDGENEIIS}

The author gratefully acknowledges the helpful assistance of Messrs. J. A. Lamb and L. G. Blalock, nembers of the Transportation Branch, ORO Supply Division. 
I. A. W. Grelia, Accident Experiences in the USA Involvins Irue B Paciraging, Interotional Aronic Jnergy Agency "Eeminar on lest Requirements Sor Packagine for use Transport of Radioacive Materials," Vienne, Austria, IAEA/Edf-147/19 (February *, 1271).

2. J. H. Ivans, Analysis of the New Brunswicr Laboratory Sample Cask, ORVL-Th-3298 (Marci 1971)

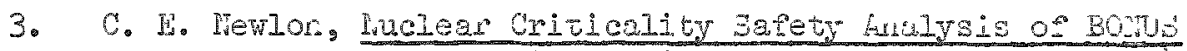
Irradiated Fuel Assemblies in ATCOR Sniopine Cask, $r-1-3045$, (October 1, 1968).

4. C. J. Jewlon and J. C. Beiley, Jupolemental pad:ation anel1 dos 100-Curie Cobalt shipmen: $K_{-11}-37$ (May 23, 1969). 


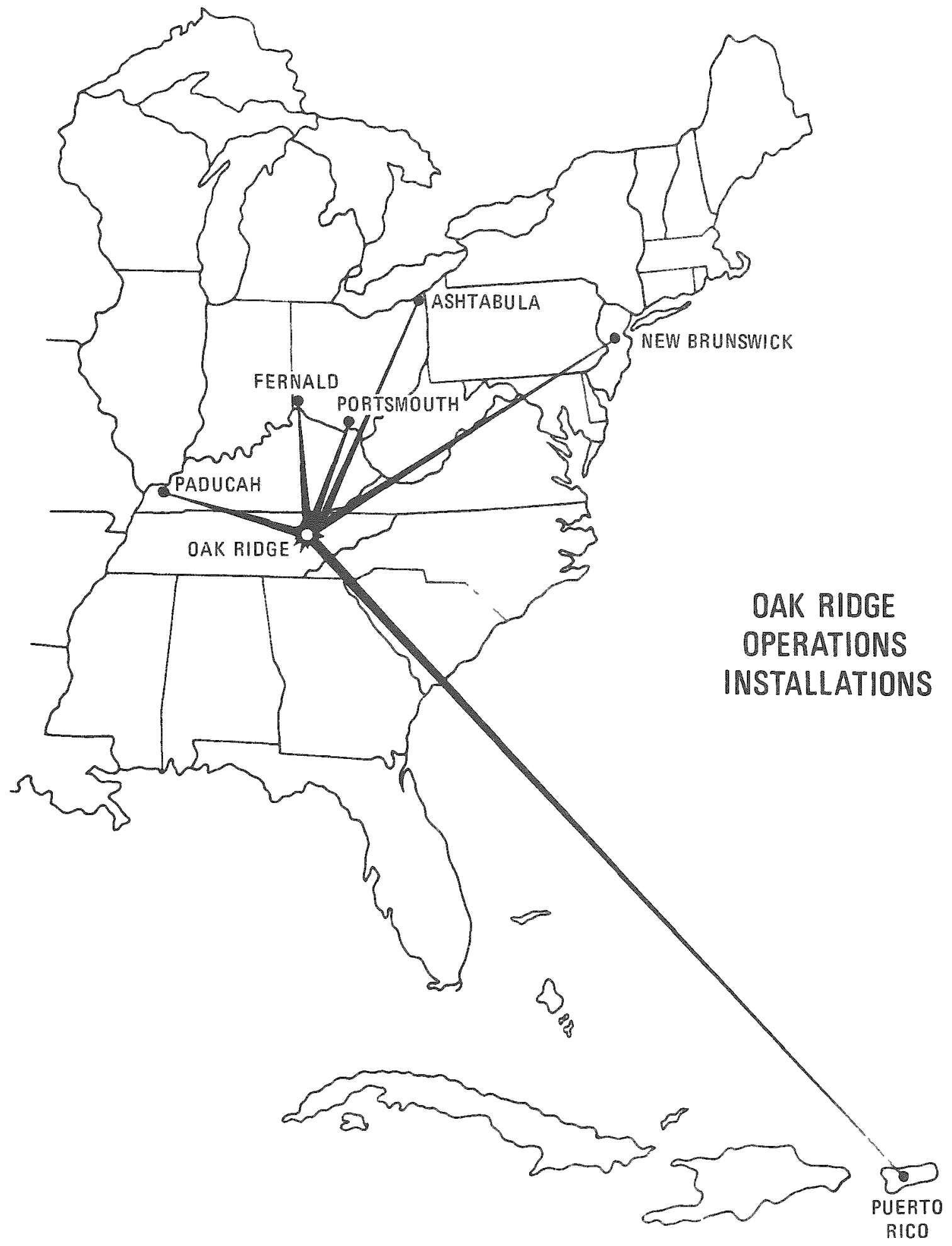

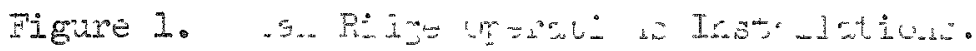




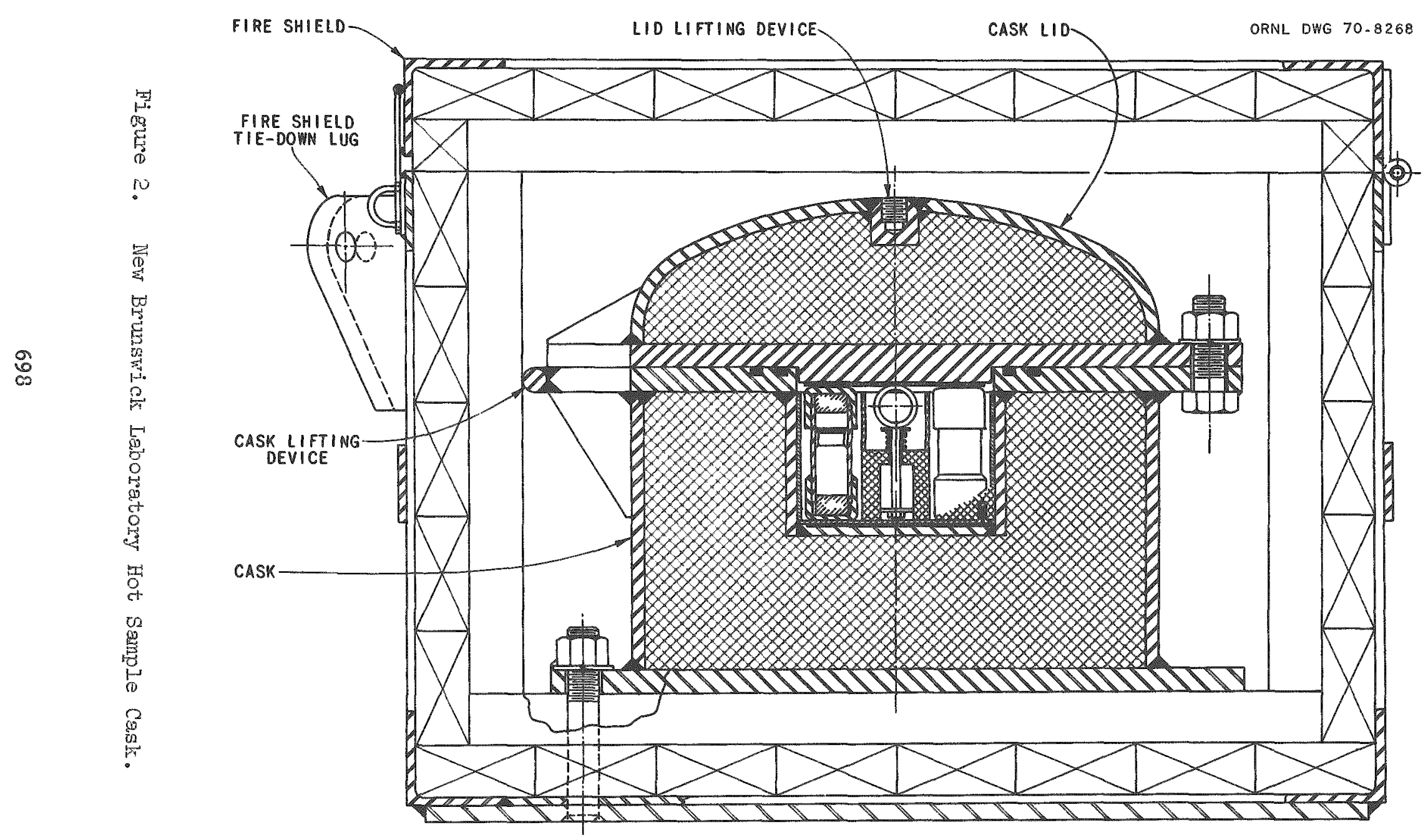




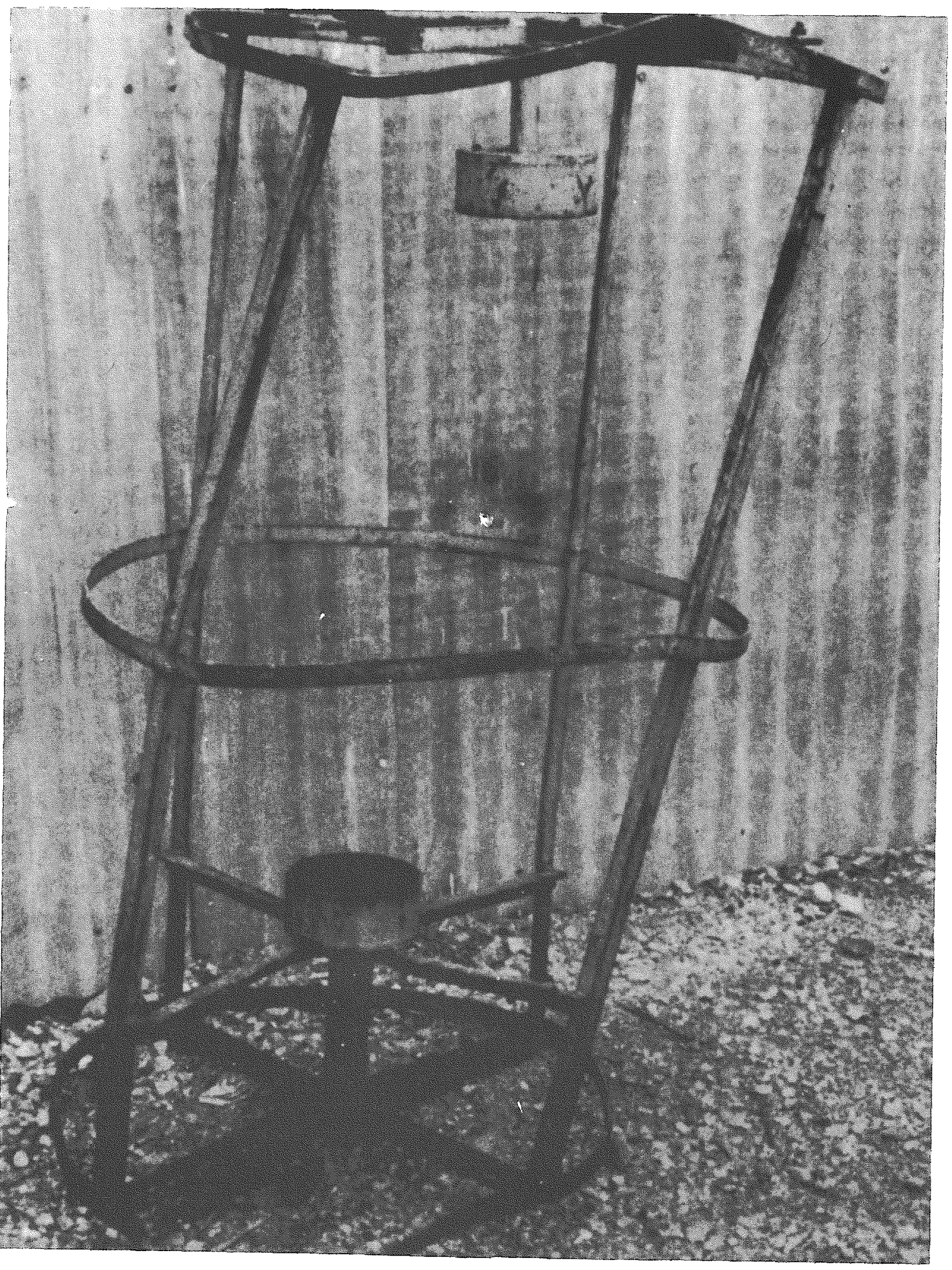

Figure 3. Old Style Birdcage - Damaged 


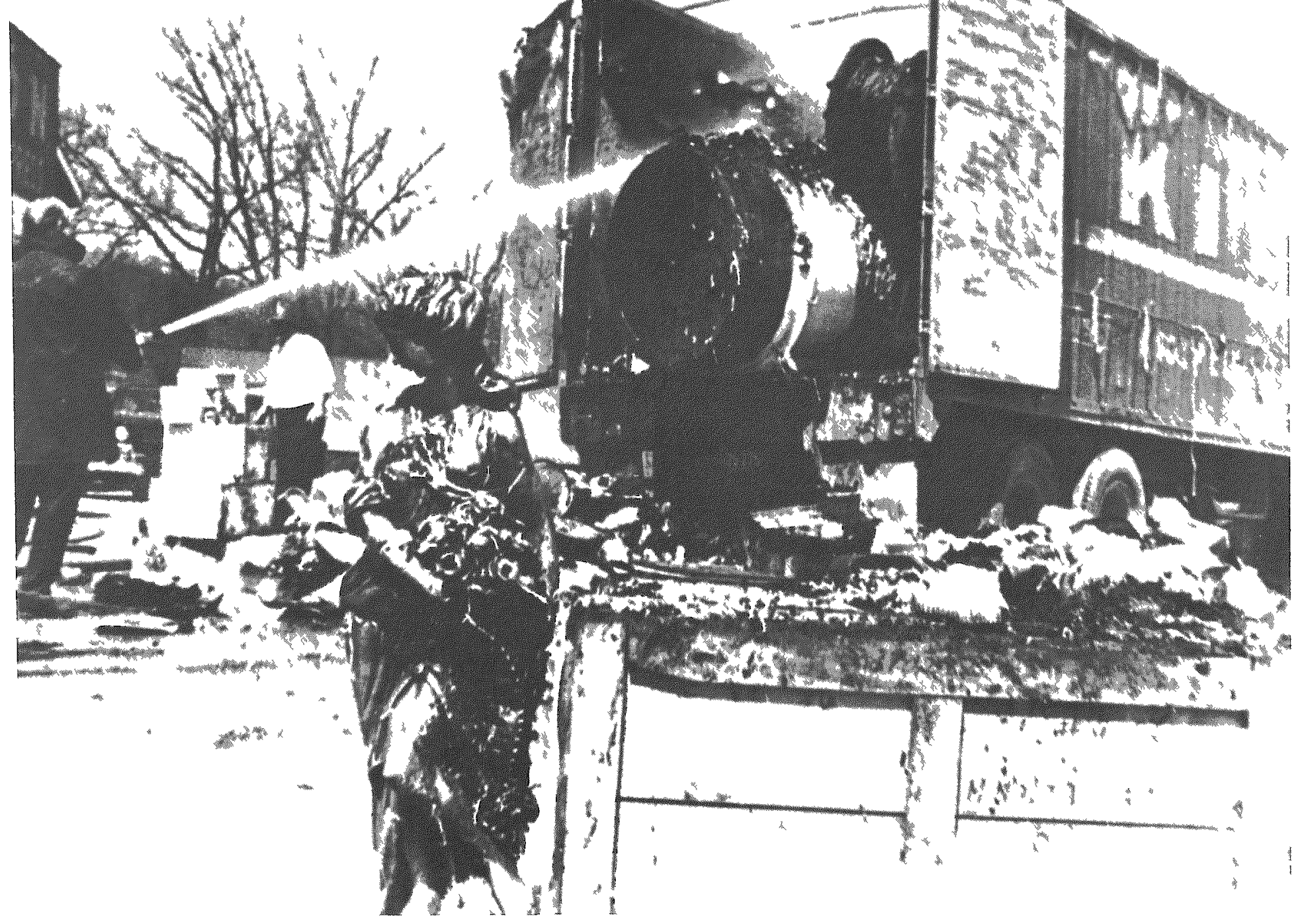

Figure 4. Motor Carrier Teminal Fire - Knorville, Tennessee, March 1969 


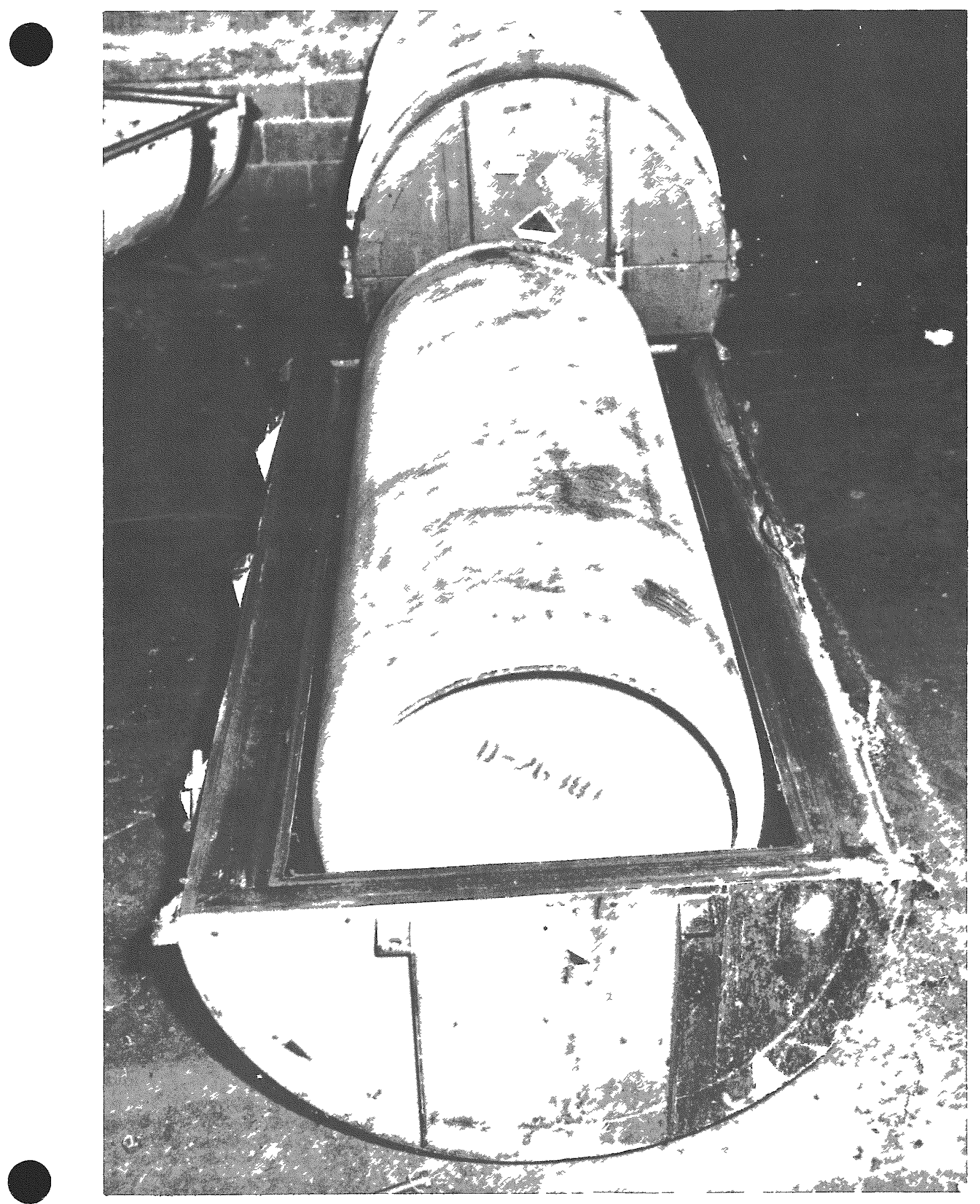

Figure 5. Protective Package after Fire 


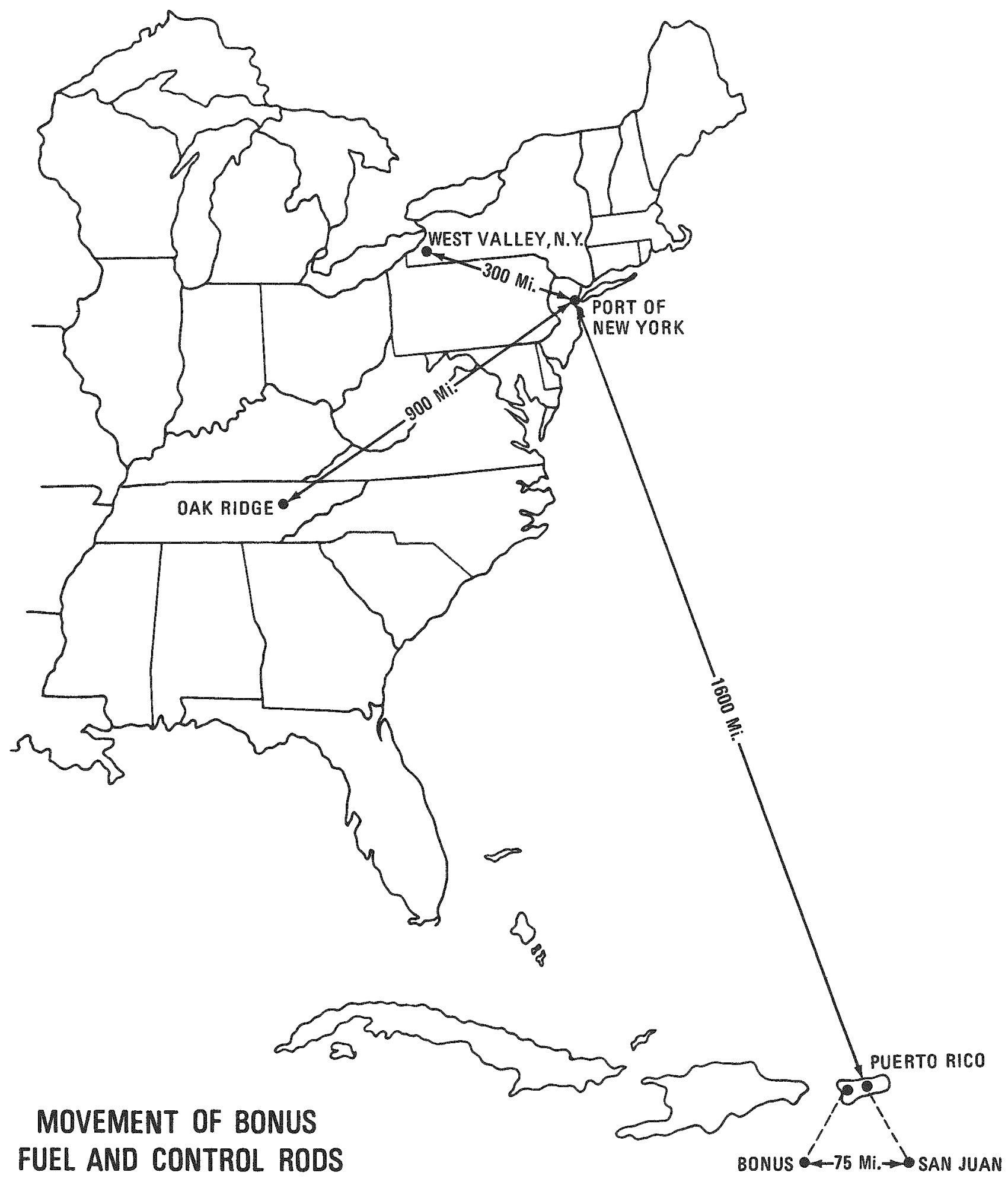

Figure 6 . 


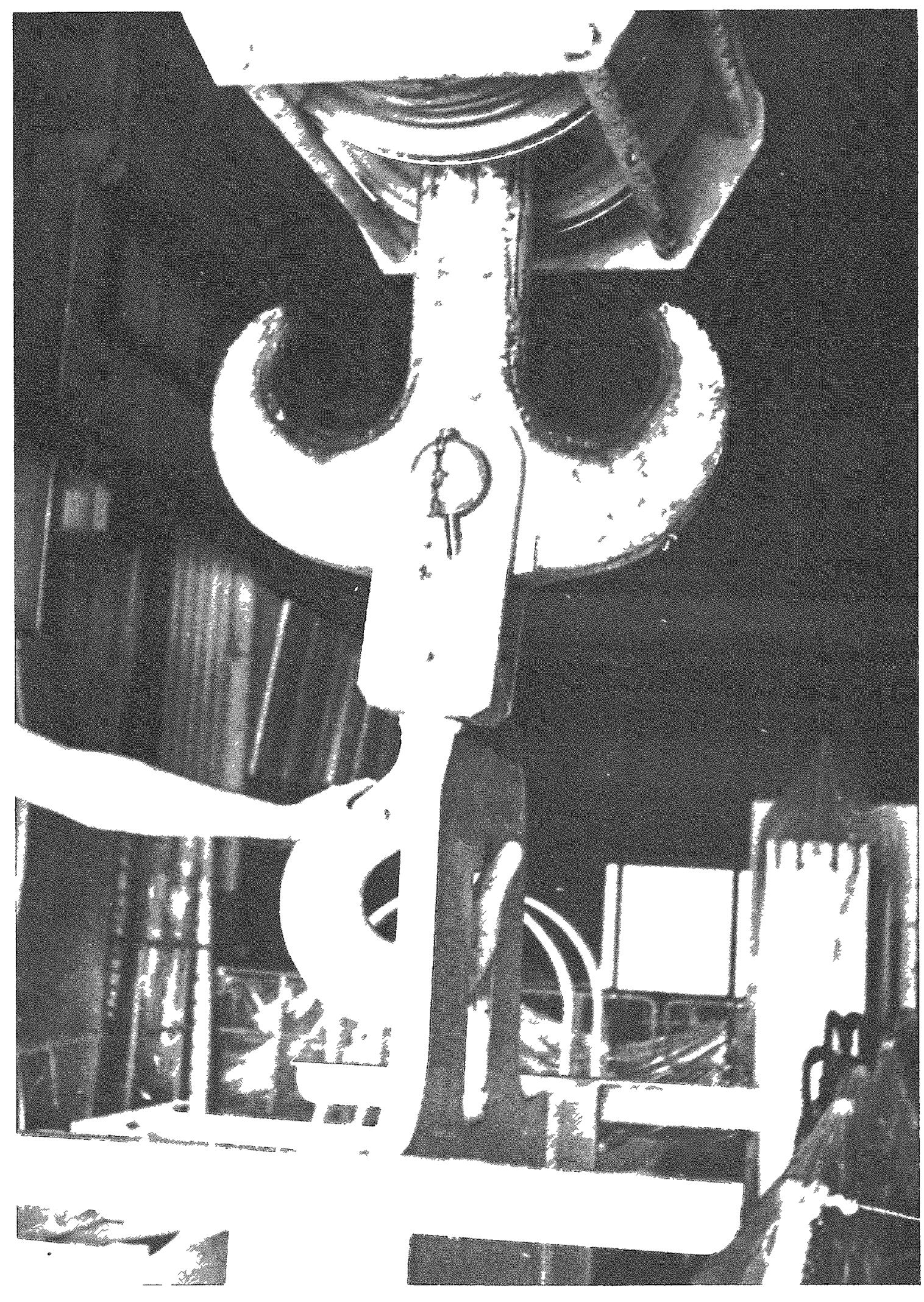

Figure 7. Dresden Regctor Crane Hook 


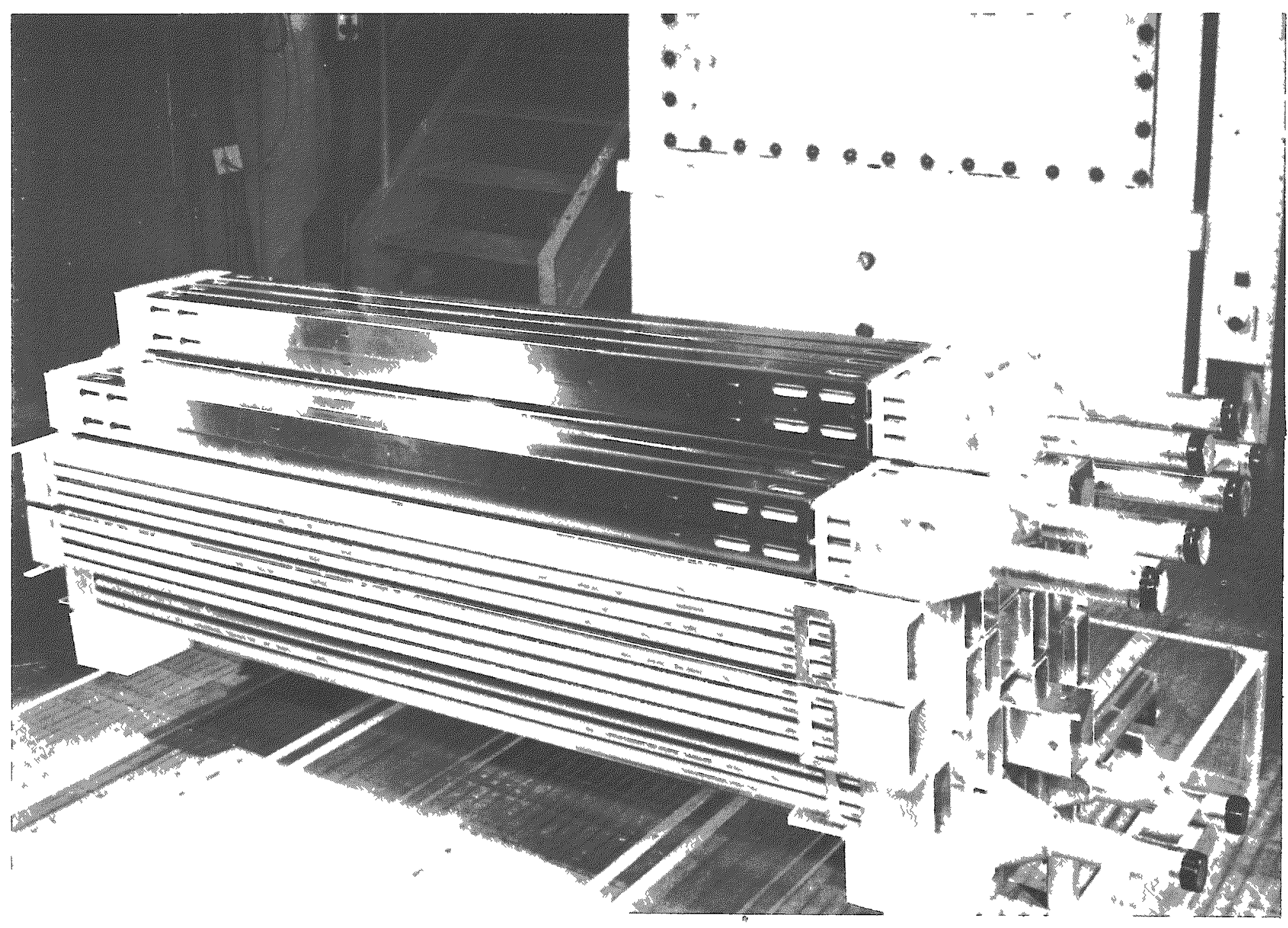

Fisule 8. BunU, Fuel ilements at $\mathrm{Y}-12$ Critical Fxpmeriments Laborstory 


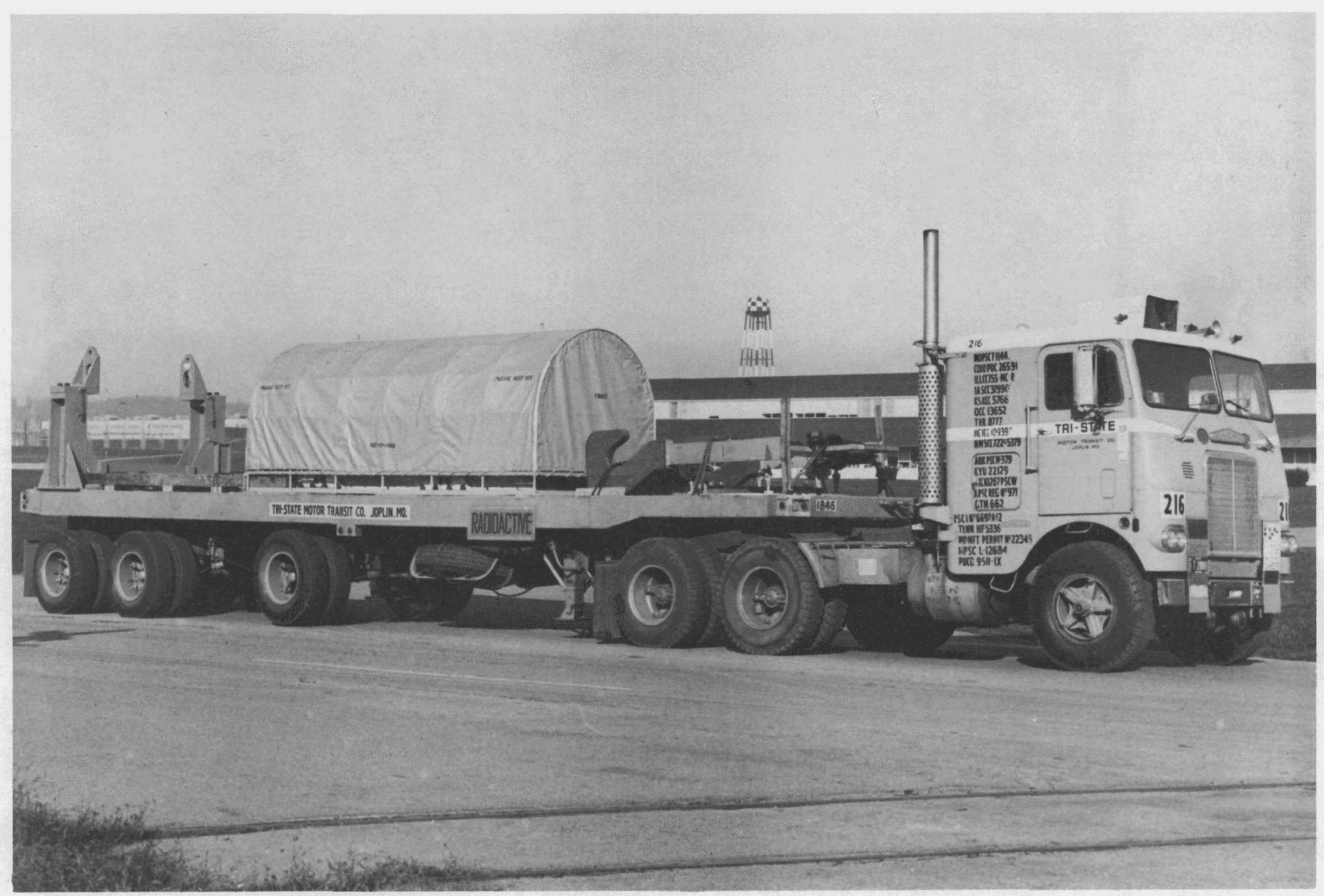

Figure 9. ATCOR Cask 


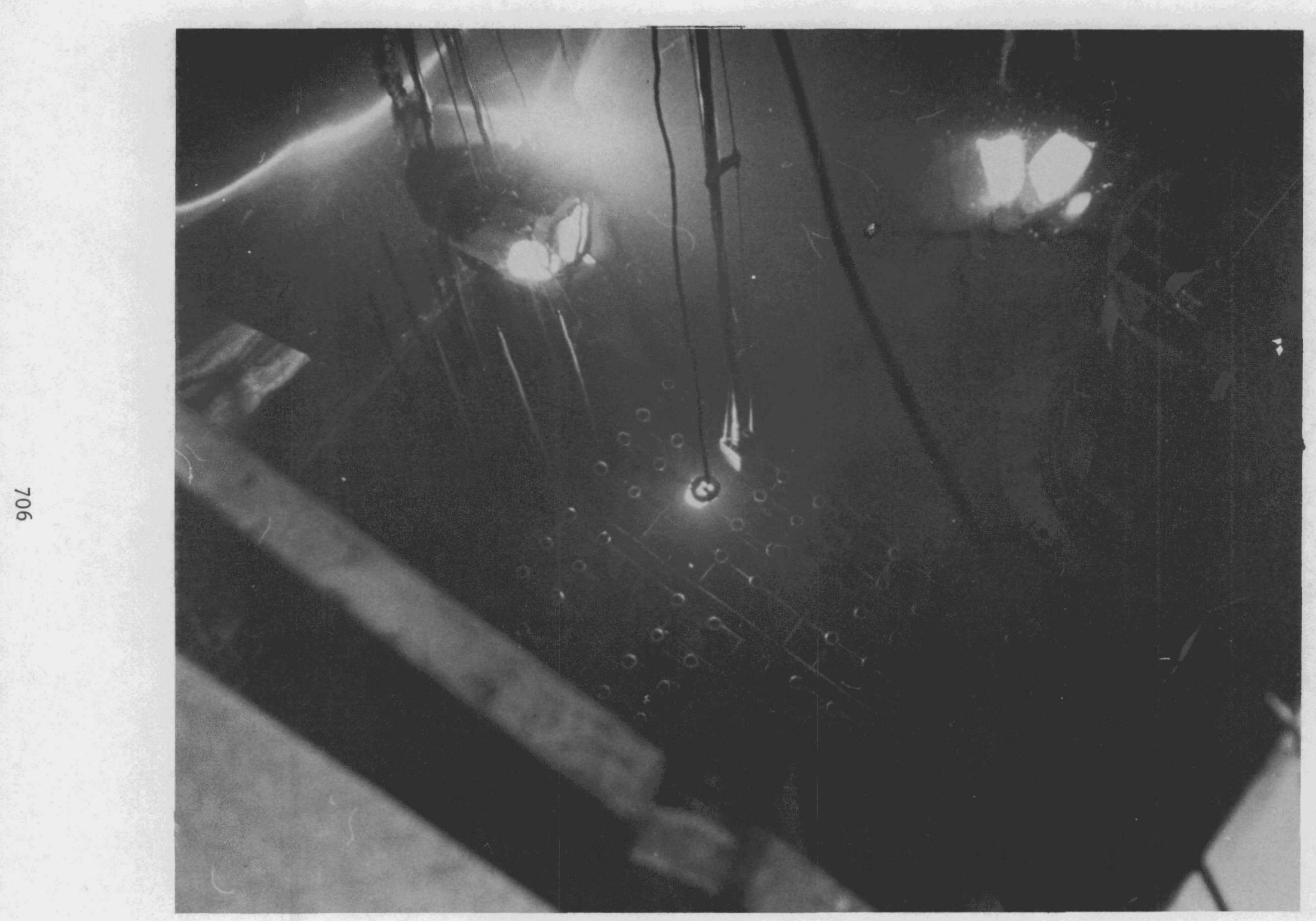

Figure 10. Fuel Basket in Storage Pool - at BONUS Reactor 


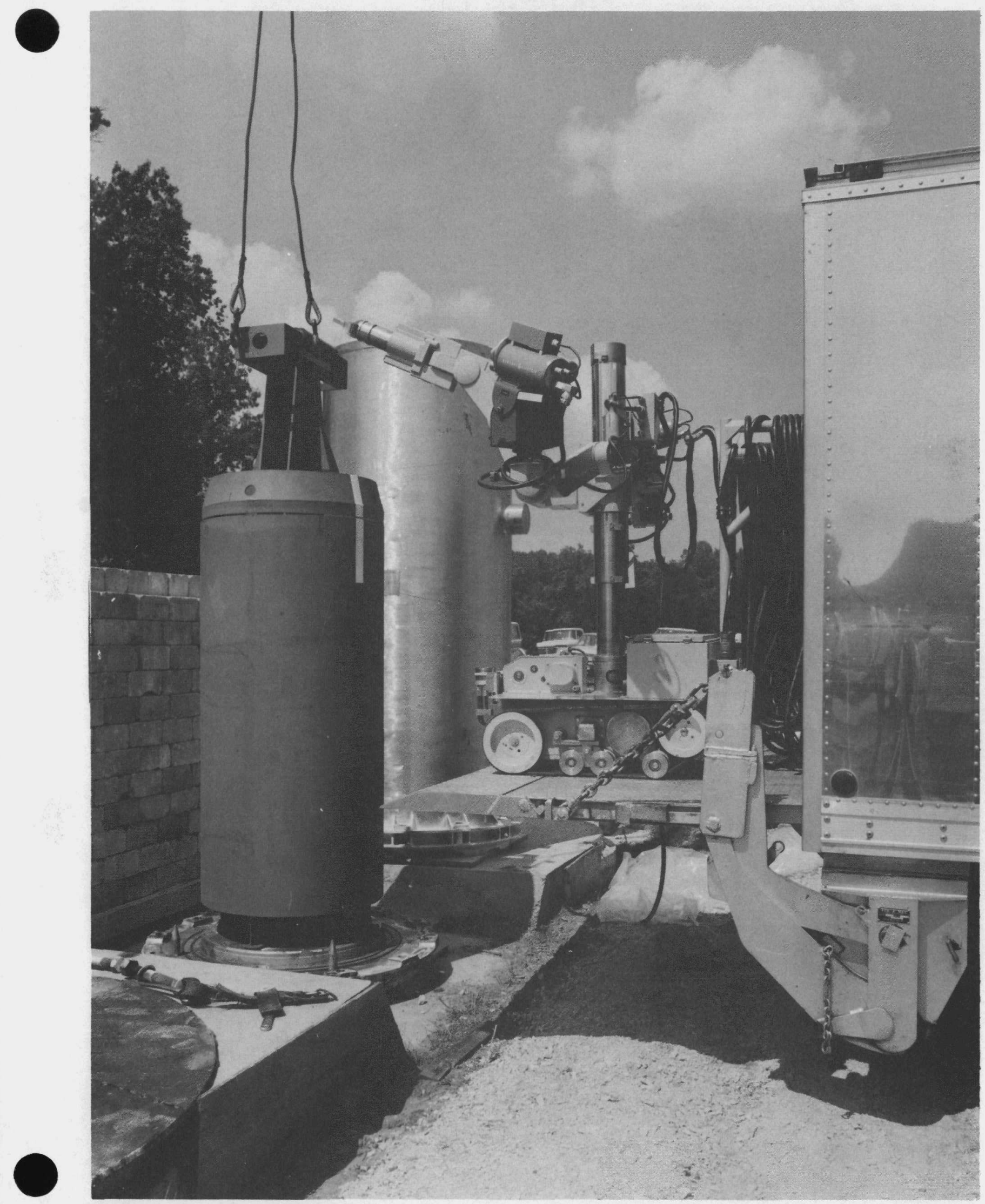

Figure 1l. ATCOR Cask and BONUS Control Rod Basket at ORNL Burial Site 


\title{
THE RESPONS IBILITIES OF THE CONSIGNOR
}

AID THE CONSIGNEE

K. R. Schende1

\section{ABSTRACT}

\begin{abstract}
The responsibilities of the consignor and the consignee with respect to the packaging and transportation of radioactive materials, are divided into three general categories-legal, practical and social. The legal responsibilities are relatively simply stated. However. the regulatory requirements imposed on the consignor and the consignee in preparation for and follow up after the actual movement also are briefly enumerated and indicated to be quite extensive. The practical responsibilities, as discussed, are generally related to financial considerations and to specific properties of or conditions associated with radioactive materials. The social responsibilities are described as relating principally to an overriding requirement for a degree of safety adequate to satisfy the professional standards of the consignor, particularly when those standards exceed the legal minimum. The responsibility for an effective, positive attitude to help to combat the unwarranted distrust of radioactive materials that appears to inflict the general public is also asserted.
\end{abstract}

The responsibilities of the consignor and the consignee, in connection with the packaging and transportation of radioactive material, can be reduced to the same essential terms as the responsibilities of any individual with an assignment to carry out, that is, to "Do the job right." Now this is the crux of the matter, the "ultimate truth". However, it really is of value only to those who already know what is required of them, but who can still profit from the reminder. To the newcomer, the uninitiated, it merely provides the questions, "Who must do the job? What is the job? When is it done right?" 
although, at this time, I would like to establish mas definition of the consignor and consignee. As a convenience, I propose to consider them as "black boxes" (to use some electronic engineering terminology.) What I mean is that the method used by the consignor to carry out his assigned responsibilities is not defined. Inside his company organization, there may possibly be a trafic group, a health physics group, a shipping department, ecc. Or just as possibly, a single person may have to do everything. lither way, for purposes of this discussion, whatever must be done by the consignor or consignee, does in fact get done in some manner.

The "What is the job" part is almost as simple--to assure the physical transier of some radioactive raterial from one place to another.

So that leaves the final question, "When is it done ight?" The various actions which contribute to the answer to this guestion are what I choose to regard as the responsibilities of the consignor and the consigrae, and are what I shall discuss in the remainder of my presencation.

It seens logical to divide the responsibilities of the consignor and the consignee into three major categories--legal responsibilities as established by applicable government licensing regulations: practical responsibilites; and social responsibilities. I have deliberatedy placed a limitation on the term "legal responsibilities" because I don't intend to include such considerations as financial liability, torts, and contracts.

The legal responsibilities of the consignor are deceptively simple and straightforward. He is required to present to the carrier, an acceptable package, properly documented and proper:y label1ed. Under certain circumstances he may be required to specify the need for placaxding the transporting vehicle, and to provide some special loading assistance or some special instructions.

Correspondingly, all that the consignee has to do is accept, ur occasionally unload, the package, and possibly to assure the carxier that there has been no contamination of the vehicle.

There have been previous discussion of the various regutatons promulgated by the Atomic Energy Comaission and the Department of Iransportation. Various states also have equivalent and compatible regulations, where applicable. So when you consider the multiplicity of rules chat exist, it will cone as nu surprise to you when I say that the consignor works like a dog to fulfill his 
his responsibilities.

First, I'm simply going to list the sequence of actions required of him, basically by various government regulations. Then I'Il go back and discuss each item a 1ittle more thoroughly. The list looks like this:

\author{
1. Ascertain that consignee is properly authorized \\ to receive the material. \\ 2. Define the package. \\ 3. Preplan the route. \\ 4. Select a carrier. \\ 5. Prepare the package. \\ 6. Load (or supervise the loading of) the vehicle. \\ 7. Provide the necessary documentation. \\ 8. Provide special instructions (if required). \\ 9. Follow in transit (if reguired). \\ 10. Process material transfer papers (if required).
}

This list is respectable, but is it really as impressive as you have been led to expect? If not, just wait.

Item I on our list is perfectly strajghtforward. The AEC and comparable state licensing regulations state that no radioactive material subject to the regulations may be transferred to a person not authorized to receive it. Small quantities and materials in forms that are either exempt or generally licensed present no problems. For any other situation, the consignor mast contact the consignee and obtain some type of adequate assurance that the consignee is duIy authorized to receive the material.

Item 2 is the sleeper on our 11st. "Define the package" it says, just three little words. However, behind them lay all of Part 71 of the AEC's regulations, and almost all of the Hazardous Materials Regulations of the DOT. Now, not everyone is going to be concerned with all of these regulations. Many consignors have a quite simple, repetitive operation which soon becomes routine. On the other hand, there is always a first time, and surprisingly often a change in activity, form, weight, volume, destination or sone other aspect of the packages makes a shipment a "first time." 
The word package, in the industry, means both the contents and the packaging (or container). Different loads, different quantities, different materials, even though they are all in the same packaging, make different packages. So, let's look at the material. Obviously, it's radioactive material, but is it anything more--a corrosive liquid, a corrosive solid, or possibly a flammable solid? These additional classes of hazardous materials also have their packing and labeling requirements. If it is solely radioactive, is it a smal1, readily packaged, Type A quantity; a larger, Type B quantity that requires a package that will withstand the hypothetical accidents; or a large quantity that requires specific licensing,--or is it an exempt quantity? Special form material (material that doesn't disperse readily) and low specific activity material are subject to less strict requirements. Don't forget to determine which Transport Group normal form material belongs to. or maybe it's fissile material that involves nuclear criticality safety controls; what is its enrichment, how much can be put in a single package, what is the material concentration, or the moderating ratio?

When the expert gets all those questions straightened out, the consignor can start looking for packagings. For non-fissile materials in small, Type A quantities, it's fairly simple. Numerous specification packagings are avallable, such as $17 \mathrm{H}$ metal drums, 15A, B, C or D nailed wooden boxes, or the Spec 12 series fiberboard boxes. However, once the Type A quantity limits are exceeded, the pickings become very silm, and usually special permits are required. Then, a whole series of questions arise, such as, "Who has an approved packaging? Can I get listed on the permit? Does the permit have to be modified for the contents I'm interested in shipping? How long will it take to get a revised permit? Has the AEC's Division of Materials Licensing approved it? Where can I procure enough of the containers? What labels do I use?" For a shipment of fissile materials, "Should it be shipped Fissile Class I, Fissile Class II, or Fissile Class III? How many packages make a load?" The questions mount up again.

Once the consignor has assured himself of an acceptable package he really is over the hump. Item 3, preplanning the move, merely involves such items as "Does the special permit (when required) limit the mode of transportation which، may be used? Are there any bridges, tunnels, turnpikes, etc. enroute which forbid or limit the movement of radioactive materials? Will the load exceed local weight, height, or width limitations on roads or bridges, etc.?" 
Then 4 involves selecting a carrien whose tarifis penic hin co wry the material involved, wichin any ruuting linications tirt nay have been decemined in teen 3, to the dastinction desired. This may develop into a problem if a cransfer to another carrier is involved, as we'll see in Item 9.

Item 5 reverls how well the consignor carrieb out Item 2 . Are tue Duiagings suirable? Is each wne complete? Is each one in usable condition? How can I repdir that puncture (or crack or whatever)? Are the contents within auy expressed limilations on activicy, iom, lhermal ourput, quantity, dryness us other property? is it properly sealed? Does it meet required external Tadiation Levels, or surface contamination levels? What Transport Inder nust be assigned? (The 1 ransport Index is an indication of el ther the e:ternal racialion levels assuided with a package or the nuclear cricicality reactivity or a pantage. It is determined such that when a vehicle loading is mantained at or below 50 units, no Eurcher radiowtive materials controls are cequiredol Ultinately. I ten 5 determines whether os mot the package san be certified.

licen $b$ is incended to assure that a corrier observes the 50 wat tule (chat vas just described) on a loak of radioactive material. It is also significant if the shipment is going "eaulusive use of vehicle" to take advantage os cercain higher radiakion levels allowed by nor regulations, or it it is a Fissila Class II shipment. The Fissile liass III designation applits to the vehicle loading as a wole, where the number, arrangement, and spacing of the packages on the vehicle are important considerations in the nuclear criticality safety of the array. Of course, simple considercions like avoiding leakage by assuring proper urientation and tie-down of the packages can be involved. Furthernure, at this point a decision must be mate on whether placarding is required on the vehicle and if so, whar placard should be used.

Item 7 is no big problen for the erperienced shipper, or even for the ineaperienced shipper who reals his Dot regulations. He hands the carrite's representative a bill of lading properly describing the load, the quanity, the labels required, and the plecards required, along with a certification that everything is in accordance with regulahions. Certain transportation modes may require that copies of any special permits which are involved also accompany the shipnent.

Tten 8 is generally applicable only when the material involved in the shipmeni requires the exclusive use of the vehicle. If the material is subject to the requirements of Parn 73 ut the Arc's regulations the Pare which deals 
with the physical security of shipments) signature service on transfers, callin procedures and times, and other very important instructions may have to be prepared, given to the carrier, and impressed on him to assure some degree of understanding of their importance.

Item 9 also is basically restricted to security shipments under 10CFR73, or to accidents and/or misroutings. Security shipments are too new, few and unusual to warrant extended discussion. Nevertheless, it should be indicated that the AEC's intent, as expressed in Part 73, is to require a shipper to undertake to arrange with a carrier to move a shipment using certain preselected connecting carriers and predetermined routes and to arrive at the destination at a specified time. This intent may well be in direct opposition to a common carrier's normal legal freedom from any such restrictions. Presently, the best that the shipper can do, apparently, is make his arrangements, cross his fingers, and hope. Accident reporting and cargo handling are really up to the carrier. However, the consignor normally retains an interest and responsibility in a shipment of this type until it reaches its destination. In the event of an accident, particularly, the shipper is peculiarly qualified to provide advice and assistance in handling damaged packages.

Item 10 is a routine requirement applicable to shipments involving more than 1 gram of special nuclear materials, and more recently, to large amounts of source materials (over a metric ton). These reports are part of the AEC's financial and safeguards accountability systems.

With this expanded understanding, let's go back and review those ten basic steps which the consignor performs to meet his legal responsibility.

1. Assure consignee's authorization

2. Define the package

3. Preplan the route

4. Select a carrier

5. Prepare the package

6. Load the vehicle

7. Provide documentation

8. Provide special instructions

9. Follow in transit

10. Process transfer papers 
There is an adage that says it is more blessed to give than to receive. However, in transporting radioactive materials, it seems to be mare blessed to receive than to ship. Certainly, the consignee's expressed responsibility to accept the package and possibly certify the absence of contamination on the vehicle can be fulfilled in far fewer steps.

The consignee's activities can be expressed as:

1. Provide authorization to receive the material.

2. Monitor for arrival of the shipment.

3. Survey load and check for damage.

4. Unload (or supervise the unloading of) the vehicle.

5. Survey and release the vehicle.

6. Process transfer papers (if required).

The consignee's activities are relatively simple. Item 1 merely requires that, at some time before the shipment is made, the consignor be provided a license number, or a copy of a license or whatever similar proof is required to satisfy him. Of course, if the consignee doesn't have a license and he wants the material, he'd better get busy.

Item 2 is urgent primarily when the shipment is subject to Part 73 of the AEC's regulations. Contact with the consignor should provide a gradually refined estimated time of arrival, and if the vehicle fails to put in its appearance promptly, specified notification to the consignor must be made. of course, any shipment which is expected, but simply doesn't arrive, is eventually going to be questioned. No one is going to completely ignore a missing shipment of radioactive materials, it's just that sometimes it takes a little bit longer.

Item 3 is performed primarily as a routine radiation protection measure. Some data must be accumulated concerning the possible radiation exposures which would be received by the consignee's employes in the course of handling the package. Radiation levels or surface contamination above specification limits could also be indications of in-transit damage to the package.

Item 4 is equivalent to the Item 6 performed by the consignor, and generally is required under the same circumstances. Consignee unloading is a requirement for certain "exclusive use of vehicle" shipments and for shipments 
of fissile radioactive material where nuclear criticality safety is a consideration.

Item 5 can present the nastiest problem to the consignee. The DOT specifies that radiation and radioactive contamination levels in the carrier's vehicle be reduced below specified levels before the vehicle can be used for non-radioactive applications. In the vast majority of movements, there is no evidence of residual radioactivity. In those few instances where it occurs, however, decontamination can be an expensive, tedious process.

Item 6, the final item on the list, again is the complement of Item 10 on the consignor's list. It is the formality which says, "I received the material you sent. I accept responsibility for it."

The items I have discussed are representative of the actions required to appropriately fulfill the responsibilities imposed by law, rule and regulation on the consignor and the consignee. I offer no warranty whatsoever that my descriptions are complete. What I have attempted is merely to create an impression of the complex nature of the requirements imposed by law on persons connected with the shipment of radioactive materials, due to their classification as hazardous materials. Now, let's turn to what I referred to earlier as the practical aspects of the responsibilities of the consignor and the consignee.

The practical aspects basically revolve around money. In our economy, practically everything revolves around money. It seems self-evident, but always bears repeating, that the consignor should endeavor to accomplish his required task with a minimum of expenditures. Now please, I'm not saying, "Ship it the cheapest way." Notice that I said "accomplish his required task." Furthermore, if you recall, at the start of my talk I said the consignor was to be treated as a black box, without specifying any of his internal operations. The consignor as a whole obviously has many needs, some measurable in dollars, such as storage space; and some measurable in customer good will, such as meeting delivery schedules. The preferred practical shipping choice balances all of these internal needs so that the transportation of the material involves the minimum overall expenditures consistent with management objectives.

Other practical considerations are associated with the nature of the radioactive material itself. Many members of the audience, I'm sure, remember the reaction of the industry when it was proposed to pretty much exclude byproduct materials from transport by air in passenger carrying aircraft. Our 
industry developed a highly effective technique of using the regularly scheduled passenger airlines to move byproduct materlals that have very short half-lives. Such materials are particularly popular in many fields because a relatively short time after being applied, they have decayed to the point that the samples can be considered to be no longer active. But as the result of this same property, any delay during the transfer between the producer and the customer involves either ordering unreasonably large quantities or trying to use orders-of-magnitude smaller activities in the experiments. In view of this very real, very practical problem, the proposed regulations were modified to assure the continued movement of such samples by passenger aircraft. That is an ideal example of how the transfer mechanism is partly dictated by the material's properties. Another obvious example is the transportation of spent reactor fuel between the reactor and the reprocessing plant. The lead encased casks used for such purposes range up to 75 tons in weight. Their movement by air, or possibly, even by highway, is out of the question. Special rail cars or barges are indicated here.

Having discussed some of the legal and practical aspects of the responsibilities of the consignor and consignee, what can be sald of the social aspects? And possibly, "social" is not even the proper word. The first and most important item under this heading is safety. The primary purpose of the majority of the legal requirements that have been imposed is to attempt to assure that an adequate degree of safety must be exercised during the skipment. Further, we have all been tuught that safety is good business and that safety is everybody's business.

But safety is a particularly significant responsibility of the consignor of radioactive materials. (And I might add, of the carrier also.) when it is necessary to satisfy his own professional opinion of what constitutes a "safe" package, a consignor should feel obligated to exceed the minimum requirements of the regulations or to spend extra dollars.

This specific obligation is partly due to the nature of what might be called the "radiation hazard." Most hazardous materials represent a stored energy situation, that is, an explosive does or doesn't explode or a flammable material does or doesn't burn. Furthermore, after the explosion or the fire, the particular hazard no longer exists. Most of what are left in the way of hazardous materials produce a definitely noticeable (and usually unpleasant) physiological reaction such as pain, nausea, unconsclousness and possibly death. For all of these materials, once they have been identified, emergency actions 
following an accident can proceed based on what the emergency crew can perceive using the normal five senses. In addition, suitable corrective or protective devices for such hazardous situations (such as respirators, fire extinguishers, insulated or non-sparking tools, etc.) are relatively standard equipment for emergency crews.

As classes, only radioactive materials and etiological materials give no warning, produce no immediate symptoms, and exhibit relatively prolonged and continuing effectiveness. Of these two classes, the etiological materials usually involve some type of physical contact, and the eventual physical reaction is customarily responsive to some type of medical treatment if diagnosed in time. As a class, only radioactive materials present a continuing hazard which requires special instruments and expertise to determine the extent to which they can be safely approached, or moved; and which can produce a range of effects which may not be readily detectable, let alone treatable.

Viewed in this light, radioactive material transfers require every appropriate safety device dictated by good shipping practices. However, it is useless, and possibly unsafe to keep on piling up precaution after precaution beyond that point.

The implications of this radiation hazard, plus radioactive materials' "Hiroshima" reputation, lead to the second aspect of the social responsibility I would assign to all persons who process, transfer or use radioactive materials. This responsibility can roughiy be described as a public relations tob. I feel that a continuing expansion in the use (and therefore, in the transportation) of radioactive materials requires that the general public be educated to the degree of safety that our industry maintains. Every individual in our industry, by which I mean the nuclear industry in all its phases, has a responsibility to help to overcome the bad public image the industry is cursed with.

We must strive to reduce to an absolute minimum the hysteria (and that's a term I use advisedly) that has become associated with radioactive materials. No one denies that they are properly classified as hazardous, but with due care and understanding it is what I consider a normal, minimum degree of hazard. Certainly, I feel much safer in one of our plants, surrounded by radioactive materials, than I do crossing a busy city street.

The most frequent and intimate asseciation with radioactive materials that most members of the public endure (?) is while the material is outside of its 
carefully controlled application sites during its transportation between sites. One significant exception would be that group of people who have been introduced to radioactive materials in the course of medical diagnosis or treatment. It is notable that in this instance, the authority of the M.D. degree and the general mystique associated with materia medica really tends to overshadow the radiation aspects. This same aura of professional confidence must always be communicated from the consignor and the consignee to the carrier's representative and, hopefully, on to any otner individual he contacts.

I feel very strongly that every personal contact, every interface (if you will) between the consignor and the consignee, and any other persen should involve this effort to sell the acceptability of the material we handle.

In summary, then, my interpretation of the responsibilities of the consignor and consignee includes legal, practical and social aspects. The legal aspects are typified by the various written rules and regulations. There are a confusing plenitude of such regulations, but careful research and normal good sense can contribute to effective compliance. The practical aspects involve mostly a financial balance, which customarily includes judgment factors requiring knowledge and experience of phases of the consignor's operations other than simple transportation charges. Finally, the social aspects deal primarily with assuring the safety of the shipment to the maximum practical degree, to provide continuing convincing evidence to all the rest of the world that the nuclear business is the world's finest. 
DEVELOPMENT OF DOCUMENTATION FOR THE TRANSPORT OF RADIOACTIVE MATERIALS.

\section{J. Fairey}

This paper was not available at the time of printing. It has subsequently been issued as BNWL-SA-3906, available from NTIS, 5285 Port Royal Road, Springfield, Virginia 22151. 
TRANSPORTATION AND HANDLING OF

RADIOACTIVE PHARMACEUTICALS AND RADIOACTIVE CHEMICALS

S. H. Sanger

ABSTRACT

The movement of Radioactive Pharmaceuticals and Radioactive Chemicals, either by surface or air or a combination thereof, has been a monumental problem from the inception of the original processing of nuclides due to the short half-life of the commodity. Many precautionary measures must be taken to insure a safe and timely delivery of these radioactive products. From the moment the nuclide has been processed, the problem of packaging and transporting, coupled with the services needed to insure fast portal to portal delivery, is extensive. Both the surface carrier and the air carrier must handle this material with precision-like speed. Packaging, handling, shipping and transporting are an integral factor in connection with the supply of this product.

\section{INTRODUCTION}

During the past five years, we have specialized in the timely and efficient delivery of medical nuclides. Originally we transported radioactive generators that had a five-day half-life and had a two-day pre-calibration factor built therein. From this early beginning, we moved through the full spectrum of nuclides, which included sodium pertechnetate with a six-hour half life. Within the past six months, we have transported the newer and even shorter half-lived nuclides, such as $F^{18}$ with its

$$
720-6
$$


unusually short half-life of less than two hours. As the scope of the Radioactive Pharmaceutical Industry and Nuclear Nedicine progressed, a larger geographical area had to be covered. This, in itself, has created many logistical problems. In previous years, nuclides with a long half-life have come into disfavor due to the lingering after-effects within the human body. Therefore, the future of the more exotic short half-lived nuclides is most promising, but the problems connected with their distribution have become more difficult.

In the early stages of transporting radioactive pharmaceuticals, the people connected with packaging, shipping and transporting were completely unfamiliar with the commodity they were handling. During these early stages, many of the truck drivers, airline pilots, cargo handlers, cargo agents and various other people connected with the radioactive pharmaceutical products had great misgivings about any commodity whose derivative was "radioactive". This superstition has continued unabated throughout the past six or seven years. However, it is encouraging to note that with the aid of training films sponsored by various manufacturers and with numerous safety meetings throughout the country, the average person coming in contact with radioactive pharmaceuticals has become more oriented with the product, and, therefore, handles his particular phase of this industry at a more efficient level.

The very fact that all nuclides are delivered on a nationwide basis prior to 8:00 AM, is a tribute to the many people who have taken the trouble to learn the proper handing and transportation of radioactive pharmaceuticals. The hospitals, research centers, universities and government facilities operate more efficiently due to the fact that they receive the source material on a timely basis.

We frequently take for granted the fact that the product arrives on time without ever considering the myriad steps needed to effect this delivery. It is necessary for the shipper to notify the carrier prior to shipment, either by telephone or teletype, the origin of the shipment, the name of the airline, flight, airbill number, name and destination of the consignee and weight and number of pieces involved in the shipment. In order for the shipper to supply the carrier with this informa- 
tion, it is necessary for him to make arrangements for reserved air freight (RAF) space. He must know how much lead time is necessary for the shipment to be at the airline prior to takeoff. In many instances, this varies from one to three hours. The coordination between the order Department, production line, Shipping Department and surface carrier used to transport the material to the airport is one of great responsibility. In the event that there are production problems or the material does not pass the required tests, it is incumbent upon the shipper to relay this information to the destination carrier. often the shipper or shipper's agent must get proof on board from the airline. Weather conditions are always creating problems, and, therefore, certain backup flignts, destinations and airlines must be considered prior to delivery of the nuclide to the originating airport. With each shipment, the restricted articles manifest must accompany the package. This indicates the particular nuclide and the activity contained therein. It is the shipper's responsibility to see that he does not exceed the transport index allowed for one airline at one time. In the event that the activity is too great and the transport index is too high, it is necessary for the shipper to book space on another flight or conceivably another airline.

Since the receiving carrier has been notified of the impending arrival of a shipment, it is necessary that he check with the airlines repeatedly to ascertain if the shipment is on the manifest of the scheduled flight. Also, he must take into consideration any delay due to weather or recovery time. Recovery time can vary from one to five hours, depending on the volume of air freight that the airline is handing, which in many instances can vary due to the time of year, holidays or type of aircraft in use. Invariably, a radioactive shipment that comes on a freighter aircraft will be delayed in recovery at the destination. A very important phase of the overall transportation picture in the pharmaceutical industry is the transshipping of a shipment from a major air carrier to a second or third level air carrier. The surface carriers at the major destination stations throughout the United states have the responsibility of seeing that these shipments are carried out effectively in order to supply hospitals and other institu- 
tions in remote sections of the country.

The surface carrier at the destination is the all important $\operatorname{cog}$ in this very large wheel of various services. The processor can pre-calibrate his material to insure against any eventuality in the tardiness of the distribution of this product. Also, the airline can negotiate 3,000 miles in five hours, but the surface carrier conceivably must cover 150 to 200 miles on the ground in a maximum time of four hours. This factor alone necessitates the pre-routing of each vehicle from this carrier. Fre-routing has certain built-in safety factors that in the event of an accident or breakdown, there will be a minimum of difficulty in locating the venicle. Each delivery must be taken in exact rotation as described in the driver's pre-routing manifest. Surface carriers who do not have two-way radios must require the driver to telephone the dispatcher at various checkpoints along the route. At all times, the driver of the vehicle must have in his possession the restricted articles manifest and should be aware of the nearest decontamination or radioactive waste-disposal location in the event of an accident or in the event a nuclide package becomes a "leaker". Teedless to say, all drivers must wear radiation-detection film badges, and all venicles must be placardod on all four sides. Since radioactive material can not be seen, touched, und is odorless, it is very important to have no comingling of this commodity with any other freight in the vehicle. Exposed or unprocessed film could receive irreparable dangge by being placed in the same vehicle with a package of nuclides. If this is an interstate movement, the ariver must also keep an hour log. This 108 is of a positive nature. It records normal proceaures as well as any irregularities. If a surface carrier transports any quantity of radioactive pharnaceuticals, a counter should be readily available at the terminal. Each vehicle should be checked after daily use to see if there nas been any background activity or spillage during the previous shift. It goes without sxying that a venicle that has only the ariver's seat is a nost witable vehicle for this iype of operation. Transpreting maides is unique in the sense that there is more paper work connected with its trassportation, xad, therefore, requires the ariver's unuivided attention with no aistraction by either an authorized or unuthorized passenger. 
Since all hospitals, research centers, universities and government facilities receive these shipments on a regular or semi-regular basis, the driver of the delivery vehicle should be supplied with a loose-leaf book with photostatic copies of the floor plan of each delivery location. In many instances, it is necessary to indicate corridors that must be used and the location at which he must park his vehicle. Since eich location has its own peculiarities, regarding the method needed to effect an expedited delivery, his instruction sheet must carefully enumerate the various steps he must follow in order to adhere to the local instructions that must be complied with at all times. In some cases, the driver will have the key to the nuclear medicine laboratory or will have to leave the package with the security Guard or some other employee of the consignee. In any case, it is most important that he receive a signature and denote the time and date that the delivery was effected. It is also most helpful to have the individual who signed, print his name on the proofof-delivery (POD) receipt so that it is legible and can be traced at a later time. A facsimile copy of a standard airbill plus numerous shipping instructions should be photocopied and added to the book along with maps and any other pictorial information that could be deemed useful.

With regard to safety precautions, a placarded vehicle with the standard black and yellow radioactive sign shown on four sides should deter the average person. Nevertheless, it is mandatory that the key be removed from the ignition and the vehicle be locked while making a delivery. At all times, fire extinguishers should be required on all vehicles. Additionally, it is of great importance for all personnel who handle radioactive material to understand the various types of labeling. Radioactive pharmaceuticals come with either a Type I, II, or III label. There are enumerable symbols and signs that have been standardized by the Federal Government, a copy of which should be readily available to all persons handing any phase of the radioactive pharmaceutical business: The strong element of safety can be best illustrated by a thorough knowledge of these symbols and labels. Color coding is a part of the safety precautions ret quired for this material. In the event a terminal is used for in-transit storage of these radioactive pharmaceuticals, it has 
been advisable to paint a certain area on the floor of the terminal in yellow paint so that all packages that are labeled as radioactive material will be placed at that spot and all personnel will endeavor to keep any other freight from this area for fear of contamination.

How to select drivers is always a difficult question to answer. It has been proven over the years that a mature driver, physically fit, is most psychologically suited for the transportation of this commodity. If this material is transported in interstate commerce, it is necessary for the driver to take a special ICC physical. Contacting the recent past employer and having the driver's finger prints checked by the local Police Department helps in the selection of a competent driver for dangerous or hazardous material. Prior to his appointment as a permanent employee, the driver should be trained over the various routes for a minimum of one week by a seasoned driver or manager. As this commodity could have certain side effects, it is most important that no driver work more than 40 hours per week. Not only does his efficiency drop, but he is prone to errors and accidents during a longer week.

In order for anybody to do a satisfactory job in the transportation of this unique commodity, it is necessary to hold meetings and continuously talk and compare ideas about the delivery of radioactive pharmaceuticals and allied products. From time to time, there are innovations in packaging and handing materials. These should be shown to the drivers prior to their usage. During the past few years, the vinyl plastic bag $h_{\text {zas }}$ been used in the consolidation of various smaller corrugated boxes. This helps eliminate the loss of an individual package, or in the event of spillage, it confines it to a specific area.

Should there be any delays or irregularities in the transportation of this commodity, it is mandatory the shipper and consignee be notified immediately. Since the surface delivery carrier must remain open 24 hours a day, 365 days a year, he is considered the fountainhead of information. Both the shipper and the consignee resort to his knowledge of the immediate whereabouts of the shipment. It is his responsibility to incept a tracer or gather any other information that might help in expediting the shipment. There is nothing more disturbing to a 
consignee than to not know the immediate wheresbouts of the radioactive pharmaceutical that had been ordered. By keeping in constant touch with the shipper and airline alike, we are able to supply this information inmediately. A close liaison between the destination carrier and the shipper's technical representative in the locale become an important part of the handling of radioactıve pharmaceuticals. Since the technical representative sells this material to the various institutions, he must be fully cognizant of the problems connected with the transportation of his product. The destination carrier should keep this individual informed ia order that he may pass on any information to the consignee whereby the case-load or diagnostic study schedules can be altered in order to coordinate with the time of delivery of the radioactive phanmaceutical.

The handing of radioactive pharmaceuticals has become a highly specialized facet of the pickup and delivery business, and it goes without saying that the finest processed nuclides popularly priced but delivered on an untimel.y basis are not as sought after as overpriced nuclides of a poorer auality delivered on a timely basis.

Since this industry is still in its infancy, there will no doubt be improved methods of effecting and expediting delivery as well as packaging improvements. Such innovgtions as telecopier machines in the vehicle, whereby the driver would receive a copy of the original airbill, manifest, or any other pertinent information are in the future. Newer and more compact vehicles with greater mobility are also being experimented with and conceivably could improve the service. With the development of more efficient surface and air transportation, the use of radioactive pharmaceuticals in the nuclear medicine profession could be as far reaching as every town and hamlet in America. 
$\triangle N$ FXPERIMENTAL STUDY ON THE DROP IMPACT

OF SPENT FUEL SHIPPING CASK

S.Aoki, S.Nakata, S.Shimamura, Y.Kanae

A.Muramatsu, H. Nakazawa

Research Subcommittee for Besign of

Spent Fuel Shipping Cask.

Japan Society of Mechanical Fingineers

\section{ABSTRACT}

Since 1968 the experimental study on the drop impact test has been performed in Japan. The test done in 1968 are mentioned in the other paper. In 1969 the $1 / 8,1 / 4,1 / 2.5$ and $1 / 2$ scale models of the assumed prototype of $80 \mathrm{t}$ in weight were fabricated and tested. In this test deceleration at the moment of drop impact were neasured with accelerometer mounted on the top surface of models. Deformations were examined,too. In addition, a high speed $16 \mathrm{~mm}$ motion picture was used to analyse the motion of model at drop impact. The result from this study showed that the relation between the maximum deceleration and reduced scale was approximately linear, and gave about $600 \mathrm{~g}$ as the value of the maximum deceleration for the $80 \mathrm{t}$ cask dropped horizontally. The deformation mode of the $1 / 8$ scale model, also of $1 / 16,1 / 8.5$ scale model in 1968 , were significantly different from that of the $1,4,1 / 2.5$ and $1 / 2$ scale models. Therefore, a model larger than the $1 / 4$ scale should be used to obtain a reliable estimation for prototype from model test.

\section{INTRODUCTION}

The experimental studies on the spent fuel shipp $\mathrm{ng}$ cask have been planned, scheduled and conducted by the Research subcommittee for Design of Spent Fuel Shipping Cask in the Japan Society of Mechanical Engimeers (JSME) since 1967, under the spontorship of the Atomic Energy Bureau in Agency of Science and Technology. In this program, the drop test facilities was built in 1968 on the basis of 
the IAEA Regulations. The capacity of lifting device was $10 t$ and the nominal fall height $9 \mathrm{~m}$. The target was made of reinforced concrete block weighing $210 \mathrm{t}$ with a steel plate of $50 \mathrm{~mm}$ thick on the surface. In 1968, using this facilities, the $1 / 16$ and $1 / 8.5$ scale model were tested and some data were obtained. Successively in 1969, larger scale models was tested.

\section{DESIGN AND FABRICATION OF SCALE MODEL}

In order to confirm the similarity between practical cask and scale model and the dependency of reduced scale on the estimation of integrity, the four kinds of scale model for the $80 \mathrm{t}$ prototype cask were prepared. The dimensions of prototype and scale models are shown in Table 1 and Fig. 1.

The shape of casks are horizontal cylinder-type consisted of inner-shell (stainless steel), lead shielding and outer-shell (low carbon stee1). The design of prototype was based on ASME Pressure Vessel Code - Section VIII and Japanese Industrial Standard to conform the IAEA Regulations and Part 72 of 10 CFR of USA. The dimension and number of bolt for lid assuming that pulse time was $0.3 \mathrm{msec}$ on the basis of the experimental result in 1968.

The scale models were painted in white and the black reference lines were drawn so as to be convenient for measuring the deformation as shown in Fig. 2 .

Table 1. Dimension of Prototype and Scale Model Cask

\begin{tabular}{|c|c|c|c|c|c|c|}
\hline \multicolumn{2}{|c|}{ Scale } & I & $1 / 2$ & $1 / 2.5$ & 1,4 & $1 / 8$ \\
\hline Weight & $t$ & 80. & 10. & 5. & 1.25 & 0.15 \\
\hline D & $\mathrm{mm}$ & 1,624 & 812 & 650 & 406 & 203 \\
\hline$d$ & $\mathrm{~mm}$ & 1,000 & 500 & 400 & 250 & 125 \\
\hline $\mathrm{L}$ & $\mathrm{mm}$ & 5,312 & 2,864 & 2,290 & 1,438 & 717.5 \\
\hline 1 & $\mathrm{~mm}$ & 5,000 & 2,500 & 2,000 & 1,250 & 631 \\
\hline$t_{1}$ & $\mathrm{~mm}$ & 56 & 28 & 22 & 14 & 7 \\
\hline$t_{2}$ & $\mathrm{~mm}$ & 56 & 28 & 22 & 14 & 7 \\
\hline$t_{3}$ & $\mathrm{~mm}$ & 16 & 8 & 7 & 4 & 2 \\
\hline$t_{4}$ & $\mathrm{~mm}$ & 16 & 24 & 1919 & 12 & 6 \\
\hline$t_{5}$ & $\mathrm{~mm}$ & 240 & 120 & 96 & 60 & 30 \\
\hline
\end{tabular}




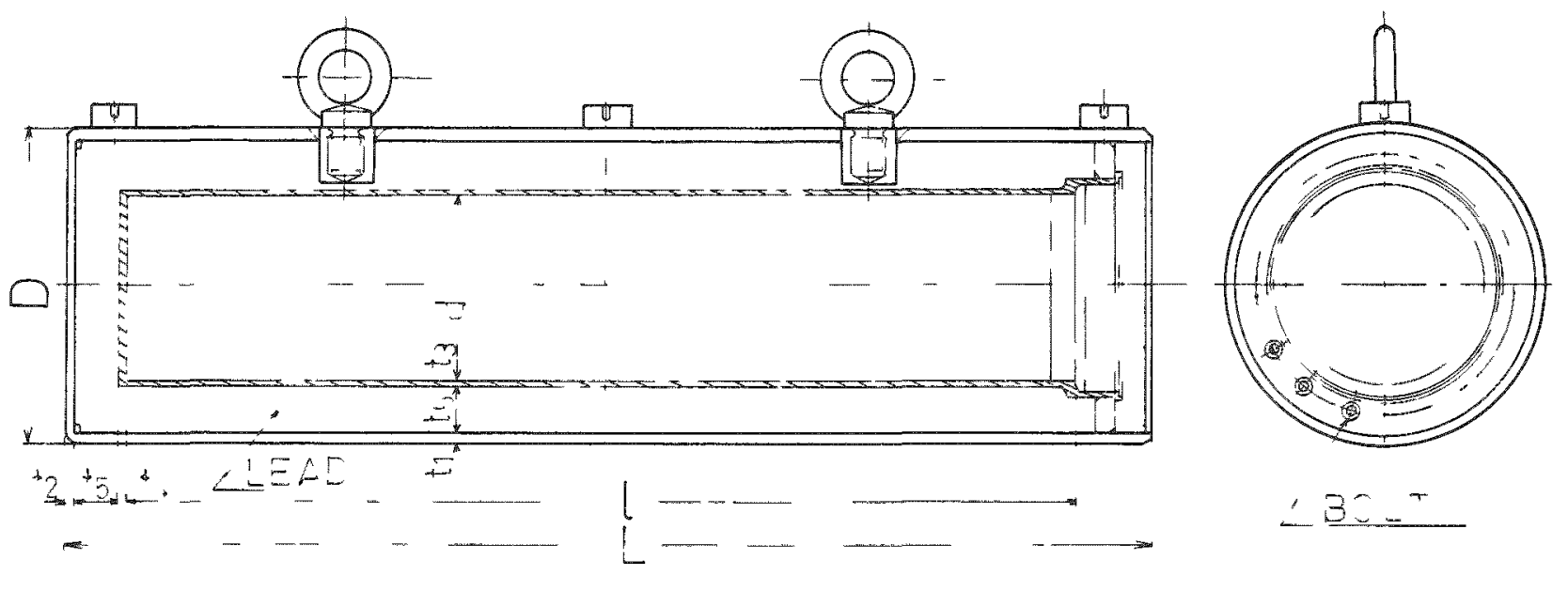

Fig. 1 ( a-k Vorol Dimen-1on

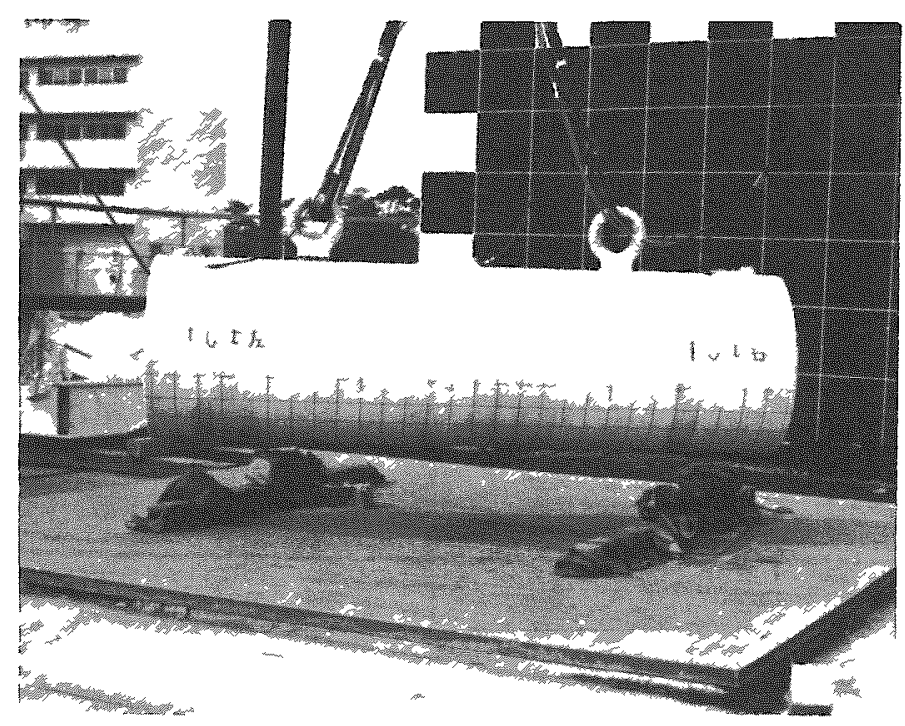

Tig. 2 I 2 acals Yodel $10 \mathrm{t}$ in Woight. thowng Refertnce Linc- 
The drop tests were always performed from $9 \mathrm{~m}$ in conformity with the IAEA Regulations (but only for the $1 / 8$ scale model with shockabsorber, 3 and $6 \mathrm{~m}$ drop tests also were done). Fig. 3 shows the drop test of the $1 / 2$ scale model just before collision.

In order to grasp satisfactorily the external force added on the model at the moment of collision and the deformations and damages caused by it, the following measurements were done;

(1) measurement of deceleration: three strain gage type accelerometers mounted on the top surface of model,

(2) measurement of deformation: by means of suitable measuring tools, the size and shape were recorded before and after every tests,

(3) damage of lid: damage of bolts and nuts for lid were examined, (4) record of motion at impact: in order to record and analyse the attitude of model during drop, at collision, and the behavior during rebound,high speed $16 \mathrm{~mm}$ motion pictures were taken.

\section{FXPERIMENT AND RESULT}

\section{Deceleration}

There were two kinds of accelerometer which could be used to measure the deceleration at impact, namely strain gagetype and piezo type. However, as the latter were strongly affected by weather condition and had some other defects, only strain gage type accelerometer was adopted in this experiment. And, to make clear the effect of measuring position on the magnitude and shape of acceleration pulse, though the attitude of model was slant, three accelerometers were mounted at the three position, namely on bottom side, center and lid side, on top surface of model by an adhesive agent.

The data of deceleration detected by accelerometers were once record on a data-recorder and later they were reproduced on an oscilloscope and an electro-magnetic oscillograph. Fig.4 shows an example of the pulse on oscilloscope for the $1 / 2$ scale model. Table 2 shows decelerations on each position for every scale models.

\section{Deformation}

As above-mentioned, the reference lines were drawn on outer surface, lid surface and bottom surface of models to locate the points of deformation. The diameter, length and radial deformation were 


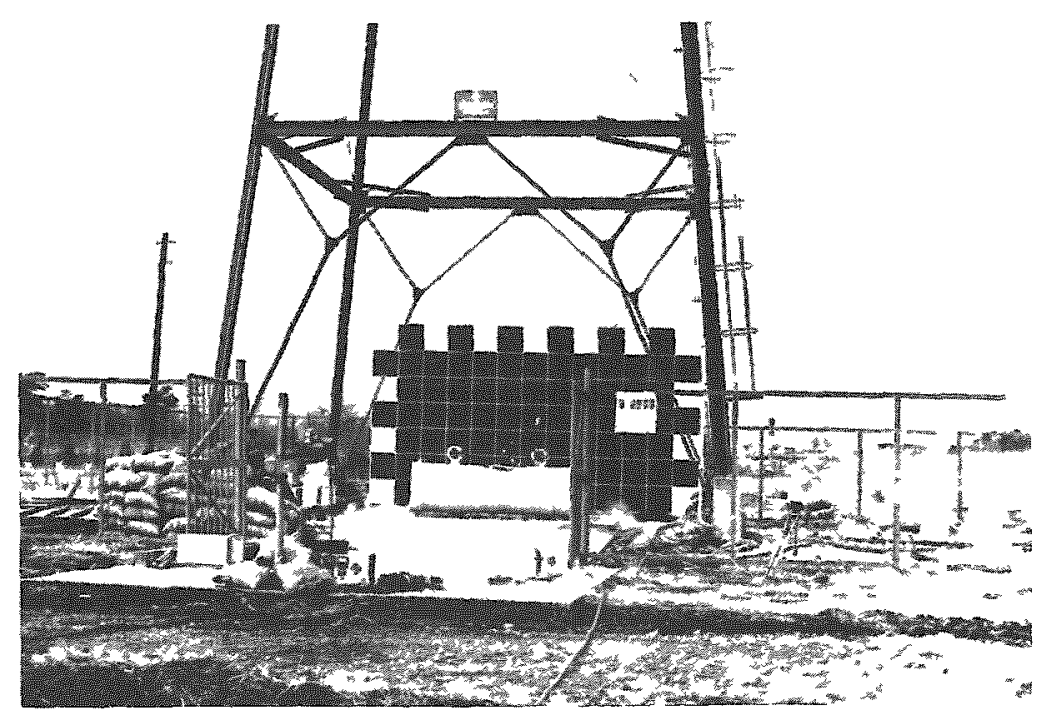

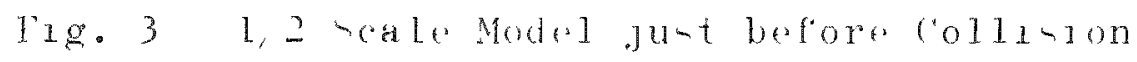

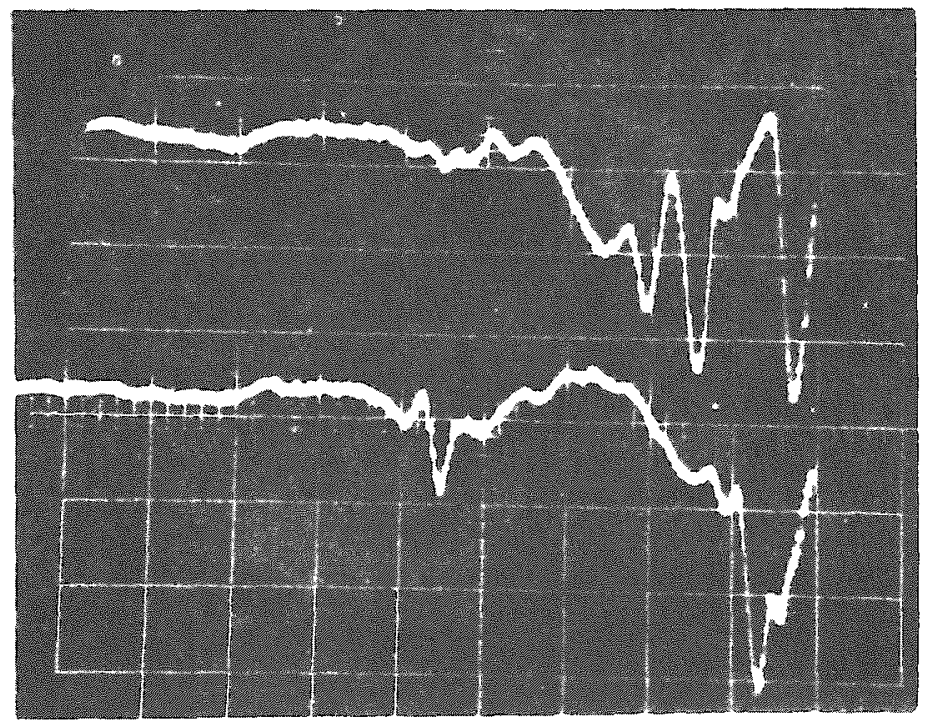

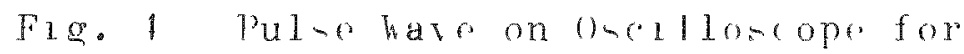
12 rala Vodrl Drop Tost 
Table 2. Deceleration for Scale Model

\begin{tabular}{|c|c|c|c|c|c|c|}
\hline \multicolumn{2}{|l|}{ Scale } & \multicolumn{5}{|c|}{ Deceleration } \\
\hline Scale & Weight $t$ & Lid Side & & Center & Bottom & Side \\
\hline $1 / 2$ & 10 & $830 \mathrm{~g}$ & & & 630 & $\mathrm{~g}$ \\
\hline $1 / 2.5$ & 5 & $1,410 \mathrm{~g}$ & & $1,100 \mathrm{~g}$ & 450 & $\mathrm{~g}$ \\
\hline $1 / 4 \mathrm{a}$. & 1.25 & $2,080 \mathrm{~g}$ & 2 & $2,200 \mathrm{~g}$ & 570 & g \\
\hline $\mathrm{b}$. & 1.25 & $2,220 \mathrm{~g}$ & & $920 \mathrm{~g}$ & 1,070 & $\mathrm{~g}$ \\
\hline $1 / 8$ a. & 0.15 & $1,710 \mathrm{~g}$ & & $1,920 \mathrm{~g}$ & 1,360 & $\mathrm{~g}$ \\
\hline $\mathrm{b}$. & 0.15 & $2,550 \mathrm{~g}$ & & $1,880 \mathrm{~g}$ & 2,230 & $\mathrm{~g}$ \\
\hline
\end{tabular}

measured before and after every tests for all models.

External Examination

The diameter change and deformation of diameter before and after test were shown in Fig.5 - 8. The deformation of diameter on the reference lines were shown in Fig.9 - 12 for $1 / 2,1 / 2.5,1 / 4$ and $1 / 8$ scale models respectively.

\section{Internal Examination}

In the case of $1 / 2$ and $1 / 2.5$ scale models, leak tests were conducted with water at $5 \mathrm{~kg} / \mathrm{cm}^{2} \mathrm{~g}$ and with air at $2 \mathrm{~kg} / \mathrm{cm}^{2} \mathrm{~g}$ during 30 minutes. In both cases no pressure drop was detected. The radial deformation of internal diameter were given in Fig.13 and 14 for $1 / 2$ and $1 / 2.5$ scale models.

\section{CONSTDERATION}

(1) The side reference lines swelled horizontally at the center as shown $\delta_{2}$ and $\delta_{4}$ in Fig.9 - 12 and Fig.13 andl4. It was common between all models.

(2) The highest reference line deformed always convexly below for all models, as shown by $\delta_{1}$ distribution.

(3) The lowest reference line deformed concavely below except the regions of both ends for the $1 / 2,1 / 2.5$ and $1 / 4$ models, as shown by $\delta_{3}$, but in the case of $1 / 8$ scale model, as shown in Fig.12, it deformed convexly below on the contrary to the other case, which was in agreement with the results in 1968.

(4) Therefore, as it seems that the deformation of the small sized scale model is quite different from that of large sized model, the scale model should be larger than a limited sized scale model so that the prototype cask may be simulated by model test. 


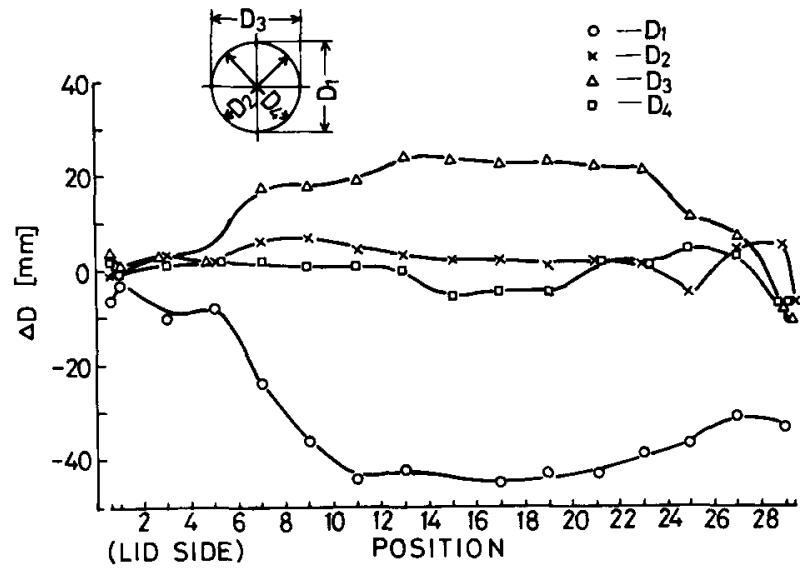

Fig. 5 Diameter Change of or $1 / 2$ Scale Model

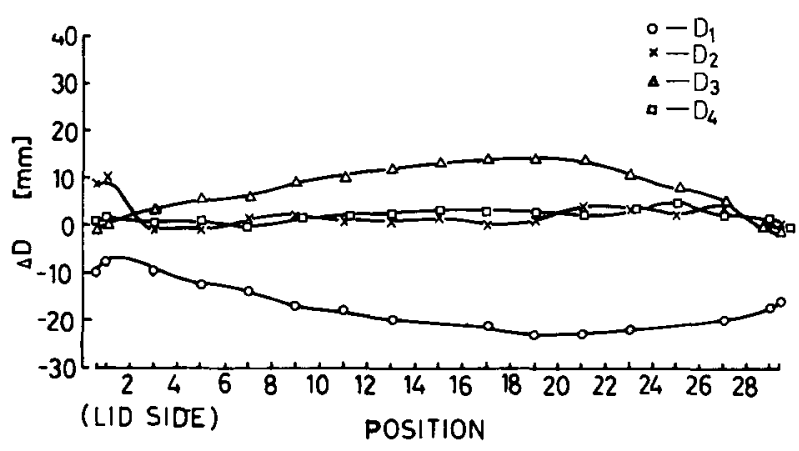

Fig. 7 Diameter Change for

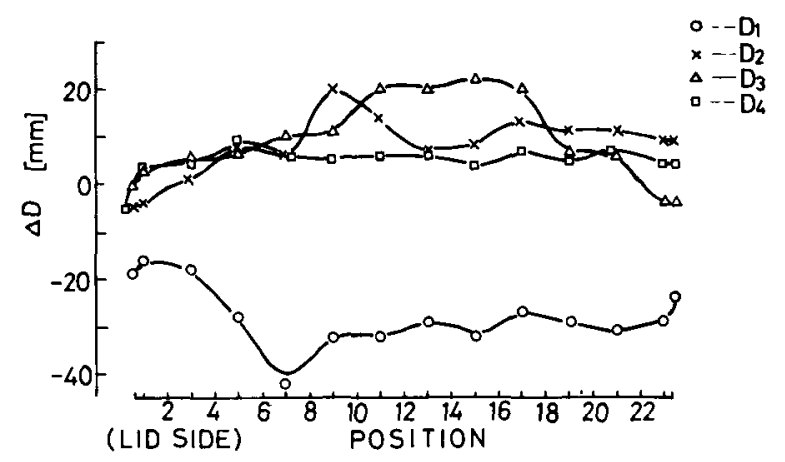

Fig. 6 Diameter Change for $1 / 2.5$ Scale Model

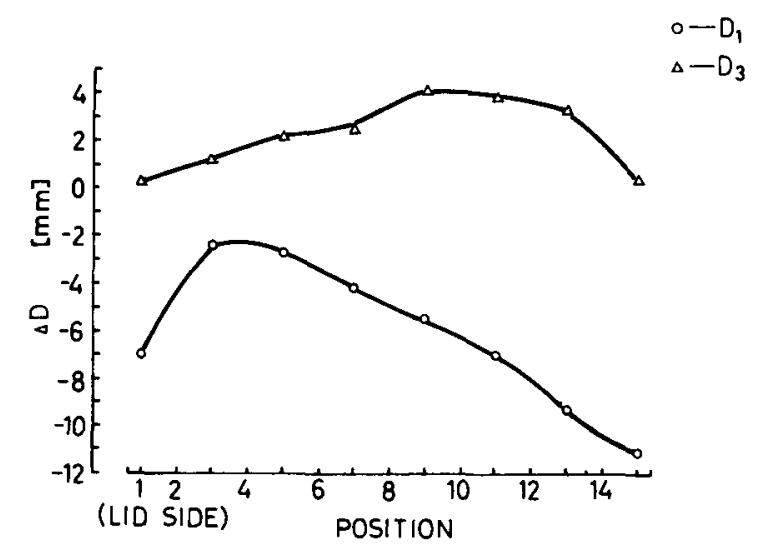

Fig. 8 Diameter Change for $1 / 8$ Scale Model 


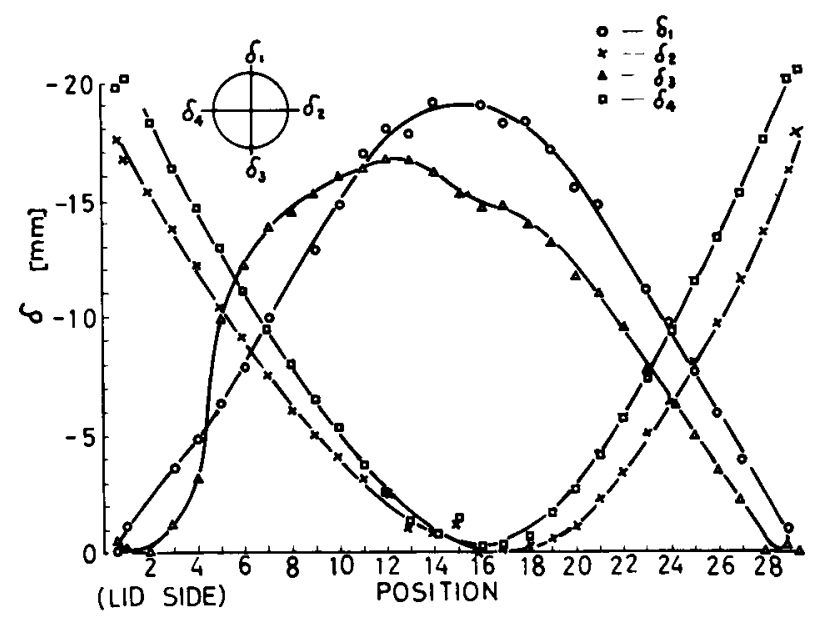

Fig. 9 Deformation of Diameter for $1 / 2$ Scale Model

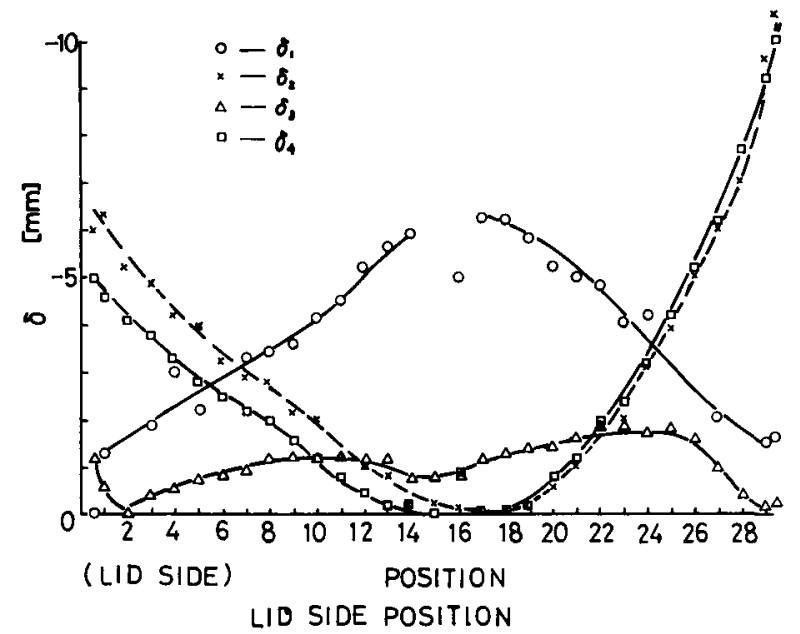

Fig.11 Deformation of Diameter for $1 / 4$ Scale Model

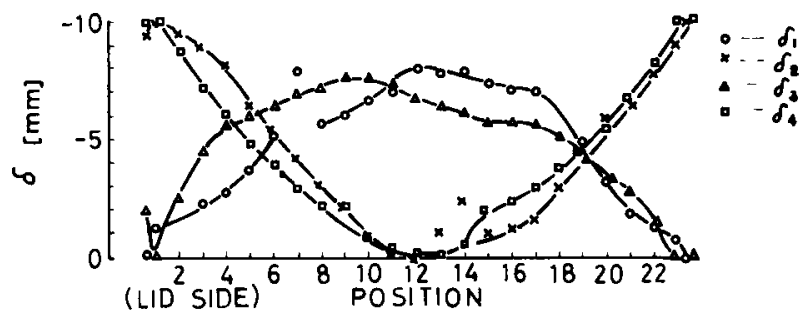

Fig.10 Deformation of

Diameter for $1 / 2.5$ Scale Model

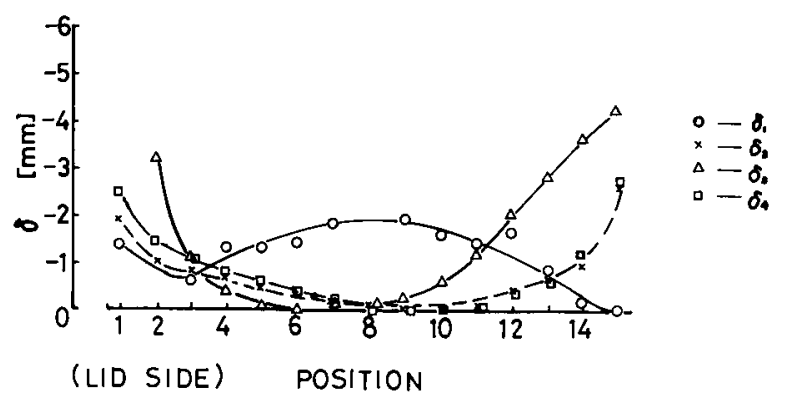

Fig.12 Deformation of Diameter for $1 / 8$ Scale Model 


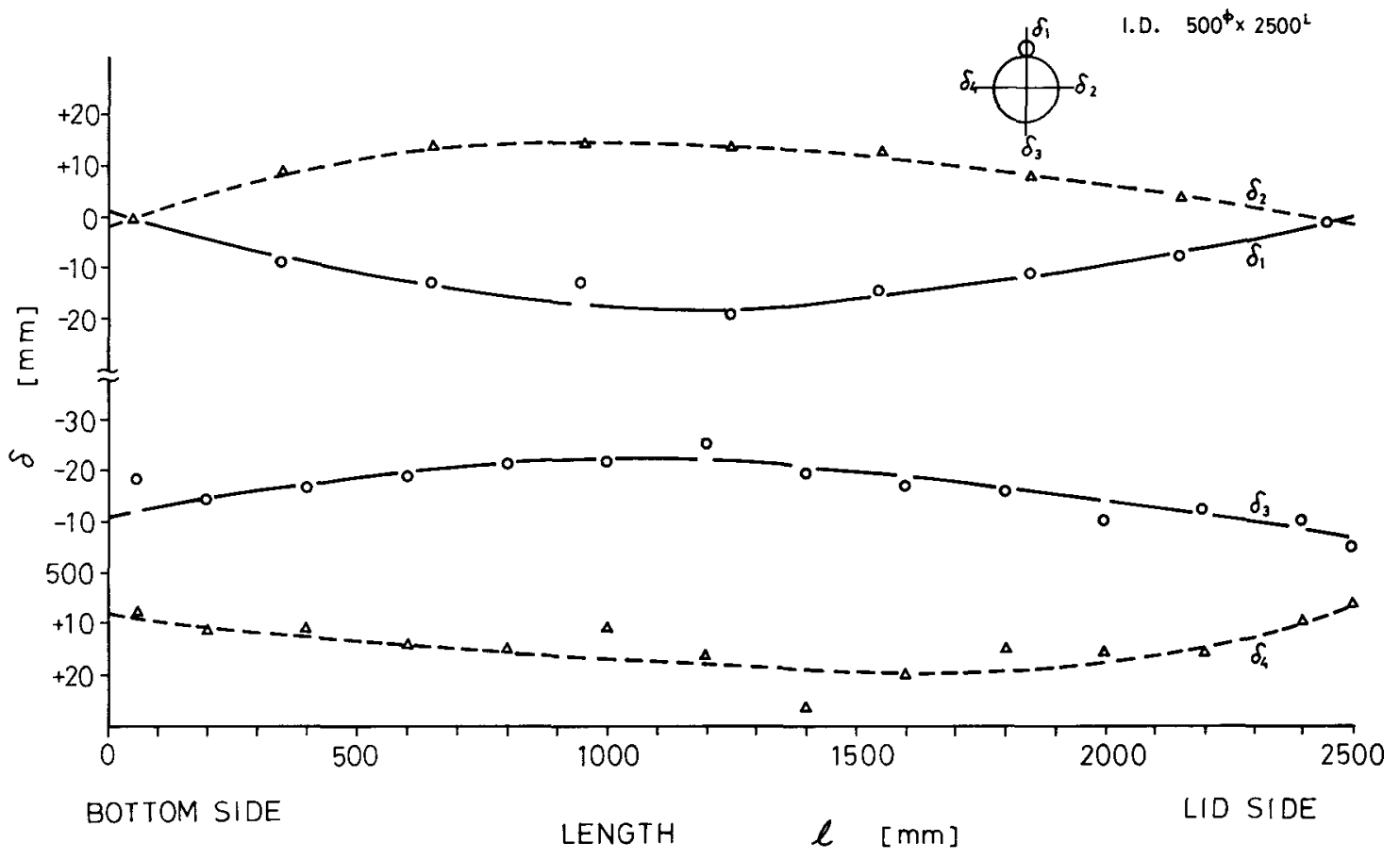

Fig. 13 Deformation of Internal Diameter for $1 / 2$ Scale Model

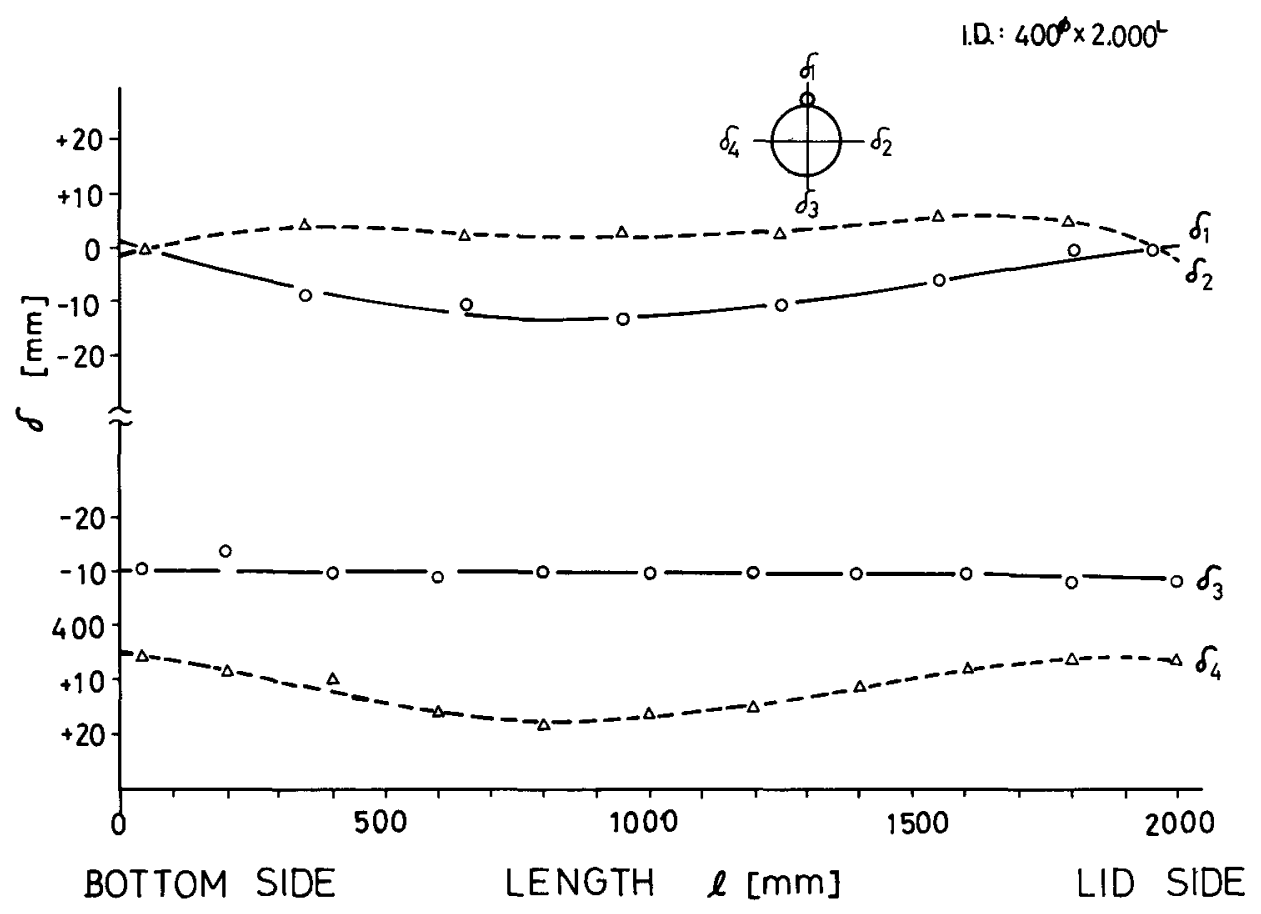

Fig. 14 Deformation of Internal Diameter for $1 / 2.5$ Scale Model 
The motion of models at drop test was recorded by a high speed motion picture (film speed 3,000 pps) and was analysed by a motion picture analyser. Fig.15 shows an example for the $1 / 2$ scale model when rebound began, after $147 \mathrm{msec}$ from the contact with target.

The models rebounded after collision and rested after few seconds. It moved always in the direction of bottom side from the first contact point. The results as follows;

$\begin{array}{lcccc} & \mathrm{T}_{\mathrm{r}} \mathrm{msec} & \mathrm{v} \mathrm{m} / \mathrm{s} & \mathrm{T}^{\prime} \mathrm{msec} & 1_{\mathrm{S}} \mathrm{msec} \\ 1 / 2 \text { scale } & 50 & 0.57 & 360 & 123.8 \\ 1 / 2.5 & 33 & 1.46 & 495 & 152 \\ 1 / 4 & 25 & 1.82 & 585 & 147\end{array}$

Here; $\mathrm{T}_{\mathrm{r}}$ : time until rebound begins after contact with target

$\mathrm{v}$ : average velocity at rebound

$T^{\prime}$ : time required before rest

$1_{\mathrm{S}}$ : distance of movement

\section{ANALYSIS \\ Relation Between Deceleration and Reduced Scale}

Assuming stress-strain relation for perfect plastic body and that whole potential energy of body is converted into crush deformation energy, the relation between fall height $H$ and external deformation $\delta$ for horizontal drop of cylinder may be given as

$$
\delta=1.4 \mathrm{R}\left(\frac{\gamma_{\mathrm{H}}}{\sigma_{\mathrm{y}}}\right)^{2 / 3}
$$

And, assuming that impulse is equal to momentum change, deceleration may be given as follows:

$$
\left(\frac{\mathrm{dv}}{\mathrm{dt}}\right)_{\max }=-\frac{\pi \mathrm{g}}{2.8} \frac{\mathrm{H}^{1 / 3}}{\mathrm{R}}\left(\frac{\sigma_{\mathrm{y}}}{\gamma}\right)^{2 / 3}
$$

Depending Eq.(2), the maximum deceleration is inversely proportional to the reduced scale. In Fig.16 the experimental results are plotted. Calculating from the dotted line, which is drawn to fit the experimental data, it seems that the maximum deceleration of prototype $(80 \mathrm{t})$ at horizontal drop impact comes to about $600 \mathrm{~g}$ or 


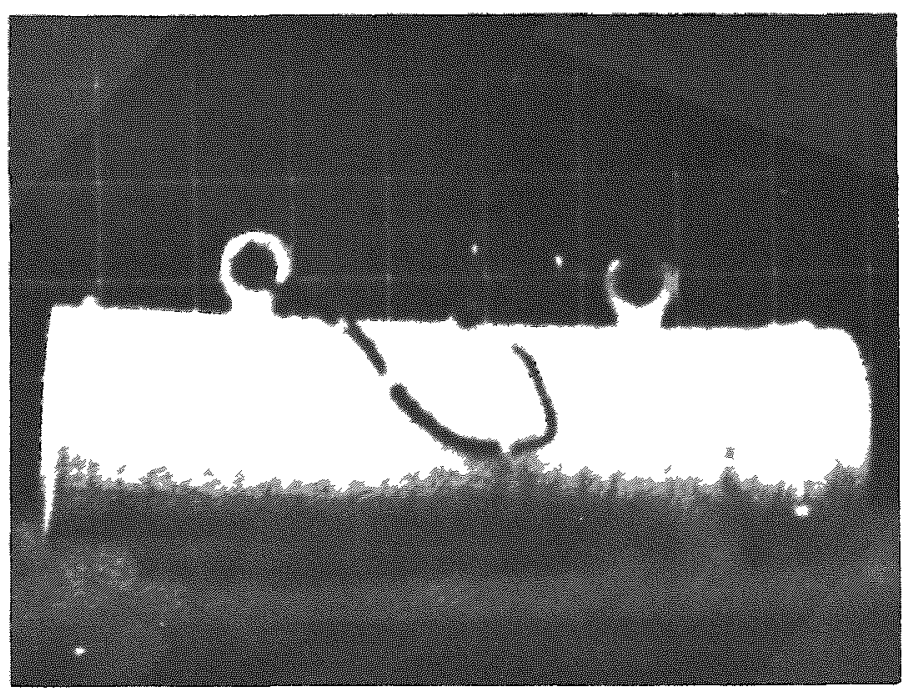

Fig. 15 The $1 / 2$ Scale Model when Rebound begins 
less than it.

Relation Between Fxternal Deformation

and Scale Model Diameter $\mathrm{D}_{1}$

If deformation $\delta$ at the center of model versus diameter $D_{1}$ is plotted as Fig.17, it seems to be quite all right to consider that the linear relation exists between $\delta$ and $D_{l}$. From this result, the external deformation of diameter in the vertical direction at the center of prototype cask ( $80 \mathrm{t}$ ) may be assumed to be approximately $80 \mathrm{~mm}$.

\section{CONCLUSION}

(1) The theoretical analysis has been applied to reveal the existence of linear relation between the maximum deceleration and reduced scale, which has been proven by the experimental results using the $1 / 2,1 / 2.5,1 / 4$ and $1 / 8$ scale models.

(2) It has been found that the deformation of cask model at drop impact strongly depends upon the reduced scale. That is, the deformation of the $1 / 4$ scale model, which is same as the result in 1967 using $1 / 8.5$ and $1 / 16$ scale models, is significantly different from the deformation of other larger scale models. Deducing from this fact,it is desirable to use the scale model larger than at least $1 / 4$ scale, in order to estimate the deformation of prototype from a scale model test.

\section{ACKNOWLFDGMENT}

The authers wish to express their gratitude to the Atomic Energy Bureau and the Japan Society of Mechanical Engineers. They also wish to express their thanks to the member of the Research Subcommittee for Design of Spent Fuel Shipping Cask and to the staffs of Government Mechanical Laboratory and Institute of Medical and Dental Engineering in Tokyo Medical and Dental University, who accomplished the series of drop impact test for a long time. 


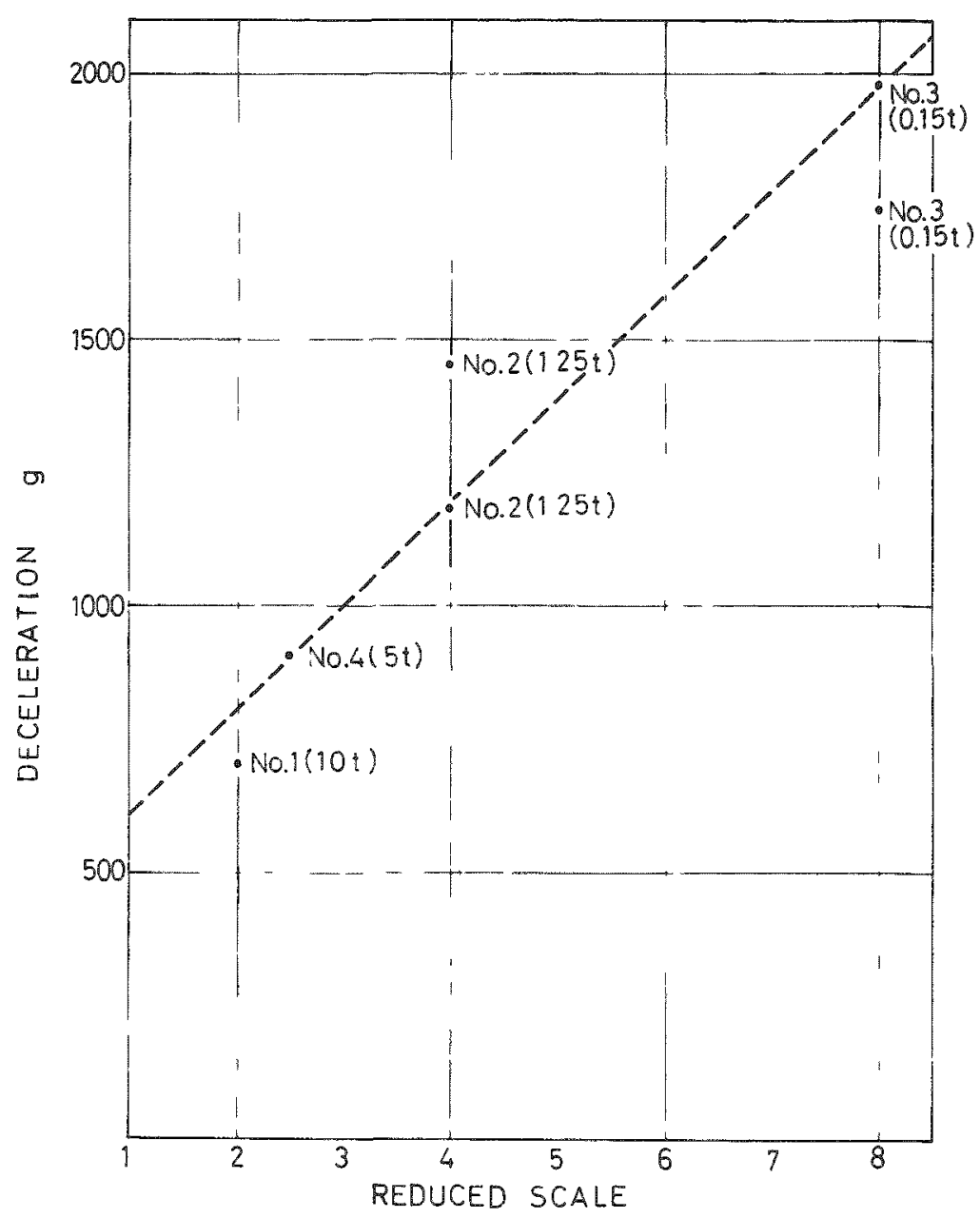

Fig. 16 Relation between Deceleration and Reduced Scale

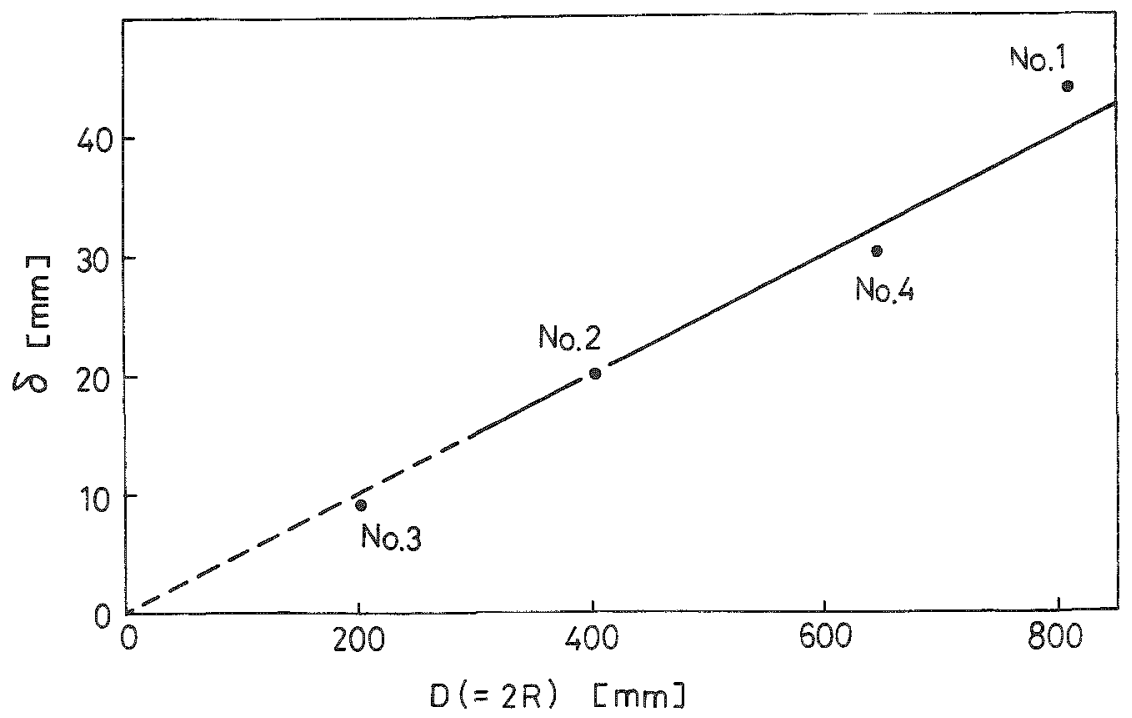

Fig. 17 Relation between External Deformation and Scale Model Diameter 
F. C. Davis

Oak Ridge National Laboratory*

Oak Ridge, Tennessee

ABSTRACT

An impact test program was conducted at Oak Ridge National Laboratory to determine the energy absorption characteristics of typical heat transfer or structural fins on shipping casks as these fins undergo dynamic, gross plastic deformation. It was assumed that the energy absorption characteristics of fins welded parallel to the longitudinal axis of a cylindrical cask are linear with respect to their length, and the test program was designed to determine the energy absorption capability per inch of fin length along the cask body. Specimens of typical fin geometries were impacted with free-falling weights dropped from known heights, and the force-time relationships occurring during each impact were recorded. A computer program was used to convert the test data into deformation-time and energy-time relationships. These relationships were correlated in a set of curves that enable the cask designer or analyst to compute the energy absorption capacity of a longitudinal fin on a cask as a function of its geometry and the percentage of deformation it is expected to experience as well as the peak force the fin would experience during the impact resulting from a 30-ft free drop onto an essentially unyielding horizontal surface.

\section{INTRODUCTION}

When a package containing radioactive or fissile material is shipped from one location to another, the package is subject to regulations governing its structural integrity and its shielding and heat dissipating capabilities. Many complex questions have arisen in connection with demonstrating the conformance of shipping packages or casks to the free-drop portion of the hypothetical accident conditions specified in these regulations. Many shipping casks have external ribs or fins welded to the outer shell to provide additional strength or for heat transfer purposes. An impact such as that specified in the first condition of the hypothetical accident will result in gross deformation of these fins, and performing a theoretical analysis to determine the energy absorbed by the fins

*Oak Ridge National Laboratory is operated by Union Carbide Corporation under contract with the United States Atonic Energy Comission. 
during the gross deformation would be very difficult. Use of analyses based on static material properties generally results in ultraconservative design because the stress for a given strain generally will be much higher under impact conditions. Thus, the impact testing program reported here was undertaken to develop a reliable method for computing the energy absorption capacity of a longitudinal fin on a cylindrical cask subjected to an impact resulting from the $30-f t$ free drop.

\section{EXPERIMENTAL PROGRAM AND APPARATUS}

The general approach adopted for the experimental program involved dropping a hammer of known weight from a predetermined height onto a specimen and recording the force-time relationship experienced by the specimen throughout the duration of the resulting impact. Force with respect to time can be converted to acceleration with respect to time by using Newton's second law. This acceleration-time relationship can be converted to a velocity-time relationship by using the equation

$$
v_{t}=v_{0}-\int_{t=0}^{t=t} a d t
$$

where

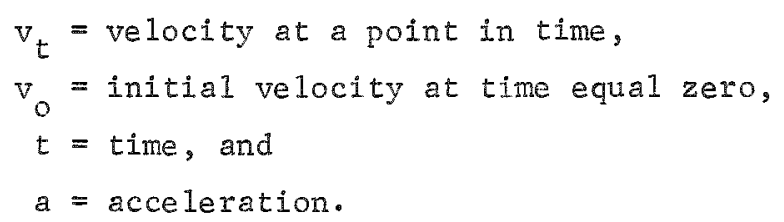

Similarly, the velocity-time relationship can be used to determine the deformation-time relationship by using the expression

$$
x_{t}=\int_{t=0}^{t=t} v_{t} d t=\int_{t=0}^{t=t} v_{0} d t-\int_{t=0}^{t=t} \int_{t=0}^{t=t} a d t d t
$$

where $\mathrm{X}_{t}=$ the displacement at a point in time. Knowing the force-time and the deformation-time relationships, the energy absorbed can be calculated from the expression

$$
\mathrm{U}=\int_{0}^{\mathrm{X}} \mathrm{p} d \mathrm{X}
$$

where

$U=$ energy absorbed for a specific amount of deformation, 


$$
\begin{aligned}
& \mathrm{X}=\text { deformation, and } \\
& \mathrm{P}=\text { applied force. }
\end{aligned}
$$

At the end of the impact duration, at which time the velocity has become zero, the calculated absorbed energy should be approximately equal to the kinetic energy of the impacting hamer at time equal zero. This gives a time at which the experimental data can be verified.

The impact lests were conducted at the Oak Ridge National Laboratorv (ORNL) Drop Tower shown in Fig. 1. This structural steel tower is $40 \mathrm{ft} \mathrm{high} \mathrm{and} \mathrm{its}$ drop base is comprised of a surface of armor plate embedded in steel-reinforced concrete. Two 3-by-3-in. angles 3/16 in. thick were attached to the tower vertically to guide the impact hanmer during its free fall. The basic structure of this hammer weighed $99 \mathrm{lb}$, but this basic weight could be increased in $21-1 \mathrm{~b}$ increments by the addition of steel blocks to the hammer and a maximum weight of about $500 \mathrm{lb}$ could be obtained. The guide rails, weights, impact hammer, and other equipment used in the impact tests are shown in Fig. 2.

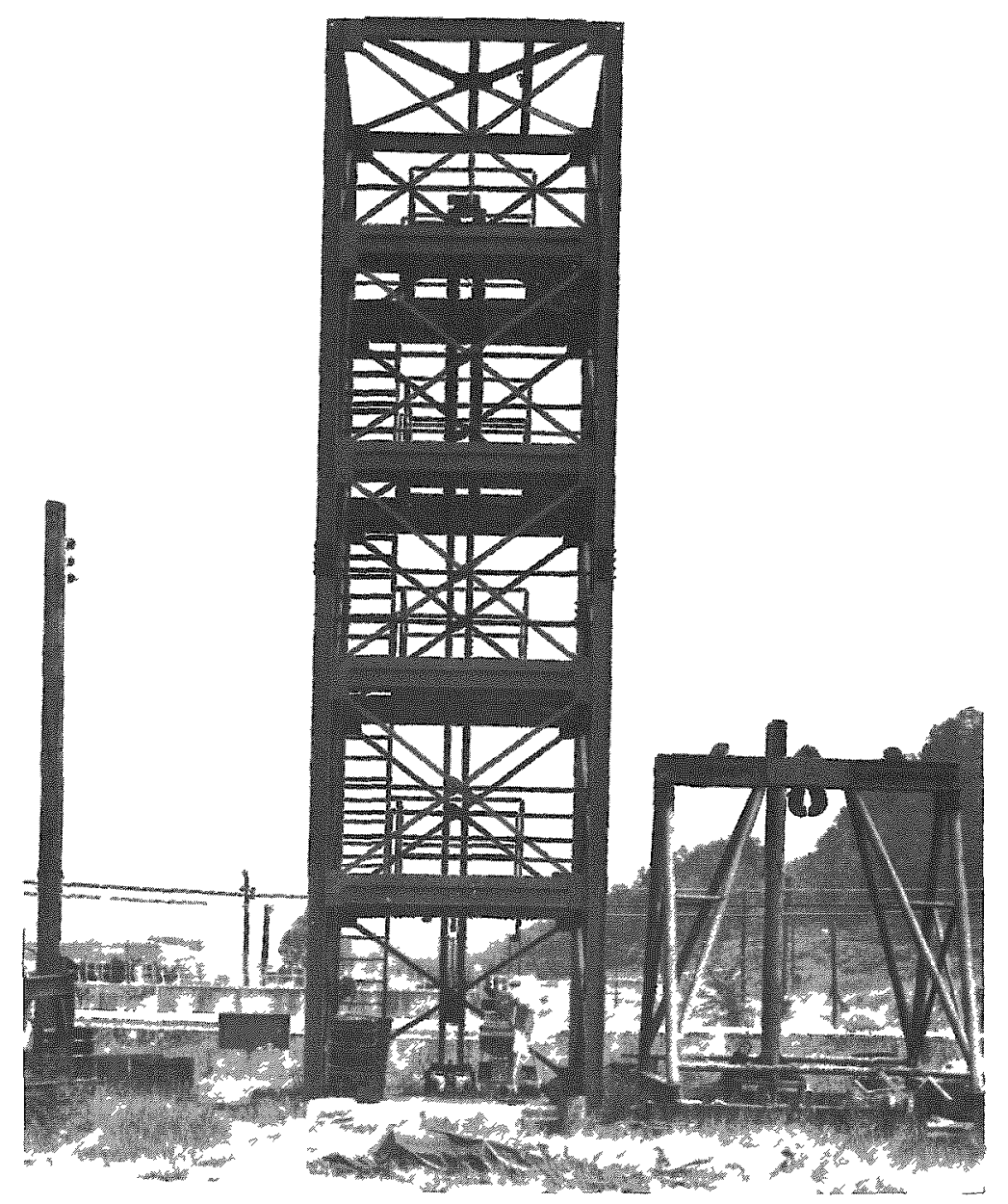

Fig. 1. The ORNL Drop Tower. 


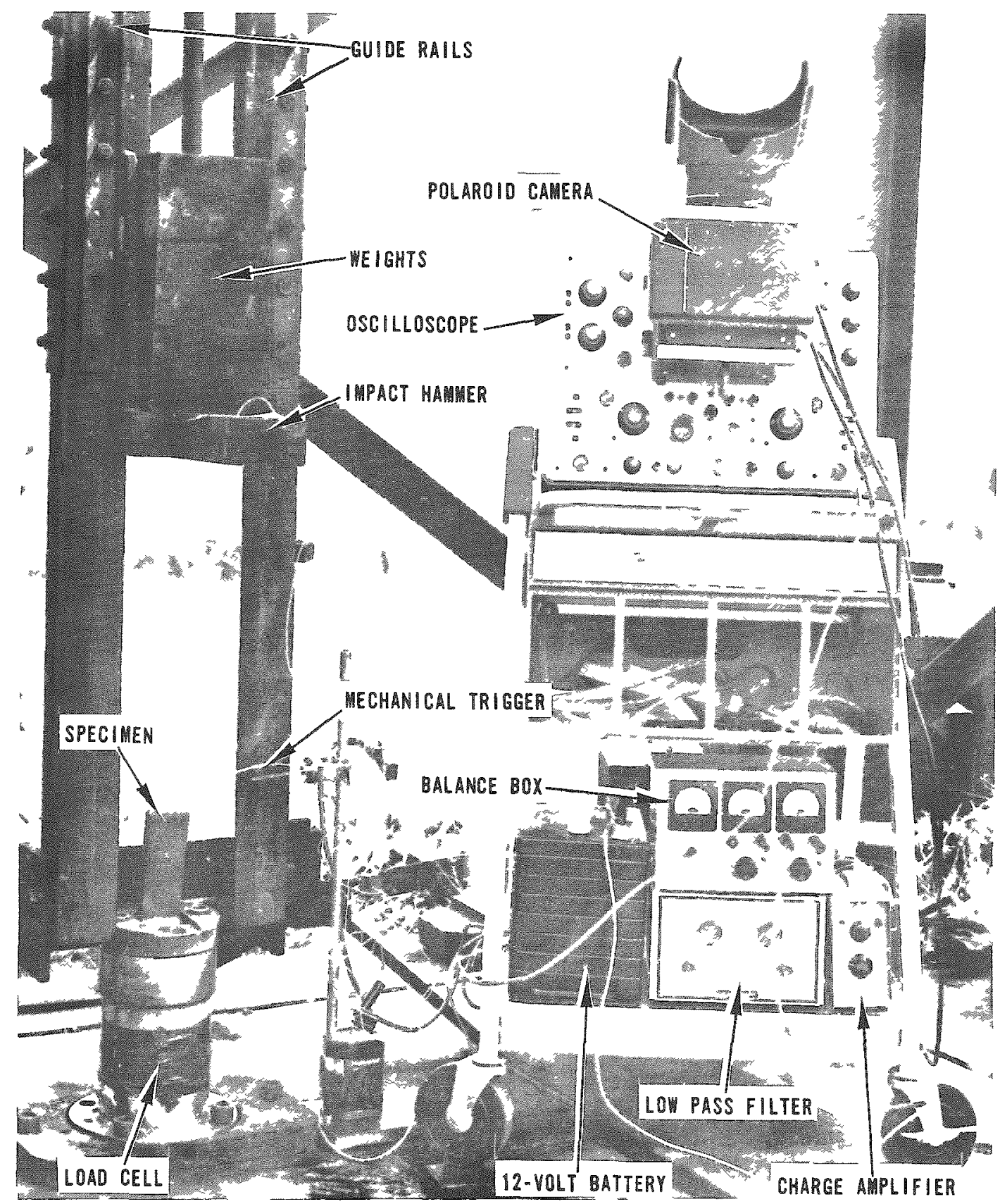

Fig. 2. Equipment Used in Cash Fin Specimen Impact Tests at the ORNL Drop Tower.

Three load cells were designed to provide different ranges of sensitivitv from 0 to 300,000 lib necessary to cover the fin geometries of interest. Bunded resistance strain gages were secured to the peripher of the load cells with epoxy resin and wired into a full Wheatstone bridge arrangement. The output of the bridge was fed to one chamel of a dual-heam oscilloscope with a dual-trace differential amplifier. During the latter half of the tests, acceleration-time relationships vere also obtained by attaching a piezoelectric acceleroneter to the hammer and feeding its output signal through a charge amplifier and a lowpass filter to the second channel of the uscilloscope. With the incorporation 
of this instrumentation, a force-time relationship and an acceleration-time relationship were recorded simultaneously for each impact.

DESIGN AND FABRICATION OF TEST SPECIMENS

Consider the cross section of a cylindrical cask with longitudinal fins along its axis impacting a horizontal level surface, as shown in Fig. 3 . It is

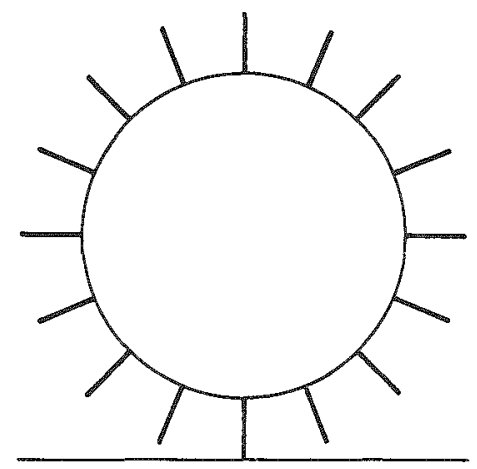

Fig. 3. Cross Section of Cylindrical Cask With Radial Fins Impacting a Horizontal Surface.

obvious that only one fin may have an angle of inclination of zero degrees, while the angle of inclination of adjacent fins will vary according to the position of the fins around the circumference of the cask. The decision was made to test fin specimens at five different angles of inclination: $0,10,20,30$, and $40^{\circ}$. The energy absorption characteristics of longitudinal fins on shipping casks were considered a linear function of the length of the fin in this program. Five specimens of each configuration shown in Fig. 4 were fabricated from ASIM A 285, Grade C, fire box quality steel, which has a yield strength of 30,000 psi.

\section{PERFORMANCE OF TESTS}

Impact tests were conducted on 275 specimens of shipping cask fins. In each test, a fin specimen of the desired geometry was securely clamped to the top of the load ce11, and the appropriate sweep rate and vertical gain were set on the oscilloscope. These settings were a function of the drop height, weight dropped, specimen geometry, and sensitivity of the load cell. The mechanical trigger was set a small distance above the top of the fin specimen. The hammer with an appropriate amount of added weight was raised to the desired drop height and released. The free-falling hanmer closed the contacts on the mechanical trigger, initiating a single sweep on the oscilloscope. Impact of the hamer on the fin 


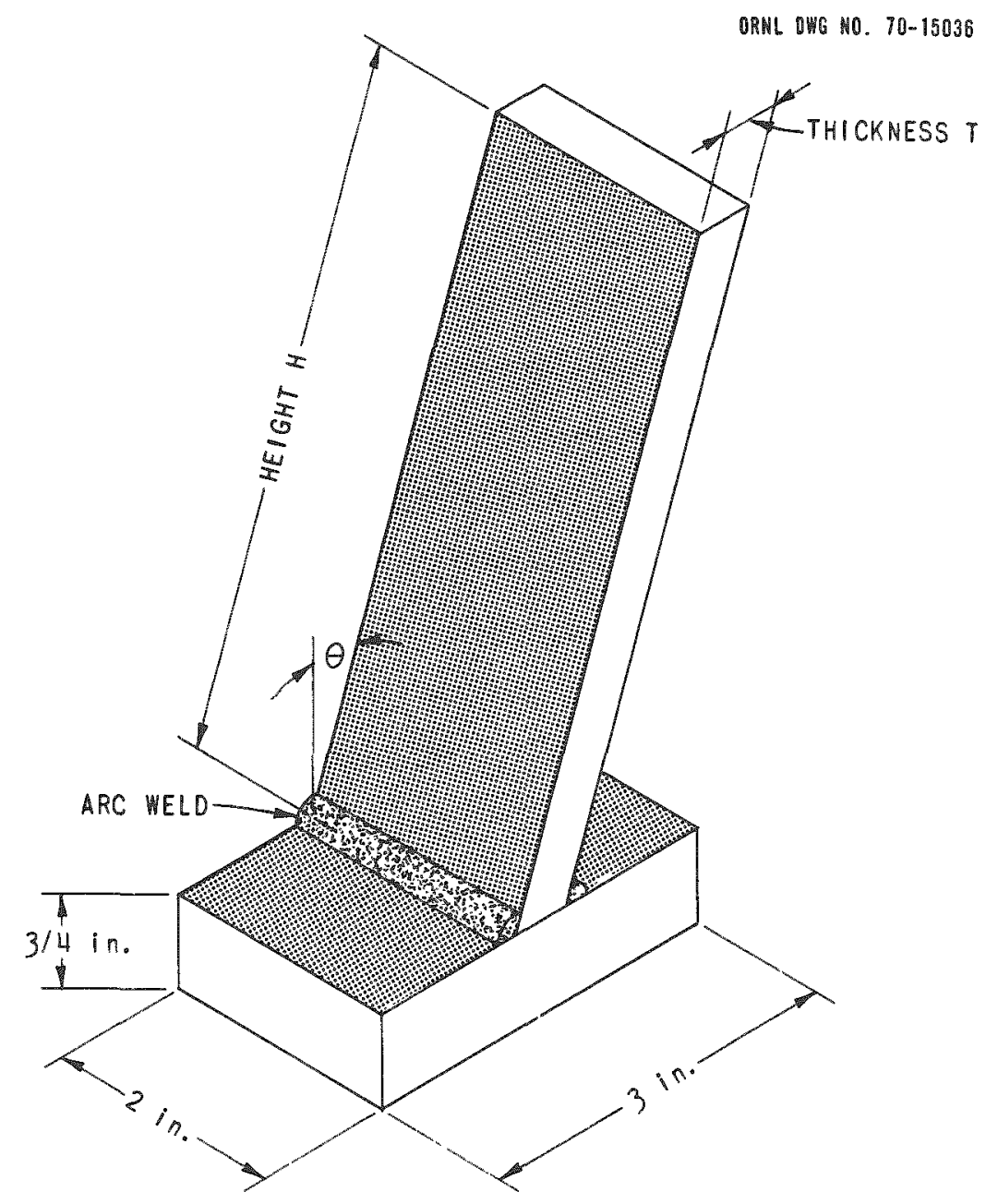

\begin{tabular}{|c|c|c|c|c|c|c|c|c|c|c|c|c|c|c|c|c|c|c|c|c|c|}
\hline \multirow{4}{*}{$\left(\begin{array}{c}\top \\
\left(i n_{0}\right)\end{array}\right)$} & \multicolumn{21}{|c|}{$\theta$} \\
\hline & \multicolumn{5}{|c|}{$0^{\circ}$} & & 10 & $0^{\circ}$ & & \multicolumn{4}{|c|}{$20^{\circ}$} & \multicolumn{4}{|c|}{$30^{\circ}$} & \multicolumn{4}{|c|}{$40^{\circ}$} \\
\hline & \multicolumn{21}{|c|}{$H\left(i n_{0}\right)$} \\
\hline & $3 \frac{1}{2}$ & 4 & 6 & 8 & 9 & 4 & 6 & 8 & 10 & 4 & 6 & 3 & 0 & 4 & 6 & 8 & 10 & 4 & 6 & & 10 \\
\hline $1 / 4$ & & $x$ & $x$ & & & & $x$ & $x$ & $x$ & & $x$ & 4 & 1 & & $x$ & $x$ & $x$ & & $x$ & $x$ & $x$ \\
\hline $3 / 8$ & & & & & & $x$ & $x$ & $x$ & $x$ & $x$ & $x$ & 4 & 8 & $x$ & $x$ & $x$ & & $x$ & $x$ & $x$ & $x$ \\
\hline $1 / 2$ & $x$ & & $x$ & $x$ & & $x$ & $x$ & $x$ & $x$ & $x$ & $x$ & 4 & ? & $x$ & $x$ & $x$ & $x$ & $x$ & $x$ & $x$ & $x$ \\
\hline $5 / 8$ & & & & & & & $x$ & $x$ & $x$ & $x$ & $x$ & 4 & 6 & $x$ & $x$ & $x$ & & $x$ & $x$ & $x$ & $x$ \\
\hline $3 / 4 \mid$ & & & $x$ & & $x$ & $x$ & $x$ & $x$ & $x$ & $x$ & $x$ & 6 & 1 & $x$ & $x$ & & $x$ & $x$ & $x$ & $x$ & $x$ \\
\hline
\end{tabular}

Fig. 4. Dimensions of Fin Specimen Configurations Tested.

specimen transmitted a force to the load cell. This force caused the strain gage bridge associated with the load cell to produce an output voltage proportional to the applied force. The voltage, which changed rapidly with time, was displayed on the oscilloscope screen and recorded by a scope camera. A typical force-time photograph recorded during an impact is shown in Fig. 5. 
OKNL PNQTO NO. 101592

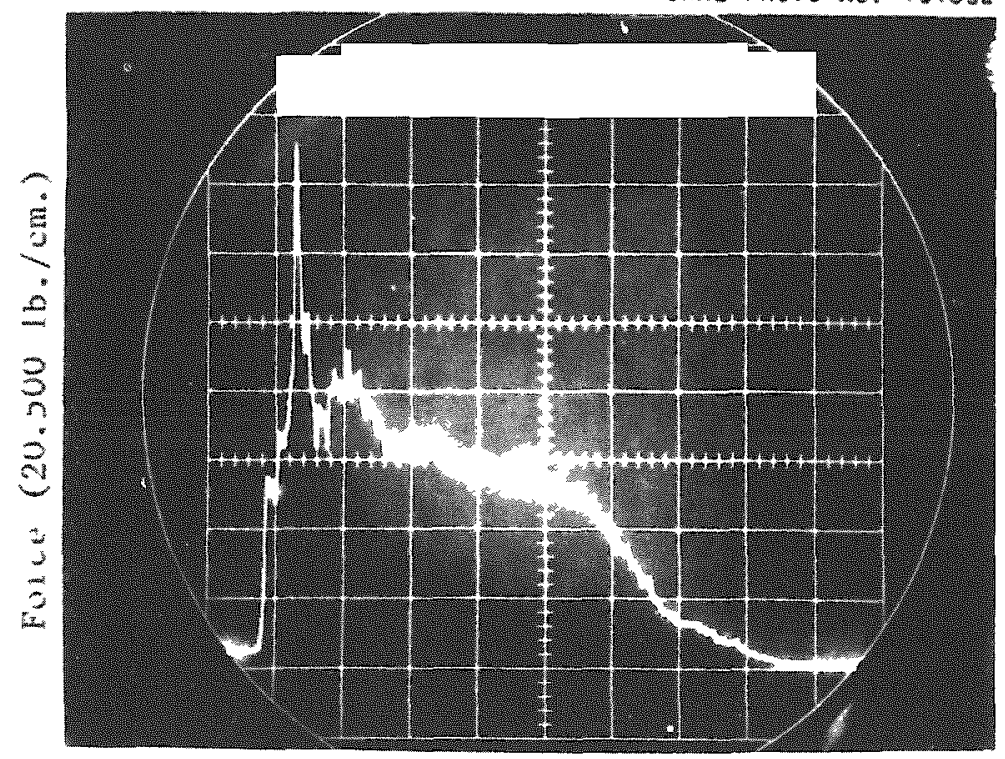

Time (1 msec. $/ \mathrm{cm}$.

Fig. 5. Force-Time Photograph Taken During Impact Test of a 3.5-in.-High Fin Specimen $1 / 2$ in. Thick With a Zero-Degree Angle of Inclination.

After 157 fin specimens had been impact tested, the decision was made to measure and record the acceleration-time relationships of the hammer during the tests because some ringing, thich caused difficulties, had appeared in the load ceil signal. An accelerometer was attached to the hammer and its output signal was transmitted to the oscilloscope through a charge amplifier and low-pass filter. Thus, the impact force-time relationship and the acceleration-time relationship for each of the remaining 118 fin specimens tested were recorded simultaneously. A typical photograph of these oscilloscope recordings is shown in Fig. 6 .

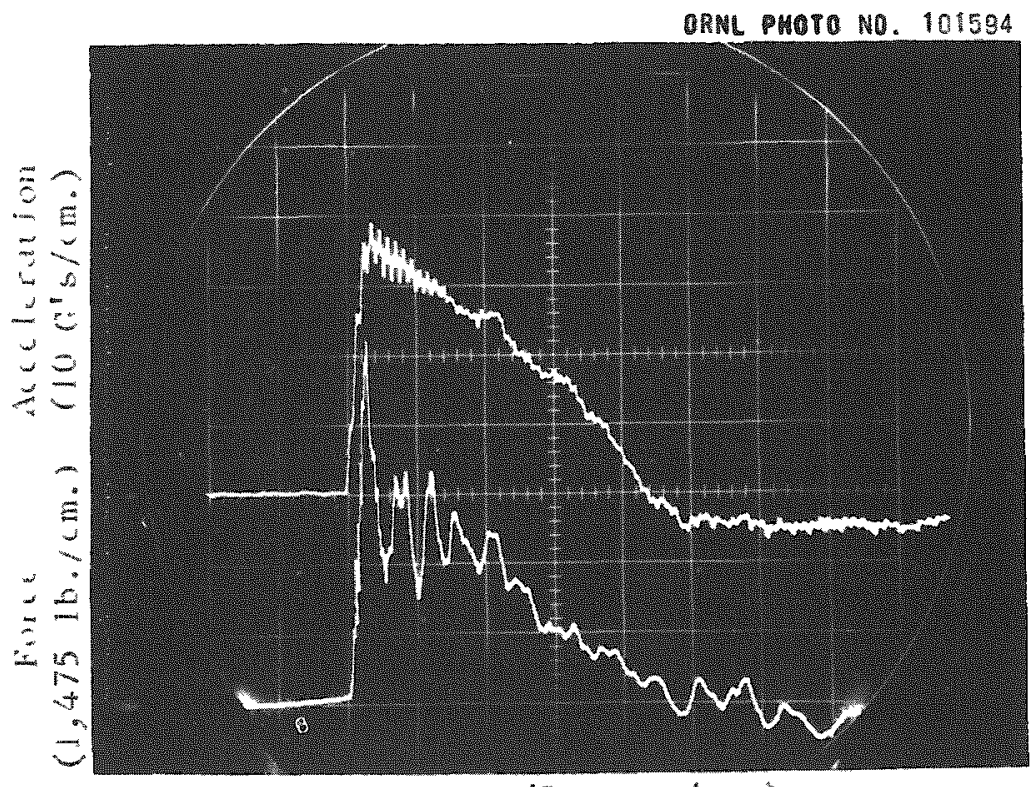

Time ( $5 \mathrm{msec} / \mathrm{cm}$.

Fig. 6. Force-Time and Acceleration-Time Photograph Taken During Impact Test of a 4-in.-High Fin Specimen $3 / 8$ in. Thick With a $40^{\circ}$ Angle of Inclination. 
From the trace or traces on each photograph, coordinates of points along the curves were read, recorded, and converted to force or acceleration values as a function of time by applying the instrumentation settings and calibration values. The acceleration-time data recorded in this manner were analyzed by applying the methods used to analyze the force-time data except that the forceto-acceleration computation was not required. The results obtained should be theoretically identical to those obtained by using the force-time data.

\section{DATA TRANSFORMATION}

A Fortran program applicable to the IBM 360 computer at ORNL was prepared to transform the force-time and acceleration-time data obtained manually from the oscilloscope photographs into absorbed energy and deformation data. The computer output included a printed copy of the final computational results and a deck of IBM cards that served as input data cards for an exiscing computer plotting program.

\section{EVALUATION OF TEST RESULTS}

Sets of curves, one of which is shown in Fig. 7, were derived from the force-time data obtained from the load cells during the impact tests, and the heights (H) of the specimens tested are given for their respective curves. These curves are plots of the absorbed energy divided by the plastic moment of each specimen tested versus the vertical deformation of the specimen multiplied by 100 and divided by the original height of the specimen. This abscissa dimension is essentially the percentage of total deformation possible. The plastic moment values used were calculated from the expression

$$
M_{p}=-\frac{b t^{2}}{4}
$$

where

$$
\begin{aligned}
M_{p} & =\text { static plastic monent of specimen, } \\
c_{y} & =\text { yield stress of specinen matcrial }=30,000 \text { psi, } \\
b & =\text { length of specimen }=2 \text { in., and } \\
t & =\text { thickness of specimen in inches. }
\end{aligned}
$$

Therefore, the static plastic moment

$$
M_{p}=15,000 t^{2} \mathrm{in}-1 \mathrm{~b} .
$$




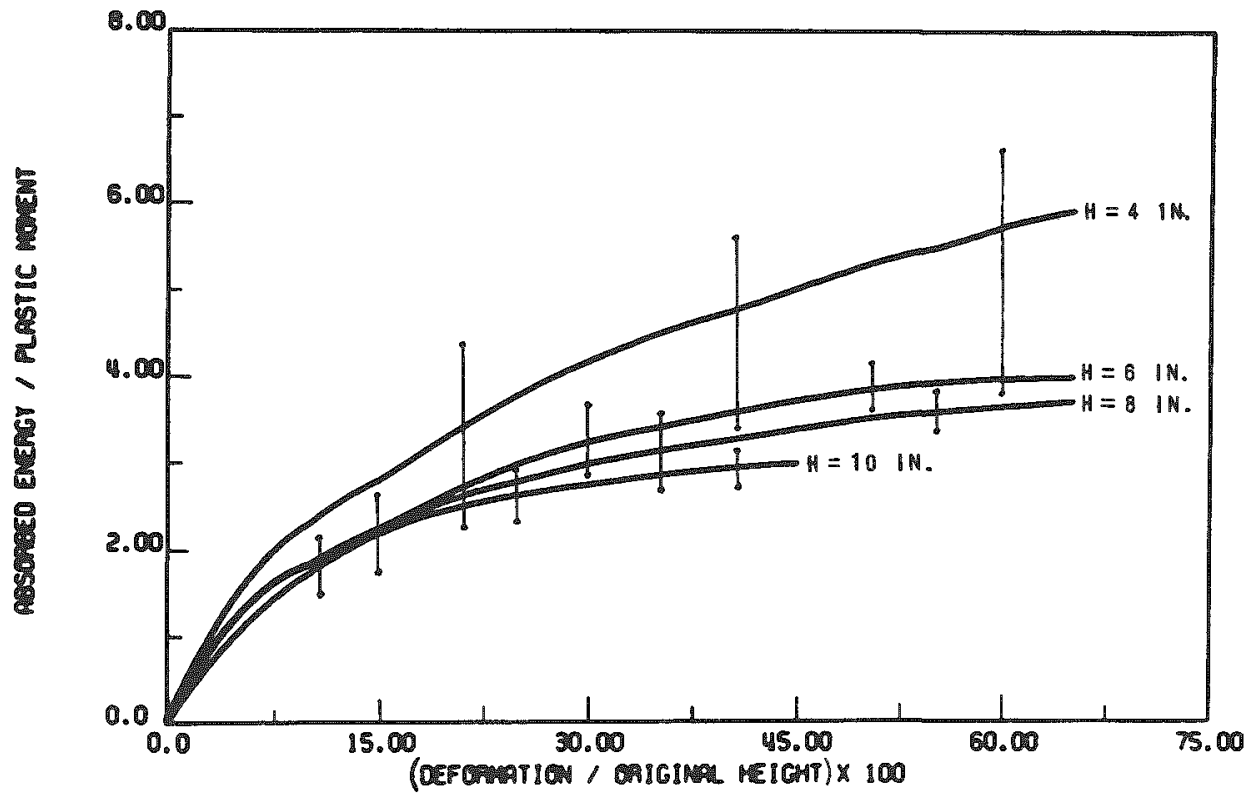

Fig. 7. The Absorbed Energy Derived From Load Ce11 Test Data Divided by the Plastic Moment as a Function of the Percentage of Deformation Experienced by Impacted Specimens with a $20^{\circ}$ Angle of Inclination.

Other sets of curves, one of which is shown in Fig. 8, were derived from the acceleration-time data obtained from the accelerometer during the impact tests.

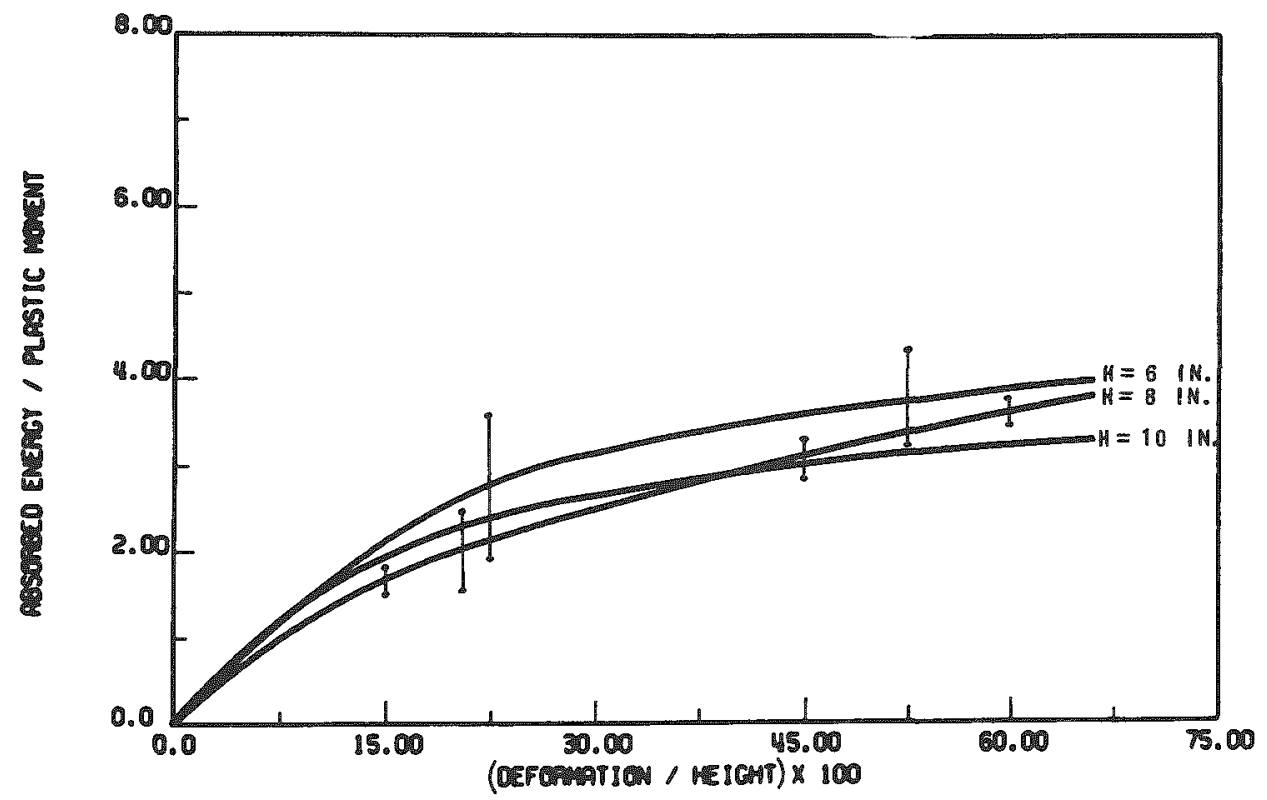

Fig. 8. The absorbed Energy Derived From Accelerometer Test Data Divided by the Plastic Moment as a Function of the Percentage of Deformation Experienced by Impacted Specimens With a $20^{\circ}$ Angle of Inclination. 
These curves are also plots of the absorbed energy divided by the plastic moment of each specimen tested versus the percentage of deformation experienced by the impacted specimen. The curves derived from the accelerometer data and those derived from the load cell data should theoretically be identical. However. careful analysis of these curves indicated that those derived from the accelerometer data show approximately 10\% less energy absorption than those derived from the load cell data. Although not large, this discrepancy remained fairly constant, and it may be the result of a calibration error. The accelerometer was not calibrated by using the instrumentation used during performance of the tests. The calibration data received from the manufacturer were used in the analysis.

There is a vast difference between the energy absorption capabilities of the stiff (angles of inclination of 0 and $10^{\circ}$ ) specimens and the less stiff (angles of inclination of 20,30 , and $40^{\circ}$ ) specimens. The reason for this vast difference is that all of the specimens with zero-degree angles of inclination and most of the specimens with $10^{\circ}$ angles of inclination failed in a double-hinge mode similar to the buckling type of failure expected of a colum restrained at one end, whereas nost of the specimens with $20^{\circ}$ angles of inclination and all of the specimens with 30 and $40^{\circ}$ angles of inclination failed in a single-hinge mode. This indicates that the transition point between single- and double-hinge modes of failure lies between 10 and $20^{\circ}$ of inclination.

The typical modes of failure experienced by the test specimens are show in Fig. 9. Shown at the top of this photograph are three impact tested specimens

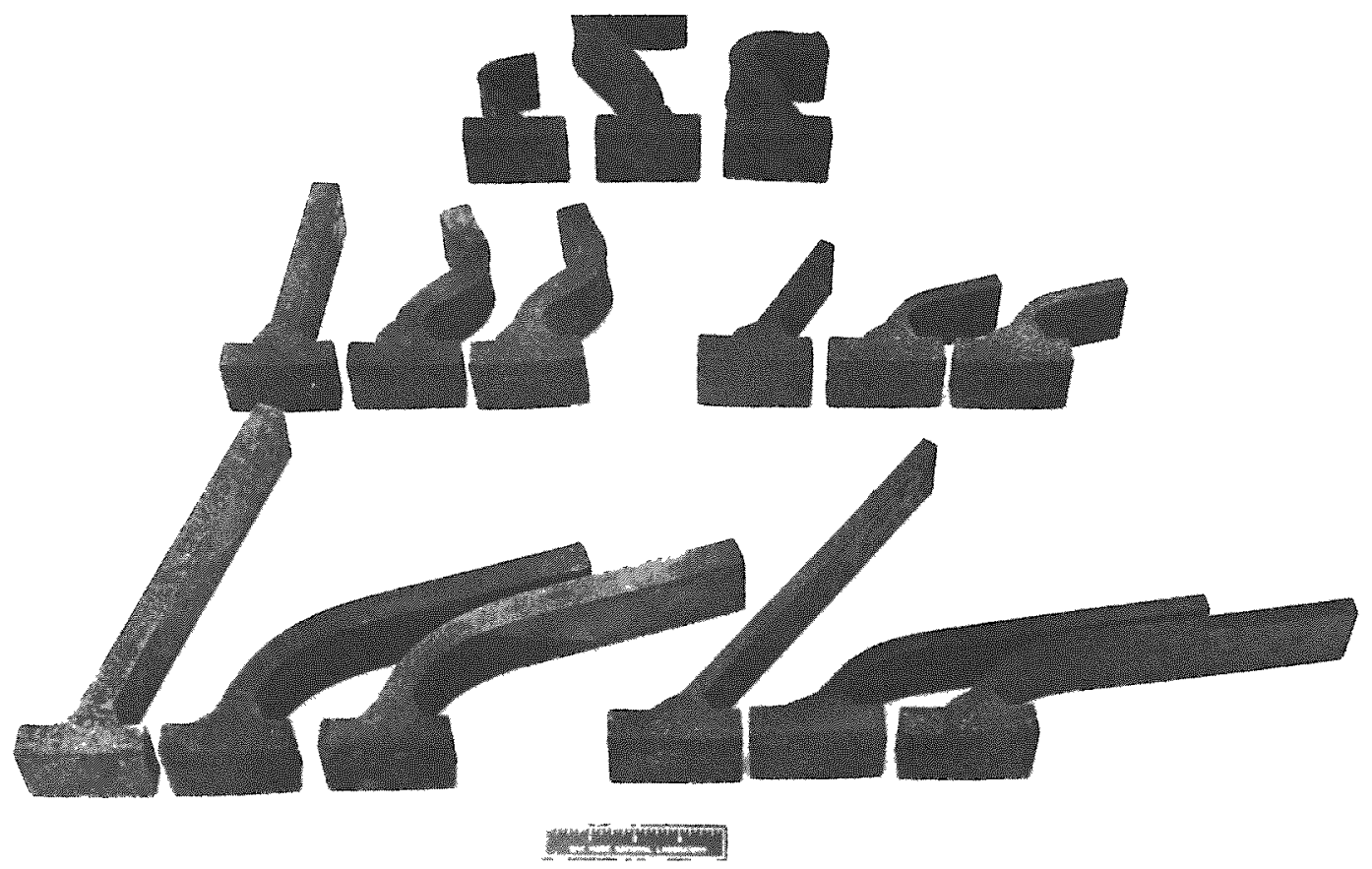

Fig. 9. Typical Fin Specimens with Angles of Inclination of $0,10,20,30$, and $40^{\circ}$ Before and After Impact. 
that originally had angles of inclination of zero degrees. The left-hand group of three specimens in the second row is comprised of specimens with $10^{\circ}$ angles of inclination, and the right-hand group is comprised of specimens with $20^{\circ}$ angles of inclination. Specimens with $30^{\circ}$ angles of inclination are shown in the lefthand group of three specimens in the bottom row, and specimens with $40^{\circ}$ angles of inclination are shown in the right-hand group in the bottom row. In each of these groups of three specimens except the first at the top of the photograph, the first specimen shown has not been impact tested and the other two have been tested.

The time durations of the impact events for the specimens which failed in a double-hinge mode ran from 2.6 to $22.2 \mathrm{msec}$, with the majority running from 7 to 15 msec. The durations of impact events for specimens which failed in a singlehinge mode were much longer, with some being up to 154 nsec. Although the impact durations of single-hinge failures were much longer, the magnitudes of the peak forces were much less than those of the double-hinge failures.

The printed computer output for each specimen tested afforded a means by which the calculated deformation could be compared with the final measured deformation. It also allowed the absorbed energy calculated from the experimental data to be compared with the energy of the falling hammer at the time of initial impact. A review of the computer output data for the specimens failing in a double-hinge mode indicated deviations of up to $30 \%$ between the calculated values of deformation and the measured values of final deformation. Larger deviations were observed for specinens that failed in a single-hinge mode. These deviations are at least partially due to the elastic springback of the specimens when the energy had been dissipated and the load removed, especially for those specimens which failed in a single-hinge mode.

The difference between the energy which was applied to the specimens and the absorbed energy accounted for in the test data were very small, being in the order of 2 to $3 \%$. This was tme for specimens experiencing either type of failure mode, single or double hinge. A relatively small amount of energy was dissipated by friction in the horizontal motion between the hamer and the top of the specimens as the collapse occurred. The horizontal motions were small for doublehinge failures where the forces between the hamer and the specimons were large, and the horizontal motions were relatively large for single-hinge failures where the forces betweon the hammer and the specimens were small. Therefore, the energies absorbed by this friction remained relatively small.

The range of data scatter is indicated by the fine vertical lines in the graphical presentation of the computer output, examples of which are shown in Figs. 7 and 8 . The curves derived from the accelerometer data were well within the data band derived from the load cell data. This correlation between the 
load cell data and accelerometer data provides a degree of assurance that the results are within acceptable engineering accuracy.

Analysis of the curves indicated that the energy absorption capabilities of a specimen are dependent upon the square of the thickness of the specimen. This is evidenced by the fact that when the energy absorbed by the specimen was divided by its plastic moment value, which is basically a constant multiplied by the square of the thickness of the specimen, and the value obtained was plotted against the percentage of deformation resulting from the impact; the result for the specimens tested was a set of curves dependent upon specimen height alone. For deformations of $10 \%$ or less, the results were almost independent of the height of the specimen. This is especially true for the specimens with angles of inclination of 0,10 , and $20^{\circ}$. For larger deformations, it is evident that the specimens with greater heights absorbed less energy for the same percentage of deformation experienced by the specimens with lesser heights.

The computer output for the peak force experienced by the specimens during impact was plotted as a function of their height divided by their thickness. A typical curve of this type is shown in Fig. 10. Buckling is the primary mode in double-hinge failures, while bending is the primary mode in single-hinge failures.

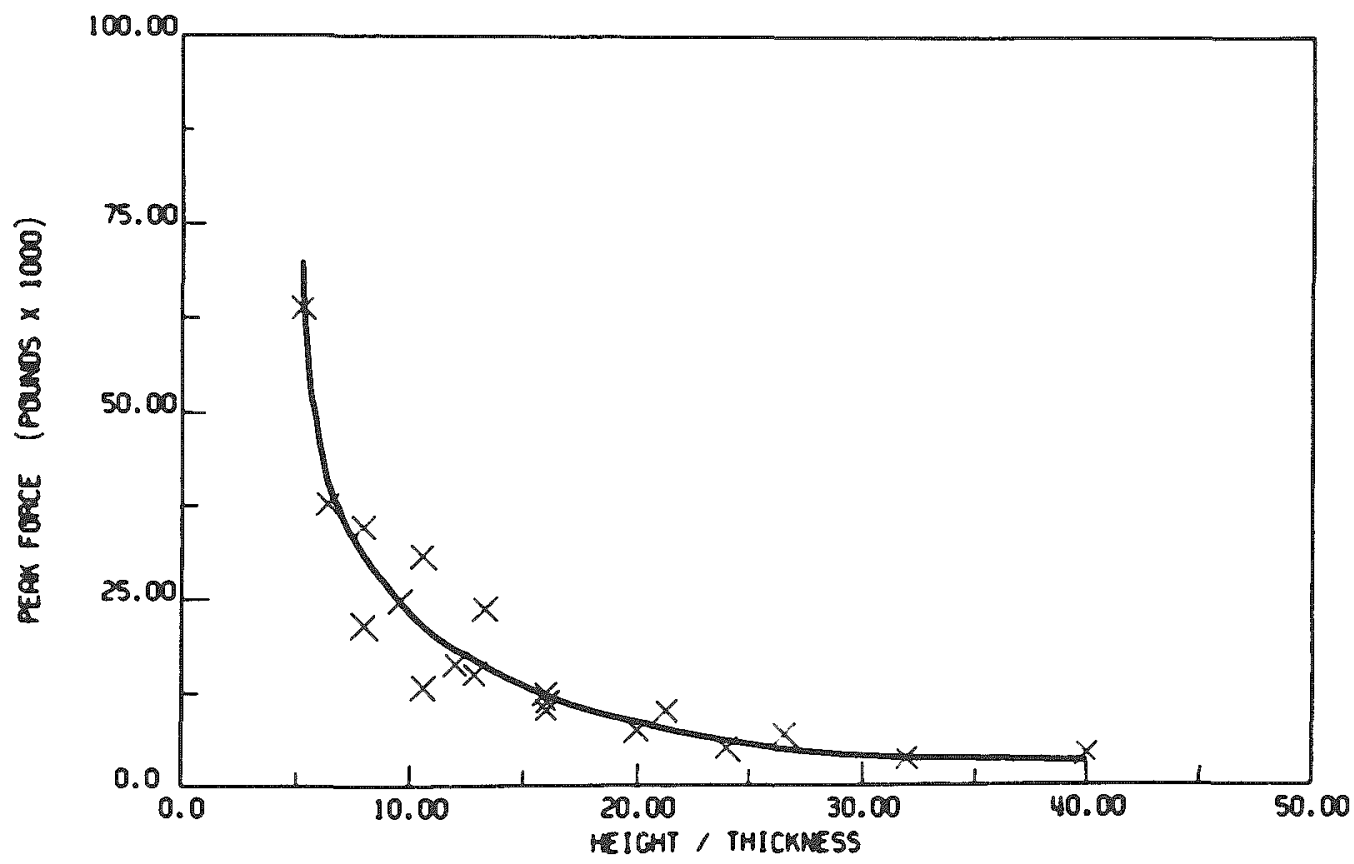

Fig. 10. The Peak Force Derived From Load Cell Test Data as a Function of Specimen Height Divided by Thickness for Impacted Specimens With a $20^{\circ}$ Angle of Inclination.

The peak force information was derived solely from the load cell data recorded during the impact tests. A low-pass filter was necessary to renove 
high-frequency noise from the accelerometer output signal. This filter attenuated the sharp peak acceleration value that actually occurred in the first part of the impact event, and this attenuation may be noted on the typical oscilloscope photograph shown in Fig. 6. Therefore, the peak force values obtained from the accelerometer data were not valid. This attenuation characteristic did not materially affect the energy absorption infornation derived from the accelerometer data because the energy values were obtained by double integration of the accelerationtime curve.

The peak force values recorded during the impact tests were dependent upon the height-to-thickness ratio of the specimens tested, and the resulting curves are very similar to critical load curves for colums with different length-toradius-of-gyration ratios. It was observed many times throughout the impact tests that the peak force value for a given specimen geometry was not dependent on the input energy of the hamner as long as the specimen was plastically deformed. The input energy could be doubled by either doubling the weight of the hammer or the drop height, but the peak force would remain essentially constant. The increased energy was absorbed by more deformation that occurred over a longer duration.

\section{CONCLUSIONS}

The objectives of this impact testing program were achieved. The energy absorption characteristics of fin specimens undergoing dynamic, gross plastic deformation were determined, and the test data were reduced to a form readily usable for computation of the energy absorption capability of external fins along the longitudina1 axis of a cylindrical cask subjected to the 30-ft free-drop condition of the hypothetical accident specified in the regulations governing shipping casks. Detailed information about the testing program and al1 of the resulting data plots that will enable the cask designer or analyst to compute the energy absorption capacity of a longitudinal fin on a cask as a function of its geometry and the percentage of deformation it is expected to experience during an impact are presented in USAEC Report ORNL TM-1312, Vo1. 9 ("Structural Analysis of Shipping Casks, Vol. 9: Energy Absorption Capabilities of Plastically Deformed Struts Under Specified Impact Loading Conditions").

The energy absorption capacity of a fin specimen was shown to be dependent upon the square of its thickness. The greater the height of the specimen, the less the energy that was absorbed for the same percentage of deformation once that deformation had proceeded into a gross range (10\% or greater). The fact that the data obtained by two independent methods during the latter portion of 
the experimental program reduced to similar curves representing the energy absorbed versus the percentage of deformation experienced by the specimens provides a degree of confidence in the results.

The peak force values observed during the impact tests were dependent upon the height-to-thickness ratio of the specimens tested, and the plots are similar to critical load curves for columns. The peak force experienced by the specimens did not appear to be a function of the impact energy of the hamer as long as plastic deformation was attained. A complete set of plots of the peak force experienced by specimens during impact versus their heights divided by their thicknesses is presented in USAEC Report ORNL TM-1312, Vo1. 9. With the weight of the shipping cask known, the peak acceleration that would be experienced by the cask subjected to the 30-ft free-drop condition of the hypothetical accident can be computed. 


\title{
- IMPACT TESTS OF MODELS AT THE SAVANNAH RIVER PLANT
}

\author{
J. W. Langhaar \\ E. I. du Pont de Nemours and Company
}

\begin{abstract}
Impact testing of small-scale models for assessing gross deformation resistance to puncture, behavior of welds, and certain other physical attributes has been theoretically established and experimentally verified. For evaluation of the strength of bolted fastenings and leakage of closures, the validity of model testing is not so well proven but is nevertheless often considered the most reliable practical method available.

The Savannah River Plant has tested numerous models in recent years and sometimes a full-size mockup of part of a package. Results in some cases have confirmed predictions and other cases have necessitated a change in design. Several of the tests are described. The need for further study of methods of modeling closures is emphasized.
\end{abstract}

\section{INTRODUCTION}

About ten years ago the validity of model testing for assessing the behavior of shipping containers under impact conditions became a subject of serious study. In 1962, Clark and Reddi ${ }^{1}$ showed that for a true geometric model the stresses, strains, and percentage deformation are for practical purposes independent of model size provided (a) the impact velocity is unchanged, (b) the resisting force continues to increase while the container comes to a stop, and (c) the stress-strain characteristics of the materials are not affected by how fast the stress is applied. The last of these is important because a quarter-scale model, for example, stops four times as fast as a full-scale model.

The requirements are approximately met in practice for impacts not resulting in rupture. ${ }^{2}$ and test work has verified this even for the puncture-type accident up to the point where shearing and penetration occur. ${ }^{3}$ A major problem is fabrication of a true model, particularly with respect to welds and fastening devices. Good correlation of results has been obtained with carefully made models as small as one-tenth scale, ${ }^{2}$ but approximately quarter scale is more reliable and easier to fabricate. Variability of physical properties throughout a structural part such as the shell of a cask, variations in details of fabrication, orientation at impact, and other factors may significantly affect a buckling pattern, so that only the general nature and magnitude of buckling can be duplicated even with full-swale testing. 
Use of models has become generally accepted as a means of demonstrating structural response to a 30-ft drop. The practice has been extended to assessment of leaktightness. although as discussed later there are some important unanswered questions in this area.

A model may be simplified by omission of features not significant for the test or by modification in some manner judged to be conservative for the test. Thus it may be a mockup of only some part of a container. Aho, it may be small-seale or full-scale. Considered in this broad sense. the Savannah River Plant has during the past few years performed several 30 -ft drop tests with models of different types. Results in some cases confirmed expectations but in other cases led to modifieation of design.

Full-size prototypes of relatively inexpensive containers have also been tested. For present purposes these are not classified as models and are not included in the discussion.

\section{DISCUSSION}

\section{Curium Cask}

This cask (Fig. 1 ) is essentially a tank of water $5 \mathrm{ft}$ in diameter and 6 ft high. with a one-inch-thick stainless steel wall. ${ }^{4}$ An internal birdcage structure supports the product capsules. External fins help to dissipate heat. The lid is recessed and protected from damage by a cover plate. The closure utilizes a 20 -inch-diameter. spiral-wound, "Flexitallic" gasket, with seating surfaces having a finish specified as $32 \mathrm{rms}$ or better. The cask is equipped with 16 fusible plugs so positioned that regardless of cask orientation at least one of these plugs will melt in the specified fire and permit escape of steam without loss of liquid water. The loaded weight is about 7 tons.

It was necessary to demonstrate that rupture of the tank would not occur and that leaktightness of the closure would be maintained after a 30 -ft drop to a flat surface and after a 40-inch drop on a 6-inch-diameter penetrator. A model was fabricated to quarter seale except that standard sizes of "Flexitallic" gasket were used and the finish of the seating surfaces was about the same for the model as for the full-size cask. The loaded weight was 220 pounds.

The model was subjected to as series of 14 drops, of which only a few were considered required for demonstration of compliance and the remainder were performed for added information. Results are given in Table 1 and in Figures 2 through 8.

The puncture tests were of particular interest because experimental work at the Franklin Institute and at Oak Ridge, represented by the correlation given in "The Cask Designer's Guide," 3 was restricted to designs with lead behind the steel plates. The degree to which the plate is stiffened by fins or edge restraint or backup material and the energy absorbed by the backup material while being pushed aside appreciably affect the thickness of steel required to avoid puncture. It was found that for a 30 -ft drop onto a penetrator, puncture occurred on the bottom but not on the side or top. The fact that the top drop was off-center may have influenced the results.

Leaktightness of the model was assessed before and after tests 1.2.5. and 7 by pressurizing with water to $70 \mathrm{psig}$ and checking for visible leaks or loss of pressure during a period of ahout 15 minutes. No leakage was found. 
Two casks of 24-inch inside diameter and 39-inch inside height. with solid stainless steel wall of 5-inch thickness, were constructed for shipping irradiated bismuth slugs (Fig. 9). The cavity was to contain water for effective heat removal and - because of the low meling point of bismuth maintain a leaktight closure with no escape of coolant or other contents even under fire conditions. The casks have a design pressure of $930 \mathrm{psig}$ at $525^{\circ} \mathrm{F}$ and are adequate for 1500 psig based on yield strength at the maximum temperature expected in the hypothetical fire. For the design contents, the calculated maximum pressure for the fire condition is about 1000 psig.

As an added safety precaution for fire conditions, a rupture disk assembly rated at 1390 psig at $525^{\circ} \mathrm{F}$ is provided in the cask cavity. Piping for pressure relief and for cask draining is incorporated in the lid. The lid closure uses a "Viton" O-ring; the flanged connection for piping on the underside of the lid has a "Flexitallic" gasket. The casks were hydrostatically tested at 1500 psig at room temperature with no visible leakage or loss of pressure.

Two 30-ft drop tests were performed, one with a quarter-scale model of the upper portion of the cask to evaluate the closure design and one with a full-scale mockup of the rupture disk assembly to evaluate its resistance to impact. Both tests led to design modifications.

The quarter-scale model (Fig. 10) was not pressurized or gasketed, because it was considered that relative movement of the lid with respect to the body would be a suitable measure of performance. Appreciable sidewise motion was not possible without gross failure. The maximum gap between lid and body after the drop was 4 mils, corresponding to 16 mils for the full-size cask or to only about $25 \%$ reduction in the compression of the O-ring. However, because of considerable damage to two of the six lid studs and nuts, the number was increased to twelve for the full-size casks and the nuts were recessed into the lid.

The initial design contemplated a single rupture disk rated at about 1400 psig at $525^{\circ} \mathrm{F}$. For the cask upside down at impact, the head of $3 \mathrm{ft}$ of water if decelerated at about $1000 \mathrm{G}$ 's might be expected to rupture such a disk. There was no sound basis for estimating the actual deceleration; furthermore, shock phenomena are not amenable to such simple analysis. Consequently, a mockup was fabricated as shown in Fig. 11 except that for the first test the dip tube and union-1ype rupture disk shown at the upper end of the tube were omitted. An available disk rated at 1322 psig at $72^{\circ} \mathrm{F}$ was used for the test. The vessel was filled with water except for a two-inch freboard and pressurized with air to the maximum expected actual operating pressure of about $140 \mathrm{psig}$. The $30-\mathrm{ft}$ drop caused the rupture disk to fail in what appeared to be a normal manner.

The design was changed to provide two disks in series with air in the tube between them. For the second test, the flange-type assembly contained a disk similar to that for the first test, and the union-type assembly contained a disk rated at $975 \mathrm{psig}$ at $72^{\circ} \mathrm{F}$. The mockup was pressurized as before, and dropped once on each end. Disassembly showed that the union-type disk had failed (as expected from the first test) but that the other disk remained intact. The modified design was therefore incorporated in the casks, except that the casks have disks of somewhat higher rating. 
PM-3A Casks

The upgrading of two casks (Fig. 12) for shipping reactor cores from McMurdo Sound is described in another paper of this Symposium. ${ }^{5}$ These casks are lead-shielded and were originally equipped with a cylindrical shroud of one-inch-thick steel for added gamma shielding during land and water transport. The shroud was not required for air transport. The shipment is dry.

Because of questionable structural integrity of the shell under hypothetical accident conditions, it was decided to extend the shroud so as to shield the entire side of the cask from radiant heat in a fire and to add similar protection for the top and bottom. The configuration of the O-ring seal was suspect with respect to lateral displacement and possible leakage under impact conditions. This O-ring was replaced by a "Gasko-seal" unit which could accommodate greater lateral movement of the lid.

A quarter-scale simplified model was fabricated to assess the integrity of the shroud, insulating plate and lid closure (Fig. 13). After a 30-ft top-comer drop (Fig. 14), the model was immersed in water, pressurized with air to $30 \mathrm{psig}$, and checked for leaks. No leakage was observed. The crash frame had protected the cask from any visible damage (Fig. 15), and measurements showed insignificant movement of the lid.

A bottom-corner drop (Fig. 16 ) did not cause exposure of any part of the cask body and thus did not disqualify the cask. However, there was failure of several attachment bolts of the shroud (Fig. 17). The model was repaired, reassembled. and dropped $30 \mathrm{ft}$ on its side. Two sections of shroud and the bottom insulating plate came off (Fig. 18 ).

The model was then equipped with cables and clips to hold the shroud together, and a smaller diameter bottom insulating plate to avoid direct impact on the edge of the plate (Fig. 19). The redesign was successful in retaining the shroud (Fig. 20 ), but the bolts holding the insulating plate failed because the insulating plate was too stiff to conform to the bending of the bottom plate of the cask. The model was again pneumatically leak-tested, with no observable leakage.

For the full-size casks, attachment of the insulating plate was strengthened and the plate was reduced in stiffness by a factor of 5 , as measured by section modulus, by making it of two steel sheets each 0.1875 -inch thick separated by 0.375 inch of hardboard. It was determined by calculation that this would conform to the heavy bottom of the cask without bolt failure for impact in ang orientation on a flat surface.

Both full-size casks were pneumatically leak-tested at 30 psig by immersion in one of the cask handling basins. These tests were considered necessary because of possible slight differences from the model with respect to the gasket and the contact surfaces.

\section{Other Containers}

In two recent asses, poisoned inserts of the eggerate type were fabricated for use in existing casks. One of these was for shipment of Borax V fuel from Idaho to SRP in the bismuth casks: the other was for shipment of Spert III fuel from Idaho to SRP in the Paducah uranium-shielded demonstration eask ${ }^{\circ}$ which a few years ago satisfactorily survived impact and fire tests. 
In order to demonstrate structural integrity of the inserts, one-half scale models of six-inch-long sections of cask and insert were subjected to a $30-\mathrm{ft}$ drop. The eask wall was simulated by a weldment of suitable stiffness resembling an I-beam rolled to a ring-shape with one flange serving as the inner cask shell and the other flange as the outer cask shell. The fuel was simulated by steel rods of suitable size and number. The Borax $V$ insert did not distort significantly. In the Spert III case there was appreciable distortion, and it was decided to provide structural reinforement rather than complicate the nuclear safety analysis.

\section{Leak Testing}

A common feature of the model tests for the casks described above was testing for leakage. Methods used were considered appropriate, taking into account the nature of the material which could leak and the regulatory requirements. For the curium cask, loss of a large percentage of the water would result in external radiation levels somewhat above regulatory linits. For the bismuth cask, a large loss of water could lead to melting of the bismuth which contains polonium: this conceivably could escape from slug cladding damaged by impact, and to a minor extent through the opening that permitted escape of water. For the PM-3A cask, the most restrictive limit was the IAEA requirement for unilaterally approved casks that no more than $0.1 \%$ of the coolant (i.e., air) should escape in one week following the accident. In all three cases the expected degree of contamination of the coolant is very low.

The tests illustrate the need for study and guidance relating to two basic questions: (1) How tight is leaktight? (2) How should one go about designing a small-scale model of a closure?

It must be recognized that absolute leaktightness or zero escape cannot be achieved. Also, it would be illogical and impractical to require the same degree of leaktightnes for all radioactive materials, regardless of toxicity, physical form, or concentration. Tests which might be applied for proving leaktightness for a prototype or a design encompass a range of more than a million in relative sensitivity. Common types of closure may vary that much in their capability. Relative toxicities per unit volume for the potential leakage vary by an even larger factor. A rational basis for design and testing is urgently needed.

Some progress is being made on this. The IAEA has proposed ${ }^{7}$ maximum leak rates which take account of the toxicity and which are considered to represent an insignificant hazard. It is nevertheless intended that good engineering and operating pratice will be followed, and that actual leakage will be as low as practical. Subcommittee N-14.2.6 of the American National Standards Institute is developing recommendations on test procedures for prototypes and on the matter of providing adequate assurance that each package presented for shipment is properly assembled. Similar studies are under way in other countries.

With regard to design principles for small-scale modeling of closures, I am not aware of any basic studies in progress. A common opinion or "educated guess" among engineers is that a gasket or O-ring for a model should have the full-size cross section, and that surface roughness and runout should be unchanged. However. the magnitude of leakage and the corresponding mechanism of leakage in a particular case may be important factors. For example, if leakage develops after a 30-it drop because of damage to the O-ring from movement of the lid, and this movement is only one-fourth as much in a model as in a prototype, then conceivably the damage and leakage could be much greater for the 
prototype than for the model. Similarly, the reduction of gasket or O-ring compression in the model would be less than in the prototype.

Suppose, on the other hand. that the closure is linearly modeled in all respects. This presumably includes surface roughness. Since sealing is due to forcing the gasket material to conform to surface roughness sufficiently so that every path for escape is blocked. it is not clear whe ther the gasket hardness should be changed. Also, if gasket damage from lateral displatement of the lid is partly dependent upon surface roughness. it is not clear that the smoother surfice and lesser displacement for a model would yield valid results.

The questions and problems with closures hate been mentioned now widn the promise or expectation of immediate answers, but rather as a suggestion that this is an important ared of shipping container design where there are large gaps in our hnowledge.

\section{SUMMARY}

The Sayannah River Plant has found model testing to be a very useful technique for assessing the performance of containers under impact conditions of the hypothetical accident. For complex and previously untested feutures of cusks. such testing is considered more reliable than calculation, and frequently there is no prictical alternative. As time gots on. the larger store of test results and the development of better basic data for reliable and inexpensive calculation should reduee the amount of testing which would otherwise be perforned.

Much of the effort has been directed toward demonstration of adecuate leaktightness. Unfortunately this is a rather nebulous area with regard to what is adequate and with regard to appropriate methods of modeling a closure. The sensitivity of tests and the degree of confidence to be established should be related to the hazard involved. Further study and technical guidance would be helpful to designers and very likely to competent authorities. 


\section{REFERENCES}

1. H. G. Clark, Jr. and M. M. Reddi, Structural Integrity of Shipping Containers for Radioactive Materials, Part I: Study of Transport Operations and Container Construction. Appendix A: Feasibility of Applying Model Theory to Simulate Impact Damage of Shipping Containers. The Franklin Institute Interim Report I-A2412-1, I. S. Atomic Energy Commission Report NYO-9859 (July 1962).

2. H. G. Clarke, Jr., Impact Resistance of Casks, American Institute of Chemical Engineers, Nuclear Engineering Part XIV, number 56, volume 61.(1965).

3. L. B. Shappert, Cask Designers Guide, ORNL-NSIC-68. (February 1970.)

4. C. A. Wilkins, et al Design and Testing of Curium Shipping Capsule and Cask, Proceedings of the Second International Symposium on Packaging and Transportation of Radioactive Materials, October 14-18. 1968. CONF 681001 .p. 344.

5. R. A. Scaggs, Upgrading of PM-3A Casks. Proceedings of Third International Symposium on Packaging and Transportation of Radioactive Materials (August 1971).

6. C. B. Clifford, Demonstration Fuel Element Shipping Cask from Laminated Uranium Metal-Testing Program, Proceedings of the Second International Symposium on Packaging and Transportation of Radioactive Materials. October 14-18, 1968. CONF 681001.p. 521.

7. Regulations for the Safe Transport of Radioactive Materials, Third Revised Draft, PL-383. International Atomic Energy Agency. November 1970. 


\section{TABLE 1. DROP TESTS OF MODEL OF CURIUM CASK}

Test
No.

Drop Situation

\section{Drop Series I \\ 130 feet, top edge impact \\ 230 feet. flat top impact \\ 340 inches, top puncture \\ $4 \quad 40$ inches, side puncture \\ 530 feet. side impact}

630 feet. flat bottom impact

730 feet, bottom edge impact

\section{Drop Series II}

830 feet. top edge impact

930 feet. flat top impact

1040 inches. top puncture

1115 feet, top puncture

1230 feet. side puncture

1330 feet. top puncture

1430 feet, bottom puncture
Damage Results

Landed on lifting lug; lug buckled. Local damage of 5 fïns. 3 bolts securing puncture shield broken. No damage to body shell.

Another lifting lug deformed.

Puncture shield permanently deflected $3 / 8$ inch. No puncture, off-center.

Local deformation of one fin: fin slightly bent.

No puncture.

Landed squarely on 6 fins. Body shell permanently deflected $7 / 16$ inch $\max$ along impact line. One horizontal internal member connected to impact side of shell buckled. product capsules remained centered in shell.

Some deformation of bottom fins.

6 side fins smashed at bottom edge. Cask bottom slightly convex.

No damage to new puncture shield.

No damage to new puncture shield.

Puncture shield permanently deflected $1 / 2$ inch.

Dead-center hit.

Puncture shield permanently deflected 11/4 inches.

Lid top slightly deflected. No puncture.

Dead-center hit.

Sheared one fin. Bent four fins. Permanently:

deformed side. No puncture.

Off-center hit. Shield permanently deflected

$11_{4}^{1 / 4}$ inches max. Two puncture shield bolts

sheared. Lid top permanently deflected

$1 / 4$ inch. No puncture.

Flat hit in center. Two fins sheared. Puncture

of bottom clear through about $3 / 4$ of pin circumference. 


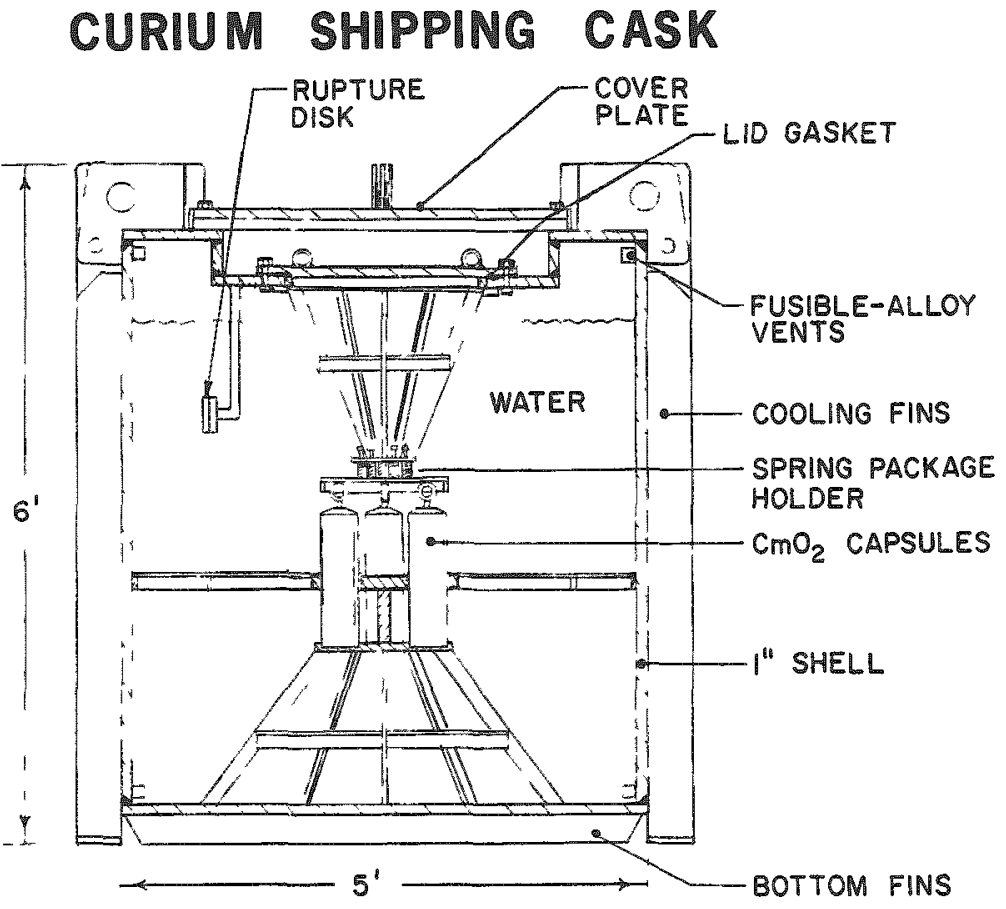

FIGURE I

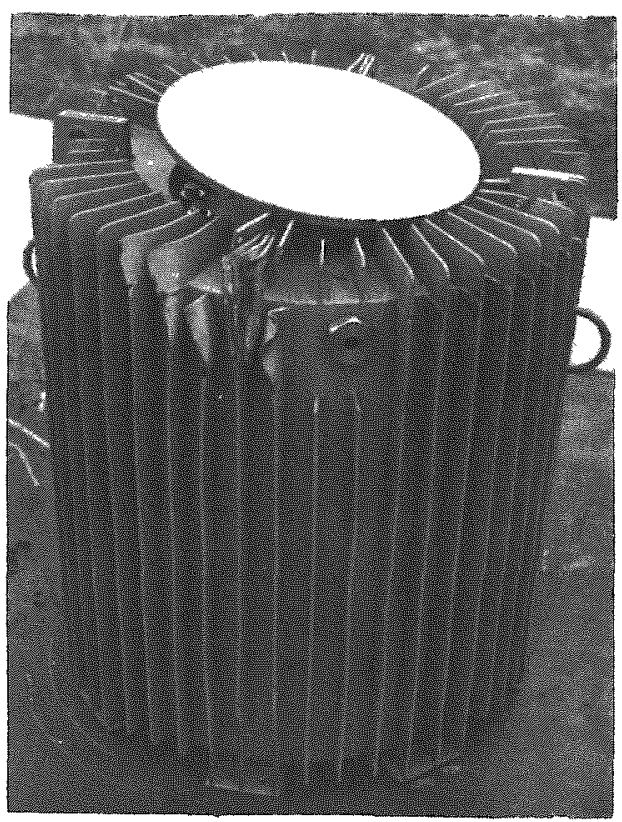

FIGURE 2 


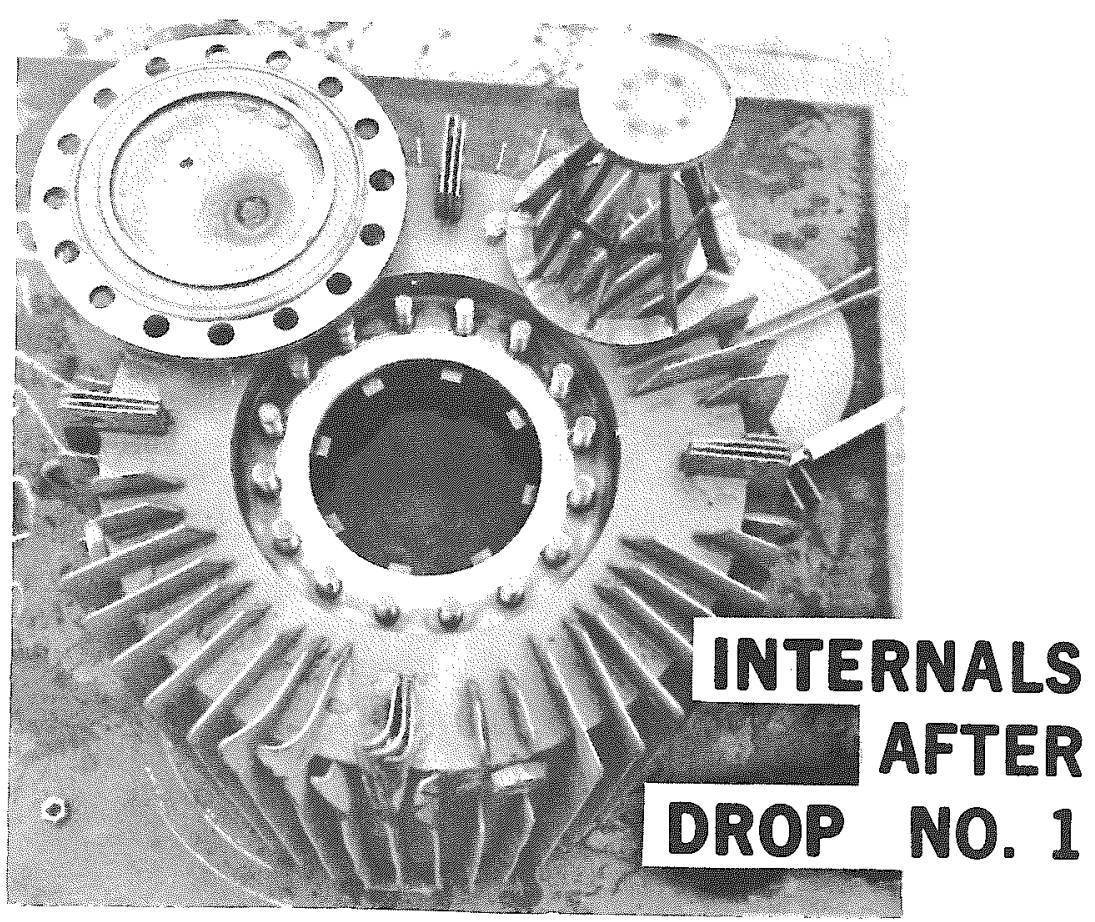

FIGURE 3

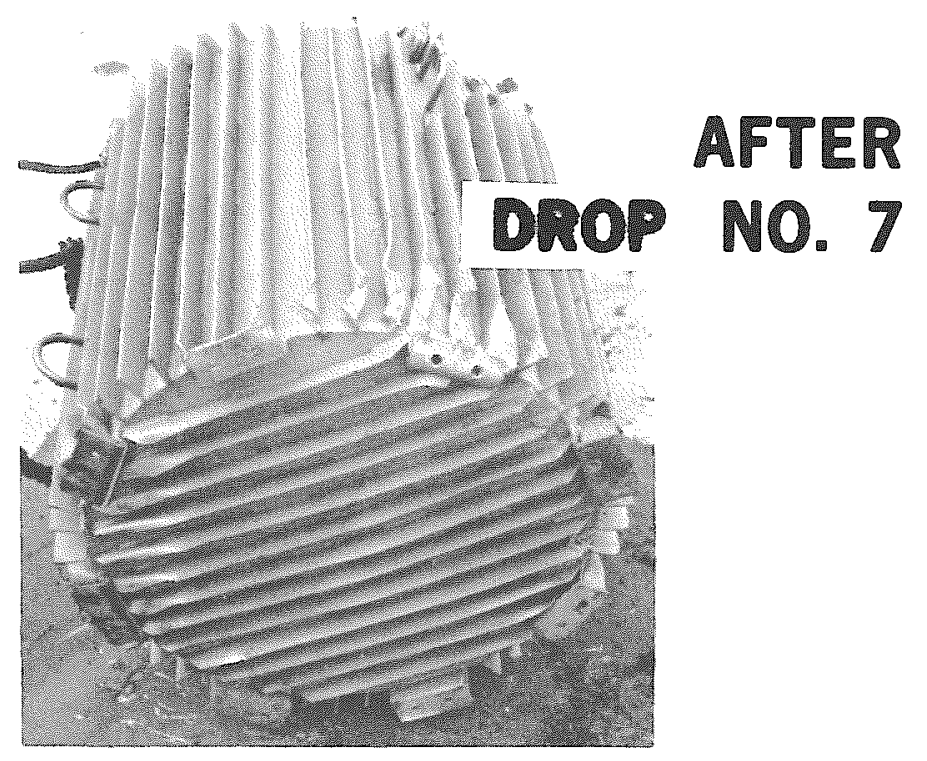

FIGURE 4 


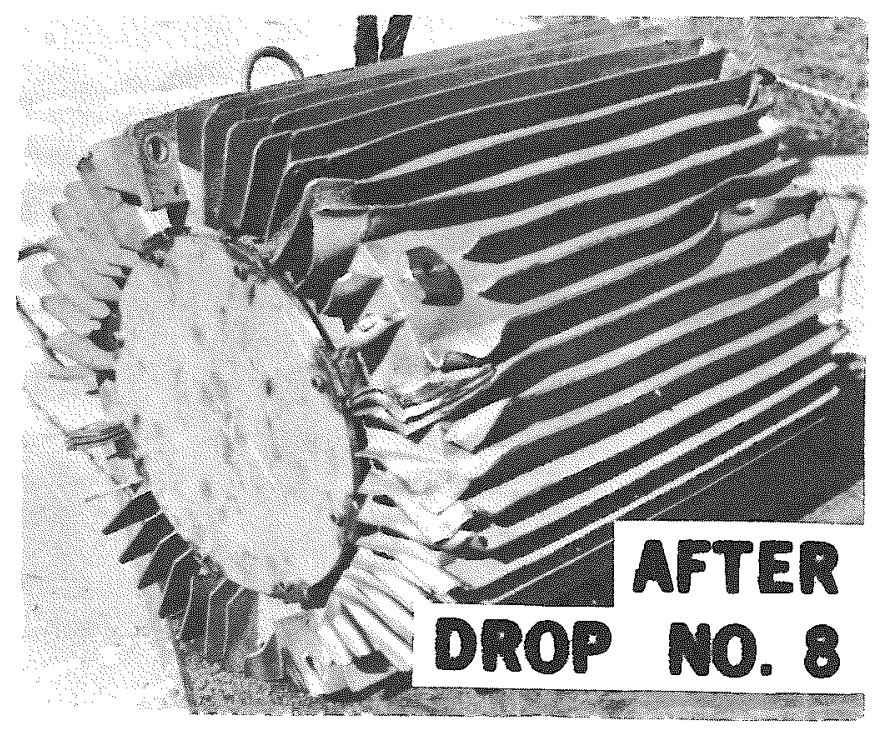

FIGURE 5

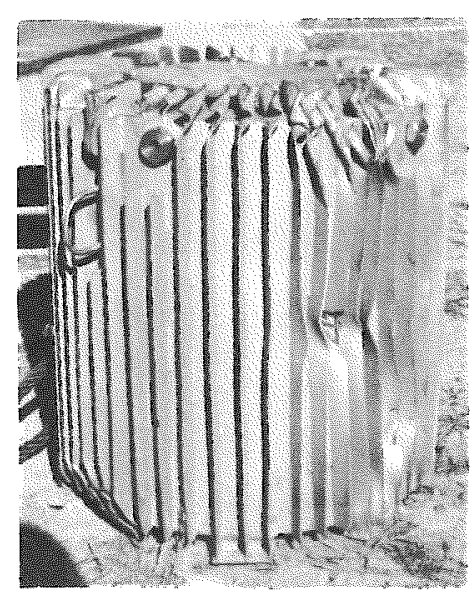

FIGURE 6

\section{AFTER DROP \\ NO 12}

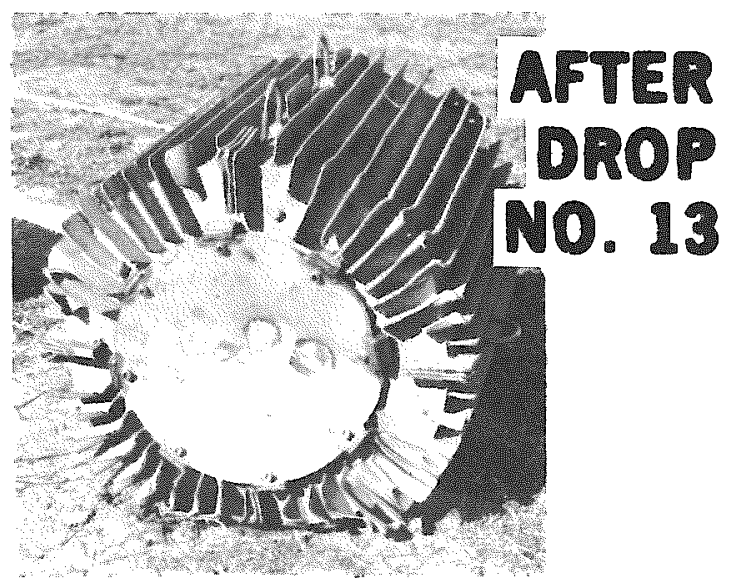

FIGURE 7

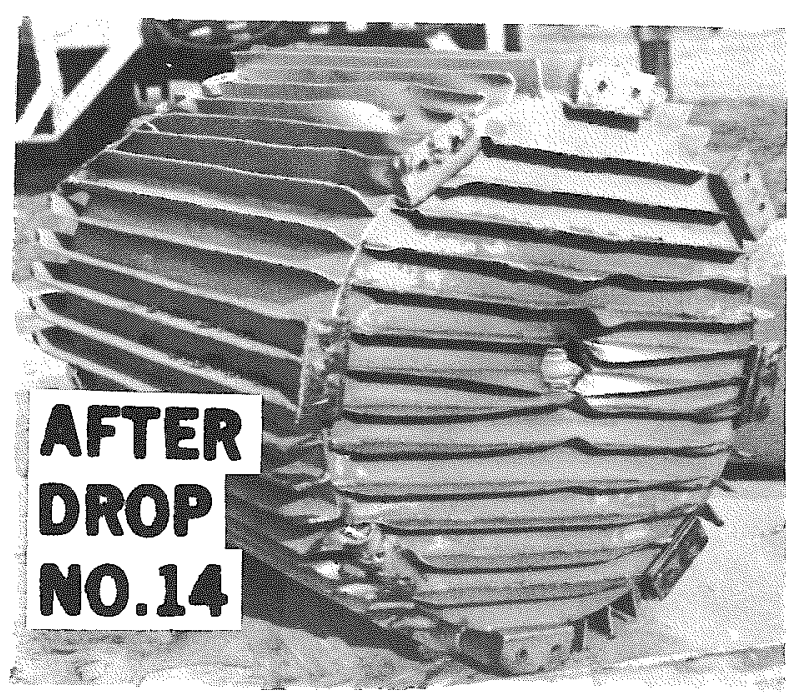

FIGURE 8 


\section{BISMUTH CASK}

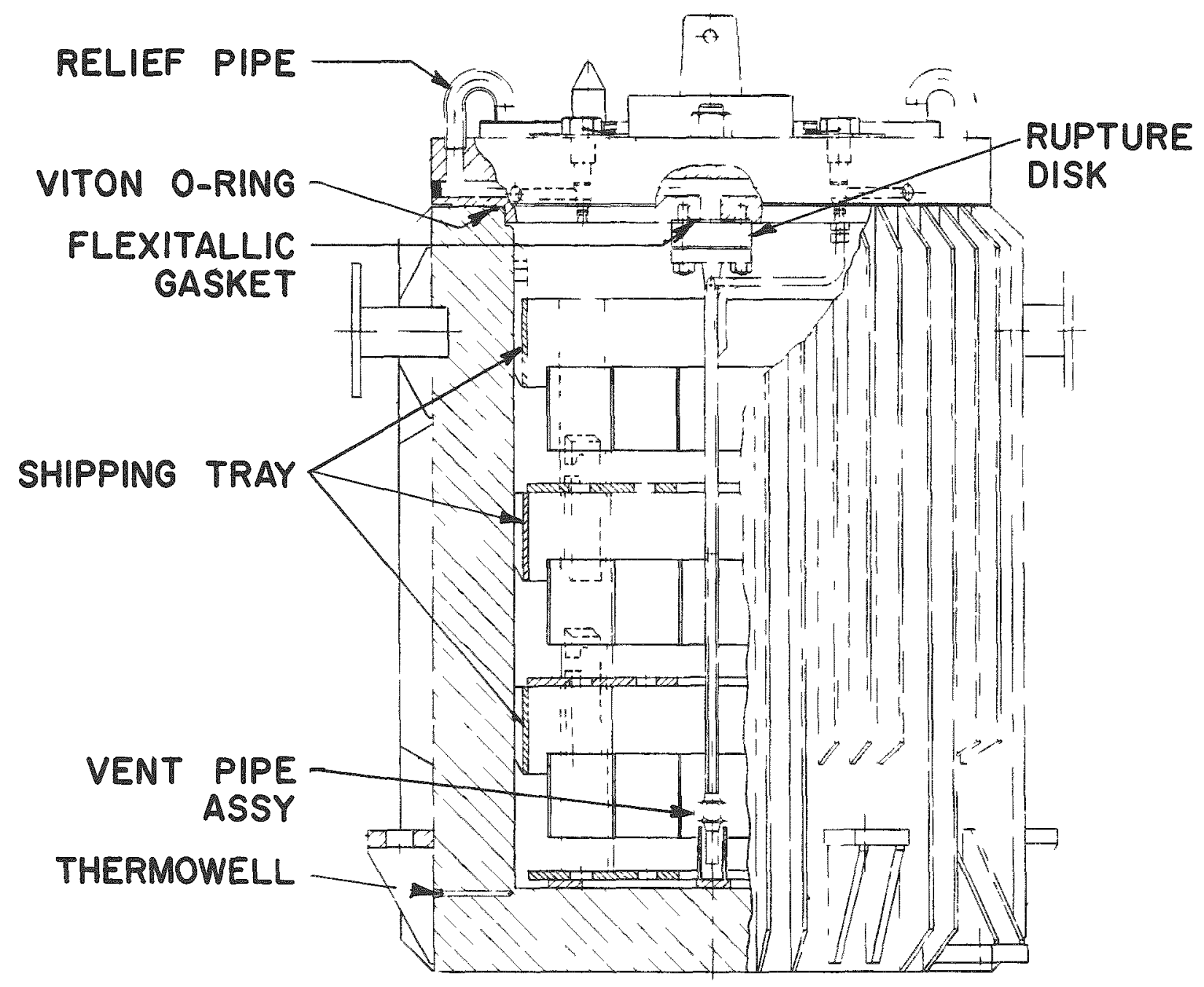

FIGURE 9 


\section{DEFORMED STUDS \& NUTS}

,

รั

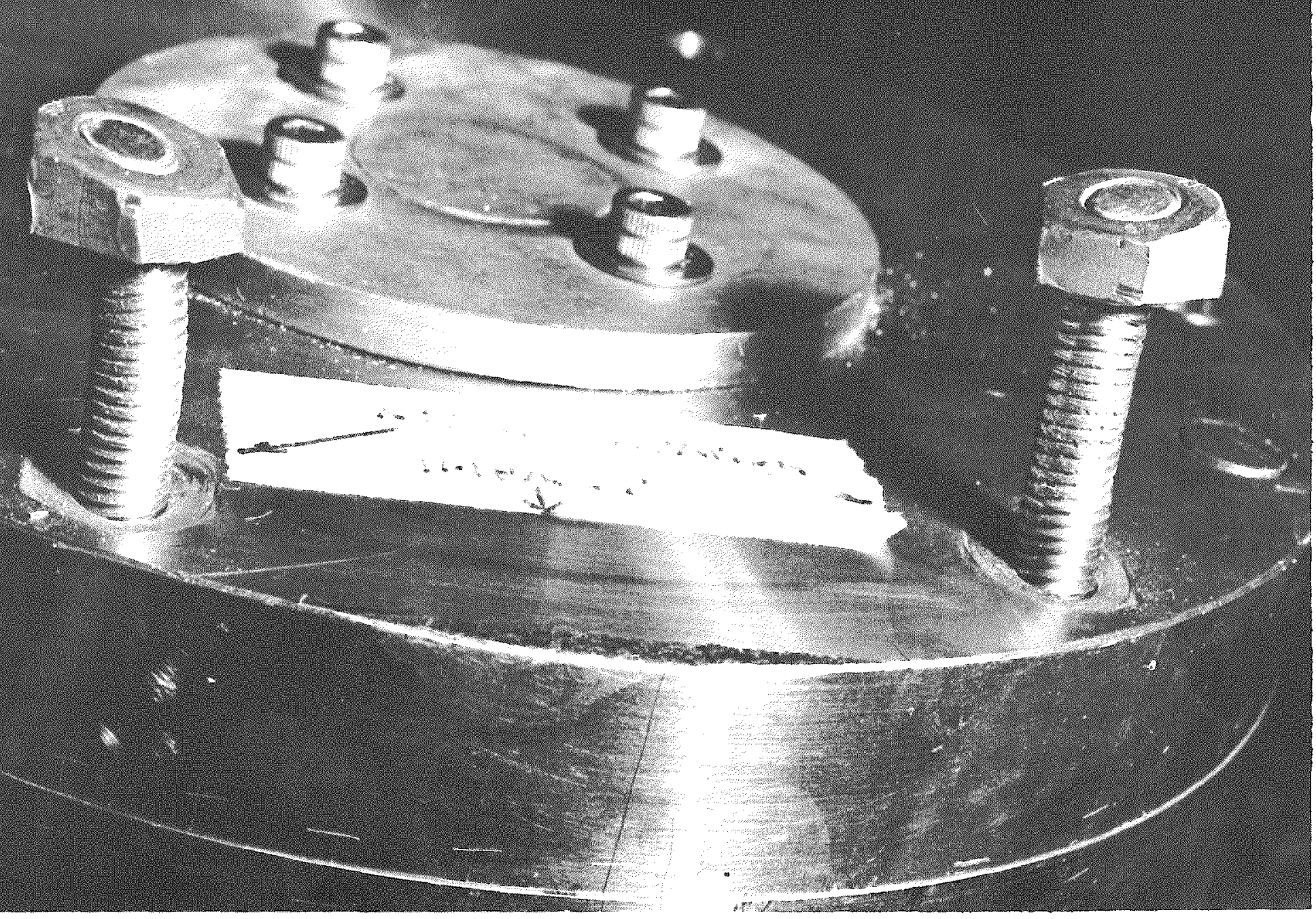

FIGURE 10 
TOTAL WEIGHT WITH WATER 260 POUNDS.

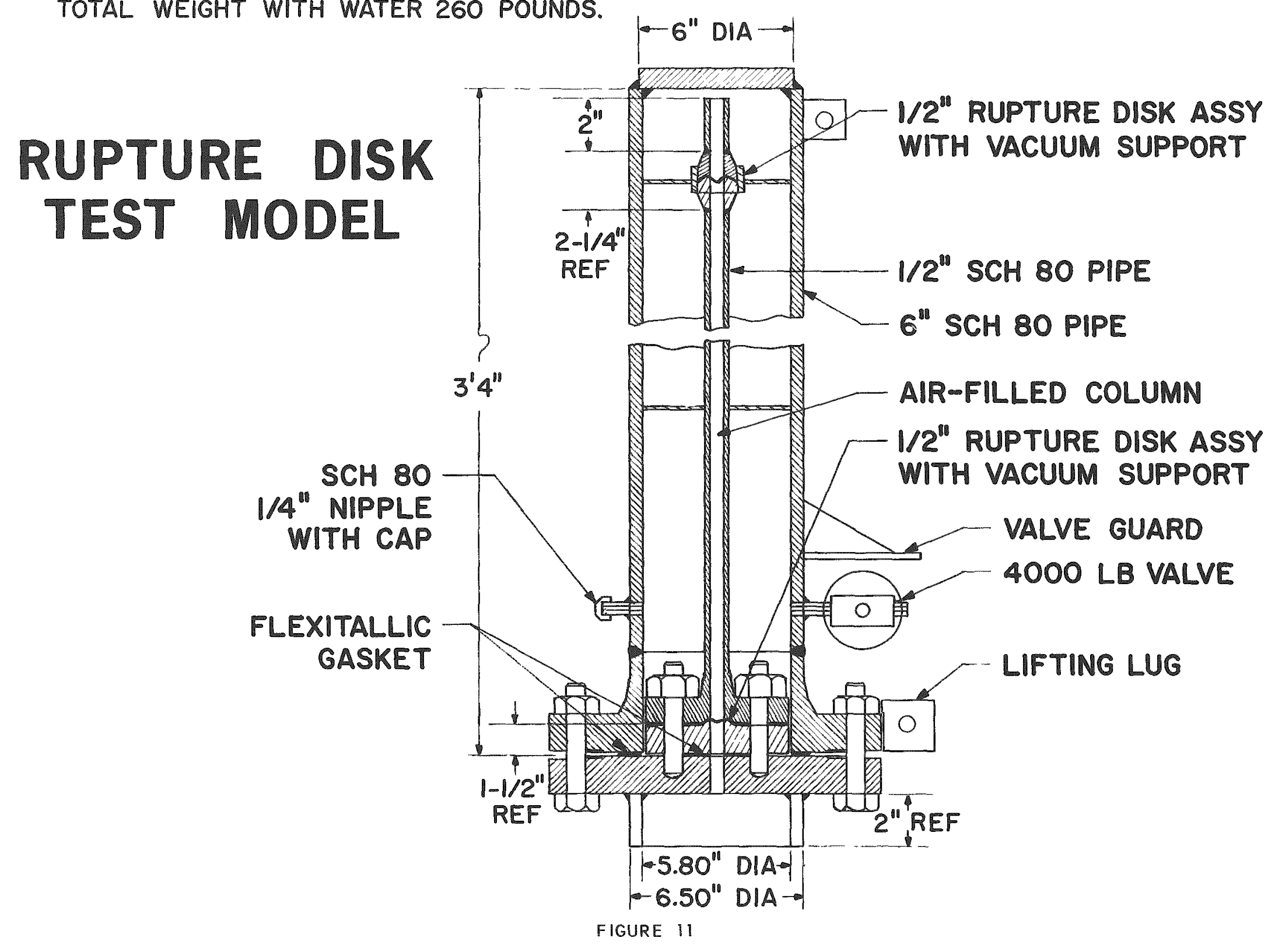




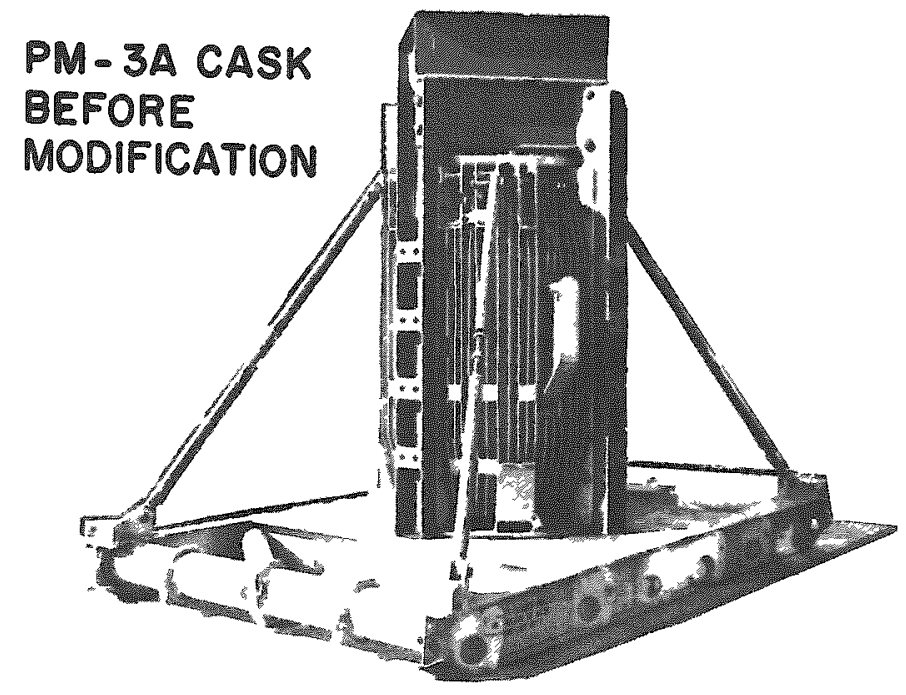

FIGURE 12
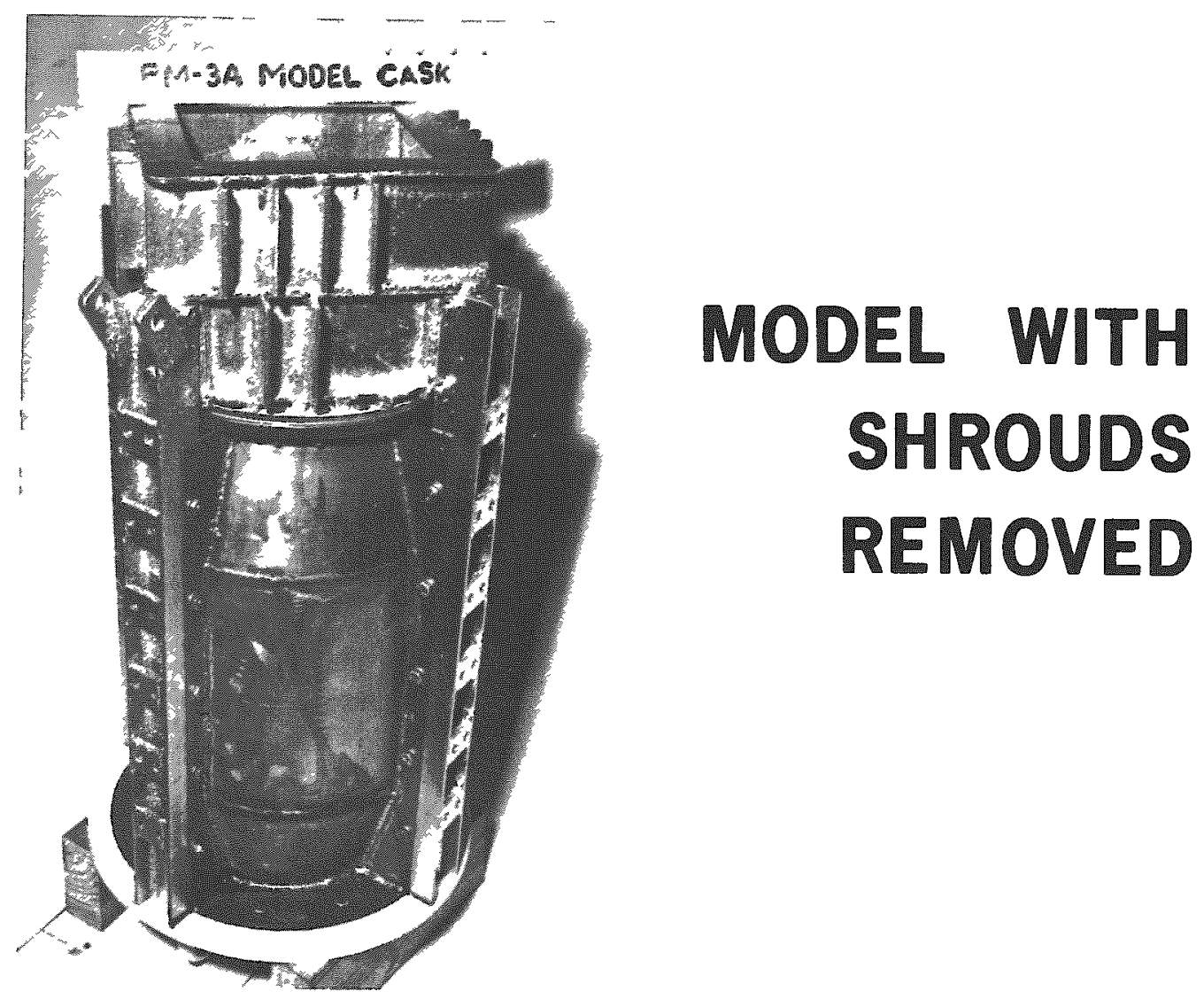

FIGURE 13 


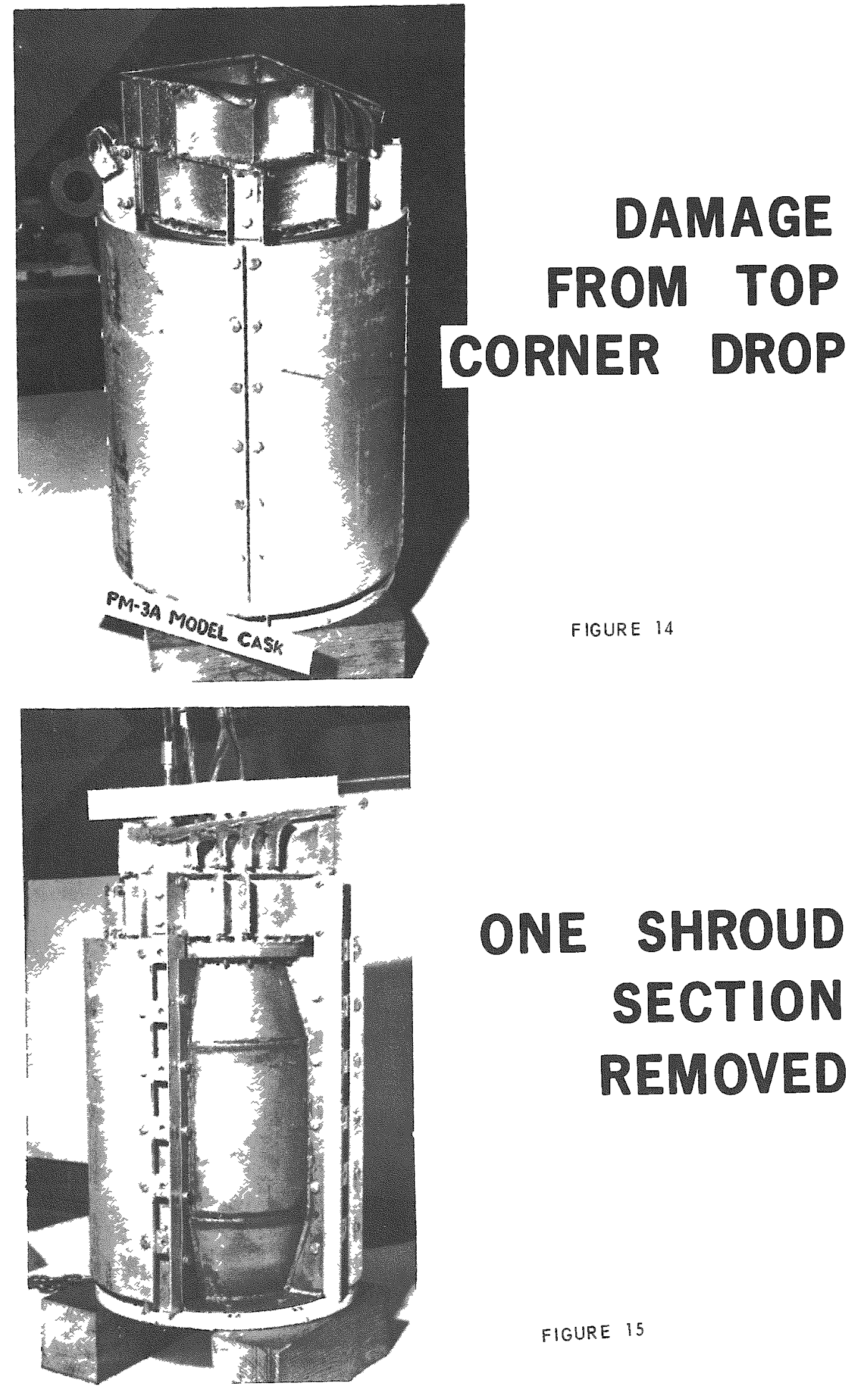




\section{BOTTOM CORNER DROP}

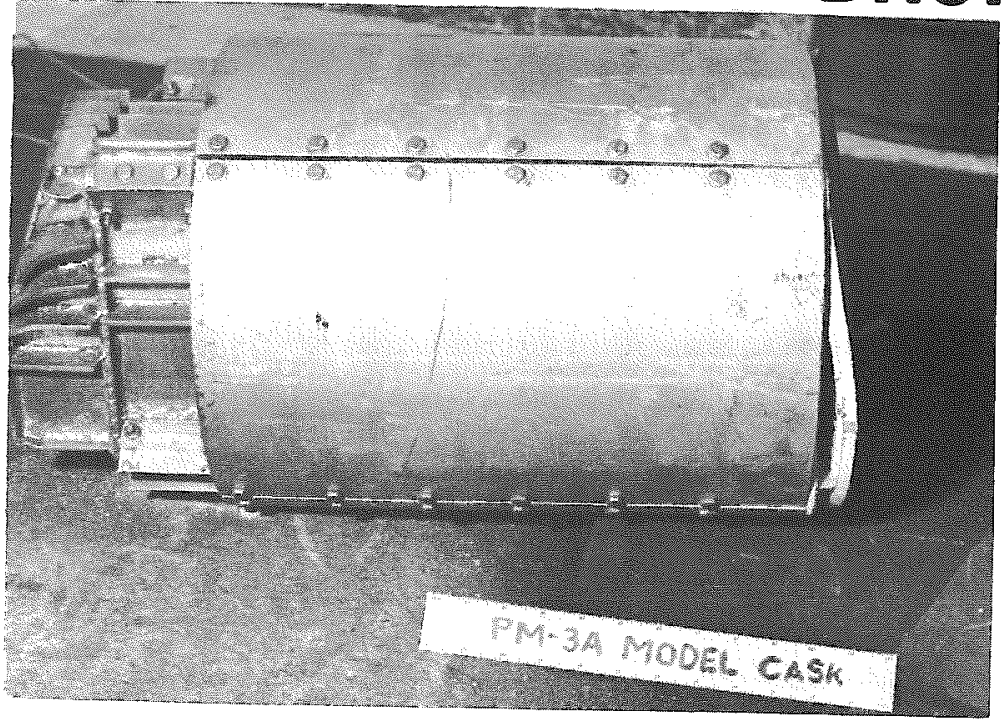

FIGURE 16

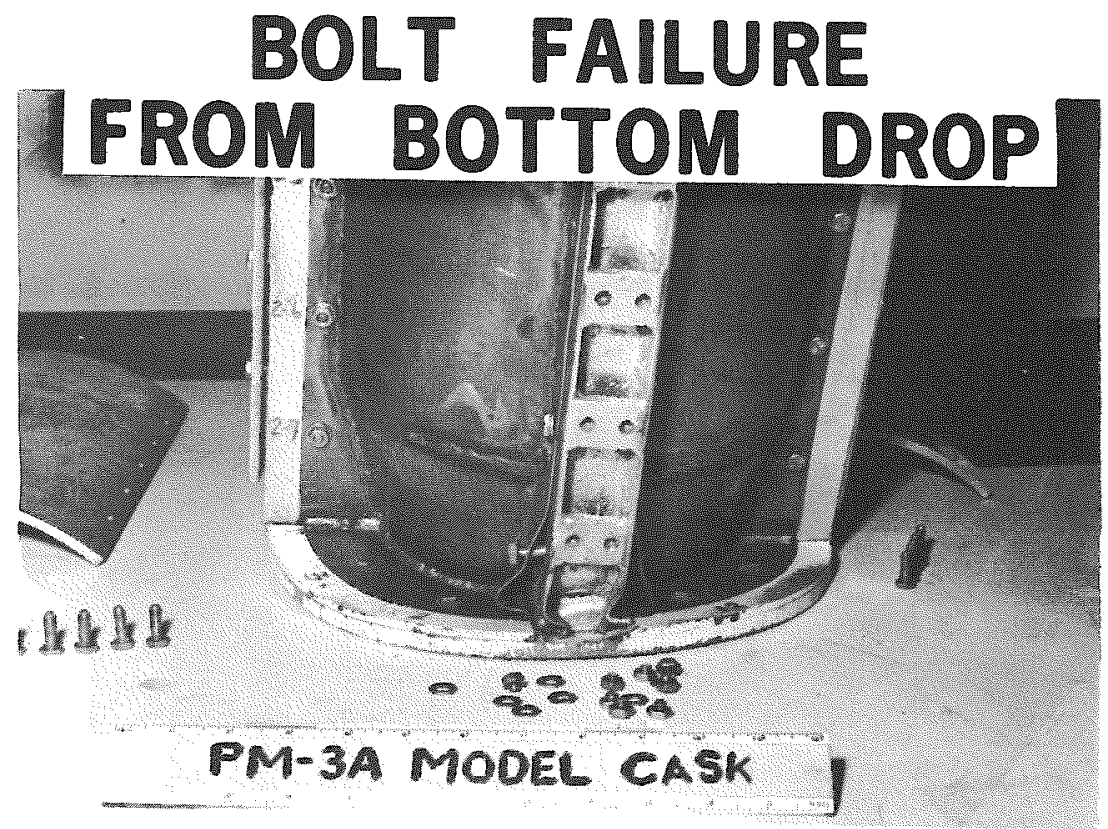

FIGURE 17 


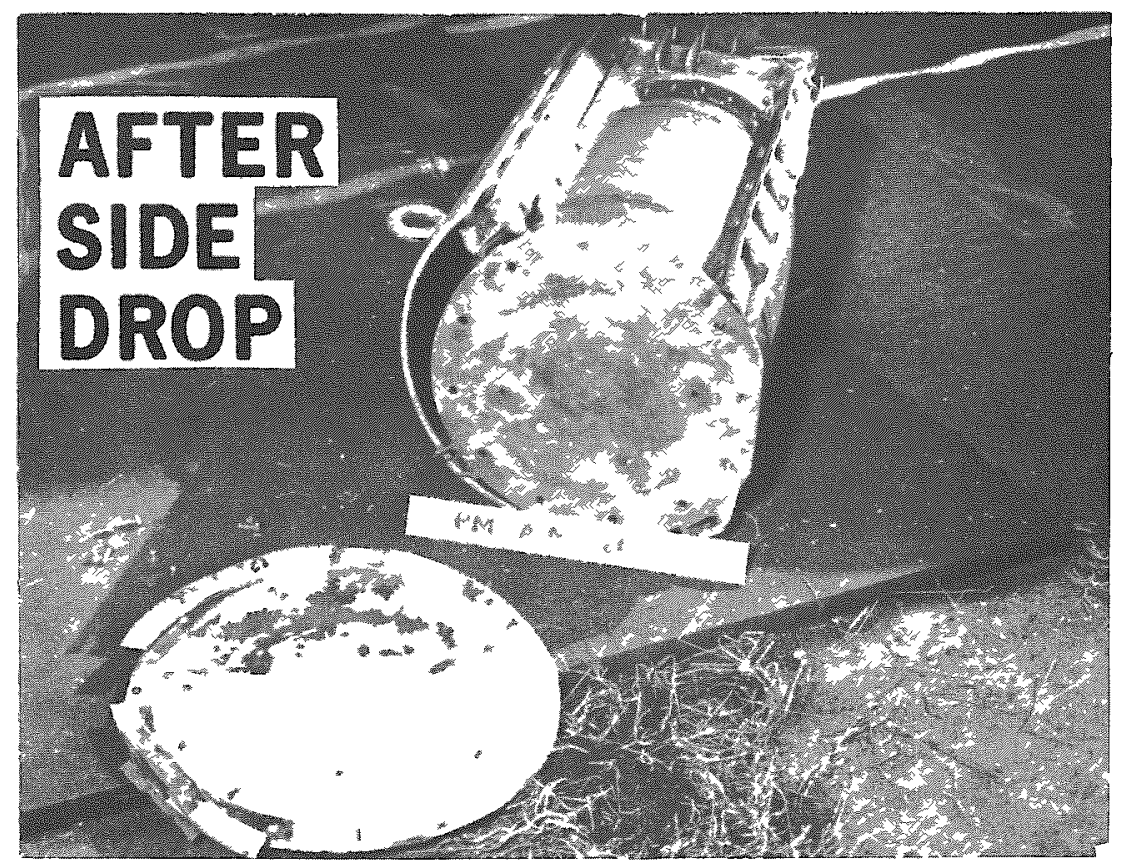

FIGURE 18 


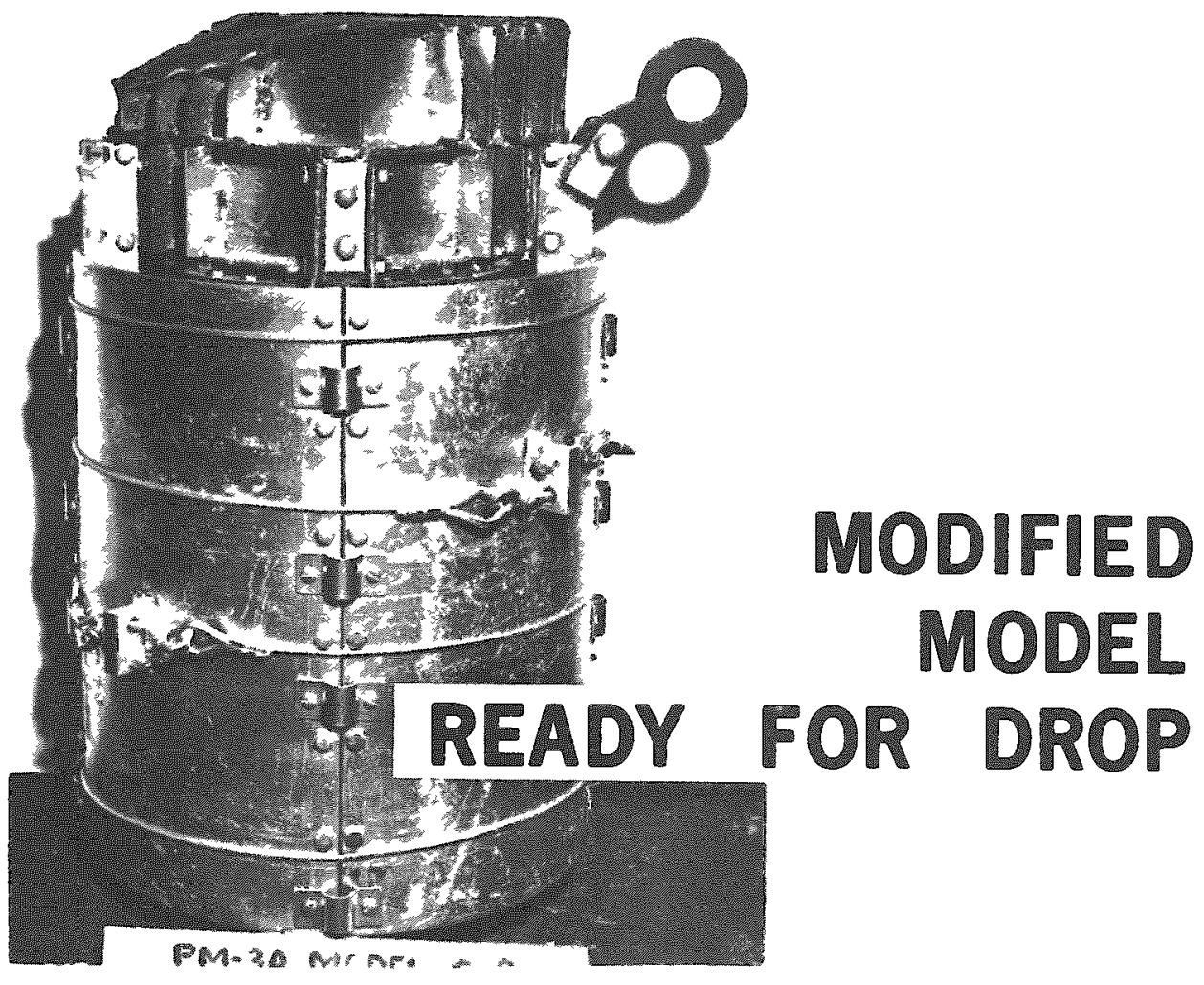

FIGURE 19

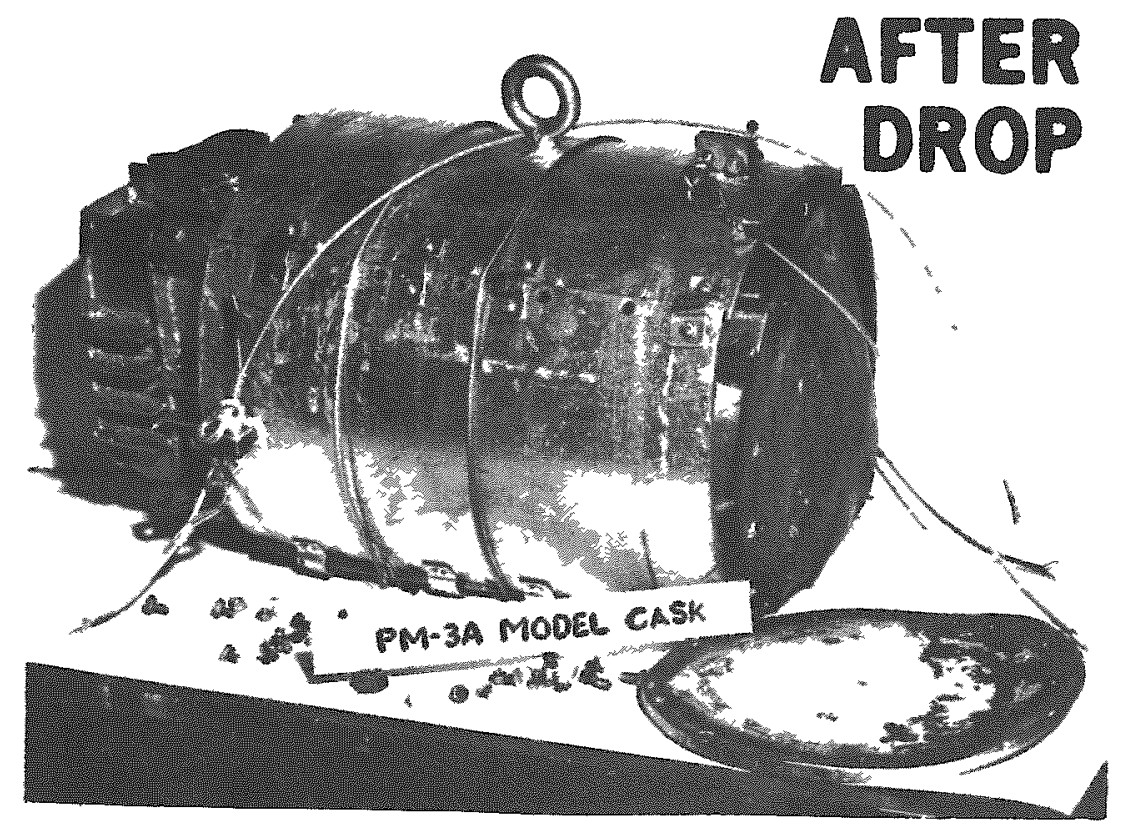

FIGURE 20 


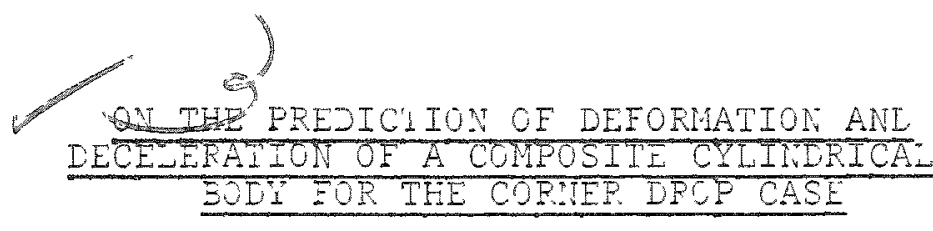

1. Lee

AESTEACT

\begin{abstract}
Jsing the concept of oynamia flow pressure, an energy balance was developed fon the inpact condition of a conner drop. The vedge shaped defonmation as well as the deceleration of a composite oylindrical body caused by a comer drop was then related to the energy level of the impact. Results predicted ly tilis empirical coprer drop conrezation were compared with the cask drop tests performed by H.G. Clarke. The agreement is reasonaziy gocd.
\end{abstract}

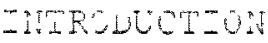

In the design of a cask for the transport of radioactive materials, the regulations" requires that "a free drop through a distance of 30 feet onto a flat essentially unyieldirg horizontal surface, striking the surface in a position for which maximum damage is expected", must ze irvestigated. "Inis statement impiies two things. One is the direct damage at the impact plare due to deformation and the other is the indirect danage at other locations due to deceleration. From a Fhysical standpoint, the maxinum direct damage would occur with the cask so oriented that the Iine passing betweer the center of gravity and the point of impact coincides with the direction of fall. The geometrical representation of the corner drop is shown in Figure 1. The idedized deformation, the exterral damage after impact, is indicated as $z$. 
Wo standard method is presently available for the estimation of the value of $z$ of a composite cyindrical body or its deceleraticr. H.G. Clanke ${ }^{2}$ has perfomed some actual comer drop tests using scale models. He suggests thet the test data maj be used to predict the defcrmation of a prototype ty means of a scaling facton. It is probable that clarke's scaling approach is the only method now availabie for a conner drop. L.B. Shappent ${ }^{3}$ has formuated a procecure to obtair the deformation for both end and side crops. Experiments were perfomed to support his fommatiors. The three positions for drop study have one thing in common, material flows or displaces under dynamic conditions. It is tnerefuse logical to present a procedure for the corner arop case similar to those giver fy shappert for which Clanke's test data can ie used as a check. whis has been worked out in a semi-analytic way and the results are promising. In carrying out the correiation for deformation, deceienation can also be obtained. The details of this work is preserted ir the following presentation.

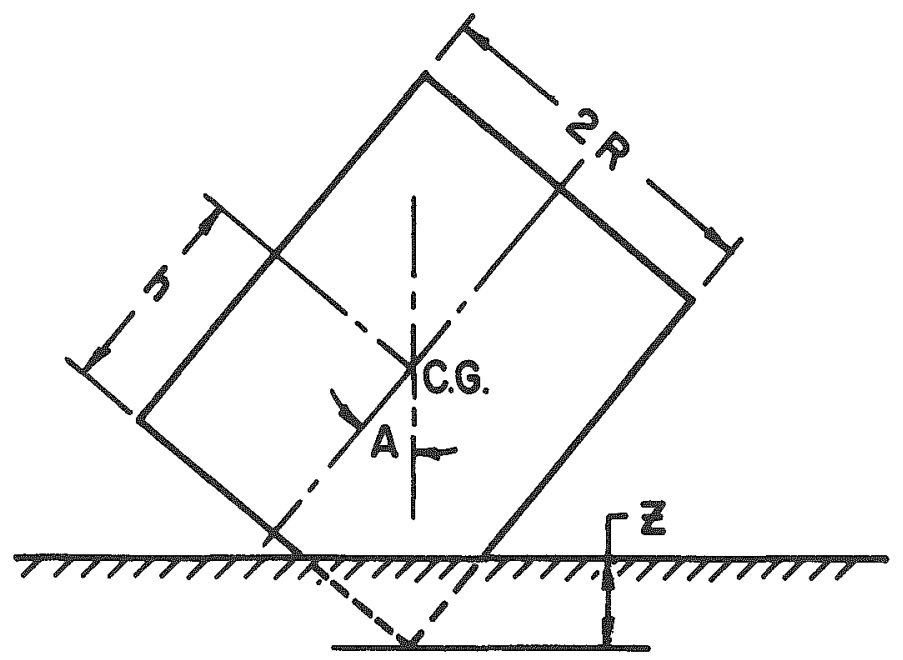

FIG. I. CORNER DROP REPRESENTATION 
When the impact velocity exceeds a certain limit, plastic deformation will take place. The material under impact will shift from its original position, that is, it flows. The displacement of material requires a certain amount of work. Relating the impact energy to the displaced volume, a parameter is obtained as

$$
k=\frac{d(E)}{d(V O I)}, i n-1 b / i n^{3}
$$

where

$$
\begin{aligned}
E & =\text { impact energy } \\
\text { Vol } & =\text { displaced volume }
\end{aligned}
$$

L.B. Shappert ${ }^{4}$ has done some impact tests on solid lead. He has found that the slope of E-Vol plot is almost constant. That means eq. (1)can be rearranged as

$$
E=K(\operatorname{VOI})
$$

where

$K$ is energy expended in displacing one unit volume. Shappert called it the dynamic flow pressure. It will be named here as the energy absorption constant to emphasize its relation to impact energy. It should be noted that $k$ is not a material constant such as strain energy or flow stress but varies with geometrical configurations due to the extra work in displacing the material. As an example, for the same deformed volume, a straight bar absorbs less energy than a wedge-shaped stock.

Equation (2) states that the energy absorbed by the deformation is proportional to the volume displaced. Shappert ${ }^{5}$ has applied this equation to an end drop as well as side drop. His predicted values were found to be very close to the test results. Based on these two cases, it would be expected that a comer drop might show similar agreement.

Consider a solid cylindrical body of weight $W$, dropped freely from a certain height $H$. According to equation (2), we have

$$
\text { WH }=K(\text { VOI })
$$

Referring to Figure 1 , it is obvious that the displaced volume is related to the deformation or simply

$$
\mathrm{Vol}=\mathrm{f}(\mathrm{Z})
$$

Thus a relation of $\mathrm{Z}$ and $\mathrm{Vol}$ has to be established before Equation 
(3) cen be applied.

\section{Wedge (Ungula) Volume of Right Circular Cylinder}

The displaced volume below the impact plane is shown in dotted Iines, Figure 1 , whereas $z$ represents the accompanying deformation. The volume of the wedge can be calculated from various formulas. One such formula ${ }^{6}$ is given below

$$
\text { VOI }=R^{3} \tan (A)\left[\sin B-\frac{\sin ^{3} B}{3}-B \cos B\right](5)
$$

where
$A=$ angle of impact
$B=$ half angle of the extended defomed arc

From the geometrical relation of the wedge shown in Figure 2, we have

$$
z=R(I-\cos B) \sin A
$$

Let

$$
\begin{aligned}
& (\mathrm{VOL})_{n}=\frac{\operatorname{VOI}}{\mathrm{R}^{3}} \\
& z_{n}=\frac{\mathrm{Z}}{\mathrm{R}}
\end{aligned}
$$

Then equations (5) and (6) become

$$
\begin{aligned}
& (\operatorname{Vol})_{n}=\tan A\left(\sin B-\frac{\sin ^{3} B}{3}-B \cos B\right)(9) \\
& Z_{n}=(1-\cos B) \sin A
\end{aligned}
$$

(Vol) $n$ and $Z_{n}$ are related by the two parametric equations ( 9 ) and (10). By eliminating $B$, the two equations can be combined into one single equation as

$$
(\operatorname{Vol})_{n}=f\left(A, Z_{n}\right)
$$

With a given value of $A$ and $z_{n}$, the nommilized volume (Vol) $n$ can be directly calculated by the use of the above equation. However, by direct computation, it has been found that the single equation can have the following simple empirical form

$$
(V O I)_{n}=c\left(z_{n}\right)^{2.38}
$$

where

$C=$ a coefficient which varies with impact angle "A" 


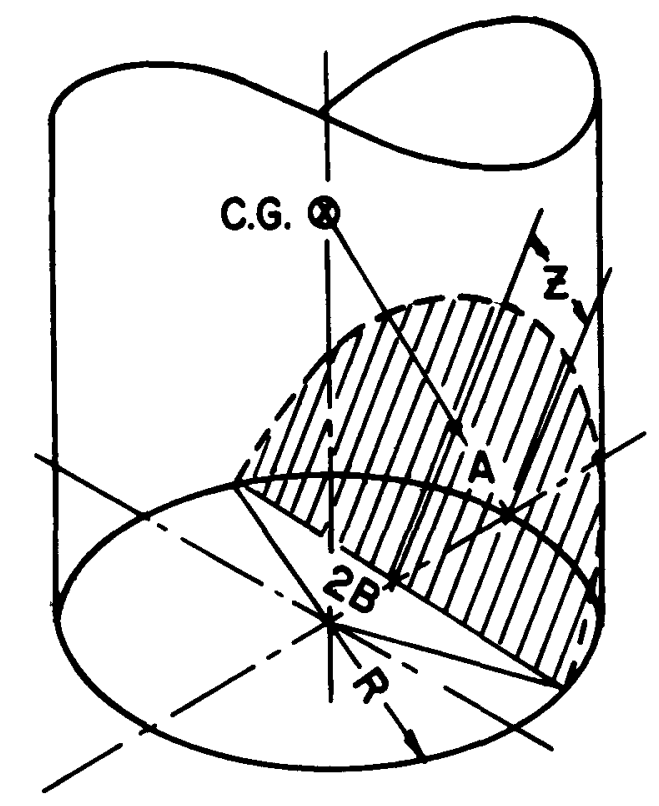

\section{FIG. 2. GEOMETRY OF CYLINDRICAL WEDGE}

According to equations (7) and ( 8 ), equation ( 11 ) may be converted back as

$$
\text { VOI }=C R^{.62}(z)^{2.38}
$$

This is the empirical equation relating the deformed volume directly to the deformation.

Energy Balance For Composite Circular Cylinder--For a solid circular cylinder, an energy balance can be set up by means of equations ( 3 ) and (12) as

$$
\mathrm{WH}=\mathrm{KCR}^{.62}(\mathrm{Z})^{2.38}
$$

However, actual casks are usually built as a composite structure with lead shielding enclosed within a steel shell. During a corner drop, the steel will be deformed first with the lead layer as its backing. After the impact starts, it will be a continuous process even if the time duration is very short. The pictures in Clarke's report ${ }^{2}$ indicate that the final shape of the crushed shell seems to be formed from small local plastic changes. During the impact, the deformed portion enlarges gradually and the plastic front moves on at a definite speed until all the impact energy is exhausted. This reveals that deformation of the steel begins 


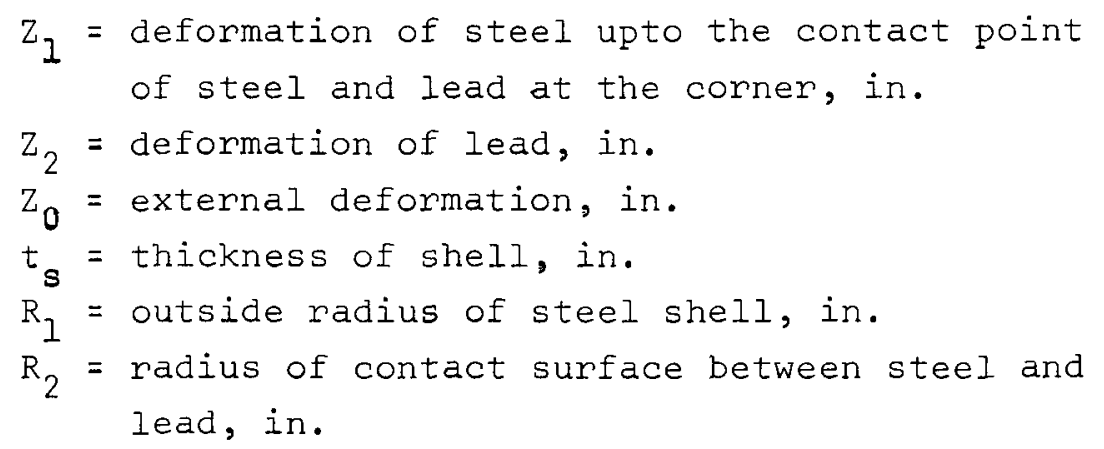

From the geometry shown in Figure 3 , the following relations can be established:

$$
\begin{aligned}
& \mathrm{Z}_{I}=2 \mathrm{t}_{\mathrm{S}} \cos \left(45^{\circ}-\mathrm{A}\right) \\
& \mathrm{A}=\tan \frac{\mathrm{R}}{\mathrm{h}}
\end{aligned}
$$

The deformed volume consists of two parts, steel and lead. For steel, the volume assumed is that under the impact plane X - X which is

$$
(V \circ I)_{s t}=C R_{I} \cdot 62\left(Z_{0}\right)^{2.38}-C R_{2} \cdot 62\left(z_{0}-Z_{I}\right)^{2.38}
$$

For lead, the deformed volume is

$$
(\mathrm{VOI})_{\mathrm{pb}}=\mathrm{CR}_{2} \cdot 62\left(\mathrm{z}_{2}\right)^{2.38}=\mathrm{CR}_{2} \cdot 62\left(\mathrm{z}_{0}-\mathrm{z}_{1}+\mathrm{t}_{\mathrm{st}}\right)^{2.38}
$$

Applying equation ( 3 ), we have

$$
\begin{aligned}
W H & =k_{s t}\left[\mathrm{CR}_{1} \cdot 62\left(\mathrm{z}_{0}\right)^{2.38}-\mathrm{CR}_{2} \cdot 62\left(\mathrm{z}_{0}-\mathrm{Z}_{1}\right)^{2.38}\right] \\
& +\mathrm{k}_{\mathrm{pb}} \mathrm{CR}_{2} \cdot 62\left(\mathrm{z}_{0}-\mathrm{z}_{1}+\mathrm{t}_{\mathrm{st}}\right)^{2.38}
\end{aligned}
$$

where

$\mathrm{K}_{\mathrm{st}} \triangleq$ energy absorption constant for steel wedge, in-lb/in ${ }^{3}$

$K_{\mathrm{pb}}=$ energy absorption constant for lead wedge, in-lb/in 3 From equation ( 16 ), the external deformation can be solved by trial and error.

\section{Comparison with Model Test Results}

The energy balance equation (16) may now be tested by applying it to clarke's tests. Before any calculation is made, the values of $K_{s t}$ and $K_{p b}$ must be specified. The deformed volume of lead is a solid cylindrical wedge for which a constant $\mathrm{K} p$ would be expected. However, the steel shell would not be so simple. With a deformation up to $\mathrm{Z}$, Figure 3 , the deformed volume is a 
as plastic deformation and continues as such throughout the duration of the impact. In regard to stress, it may be said that the deformed material fails at same stress condition. Therefore it is reasonable to assume that the impact energy absorbed by a steel shell is directly proportional to the volume of displaced material. This means equation ( 3 ) can also be applied to steel corner.

Figure 3 shows a composite cylinder with the dimensions defined in the following:

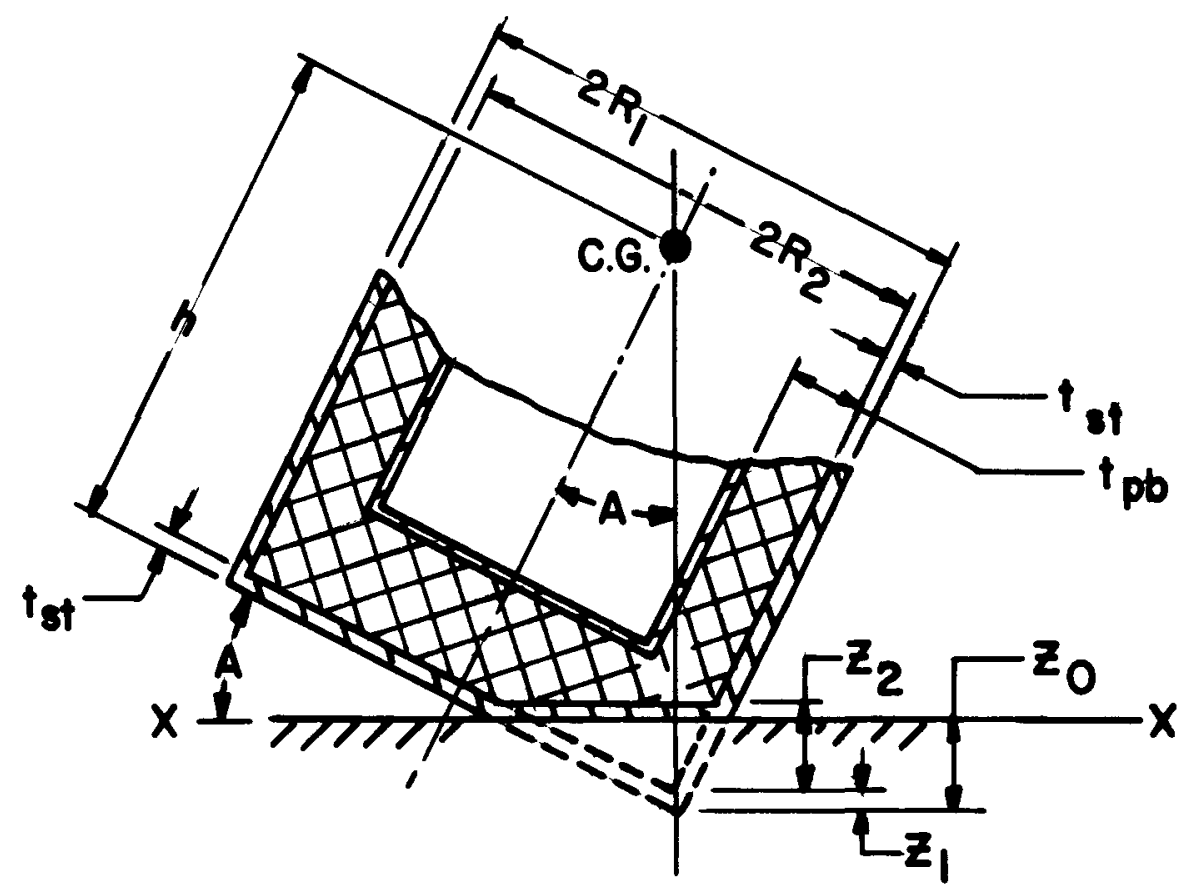

FIG. 3 IDEALIZED DEFORMED COMPOSITE CYLINDER 
solid wedge for which $K_{s t}$ remains constant. After this limit is exceeded, the geometry is changed. A solid wedge becomes two formed steel plates. For thin shell structure, the solid wedge is only a small portion of the total deformed mass. But for thick shell, the energy absorbed by the solid wedge will predominate in the lumped energy absorbing constant. Therefore it is expected that thin shell would not have the same $k_{s t}$ as for a thick shell. In the extreme case, it became a solid wedge if

$$
\mathrm{Z}_{0}<\mathrm{Z}_{\mathrm{I}}
$$

In order to be as consistent with the test data as possible, the values used for models are tabulated as follows

Table 1. Values of Energy Absorption Constant used for Comparison with Tests Energy Absorption Constant, in-lb/in ${ }^{3}$

\begin{tabular}{|c|c|c|c|}
\hline & $C L-0.05$ & $C L-0.106$ & $C L-0.173$ \\
\hline c & 50,000 & 60,000 & 110,000 \\
\hline$K$ & 8,000 & 8,000 & 8,000 \\
\hline
\end{tabular}

Based on the above assumed values, deformations on Clarke's test models are calculated using equation (16). The results have been added to a plot of Clarke's test results to enable comparison (Figure 4). Clarke's test report showed only a few points. Indeed, it may not represent the general trend of deformations since the impact test is hardly reproducible and usually there is much scatter even for low-velocity levels. In Figure 4, test data points are shown and the solid lines represent the calculated values.

\section{DECELERATION}

When a mass is dropped freely from a height, the motion will be stopped in a short time after the mass touches the impact plane. During impact the velocity decreases from its initial value at contact because of the energy loss. Without resilience, the velocity would become zero after the impact is completed. The rate of change of the velocity, the deceleration, has an important role in the design of a transportation cask. It is obvious that the deceleration is a function of deformation. Since the deformation has been correlated with deformed volume as given by equation (13), it is possible now to estimate the deceleration directly for a 


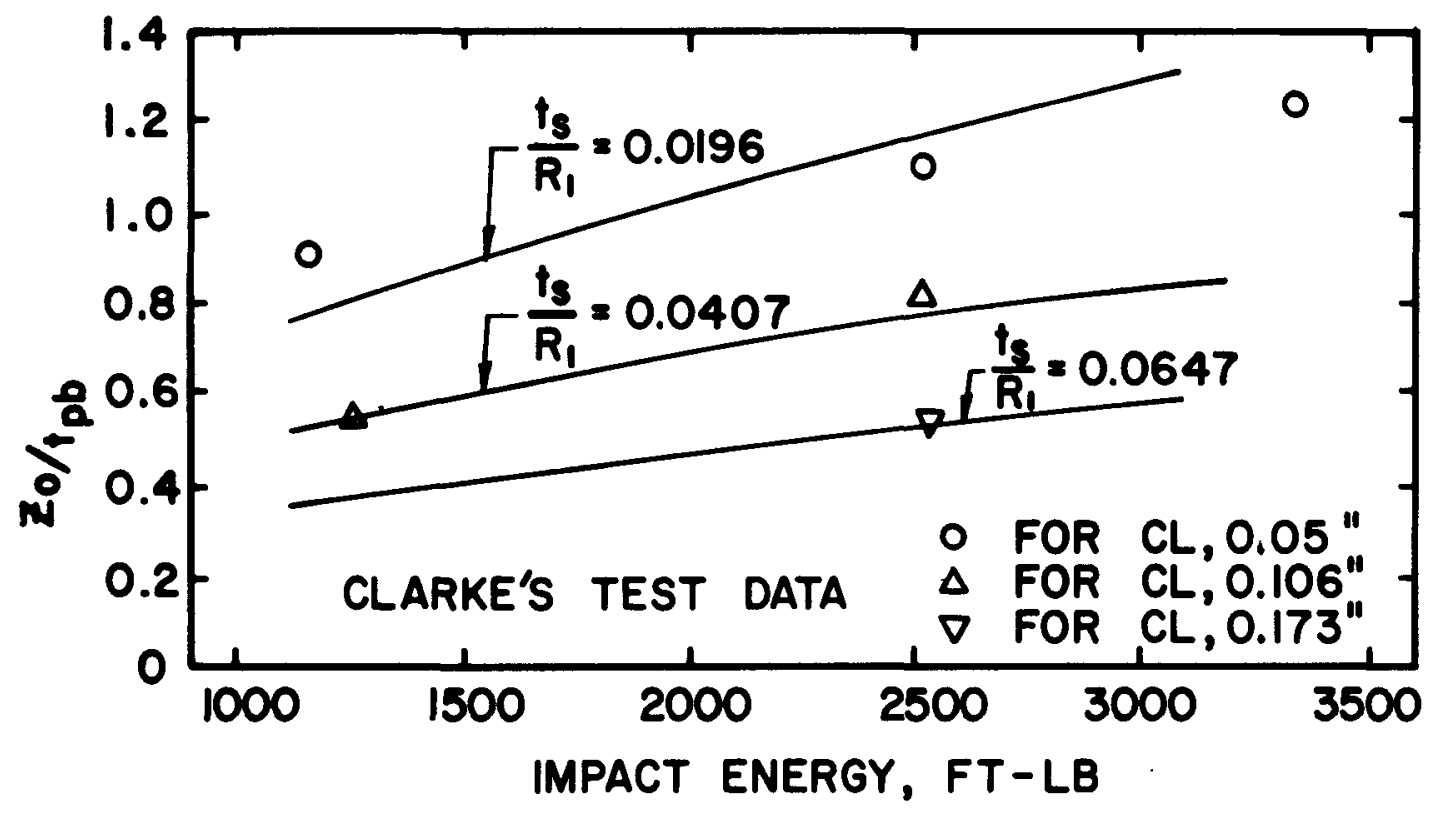

FIG. 4. EXTERNAL DEFORMATION

corner drop.

The enengy loss at a deformation level $\mathrm{Z}$ is

$$
E_{1}=12 \mathrm{~W} \frac{V_{0}{ }^{2}-V^{2}}{2 g}, i n-1 b
$$

where

$$
\begin{aligned}
& \mathrm{V}_{0}=\text { initial velocity, } \mathrm{ft} / \mathrm{sec} . \\
& \mathrm{V}=\text { remaining velocity at position } \mathrm{Z}=\mathrm{Z} .
\end{aligned}
$$

Relating to displaced volume of a solid cylinder, the energy absorbed is

$$
E_{a}=K C(R) \cdot 62(Z)^{2.38}
$$

From energy balance,

$$
\begin{gathered}
E_{I}=E_{a} \\
I 2 \mathrm{~W} \frac{V_{0}^{2}-V^{2}}{2 g}=\mathrm{KC}(\mathrm{R}) \cdot 62(\mathrm{Z})^{2.38}
\end{gathered}
$$


Differentiating equation (19) with respect to time, $t$

$$
12 \mathrm{~W} \frac{(-) 2 \mathrm{~V}}{2 \mathrm{~g}} \frac{\mathrm{dv}}{\mathrm{at}}=2.38 \mathrm{KC}(\mathrm{R})^{.62}(\mathrm{z})^{1.38} \frac{\mathrm{dz}}{\mathrm{dt}}
$$

where

(-) $\frac{d v}{d t}=a$, deceleration, ft/ $\sec ^{2}$

$1 / 12 \frac{\mathrm{dz}}{\mathrm{dt}}=\mathrm{V}, \mathrm{ft} / \mathrm{sec}$

rearrange equation (20) and simplify,

$$
a=2.38 \frac{g}{w} K C(R)^{.62}(Z)^{1.38}
$$

in terms of g's, the deceleration is

$$
\begin{aligned}
N_{g} & =\frac{a}{g}=\frac{2.38}{w} K C(R) .62(Z)^{1.38} \\
& =\frac{2.38}{w} K C(R) .62 \frac{(Z)}{Z} 2.38
\end{aligned}
$$

when the motion is completely stopped, the maximum deformation level is reached, say $Z=Z_{0}$, then all the impact energy is absorbed. Equations (19) and (21) become

$$
\begin{gathered}
W H=K C(R) \cdot 62\left(Z_{0}\right)^{2.38} \\
\text { and } \quad \max . N_{g}=\frac{2.38}{w} K C(R) \cdot 62{\frac{\left(Z_{0}\right)^{2}}{Z_{0}}}^{2.38}
\end{gathered}
$$

combine equations (22) and (23), we obtain

$$
\max . \mathrm{N}_{g}=2.38 \frac{\mathrm{H}}{\mathrm{Z}_{0}}
$$

where

$$
\begin{aligned}
& \mathrm{H}=\text { height of drop, } 360 \text { inches } \\
& \mathrm{Z}_{0}=\text { maximum deformation, in. }
\end{aligned}
$$

By the same procedure, the maximum deceleration for a composite structure of steel and lead (Figure 3) would be

$$
\mathrm{N}_{\mathrm{g}}=2.38 \frac{\mathrm{H}}{\mathrm{Z}_{0}}(\mathrm{M})
$$


where

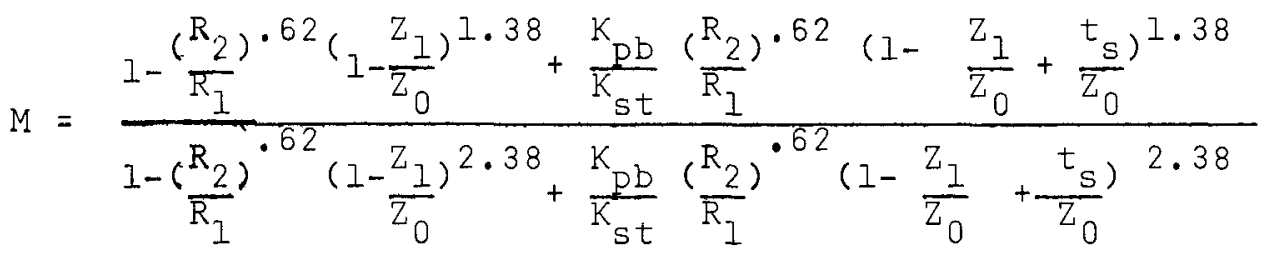

$$
\begin{aligned}
& =\text { the correction factor which has a maximum value of } 1 \text {. }
\end{aligned}
$$

For a corner drop, both the direct effect on deformation at impact plane and the indirect effect on deceleration can be estimated by means of the empirical equations. The comparison between the predicted and the test values shows good agreement. In adjusting the curves, the value of the energy absorbing constant has to be varied with shell thickness. The curve for CL-0.05 does not fit very well with the three test points. However, the test data for CL-0.05 seems not to be consistent with the data for the other models. From physical considerations, the thin shell model should have the largest slope for deformation when impact energy is the variable. In other words, the slope of the deformation-energy curve at each impact level should follow the inequality relations

$$
\left(\frac{\mathrm{dZ}}{\mathrm{dE}}\right)_{C L-0.05}^{>}\left(\frac{\mathrm{dZ}}{\mathrm{dE}}\right)_{C L-0.106}^{>}\left(\frac{\mathrm{dZ}}{\mathrm{dt}}\right)_{\mathrm{CL}-0173}
$$

Comparison with the test data shows the three points for CL-0.05 not to be in agreement with the above inequality expression. It may be concluded that this inconsistency in the test data is probably due to scatter. Without the availability of more elaborate tests (including unequal thicknesses of shell and bottom) the present approach offers a handy and reasonably method for the prediction of deformation and deceleration for a corner drop. 


\section{REFERENCES}

1. Code of Federal Regulations, Title 10, Part 71, Packaging of Radioactive Material for Transport.

2. H.C. Clarke, "Some Studies of Structural Response of Casks to Impact", Proceedings of the Second International Symposium of Packaging and Transportation of Radioactive Materials, pp. 373-398, (1968).

3. L.B. Shappert, Irradiated Fuel Shipping Casks Design Guide, ORNL-TM-2410, pp. 48-53, (1969).

4. L.B. Shappert, A Guide to the Design of Shipping Casks for the Transportation of Radioactive Material, ORNL-TM-68I, pp. 101-104, (1965).

5. Reference 3, pp. 54-55.

6. O.W. Eshbach, Handbook of Engineering Fundamentals, Item 32, pp. 2-42, (1936). 


\section{ECONOMICS, COMPOSITIONS AND PROCESS EQUIPMENT FOR RADIOACTIVE WASTE SOLIDIFICATION}

L. Rutland

ABSTRACT

From ecological and safety considerations, solidification of radioactive wastes results in a desirable waste product form for transportation and subsequent disposal. Government regulations may and some commercial burial facilities now require radioactive wastes from nuclear plants to be handled as a free standing solid waste product. Suitable solidified radioactive waste product compositions, economic considerations associated with transportation and disposal, and a waste solidification process system are discussed.

\section{INTRODUCTION}

Large volumes of low and intermediate activity levels of radioactive wastes may be generated in nuclear reactor process systems and coolant purification systems. Unlike radioactivity induced in metallic reactor components which are essentially noncorroding, these radioactive wastes when buried for disposal are more susceptible to dispersion in the environment and may therefore be termed "available".

The radioactive waste materials considered in this paper are ion exchange resins, filter sludges, and evaporator concentrates. The radioactive components contained within these materials are better isolated from the biosphere if the wastes are cast in a solidified matrix. Cement or cement containing mixtures have been to date the most popular medium to achieve a free standing solidified waste product for disposal by burial. 
Current Department of Transportation regulations concerning the packaging and transportation of radioactive materials do not require a free standing solidified waste product for transportation. It is obvious however that a solidified waste product would be desirable to reduce dispersion and facilitate cleanup in case of accidental rupture of a transportation container bearing these waste materials. On the other hand, most commercial burial facilities do require a free standing solidified radioactive waste material in order to be accepted for burial. It becomes apparent that it would be prudent for nuclear power utilities to provide at least the flexibility of adding solidification capability in the future should Department of Transportation regulations be changed or that all burial sites require a solidified waste product.

Indeed, the location of a nuclear power plant or specific conditions may make the solidification of the radioactive waste materials in question the most economical waste product form for disposal. Vital to the cost of radioactive waste disposal are the compositions of solidified radioactive waste materials. Compositions are discussed in the following sections as well as some economic considerations of solidification. Also discussed is the process system provided by ATCOR Inc. for the solidification of these materials.

\section{COMPOSITIONS OF SOLIDIFIED RADIOACTIVE WASTES}

Specifications for cemented radioactive waste have not been issued by governmental agencies or private burial facilities. As a guideline for a satisfactory solidified product, ATCOR Inc. recommends the two following properties for a disposable waste product:

1. the waste product should be free standing

2. the cemented product should remain intact after complete submergence in water.

As a result of experimentation, specific mixtures of the various wastes (resins, filter sludges or evaporator concentrates) and cement have been developed which satisfy the above two conditions. An acceptable mixture suitable for the solid waste 
materials, bead resin, powdex, filter sludges or even mixture of these materials is one part of moist dewatered solid to an equal part of dry cement with sufficient water then added for hydration. This is an acceptable composition for unspecified mixtures of the solid waste materials, however, more specific proportions can be specified with a single waste material (rather than mixtures of the various waste materials) to maximize the amount of radioactive waste in the cemented mixture.

For planning purposes it is useful to consider that dewatered solids for disposal comprise about two thirds of the cemented mixture while cement itself comprises the remaining one third, by volume. The volume of a cemented waste product after mixing of the individual components may be obtained from the following expression:

Cemented waste volume = Volume of dewatered waste material + 0.5 volume of dry cement

Similarly, one volume of evaporator concentrates with an equal proportion by volume of dry cement results in an acceptable mixture.

The density of the cemented waste products is approximately 100 pounds per cubic foot of mixture.

ECONOMIC CONSIDERATIONS FOR SOLIDIFIED WASTE PRODUCTS

At present the decision to solidify waste is optional since some commercial burial facilities will still accept unsolidified dewatered wastes. Aside from the desirable ecological or safety features of solidified wastes, it will be seen that it may even prove to be cheaper to solidify radioactive wastes. The overall economics depend on the proximity to a particular burial site or whether dewatered wastes (resins or filter sludges) or evaporator concentrates are to be disposed of.

Dewatered Solids (resins or filter sludges)

With dewatered solids, solidification tends to increase disposal costs since the addition of cement or cement mixtures:

1. makes for a heavier waste product 
2. reduces the amount of radioactive waste in the transportation package

3. involves the added cost of the cement itself.

If however, the nuclear power plant is located closer to a burial facility which requires solidification, the reduced transportation costs (for example, shipping to Morehead, Kentucky) may more than offset the cost factors noted above. Also, if activity levels are sufficiently high to require a shielded transportation cask then items 1. and 3 . above become second order effects and therefore increase costs only slightly.

In this case, the weight of the contents is usually small compared to the weight of the shielding material in the transportation container and the cost of cement is small compared to the transportation costs.

While it appears that solidification reduces the actual volume of radioactive waste in a particular shipment (item 2.), it should be noted that there is a compensating effect with solidification. The addition of cement increases the density of the waste product and thereby increases the self attenuation of radiation by the mixture itself. Whereas the volume of the radioactive waste is increased by about $50 \%$ the radiation dose rate on the surface of the transportation container will be reduced by a similar degree. Thus, with a solidified waste product, the number of curies of solidified radioactive material that can be shipped is about the same as with an unsolidified (dewatered) product.

\section{Evaporator Concentrates}

Evaporator concentrates cannot be shipped as a liquid and must at least be contained with an absorbent such as vermiculite. Solidification of evaporator concentrates with cement does not impose a penalty by virtue of increased volume since a cemented mixture of evaporator concentrates could contain about as much liquid radioactive waste as a vermiculite absorbed product. In addition the increased self attenuation would be beneficial and solidification in cement would then be the desirable product form for disposal. 
Some nuclear power plants have separate systems to collect, concentrate and package for disposal resin, filter sludges and evaporator concentrates. This makes for a diversity of process equipment, transportation packages and shielded transportation containers. Actually, radioactive resins, filter sludges, evaporator concentrates could all be handled in a similar manner and shipped in the same type of transportation container. The result is a savings in capital equipment and greatly simplified handling procedures.

The ATCOR solidification system (presently installed in a major nuclear power utility) accepts resins, filter sludges or evaporator concentrates and conditions waste material. This waste and a separate feed of cement are metered into a continuous smalI volume mixer. The cemented radioactive waste product is then discharged directly into a transportation package. Controlled discharge of the waste as a moist material precludes the possibility of airborne contamination. An efficient dust collector prevents release of cement dust into the plant or ventilation system.

Full instrumentation is provided on the control panel for complete readout of flow rates and operating condition of components. Interlocks and alarms are provided to prevent operation in an unsafe manner. For example, no cement waste can be discharged unless a waste container is properly in place and no radioactive waste can be fed unless cement is also being provided. While control of individual components is possible under the manual mode of operation, normal operation makes full use of functional controls. Operator error is minimized since controls are automated such that sequential operation of functional pushbuttons and controls cannot be performed unless the previous step has been completed and the system is in the required configuration.

Some advantages of the ATCOR solidification system are listed:

1. A single process system can handle bead resin, powdered resin, filter sludges, evaporator concentrates and can even solidify spent filter cartridges in a transportation container. 
2. Proportions of waste and cement can be altered to suit the specific waste material to maximize the amount of radioactive waste in the disposal product. Transportation and disposal costs are reduced.

3. Operation is inherently clean to prevent either radioactive or non-radioactive spatter or airborne contamination.

4. Filling of a package takes minimal time, for example only about five minutes for a 55 gallon drum.

5. No expensive special drums or time consuming prefilling of drums is required. Prefilling mixtures in other systems can separate and result in a nonfree standing waste product.

6. Internal surfaces of process equipment in contact with radioactive cement is small. Equipment is automatically flushed after completion of waste processing such that no cement bearing flush water enters plant piping systems.

7. Fully interlocked functional controls minimize the possibility of operator failure or system operation in an unsafe manner.

8. No manual connections or handling is required so that radiation exposure to personnel is minimized.

9. Filling of transportation packages with highly radioactive waste can be performed remotely without the need for separate shielding for individual packages. 
Present regulations do not require solidification of radioactive waste for transportation and disposal. It was shown however that solidification could actually result in lower waste disposal costs depending on the proximity to neighboring burial facilities and also depending on whether the waste is a dewatered material or evaporator concentrate. With a preponderance of radioactive waste in the form of evaporator concentrates it seems that solidification with cement is clearly preferable to the use of an absorbent. While solidification reduces the quantity of waste shipped in a container self attenuation by the waste itself permits equal curie content in solidified form as in unsolidified form. In any case, the advantages of solidification make it the desired disposal product form even in cases where solidification results in somewhat increased costs.

A solidification system is currently available which can handle bead type resin, powdered resin, filter sludges, evaporator concentrates and even spent filter cartridges. This system can fill cemented waste into standard and readily available containers so that the nuclear power utility can freely select its waste disposal contractor. Operation of this system offers the advantages of

1. reduced manpower requirements for processing of wastes.

2. reduced radiation exposure to operating personnel.

3. maximum waste content in cemented mixtures for lowest disposal costs. 
ABSTRACT

\begin{abstract}
Knowledge of the criticality of spaced subcritical spherical masses in water-reflected cubic arrays can be used to estimate allowable mass limits for containers of fissile material in transportation. Calculated criticality data for representative fissile materials are tabulated. The methods of calculation as well as the techniques required to employ the data in the solution of arbitrary problems of array criticality are described. Monte Carlodetermined critical arrays characterize criticality for various forms of fissile materials and the factors affecting their criticality. Applications of the data and methods to typical transport containers are given.
\end{abstract}

\title{
TNTRODUCTION
}

The problem of providing an acceptable shipping container for fissile materials is complex. Setting aside the practical difficulties of regulatory requirements in $10 \mathrm{CFR} 70$ and of design, testing, and documentation, there is left the question of criticality evaluation. To the need for determination of the criticality of air-spaced units of fissile materials, one can add the separate influences of reflection, moderation, rearrangement of units, mixtures of fissile materials, and finally, the neutron scattering and absorption properties of the container and insulating materials. Sufficient theories and techniques are available today to satisfy administrative and regulatory requirements in this regard. For economic reasons alone, it is desirable that verification of subcriticality be simple, direct, and easily substantiated.

Ito seems reasonable to begin with the criticality of hydrogen-reflected, air-spaced units in regular geometry. This will provide both a common orientation for analyses and, incidentally, a basic value for the reactivity of the arrays of fissile material. One can then compensate for the reactivity effect of changes in the array configuration and structure by an acceptable scale, measured in terms of the mass reduction equivalent to the reactivity change. Fortunately, a good beginning to, and understanding of, this basic requirement has recently appeared. It is contained in the output of a group active in the

$$
792-4 c^{\circ}
$$


nuclear standards effort sponsored by the American Nuclear Society. The ANSS-8 Standards Subcomittee on "Fissionable Materials Outside of Reactors" has produced a "Guide for Nuclear Criticality Safety in the Storage of Fissile Materials." The preparation of this Guide has necessitated the investigation and evaluation of factors complicating the analysis of criticality of simple arrays, including those mentioned above except for container and insulating materials. While one might, in general, investigate the influence on the neutron multiplication factor of the scattering and absorbing properties of materials occupying the space between the units of the arrays, the required effort lacks both support and interest. An alternative is to be content with two complementing but separate bodies of information: descriptions of critical arrays and the criticality analyses of a limited number of containers. The import of the Guide is the tabulations of masses of fissile materials that may occupy fixed volumes in water-reflected arrays. Following a discussion of these calculated criticality data and some of the interpolative techniques which render them useful to practical problems, the factors affecting criticality will be treated and the application of the result to transport suggested.

\section{ARRAY CRITICAIITY}

The materials considered were the three principal fissile isotopes, ${ }^{235} \mathrm{U}$,

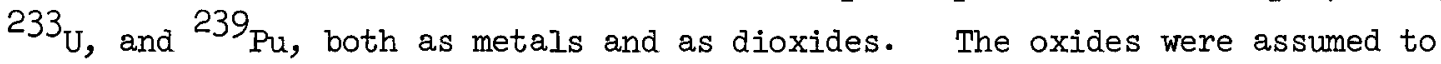
contain various quantities of water with concomitant reduction in their theoretical densities. The ${ }^{235}$ U-enriched uranium considered had concentrations of the fissile isotope ranging from 30 to 100 wt \% with the remainder being ${ }^{238} \mathrm{U}$. Uranium of lower enrichments can be evaluated by similar techniques. The uranium-233 was assumed isotopically pure. The plutonium was assumed to be composed of ${ }^{239} \mathrm{Pu}$ and ${ }^{240} \mathrm{Pu}$ although other plutonium isotopes were appropriately included in them. The notational convention of $U(x)$ or $\mathrm{Pu}(\mathrm{x})$ was adopted, designating the content of ${ }^{235_{U}}$ or ${ }^{239} \mathrm{Pu}$ in wt $\%$. The water content was expressed in terms of the ratios of hydrogen atoms to all uranium or to all plutonium atoms without regard to isotopic composition. These ratios ranged from zero to twenty. This treatment of materials may seem idealistic but, nevertheless, is acceptable under the desired margins of subcriticality in practical application and does provide a suitable point of departure for nuclear safety analyses.

The fissile materials were considered as spherical units centered in the cubic cells of an array. It has been demonstrated ${ }^{l}$ that spheres define mass limits per cell which may be conservatively applied to units of other shapes 
contained in reflected arrays of sizes that may be of concern to most storage and transport problems. The number of calculations necessary to characterize the criticality of a given fissile material is minimized by considering reflected cubic arrays in which each unit is centered in a cubic cell. For each array of a given number of units with specified cell dimension there is determined a unique radius, $r_{c}$, for each form of fissile material. The calculations defining criticality were performed with the KENO ${ }^{2}$ Monte Carlo code and the 16-group Hansen-Roach ${ }^{3}$ neutron cross-section sets. This code and the crosssection sets constitute a validated method ${ }^{4}$ for defining criticality of uniform arrays of fissile materials.

Validation implies evaluation of the method of calculation by correlation with experimental data to establish bias over the area of applicability. Two additional provisions are required. The degree of consistency of the crosssection sets used with differential and with appropriate integral data should be established. Finally, the computer program should be checked to assure that it performs the intended mathematical operations properly. In the absence of confirming experimental data, sufficient conservatism should be employed to assure subcriticality in practical applications.

Table I summarizes the calculated critical spherical radii for four fissile materials, $\mathrm{U}(93), \mathrm{Pu}(100),{ }^{23} 3_{\mathrm{U}}$, and $\mathrm{U}(30) \mathrm{O}_{2}$ at an $\mathrm{H}: \mathrm{U}$ of 10 . The format is similar to that adopted for presentation in the Guide. Arrays of seven different sizes, each composed of cells of six different dimensions, comprise a total of 42 arrays for each material considered. The arrays ranged from 64 to 1000 units and the cell half dimensions from 12.70 to $30.48 \mathrm{~cm}$.

Let us digress for a moment and consider some relationships among those tabulated data that will enable a more comprehensive understanding and will extend their range of applicability, now limited by fixed radii, dimensions of cells, and number of units. Each entry of Table $I$ describes an array by specifying the half dimension of a cell, $a_{n}$, where the subscript $n$ is the number of units along an edge of the array, and by the corresponding radius, $r_{c}$, of the fissile unit. The reflected cubic array then contains $N\left(=n^{3}\right)$ spheres of radius $r_{c}$ whose centers are spaced a distance of $2 a_{n}$. The values of $n$ and of $a_{n}$ for each value of $r_{c}$ may be related through a coupling parameter $N_{N}^{2}$ by the relation ${ }^{4}$

$$
\mathrm{NB}_{N}^{2}=\frac{3 \pi^{2}}{4} \frac{n}{a_{n}^{2}}\left(1-\frac{0.312}{1 / N}\right)^{2}
$$

A graphical representation of all the data contained in Table 1 is shown in Fig. I where $\mathrm{NB}_{N}^{2}$ is given as a function of $a_{n}$ and the lines labeled $n=4,6$, 
Table 1. Spherical Radius in Centimeters of the Fissile Material Required for Criticality in Water-Reflected Cubic Arrays

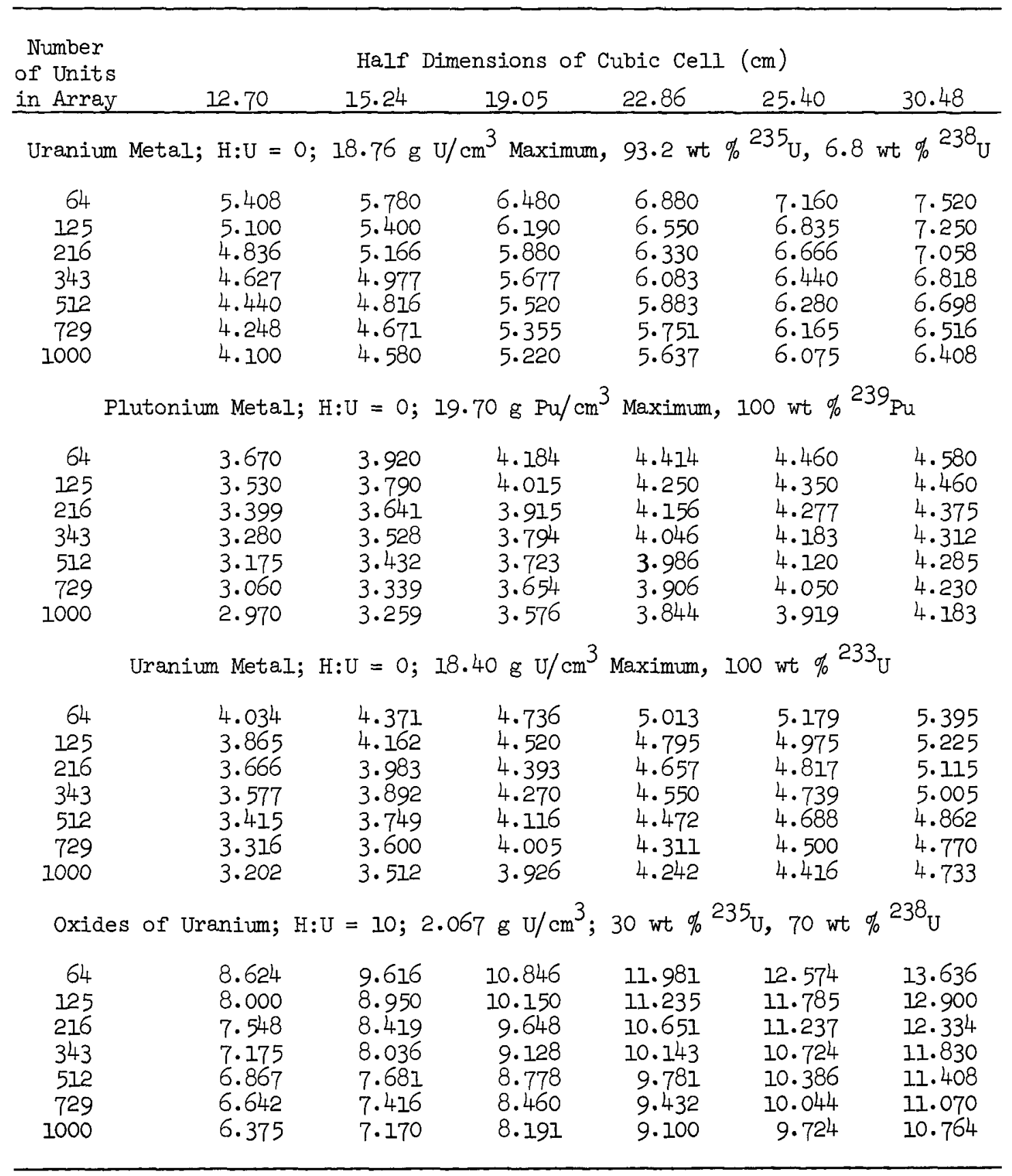




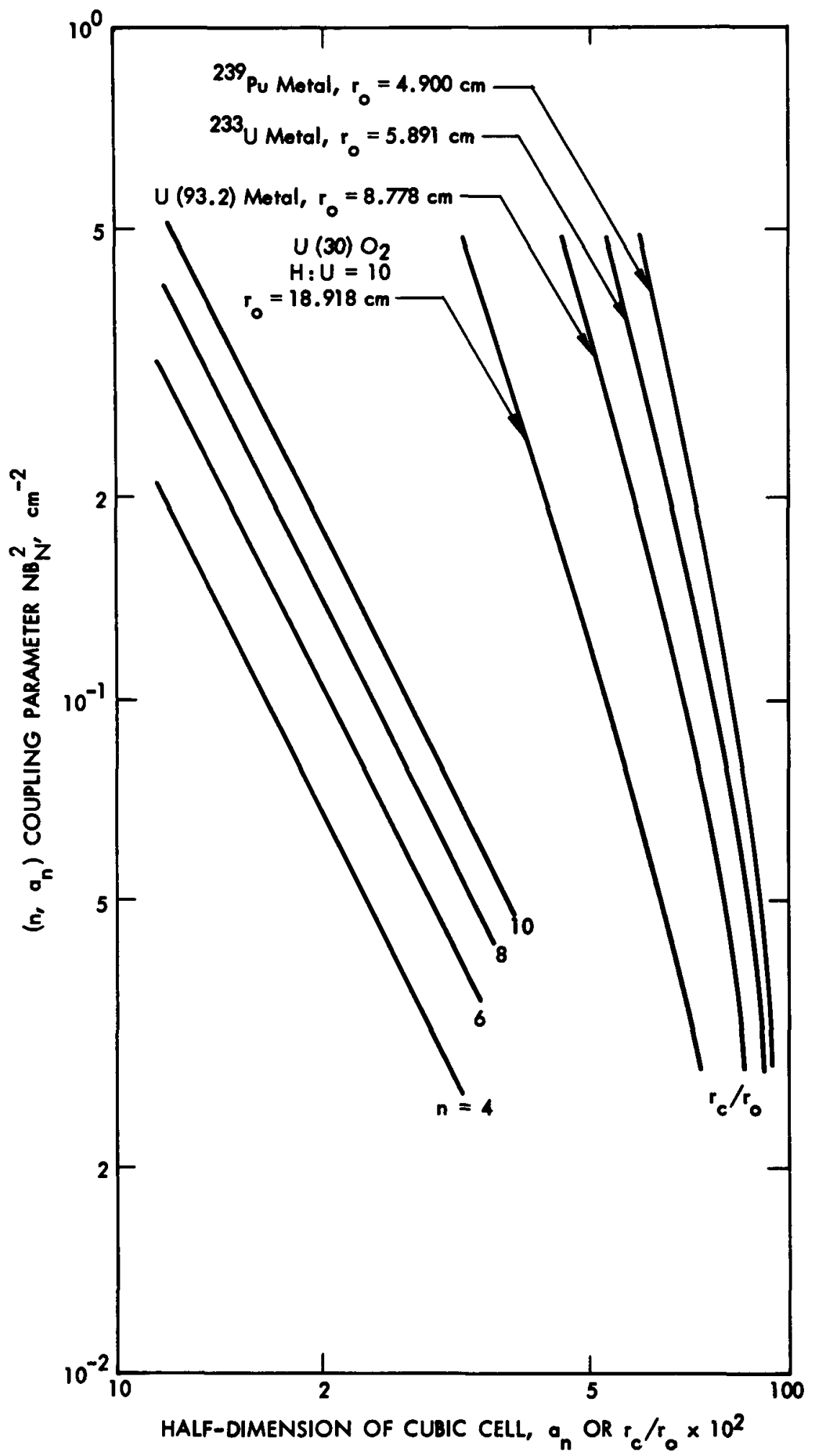

Fig. 1. Calculated Criticality or Water-Reflected Array Showing the Relationship Between Half-Dimension of Cubic Cells, Number of Units along Edge of Cubic Array, and Spherical Radius of Fissile Materials. 


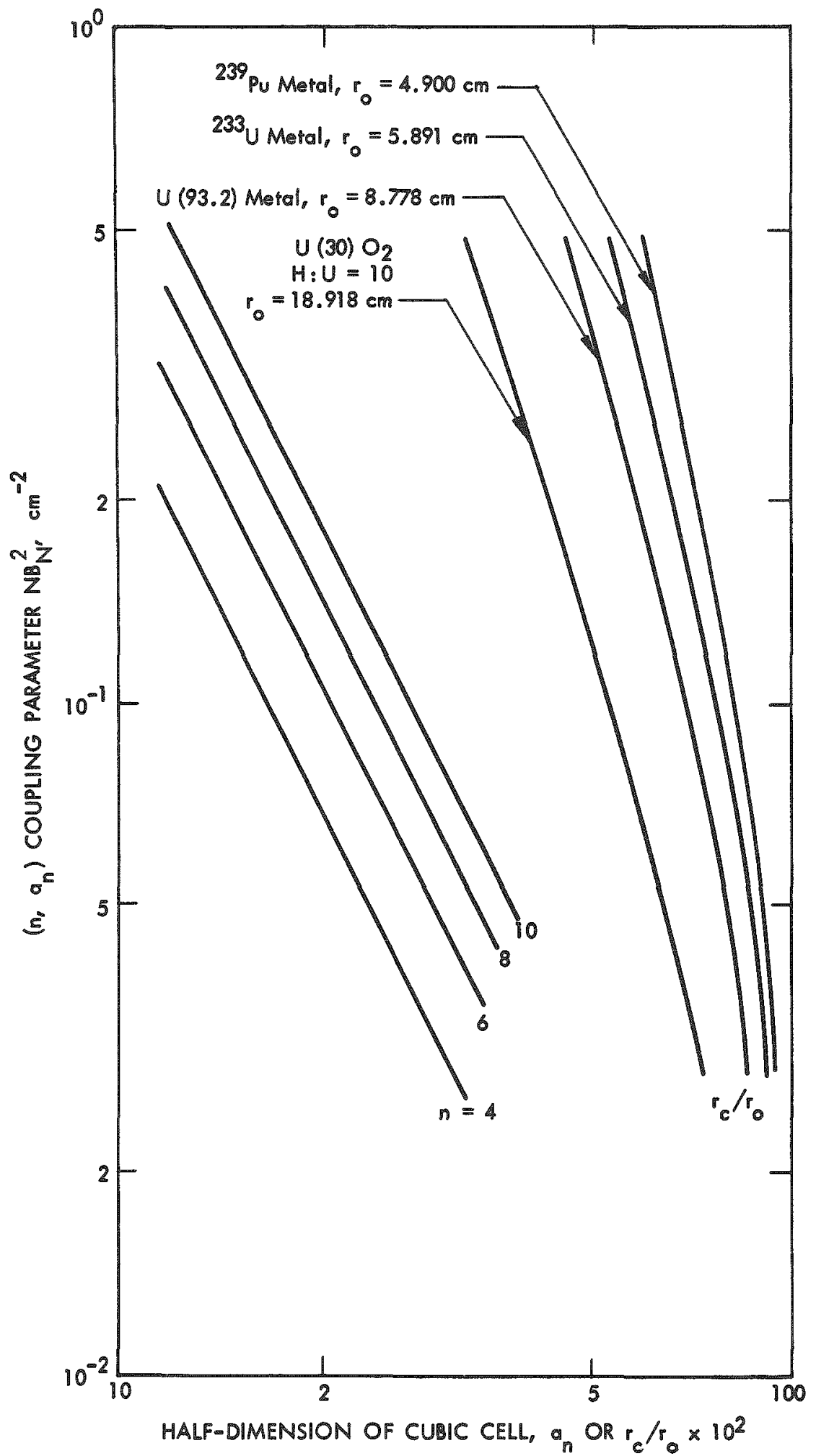

Fig. 1. Calculated Criticality or Water-Reflected Array Showing the Relationship Between Half-Dimension of Cubic Cells, Number of Units along Edge of Cubic Array, and Spherical Radius of Fissile Materials. 
8, and 10 are specified by Eq. (1). Since each of the calculated arrays has a corresponding unique spherical radius for the fissile unit, each value of $r_{c}$ may be associated with the $\mathbb{N B}_{N}^{2}$ value determined by Eq. (I). The relation is presented to the right of the figure as the dimensionless ratio of $r_{c}$ to the calculated unreflected critical raius $r_{0}$ for each of the fissile materials considered. The curves in Fig. I allow interpolation of data derived for the specific arrays recorded in Table 1, thereby enabling application to many other situations. Since the relation between $n$ and $a_{n}$ is invarient to the type of fissile material present in the arrays, as few as seven calculated arrays of a given fissile material, properly selected over a range of interest, are sufficient to characterize that material.

An additional observation to come from the efforts of Alss-8 and, perhaps, a key to establishing uniformity in the selection of sefety maxgins, i.e., a defined degree of subcriticality, is a relation derived from the behavion of the array neutron mutiplication factor in response to a reduction in the radius of the spherical units. It was determined that the calculated $k_{e f f}$ of the array does not exceed the fraction $r / r_{c}$ where $r$ is the radius of soherical units in the subcritical array. It was also demonstrated that this relation holds over a wide range of $k_{\text {eff }}$ values and under a variety of conditions. Application of this relation between $k_{e f f}$ of the array and changes in the ratio of radii permits adjustments in the array necessary to compensate for the effects on reactivity of the perturbations noted previously, provided the magnitudes of the changes in $k$ eff resulting from the perturbations is mom. For example, factors which decrease the reactivity are changes in the shape of the unit, the cell, or the array, provided reasonable separation of units is not abandoned. Factors wich may increase the reactivity are change in the arrangement of units in the tiers of an array from square to triangular, adding hydrogenous moderation to the space between units, or replacing the water reflector by concrete. Whereas one does not, in general, take credit for the former, he certainly is required to debit the latter.

\section{APPLICATIONS TO TRAITSPORT}

Regulations, through the assignment of transport indices for Class II shipments, define the range of array sizes over which the number of containers must be examined for subcriticality when reflected by water. The smallest index that may be assigned to a containex is 0.1 and corresponds to an upper limit of 2500 containers since the sum of the indices per shipment cannot exceed 50 and there is a factor of 5 for commingling of shipments. The largest 
assignable index of 10 defines the smallest number of containers as 25. These limits extend beyond the range given in Table 1 . The larger limit is resolvable through Fig. I but the lower limit is outside the valid range of Fig. I and should be treated separately by other methods. A demonstration of applicability of the calculated criticality data to transport is facilitated by considering a specific container, say, the 55-gal drum. If the capacity of the drum is utilized to define $a_{n}$, the need to consider various arrangements is obviated and the resultant arrays of arums made conservative by a few percent in $k_{\text {eff }}$.

A cube with a half dimension of $29.6 \mathrm{~cm}$ has a capacity equal to that of the 55-gal drum. Entering Fig. I at $a_{n}=29.6 \mathrm{~cm}$, the corresponding values of $\mathrm{NB}_{\mathrm{IN}}^{2}$ for various values of $\mathrm{n}$ are fixed. The radius of the appropriate spherical units can then be determined from the values of $r_{d} / x_{0}$ having the same value of $\mathrm{NB}_{\mathrm{IN}}^{2}$ for each $\mathrm{n}$. The results of these operations are presented in Fig. 2 , where the number of units in a reflected cubic array is given as a function of the parameter $r_{c} / n$ for the four materials. The near linear portrayal show is typical of such representation. Some discrete values of the transport index are shom, for information, at the right ordinate of the figure. The results of Fig. 2 allow estimates of mass limits corresponding to transport indices. As a particular application, consider the 6-I specification container. This 55-gal drum has an inner container of schedule 40 pipe with an i.d. of 5.25 in., a wall thickness of $0.25 \mathrm{in.}$, and a usable height of $17.95 \mathrm{in}$. The region between the inner and outer containers is filled with vermiculite at a packed density of $0.1 \mathrm{l} / \mathrm{g} / \mathrm{cm}^{3}$. If one were to determine the mass limits allowed per container utilizing the kHIo code and including the container materials, a comparison could be made with those limits inferred from the criticality data of Fig. 2. Iet us suppose the mass limits required are for cubic arrays of the containers having a $\mathrm{k}_{\text {eff }}=0.97$ when reflected by an 8 -in. thickness of water and that the masses are further reduced by an amount equivalent to $\sim 3 \%$ in $\mathrm{k}_{\text {eff }}$ to provide a contingency for a triangular pattern of the drums. These mass limits are summerized in Table 2 where they are compared to limits determined from Fig. 2 for the same $\mathrm{k}_{\mathrm{eff}} \mathrm{f}^{\circ}$ It is evident that limits based on the analysis of calculated data for air-spaced units are slightly conservative.

A similar analysis was carried out for the $5-M$ specification container and the results are compared in Table 3 . The 6 -M container has a $2 R$ inner container centered in a nominal 10-gal steel drum and utilizes celotex as the insulating material. Unlike the $6-\mathrm{L}$ container, the mass limits for the $5-M$ container were not established by Monte Carlo calculations and, therefore, do not represent limits having a miform margin of sarety. Nonte carlo calculations were used simply to confirm subcriticality. 


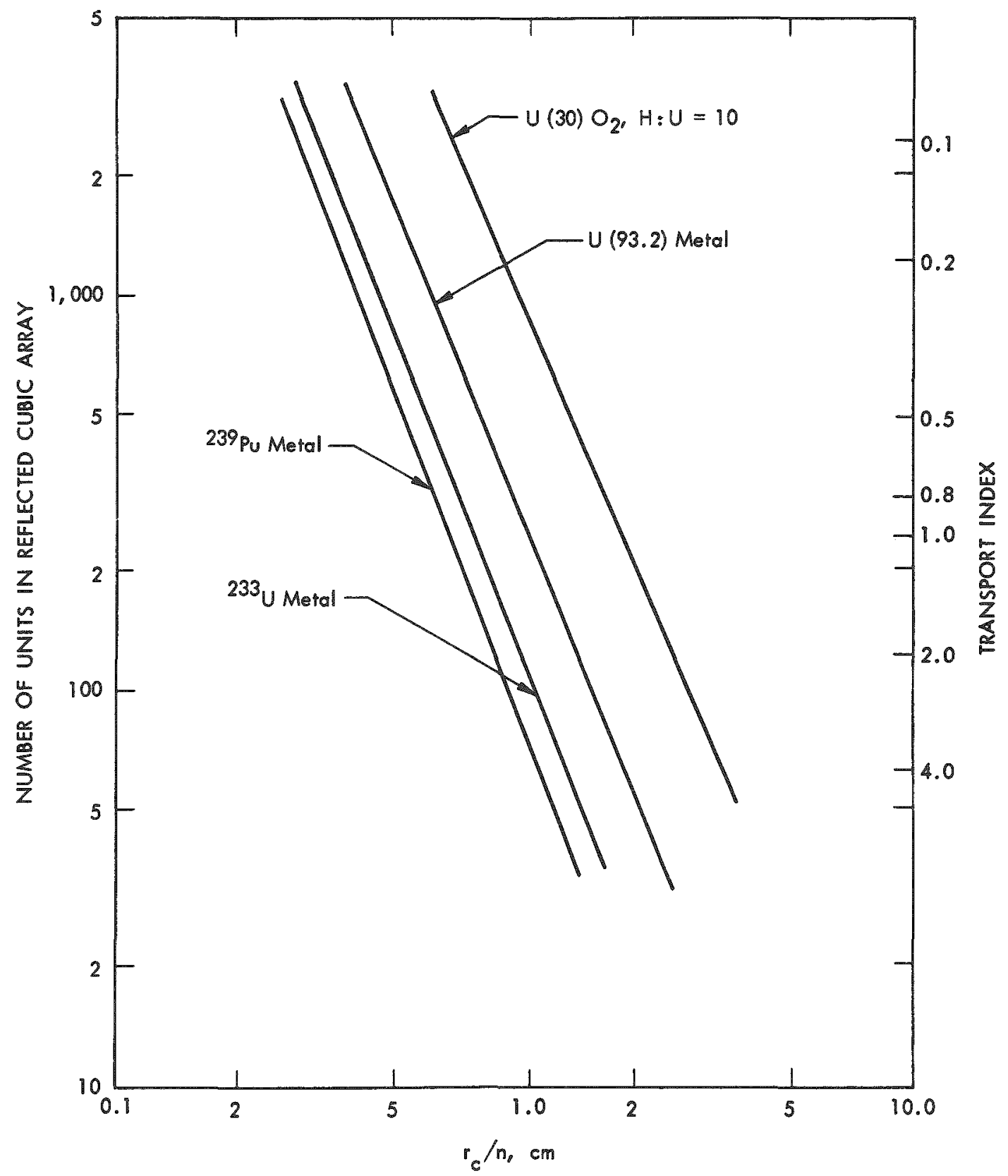

Fig. 2. Representation of Calculated Criticality of Water-Reflected Cubic Arrays Having Cubic Cells of Half-Dimension $29.6 \mathrm{~cm}$ (55-gal drum). 
Table 2. Comparison of Metal Mass Iinits Calculated for the 6-I Specification Containers with Those Derived from Calculated Critical Arrays of Airm Spaced Spherical Units

\begin{tabular}{|c|c|c|c|c|c|c|}
\hline \multirow[b]{2}{*}{$\begin{array}{l}\text { Trans- } \\
\text { port } \\
\text { Index }\end{array}$} & \multicolumn{2}{|c|}{$\mathrm{Fu}(100), \mathrm{ig}$} & \multicolumn{2}{|c|}{$233_{\mathrm{U}}, \mathrm{kg}$} & \multicolumn{2}{|c|}{$\mathrm{U}(93.2), \mathrm{kg}$} \\
\hline & $\begin{array}{l}6-I \\
\text { Con- } \\
\text { tainer }\end{array}$ & $\begin{array}{l}\text { Calculated } \\
\text { Spaced } \\
\text { Units }\end{array}$ & $\begin{array}{l}6-I \\
\text { Con- } \\
\text { tainer }\end{array}$ & $\begin{array}{c}\text { Calculated } \\
\text { Spaced } \\
\text { Units } \\
\end{array}$ & $\begin{array}{c}6-\mathrm{I} \\
\text { Con- } \\
\text { tainer }\end{array}$ & $\begin{array}{l}\text { Calculated } \\
\text { Spaced } \\
\text { Units }\end{array}$ \\
\hline $\begin{array}{l}0.1 \\
0.2 \\
0.3 \\
0.5 \\
1.0 \\
2.0\end{array}$ & $\begin{array}{l}5.27 \\
5.61 \\
5.82 \\
6.21 \\
6.50 \\
6.98\end{array}$ & $\begin{array}{l}4.83 \\
5.16 \\
5.43 \\
5.86 \\
5.29 \\
6.83\end{array}$ & $\begin{array}{l}7.58 \\
8.04 \\
8.31 \\
8.77 \\
9.15 \\
9.86\end{array}$ & $\begin{array}{l}5.26 \\
6.89 \\
7.38 \\
7.79 \\
8.94 \\
9.74\end{array}$ & $\begin{array}{l}17.3 \\
19.5 \\
20.8 \\
23.0 \\
25.6 \\
28.8\end{array}$ & $\begin{array}{l}13.3 \\
17.4 \\
18.6 \\
20.5 \\
23.9 \\
27.3\end{array}$ \\
\hline
\end{tabular}

Table 3. Comparison of Metal Mass Limits Established for the 5-M Specification Containera with Those Derived from Calculated Critical Arrays of Air-Spaced Spherical Units

\begin{tabular}{|c|c|c|c|c|c|c|}
\hline \multirow[b]{2}{*}{$\begin{array}{l}\text { Trans- } \\
\text { port } \\
\text { Index }\end{array}$} & \multicolumn{2}{|c|}{$\mathrm{Pu}(100), \mathrm{kg}$} & \multicolumn{2}{|c|}{$233_{\mathrm{U}}, \mathrm{kg}$} & \multicolumn{2}{|c|}{$\mathrm{u}(93.2), \mathrm{kg}$} \\
\hline & $\begin{array}{c}6-M \\
\text { Con- } \\
\text { tainer }\end{array}$ & $\begin{array}{l}\text { Calculated } \\
\text { Spaced } \\
\text { Units }\end{array}$ & $\begin{array}{c}6-\mathbb{M} \\
\text { Con- } \\
\text { tainer }\end{array}$ & $\begin{array}{l}\text { Calculated } \\
\text { Spaced } \\
\text { Units }\end{array}$ & $\begin{array}{c}6-M \\
\text { Con- } \\
\text { tainer }\end{array}$ & $\begin{array}{l}\text { CaIculated } \\
\text { Spaced } \\
\text { Units }\end{array}$ \\
\hline $\begin{array}{l}0.1 \\
0.2 \\
0.5 \\
1.0 \\
2.0\end{array}$ & $\begin{array}{l}3.1 \\
3.4 \\
4.2 .2 \\
4.5 \\
=-\end{array}$ & $\begin{array}{l}2.72 \\
3.19 \\
3.87 \\
4.45 \\
6.04\end{array}$ & $\begin{array}{l}-- \\
-- \\
-- \\
-- \\
--\end{array}$ & $\begin{array}{l}3.19 \\
3.72 \\
4.65 \\
5.43 \\
7.71\end{array}$ & $\begin{array}{r}7.2 \\
8.7 \\
11.2 \\
13.5 \\
-\infty\end{array}$ & $\begin{array}{r}6.36 \\
7.56 \\
11.66 \\
17.43 \\
20.50\end{array}$ \\
\hline
\end{tabular}

Federa1 Register, Vo1. 33, No. 194, oct. 4, 1969.

Maximum allowed mass due to 10-watt decay heat Iimitation. 
Although one may be tempted to conclude that the presence of the container and insulating materials allows larger mass limits, it would be an improper generalization. The presence of steel is probably the major cause for the increased mass. This is evidenced by the increasing mass differences as the number of containers in the array increases. A significant advantage of the steel in these containers is that the thickness is sufficient to override ${ }^{5}$ the increase in reactivity that otherwise would result at optimum hydrogenous moderation in the arrays.

Although limits were not developed for the wet oxides of $U(30) 0_{2}$, since they are not permitted in these specification containers because of excess water content, the data were included to demonstrate that the presence of water in a unit does not complicate the analysis. The representations of this material in Fiss. I ana 2 confirm the suitability of the method to characterize the criticality of such materials.

\section{REMARTS AND SUMMARY}

At the very least, the utility of the Guide and the simple techniques portrayed above are beneficial in providing both a point of departure and guidance to more detailed criticality analyses of shipping containers. If, through continued effort, the Guide can be expanded to effectively serve as a basic reference for the evaluation of criticality, there will follow a uniformity or ordering in the margins of safety employed. This, in turn, will lead to a needed, evaluated scale for the determination of the degree of risk. Such an evaluated degree of $r i s k$ is necessary to a more proper economic balance in transportation costs to industry.

It is appropriate to issue a wora of caution regarding the Guide. Whereas the information presented represents a correlation among unit masses, cell dimensions, number of units, and the exrey neutron multiplication factor, it shoula be realized that the Guide is a supplement to, and does not substitute for, good nuclear safety practices. The mass limits given define recommended capacities for cell volumes in specified arrays and necessitate individual analyses for their implementation. For exemple, a $26 \mathrm{~kg}$ U(93.2) metal limit in 2-It cubic cells comprising a bl-unit array has a $k_{\text {eff }}$ of 0.93 but there are definite possibilities of single-unit criticality which must be considered when handling such a mass.

The tabulated critical parameters given in this presentation are a portion of the data establishing the subcritical limits in the Guide itself. A total 
of 40 different forms of fissile materials are presented. These can be augmented in the future and possibly at an accelerated pace were those individuals performing criticality analyses to characterize the materials under consideration in the format given here. It would facilitate the utility of such information were validated methods of analysis also used.

The references cited contain further material and discussion concerning the influence on array reactivity of changes in the various conditions of the reference arrays, such as shape, reflection, moderation, commingling of different units, neutron coupling between arrays, etc. The concepts and results are applicable to criticality analysis in transport.

\section{REFERENCES}

1. J. T. Thomas, Uranium Metal Criticality, Monte Carlo Calculations and Nuclear Criticality Safety, Y-CDC-7, UCC, Oak Ridge Y-I2 Plant (1970).

2. G. E. Whitesides and N. F. Cross, KENO-A Multigroup Monte Carlo CriticaIity Program, CTC-5, UCC, Computing Technology Center (1909).

3. Gordon E. Hansen and William H. Roach, Six and Sixteen Group Cross Sections for Fast and Intermediate Critical Assemblies, IAMS-2543, Ios Alamos Scientific Laboratom (190i).

4. J. T. Thomes, The Criticality of Cubic Arrays of Fissile Material, Y-CDC10 (to be published).

5. J. T. Thomas, Some Effects of Interspersed Moderation on Array Criticality, $\mathrm{Y}-\mathrm{CDC}-5, \mathrm{JCC}$, Oak Ridge $\mathrm{Y}-12$ FIant (1959). 


\title{
CRITICALITY SAFETY EVALUATIONS OF SHIPPING
}

CONTAINERS USED BY IDAHO NUCLEAR CORPORATION AT NRTS

\author{
J. K. Fox \\ W. G. Morrison \\ Idaho Nuclear Corporation
}

\begin{abstract}
This report gives the results of several criticality safety evaluations of fuel shipping containers. The containers included casks for shipping irradiated fuels, as well as containers for unirradiated fuels and other fissile materials. These containers all contain poisons such as cadmium and boron to assist in maintaining subcriticality and their presence must be assured. Most of the containers evaluated gave keff values that are quite low even for the most reactive credible condition. The $k_{\text {eff }}$ values obtained for these conditions were between about 0.40 and 0.85 for the containers tested. In some cases, the $k_{\text {eff }}$ values were below unity even when poison was omitted. The methods used involve the use of several reactor codes. The accuracy of these methods have been thoroughly checked by comparisons with clean critical experiments.
\end{abstract}

\section{INTRODUCTION}

Criticality safety evaluations are performed routinely by Idaho Nuclear Corporation on all new or special uranium shipping or transier containers under its jurisdiction at the NRTS. This paper describes the calculational methods used and results obtained for some of these evaluations. Routine shipments include new and irradiated fuel elements for various reactors and both solid and liquid products from the Idaho Chemical Processing Plant. Also, numerous special shipments of fissile materials are made and received in connection with Idaho Nuclear Corporation activities. 
Most of the fuel elements handled are alloys containing highly enriched uranium. Shipping boxes for the unirradiated test reactor fuel elements contain planar series of poison sheets and polyethylene between layers of fuel and have been evaluated on the basis of dry and flooded conditions. Casks for transfer or receipt of irradiated fuel elements contain lattices of poison plates to provide for multi-element shipments. These casks are normally loaded and unloaded under water and must be evaluated for the flooded condition. Since all of the containers evaluated contain neutron poisons, it is necessary to verify the presence of the poison for any new container before it can be used at Idaho Nuclear Corporation.

The ICPP product shipping containers are evaluated for both dry and flooded conditions. For flooded conditions, the problem is essentially an evaluation of a single reflected unit because the size of the outer container is such that there is no interaction. Dry arrays are evaluated on the basis of conservative assumptions, e.g., some water present in the free space inside the inner container and array sizes normally larger than will be encountered in shipments or storage.

A number of calculational techniques are used for the criticality evaluations. The KENO-II ${ }^{1}$ Monte Carlo criticality program is the most versatile program in use at the NRTS. It has the advantage of treating three dimensions and complicated geometries of single units or arrays of mixed units. The we11-known Hansen-Roach 16-group cross section sets ${ }^{2}$ have been used exclusively up to the present with the KENO program. One- and two-dimensional neutron transport programs $\mathrm{SCAMP}^{3}$ and $\mathrm{DOT}^{4}$, respectively, are used as appropriate. Normally the 16-group Hansen and Roach cross section sets are used with these programs; however, other group structures using ENDF-B cross sections can be used. The PHROG ${ }^{5}$ and INCITE $^{6}$ programs are used to generate these cross section sets. Both programs use the B-1 approximation to the transport equation for spectrum calculation. PHROG is used for the fast constants and INCITE for the thermal range.

Diffusion theory programs are used in some evaluations. These include the versatile two-dimensional $\mathrm{PDQ}-7^{7}$ and the one-dimensional FOG ${ }^{8}$ program. The few-group nuclear constants used with these programs are also generated by the PHROG and INCITE programs. Diffusion theory has been found adequate for well moderated problems where there are no voids. Extensive calculations have been performed with all of these programs in comparing them with clean 
critical experiments covering a wide range of conditions. The excellent agreement in results of the comparison provides great confidence in our ability to determine the criticality safety of shipping and transfer containers used by Idaho Nuclear Corporation.

\section{UNIRRADIATED FUEL SHIPPING CONTAINERS}

\section{ETR Shipping Boxes}

These boxes are intended for shipping unirradiated (new) fuel and are made mainly of wood that has been treated to retard fire. Later, a second box was fitted over the first one to gain additional fire resistance. Thus, the present boxes are double walled. A sketch of one of these boxes is shown in Figure 1. The box holds six elements in two layers. The layers are separated vertically by a sandwich construction containing two layers of cadmium separated by a one-inch polyethylene plate. There is also a poison sandwich at the top and bottom. Infinite arrays of these boxes were calculated using PDQ with the derivative B.C. applied at each outer edge. The XY layout treated each material explicitly as a separate region. Since a density analog treatment shows that dry box arrays are very subcritical, it was assumed that all voids were filled with water. Inside each element the plates and water gaps were homogenized. A sketch of the PDQ layout is shown in Figure 2 (only one quadrant is required because of symmetry). A $k_{e f f}$ of 0.64 was obtained with a water density of 1.0 in all voids. If the fuel has full density water and all other voids contain water at a density of 0.3 , the $k_{\text {eff }}$ is 0.69 . Thus, the ETR box arrays are safe under any foreseeable condition.

\section{ATR Shipping Boxes}

The ATR new fuel shipping boxes are constructed in a manner similar to that used for ETR fuel. The main difference being that each box contains four fuel elements in one layer. The box contains two cadmium and polyethylene sandwiches so that there are two of these between layers of fuel when boxes are stacked vertically. The PDQ four group analysis was very similar to that used for ETR fuel. Assuming an infinite array to be water flooded, the $k_{\text {eff }}$ was calculated based on an element loading of 1500 grams U-235. The actual loading averages about 1075 grams per element. The calculated $k_{\text {eff }}$ was 0.58 . Reducing the water density in all voids except those between fuel plates again raised the $k_{\text {eff }}$ several percent. However, it is not felt that this is a credible condition. 
The solid $\mathrm{UO}_{3}$ product from ICPP is shipped in Y-12 model FD Foamglass shipping containers (DOT $\|_{5463)}$. A sketch of this shipping container is shown in Figure 3. This container has been approved for fissile Class I and Class II with authorized contents of 3.7 and $19.0 \mathrm{~kg} \mathrm{U}-235$, respectively, as uranium metal or dry uranium compounds enriched to at least 75 percent in U-235. The maximum physical loading for ICPP product is about $13.6 \mathrm{~kg} \mathrm{VO} 3$ or $11.3 \mathrm{~kg}$ uranium. Normally the $\mathrm{VO}_{3}$ product is stored in the vault in the shipping containers. Consequent $1 \mathrm{v}$, the criticality safety evaluations of the packaged $\mathrm{UO}_{3}$ in the shipping containers were made for both cubic arrays and conditions of vault storage. The KENO II program was used for this evaluation. Vault arrangements, as well as cubic arrays of shipping containers, were calculated. A thick concrete reflector surrounded all of these arrays. Results are as follows:

$\begin{array}{lll}\text { Vault Array } & 2 \times 20 \times 3 & k_{\text {eff }}=0.393 \pm .005 \\ \text { Cubic Array } & 5 \times 5 \times 5 & k_{\text {eff }}=0.400 \pm .007 \\ \text { Cubic Array } & 8 \times 8 \times 7 & k_{\text {eff }}=0.488 \pm .006\end{array}$

Storage of cans of $\mathrm{UO}_{3}$ in the shipping containers is quite conservative. However, the capacity of the vault is still adequate. The calculated $k_{e f f}$ for the $8 \times 8 \times 7$ cubic array reflects a lower loading than that allowed in the DOT permit. The $k_{\text {eff }}$ obtained by Crume?, et 21 , was $0.90 \pm .01$ for the same array with the maximum loading allowed.

\section{CASKS FOR SHIPPING IRRADIATED FUEL}

\section{ATR Poisoned Transfer Casks}

The ATR transfer cask is used to transfer spent ATR fuel from the reactor canal to the ICPP for reprocessing. A sketch of the cask is shown in Figure 4. The ATR fuel is shaped as a $45^{\circ}$ segment of an annulus, and each element fits between Boral radial fins so that eight elements complete an annulus. In the center is a box, sized so that only one element can be inserted. The radial fins contain canned Boral plates 0.125 inches thick. To mockup the cask for a PDQ-7 calculation using XY geometry, the inclined $45^{\circ}$ fins had to be converted into small horizontal and vertical steps, as shown in Figure 5. For the $Z$ direction, an input buckling corresponding to the 48-inch fuel length plus reflector savings was used. To assure conservative results, it was assumed that each fuel element contained 1500 grams U-235 and that no boron was present. The actual new fuel loading averages about 1075 grams U-235. 
Since the cask is loaded and unloaded under water, the flooded condition was used in the calculations. An infinite reflector of water was assumed in place of the actual lead water combination. The effect of Boral was determined by doing two calculations in which aluminum was substituted for Boral. The results are as follows:

1. Nine elements with Boral present

2. Nine elements with Al replacing boron

$k_{\text {eff }}=0.75$

3. Eight elements (Center element out) with Boral present

$k_{\text {eff }}=1.16$

$k_{\text {eff }}=0.62$

4. Eight elements (Center element out) with Al replacing boron $k_{\text {eff }}=1.014$

Thus, it is seen that the presence of the Boral is quite important. For this reason, it is standard practice to use a source-detector nethod to verify the presence of poison in new casks.

\section{ETR Poisoned Transfer Casks}

The ETR transfer cask is used to transfer spent ETR fuel from the reactor canal to ICPP. A sketch of the cask is shown in Figure 6 . The three by three array of element boxes has a sheet of cadmium around the central box only. This position is blanked off so that only eight elements can be inserted. The array was mocked up for a PDQ calculation in XY geometry. Fuel element, side plates, stainless steel partitions and cadmium were made into explicit regions. A water flooded condition was assumed. The fuel plates were homogenized with the water gaps. Since the elements are smaller than the lattice boxes, they were centered and surrounded by a water gap. To account for leakage in the $Z$ direction, an input buckling corresponding to the fuel length plus reflector savings was used. Four group constants were obtained based on each element containing 788 grams U-235, but no boron. Blackness theory was used for the cadmium membrane. An infinite water reflector was substituted for the water and lead mixture. The calculated $k_{\text {eff }}$ was 0.747 .

\section{National Lead Casks}

Over the past several vears, two similar casks designed for MTR-type irradiated fuel have been evaluated. These were designed by the National Lead Company. Each utilized Boral plates between rows of fuel in a rectangular 1attice. The plates are of a sandwich construction with the Boral canned in aluminum. The fuel elements are essentially in contact in the rows. The first cask was designed to contain 28 elements in a circular lead cask. This 
cask is assigned DOT SP 5786. A PDQ calculation was run with the cask loaded with BMI type fuel (3.1 $\times 3.2$ inches, 24 inches 10 g). With each element loaded to 220 grams $U-235$, the calculated $k_{\text {eff }}$ is 0.73 . If the loading is increased to 550 grams, the $k_{\text {eff }}$ is 0.935 .

The JMTR cask for Japanese fuel is a more recent version, designed to contain 41 -inch by 3 -inch elements. It is very similar to the above cask, except for size. For this evaluation, the mixed box version of kENo was used. Because of the circular outer container, the rows are of varying length and columns of elements are staggered. This complicates the box layout. Another complication is the gaps in the Boral plates at their center. A simplified sketch of the lattice is shown in Figure 7. By making each element into two or more boxes and using different box widths for the Boral gaps, it is possible to mockup the array quite accurately. Problems of symmetry were such that about 19 different box types are required. Each fuel element has 350 grams $U-235$ in a 29.5 inch active length. With the cask assumed to be water flooded and reflected, the $k_{\text {eff }}$ obtained is $0.71 \pm .008$. If a lead reflector is used, the $k_{\text {eff }}$ obtained is $0.68 \pm .008$. In an independent mockup a $k_{\text {eff }}$ of $0.74 \pm .01$ was obtained for the water flooded case.

Evaluation of Savannah River 70-Ton Cask for HTRE and Other Fuels

The NRTS inventory of miscellaneous irradiated nichrome and stainless steel fuels was transferred to the Savannah River plant in 1966-1968. One of the 70-ton Savannah River casks described in report DP-35710 was modified slightly and used for these shipments. B of E permit No. 2189 was assigned to the cask for these transfers. Twelve shipments were made with the total U-235 loading per shipment varying from about $54 \mathrm{~kg}$ to $141 \mathrm{~kg}$. The fuels were essentially all 93 percent enriched $\mathrm{UO}_{2}$ nichrome cermets clad with nichrome except for one shipment which consisted of 3 and 4 percent enriched $\mathrm{TO}_{2}$ fuel rods clad with stainless steel. Rods, plate, and annular ring-type fuels were al1 represented. The cask, shown in Figure 8, contained five positions for fuel. These positions were separated by four poison plates made of cadmium clad with stainless steel. Clips for holding stacks of horizontal fuel elements and spacers were fabricated to fit into the positions, so that almost exact fuel arrangement dimensions could be maintained. Depending on the size and $U-235$ loading of the various fuel elements, slabs of fuel elements could be placed in either positions 1,3 and 5 or positions 2 and 4. Slabs of fuel in positions 1 and 5 were more reactive than the same slabs of fuel in positions 2 and 4 , because of the poison separator plates. None of the shipments utilized all of the positions at one time. The one-dimensional neutron 
diffusion program FOG-3 was used for determining which slots to fill and evaluation of all of the loadings. The calculated $k_{\text {eff }}$ s were in the 0.8 to 0.96 range. However, very conservative assumptions were used, e.g., no burnup, uniform loading in the slabs equal to the highest loaded fuel element, and slab thickness equal to the maximum diameter of any of the fuel elements. Check calculations on critical arrays of cylindrical fuel elements showed that slab thicknesses based on an equivalent cross sectional areas agreed with the experimental results. Also, nuclear constants were for homogeneous fuel cells with no disadvantage factors considered.

\section{Paducah Depleted Uranium Casks}

The Paducah depleted uranium cask is proposed for the shipment of Spert IIIC fuel to SRP. This fuel is in the form of 4.8 percent enriched oxide pins 0.466 inch $0 D$. The cask is modified by the insertion of a cadmiun poisoned box lattice with the pins stacked in contact in the boxes. A sketch of the lattice is shown in Figure 9. The first proposal was to fill only the five rectangular boxes. This was mocked up for a PDQ calculation in XY geometry. With the fuel assumed to be at near optimum spacing ( 0.5 inch $E$ to $E)$ and the cask flooded, the $k_{\text {eff }}$ obtained was 0.63 . The $k_{\text {eff }}$ was only 0.32 for a closepacked assembly. A problem was also run in $R Z$ geometry, where the lattice was replaced by a cadmium liner against the inside walls and the fuel filled the cask. With this arrangement, there is more fuel and the cadmium is much less effective. The homogenized fuel corresponded to optimum spacing. This case gave a keff of 0.86 .

KENO II was used when it was later decided to completely fill the cask with loose Spert IIIC pins. One problem used the generalized geometry version of the code with the fuel assumed to be close-packed and homogenized into each lattice box. The keff obtained was $0.68 \pm .01$. In a second problem, the mixed bow version was used. The fuel pins were pur in explicitly in a square lattice with a center-to-center spacing of 0.5 inches. This mockup required five box types and used a water reflector. The calculated $k_{\text {eff }}$ was $0.846 \pm .011$. For this calculation, the knight corrected $\mathrm{U}-238$ cross-sections were used. An additional calculation shows water is a better reflector than depleted uranium. 
Evaluation of the Pegase Poisoned Fuel Cask

The Pegase irradiated fuel shipping cask was designed for shipping 25 ETRtype fuel elements, each containing 380 grams $U-235$ before burnup. The cask contains a stainless steel axle and tube with five vertical equidistant grooves machined for receiving five radial boron stainless steel plates. Thus, five compartments are formed by the central tube, the inner she11 and the five radial plates. Machined aluminum blocks, each with five lodgements for fuel elements, fit into the five compartments. A sketch showing the arrangement is shown in Figure 10. The criticality safety evaluation of this cask considered complete water flooded conditions, both with and without the 0.5 w/o natural boron in the stainless steel radial plates. These calculations were performed on the IBM-7044 with the PDQ-40 diffusion code in XY geometry. The calculated $k_{\text {eff }}$ was 0.63 with the boron present and 0.67 for no boron present in the stainless steel plates. An additional calculation was performed in which the uranium loading in the fuel elements was doubled. This yielded a $k_{\text {eff }}$ of 0.80 with boron present.

\section{CONCLLSIONS}

The results of the calculations show that each of the containers evaluated is safe under the most reactive credible condition. These containers all have a rather large factor of safety to allow for uncertainties in the evaluations. However, the methods have been thoroughly verified by comparisons with experiment, both by the present authors and many others. In other words, the procedures and methods used at the NRTS by Idaho Nuclear Corporation have been found to be adequate for criticality safety evaluations of various shipping containers. The effects of damaged containers was not discussed. However, it is felt that credible wreck damage would not compress the fuel arrays appreciably. Thus, the reactivity would remain essentially constant. 
1. G. E. Whitesides and N. F. Cross, KENO - A Multigroup Monte Carlo Criticality Program, USAEC Report CTC-5, Union Carbide Corp., Nuclear Division (1969).

2. G. E. Hansen and W. H. Roach, Six and Sixteen Group Sections for Fast and Intermediate Critical Assemblies, USAEC Report LAMS-2543, Los Alamos Scientific Laboratory (1960).

3. C. I. Beck, Letter: Input Description of SCAMP Codes, Private Communication, Idaho Nuclear Corporation.

4. F. R. Mynatt, DOT - Two Dimensional Descrete Ordinates Transport Code, USAEC Report CCC-89, Union Carbide Corp., Nuclear Division.

5. R. L. Curtis, et al, PHROG - A Fortran IV Program to Generate Fast Neutron Spectra and Average Multi-Group Constants, USAEC Report IN 1435 , Idaho Nuclear Corporation (1971).

6. R. L. Curtis and R. A. Grimesey, INCITE - A Fortran IV Program to Generate Therma1 Neutron Spectra and Multi-Group Constants Using Arbitrary Scattering Kernels, USAEC Report IN 1062, Idaho Nuclear Corporation (1967).

7. W. R. Cadwe11, PDQ-7 Reference Manual, USAEC Report WAPD-TM-678, Bettis Atomic Power Laboratory (1967).

8. H. P. Flatt, The FOG One-Dimensional Neutron Diffusion Equation Codes, USAEC Report NAA-SR-6104, Atomics Internationa1, Division of North American Aviation Corporation (1961).

9. E. C. Crume, et a1, Evaluation of a Shipping Container for Enriched Uranium Metal and Dry Compounds, USAEC Report Y-KC-106, tnion Carbide Corporation, Nuclear Division (1967).

10. W. H. Piper and J. W. Langhaar, 70 Ton Shipping Cask for the Savannah River Plant - Design and Fabrication, USAEC Report DP-357, E. I. du Pont de Nemours \& Co., Atomic Energy Division (1959). 
3/4" Plywood ___ -

16 Ga Sheet Steel Shell

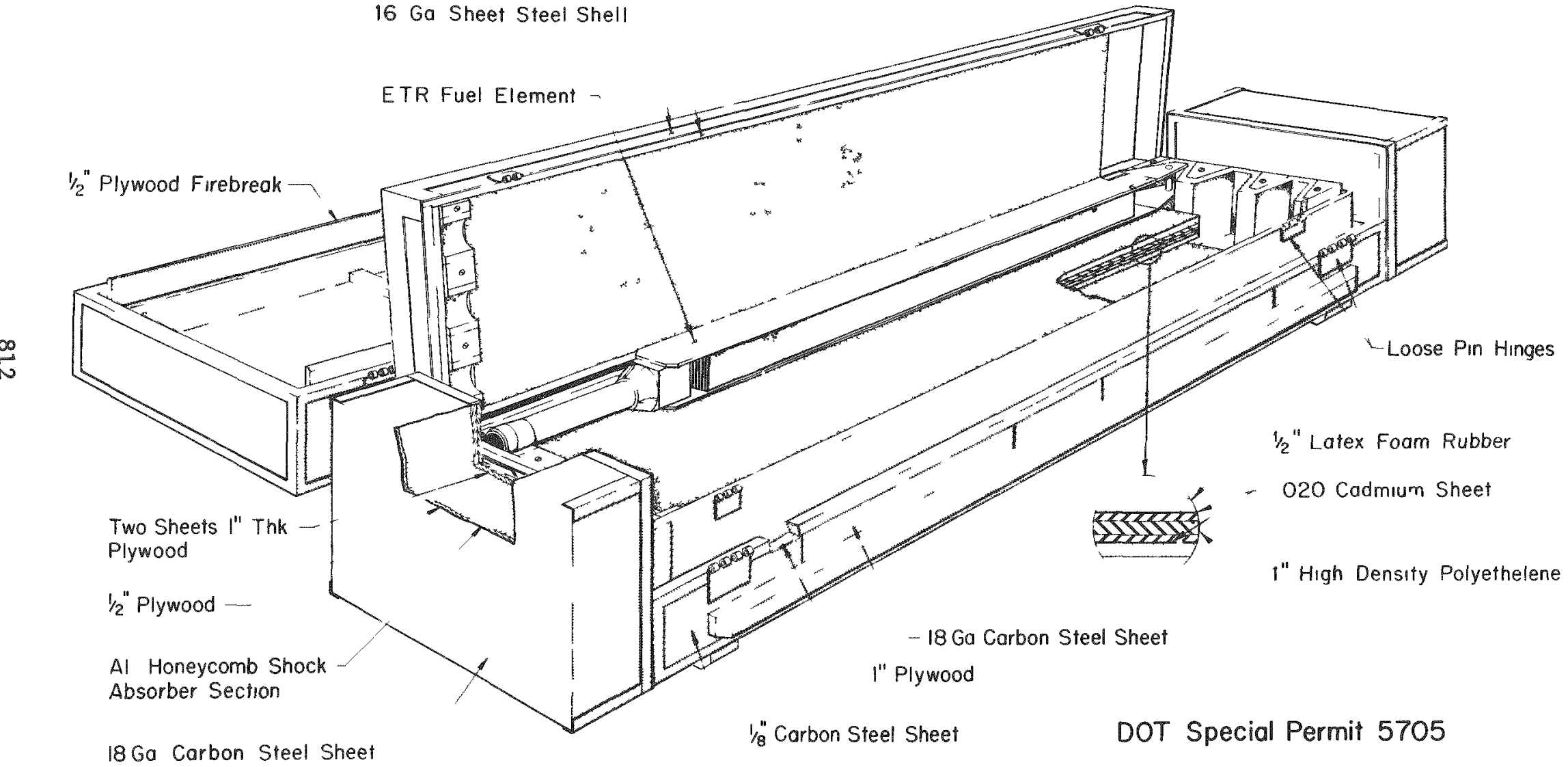

INC-D-12468

Figure 1. ETR Shipping Box. 


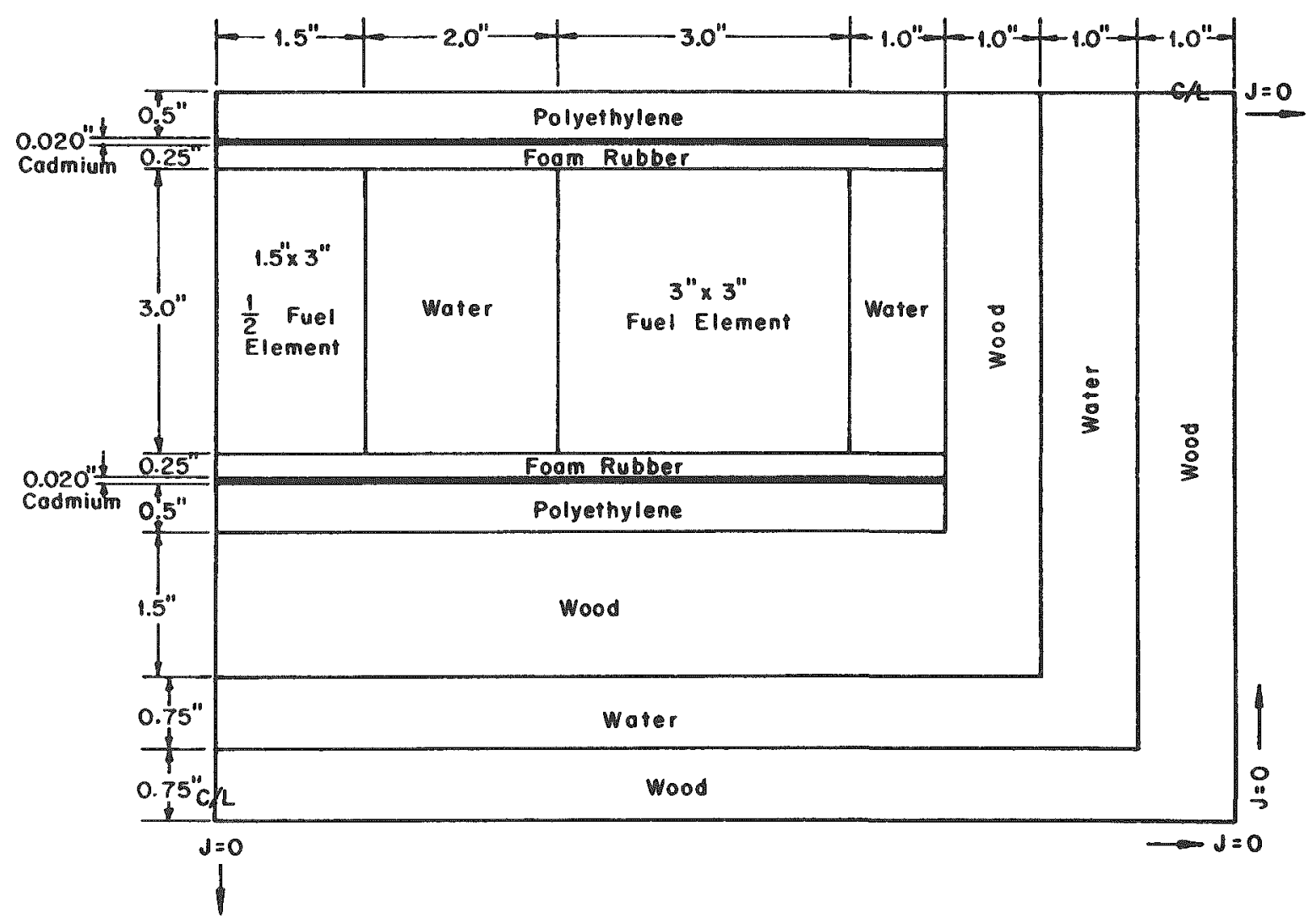




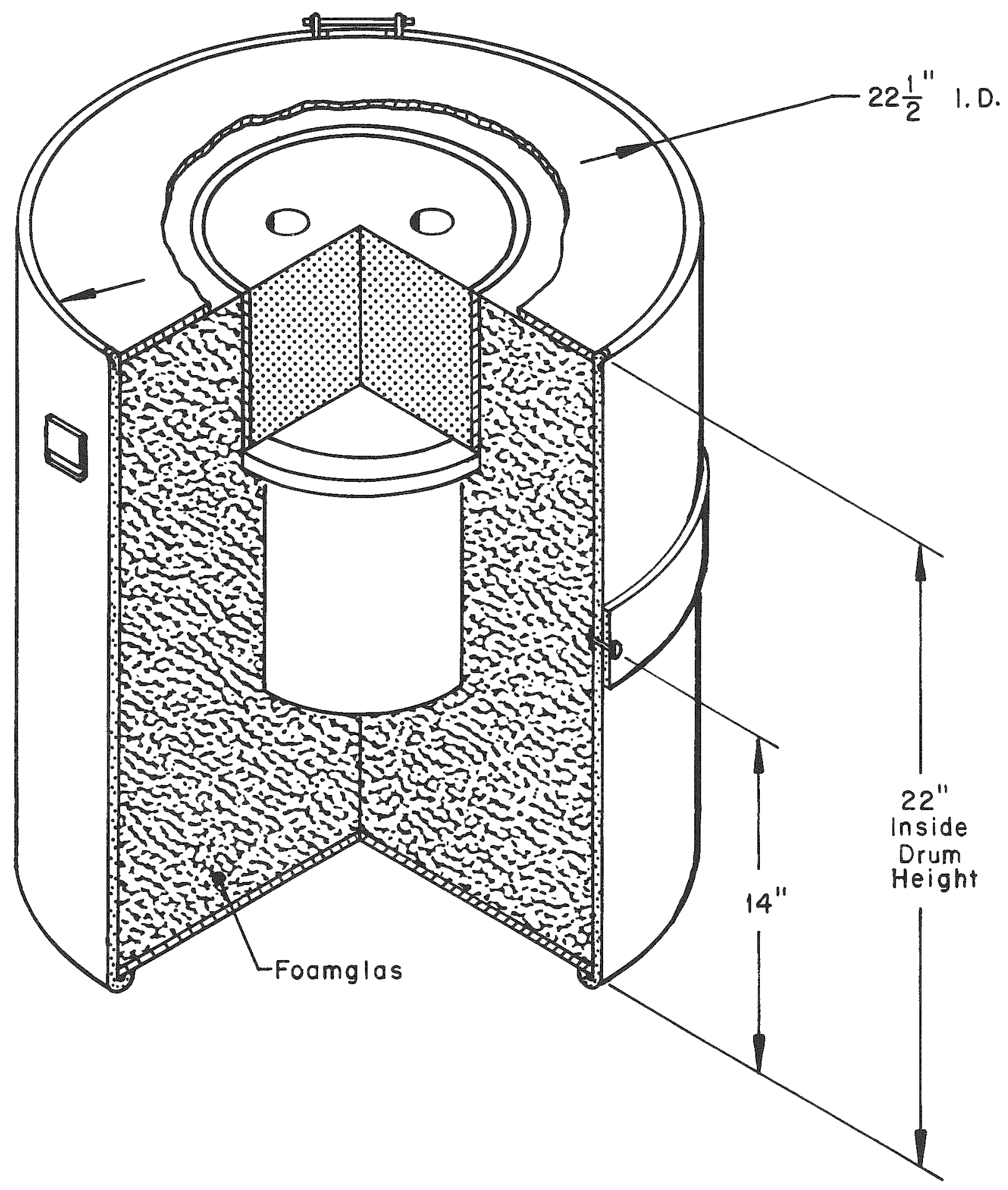




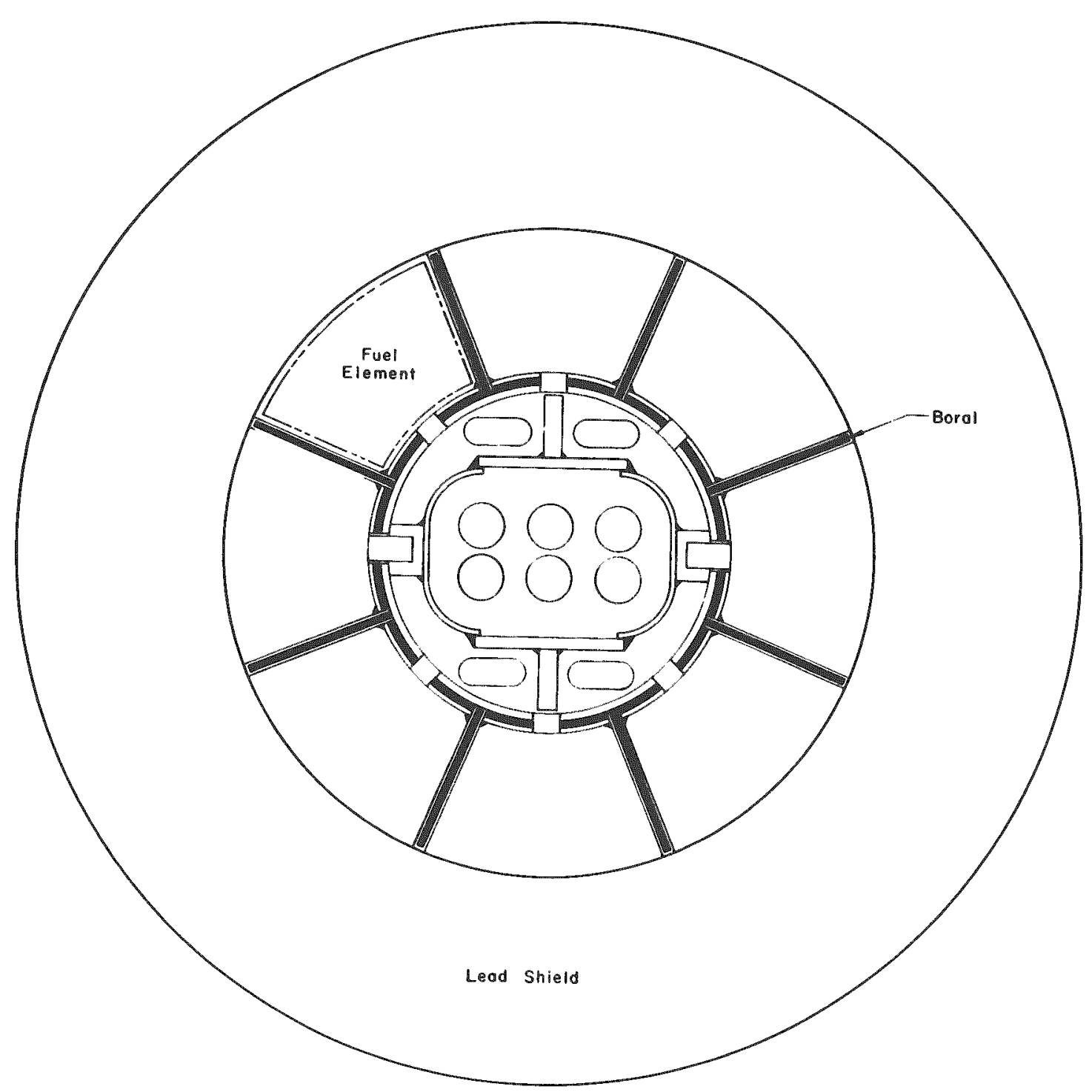

INC-C-18861

Figure 4. ATR Transfer Cask. 


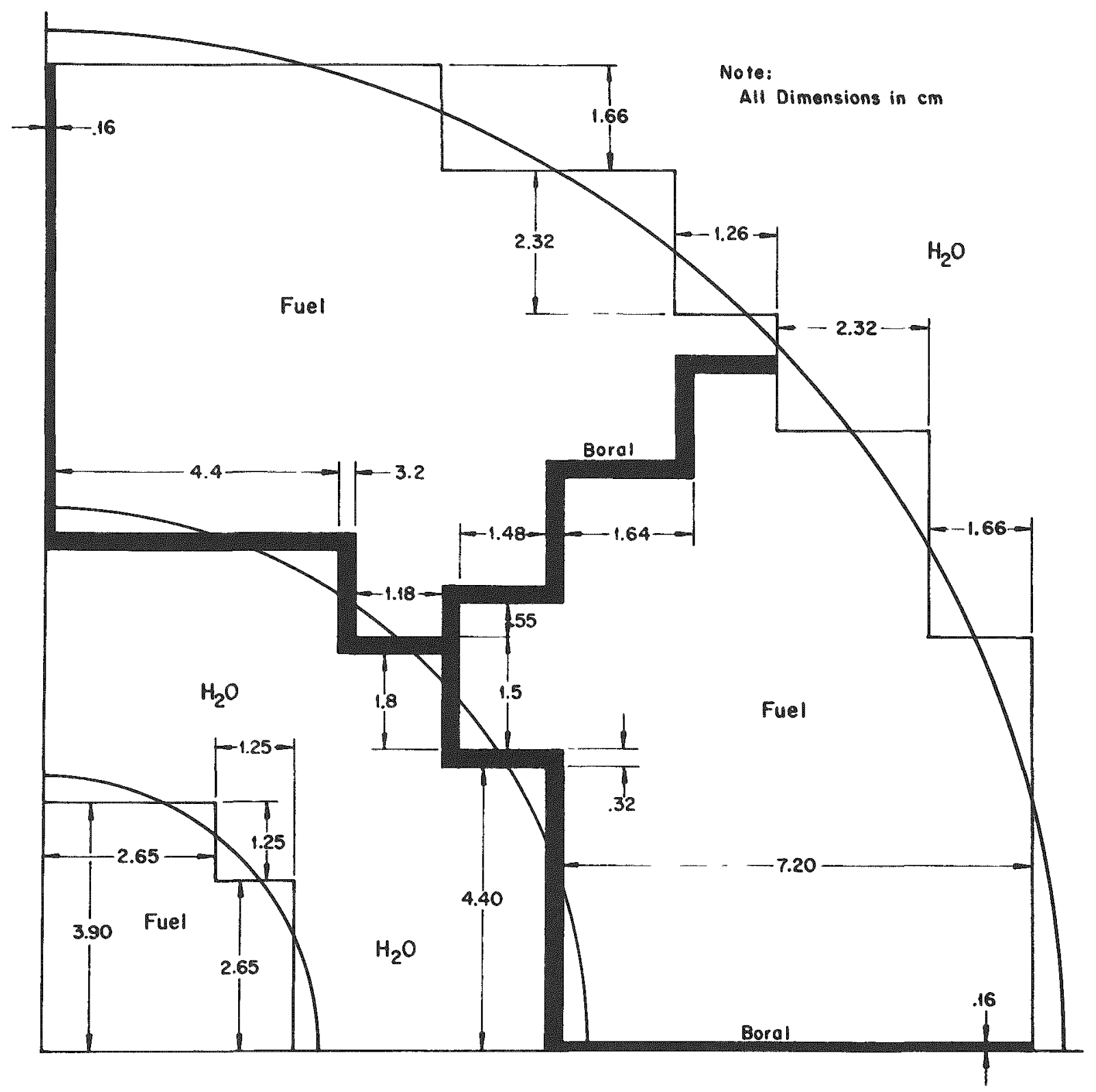




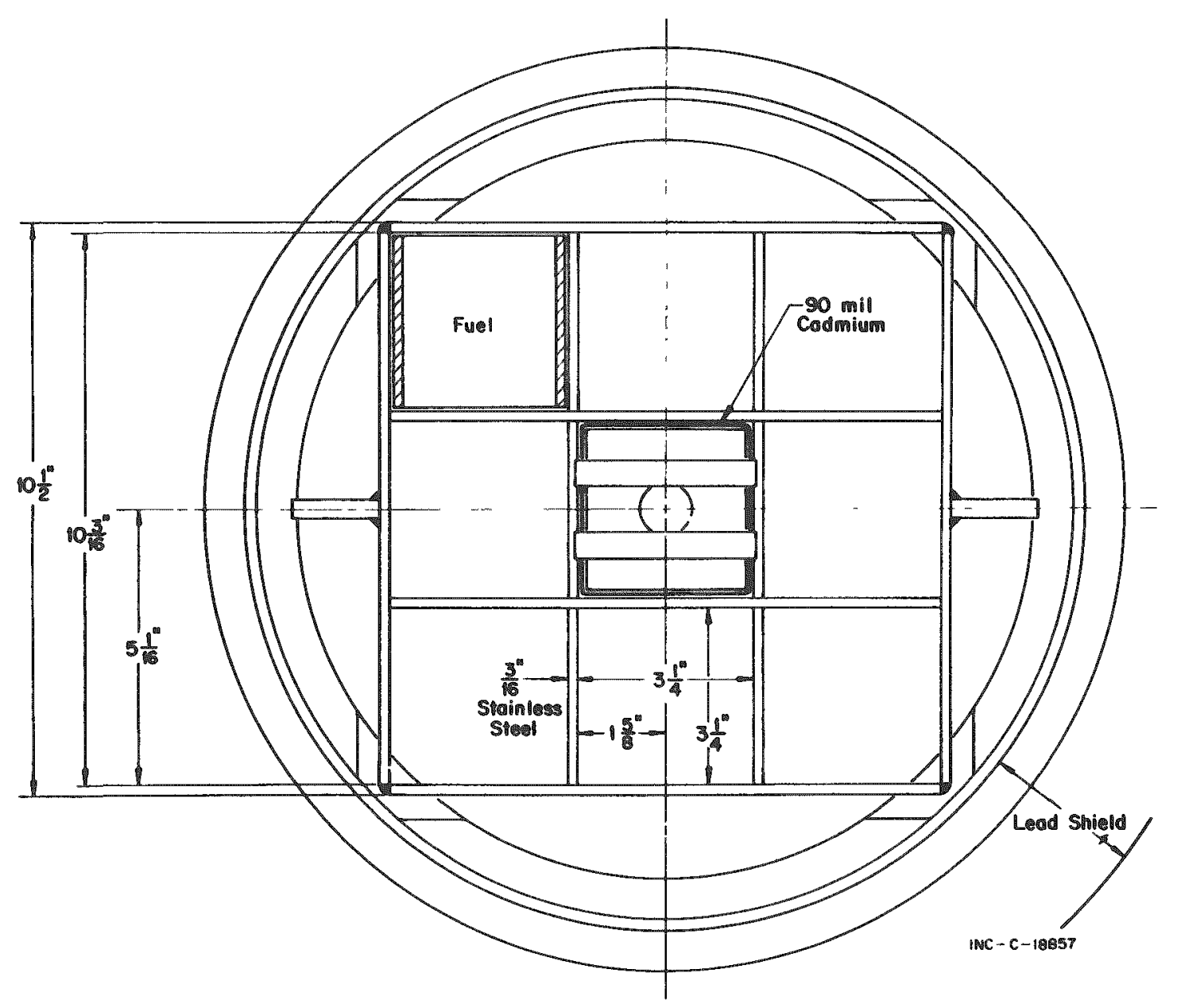




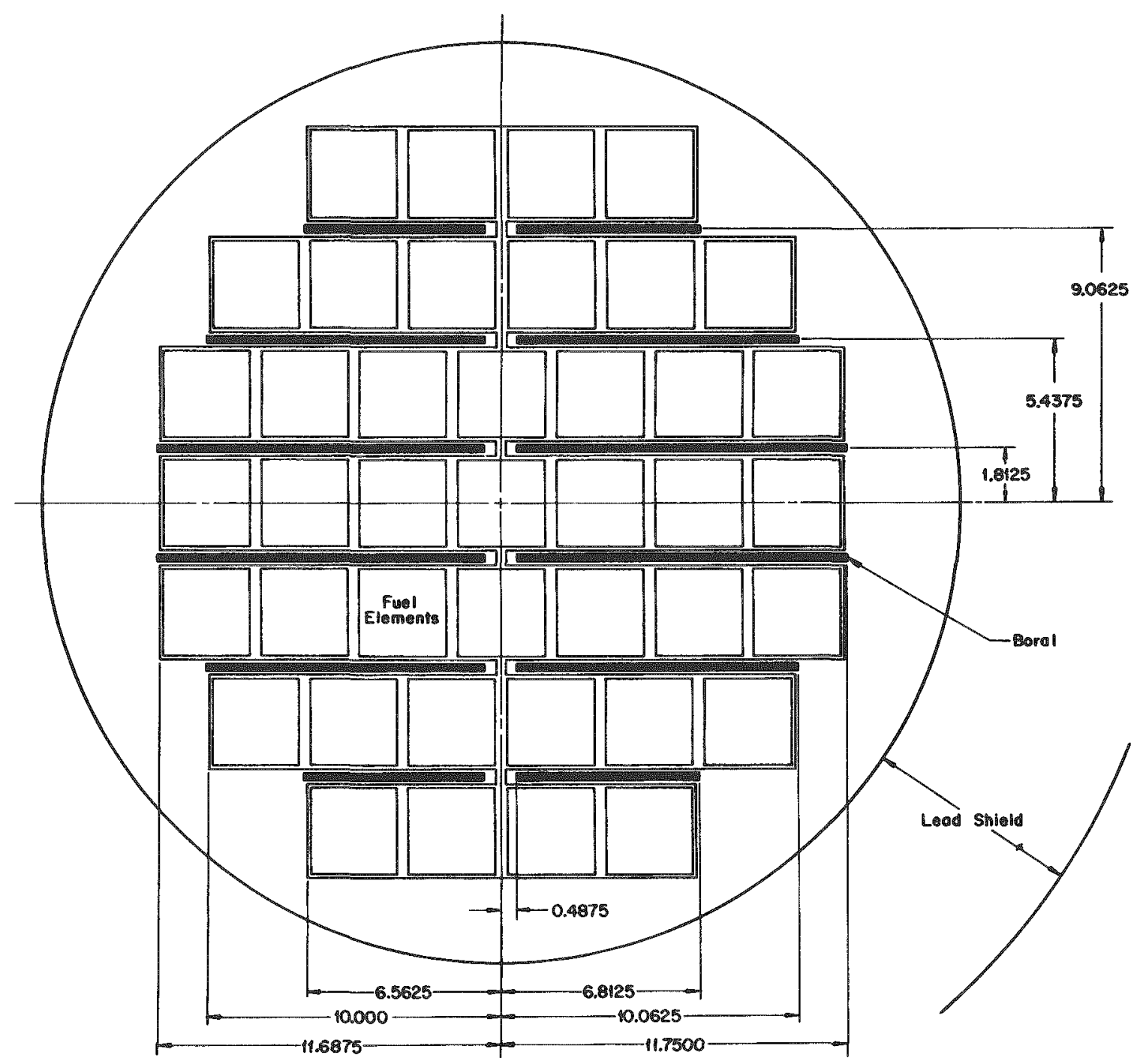

INC-C-18860

Figure 7. JMTR Fuel Cask. 

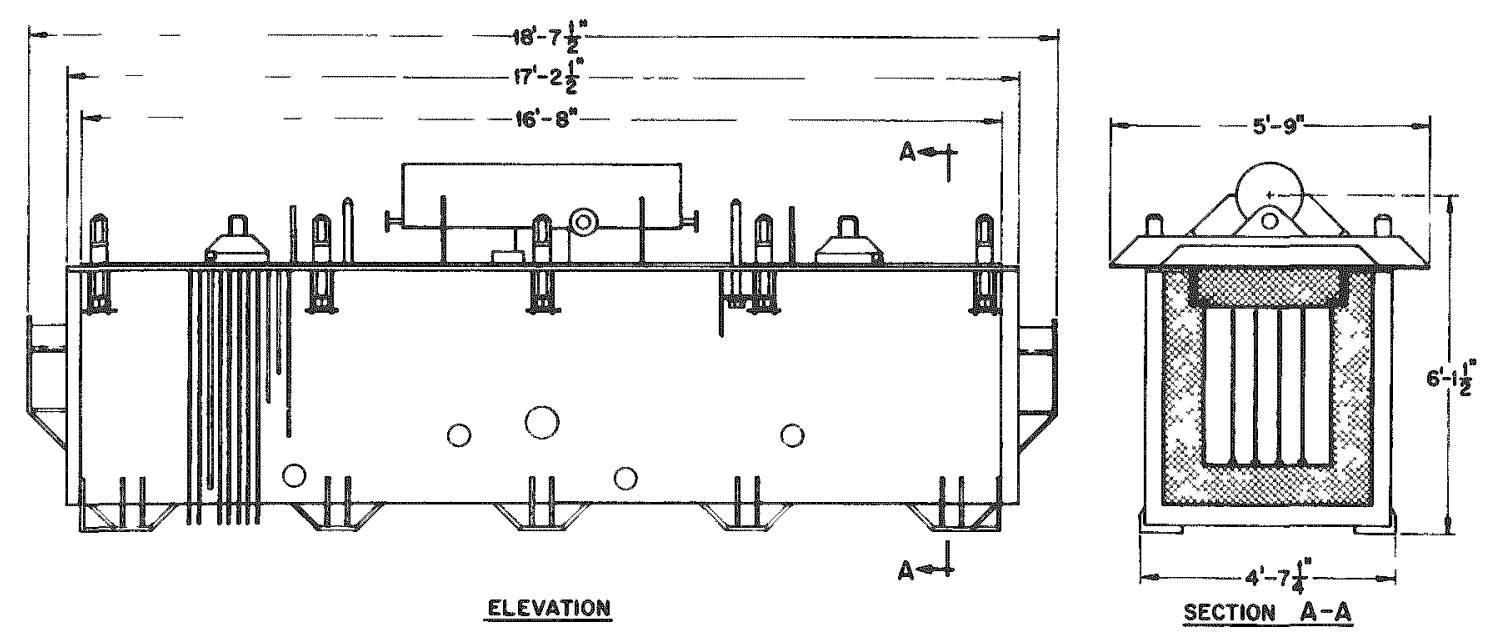

INC-B-18859

Figure 8. Savannah River 70-Ton Cask. 


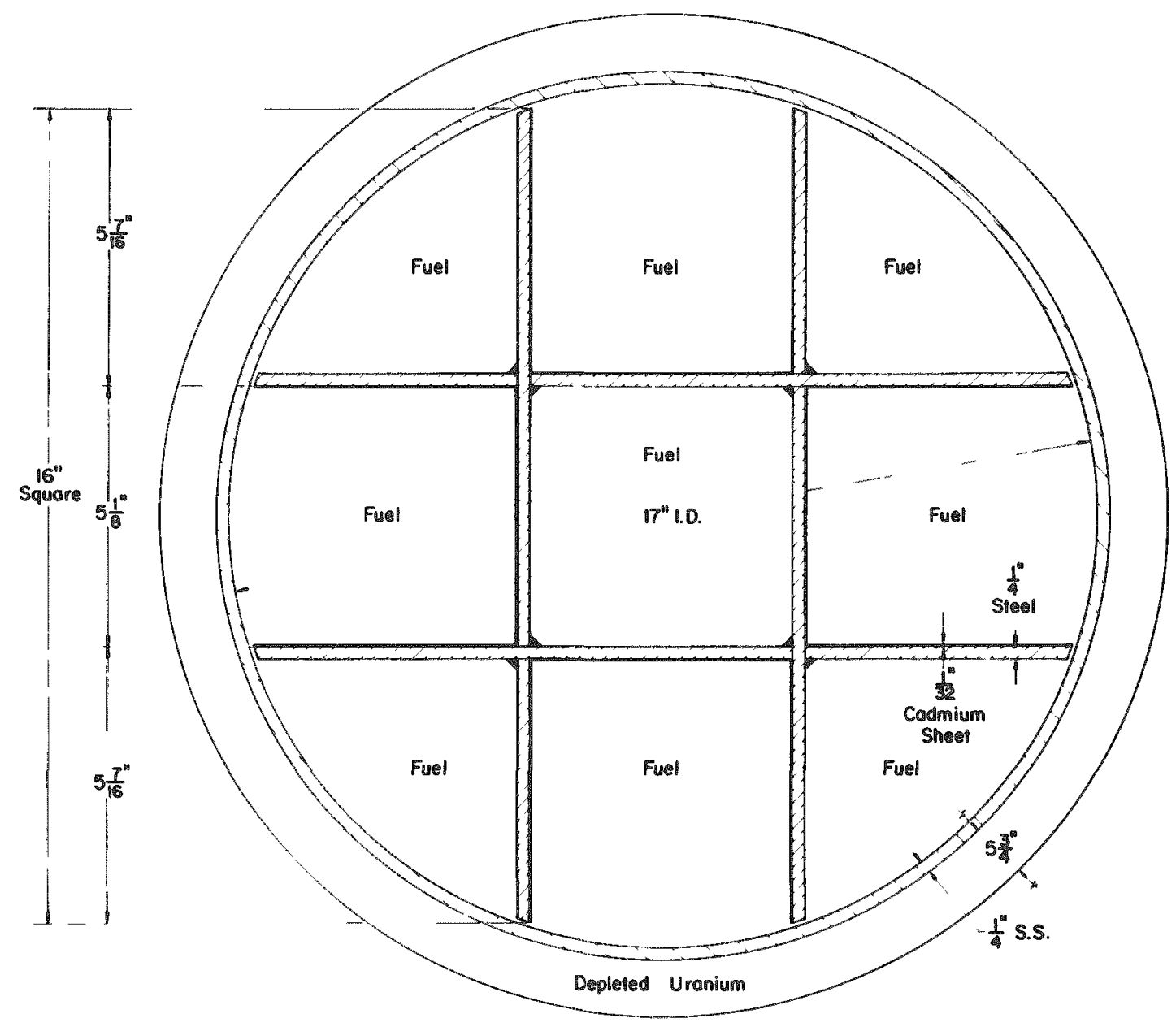

INC-D-18856

Figure 9. Paducah Depleted Uranium Cask. 


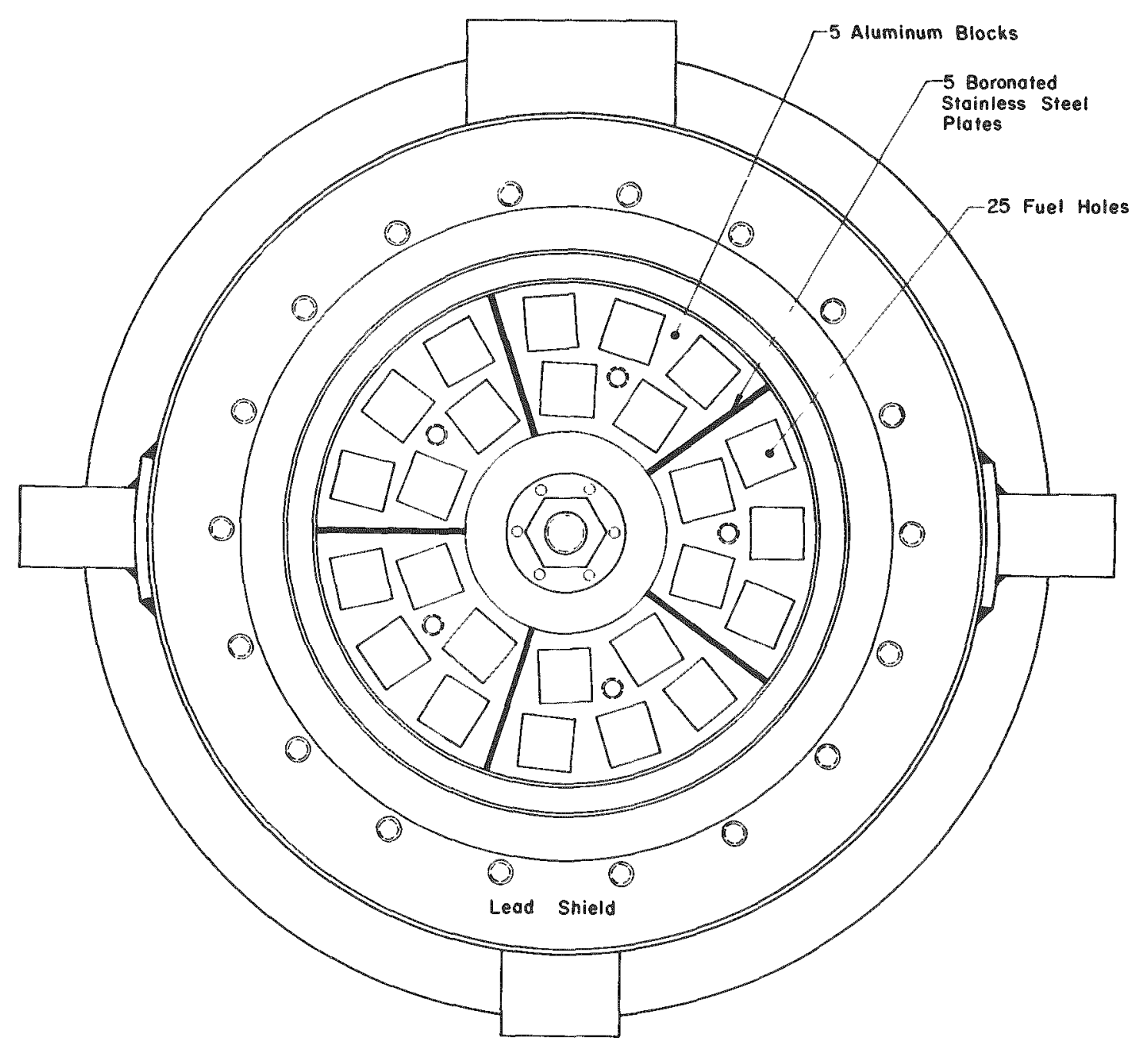




\title{
ATMX RAILCAR - NUCLEAR SAFETY EVALUATION
}

J. D. McCarthy

ABSTRACT

\begin{abstract}
A Nuclear Safety Analysis of the ATMX-600 Series Railcar shows that this railcar meets the requirements for Class I Shipments, as specified in the Appendix to AEC Chapter 0529. This railcar is used for shipping waste material mixed with fissile material.
\end{abstract}

\section{INTRODUCT ION}

The ATMX-600 Series Railcar, a double-walled steel car, was originally built to transport explosive ordinance. For a complete description of this railcar, refer to RFP-1411.

It was necessary to provide a Nuclear Safety evaluation prior to the use of this car for the transport of radioactive waste material. This evaluation gives the limiting criteria for Class I shipments as specified in the Appendix to AEC Chapter 0529.

The criteria specify the size of waste containers as a function of the amount of fissile material in combination with nonfissile material permitted in the container.

\section{PACKAGING CONF IGURATION}

The data pertinent to a Nuclear Safety evaluation of this railcar are: 
The ouler structure is an ATMX-600 Series Railcar (Figure 1). The useable inner dimensions are:

$$
\begin{aligned}
& \text { length - } 50 \text { feet } 0 \text { inches } \\
& \text { widh - } 9 \text { feet } 4 \text { inches } \\
& \text { height - } 9 \text { feet } 2 \text { inches }
\end{aligned}
$$

Waste Containers

The containers (Figure 2) are:

I. Specification ICC-17H 30-gallon containers 2 having the following dimensions:

$$
\begin{aligned}
& \text { minimum inner diameter }-18.187 \text { inches } \\
& \text { minimum inner height }-27.219 \text { inches } \\
& \text { minimum thickness }
\end{aligned}
$$

and $/$ or $^{2}$

2. Specification ICC-17H 55-gallon containers ${ }^{3}$ having the following dimensions:

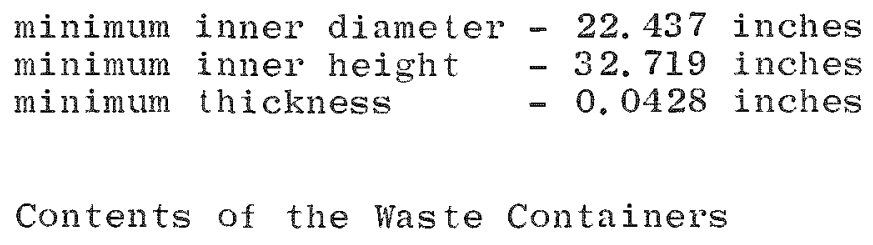

The fissile material used in this evaluation is specified below. These numbers were chosen because they are a practical limit and an amount which can be shown to be acceplable from a criticality aspect.

1. A maximum of $100 \mathrm{~g}$ Pu-239 mixed with non-fissile material (such as graphite, paper, plastic, etc.) in the ICC-17H 30-gallon container.

and $/ O x^{\circ}$

2. A maximum of $200 \mathrm{~g}$ Pu-239 mixed with non-fissile material (such as graphite, paper, plastic, etc.) in the ICC-I7H 55-gallon container. 
Normal Conditions of Transport

The requirements for Class I Shipments are specified in the Appendix to AEC Chapter 0529. These regulations specify the normal and accident conditions that must be applied to ICC-17H $30-$ gallon containers and the ICC-17H 55-gallon container with the restriction that these containers are placed in the ATMX-600 Series Railcar.

Under normal conditions, the nuclear safety requirements for Class I shipments is that any number of containers is sub-critical in any arrangement with optimum moderation. Interpreting the phrase "any ariangement" to mean "any arrangement under normal handling conditions", this requirement is met. The following evaluation shows that an infinite number of these $1 \mathrm{CC}-17 \mathrm{H} 30-$ gallon containers and/Or ICC-17H 55-gallon containers are subcritical in an infinite planar array of ATMX-600 Series Railcars.

Assumptions used in the Analysis

For this analysis, the containers were assumed to be undamaged and in a fully reflected array with optimum moderation.

In the calculations, the material in the containers was considered to be uniformly distributed through the containers.

\section{Analysis}

Previous calculations 4 have shown that the most reactive configuration for this type of waste is a composition of $200 \mathrm{~g}$ Pu-239 and graphite per container. The addition of water to a graphite$\mathrm{pu}$ system results in a less reactive system. The amount of graphite in a drum must be limited to a maximum of 200 pounds of graphite since calculations show that 300 pounds of graphite will result in a more reactive system. The 200 pound graphite limit is also compatible with that used at Rocky Flats.

Using $\mathrm{Pu}$ and 200 pounds of graphite as the composition of the material in the 30-gallon and 55-gallon containers, a series of 
calculations* were run. These calculations determined the critical height of an infinite number of cylinder cells. The DTF calculations 5 were done on the CDC-3800 with sixteen group cross sections ${ }^{6}$ and $S_{4}$ approximation.

The configuration for the cell calculations was an infinite planar array of cylinders (Figure 3). The composition of the material in the containers and the dimensions for the arrangement of the containers are:

ICC-17H 30-Gallon Containeis

Material: $100 \mathrm{~g}$ Pu-239 and 200 pounds of graphite per container

Inner Diameter: 18.18 inches

Gap Between Containers: 0.629 inches

Container Wall Thickness: 0.0378 inches ICC-17H 55-Gallon Containers

Material: $200 \mathrm{~g}$ Pu-239 and 200 pounds of graphite per container

Inner Diameter: 22.43 inches

Gap Between Containers: 0.629 inches

Container Wa11 Thickness: 0.0428 inches

The results of the DTF-II calculations (after adjustment for reflection on the top and bottom of the array) indicate that the critical height of an infinite reflected slab of 30-galion containers in the configuration specified is 121.2 inches and the critical height of an infinite reflected slab of 55-gallon containers in a similar configuration specified is 166.8 inches.

Since the useable height of the ATMX-600 series railcar is 110 inches, an infinite number of these 30-gallon and/ox 55-gallon containers, packaged as specified above, is sub-critical in an infinite number of fully reflected railcars.

\section{Accident Conditions for Transport}

Another of the requirements for Class I shipments, as specified in the Appendix to AEC Chapter 0529, is that two hundred

* Calculations done by D. C. Coonfield, L. E. Jackson, Rocky Flats Division, The Dow Chemical Company, 1968. 
fifty (250) of these ICC-17H 30-galion and/Or 55-gallon containers must be sub-critical in any arrangement with full reflection on al1 sides and optimum moderation. The condition of each container is to be that which would result if each container was subjected to the hypothetical accident conditions specified in Annex 2 of the Appendix to AEC Chapter 0529.

Assumptions used in the Analysis

The containers were assumed to have the same spacing in the array as the undamaged containers and the material in the containers was assumed to be uniformly distributed through the containers.

The containers were assumed to be in an array with full reflection and optimum moderation.

\section{Analysis}

The 30-gallon and 55-gallon containers were assumed to have the same spacing in the array as the undamaged containers since the package-to-package spacing will not change to any large extent under accident conditions 7 as defined in the Appendix to AEC Chapter 0529.

The contents of the 30-galion containers were assumed to be $100 \mathrm{~g}$ of Pu-239 and 200 pounds of graphite per container and the contents of the 55-gallon containers were assumed to be $200 \mathrm{~g}$ Pu-239 and 200 pounds of graphite per container. These containers have optimum moderation, as explained above, provided the graphite was limited to a maximum of 200 pounds.

The reflected critical infinite slab thickness, calculated for 30-gallon containers, was converted to a reflected cubic array by equating the Buckling equations.

Infinite Slab:

$$
\begin{aligned}
& \mathrm{B}_{\mathrm{S}}{ }^{2}=\left(\frac{-}{\mathrm{T}+2 \delta}\right)^{2} \\
& \text { where: } \mathrm{T}=\text { infinite critical slab thickness } \\
& \quad \delta=\text { extrapolation length }
\end{aligned}
$$


Cubic:

$$
\begin{aligned}
& \mathrm{B}_{\mathrm{C}}=3\left(\frac{-}{\mathrm{h}+2 \delta}\right)^{2} \\
& \text { where: } \quad \begin{aligned}
\mathrm{h} & =\text { length of edge } \\
& \delta=\text { extrapolation length }
\end{aligned}
\end{aligned}
$$

The extrapolation length ( $\delta$ ) used for the slab was 2.47 inches 8 and for the cubic array was 2.23 inches 8 .

For the 30-gallon containers, the calculated value of $\mathrm{T}$ was 121. 2 inches. This gives a value of $h$ equal to 213.76 inches.

The number of 30-galion containers on an edge of the base of the cubic array is obtained by dividing the length of the base by 18.88 inches (the inner diameter of the container plus two wall thicknesses plus the air gap) and the number of containers high is obtained by dividing the height of the array by 27.22 inches (the inner height of the container).

The critical number of 30-gallon containexs in a cubic array is:

$$
\begin{aligned}
N_{C} & =(\text { number on edge })^{2} \text { (number high) } \\
& =(11.32)^{\circ}(7.85) \\
& =1005
\end{aligned}
$$

This shows that two hundred fifty (250) ICC-17H 30-galion containers are sub-critical in a cubic array with full reflection and optimum moderation.

This same type of analysis, when applied to the 55-gallon containers, gives a critical number of one thousand four hundred thirty one (143I) ICC-17H 55-gallon containel's, loaded as speciabove.

This shows that two hundred fifty (250) ICC-17H 55-gallon containers are sub-critical in a cubic array with full reflection and optimum moderation.

Crates containing contaminated equipment, etc., will be limited to $5 \mathrm{~g}$ of Pu-239 per cub foot. This system is a less reactive system than has been shown for the graphite-pu system of 30-gallon containers and 55-gallon containers.

Therefore, these 30-gallon containers, 55-gallon containers, and crates meet the requirements as specified in Section II.H for 
Class I shipments, provided these drums are packaged in the ATMX600 series railcar.

\section{SUMMARY}

This evaluation has shown that this method of transporting fissile waste material is acceptable from a criticality aspect.

It has been shown that for normal conditions of transport, an infinite number of 30-gallon containers, 55-galion containers, and crates are sub-critical in an infinite planar array of ATMX600 railcars with full reflection and optimum moderation.

The analysis for accident conditions of transport has shown that at least two hundred and fifty (250) of these 30-gallon containers and 55-gallon containers are sub-critical in a cubic array with full reflection.

This evaluation has been shown to be based on the waste being distributed among:

ICC-17H 30-galion containers containing a maximum of $100 \mathrm{~g}$ pu-239 and non-fissile material (with the further limitation that the non-fissile material does not contain more than 200 pounds of graphite per containei). and/or

ICC-17H 55-gallon containers containing a maximum of $200 \mathrm{~g}$ Pu-239 and non-fissile material (with the further limitation that the non-fissile material does not contain more than 200 pounds of graphite per container). and/or

Crates containing contaminated equipment, etc., with a Iimitation of a maximum of $5 \mathrm{~g}$ Pu-239 per cubic foot.

The ATMX-600 series railcar as a means to transport radioactive and/or fissile material has been issued DOT SP 5948 which incorporates the limitations specified above. 


\section{REF ERENCES}

1. F. E. Adcock, ATMX-600 Series Railcar for Radioactive Waste Shipments, RFP-1411, The Dow Chemical Company, Rocky Flats Division, Golden, Colorado, January 7, 1970.

2. Steel Shipping Container Institute, American Standard Specifications for Metal Drums, MH 2.13-1960, page 6, American Institute, New York, 1960.

3. Steel Shipping Container Institute, Specifications for Metal Drums and Pails, MH 2.5-1965, page 10, American Standards Institute, New York, 1965.

4. Internal Report, The Dow Chemical Company, Rocky Flats Division, Golden, Colorado, 1968.

5. B. G. Carlson, W. Guber, M. Shapiro, and W. J. Worlton, DTF Users Manual, UNC Phys/Math-3321, United Nuclear Corporation, White Plains, New York, Volume I, Nov. 1963, Volume 2, May, 1964.

6. G. E. Hansen and W. H. Roach, Six and Sixteen Group Cross Sections for Fast and Intermediate Critical Assemblies, LAMS2543, University of California, Los Alamos Scientific Laboratory, Los Alamos, New Mexico, December, 1960.

7. F. E. Adcock, Internal Report, The Dow Chemical Company, Rocky Flats Division, Golden, Colorado, December 4, 1967.

8. H. C. Paxton, Criticality Control in Operations with Fissile Material, Los Alamos Scientific Laboratory of the University of California, Los Alamos, New Nexico, 1966. 


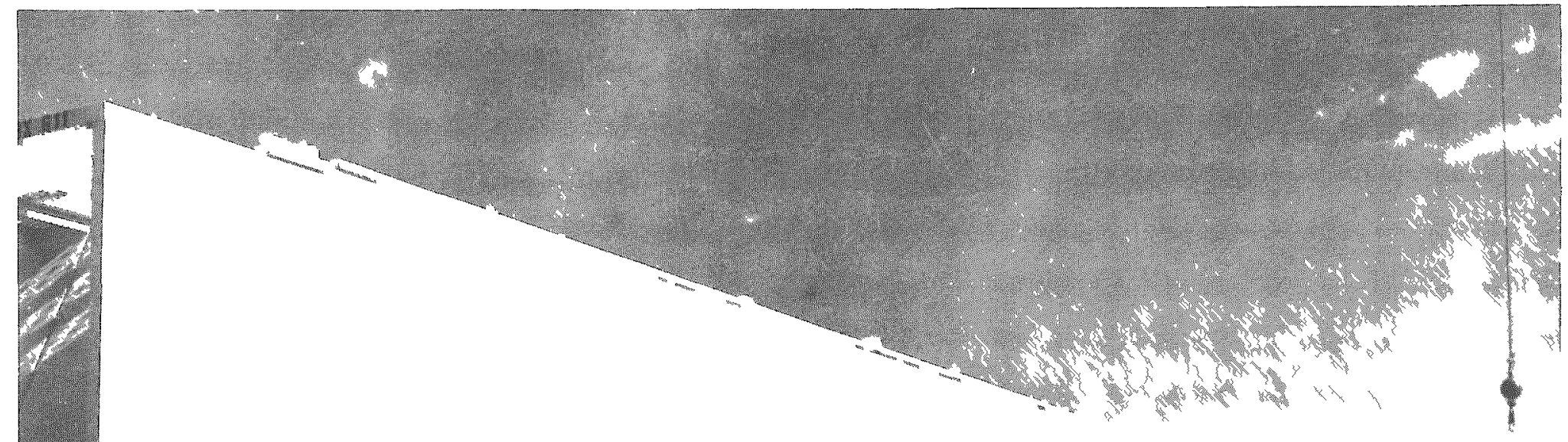

\section{$\operatorname{ATM} \times 611$}

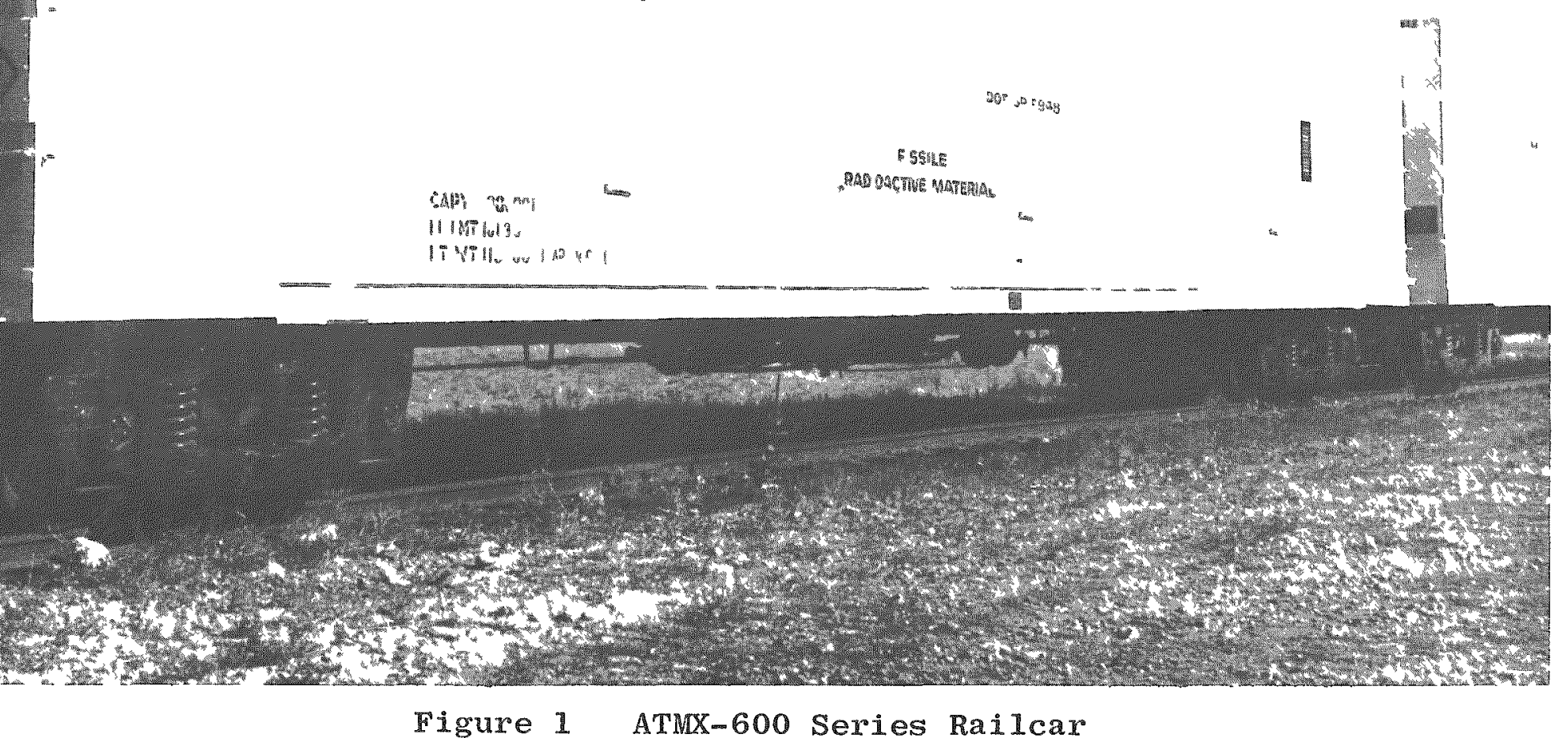

Figure 1 ATMX-600 Series Railcar 


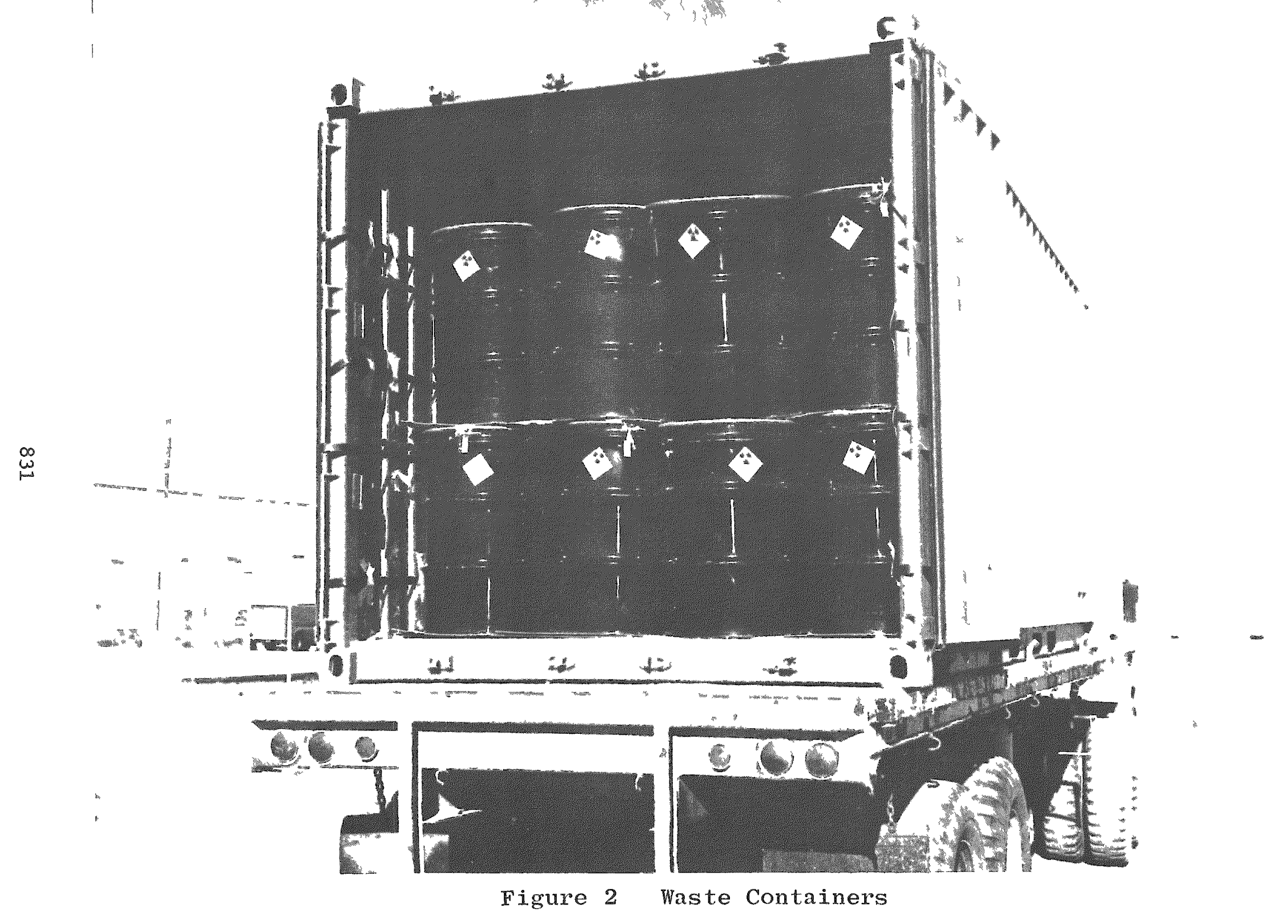




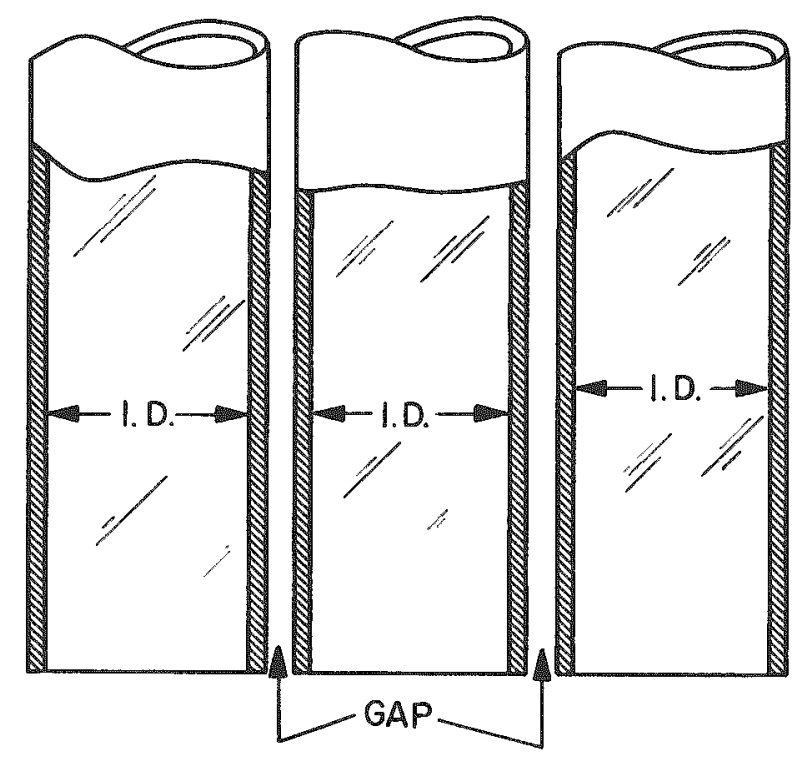

Figure 3 Arrangement Used in Calculations 
$\checkmark$ STUDY ON FIRE RESISTIVIIY FOR IRRADIATED FUEI SHIPPING CASKS

T. Moriya

H. Shimada

ABSTRACT

The purpose of this study is to assess the fire resistivity of spent fuel casks. Heat durability experiments were nade in a furnace for two cask models of different dinensions. It was found that when the experimental results were analysed with an Analog computer, the air gap between the lead shield and the outer shell affects largely the heat resistivity of casks. The analysis in which the heat generation from spent fuel is taken into consideration suggests that the prototype casks are fireresistive enough for their lead to be kept unmelted against the $800^{\circ} \mathrm{C}$ fire of a period of $30 \mathrm{~min}$.

\section{INTRODUCTIOIS}

Casks usea to trensport radio active spent fuel require high fire resistivity to cope with possible fire accidents with which they would meet. The assessment of the heat resistivity of casks of different dimensions were performed by experiments and theoretical analysis.

\section{DISCRIPTION OF CASKS AND FURNACE}

Casks refered to in this paper are spent fuel shipping containers which are cylindrical and composed fo three layers, an outer shell of steel, a lead shield and an inner shell of stainless steel. Details of two different scale cask models used in our tests as well as those of prototype casks are presented in Table 1. A tunnel shaped furnace the inside dimension of which is $1.6 \mathrm{mx} 2.6 \mathrm{~m} \times 1.6 \mathrm{~m}$ was used for the tests. In addition to the two front and rear sliding doors, the furnace has two bottoms separable from it, each of whlch has four wheeis under it and can be noved on two parallea raiis. One of the two bottoms, which are called trucks hereafter, is used for preheeting period and the other for experiment period. When a test is started, the truck on which a specimen is mounted replaces the other one which 
has served as the bottoms of the furnace during the preheating period.

Table 1 Dimerisions of Casks

\begin{tabular}{ccccc}
\hline & & $\begin{array}{r}\text { Prototype Cask } \\
\text { Iro. }\end{array}$ & No. I Cask Nodel & I0.2 \\
\hline Outer Diameter & $D(\mathrm{~mm})$ & 1600 & 800 & 400 \\
Inner Diameter & $d(\mathrm{~mm})$ & 1000 & 500 & 74 \\
Outer Shell & $t_{1}(\mathrm{~mm})$ & 38 & 19 & 10 \\
Lead & $t_{2}(\mathrm{~mm})$ & 250 & 125 & 150 \\
Inner Shell & $t_{3}(\mathrm{~mm})$ & 12 & 6 & 3 \\
Length & $L(\mathrm{~mm})$ & 5200 & 800 & 600 \\
Weight & $W(\mathrm{~kg})$ & 80000 & 3000 & 636 \\
\hline
\end{tabular}

FIRE TESTS

The top and bottom of a cask model on the truck outside are covered with asbestos heat insulator and firebrick for the purpose of heating the model only from its side. Chromel-alumel thermocouples are set at various points in the funnace, the outer shell, the lead layer and the cavity center for measuring their temperatures. The locations of the thermocouples for No. I and Iro. 2 models are shown in Fig. I. When the inside temperature of the furnace is raised to approximately $900^{\circ} \mathrm{C}$, a cask model on the truck is conveyed into the furnace by an electic motor after the other truck is pushed out. The cask model is pulled out after a heating period of $30 \mathrm{~min}$. at $800^{\circ} \mathrm{C}$ and is cooled to the ambient temperature. During the experiment, temperatures of various points in the furnace and the model are recorded contiruously.

\section{RESULTS}

The experimental results for $\mathbb{N o}$. $I$ and No. 2 cask models are shown in Fig. 2 and 3 respectively. The tempersture distribution in No. 1 cask 
model after a heating period of $30 \mathrm{~min}$. and that in No. 2 cask model after a heating period of $20 \mathrm{~min}$. are shown in Fig. 4 and 5 respectively. Those figures clearly show that in every experiment the outer shell temperature is much lower than the inner lead temperature. It is considered that the temperature discrepancy between the outer shell and the inner lead resulted from the very thin air gap between them. As shown in Fig. 2 and 3 , though the outer shell temperature began to drop immediately after the cask model was pulled out of the furnace, the inner shell temperature still continued to rise to approximately $260^{\circ} \mathrm{C}$ from $140-200^{\circ} \mathrm{C}$ during the cooling period after a heating period of $30 \mathrm{~min}$. Therefore, whether the lead wovld be melt or not cannot be discussed without paying attention to the lead temperature during the cooling period.

\section{ANALYSIS}

The heat resistivity of casks must be evaluated by the radiation shielding ability and tightness arter the tests. It is generally considered if the lead was melted. So, the temperature of loa can be used as a yard stick of the heat resistivity of casks. Only for one dimensional heating from radial direction (see Fig. 6), heat conservation differential equations given below are solved with the Analog computer.

$$
\begin{aligned}
& \frac{\lambda_{1} S_{1}}{\Delta r_{1}}\left(\theta_{1}-\theta_{2}\right)-\frac{\lambda_{1} S_{3}}{\Delta r_{1}}\left(\theta_{2}-\theta_{3}\right)=M_{13} \frac{d \theta_{2}}{d t} \\
& \frac{\lambda_{2} S_{4}}{\Delta r_{2}}\left(\theta_{4}-\theta_{5}\right)-\frac{\lambda_{2} S_{5}}{\Delta r_{2}}\left(\theta_{5}-\theta_{6}\right)=M_{46} \frac{d \theta_{5}}{d t} \\
& \frac{\lambda_{2} S_{6}}{\Delta r_{2}}\left(\theta_{6}-\theta_{7}\right)-\frac{\lambda_{2} S_{8}}{\Delta r_{2}}\left(\theta_{7}-\theta_{8}\right)=M_{68} \frac{d \theta_{7}}{d t} \\
& \frac{\lambda_{2} S_{8}}{\Delta r_{2}}\left(\theta_{8}-\theta_{9}\right)-\frac{\lambda_{2} S_{10}}{\Delta r_{2}}\left(\theta_{9}-\theta_{10}\right)=M_{810} \frac{d \theta_{9}}{d t} \\
& \frac{\lambda_{3} S_{10}}{\Delta r_{3}}\left(\theta_{10}-\theta_{11}\right)-\frac{\lambda_{3} S_{12}}{\Delta r_{3}}\left(\theta_{11}-\theta_{12}\right)=M_{1012} \frac{d \theta_{11}}{d t} \\
& \frac{\lambda_{4} S_{12}}{\Delta r_{4}}\left(\theta_{12}-\theta_{13}\right)=M_{1214} \frac{d \theta_{13}}{d t}
\end{aligned}
$$




$$
\begin{aligned}
\alpha_{1}\left(\theta_{0}-\theta_{1}\right) & =\frac{\lambda_{1}}{\Delta r_{1}}\left(\theta_{1}-\theta_{2}\right) \\
\frac{\lambda_{1}}{\Delta r_{1}}\left(\theta_{2}-\theta_{3}\right) & =\alpha_{2}\left(\theta_{3}-\theta_{4}\right) \\
\alpha_{2}\left(\theta_{3}-\theta_{4}\right) & =\frac{\lambda_{2}}{\Delta r_{2}}\left(\theta_{4}-\theta_{5}\right) \\
\left(\theta_{5}-\theta_{6}\right) & =\left(\theta_{5}-\theta_{7}\right) \\
\left(\theta_{7}-\theta_{8}\right) & =\left(\theta_{8}-\theta_{9}\right) \\
\frac{\lambda_{2}}{\Delta r_{2}}\left(\theta_{9}-\theta_{10}\right) & =\frac{\lambda_{3}}{\Delta r_{3}}\left(\theta_{10}-\theta_{11}\right) \\
\frac{\lambda_{3}}{\Delta r_{3}}\left(\theta_{11}-\theta_{12}\right) & =\frac{\lambda_{4}}{\Delta r_{4}}\left(\theta_{12}-\theta_{13}\right)
\end{aligned}
$$

where

$$
\begin{aligned}
\lambda: & \text { thermal conductivity of materials } \\
M: & \text { heat capacity of each element. } \\
s: & \text { surface area } \\
\alpha_{1}: & \text { total heat transfer coefficient at surface } s_{1} \\
d_{2}: & \text { themal conductance of gap } \\
\theta_{0}: & \text { fire temperature } \\
\theta_{1}-\theta_{14}: & \text { temperature in cask }
\end{aligned}
$$

The thermal conductance $\alpha_{2}$ of the air gap between the outer shell and the lead shield was taken into consideration in the anlysis. The total heat transfer coefficnet at the surface of the outer shell $d_{1}$ is the sum of the radiation heat transfer coefficient $d_{r}$ and the convection heat transfer coefficient $d_{c}$ which is constent.

The total heat transfer coefficnet $d_{1}$ is given by

$$
d_{1}=\sigma \varepsilon F \frac{\left(T_{0}^{4}-T_{1}^{4}\right)}{T_{0}-T_{1}}+a_{c}
$$


where

$$
\begin{array}{ll}
\mathrm{T}_{0}: & \text { fire temperature }{ }^{\circ} \mathrm{K} \\
\mathrm{T}_{1}: & \text { temperature of surface of cask }{ }^{\circ} \mathrm{K} \\
\sigma: & \text { Stefen-Boltzmann constant } \\
F: & \text { geometric shape-emissivity factor }
\end{array}
$$

The outer shell temperature $\theta_{2}$ and the lead shield temperature, $\theta_{5}$, $\theta_{7}$ and $\theta_{9}$ of each of No. 1 and No. 2 cask models were computed. The results of the computation is as follows.

The experimental value agreed considerably well with the computed value when the thermal conductance of the air gap for No. 1 and No. 2 models was given as 40 and $55 \mathrm{kcal} / \mathrm{m}^{2} \mathrm{~h}^{\circ} \mathrm{C}$ respectively. The thermal conductance of the air gap was assumed to be constant regardess of the tempers.ture.

The computed temperature-time curves of No. 1 and No. 2 cask models are shown in Fig. 2 and 3 in broken lines respectively. The size of the gap estimated from the value of $d_{2}$ based on the thermal conductance of air at $350^{\circ} \mathrm{C}$ is $1.03 \mathrm{~mm}$ for $1 \mathrm{No} .1$ cask model and 0.75 for No. 2 cask model. The gap which is formed by contraction of lead when each cask model is moulded was estimated by calculation to be $0.94 \mathrm{~mm}$ for $N$ o. I cask model $0.79 \mathrm{~mm}$ for $N 0.2$ cask model. The gap calculated based on the value of

2 was in a near agreement with that from the calculation of contraction. Therefore, it may be possible to know the extent of gap by calculation when materials and dimensions are known.

$$
\mathrm{d}_{2} \text { of prototype casks can be obtained as } 22 \mathrm{kcal} / \mathrm{ma}^{2} \mathrm{~h}^{\circ} \mathrm{C} \text { by the }
$$
estimation from the gap size calculated from the contraction.

Spent fuel contained in casks generates some heat as it decays. The rate of heat generation from the fuel is negligibly small compared with that of the heat transfer to casks from fires. In the computer analysis, as the initial cask temperature dpending on the decay of the fuel, $120^{\circ} \mathrm{C}$ was used each for No. I cask and prototype cask as initial value, though the term of the heat generation rate from the fuel was not added to the 
equation. The cask temperature, $120^{\circ} \mathrm{C}$ was estimated from the results of experiments conducted concerring heat extraction from casks. The temperature time curves of No. I caks from the computer analysis is shown in Fig. 7 . In these curves, melting of lead is not taken into consideration. Accoraing to Fig. 7, the temperature of lead rises to $315^{\circ} \mathrm{C}$ in $30 \mathrm{mir}$. and exceeds its melting point during the cooling period. It means that the Iead begins to melt during the cooling period after the heating period of $30 \mathrm{~min}$. .

As for the prototype cask, temperature-time relations at various points of the cask against the standard tire $\left(800^{\circ} \mathrm{C}, 30 \mathrm{~min}.\right)$ were obtained from the theoretical computation using some velues of $\mathbf{d}_{2}$ not less than $22 \mathrm{rcal} / \mathrm{m}^{2} \mathrm{~h}^{\circ} \mathrm{C}$ mentioned above.

The temperature-time curves of the outer shell and of the lead surface obtained from the computation are shown in Fig. 8. Accoraing to Fig. 8, the temperature of outer shell rises to approximately $570-010^{\circ} \mathrm{C}$, but the maximum temperature of the lead, which varies depending on the heat conductance of the air gap, does not go up to over $260^{\circ} \mathrm{C}$ which is lower than the melting point of lead, $327^{\circ} \mathrm{C}$.

It can be considered that this kind of prototype cask is safe enough from the standard fire. 

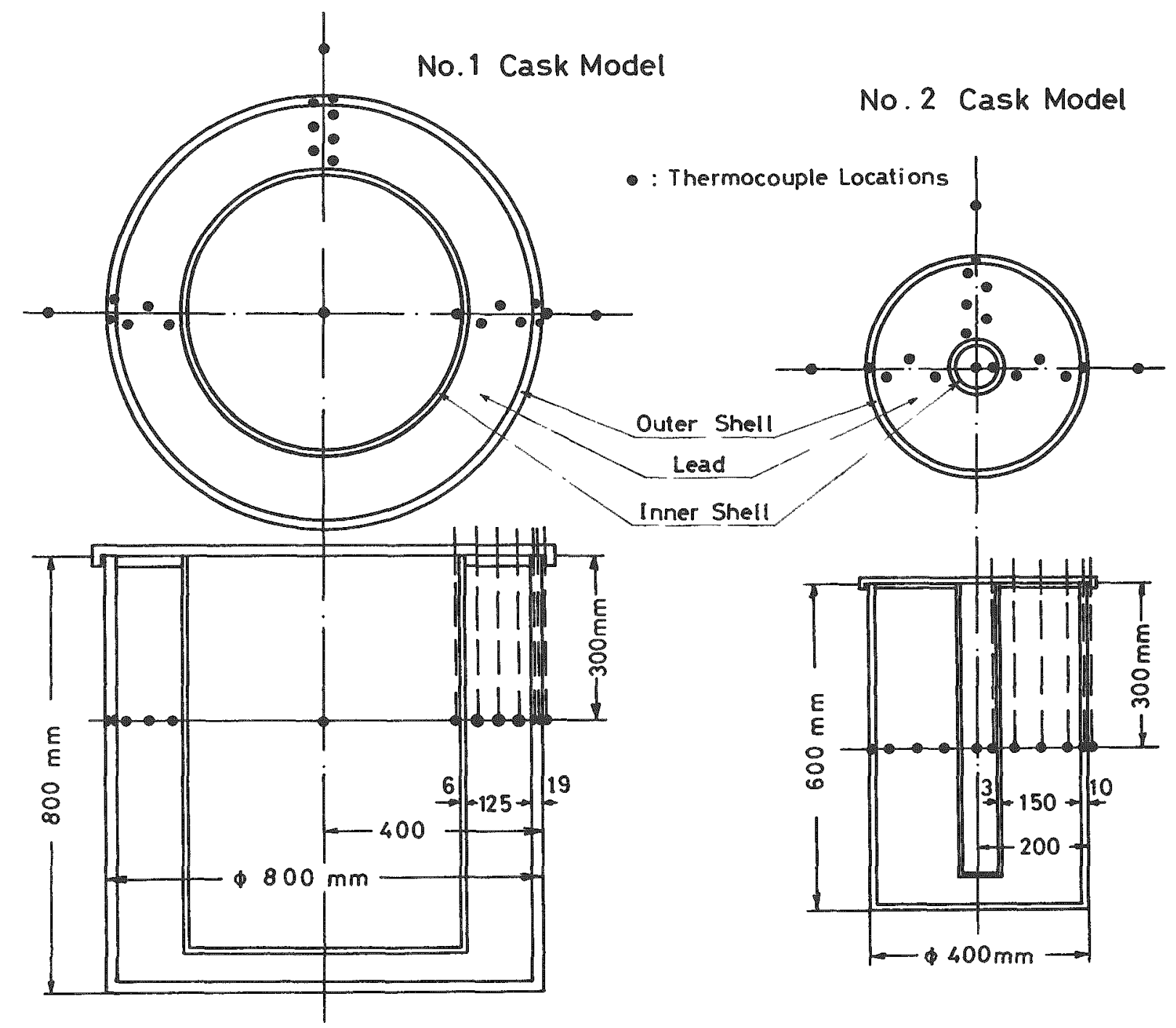

Fig. 1 Cross-Sections and Thermocouple Locations of No. 1 and No. 2 Cask Models 


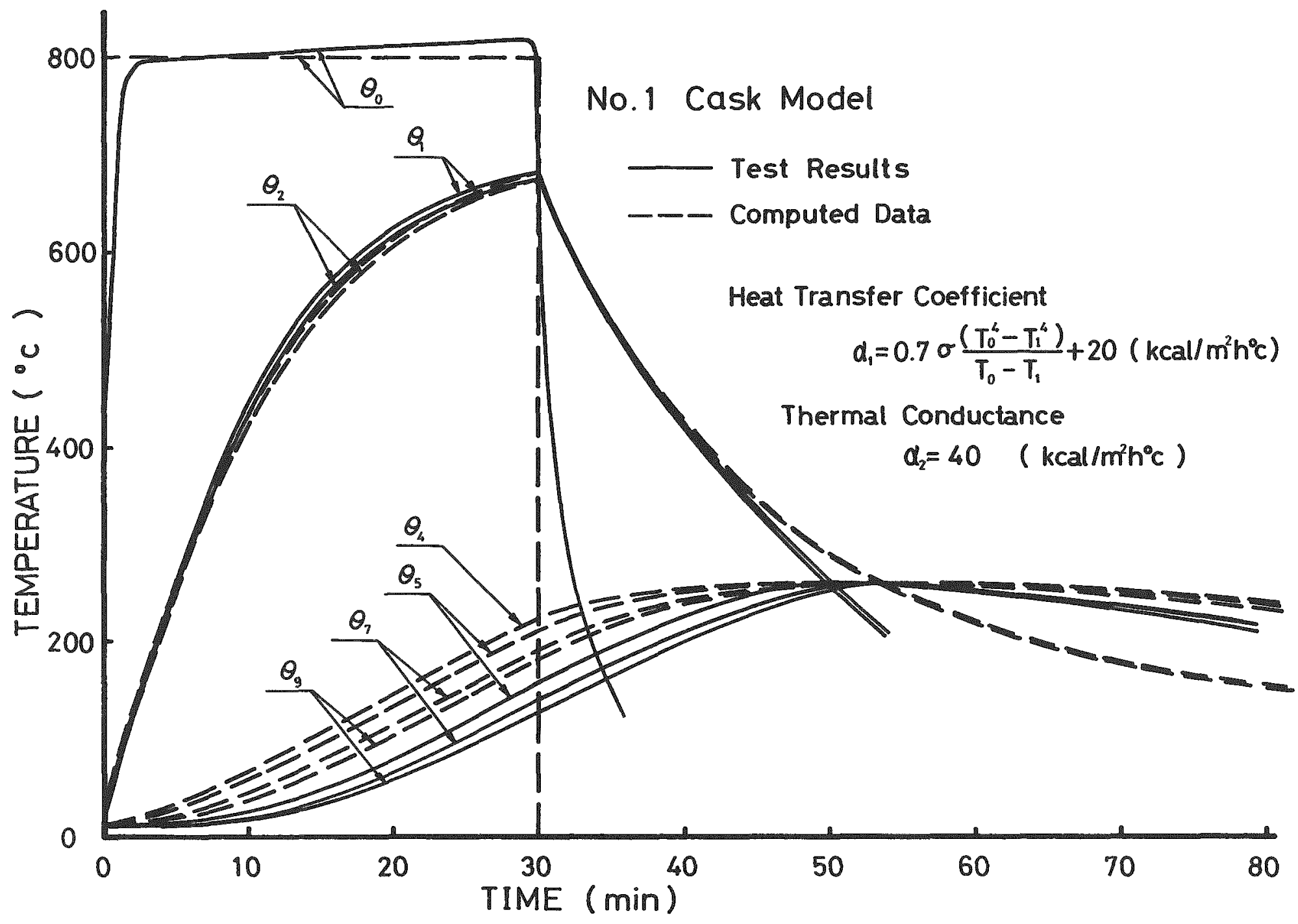

Fig. 2 Temperature vs. Time Curves of No. 1 Cask Model 


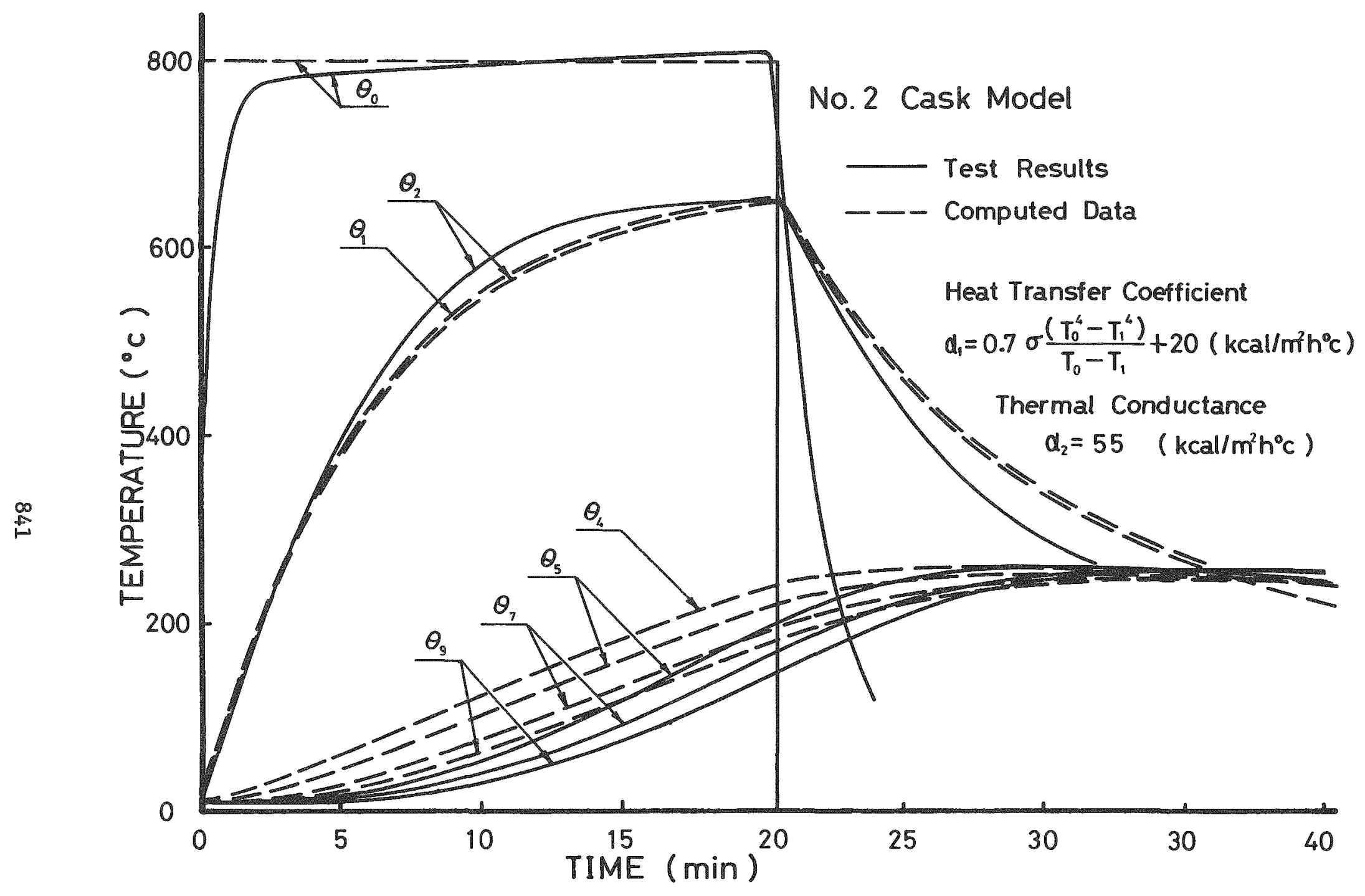

Fig. 3 Temperature vs. Time Curves of No. 2 Cask Model 


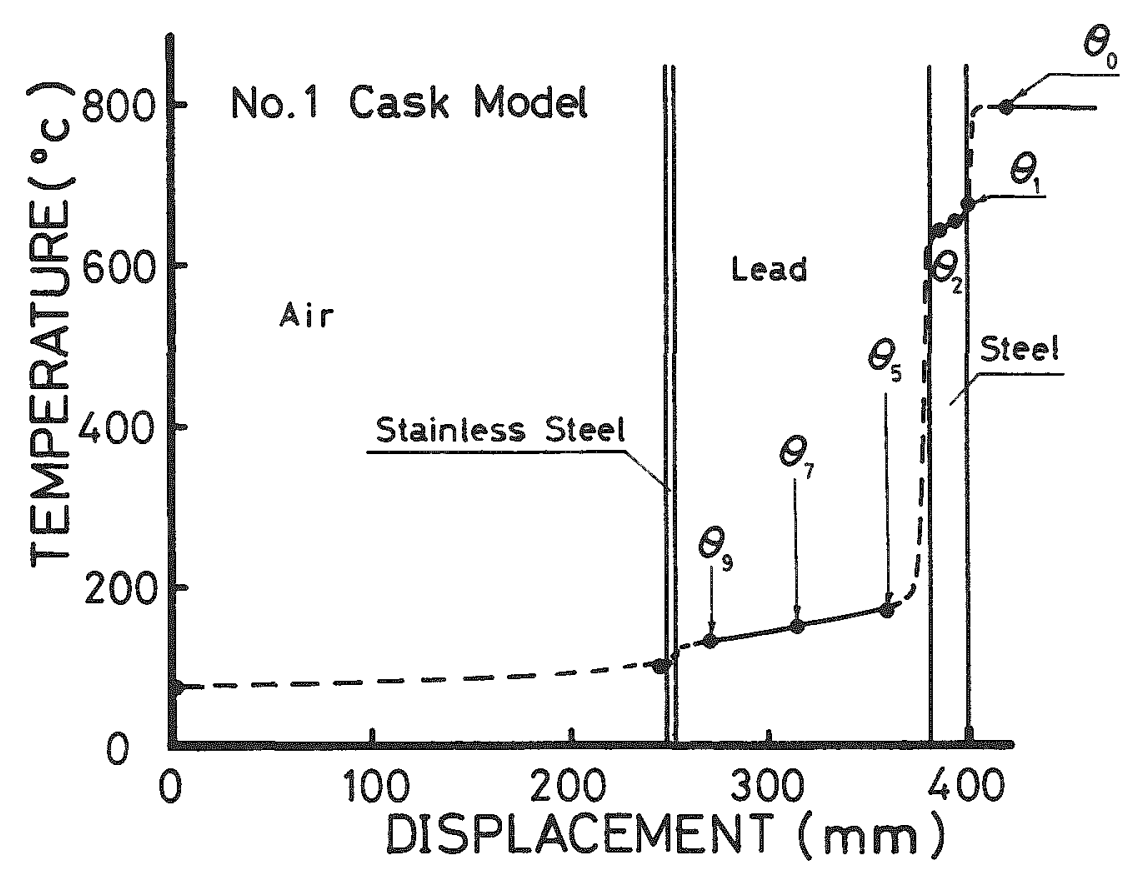

Fig. 4 Temperature Distribution Cruve of No. I Cask Modle at 30 min after Start of Fire Test.

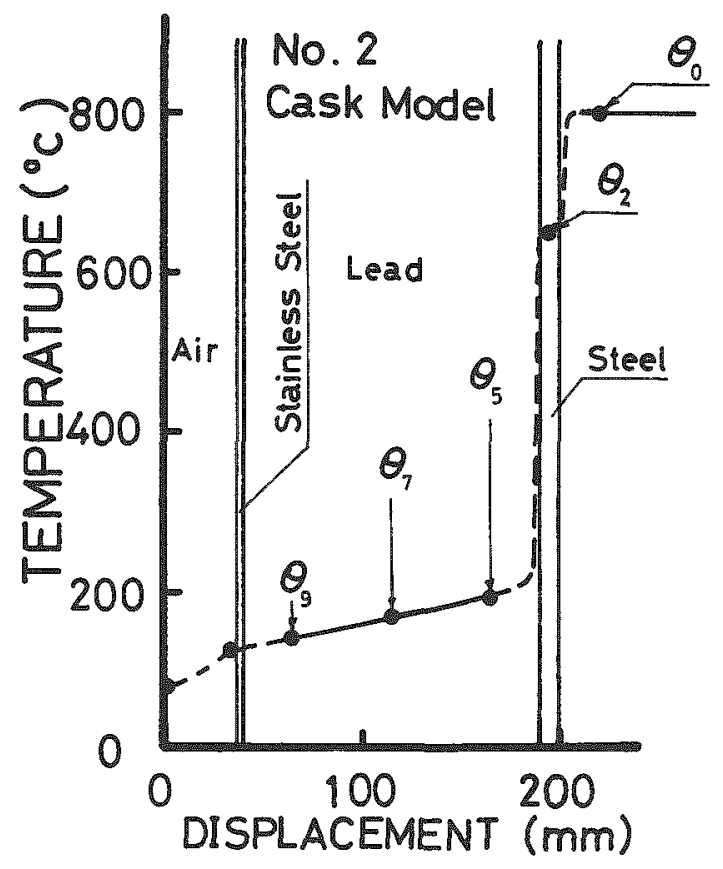

Fig. 5 Temperature Distribution Curve of No. 2 Cask Model at 20 min after Start of Fire Test. 


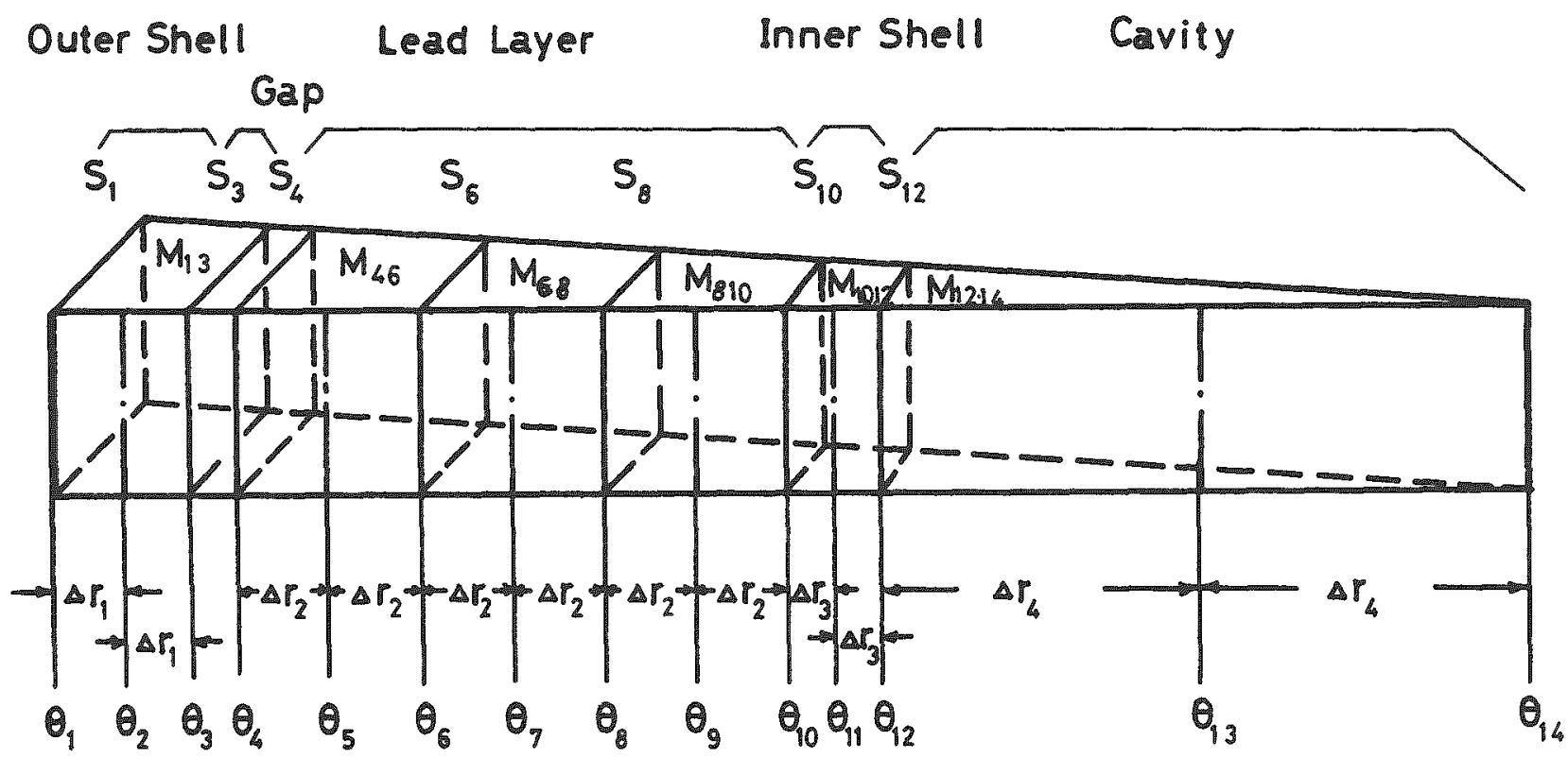

Fig. 6 Illustration of a Cask Element Divided in to Several Parts for Analysis. 


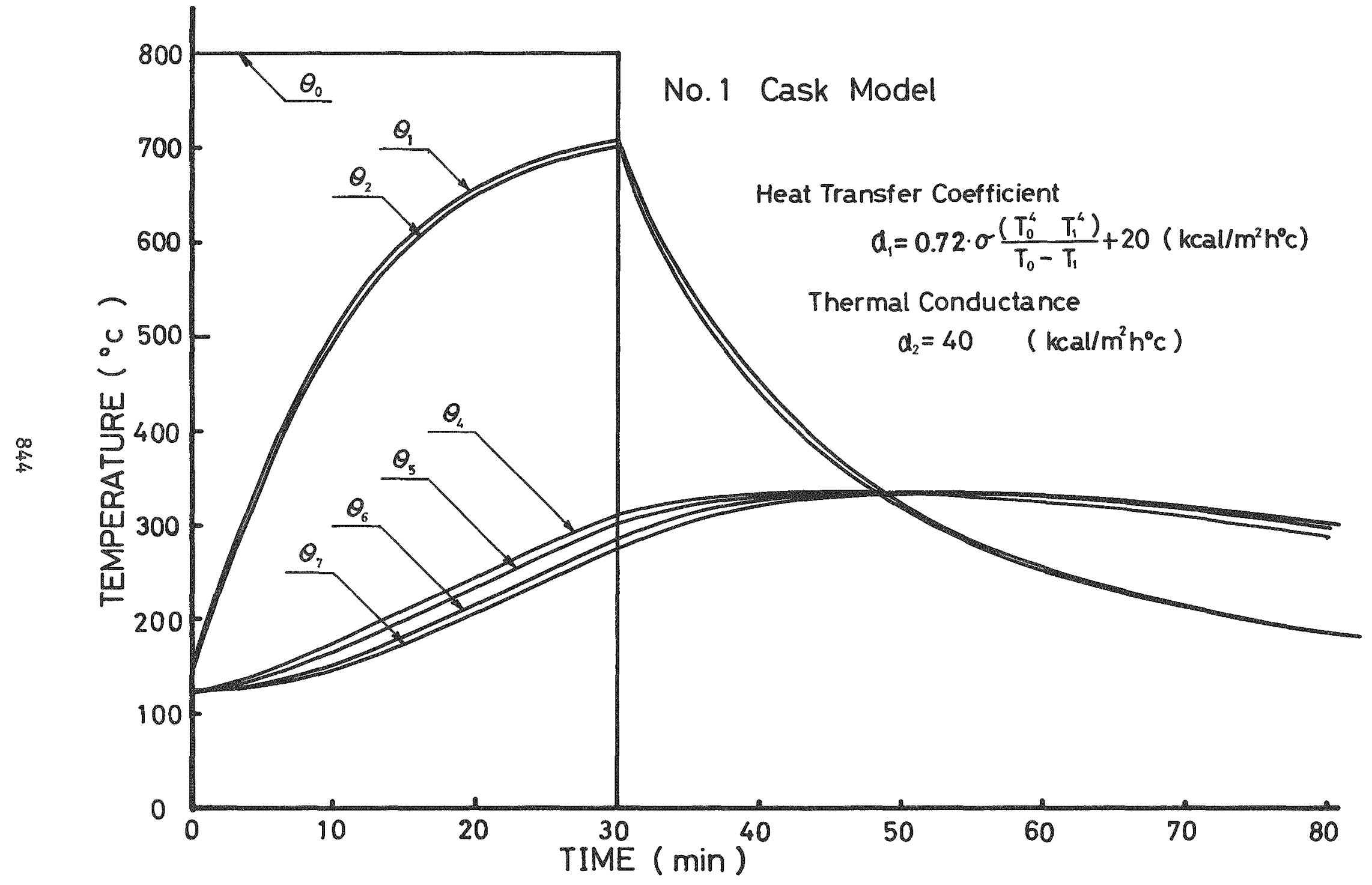

Fig. 7 Temperature vs. Time Cruves of No. I Cask Model for Standard Fire. 


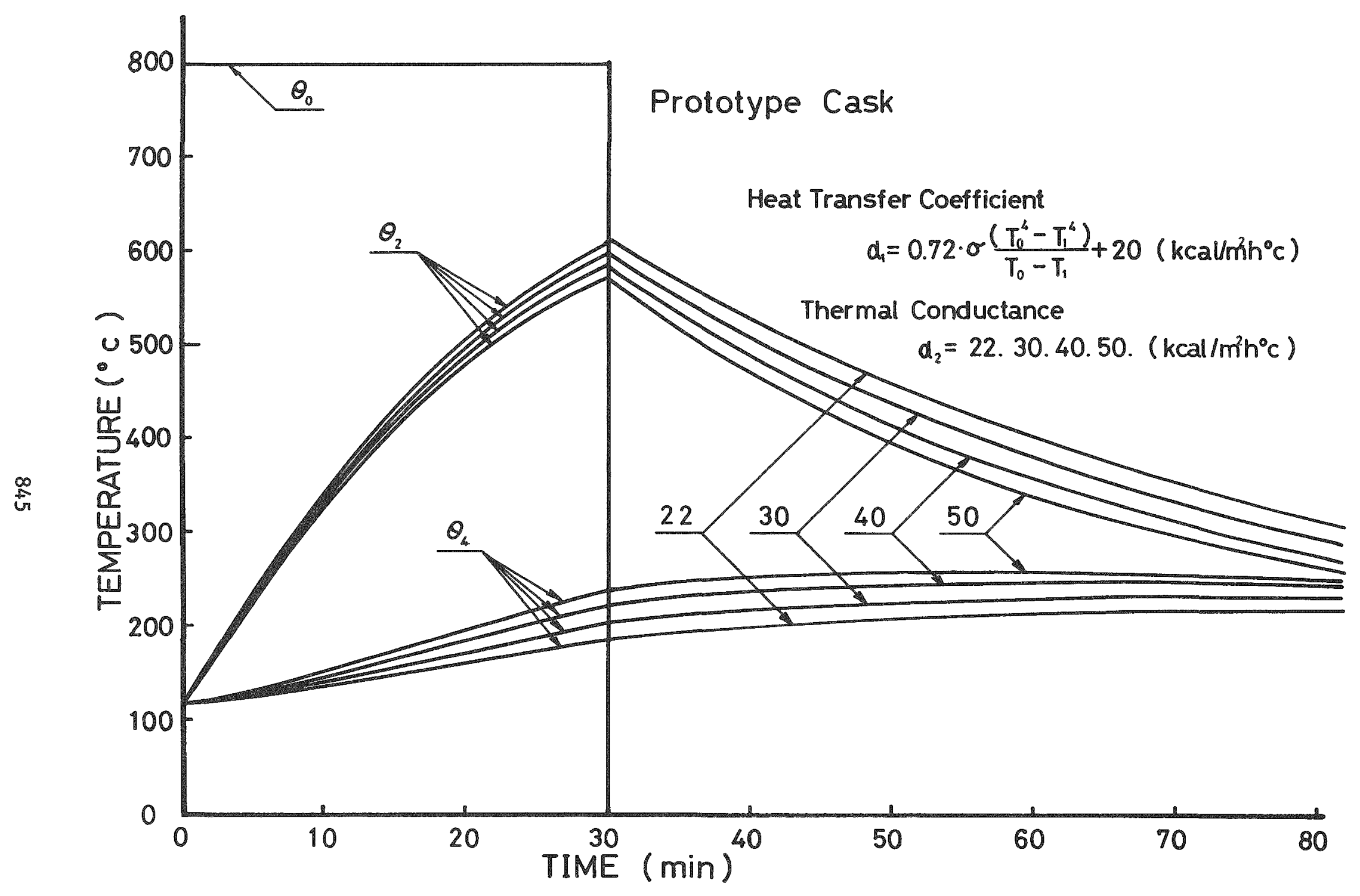

Fig. 8 Temperature vs. Time Cruves of the Outer shell and the Lead Surface of Prototype Cask for Standard Fire. 
HEAT TRANSFER CALCULATIONS FOR SPENT FUEL DURING

HYPOTHETICAL ACCIDENT CONDITIONS

C. J. Anderson

This paper was not available at the time of printing. It has subsequently been issued as BNWL-SA=3906, available from NTIS, 5285 Port Royal Road, Springfield, Virginia 22151.

\section{A THERMAL TEST EVALUATION METHOD FOR LEAD \& URANIUM SHIELDED CASKS}

J. C. Glynn

R. H. Odegaarden

This paper was not available at the time of printing. It has subsequently been issued as BNWL-SA-3906, available from NTIS, 5285 Port Royal Road, Springfield, Virginia 22151. 
SHIPPING CONTAINER DESIGN FOR FIRE ACCIDENT PROTECTION, MINIMUM RESTRICTION TO DECAY HEAT REMOVAL
A. W. Serkiz
E. C. Lusk

BATTELLE

Columbus Laboratories

\section{ABSTRACT}

Fire survival requirements impose various constraints on the design of nuclear material shipping container designs. The result has been, in many cases, a bulky package which is difficult to handle, load or unload, and quite susceptible to environmental conditions. Casks which must ship spent fuel assemblies having a high level of decay heat are presently considered to be a major design problem. However, the small casks (which of ten have a negligible amount of decay heat) must also survive the fire environment and not lose their shielding capability as specified by.the AEC-DML regulations. Methods used in the past have included wood overcoats, concrete or water impregnated materials, and more recently, organic materials such as used in the Paper Tiger concept. This paper outlines several design techniques which have evolved over a number of years at Battelle-Columbus and which are based on the optimal use of various cask components to serve a multiple function (i.e., structural and thermal protection). Several of the more obvious techniques are the use of external heat rejection fins, multiple or laminated structural shells, and water-filled outer shells which also serve as neutron shields. This paper presents several cask concepts and the calculated thermal response of these cask systems when they were subjected to the hypothetical fire specified in the AEC 10-CFR-Part 71 regulations. 
of the accidents postulated in the AEC regulations 10-CFR-Part 71 , the thirty minute, $1475 \mathrm{~F}$ industrial fire poses the most severe and thermal environment that the cask will experience. Exposure of the shipping container in this environment could result in the melting and potential loss of part of the biological shield, as well as possible overtemperaturing of the internal contents, particularly of the fuel assembly claddings with the subsequent release of fission products. Since the industrial fires postulated are defined as an equivalent thermal radiative source having an effective emissivity of 0.9 , utilization of cask design concepts, which would effectively block this radiant heat input, would enhance container survival. However, indiscriminate utilization of radiation shields has the obvious drawback of resulting in too high a thermal impedance.

Over the past ten to twelve years, Battelle-Columbus cask designers have evolved a variety of cask designs and, in general, drawn on the philosophy that various cask components can serve a multiple function. Illustrative of this approach is the use of decontamination shells (which are placed on the exterior of the cask surface to ease cleaning) to serve as a fire buffer. Cooling fins, which are required to dissipate high decay heats and also to reduce g-loads at impact can also serve as fire buffers because of their thermal decoupling characteristics. The more recent cask designs which require a water jacket on the exterior of the cask in a hybrid neutron shielding concept provide water which can be allowed to boil, and therefore, absorb the thermal input from the fire. In all these cases, we have taken advantage of components that are required for other functions to naturally impede the thermal pulse from the hypothetical fire. The next section will illustrate three typical systems and the calculated thermal response when the cask system is subjected to 10-CFR-Part 71 regulations.

Typical Cask Systems and Calculated Results

Three types of cask designs will be described next, and can be categorized as follows:

- Thermally decoupled

- Fin shielded

- Water shielded.

These categories are generally descriptive, and will be detailed next. 


\section{Thermally Decoupled Cask Systems}

This type of cask is generally one where the decay heat load is sma11, and is typically a small cask such as the BCL-3 cask shown in Figure 1. On the other hand, these casks can go up to the $63,0001 \mathrm{~b}$ class as evidenced by the Peach Bottom No. 1 cask which has an external envelope of 173 inches long $\mathrm{x} 42.6$ inches in diameter. As the above title imples, the "thermally decoupled" cask makes use of a secondary exterior thin-walled shell (typically stainless steel for corrosion and decontamination reasons) which is separated from the primary "outer shell" with a $1 / 8 \mathrm{in}$. $\pm 1 / 16 \mathrm{in}$. air gap thickness. The air gap thickness is normally kept small to provide for some thermal coupling to the exterior. Separation of outer plate from the primary cask shell is accomplished by means of a myriad of "weld spots". The outer shell is also seam welded at several axial positions for structura1 coupling.

A typical cask fire analysis is illustrated in Figure 2, and was submitted as part of the Peach Bottom No. 1 Safety Analysis Report. The thermal decoupling is quite evident as evidenced by the temperature differences between the fire buffer shell and the outer liner. Zero lead melt is predicted and the analysis techniques were adjudged adequate to justify fire survival. It should also be noted that this "cover" method is particularly adaptable to upgrading cask systems operating under the "grandfather clause", as was done with the ATCOR cask several years ago. Figure 3 illustrates the predicted thermal history of various components of the ATCOR cask. The thermal decoupling is again evident.

\section{Fin Shielded Cask Systems}

An illustration of a cask system relying on the heat rejection fins to effectively buffer the fire pulse is shown in Figure 4. This is the NFS-100 cask which was designed and licensed by Battelle-Columbus for Scientific Advances, Inc., who in turn was under contract to Nuclear Fuel Services, Inc. The heat rejection fins that were designed to dump waste decay heat during normal operation, also act as radiation shields. This can be deduced by examining the fin cavity region and its interaction with the radiant thermal source as shown in Figure 5. This figure also contains the geometric view factors for the fins and the cylindrical she11. The heat transfer which would occur can be expressed by the Stefan-Boltzmann equation results in Equation (1). It is evident that the geometric view factor area product is the key parameter. 


$$
\begin{aligned}
q_{\text {net }}= & \left(F_{\text {fins }} \cdot A_{\text {fins }}+F_{c y 1} \cdot A_{c y 1}\right)\left(\varepsilon_{\text {surface }}{ }_{j} T_{\text {surface }}^{4}-\right. \\
& \left.\varepsilon_{\text {flame } j} T_{\text {flame }}^{4}\right)
\end{aligned}
$$

Of interest, is the summation of the FA products divided by the total area, or for the NFS-100 cask.

$$
\frac{\Sigma F A}{\Sigma A}=0.20
$$

This ratio is in effect, the thermal radiation blocking afforded by the fins during the 30-minute fire. A 80 percent reduction is significant. Therefore, these same fins which are effective as heat dissipators during normal shipment, can impede the fire pulse.

The "blocking action" afforded by the fin cavity is shown in Figure 6 which contains calculated temperature histories for the NFS-100 cask system analyzed with and without fins when exposed to the hypothetical fire. The temperature response of nodes 17 and 18 (the fin material) illustrates the thermal gradient which can be sustained by the fin during the duration of the fire without undue conduction of the heat into the cask shield region. Utilization of the fins in the analysis results in predicting a zero lead melt while the simplified approach still utilized by some analysts (which discards the thermal shielding afforded by the fins) results in a prediction of $3 / 4$ " lead melt for a total lead thickness of 8.75 inches. The "blocking" effectiveness of the fins is self evident. This "thermal blocking" is collaborated by the data presented in Lusk's (1) paper describing the remelting of the NFS cask lead volume which took 17 hours to effect.

\section{Water Shielded Cask Systems}

The high burnup levels $(35,000-50,000 \mathrm{MWD} / \mathrm{MT})$ projected for PWR and BWR fuel assemblies, have necessitated the incorporation of neutron shielding in the next generation shipping casks. Our studies on behalf of the Whitehead \& Kales Company have revealed that a minimum weight cask system results from use of water both within the cask cavity, and external to the lead gamma shield. This has been termed a hybrid (or split) shield concept and requires approximately six inches of water which is contained within an external water jacket. Pressure relief valves will permit venting pressure at a predetermined level to prevent jacket rupture, while accommodating a large heat input by means of phase change. 
A calculated fire transient for a water-shielded system is show in Figure 7. These calculations represent the anticipated thermal response for a two-element PWR truck-type cask. Since this cask has a rectangular inner cavity, three thermal histories are shown to illustrate the cornerside thermal coupling which is often discussed. The effectiveness of the fins is again evident with the water effectively isothermalizing the system. Less than three percent of the water was calculated to vaporize at $350 \mathrm{~F}$ (the pressure valve setting chosen). Loss of more than a small volume of the water due to the structural accidents postulated is minimized by compartmentalizing the outer water jacket as well as the use of a supplemental crash system. The thermal model was composed of 53 nodes and provided for natural circulation of the water.

\section{ANALYTICAL TOOLS EMPLOYED}

Although a variety of generalized heat-transfer codes (i.e., THT-D ${ }^{(2)}$,
TRCMP (3) , CINDA-3G transfer analyses of cask systems have been carried out with the THT-D code. The THT-D code is a generalized computer progran capable of analyzing multidimensional transient heat-transfer problens for both transient and steady-state conditions. Temperature solutions are obtained by iterative solution of simultaneous heat-balance equations derived within the program by finitedifference techniques. The use of simultaneous equations (the implicit method of formulating heat balances) precludes any stability limitations on time increments and permits a direct steady-state solution at any stage of the calculation, including solutions which serve as initial conditions for a transient. Convergence of a solution is controlled by the preset tolerances on either temperature tolerance, or heat balance, or both. The key features of the program are its:

(1) Capability to use temperature-dependent material properties in calculations

(2) Capacity to handle time-variant boundary conditions

(3) Ability to calculate node-to-node heat transfer by the simultaneous mechanisms of conduction, convection, and radiation including internal heat generation

(4) Ability to accommodate melting of nodes by means of a latent heat option for isothermal phase change. 
Based on long-term utilization (i.e., 15 years) by various companies and a demonstrated correlation with actual heat transfer systems, IFI-D has been accepted by the AEC-DML as an acceptable analytical tool. We have (at $B C L$ ) run our own comparative analyses to determine the adequacy of this computer code.

\section{ACKNOWLEDGMENTS}

Acknowledgment is extended to all those sponsors who have engaged Battelle's Columbus Laboratories for the design and licensing of shipping containers over the past 12 - 15 years, and in particular, to the Whitehead \& Rales Company, Scientific Advances, Inc., Nuclear Fuel Services, Inc., and the ATCOR Company whose sponsored cask design activities have been used for illustrative purposes within this paper.

\section{REFERENCES}

(1) E. C. Lusk, Lead Remelt Experience with 60 Ton Cask, to be published in the proceedings for the Third International Symposium, Packaging and Transportation of Radioactive Materials (August, 1971).

(2) Skirvin, S.C., "User's Manual for the 'LHT-D Comput Program (Transient Heat Transfer - Version D)", GE-MMPO Report P.0. No. 036-926052-T0602, (June 23, 1966).

(3) Edwards, A.I., "TRUMP: A romnuter Program for Transient and Steady-State Temperature Distributinn in Multilmensional Systems", LRL-University of California, Report No. UCRL-14754, Rev. II, (JuIy 1, 1969).

(4) Connor, R.J., Kannady, R.E., Jr., and Almanza, J.E., "Adaptation of Chrysler Improved Numerical Differencing Analyzer to CDC 6000 Series Computers", Martin Marietta Corporation, Report No. M-68-22, (November, 1968). 
Permut No. $-\$ P-5950$

Modes of Transportation - a11 except by watex Masimum Thermal Decay Heat $=200$ watts

* Maximur Fissile Contents:

Fissile Class $I=100 \mathrm{gms} U-235$ equdv. mass

Fissile Class III $=2,000$ gras $U-235$ equiv. mass

Lid Weight $=185 \mathrm{lbs}$

Tota1 Cask Welght $=2,5001 \mathrm{bs}(1,136 \mathrm{kgs})$

F1oor Loading $=4281 \mathrm{bs} / \mathrm{sq}$ ft $(195 \mathrm{~kg} / \mathrm{sq} \mathrm{ft})$

Cask $D$ sameter $=18.50$ Inches $0 . D$.

Cask Height $=25.94$ inches overal1

Base Plate $=24.00^{\prime \prime} \times 24.00^{\prime \prime}$

(2) $1 / 2$ " dameter eye bolts required to remove $11 \mathrm{~d}$ Non "Special Form" type B and large quantity material requre inner can - pex drawting BCL-3-38

* Refer to DOT $-\$ P-5950$ permit.

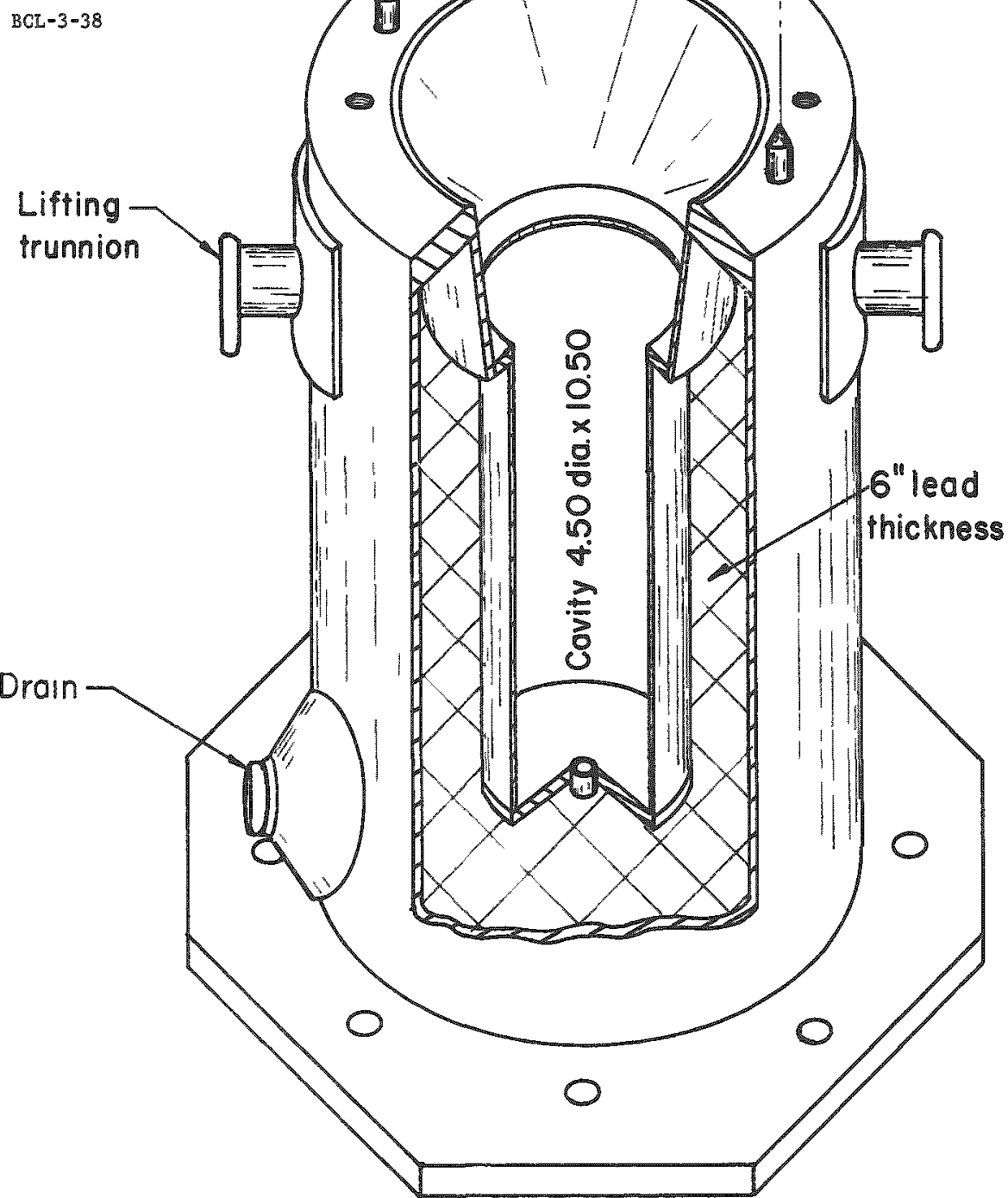

Fig. 1. Battelle Memorial Institute BCL-3 Series, Radioactive Material Shipping Container 


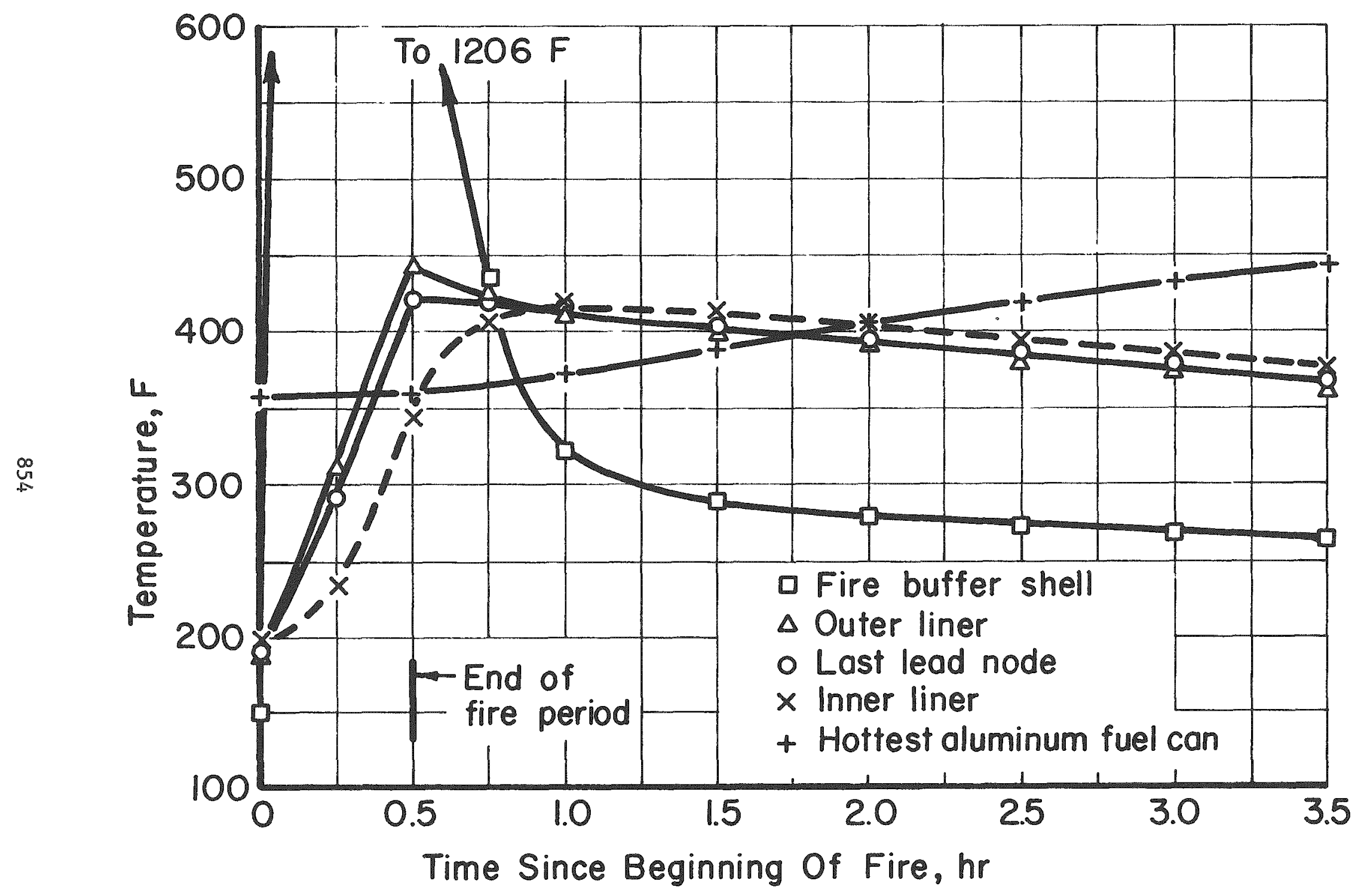

Fig. 2. Temperatures Versus Time for W\&K PB No. 1 Cask System (During and After Hypothetical Fire Accident) 


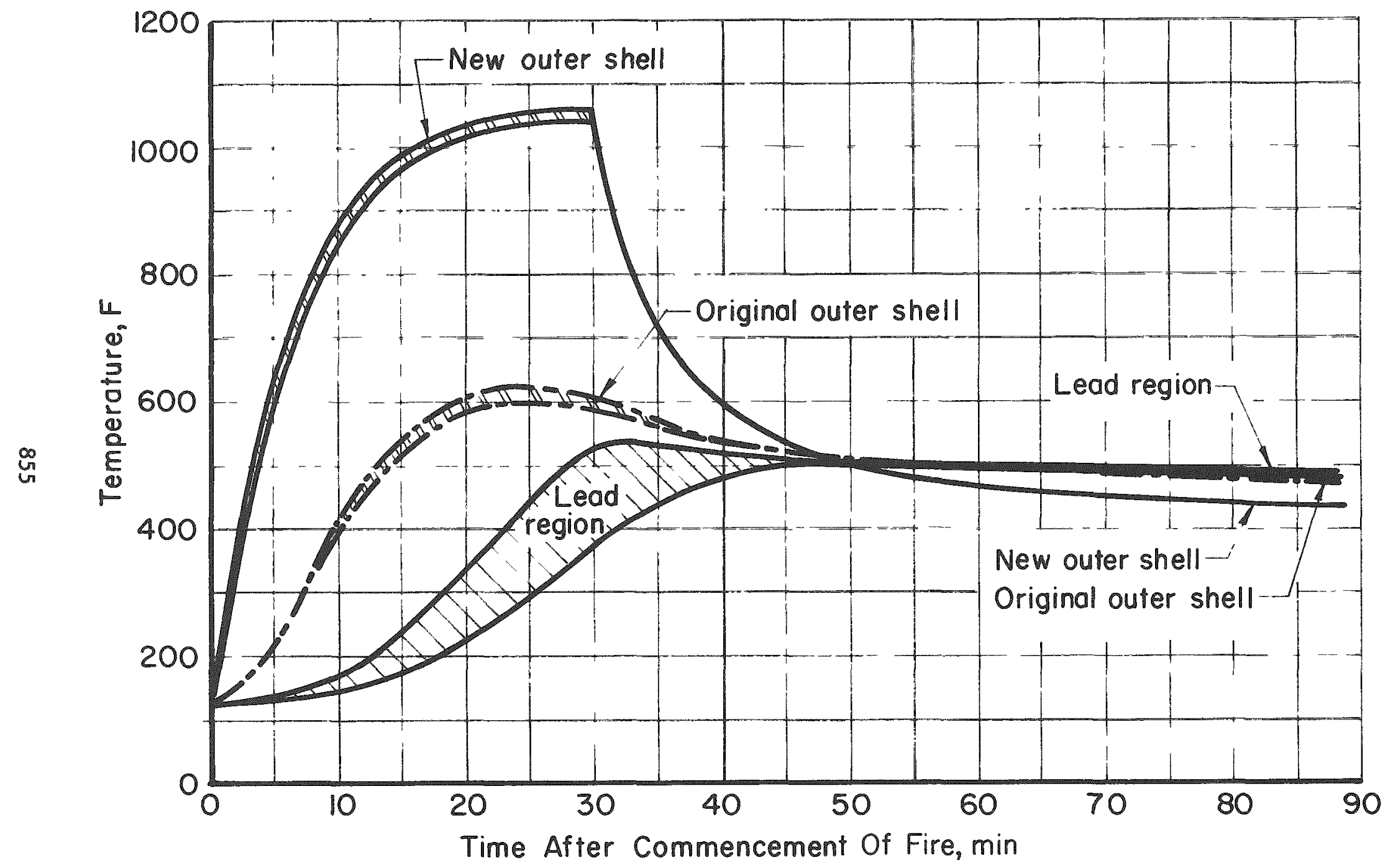

Fig. 3. Temperature History of the Cask Cylindrical Region for the ATCOR Cask 


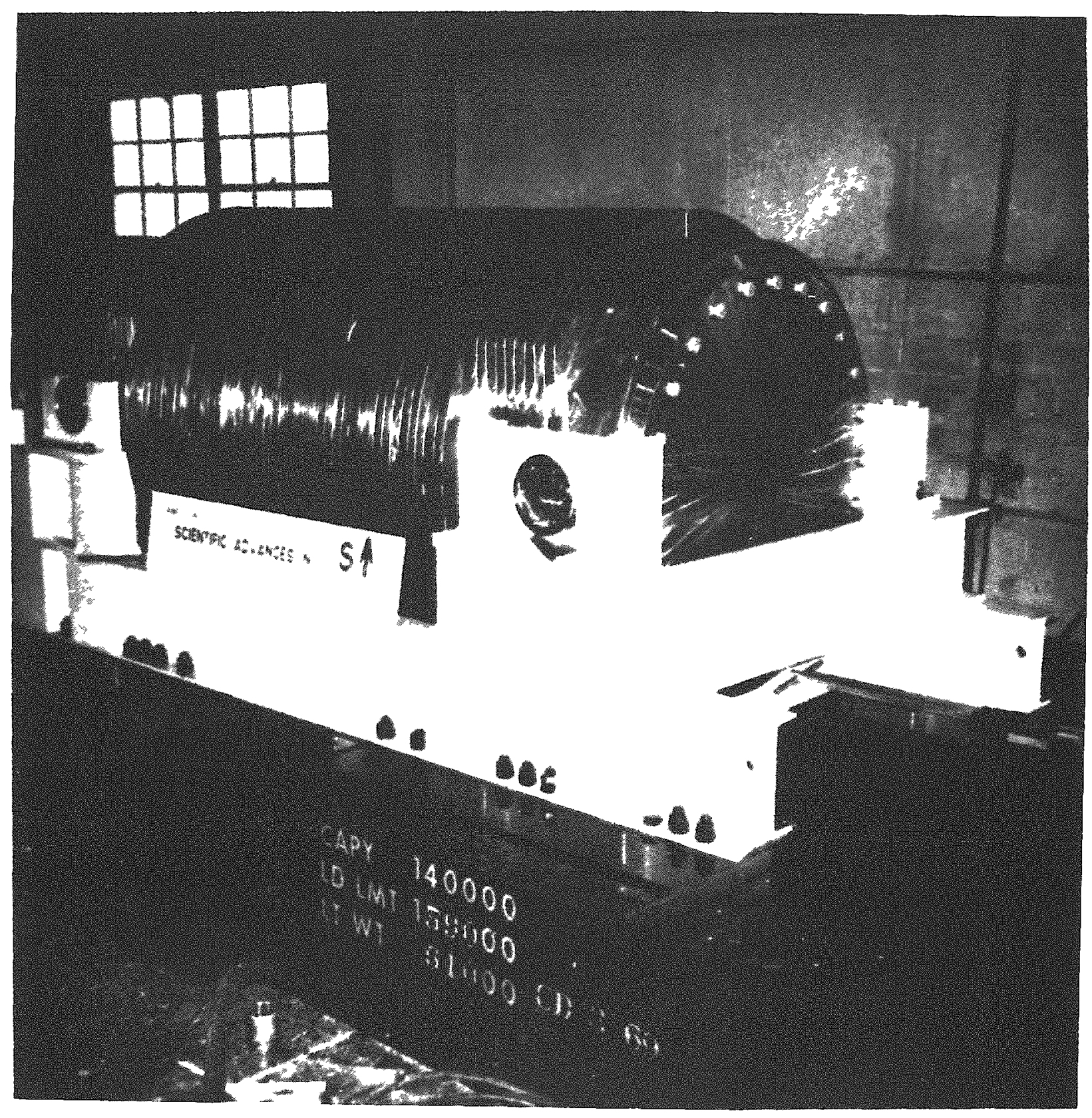

Fig. 4. NFS-M100 Cask System 


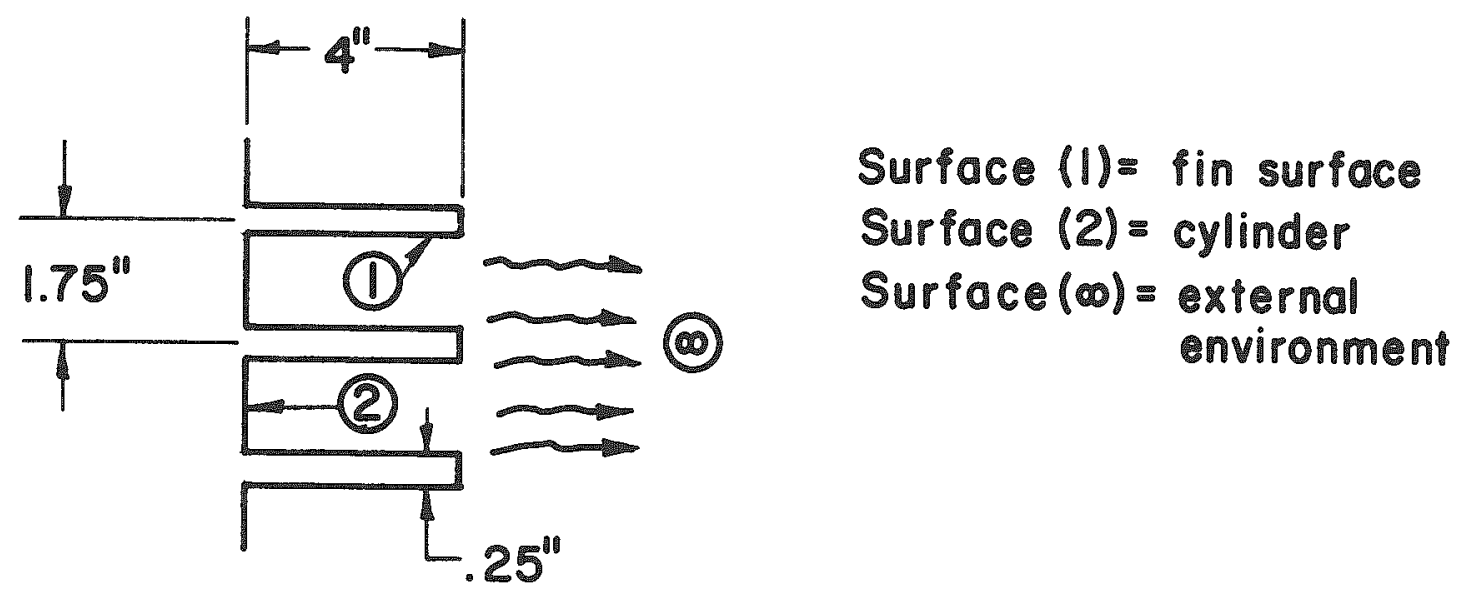

$$
\begin{array}{ll}
F_{G_{1-\infty}}=0.17 & F_{G_{2-\infty}}=0.18 \\
F_{G_{1-1}}=0.69 & F_{G_{2-2}}=0 \\
F_{G_{1-2}}=0.14 & F_{G_{2-1}}=0.42 \times 2^{*} \\
\Sigma_{F_{G}}=1.00 & \Sigma_{F_{G}}=1.00
\end{array}
$$

* Note that the cylinder sees iwo fins simultaneously

Fig. 5. Geometric View Factors for a Typical Fin-Cylinder Cavity 


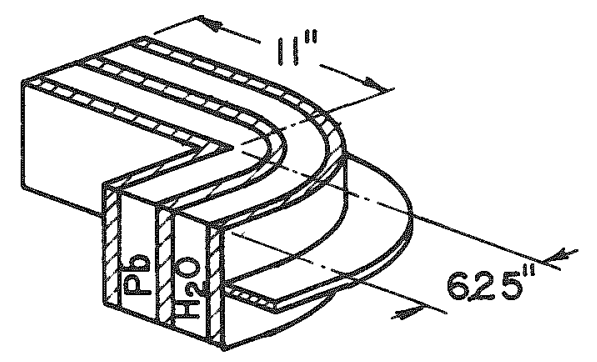

Inner liner $=0.75^{\prime \prime}$

Lead $=7.5^{\prime \prime}$

Outer liner $=0.5^{\prime \prime}$

Water $=6.0^{\prime \prime}$

Water jacket $=0.25^{\prime \prime}$

Fin height $=4.0^{\prime \prime}$
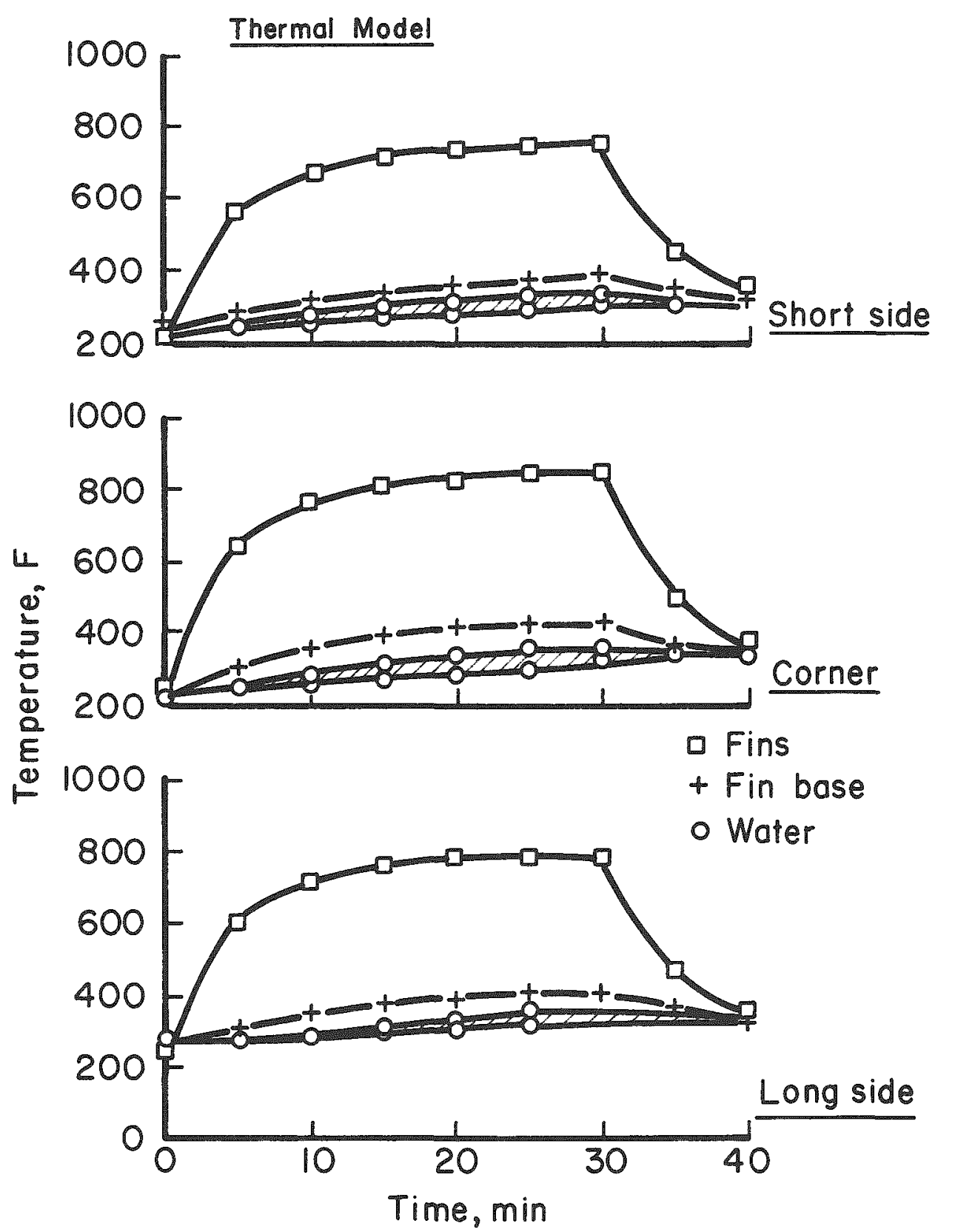

Fig. 6. Computed Temperature Histories for the NFS-1no Cask System 


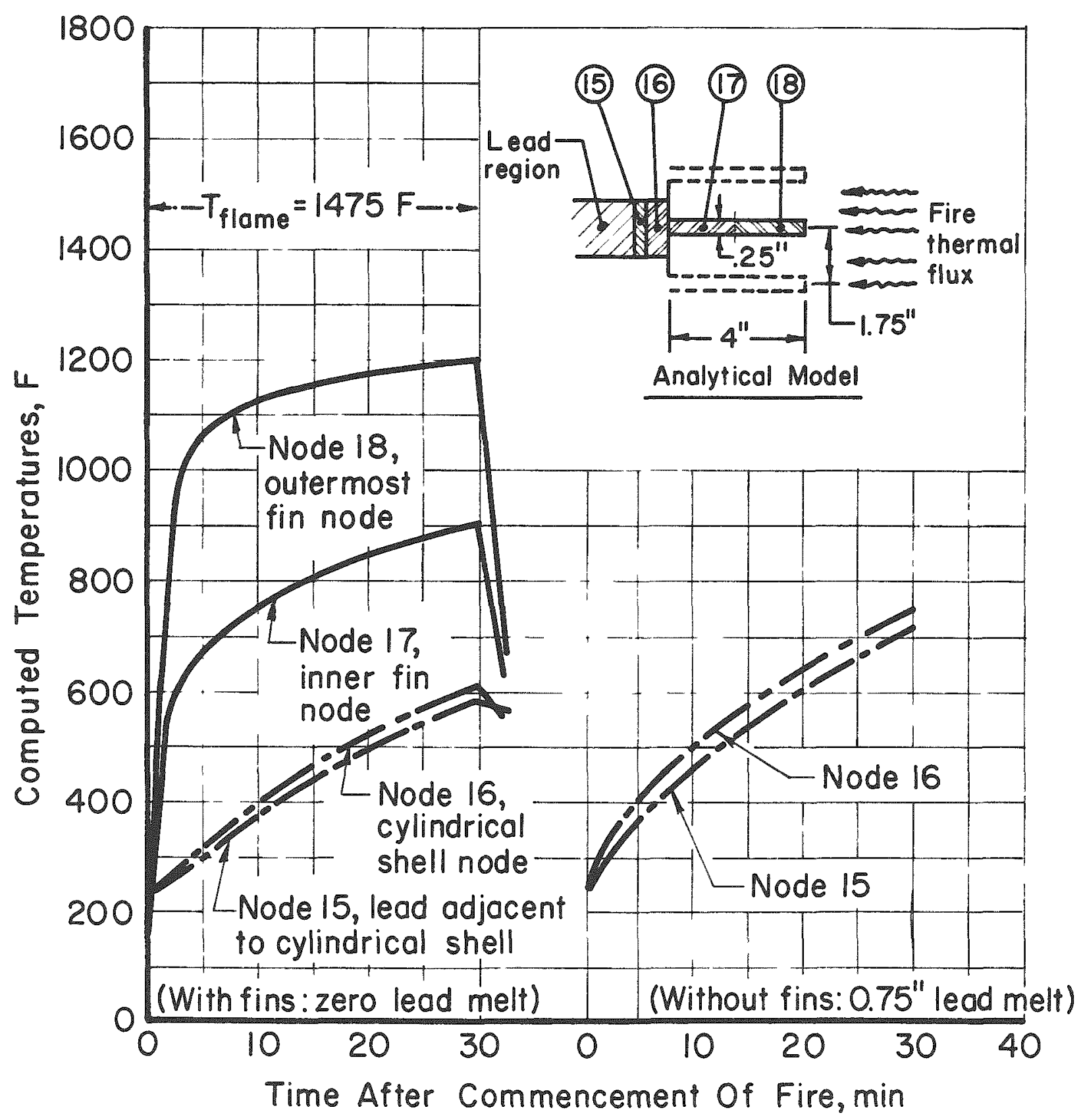

Fig. 7. Computed Temperature Histories for a Two-Element PWR Cask 


\section{EVALUATION OF PLUTONIUM PRODUCT FORM ON SAFETY DURING TRANSPORTATION}

$$
\text { I. M. Knights }
$$

This paper was not available at the time of printing. It has subsequently been issued as BNWL-SA-3906, available from NTIS, 5285 Port Royal Road, Springfield, Virginia 22151. 


\section{- DRUF TESTS OF SHIPPING CONAIAERE FUR PWT TYPE IEKW FUEIS}
บ. Sekj
S. Aoki
S. Nakata
S. Shimamura
I. Kanae
T. Koguchi

ABSTRECT

For the purpose of evaluating shock absorbing characteristics and structural integrity, a series of crop tests was conducted on two sizes of prototrpe shipping container for light water reactor new fuel assemblies. The No. I prototype container, which was designed to ship large PVE fuel assemblies, was drop tested from the height of up to $90 \mathrm{~cm}$ onto an essentially unyieloing horizontal surface installed at the Goverment Mechanical Laboratory of Japan, while the No. 2 prototype, which was designed to ship smell fuel, was drop tested from the height of up to $1.2 \mathrm{~m}$ and $9 \mathrm{~m}$. Decelerations at the fuel receptacle and the container shell, displacement of the fuel receptacle, and dimensional changes of shell were recorded ard evaluated.

\section{INTRODUCTION}

In the design of shipping containers for new fuel assemblies, the following two aspects are to be taken into account:

(1) Constructional integrity to meet the requirements of Sefety Regulations for shipping container concemed.

(2) Protection of fuel assembly from shocks and vibrations encountered during handling and shipping.

The constmactional integrity of the container will be more important and particularly because the shipping container for Pu-bearing $\mathrm{UO}_{2}$ new fuel 
assemblies for light water reactor falls in the classification of the type $B$ packaging (or the large quantity packaging). From the point of view of nuclear safety, the container shell must have excellent shock absorbing characteristics in order to prevent fuel rods from fallure at the time of $9 \mathrm{~m}$ drop, on the other hand it is required to have a rigidity to keep reasonable spacings between the fuel assemblies in damaged containers to avoid criticality.

In order to design effective shock absorbing suspension system, its transmissibility, T, must be small at the input frequency range. It can be more clearly understood by the following equations for forced vibration of a damped single degree of freedom system;

$$
T=\sqrt{\frac{1+\left(2 \zeta \frac{\omega}{\omega n}\right)^{2}}{\left(1-\left(\frac{\omega}{\omega n}\right)^{2}\right)^{2}+\left(2 \zeta \frac{\omega}{\omega}\right)^{2}}}
$$

and

$$
A=A_{0} I
$$

where, $\quad T=$ transmissibility

$$
\begin{aligned}
\omega & =\text { input frequency } \\
\omega n & =\text { undamped ratural frequency of system } \\
S & =\text { damping ratio } \\
A & =\text { resultant system acceleration } \\
A_{0} & =\text { input acceleration }
\end{aligned}
$$

To make the value of $\mathrm{T}$ small, $\mathcal{O}_{\mathrm{n}}$ must be small in compare with $\mathcal{U}$. However in practice, $W_{n}$ mst be so determined as to deviate the frequency range of $2 \sim 4 \mathrm{HZ}$, which nomally encounters at vehicle deck during transportation.

\section{-ESCRTPTIOR OF PROTOTYPE CONTAINERS}

Taking the above mentioned factors into account, prototype containers for trensporting new fuel assemblies were designed and fabricated. Principal 
particulars of the prototypes are shown in Table 1, while scheratic drawing is show in Figure 1. The prototype convainers tested consist basically of a split trpe horizontal cylindrical shell of steel plate ir which a fuel assembly (or two assemblies) is accormodated on a receptacle with shock absorbing means provided. Two sizes of production prototype, ito. I and Mo. 2 containers, were loaded with dumy loads simulatirg the weight of fuel assemblies and instmmented with accelerometers.

\section{Table 1. Erincipal Earticulars for Frototrpe Containers}

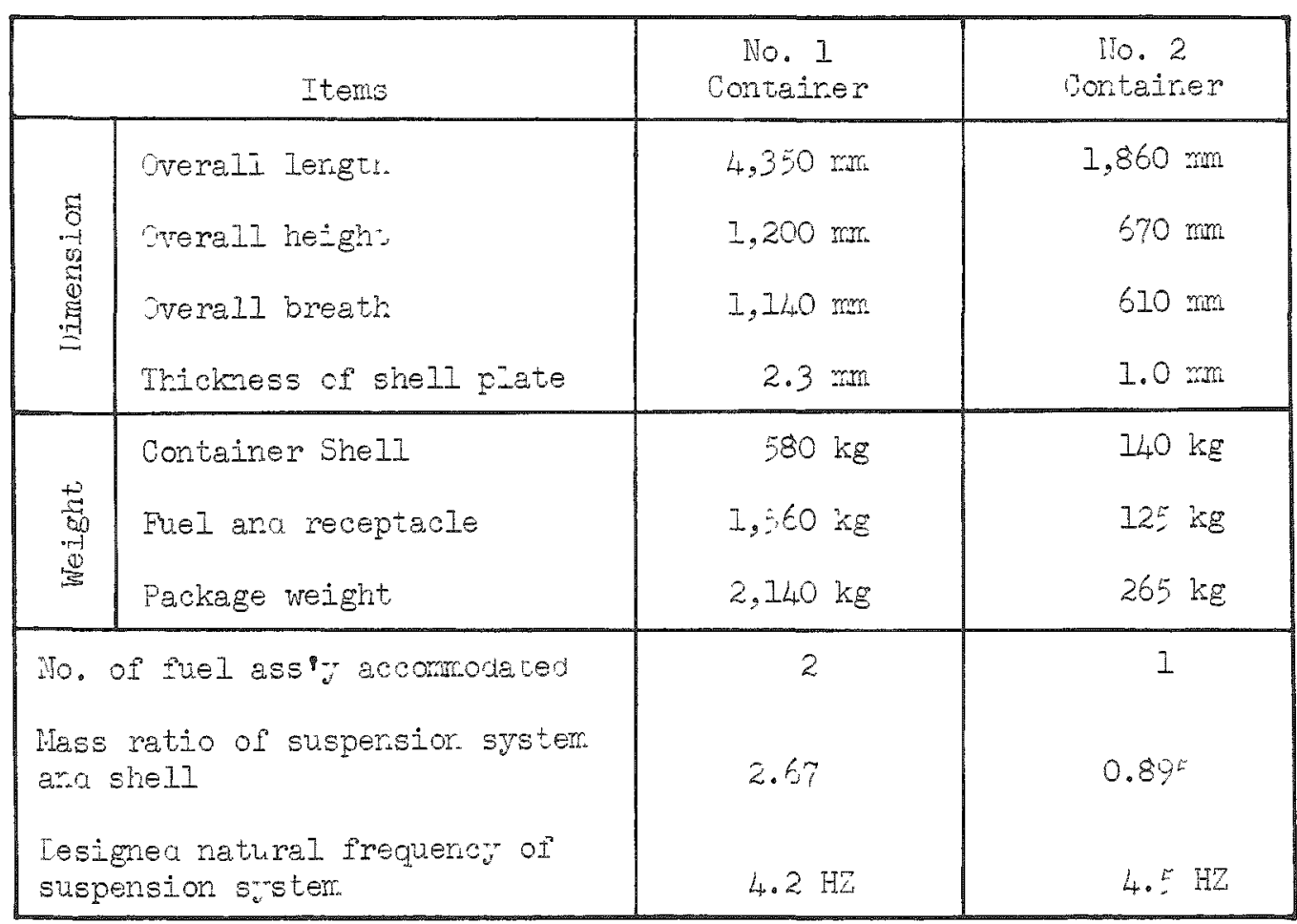

TESI FECILITY RIT EOUIDERT

Irop Test Facility

1. crop test facility insteliea at the Govemment irechanical Iaboratom of Japan built specially for arop testing spent fuel shipping cask models was employed. It essentielly consists of a steel tower with a lipung device of 10 tor - capacity and a target lavirg an essentially urieldirg horizontal surface as required by J.S. LDC and IAIf regulations. 


\section{Instumentation and Data Processing}

Strain gage and piezoelectric type accelerometers were fixed at the fuel receptacle and the container shell. Output signals from the accelerometers were amplified and recorded on a magnetic tape. The data stored were then filtered and reproduced in visible form by means of a recording oscillograph. A part of the data on the magnetic tape was recorded on continuous loops of magnetic tapes and analysed to yield power spectral density by means of a tracking analyser. For the detection of displacement of the fuel receptacle at the time of impact, simple displacement monitors were installed at the bottom of the container shell. Iynamic behaviors of the container were recorded by $16 \mathrm{~mm}$ cinecamera and high speed cinecamera.

\section{DROP TESTS}

\section{$1.2 \mathrm{~m}$ Drop Tests}

The No. I container was flat, comer and edgewise rotational drop tested up to the height of $90 \mathrm{~cm}$, while the No. 2 container was flat drop tested up to $120 \mathrm{~cm}$. Deceleration peaks measured at the shell and the fuel receptacle are plotted in Figure 2. Deceleration ratio of the receptacle and the shell, which is considered to be the transmissibility, $T$, of the receptacle is also plotted in Figure 2. Deceleration data recorded on continuous loops of magnetic tape were analysed and power spectral density diagrams were obtained. Typical examples of PSD diagram of the No. 2 containers are show in Figure 3. Displacement of the fuel receptacle due to the drop shock is plotted in Figure 4. Dimensional measurements of the shell before and after the drop tests have shown that there existed no appreciable deformations, and clamping bolts at shell flanges remained sound.

\section{9 m Drop Test}

The No. 2 container was so drop tested as the cover of the container flatly strikes the target. It comply with the requirements of the regulations 
for $9 \mathrm{~m}$ (30 ft) drop test since the meximum demage is expected when the cover flatly strikes the target. It is because the fuel spacings in the damaged containers are of primary irnortance for the nuclear criticality assessment, rather than the leak tightness of the container. Leceleration peak as high as $390 \mathrm{G}$ was recorded at the fuel receptacle. In Figure 5 and 6 results of dimensional measurement on the deformed container are shown. From above figures, it is clear that the container lost the volume considerably, but collapsed areas were confined to roughly one-half of the periphery of the cover. Cover clamp bolts remained sound, but leak-tightness was lost at flanges and some broken areas of the cover.

\section{DISCUSSIOISS AND RESULTS}

(1) Let Wi be the weight of fuel ard receptacle (suspension system) and Wo be that of she11. When the container drops from the height, 5 , then the potertial energy possessed by the conteiner, Is, is

$$
E=\left(w_{i}+w_{0}\right) H
$$

which is entirely transformed into kinetic energy, Ek, at the impact. Neglecting the losses, E equals Ek. From the deceleration-time-histories It is found that the deceleration peak of the fuel receptacle delayed certair amount of time from that of the shell. It implies that at the instant of impact, the container receives the kinetic energy equivalent to $E=$ WoH, rather than $E=\left(w_{i} \rightarrow\right.$ Wo $) \mathrm{H}$. find certain time later, the cortainer shell recelves the compressive force trensfomed from $\mathrm{EI}=\mathrm{WiH}$ through the suspension sprirgs. As a result, damage to the cortainer will be greatly reduced then in the case of container which has no elastic suspension system.

(2) Fuel receptacle suspension system showed superior shock isolation characteristics and demonstrated a correctness of design. 
(3) Use of elastic suspension systen reduced shocks to the shell also, thus minimizing the jamage of the shell.

(4) Relatively less rigid shell design greatly reduced shocks to the fuel receptacle at the $9 \mathrm{~m}$ drop test. It contributed much to the protection of fuel rods from failure.

(5) Collapse pattem and amount of collapse at the container shell may be affected by the relation between modulus of section of circumferential ribs and the radius of the shell.

AGKNONLEDGEMENTS

Tharks are due to Dr. Murematsu who helped us in the work of high-speed cinematogrphy.

\section{PEFERENCES}

1. S. Aoki, IAEA/SM-I 47/3 Experimental Studies on the Spent Fuel Shipping Cask in Japan, Proc. IAEA Seminar on Test Requirements for Dackaging for the Transport of Radioactive Materials, Feb. 1971. 

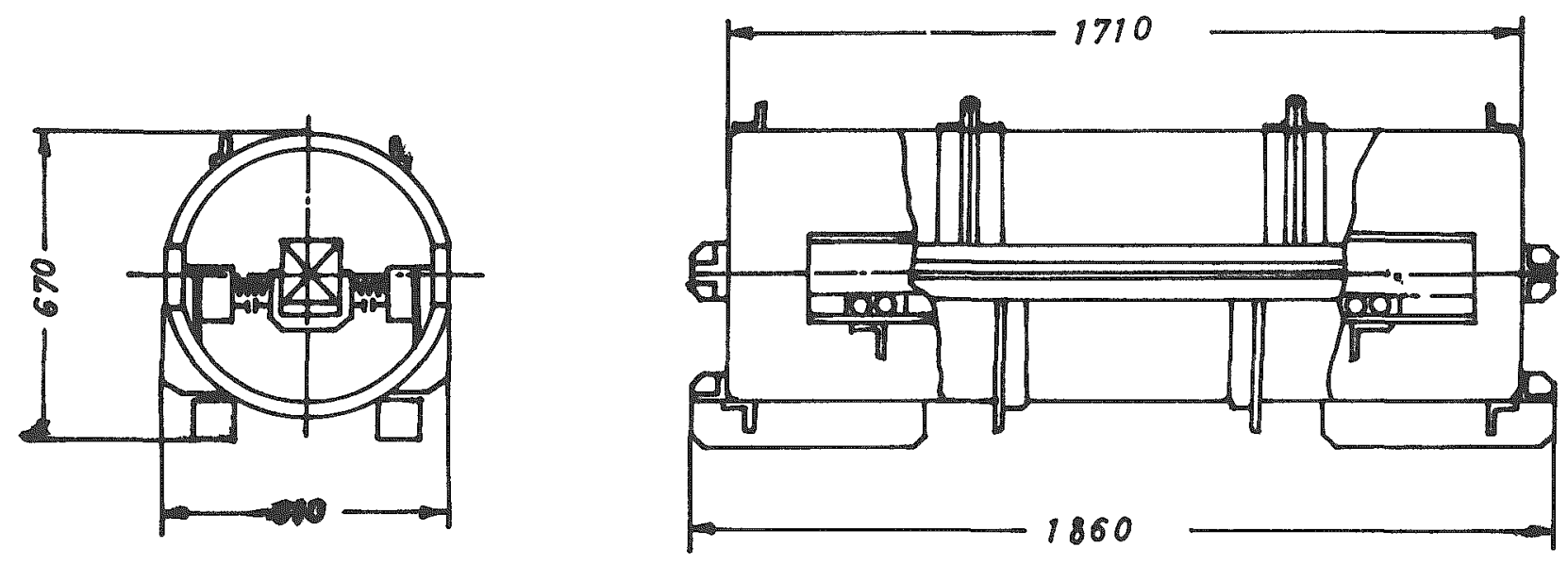

NO.2 CONTAINER

$\stackrel{\circ}{g}$
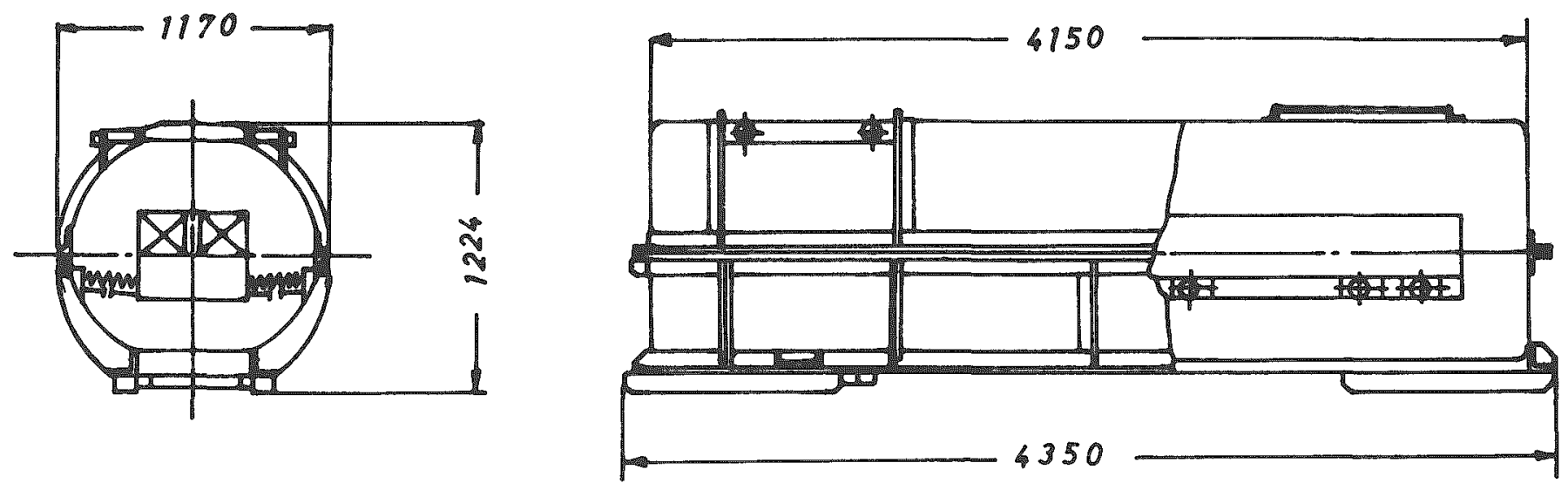

NO. 1 CONTAINER

Fig. 1. Schematic Nrawing of No. 1 and No. 2 Containers. 


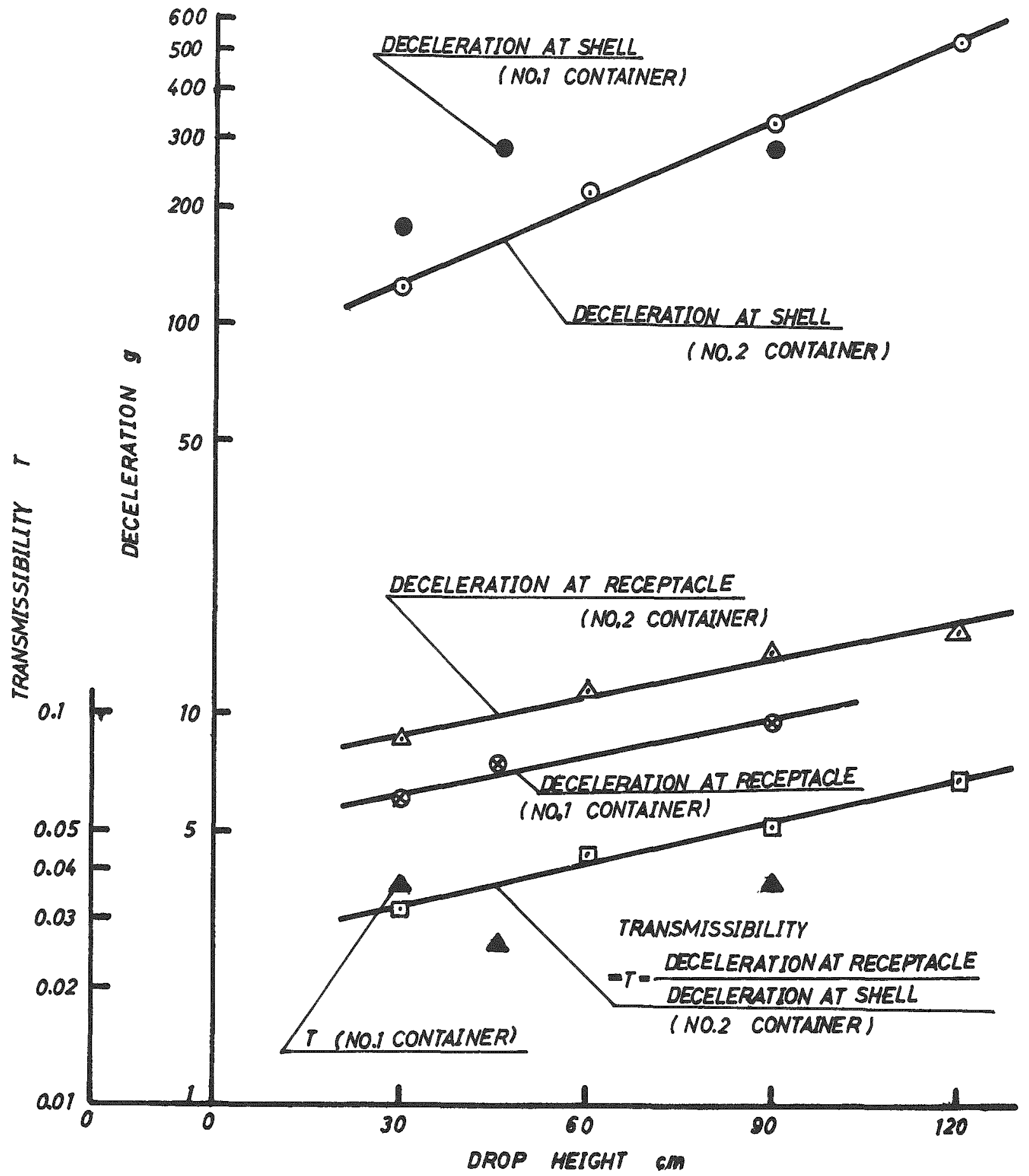

Fig. 2. Iecelerations Measured at Fuel Receptacle and Shell VS. Drop Height, and Transmissibility VS. Drop Height. 


\section{NO.2 CONTAINER}

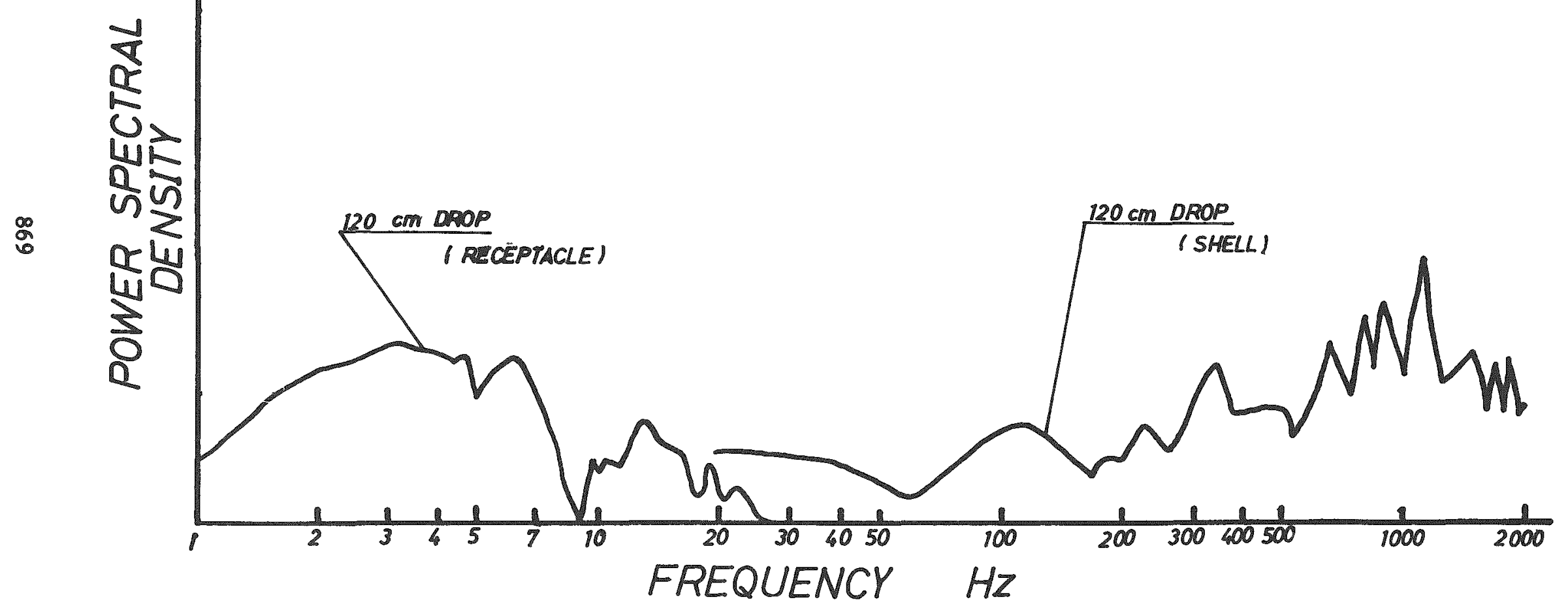

Fig. 3. Power Spectral vensity Jiagram of neceleration at $120 \mathrm{~cm}$ Urop Test for No. 2 Container. 


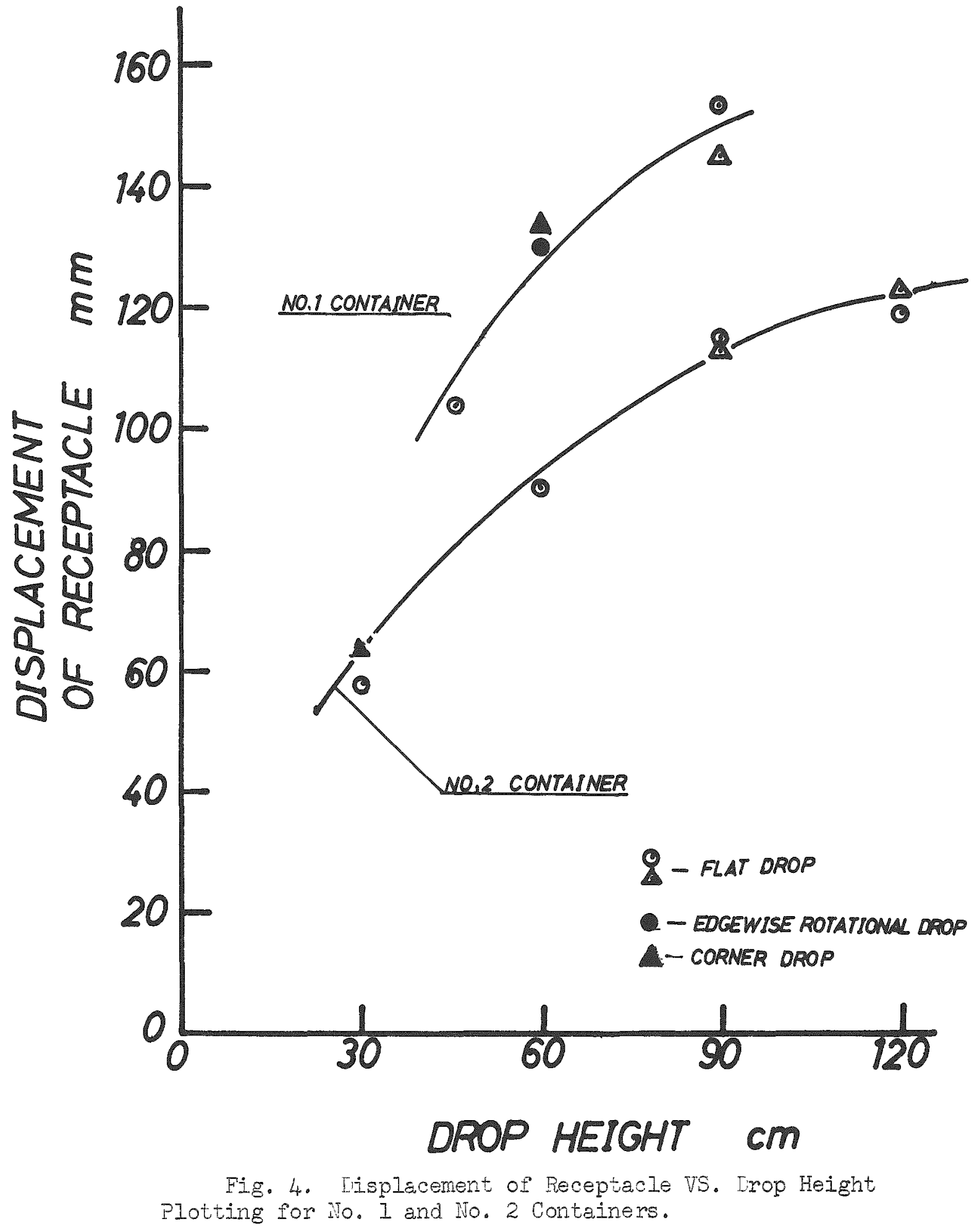




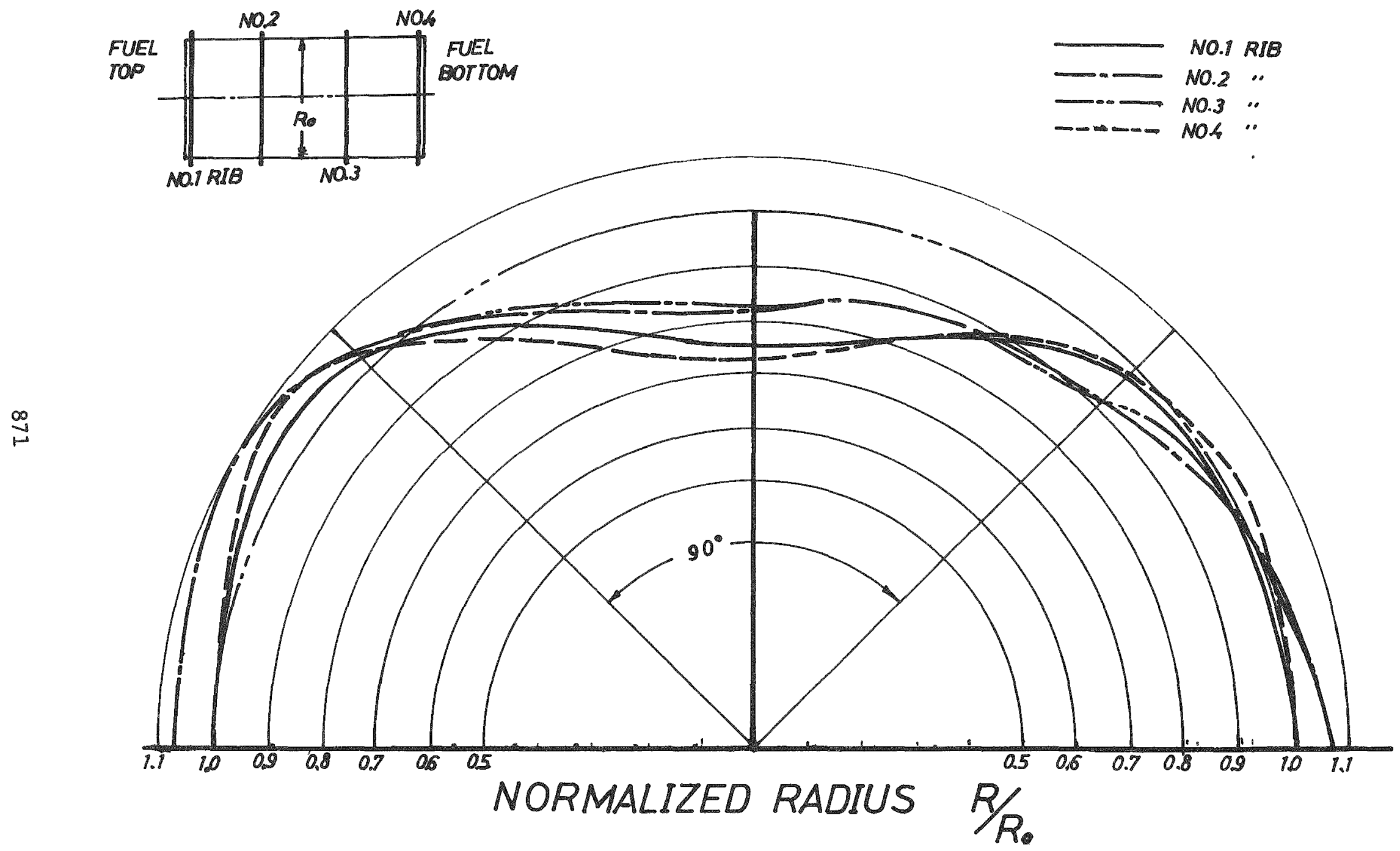

Fig. 5. Plastic Deformation of Circumferential Ribs after the Crash. 


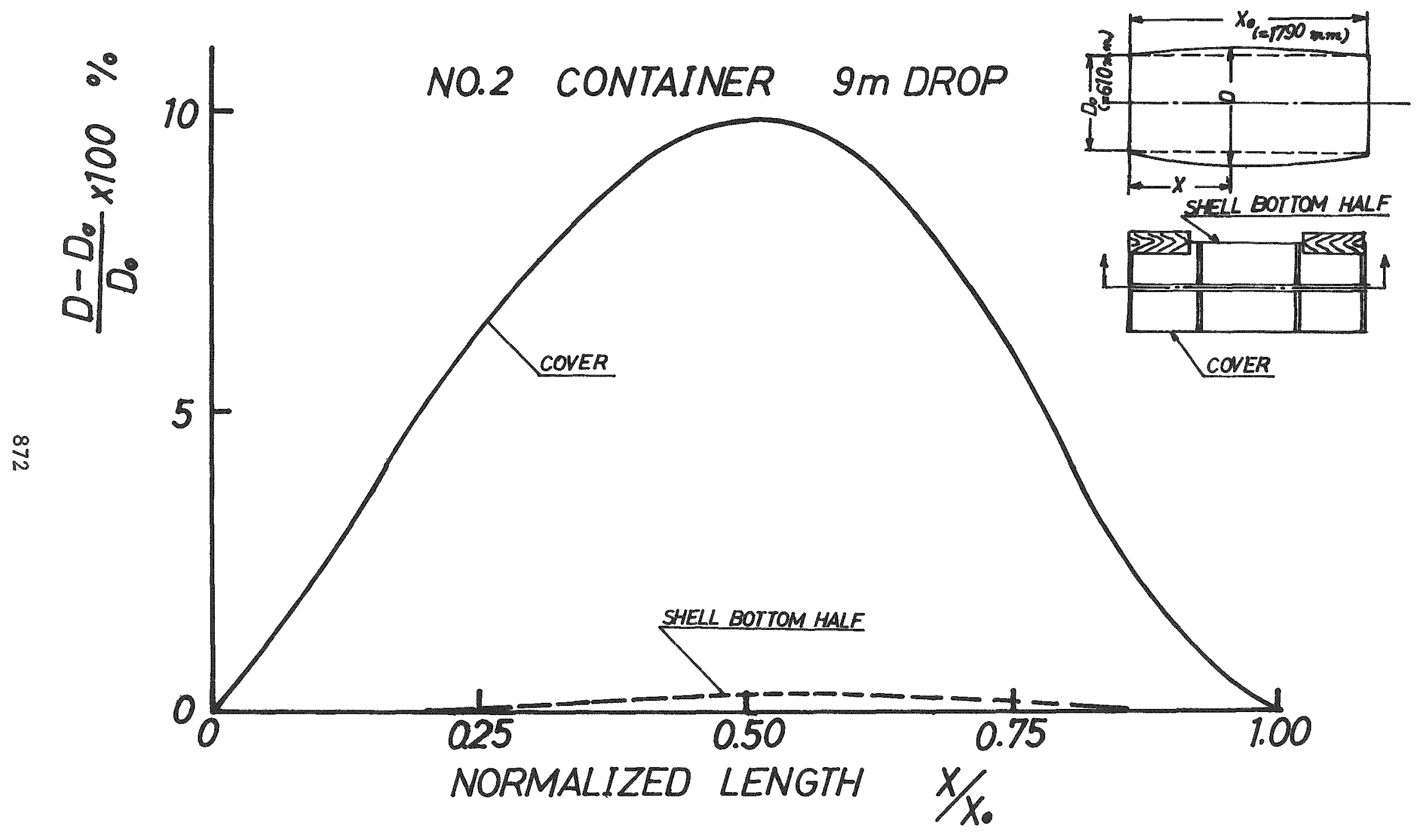
Crash.

Fig. 6. Plastic beformation of Shell planges after the 
1 SHIPPING PACKAGE FOR UNIRRADIATED POWER REACTOR FUEI ASSEMBIIES

R. E. Kropp

ABSTRACT

A package for the shipment of unirradiated power reactor fuel assemblies was designed, tested and then used during the past four years. This package is identified as model UNC 2800 and was issued DOT Special Permit No. 5419. Evaluations were performed using criteria set forth in the REC and DOT Regulations for fissile material packages. Nuclear safety analyses were performed using empirical techniques. Although less exacting than computer analyses, these techniques yieled conservative results. Operating needs resulted in modification of the loading of this package. Nuclear safety analyses associated with this modification were performed using reactor design computer codes.

\section{INTRODUCTION}

A shipping package for unirradiated, low enrichment uranium, power reactor fuel assemblies was designed and tested in 1967. It was developed to provide a single package type for the shipment of Boiling Water Reactor (BWR) or Pressurized Water Reactor (PWR) fuel assemblies at enrichments up to $2.34 \%$ and $3.5 \%$ respectively. Operational requirements included ease in loading and unloading plus a replaceable assembly holder. Modes of transport were to be motor vehicle and rail. Plans called for a ten-year life span for this package prior to replacement by advanced design models. 
The package consists of a U-shaped strongback fuel assembly support 9 inches high by 10 inches wide by 192 inches long constructed of 7-gage steel and also having adjustable end clamps and cross support brackets. The fuel assembly support is shock mounted to an outer container by shear mounts. The outer container is a 12 -gage steel cylinder 36 inches I.D. by 207 inches long with a flange closure, skids, stacking brackets and roll rings. The package is identified as model UNC-2800 and issued DOT Special Permit No. 5419.

\section{DESIGN AND TESTING}

\section{Basic Design Criteria}

Original design requirements were that individual packages hold either two BWR fuel assemblies or one FWR fuel assembly and that packages could be shipped in truck load quantities while meeting the criteria for Fissile Class II and III shipments. Structural requirements were established such that the container woula meet the U. S. Atomic Energy Comission's hypothetical accident conditions and the U. S. Department of Transportation's Special Test Criteria for Type B Packages. The package was required to hold a 1,510 pound load (net weight). After construction, the empty package weighed 2,340 pounds (tare weight) resulting in a gross weight of 3,850 pounds. Structural Evaluation

\section{Test Description}

The steel inner container was loaded as shown on Figure 1 with metal dumy fuel assemblies to simulate the weight of the SNM bearing material for which this package would be used. The inner container and the outer container were then sealed in the same manner as that for shipments. The loaded package first was dropped 40 inches upon a 6-inch diameter by 8-inch high steel spike as shown on Figure 2. The container was dropped on the bottom center of a welded seam. A 30 foot free fall test was next conducted in the facilities of a neighboring scrap yard. The package was raised by a crane to a 30 foot 
height at approximately a $45^{\circ}$ angle from the end as shown on Figure 4. The height was ascertained by a premeasured weighted cord hanging fxom the container. A quick release mechanism was utilized to unlatch the package which fell perfectly at approximately a $45^{\circ}$ angle landing on the bottom cornex of the container. A second 30 foot drop test was then made. The package was oriented to fall flat upon one flanged side where the top and bottom shells were joined as shown on Figure 7 . The drop test was perfectly executed and the package fell horizontally on the intended flange.

Thermal and water immersion tests were not performed. These tests were omitted since: (1) only materials which will not thermally decompose would be shipped in these containers, and (2) the nuclear safety of individual packages and arrays was to be evaluated assuming the in-leakage of water. Test Results

After the puncture test, the package experienced a three inch deflection in the impact area, deforming uniformly up to the central roll rings. There was no evidence of any damage to the welded joint. The results of this test are best shown on Figure 3. The corner free fall test caused significant crumpling at the impact end of the package. The end roll ring deformed first and then broke off the package. The shell itself on the corner was crumpled approximately five inches. The deformation did not extend significantly back to the package shell. There was some indication, due to bumps in the outer shell, that some movement of the strongback brackets had taken place. The results of this test are shown on Figures 5 and 6 . The side free fall test resulted in mostly superficial damage. The fork truck lifting brackets which are welded to the outerside of the package for lifting and stacking purposes were crushed. But there was no indication of damage to the flanged joint except the one end where the flange was dented slightly and the corner bolt sheared off. There was additional indication that movement of the internal strongback brackets had taken place. Results of this test are shown on Figure 8. 
Upon removing the top cover it was observed that the durmy fuel assemblies were in place in the strongback channel. All internal clamps holding the dunny fuel assemblies down were in place. There had been approximately a 3/4-inch shift of the end brackets securing the ends of the dumny fuel assemblies at the end where the package fell during the $45^{\circ}$ angle test. There was evidence of damage to the outer shell at the joints where the gusset brackets of the strongback had moved laterally into the shell. This lateral movement is made possible by the shock mount installation. The shock mount brackets on both the strongback and the shell were significantly deformed and some of the bolts securing the shock mounts to the shell brackets had sheared off. The shock mount, however, had returned the strongback to the approximate center position of the shell. There was a two inch lateral displacement of the strongback toward the flange side that impacted, and the end opposite the $45^{\circ}$ impact point experienced a two inch downard drop. The effects of the tests on the inside of the container are best shown in Figures 9 and 10 . It appears that the dunmy fuel assemblies after undergoing two 30 foot drop tests experienced two inch lateral and vertical displacements within the 36 inch diameter shell and that the external deformation was so limited as to prevent any other packages from approaching the fuel location closer than would occur with an undarnaged package array.

\section{Nuclear Safety Considerations}

Original nuclear criticality safety evaluations were performed using the Density Analog Method. ${ }^{1}$ Optimum water moderation in the interstices of the fuel assemblies was assumed under both normal and accident conditions. Although fuel assemblies are shipped dry, this assumption yielded conservative analytical results. Also, the neutron absorption effects of the steel in the package were neglected. Results of this analysis are shown on Table 1. 
Based on the size and weight, 40 packages were selected for fissile Class II Shipments. This resulted in a 1.0 Transport Index based on the " 40 urit" rule which was changed to a 1.3 Transport Index upon adoption of the "50 unit" rule. Table 1. Nuclear Safety Results Based on Density Analog Calculations

\begin{tabular}{llcccc}
$\begin{array}{c}\text { Assembly } \\
\text { Type }\end{array}$ & $\begin{array}{c}\text { Transport } \\
\text { Conditions }\end{array}$ & $\begin{array}{c}\text { Moderation } \\
\text { Ratio } \\
\text { (H/U-235) }\end{array}$ & $\begin{array}{c}\text { Number of } \\
\text { Containers } \\
\text { Critical }\end{array}$ & $\begin{array}{c}\text { Allowable } \\
\text { Fissile } \\
\text { Class II }\end{array}$ & $\begin{array}{c}\text { Allowable } \\
\text { Fissile } \\
\text { Class III }\end{array}$ \\
\hline BWR & Normal & 165 & 4320 & 864 & 2160 \\
BWR & Accident & 165 & 2459 & 1229 & 2458 \\
PWR & Normal & 121 & 1555 & 311 & 778 \\
PWR & Accident & 121 & 932 & 465 & 931 \\
\hline
\end{tabular}

RECENT MODIFICATIONS

In 1970 , it was desired to increase individual container loadings from two to four BWR fuel assemblies to reduce shipping costs. Also, transportation modes needed to be extended to include aircraft and vessel. Additional structural evaluation was not required since the proposed load (net weight) did not exceed that oxiginally tested. Revised nuclear criticality safety evaluations were performed using reactor design computer codes. This was done to factor in the neutron absorption effects of the steel in the package. Individual containers and arrays of them are not considered hydrogen moderated and, therefore, are subcritical. Under accident conditions, water inleakage is possible. Accident condition analysis was performed using a combination Transport-Diffusion Theory Model. This model uses the LOCALUX $-3^{2}$ Code to determine the diffusion coefficient and macroscopic cross sections for the fuel-moderator-inner container region and within the outer container region. Diffusion coefficients and macroscopic cross sections for the regions between the inner and outer container and outside the outer container were calculated using the FORM ${ }^{3}$ and TEMPEST ${ }^{4}$ Codes. Array infinite multiplication factors and critical buckling were then obtained using the AIM-6 Diffusion Code (an 
extension of AIM-55). The results shown on Table 2 indicate that the infinite multiplication factor is less than unity under all cases. The maximum infinite multiplication factor occurs with optimum water moderation in the interstices of the fuel assemblies and no water between inner and outer portions of the container or between individual packages. Increasing water density between inner and outer container and increasing water thickness between individual packages results in decreased infinite multiplication factors.

Since the infinite multiplication factor is less than unity for all conditions, this package was shown to meet the requirements for Fissile Class I for BWR fuel assemblies.

SUMMARY

Four years operational experience with this package has been good. It has proved to be the versatile package it was designed to be. Anticipated future modifications include the shipment of longer assemblies and assemblies with increased enrichments. The use of advanced computer codes with Monte Carlo considerations also should provide more accurate assessments of the nuclear safety of individual packages as well as arrays of them.

\section{ACKNOWLEDGEMENT}

The assistance of Mr. E. Fass of the Research and Engineering Center for his aid in obtaining computer analysis is gratefully acknowledged. 
Table 2. Koo Vs. Amount of Water Between Inner and Outer Container and Water Outside the outer Container

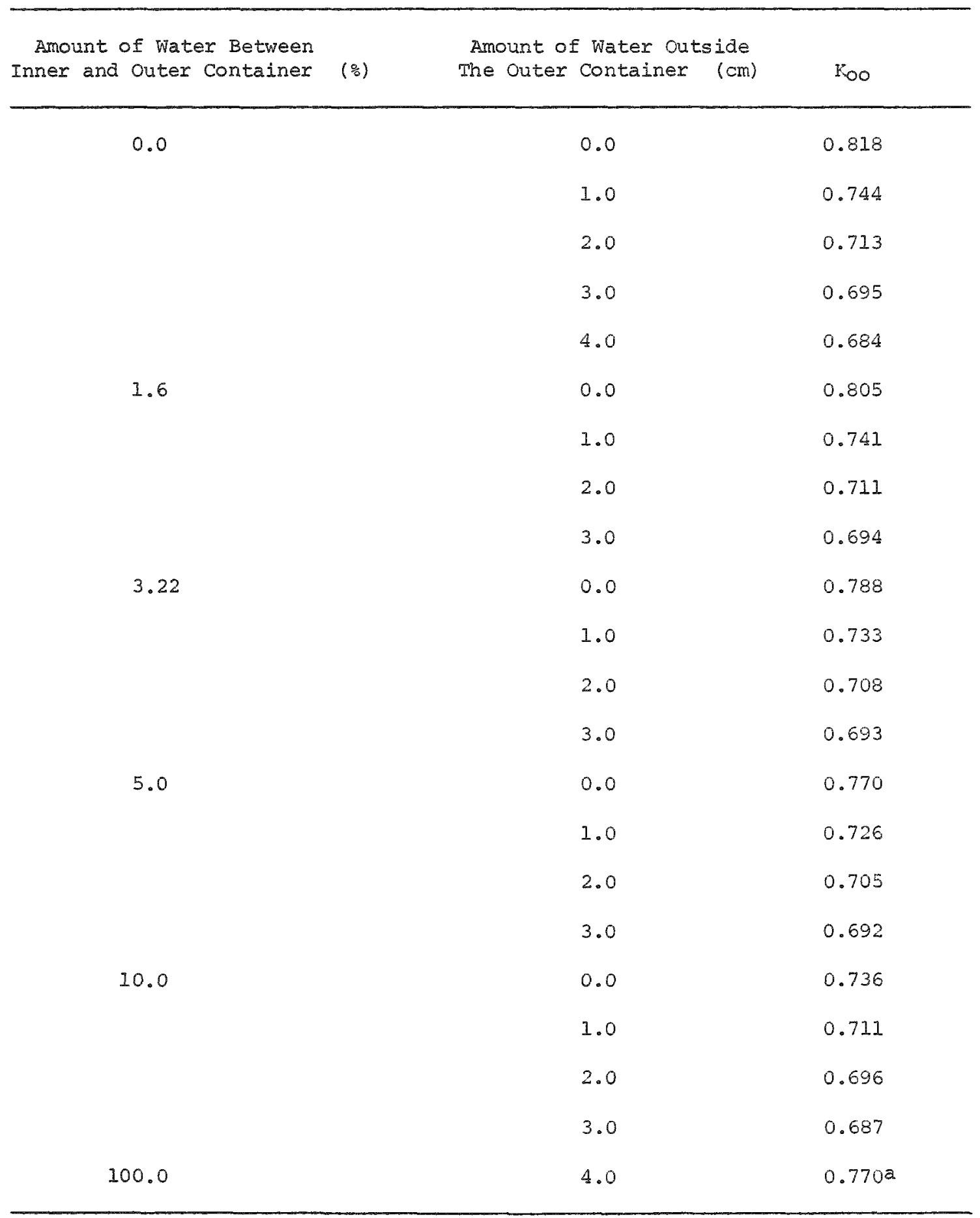

aNote that flux is assumed to be zero at the boundary. 
REFERENCES

1. H. C. Paxton, Criticality Control in Operations with Fissile Material, IA-3366 (January 1966)

2. S. Kellman and R. R. Calabro, LOCALUX-3-A Depletion Program for Multizoned Reactor Assemblies, UNC-5230 (July 1969)

3. D. J. McGoff, Form - A Fourier Transform Fast Spectrum Code for the IBM-709, NAA-SR-Memo-5766 (September 1960)

4. R. H. Shudde and J. Dyer, TEMPEST - II - A Neutron Thermalization Code, AMTD-111 (June 1962)

5. H. P. Flatt and D. C. Baller, AIM-5 - A Multigroup one Dimensional Diffusion Theory Code, NAA-SR-4694 


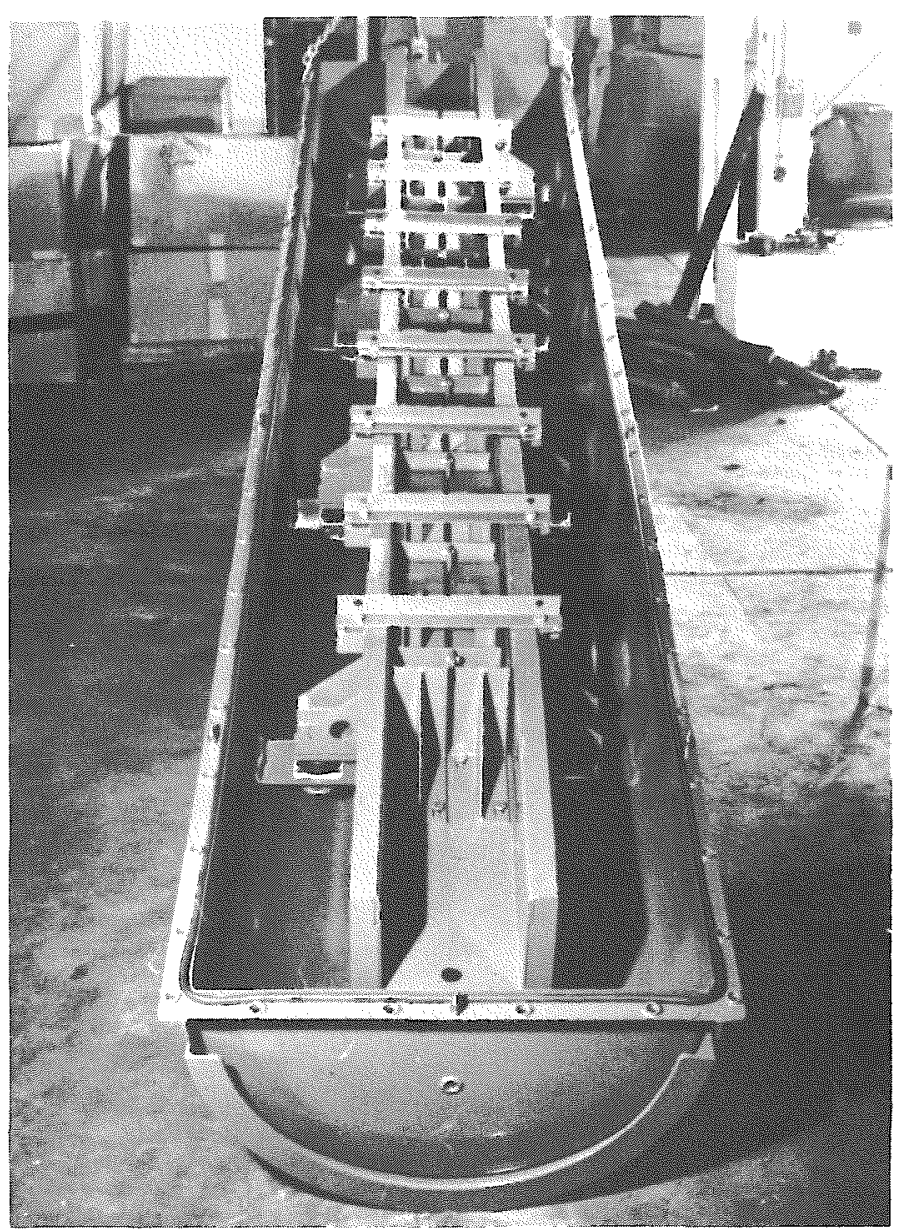

FIGURE 1 - COntainer Open shewing Durmy Lead - CONTAINER UNC-2800

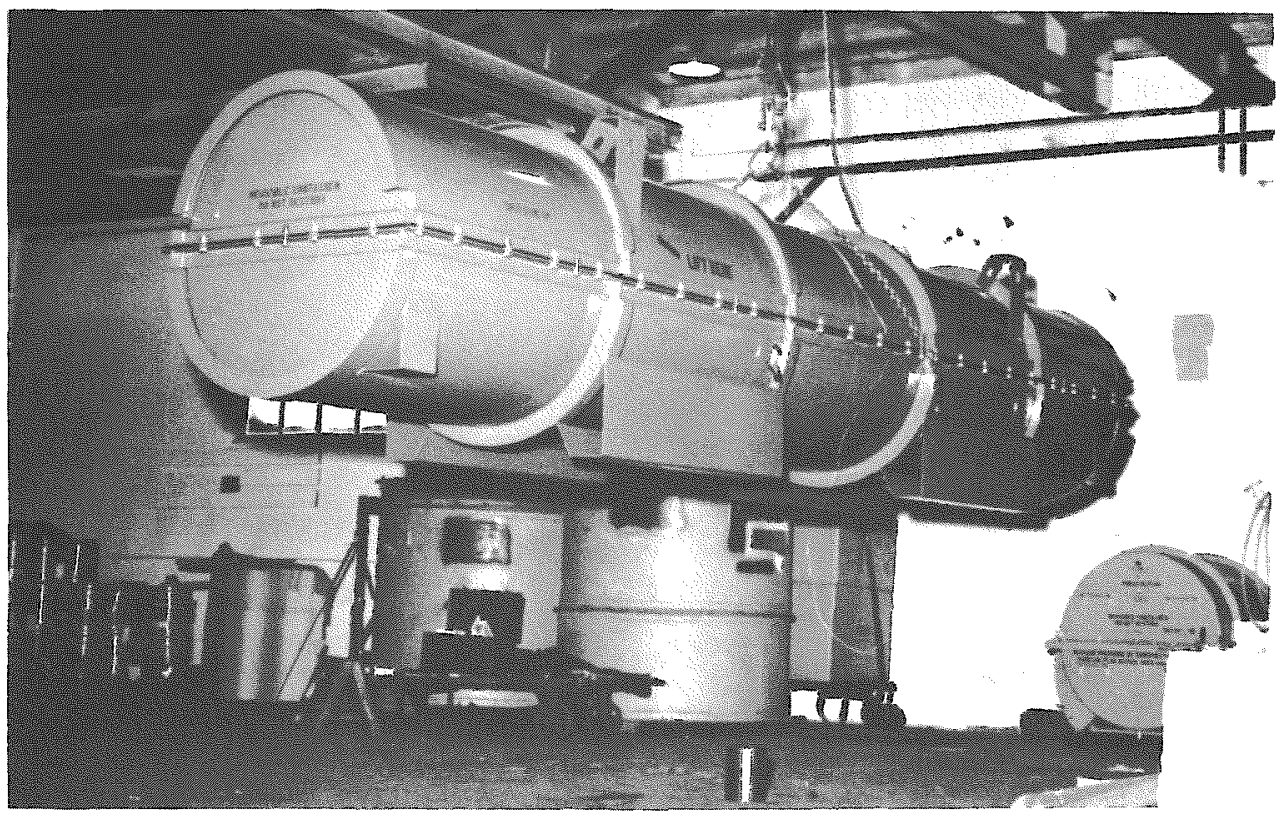

FIGURE 2 - Container at glevation Prior to Puncture Test 


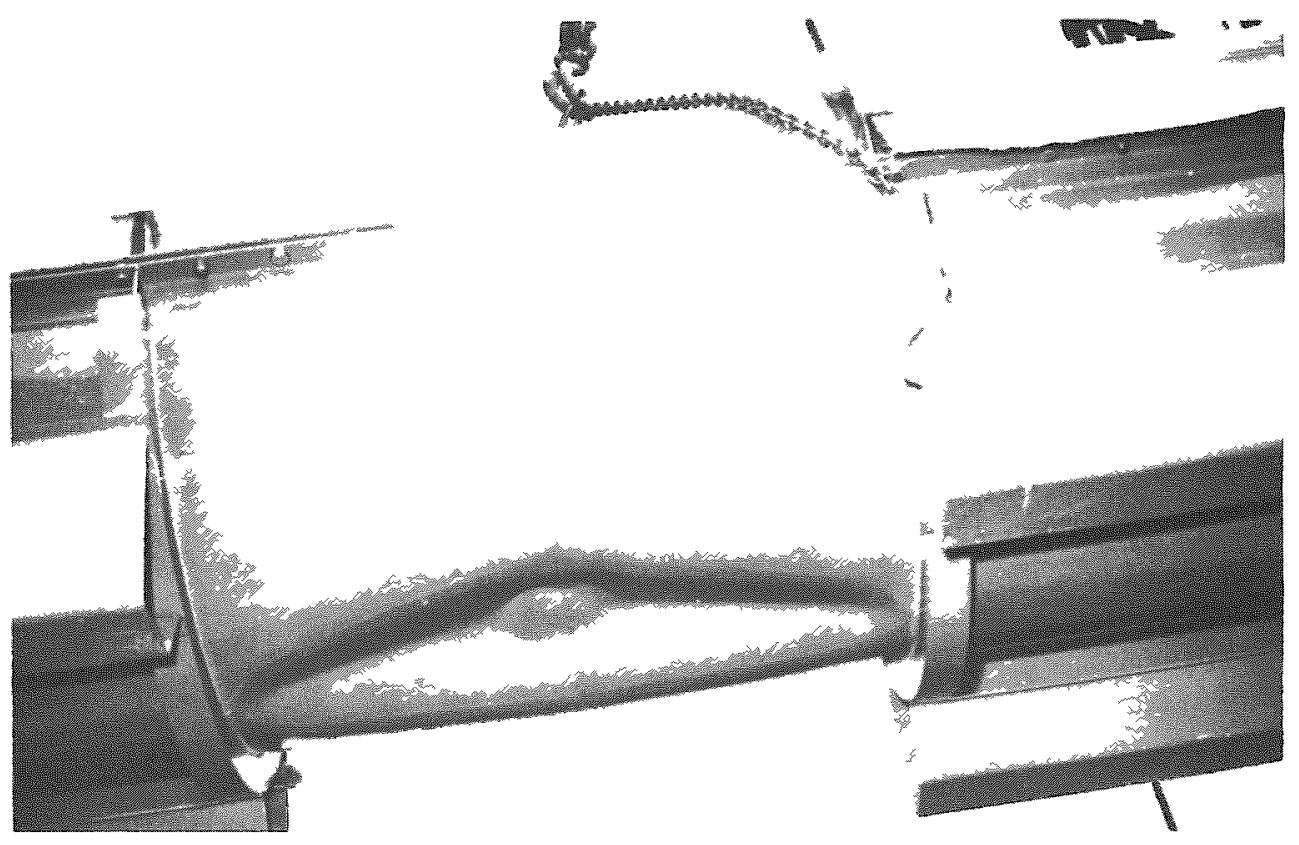

FIGURE 3 - DeFram tson After Puncture Test

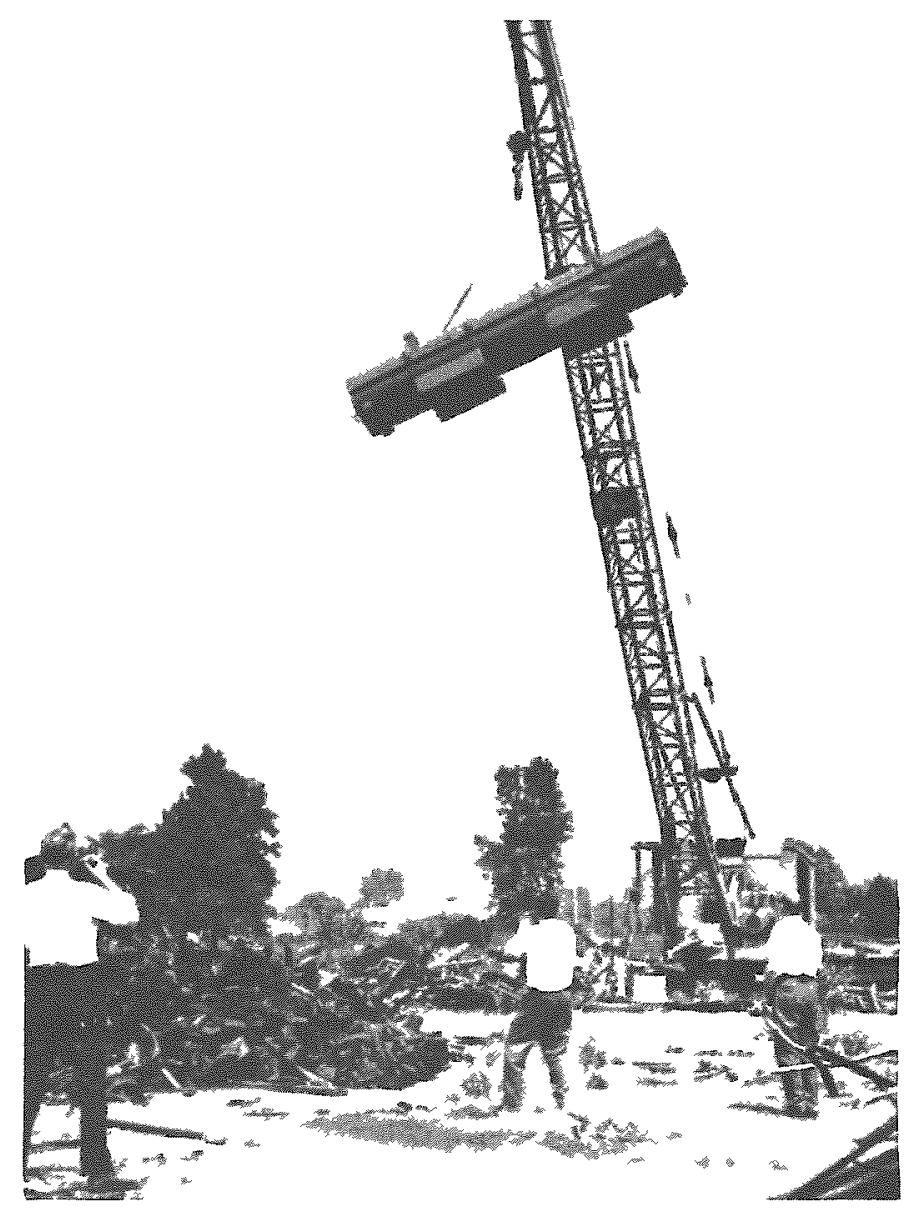

PIGuRE 4 - Contaner at Elevation Prior to Corner Free Fall Test 


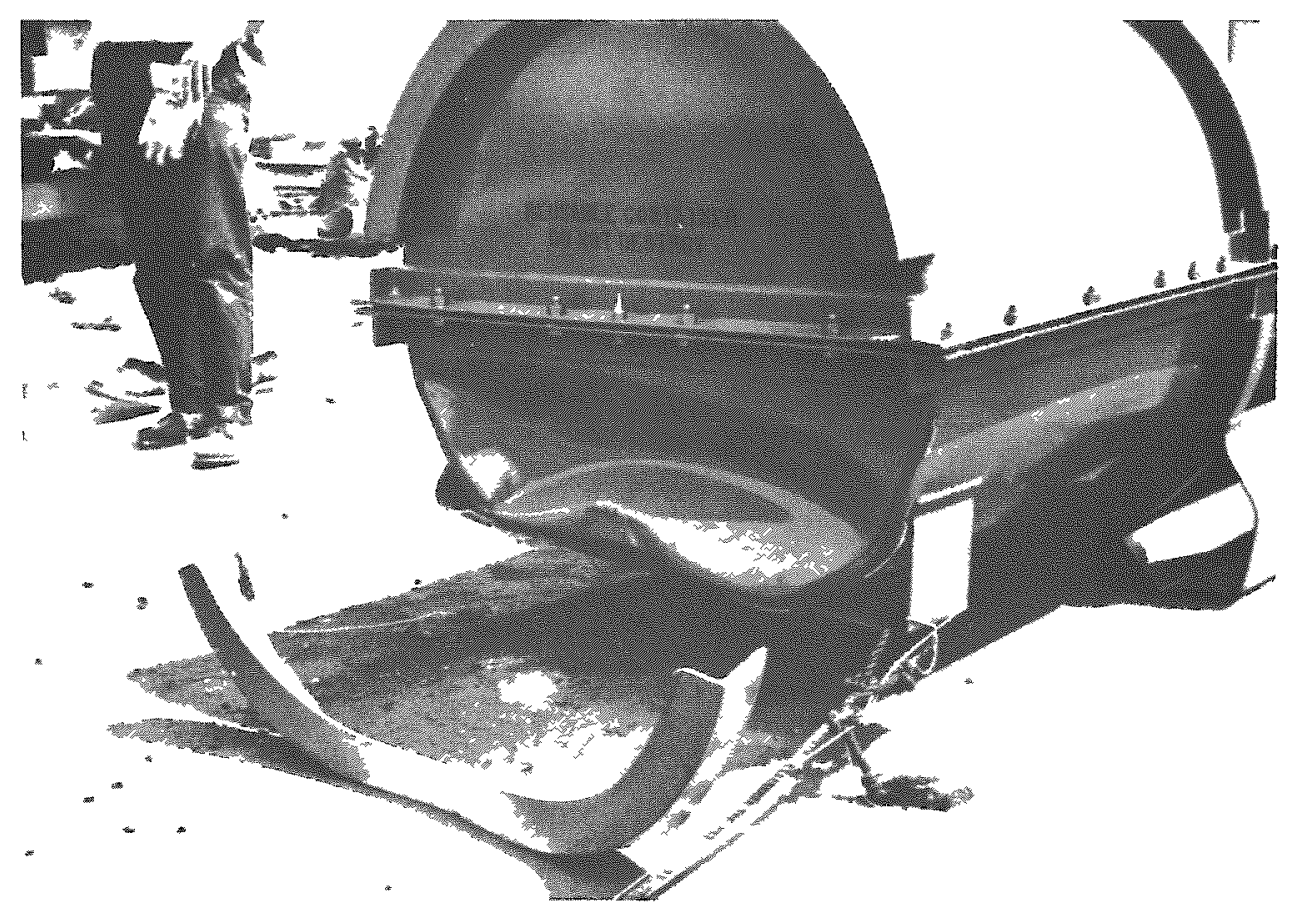

FIGURE 5 - Deforwation Due to Corner Free Pell Test

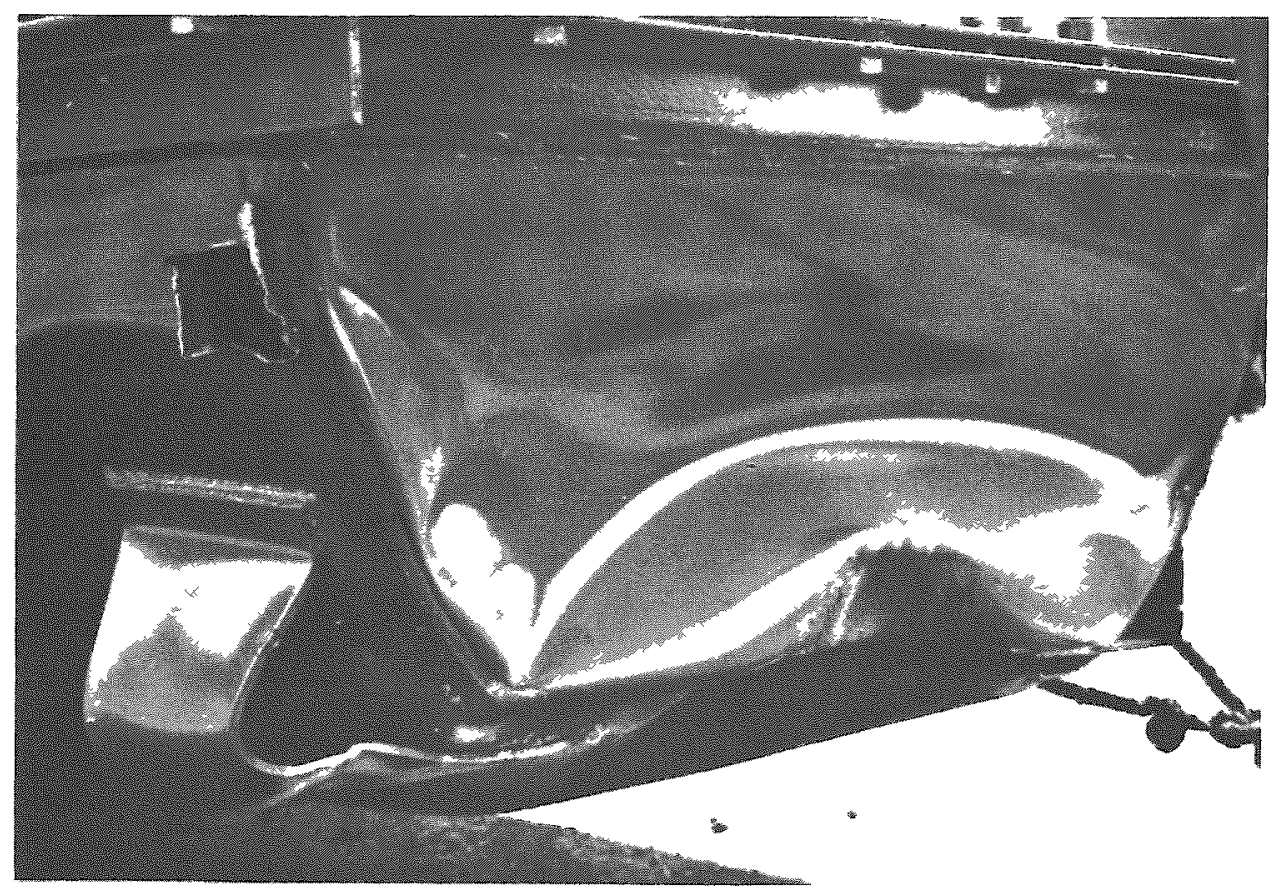

FIGURE 6 - Detalls of Defermation Due co Corner Free Fall Tert 


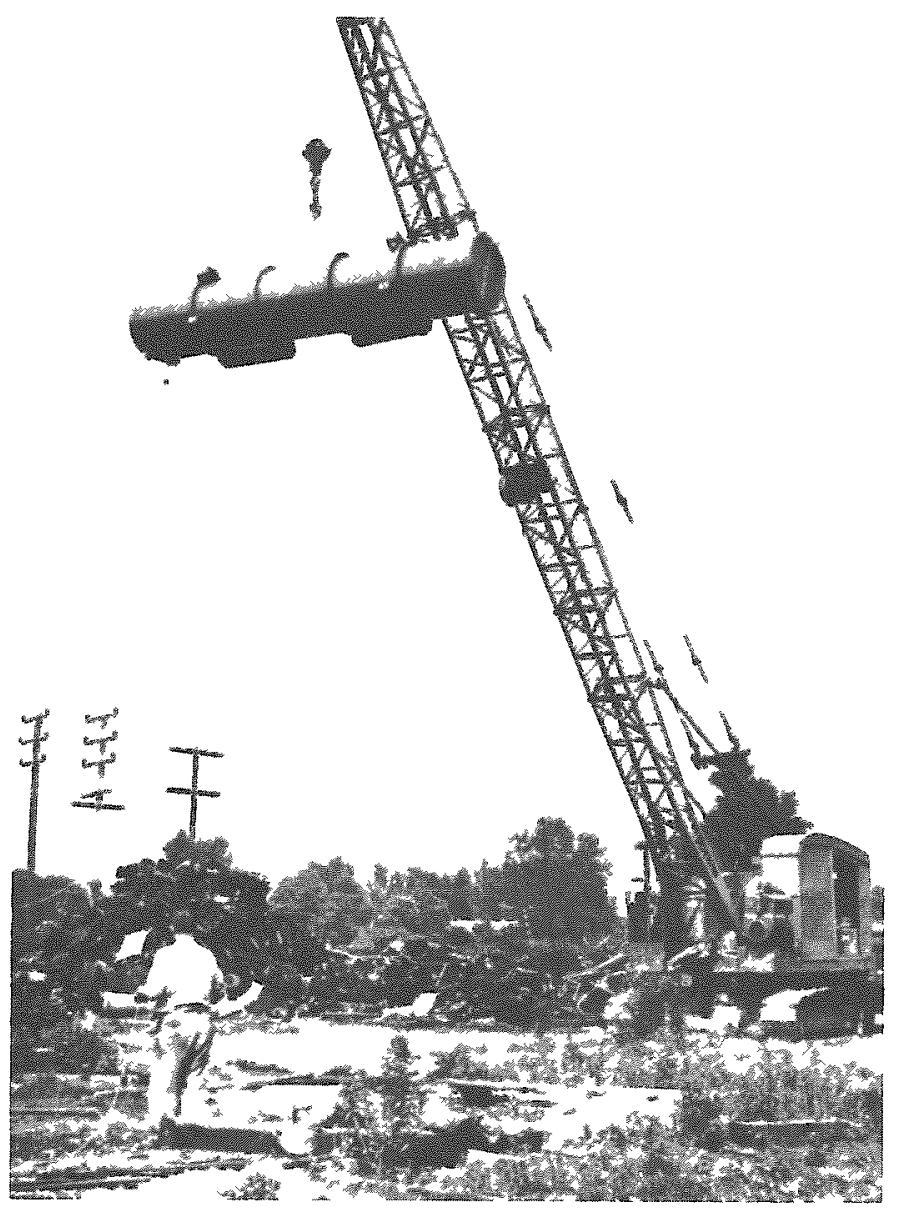

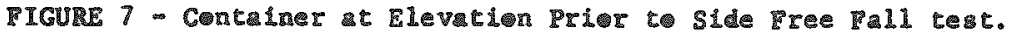

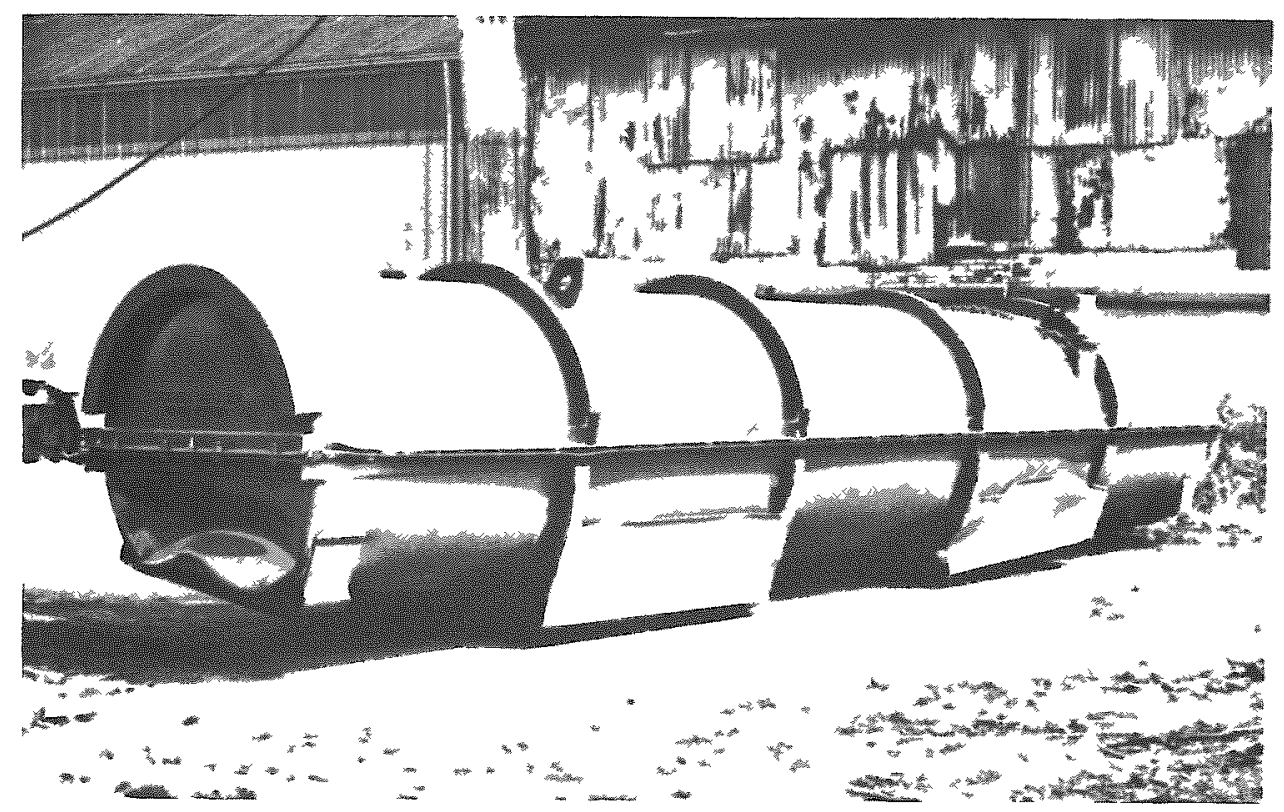

PICURE 8 - Defora then Due to side Free Pall Test 


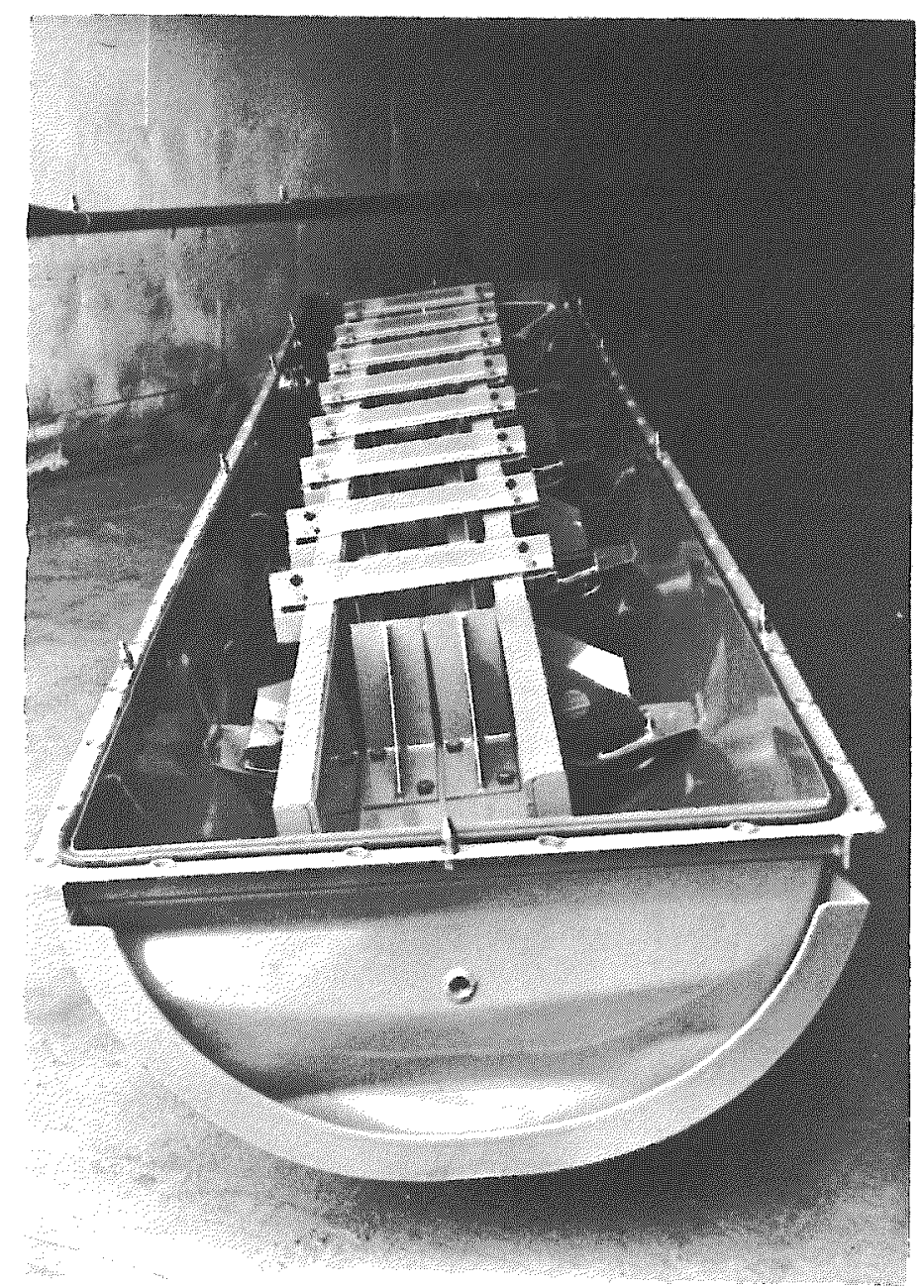

TIGUR 9 - Container Open Shwing Internd Dofomaton Due to All Tests

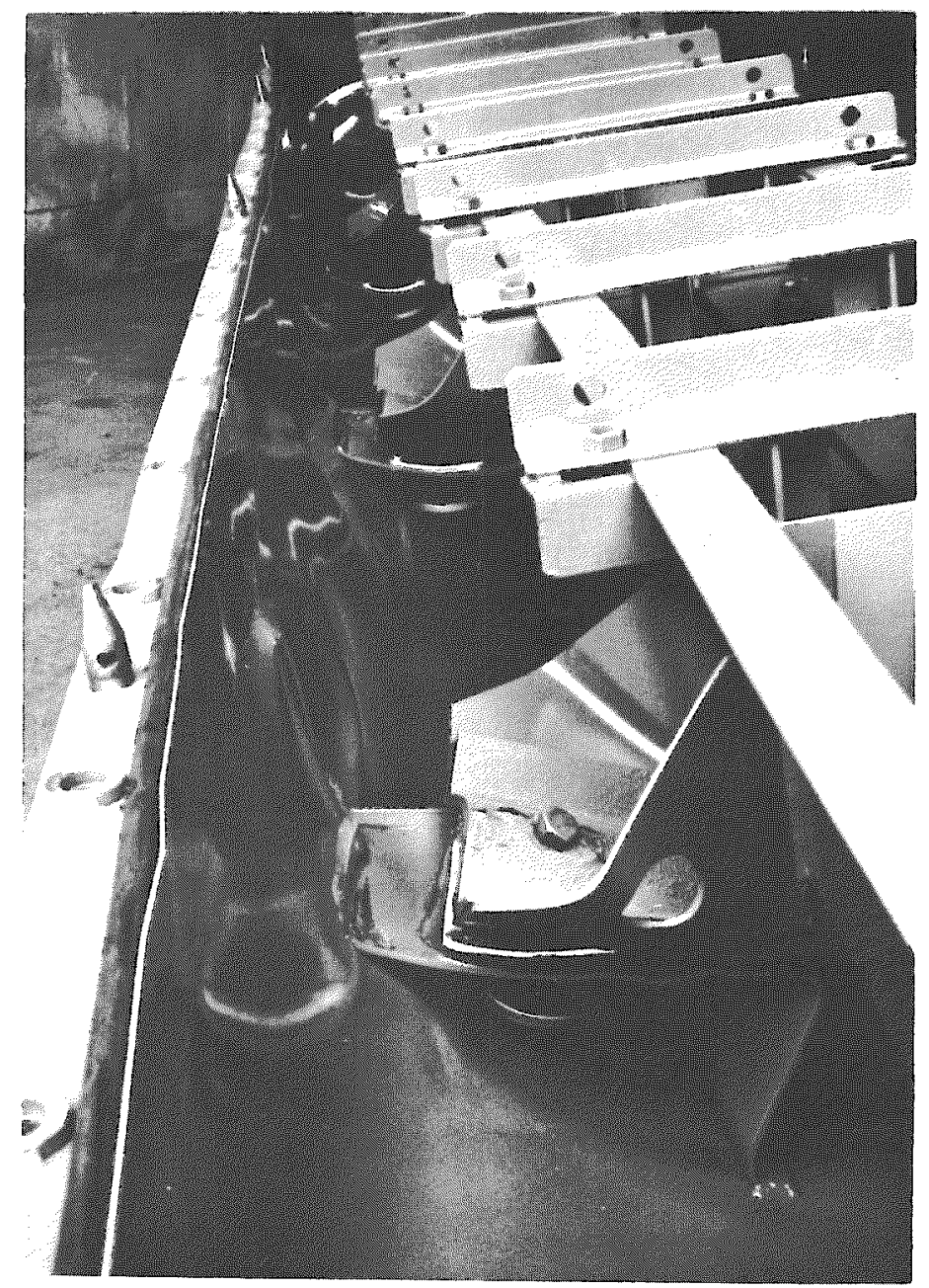

PIGUR 10 - Decall of Internal Deformaten Due t. 11 Tests 


\section{A SIMPLE SHIPPING SYSTEM FOR POWER GRADE PLUTONIUM OXIDE}

R. E. Giebel

R. G. Leeb1

This paper was not available at the time of printing. It has subse-

quently been issued as BNWL-SA-3906, available from NTIS, 5285 Port Royal Road, Springfield, Virginia 22151.

\section{TIEDOWN SYSTEMS FOR CASKS}

E. E. Lewallen

This paper was not available at the time of printing. It has subsequently been issued as BNWL-SA-3906, available from NTIS, 5285 Port Royal Road, Springfield, Virginia 22151. 
COMPACT METALLIC IMPACT LIMITERS FOR SHIPPING CONTAINERS

\author{
R. J. Burian E. C. Lusk
}

BATTELLE

Columbus Laboratories

ABSTRACT

Two types of all-netal inpact liniters have been developed to protect radioactive shipping containers from damage due to accident conditions such as those outlined in the AEC 10-CFR-Part 71 Regulations. One type is designed to protect the shipping container from blows directly on the end or on an edge at the critical oblique angle. This type of impact limiter is comprised of a cluster of metal tubes or a welded metallic honeycomb within a specific array. The kinetic energy of the container is absorbed by plastic strain of the tubes or honeycomb structure, which in turn protects the cask from deformation and excessive forces which could damage the container or its contents. This type of impact structure is fully enclosed in a metallic shell (normally stainless steel) for corrosion reasons and easing decontamination. The development of the design is detailed below and the mechanics of applying the design equations are also illustrated.

The second type of limiter is designed to protect the shipping container from inpact on the side. This design incorporates metallic tubes, partialy filled with water, attached to the surface of the shipping container so that the tube axis is parallel to the container axis. Upon impact the tubes are deformed causing the pressure in the tubes to increase. At a preodesigned pressure, relief ports open and the water is expelled through orifices. The kinetic energy of the cask is absorbed not only by plastic deformation of the tube but also by the inertia and viscous losses in the water as it is expelled. The water also serves as a neutron moderator for containers which are used to ship neutron emitting materials. 
The primary concern in the shipment of any radioactive material is nuclear safety. To assure a high degree of safety, the Atomic Energy Commisson in the 10-CFR-Part 71 Regulations has outlined a group of hypothetical accident conditions which a shipping container must survive while maintaining adequate shielding, containment, and subcritical conditions. The 10-CFR-Part 71 Regulations require a shipping container withstand a hypothetical accident in which the cask free falls 30 feet onto a hard, unyielding surface without failure of the "containment" seal, without change in the container's criticality conditions, and without loss of shielding beyond defined limits. It is often necessary also to limit the impact forces to prevent failure of the fuel-pin cladding or damage to failed fuel canisters within the cask.

Three orientation attitudes lead to the greatest probability of severe damage or cask deformation: (1) end-on impact, (2) flat-side impact, and (3) oblique impact on an end edge at such an angle that the Iine of reaction of the impacting force passes directly through the cask's center of gravity (Figure 1). If it can be shown that a container is capable of surviving the 30-foot free-fall condition in these critical attitudes, the likelihood is high that the container will be able to survive impact in intermediate attitudes.

To preclude excessive deformation or unacceptability high impact forces, the container is often covered or surrounded with cushioning material. The diversity of irradiated materials and equipment and unirradiated fissile materials leads to shipping containers of vastly different design and weight; thus, the energy absorbers are often very different. This paper is confined to two impact absorbers designed and conceived at Battelle-Columbus for use with the heavier containers (casks) for the shipment of radioactive powerreactor fuels.

Many types of impact absorbers have been used with shipping casks. Some earlier designs of pipe and/or I-beam cages supported the cask in the center. Some designs incorporated rubber mountings at strategic locations, other designs utilized massive fins on the side and end of the cask to absorb the impact energy by deformation of the fin, thereby protecting the cask itself. Other designs utilized wooden overcoats to absorb the energy. Many of these impact absorbers were heavy and bulky, increasing the envelope volume as much as an order of magnitude over the volume of the cask itself. Others interfered with removal of heat from the cask. 
During the past year, Battelle-Columbus has been developing designs for impact absorbers that overcome many of the shortcomings of presently employed absorbers. This paper discusses two of these designs, one of which has been found acceptable by the Department of Materials Licensing for use in the Peach Bottom No. I cask. This absorber (a tube cluster) is best suited for protection of the cask from end-on and corner impacts. The second design, which is still being studied, is best suited for protection of the cask from impact on the side. The development of both of these designs was undertaken for the Whitehead $\delta$ Kales Company in Detroit, Michigan.

Tube-Cluster Impact Limiter

The tube-cluster impact-1imiter design was evolved to protect the cask from the end-on, and critical-angle edge-impact conditions (Figures la and 1c). This impact limiter is composed of metallic tubes (or pipes) joined together in a group or cluster (Figure 2). The tube cluster is fitted between end plates but need not be joined to them. For purposes of tube containment, cleanliness, and ease of decontamination, a thin metallic wrapper surrounds the cluster and is welded to the two end plates. The impact limiter is attached to the cask so that one end plate rests directly on the flat end surface of the cask. A severe blow on the end (or at an oblique angle), such as the cask would experience in a 30-foot free fall, will collapse the tube cluster thus absorbing the kinetic energy of the cask through plastic strain of the tubes. In this way the impact forces are held to a tolerable level and the cask is not deformed.

\section{Design Theory}

Specific energy, the parameter used to evaluate the worth of a crushable energy-absorbing device, is the ratio of the maximum energy the structure can absorb to the weight of the structure, or

$$
E_{s p}=\frac{E_{a b}}{W}=\frac{E_{a b}}{\rho_{u} A h} \text {, }
$$


Where

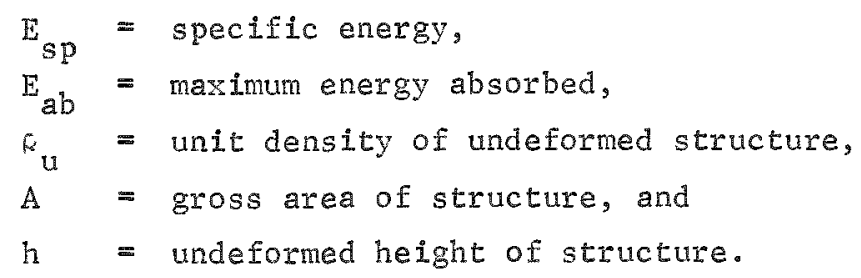

The absorbed energy is equivalent to the work required to deform the structure,

$$
E_{a b}=\frac{\sigma_{m c A d}}{O_{u} A h}=\frac{\sigma_{m c} d}{P_{u} h},
$$

where

$$
\begin{aligned}
& \sigma_{\mathrm{mc}}=\text { mean crushing stress, } \\
& \mathrm{A}=\text { area upon which the crushing stress acts, and } \\
& \mathrm{d}=\text { deformed distance. }
\end{aligned}
$$

Therefore,

$$
E_{s p}=\frac{\sigma_{m c A d}}{P_{u} A h}=\frac{C_{m c} \eta}{P_{u}} .
$$

The term $\eta$ (the ratio of the deformed distance to the height of the undeformed structure), often called the thickness efficiency or stroke efficiency, is a measure of the distance the structure can deform before "bottoming" occurs.

In 1964, McFarland* investigated the energy-absorption properties of the three types of all-metallic structures shown in Figure 3. His studies involved both static and dynamic loading (impact velocities up to 50 fps). The typical collapse mode of the structures was the formation of convolutions as shown in Figure 4. The energy absorbed during the collapse of the structures correlated with a rigid-plastic mode of strain response.

* McFarland, R. K., Jr., "The Development of Metal Honeycomb Energy - Absorbing Elements", Jet Propulsion Laboratory, Pasadena, California, Technical Report No. 32-639 (July 24, 1964). 
Utilizing McFarlands investigation we developed the following expressions for the mean crushing strength of the three types of structures:

$$
\begin{aligned}
& \text { Closed-packed tubes: } \underset{\mathrm{mc}}{\sigma_{\mathrm{mp}}}=55.13 \sigma_{\mathrm{y}}\left(\frac{\boldsymbol{t}}{\mathrm{s}}\right)^{2} \\
& \text { Looseapacked tubes: } \quad c_{\text {mp }}=47.74 c_{y}\left(\frac{t}{s}\right)^{2} \\
& \text { Hexagonal cell: } \sigma_{\mathrm{mex}}=40.53 \sigma_{\mathrm{y}}\left(\frac{t}{s}\right)^{2} \text {, }
\end{aligned}
$$

where

$$
\begin{aligned}
\tau_{y}= & \text { yield stress of the material of construction, and } \\
\left(\frac{t}{s}\right)= & \text { ratio of thickness to the characteristic dimension, } \\
& \text { Figure } 3 .
\end{aligned}
$$

The "thickness efficiency" of three structures, being the same within 5 percent, can be expressed as

$$
r_{1}=88.13-329\left(\frac{t}{s}\right)
$$

The unit weight is a function only of the geometry of the structure and is defined for the three configurations in Figure 3.

In the actual mechanics of limiter design, additional relationships must be considered. The weight of the impact-limiter tubes can be expressed as the ratio of the kinetic energy of the cask to the specific energy of the Iimiter. Then

$$
W_{\text {tube }}=\frac{E_{h_{1}}}{E_{s p}}=\frac{W_{H}}{E_{s p}} \text {, }
$$

where

$$
\begin{aligned}
& W=\text { the cask static weight, and } \\
& H=\text { the fall height. }
\end{aligned}
$$

The limiter tube weight can also be expressed as

$$
w_{\text {tube }}=\mathrm{Ah}_{\mathrm{P}_{\mathrm{u}}}
$$


where

$$
\begin{aligned}
& A=\text { gross area of the limiter, } \\
& h=\text { Iimiter height, and } \\
& \nu_{u}=\text { unit weight. }
\end{aligned}
$$

Combining Equations (3), (8), and (9) and solving for the limiter height yields

$$
h=\frac{E_{h}}{\sigma_{m c} A}=\frac{W H}{\sigma_{m} A}
$$

This is the minimum limiter height required to prevent bottoming of the limiter before all the kinetic energy is absorbed.

Assuming then that the mean crushing stress is constant during the limiter collapse, the impact force in $G$ units can be expressed as

$$
g=\frac{E}{W}=\frac{\sigma_{m c} A}{W}
$$

These relations then permit the design of an impact limiter for virtually any weight vessel and any desired impact force.

\section{Mechanics of Design}

Equations (4), (5), and (6), show that the close-packed tube configu" tion results in the stiffest structure followed, in order, by the loose packed array and the hexagonal-cell structure. The hexagonal cell structure, provides more versatile design since a cell size can be chosen that will give a limiter having the exact crusing stress desired. These structures probably would have to be fabricated for each application as they are not normally "shelf" items. We found it to be more cost effective to utilize commercially available tubing. Commercial tubing is restricted to specific wall thicknesses and tube diameters, however, and the designer must compromise on a structure having a mean crushing stress reasonably close to that desired, unless special tube sizes can be obtained.

In tube selection, curves such as those shown in Figures 5 and 6 for a loose-packed array can be used. From these curves, the required value of $\mathrm{t} / \mathrm{s}$ can be determined for a known cask weight and gross area available for the impact limiters, and a standard tube having a $t / s$ value acceptably close can be used. Once a tube size is selected on the basis of Figure 5 , the total weight of the tubes in the impact limiter can be selected from curves 
similar to those shown in Figure 6 for a loose-packed array. The weight of end plates, side shell, and any attachments for handing, etc., must be added to get the total weight of the impact limiter. The minimum required height of impact limiter can be obtained directly from Equation (10).

The metallic tube-cluster impact limiter can also be designed to protect the cask for the end-edge (corner) impact condition. Many casks have a large aspect ratio (length to diameter ratio). Thus, in corner impact where the line of action passes through the cask's center of gravity, the critical cask impact angle (Figure $1 \mathrm{~b}$ ) is only 15 to 25 degrees from the vertical. Since the impact limiter is designed primarily for axial impact loading, it will perform less efficiently for corner or oblique loading. Therefore, it was assumed that the effective resistance and energy absorption of the impact limiter during oblique impact can be expressed as a function of the impacting angle, or

$$
E_{s p}^{\prime}=E_{s p} \cos \alpha
$$

The specific energy, however, is directly proportional to the mean crushing stress of the impact limiter. Therefore,

$$
\sigma_{\mathrm{mc}}=c_{\mathrm{mc}} \cos \alpha,
$$

where

$$
\begin{aligned}
c_{m c}^{\prime}= & \text { an effective mean crushing stress acting on the } \\
& \text { area of the deformed impact limiter } \\
c_{m c}= & \text { mean crushing stress for axial loading. }
\end{aligned}
$$

From Figure 7 , it is seen that as the cask deforms during impact, and the deformation distance (d) increases, the area $\left(a_{c}\right)$ upon which the effective crushing stress ( $\sigma^{\prime}{ }_{\mathrm{mc}}$ ) acts also increases, and the decelerating force increases.

A computer program was written to evaluate the maximum impact load that the cask will experience in the corner-impact orientation. The design equations presented above were solved for small finite steps of 1 imiter deformation, and the cask velocity was reduced to zero by successive iterations. A subsequent calculation was required to assure that, up to the maximum impact load, the limiter would not fail by shear due to the transverse component of the impact force. 
For the oblique corner attitude, the effective crushing stress is never as great as that for direct end impact, and the resisting force is not constant since the contact area of the deformed volume increases as the deformation distance increases. Consequently, greater axial deformation of the limiter is required to absorb all of the kinetic energy. The weight of the tubes and wrapper is proportionally increased, although the weight of the end plates and other attachments is unchanged.

The tube-cluster limiter has an advantage not attributable to some impact absorbers presently in use. Its all-metal construction and the axial orientation of the tubes provide relatively good heat transfer during normal operation. However, it still has good thermal impedance to protect the cask from high heat fluxes of short duration such as the hypothetical fire conditions stipulated in the AEC 10-CFR-Part 71 regulations.

The impact Iimiters designed for the Peach Bottom No. 1 shipping cask are shown in Figure 8 . The cask weighs $61,600 \mathrm{lb}$ fully loaded. The impact limiters comprise approximately 225 tubes made of mechanical stee1 tubing having a yield stress of $60,000 \mathrm{psi}$. The $2-1 / 2-$ inch-OD $\mathrm{x} 0.095$ inch thick wall tubes are 8.5 inches 1ong. (For end-impact only, the tubes would need to be only 5-1/4 inches long.) They are welded together in a loosepacked array and sandwiched between two, 1/4-inch stainless steel plates to provide a bearing surface for the tubes. For ease of surface decontamination, the side of the limiter is enclosed with a $1 / 8$-inch stainless steel wrapper welded to the top and bottom plates. A skirt ( 1 inch thick and 4 inches long) is welded to the bottom plate and fits over the end of the cask. It is designed to take the transverse load for the oblique impact condition. Four holes penetrate the top end plate and tube cluster of the limiter to permit bolting the limiter to the cask through the bottom end plate. The limiter weighs $630 \mathrm{lbs}$; and of this $385 \mathrm{lb}$. is attributed to the tubes.

This limiter design has many advantages over others that have been used. It is compact and easy to decontaminate. It provides complete prom tection for the end of the cask, thereby making it easy to demonstrate cask closure integrity after an impact of the nature stipulated in the regulations. It is all metallic, thereby making it sturdy and capable of withstanding moderately "rough" handling. The all-metal construction also makes it relatively unaffected by neutron exposure. Its compactness enables constructing exposed surfaces of corrosion-resistant materials at reasonable cost. It completely covers the end of the cask, thereby protecting it from the high thermal flux incident during an accidental fire exposure. Finally, and of special concern to the designer, it can be quickly analyzed and the tradeoffs rapidiy and easily evaluated. 
The tubular structures are highly efficient and result in a compact limiter, but the fabrication requires time-consuming joining of many small pieces. Battelle is investigating the properties of an all-brazed honeycomb structure that is commercially available on a special-order basis and for which substantial crush-strength data are available.

Hydraulic-Tube Impact Iiniter

The necessity of shipping "high burnup" and Pu recycle fuels in the near future has established the need for neutron shielding. Consequently, future-generation shipping casks will provide both gamna-ray and neutron shielding. Our preliminary designs for casks include a water jacket around the gamma shield. In Battelle's work for Whitehead \& Rales, we examined the feasibility of making the water jacket double as an impact limiter for sideimpact conditions. The basic concept is relatively simple - the kinetic energy is absorbed by throttling the water through a series of orifices, similar to the way in which hydraulic shock absorbers operate in autonotive vehicles.

The design now being examined is in Figure 9. As illustrated, the water jacket consists of an annulus divided into several compartments by pipes or tubes extending the length of the cask. Each isolated compartment is filled with water, leaving a small air space for thermal expansion of the water and initial impact-load cushioning. The orifices fitted in the ends and along the pipe are covered and sealed with poporf plugs. Upon side impact, one or more of the compartments will collapse, causing the pressure of these compartments to rise rapidly. The pop-off plugs will then open, permitting the water to eject through orifices and absorb the kinetic energy of the cask.

A computer program written to assist in the analyses takes into account the energy dissipated by ejection of the water through the orifices, the energy absorbed in the viscous and inertia forces developed in the fluid, and the energy absorbed in deforming the metal pipes.

Parametric studies designed for better understanding the system and to assist in planning an experimental program are continuing. Preliminary results are enlightening, and modifications of the designs have been indicated. It was hoped that one orifice at each end of each compartment would be adequate. The preliminary analyses have revealed, however, that even with fully open ends the water could not be expelled fast enough to prevent the 
tubes from rupturing. Consequently, it appears necessary to consider placing orifices at intervals along the pipe. Placement may be critical, to assure that the orifices will not be obstructed during the impact. Alternative designs include placing one or more smaller pipes in each compartment, and using a metallic honeycomb to absorb the energy after the pipe ruptures. Although this design shows promise, additional analysis and experimentation must be performed to establish a practical design. 


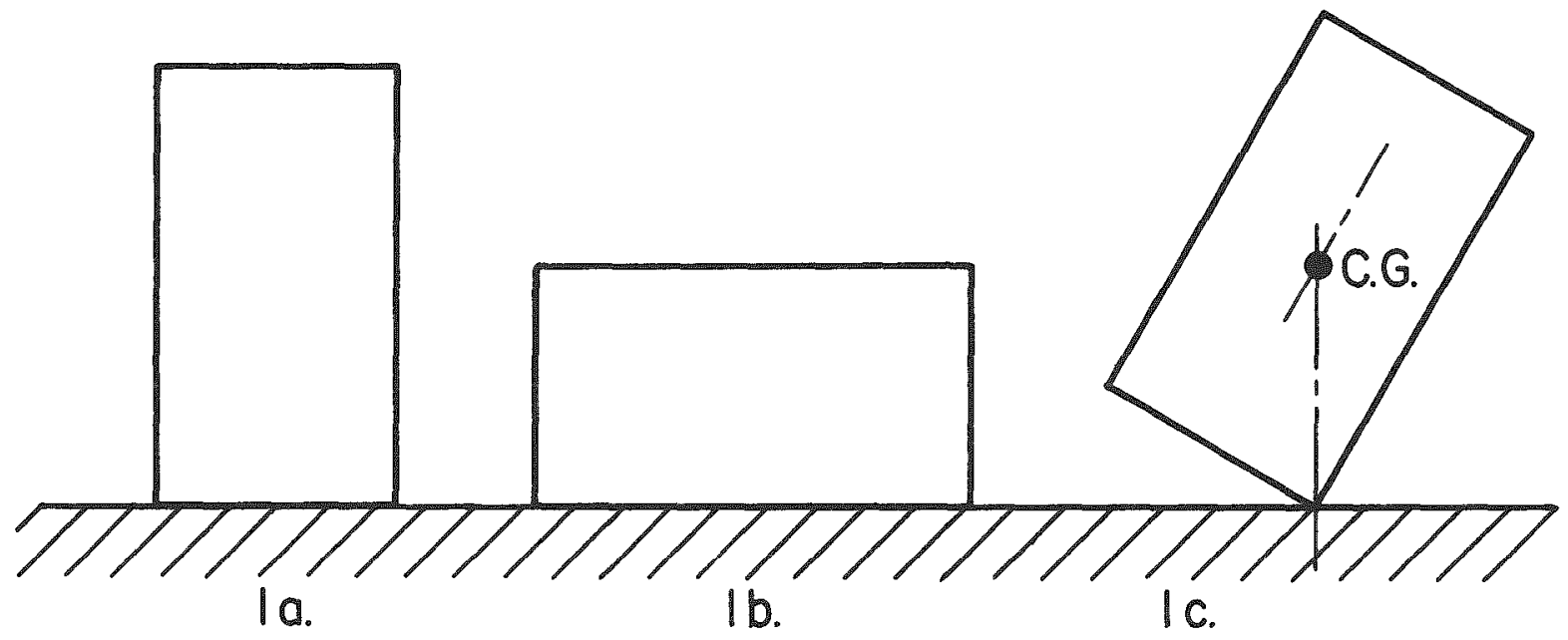

End Impact

Side Impact

Critical Angle Edge Impacł

Fig. 1. Orientations of Cask at Impact for Which the Highest Probability of Damage to Cask and Contents Exists

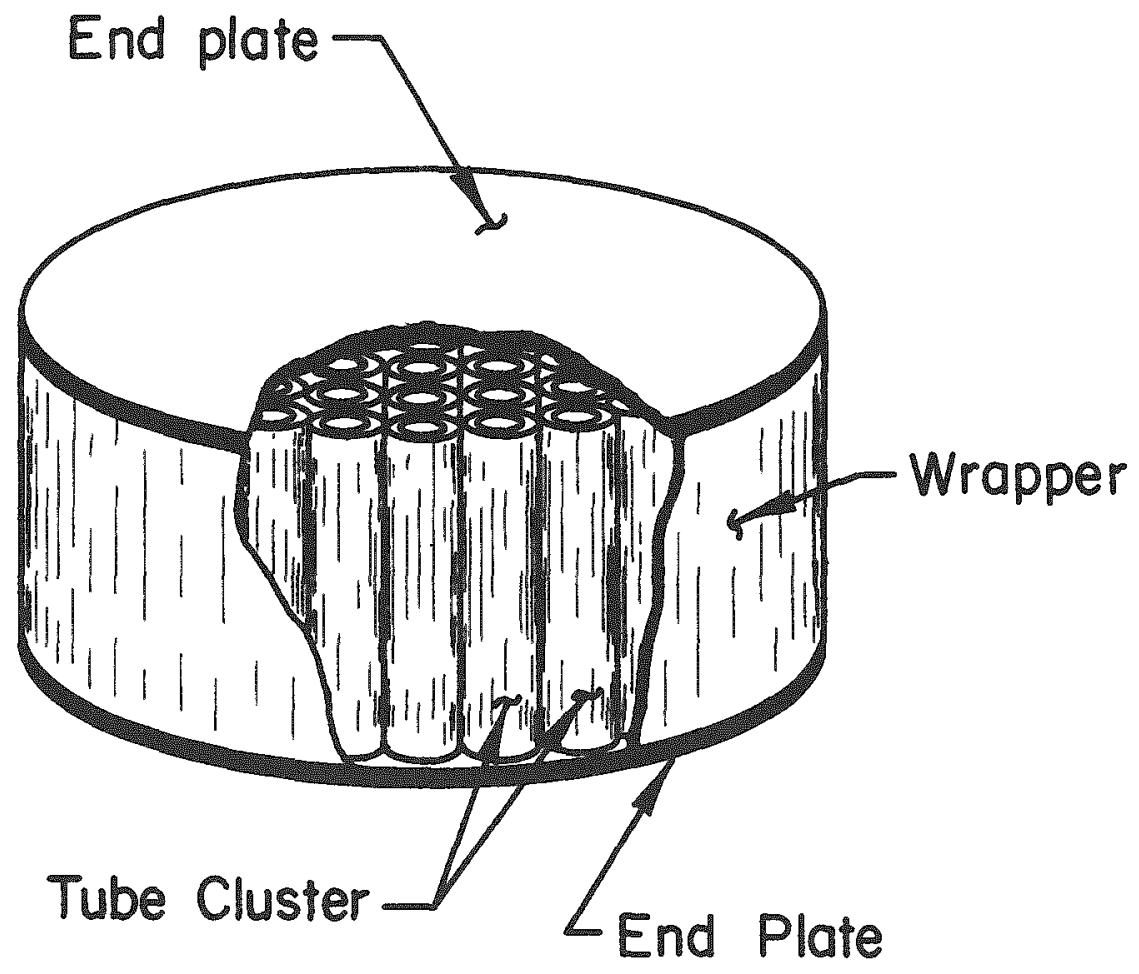

Fig. 2. Tube Cluster Impact Limiter 

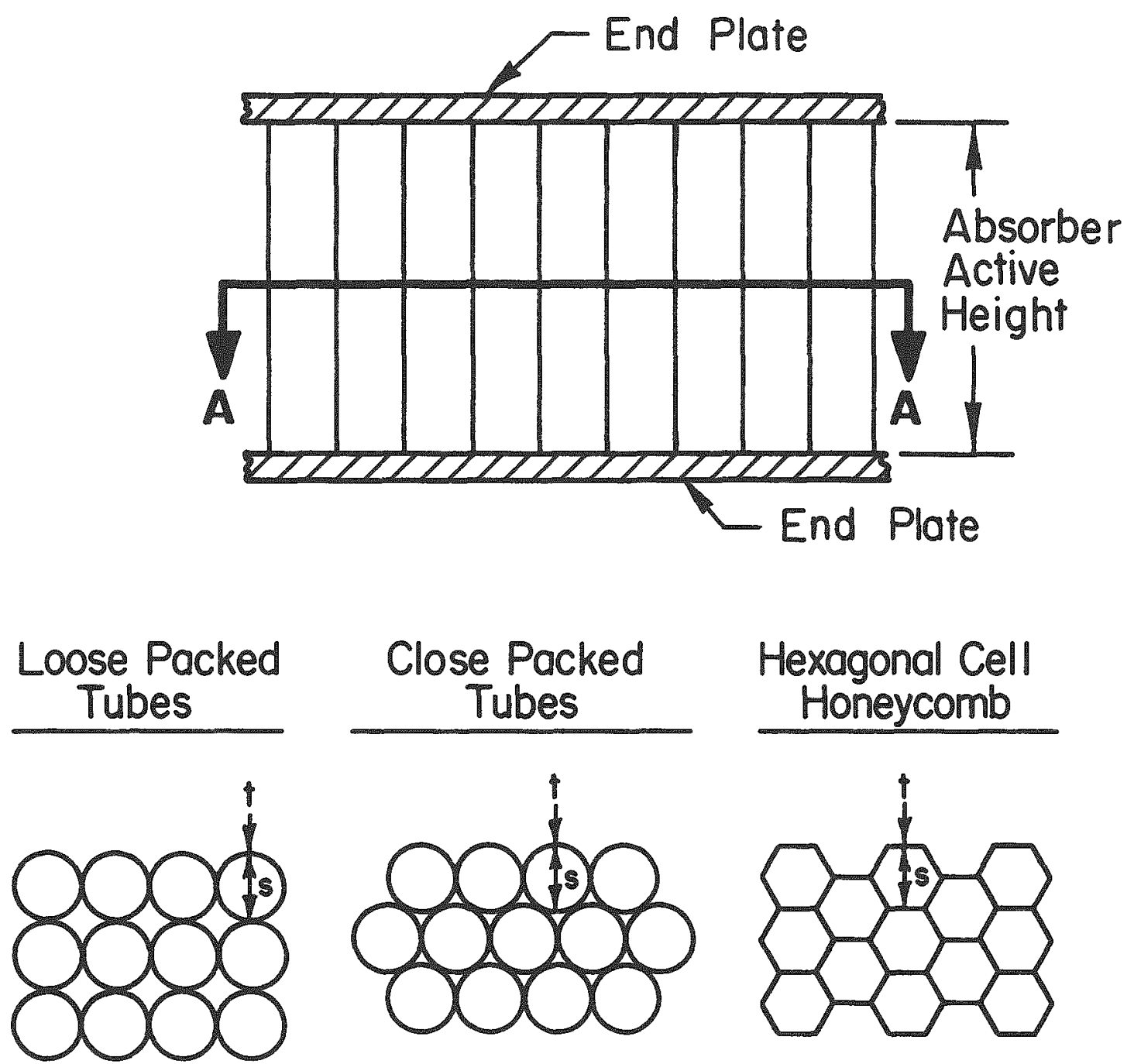

$$
p_{u}=\pi \rho \frac{1}{s}
$$

Close Packed Tubes

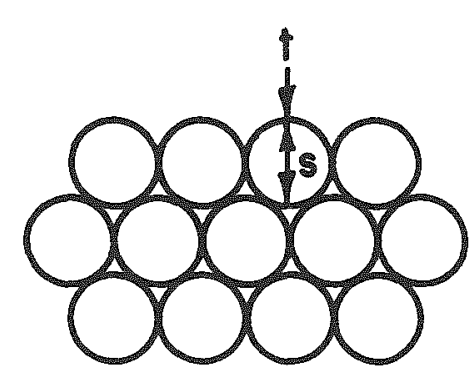

$$
P_{u}=\frac{2 \pi}{\sqrt{3}} \rho \frac{1}{s}
$$

Hexagonal Cell Honeycomb

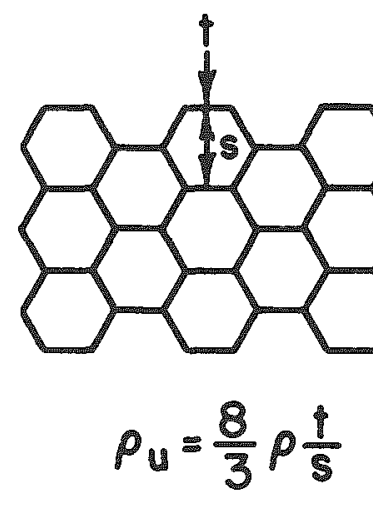

$$
\begin{aligned}
& P_{u}=\text { Unit weight } \\
& P=\text { Material specific weight } \\
& t=\text { Wall thickness } \\
& s=\text { Mean diameter or cell size }
\end{aligned}
$$

Fig. 3. Three Types of Tube Cluster Impact Limiters 


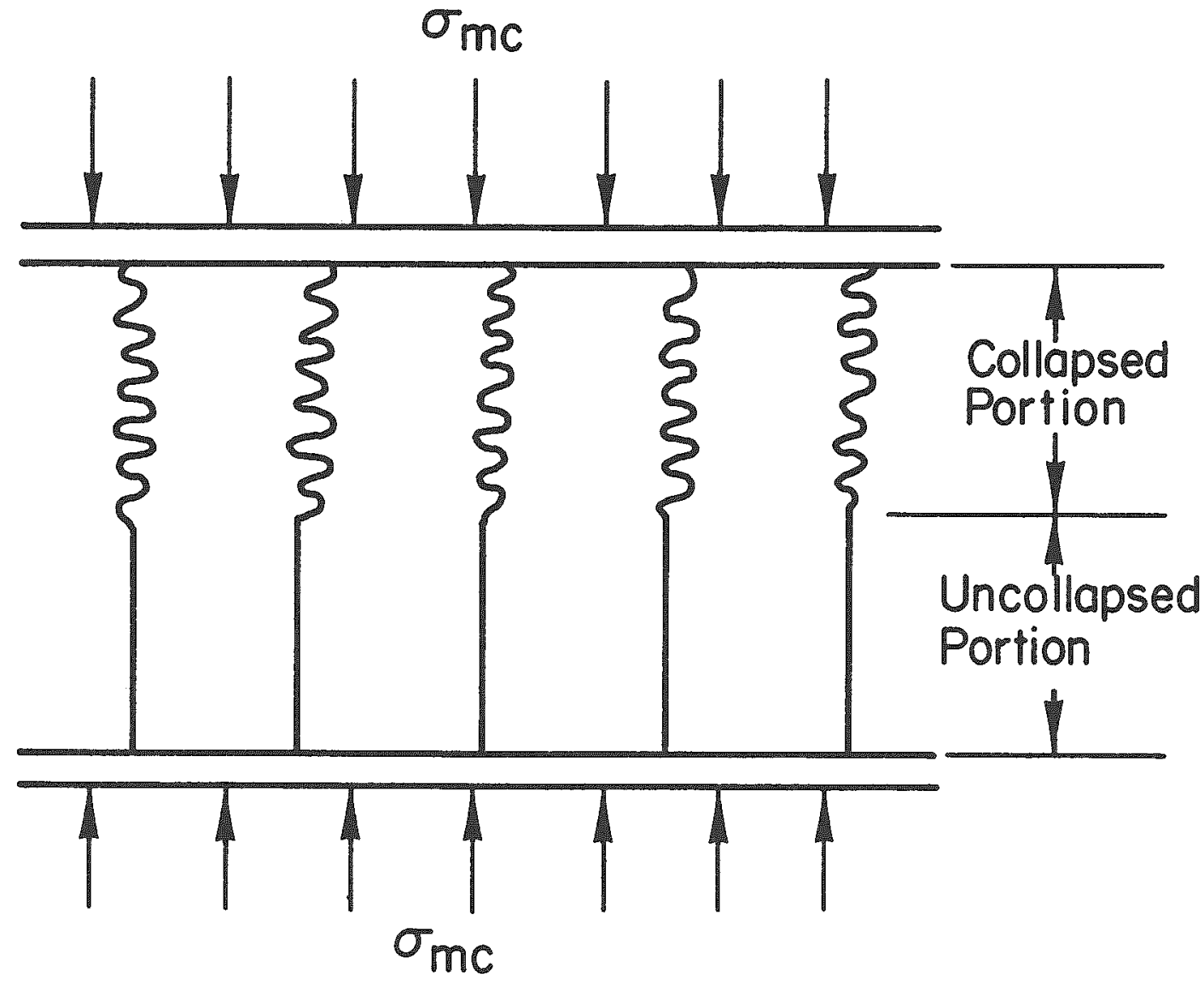

Fig. 4. Typica1 Collapse Mode of Tube Cluster Impact Limiters 


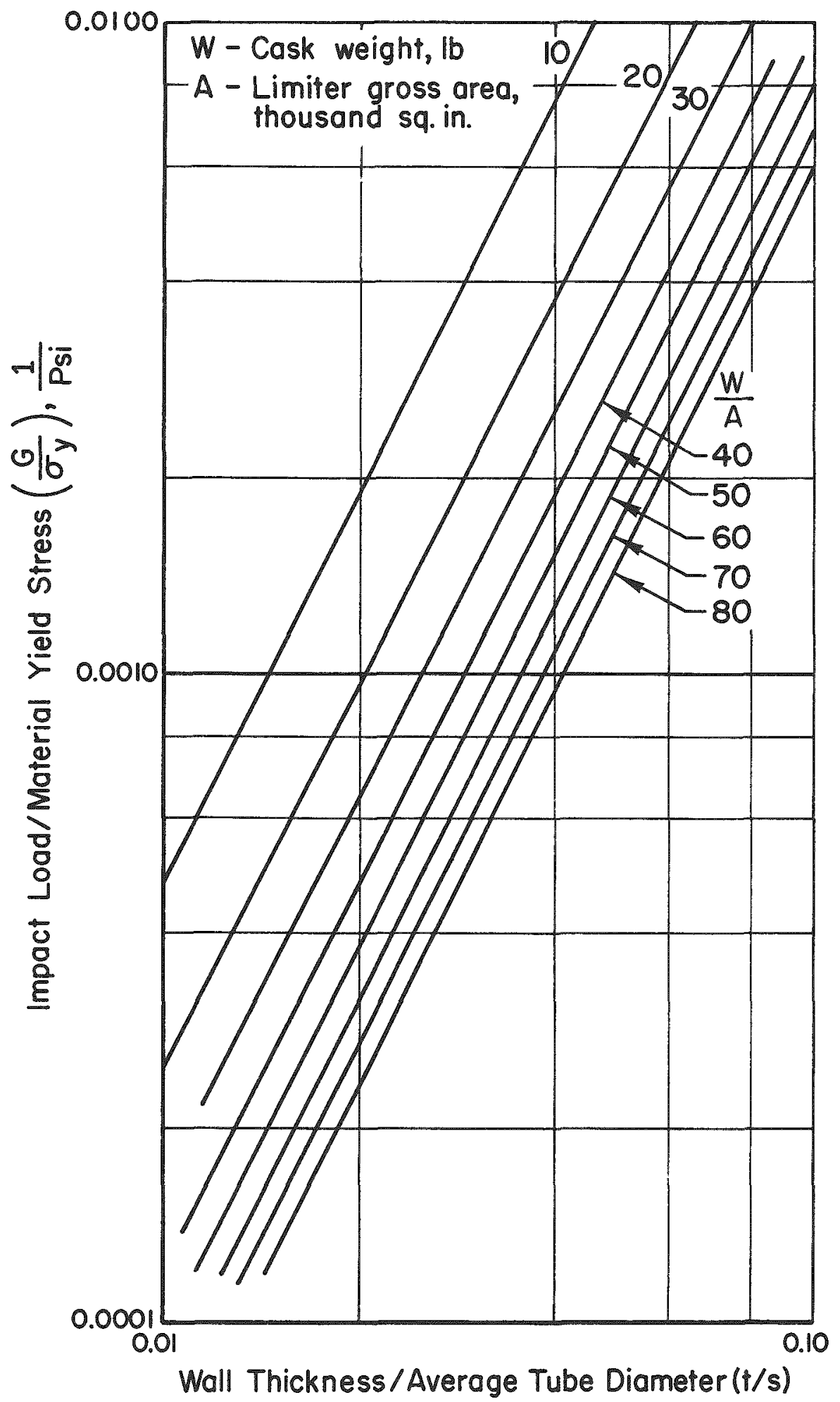

Fig. 5. Tube Cluster Impact Limiter Tube Size Selection Curves for Loose Packed Array 


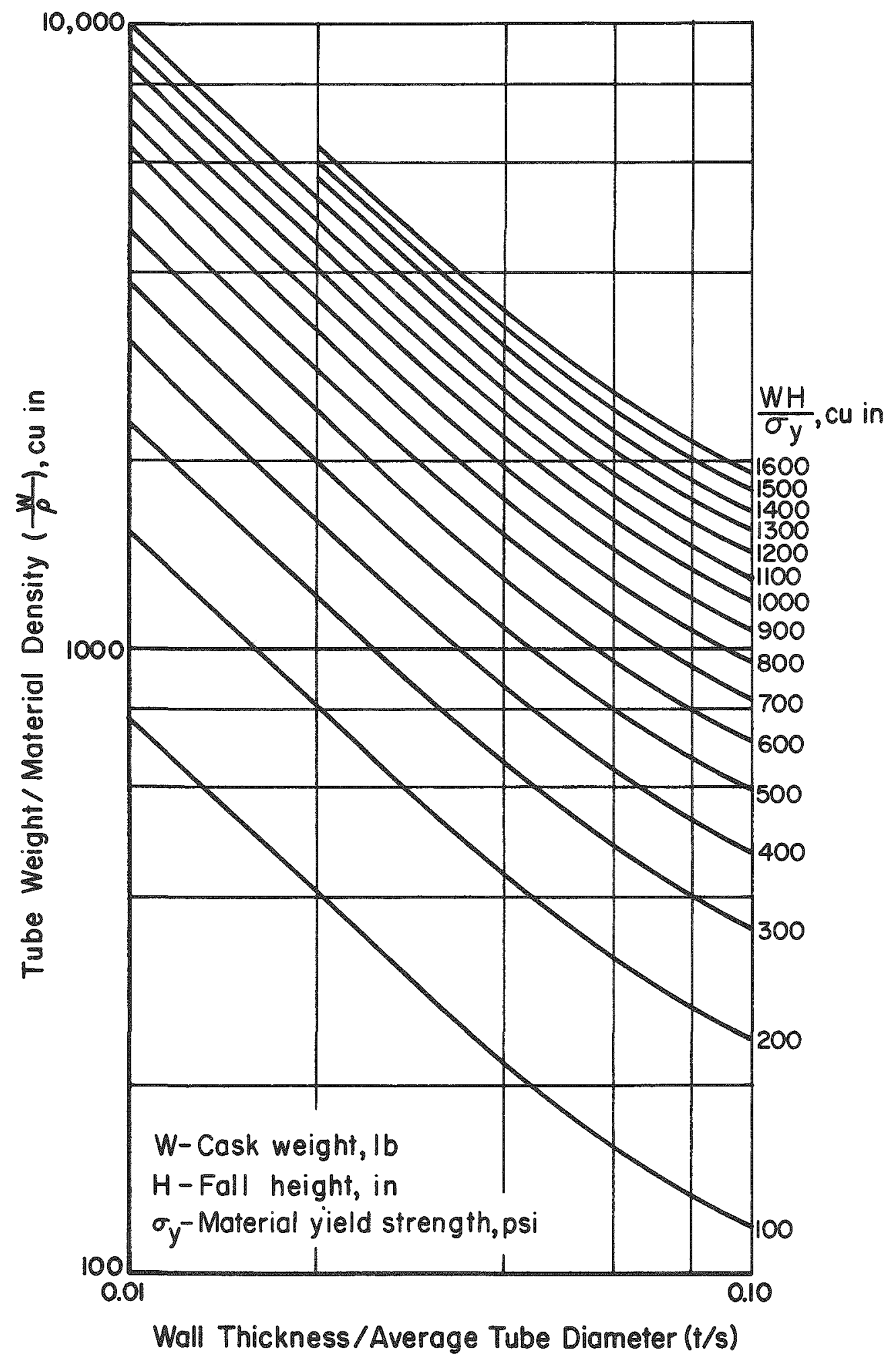

Fig. 6. Tube Cluster Impact Limiter Tube Weight Curves for Loose Packed Array 


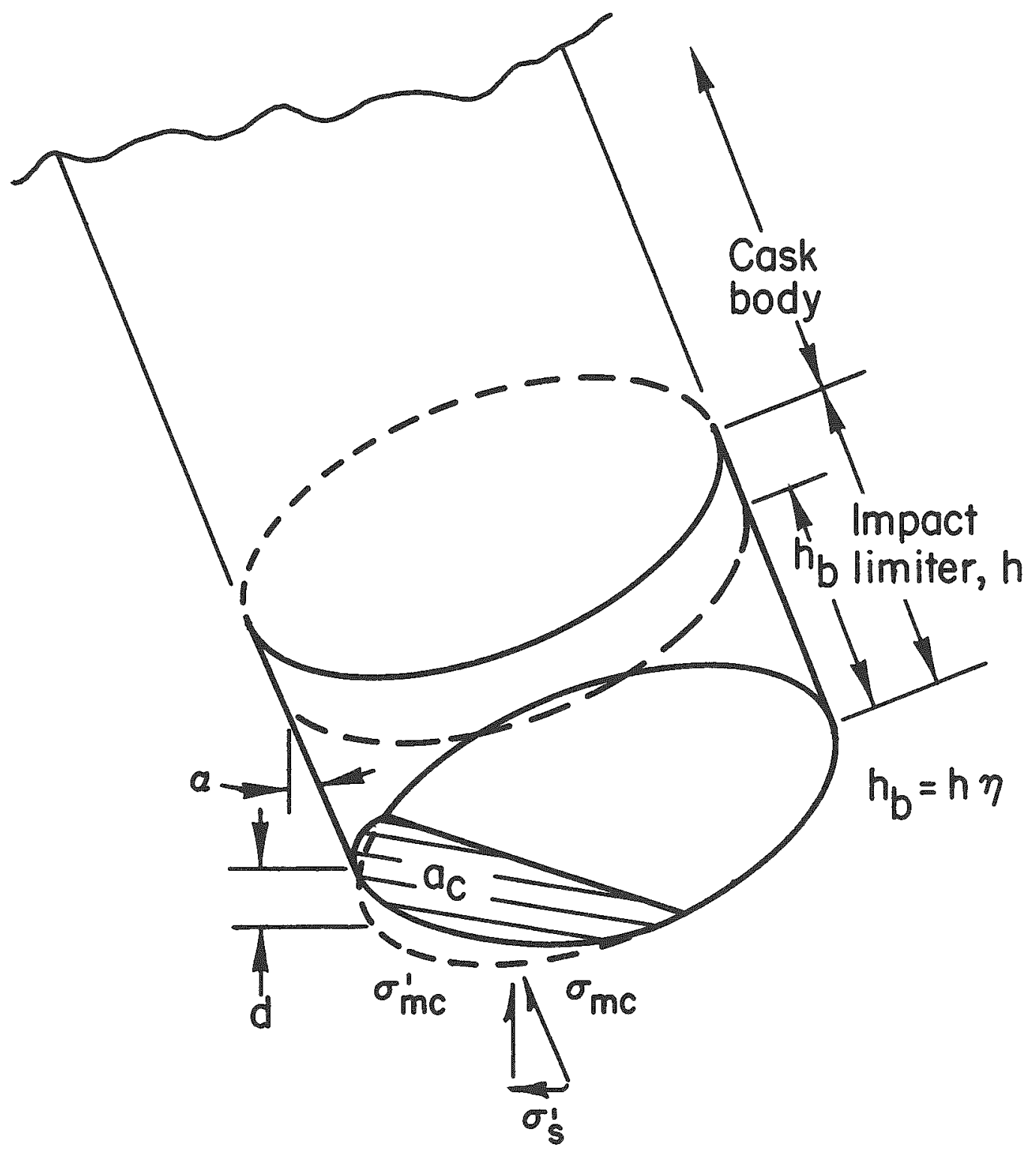

Fig. 7. Model of Tube Cluster Impact Limiter During Impact at an Oblique Angle 


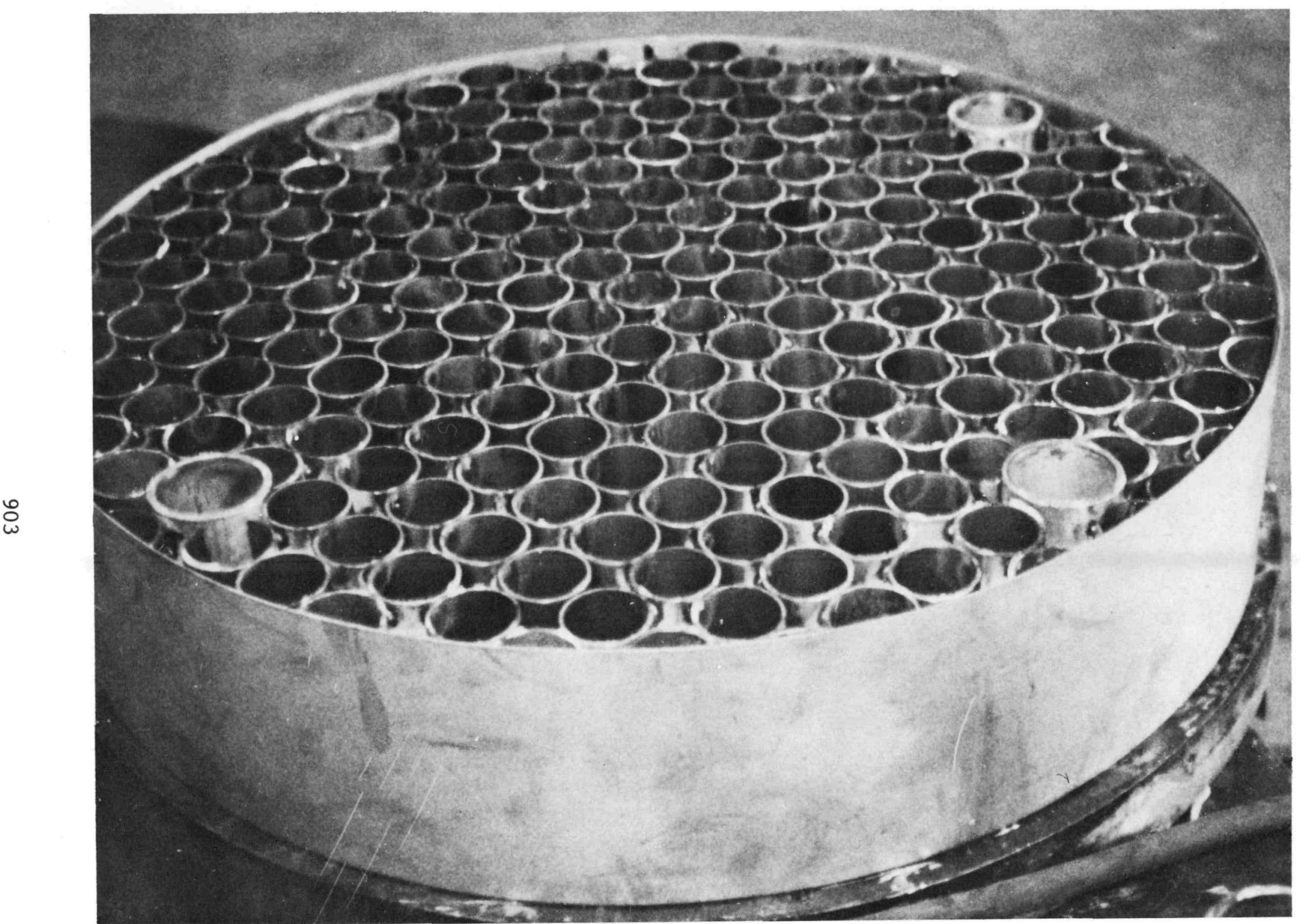

Fig. 8. Tube Cluster Impact Limiter Designed for Use on the Peach Bottom No. 1 Shipping Cask Before Attachment of Top End Plate 


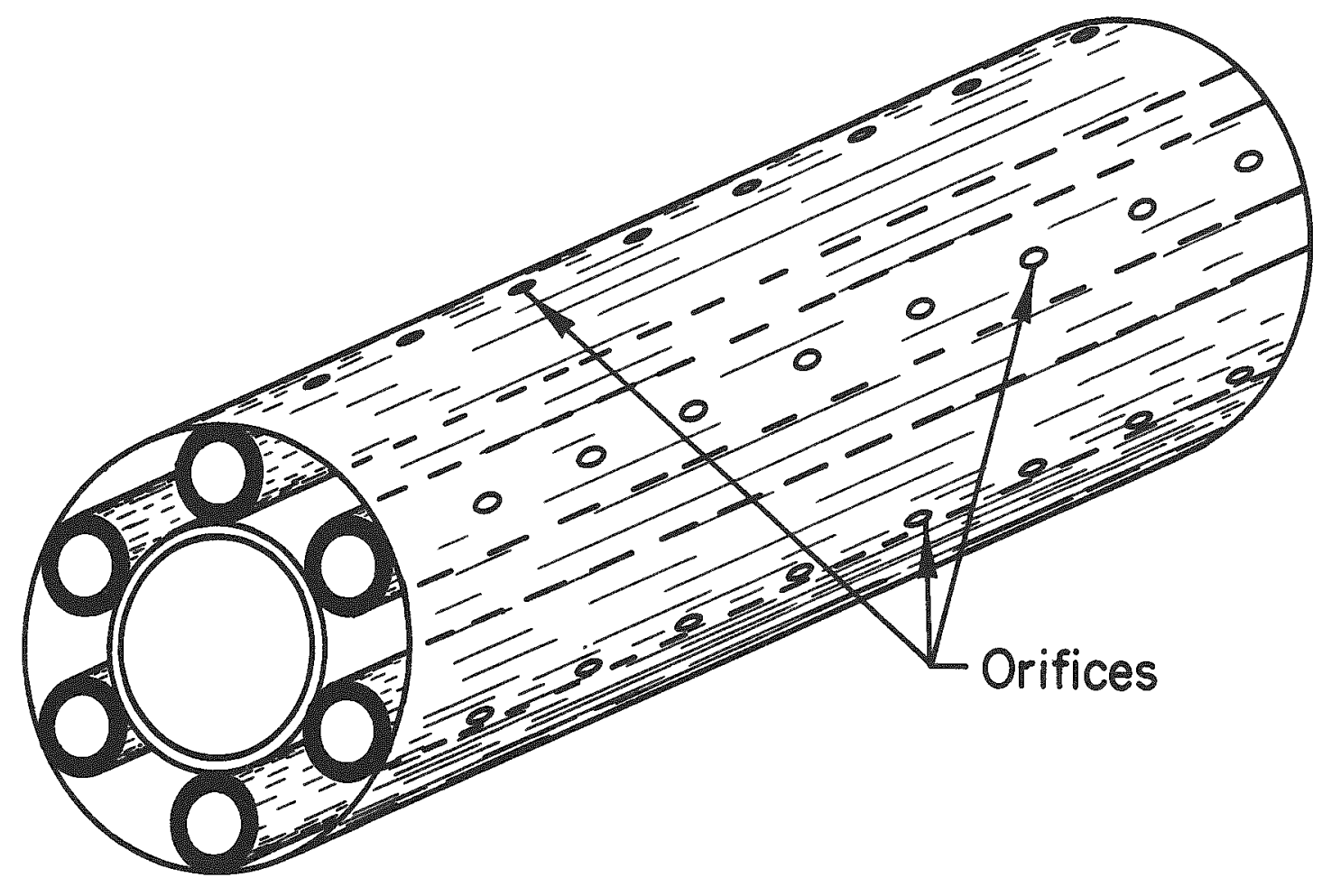

Fig. 9. Hydraulic-Tube Impact Limiter 
At the suggestion of Division of Construction, Headquarters $\mathrm{AEC}$, the Union Carbide Corporation invited the Environmental Criteria Group of Sandia Laboratories to participate in a transportation test involving the transportation of a radioactive materials ( $R A M$ ) cask from Paducah, Kentucky, to Oak Ridge, Tennessee, by railroad and the return to Paducah by truck. Sandia instrumented the vehicles and measured the shock and vibration inputs to the RAM cask. This paper reviews the conduct of the Sandia data experiments, describes the instrumentation, discusses the data reduction techniques used, and presents the resulting data in summary form. The summarized data provides a comparison of the intensity of the shock and vibration encountered in the rail and truck transport environments.

The main purpose of the Sandia participation was to obtain data to be used in applied research pointed towards developing descriptions of environmental inputs to cargo, and more specifically the following points:

1. To develop a more complete description of the rail transport dynamic environment than had theretofore been available.

2. To develop a description of in-transit rail transport shock as opposed to switching yard shock.

3. To provide additional information on the truck environment to supplement the results of prior work.

\footnotetext{
*This work was supported by the U. S. Atomic Energy Commission.
} 
4. To provide a means of comparison between environmental levels within the two modes of trans port.

The rail shipment covered approximately fivehundred miles of varied terrain.

The truck shipment was approximately threehundred miles in length. A team of Sandia engineers and technicians planned the experiment and carried it out. Data reduction and interpretation was part of the Sandia contribution. The instrumentation system was operated remotely from the cabooses of the trains involved, but directly from the cab of the truck. Piezoelectric accelerometers were employed to measure shock and vibration.

Summaries of the reduced data as well as the methods of data reduction are discussed. Summaries of the reduced data are presented in a form which permits comparison of the environments produced by rail and truck modes of transportation at the "input to cargo" interface.

When the variable dynamic characteristics of general cargo are considered in conjunction with these environment comparisons, the differences in the two modes of transport are found not to be significant from a shock and vibration standpoint.

\section{FORFWORD}

The Oak Ridge Nuclear Safety Information Center Cask Designer's Guide (ORNL-NISC-68) indicates that no description of the vibration and shock normally incident to transport of radioactive materials is described in Annex I of AECMI 0529.

This paper is the record of an attempt to quantify the nature and magnitude of the normal vibration and shock environment incident to rail and truck transport. The authors hope this paper will be useful as an estimate which can be used by designers of casks and tiedown systems, and by those who are attempting to establish test criteria for general cargo systems. 


\section{INTRODUCTION}

In the spring of 1968, Sandia Laboratories Criteria and Heat Transfer Division 1543 participated in a program to measure the dynamic (shock and vibration) environment of a shipment which was being transported by rail from Paducah, Kentucky to Oak Ridge, Tennessee, and returned to Paducah via truck. The cargo was a laminated uranium Fuel Element Shipping Cask and Tiedown System which had been developed by the Nuclear Division of Union Carbide Corporation at Paducah. $(1,2)$ A portion of the Union Carbide cask development effort required subjecting the cask tiedown system to shipment by rail and truck. It was suggested by the Division of Reactor Development and Construction, Headquarters, AEC, that the Environmental Criteria Group, Sandia Laboratories, had, in addition to a capability for making measurements of the dynamic shipping environment, a number of other, in-house uses for the type of data that could be obtained. As a result, an invitation to join in the test was issued by Union Carbide and accepted by Sandia.

Operation of an AEC/DOD Environmental Data Bank is a primary function of the Sandia Environmental Criteria Group. (3) Data deposited in the Bank is obtained by various means including direct measurement. The work reported in this paper is the result of such a direct-measurement activity. In addition to the primary purpose of providing a description of the dynamic environment of the trip for the Data Bank, the following complementary objectives concerning the data were satisfied during the program.

1. Measurement of the rail and truck transport environment under identical loading conditions and with identical instrumentation.

2. Measurement of the rail transport environment using more precise techniques and sophisticated instrumentation than had been utilized in previous work.

3. Further measurement of the truck transport environment to supplement other truck environment measurement work. 
Activity Assignments

Discussions with Union Carbide personnel resulted in a division of assignments in the general conduct of the transportation program. Union Carbide provided the following:

1. Caroo (cask and tiedown system).

2. Railcar and truck modified as necessary to accommodate cask and tiedown system.

3. Space to work and assistance to Sandia personnel in setting up instrumentation.

4. Arrangement with the carriers for cooperation as required to carry out the joint test program.

5. Arrangements for on-board transportation of Sandia personnel during the actual testing.

6. The packaging and shipment of instrumentation to Albuquerque at the conclusion of the program.

Sandia Laboratories: (1) Provided, installed, maintained, and operated environment-measuring instrumentation, and (2) reduced, interpreted, and reported on data obtained. Each organization separately funded the costs of its activities and personnel.

\section{Preliminary Joint Plans}

A preliminary joint plan was developed during early discussions. The first portion of the shipment would be by rail. The railcar would be a flat car belonging to Union Carbide. The cargo system would be loaded and the environment measuring instrumentation mounted, checked, and calibrated at the Union Carbide plant in Paducah, Kentucky. Movement from that point to railroad switching yards would be unattended. Shock/ vibration environment encountered within switching yards, including 
normal switching of the car, would be recorded. Novement from Paducah to Louisville, hentucky would be accompanied by Sandia personnel and recordings made of shock/vibration produced by notable events enroute. Movement on the railroad from Louisville to Corbin, Fentuckv, and from Corbin to Knoxville, Tennessee, would be accompanied by Sandia personnel and additional environment recordines made. Movement from knoxville to Oak Ridge, Tennessee, would be unaccompanied.

Cpon arrival at Oak Ridge, the car would be routed to the Union Carbide $\mathrm{Y}-12$ plant, the carco removed from the car and reinstalled on a flat-bed trailer. Environment measuring instrumentation used on the railroad car would also be transferred to the trailer and the cargo hauled over the road back to the L'nion Carbide plant at Paducah. Sandia personnel would accompany this shipment and record shock/vibration produced durine truck trans port events.

Sandia Test Details

Guidelines

Sandia activity in conjunction with the Tnion Carbide shipment consisted of determination of the kinds of events which should be measured, determining the shock and vibration parameters which we needed to measure in order to make a description of the transportation environment more complete and utilization of the capabilities of our data recording equipment to its fullest extent during the actual shipment. Several guiderules were established in the planning:

a. Measurements taken would provide a statistical sample of shock/vibration produced by various events in each mode of trans port.

1. The entire rail trip route would be investigated before making the shipment to determine the events to be sampled in transit.

2. Truck events measured would be according to a list of events developed in prior truck tests. 
b. As many locations on the vehicle and cargo as possible would be instrumented but the key locations evaluated would be those which described the "input to cargo" interface of the vehicle/cargo systems.

Event Sampling Determinations

The preliminary survey of the proposed rail route showed six events were significant from a shock/vibration standpoint. The events checklist used in the instrumented test was as follows:

1. Run-in/run-out shock

2. Crossing bridges

3. Traversing tunnels

4. Crossing of switches

5. Crossing of other tracks

6. Switching yard activity

In a prior, more extensive truck test program, (4) seventeen events, characterized for the most part as road types were determined to be sicnificant from a shock or vibration standpoint. The events checklist used in this test, based upon this prior work, was as follows:

1. Acoidents/Incidents

2. Tonpaved Road

3. Hills (climbing)

4. Hills (descending)

5. Paved Detours

6. Overpasses

7. Concrete Interstate Roads

8. Parking Lot Maneuvers

9. Asphalt Interstate Road 
10. Bumps

11. Blacktop Over Concrete, Two-Iane

12. Railroad Crossings

13. Bridges

14. Concrete Two-Lane Road

15. Blacktop Two-Lane Road

Instrumentation

The rail car used was USAX38655. The loaded car is shown in Figure 1.

The cask was positioned at the center of the car and tied down by tie rods through the floor to the car frame and to plates which had been welded to the car frame. These are shown in Figure 2. The instrumentation was placed on the aft end while the forward end of the car was occupied by auxiliary equipment relating to the cargo.

The transducers were located in positions considered to give a complete picture of the dynamic environment.

The accelerometers were located on the forward tie down plate. Five accelerometers and a pressure transducer were mounted to monitor the cask and its skid. The pressure transducer is shown in Figure 3 as is the triaxial accelerometer group on the skid floor. A vertical accelerometer was mounted on each trunnion plate as may be seen in Figure 3.

Upon reaching the terminus of the rail transport demonstration test at Oak Ridge, Tennessee, the Union Carbide cask was transferred to a flatbed tractor-trailer rie for the demonstration test return trip by truck to Paducah, Fentucky.

Figure 4 shows the completely instrumented truck. The battery power supply and recording system are located ahead of the cask. The remote control lines to the truck cab were led from the recorder into the window of the truck cab. Note the location of a large C-clamp, mounted on the fifth wheel support of the trailer, near the spare tire. 
This clamp mounted a triaxial accelerometer cluster at this point. This cluster was used by the instrumentation operator in the truck cab to estimate visually the accelerations being encountered in transit.

Figure 5 shows the equipment available to the instrumentation operator in the truck cab. From left to right are:

1. Monitoring device for the accelerometers near the fifth wheel.

2. Voice microphone input to tape recorder on truck.

3. Control box for recorder system on truck.

4. Hand-held tape recorder for additional commentary, and

5. Checklist of events to be sampled.

Performance of Environment Measurement Tests

\section{Rail Tests}

The rail car containing the Union Carbide cask tiedown system and Sandia instrumentation was moved to the switching yards of the first railroad to be used. Sandia engineers met the car at the switching yards, where switching shock measurements were taken.

Through the cooperation of railroad personnel, a number of events were recorded. The procedure used was for the Sandia engineer observing the events being performed to activate the recorders by radio signal just prior to impact, and to place a code number on the tape after the event, also by radio control. At the same time, another Sandia engineer made a running commentary about the event on a hand-carried tape recorder, and also recorded the event code number. This made possible the correlation of test data with event data during data reduction efforts. 
After switching yard activity was completed, the instrumented car was spotted on the trip train immediately ahead of the working caboose. The Sandia test group was housed in an additional caboose immediately ahead of the test car. The test group included the Project Test Engineer and an instrumentation technician, both from Sandia, and a travelling engineer from the participating rallroad. This engineer was very well acquainted with the route. His assistance was invaluable, particularly during the night, in pinpointing locations where data measurements were to be taken.

The car was attached to three different trains during the trip. The lencth of the trains varied from 65 to 120 cars. On one 1 eg of the trip, the terrain was such that run-ins were essentially absent. On other legs. even though the trains were handled with great skill, run-ins were not eliminated completely. We found that many normal events encountered in rail transport tend to occur regardless of operator skill, due to such things as train condition, train length, roadbed conditions, and the topography. The route used covered approximately 500 miles.

Truck Tests

Following installation of the cask and instrumentation on the truck, the load was returned by highway to Paducah, a distance of approximately 300 miles.

One incident measured during this truck trip was an outgrowth of tornados and heavy rains in the area during the trip. Streams and rivers were running quite high and at one location, a stream had overrun its banks at a bridge crossing. The approach to the bridge was flooded to a depth of several feet, for a distance of $50-75$ yards.

Upon entering this flooded roadway, a definite "floating" effect was experienced and the side pressure of the flood waters tended to force the truck off the road bed. (An overtumed tractor-trailer van which had been caught in the flood crest some time earlier could be seen about 100 yards downstream.) 
From a shock/vibration standpoint, the data sample obtained during this event indicated it had no shock/vibration significance. (It might have, however, had the vehicle overturned.)

With regard to bumps encountered and crossing railroad tracks, since this test was to duplicate "normal" events, bumpy areas were traversed at slow speeds, and railroad tracks were crossed slowly after coming to a full stop. Upon completion of the normal trip, however, some special high speed runs over bumps and railroad crossings were made.

Upon arrival at the Union Carbide plant at Paducah, the cask/tiedown system was examined by Union Carbide personnel, internal cask pressure was checked, and Union Carbide determined their normal transit test had been successful.

\section{Data Reduction}

Data reduction was accomplished in five steps:

1. Composite oscillograph playback

2. Bandpass os cillograph record playback

3. Calculation of shock spectra from acceleration time histories

4. VIBRAN reduction

5. VAIL combinations

The composite playback is a real-time oscillograph analog record of the data. Playback was through a $2 \mathrm{kc}$ low pass filter. The playback was examined to determine whether data had been obtained, and which data sections could be considered for further detailed reduction. The second step was to take the sections where more detailed data reduction was warranted and display them on a bandpass oscillograph playback record. Examination of bandpass records permitted the choice of still shorter time segments containing the most representative acceleration amplitudes for detailed computer analysis. Certain specific events were reduced in shock response spectrum form. These were events in which a very short burst of shock-like high amplitude was found. The other events 
were reduced in VIBRAN form. This VIBRAN operation resulted in a statistical presentation of acceleration amplitudes that were present within certain frequency bands (see Figure 6). Each number shown within a frequency band represents the percentage of acceleration peaks which reached the level shown on the ordinate. The program additionally computes the RMS acceleration amplitude for each frequency band, computes the overall (Broad Band) RMS acceleration amplitude and reports the total number of peak acceleration amplitudes that were counted in the sample. As a next step, the VIBRAN records for each event sampled were combined in the VAIL program. This computer program permitted the combination of all VIBRAN events in a summary form containing the same type of information as the individual VIBRAN events records.

For this paper, the VAIL program summarized the data samples obtained from each event at the "input" to cargo location on the vehicles for each of the three axes of the vehicle. This reduces all the vibration data taken in these tests to six statistical data presentations of the vibration environment experienced in the Union Carbide shipping program.

\section{Summary of Results}

\section{General}

A brief synopsis of the measurement program results was given by Clifford ${ }^{(2)}$ in his paper at the Second International Symposium. The data herein is an amplification which provides more detalled descriptions of the environments.

Shock

Rail Test Results. - Rail transit imposed shocks upon the cargo from various events. The most severe shocks were found during switching and coupling activities associated with shunting cars in yards and making up trains. The shocks measured during this test (on the order of $2-5 \mathrm{mph}$ ) 
have a very high probability of occurrence (0.95); they should be considered as happening during every rail journey. Shocks measured during this test are shown in shock response spectrum envelopes in Figure 7. Shock response spectra are, in essence, predictions of the reaction of cargo systems having various natural frequencies to the input accelerations or shocks which are being considered. In Figure 7 for instance, the lowermost rail spectrum (crossing railroad tracks and switches) indicates that a cargo system with a natural frequency of $10 \mathrm{~Hz}$ will respond with a maximum $1 \mathrm{~g}$ peak acceleration to this type of event. How ever, if the natural frequency of a cargo system is $100 \mathrm{~Hz}$, a response approaching $6 \mathrm{~g}^{\prime} \mathrm{s}$ may be expected. The spectrum was reduced from data taken during the crossing of railroad tracks that were laid at $90^{\circ}$ to those on which the test car was running. Speed was approximately $45 \mathrm{mph}$. The upper rail spectrum was obtained during a normal speed coupling event with the test car coupled to the engine. The car then was coupled to another car at a speed estimated at $3 \mathrm{mph}$.

While in motion, the responses of the car to shocks induced by runin, run-out, crossing other tracks and switches show the following characteristics:

1. Regardless of the original direction of the input shock, in the lower frequencies $(1-3 \mathrm{~Hz})$ the response amplitude is higher in the transverse axis than in the other axes.

2. Regardless of the original direction of the input shock, in the frequencies above $30 \mathrm{~Hz}$ the response amplitude is higher in the vertical axis than in the other axes.

Truck Test Results. - The events which were found to produce the highest shock damage potential in the truck transport test were encounters with bumps, dips, or potholes and crossing railroad tracks at high speeds.

In general, bumps and potholes appear to produce the most severe overall conditions for cargo systems in truck transport, but the recurrent shock event, crossing railroad tracks, appears to have a higher damage potential for cargo having natural frequencies above $15 \mathrm{~Hz}$ than below 15 Hz. In all events measured, the vertical axis of the truck produced the highest damage potential amplitudes. 
The composite truck cargo damage potential spectra for shock are shown as Figure 8.

Vibration

Rail Tests. - - The vibration records obtained in the rail portion of the test tended to reinforce the results of previous work. Earlier work with less sophisticated equipment has shown few vibration amplitudes higher than $1 \mathrm{~g}$. The present work had the same results. However, in the two frequency bands in which the highest amplitudes are found, the $0-5 \mathrm{~Hz}$ and $5-10 \mathrm{~Hz}$ bands, the data cannot be considered in the same manner as the data above $10 \mathrm{~Hz}$. An analys is of the amplitude distribution within these low -frequency bands shows no resemblance to vibrationlike distributions. It appears that a substantial number of the peaks in these bands are the result of recurring transient impulses rather than steady state vibration. If the frequency bands from $0-10 \mathrm{~Hz}$ are disregarded, the vibration levels are, without exception under $0.72 \mathrm{~g}$ in amplitude.

The data obtained were combined into summaries by program VAIL. When combined, the total number of peaks counted in each frequency band ranged from 2500 in the low frequency band to more than 75,000 in the high-frequency band. As a result, the amplitude distribution within each band may be treated statistically. Analysis of the distributions, except in the lowest two bands indicates that the distribution resembles a Gaussian one.

The 99 percent level was calculated for each frequency band. The result is displayed in Figure 9 . It is noteworthy that in all bands, the amplitudes of the peaks in the vertical axis were higher than those in the other axes. In general, the transverse axis shows higher levels than the longitudinal, although in the frequency bands between $20 \mathrm{~Hz}$ and $60 \mathrm{~Hz}$ this general order is reversed.

Truck Tests. --Vibration data for the truck portion of the test was treated in the same manner. Here again, the lower (0-10 Hz) frequency bands show a high proportion of intermittent, shock-like inputs, but the rest of the data has a distribution which resembles Gaussian random. 
Figure 10 is a representation of the 99 percent level of the vibration measured. The vertical axis once again predominates. In general, the longitudinal axis is second in amplitude, although in the bands between 10 and $45 \mathrm{~Hz}$, the transverse axis shows higher values. In the 60 to 87 $\mathrm{Hz}$ band, the longitudinal and transverse axes are equal in amplitude. Comparisons of Truck vs Rail Transport

The comparisons that we made indicate that while the dynamic environments of rail and truck transport in this test differ in precise detail, the overall environment input to cargo differs little.

Figure 11 compares two typical shock spectra envelopes. During transit, the rail shock switching spectrum indicates there is a lower shock response damage potential for cargo having natural frequencies of $3-25 \mathrm{~Hz}$ than that generated by the truck when it is in transit. At $25 \mathrm{~Hz}$, however, the rail shock response damage potential spectrum becomes higher than the truck spectrum and maintains that position for the rest of the record. The events from which these spectra were derived are normal and may be encountered often in the course of a trip.

If one considers, that for the most part, massive cargo such as RAM containers with their tiedowns tend to have natural frequencies from 3 $60 \mathrm{~Hz}$, neither mode offered a distinct advantage from a shock standpoint in this test.

Figures 12 through 14 are comparisons of rail and truck vibration in each of three axes. In both modes, the vertical axis predominates. It is evident that in many frequency bands, there is little difference. It should be reiterated that the data below $10 \mathrm{~Hz}$ reflect, to a large degree, recurrent, shock-like impulses for these modes of transport rather than vibration. In this area, the shock spectra referred to above provide the better comparison.

In the transverse and longitudinal axes, again there is little to choose between rail and truck transport. The levels in general are quite low, rarely higher than $0.1 \mathrm{~g}$. 


\section{Conclusions}

The shock and vibration environment produced in rail and truck modes of transport on an identical cargo/tiedown system were measured and quantified. Comparisons of data for each mode in this test indicate no distinct difference was offered by either mode with $x$ egard to normal environment intensities encountered.

\section{REFERENCES}

1. Stitt, D. H. and Smith, V. A., "Demonstration Fuel Element Shipping Cask from Laminated Uranium Metal-Design and Fabrication, " Proceedings of the Second International Symposium on Packaging and Transportation of Radioactive Materials, 1968, Union Carbide Corporation and USAEC, pp. 50-1520.

2. Clifford, C. B., "Demonstration Fuel Element Shipping Cask from Laminated Uranium Metal-Testing Progxam, "Proceedings of the Second International Symposium on Packaging and Transportation of Radioactive Materials, 1969, Union Carbide Corporation and USAEC, pp. 521-556.

3. Gens, Mark B., "The Environmental Operations Analysis Function," 1967 Proceedings, Institute of Environmental Sciences, 13th Annual Technical Meeting, Vol. I, pp. 29-38.

4. Foley, J. T., The Environment Experienced by Cargo in a Flatbed Tractor-Trailer Combination, SC-RR-66-677, Sandia Laboratories, Albúquerque, New Mexico, December 1966.

5. Gens, M. B., The Rail Transport Environment. The Journal of Environmental Sciences, 70 July/Aug., pp 14-20.

6. Foley, J. T., Gens, M. B., Shock and Vibration Measurements During Normal Rail and Truck Transport, SC-M-71-0241, Sandia Laboratories, Albuquerque, New Mexico, September 1971. 


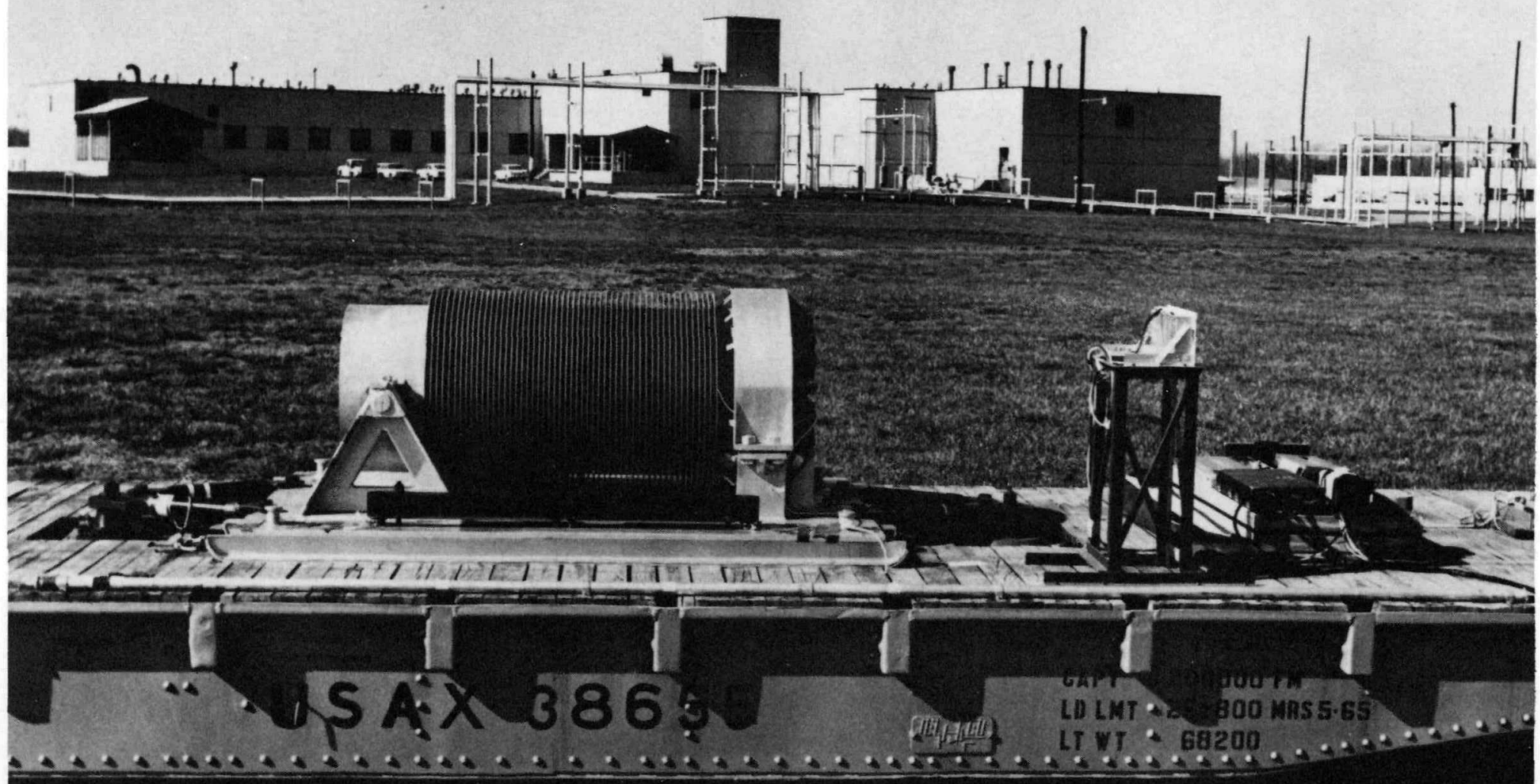

D70-1482

Figure 1. Rail Car - Instrumented 


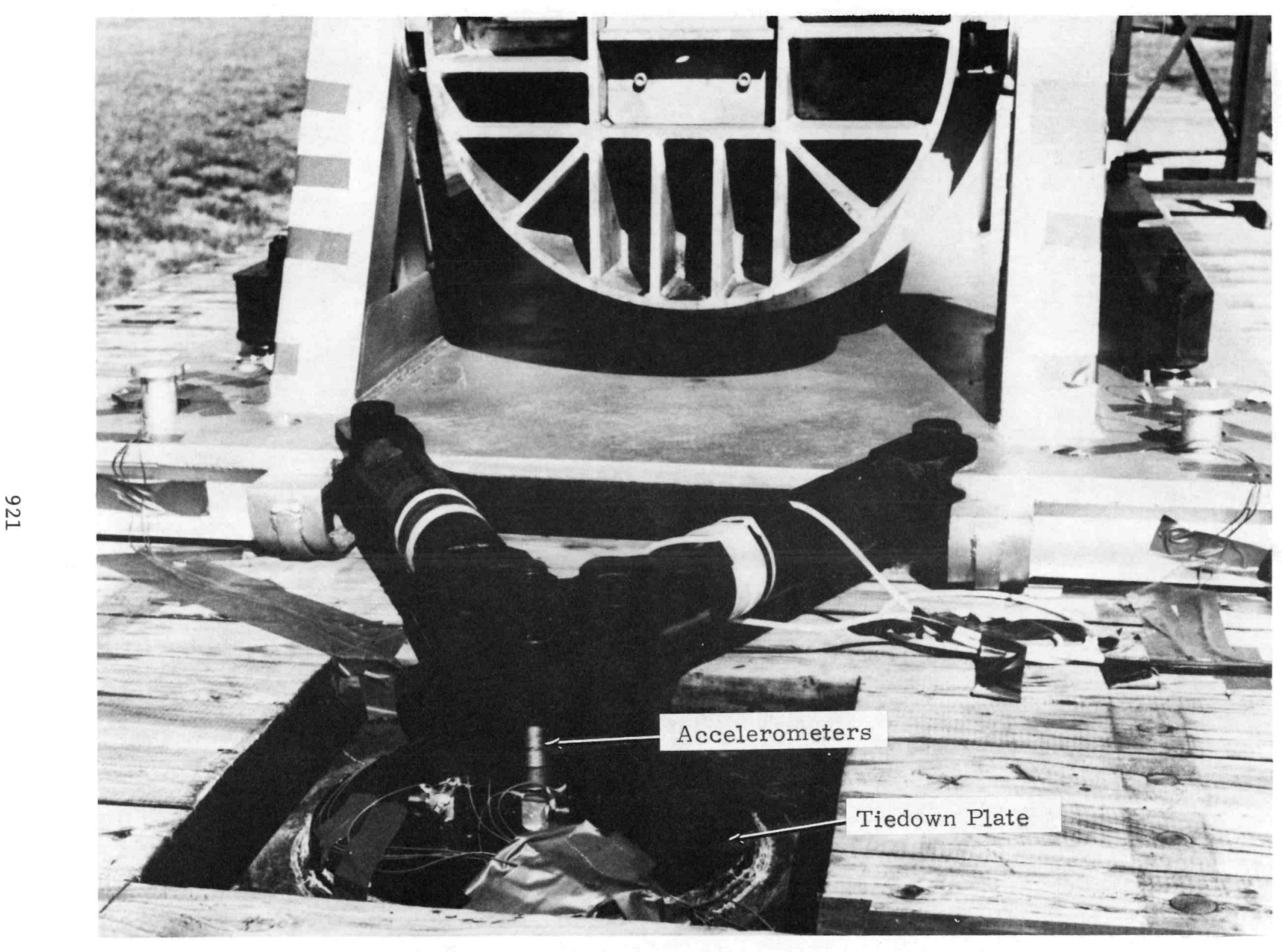

D70-1480

Figure 2. Tiedown Plate - With Instrumentation - Rail Car 


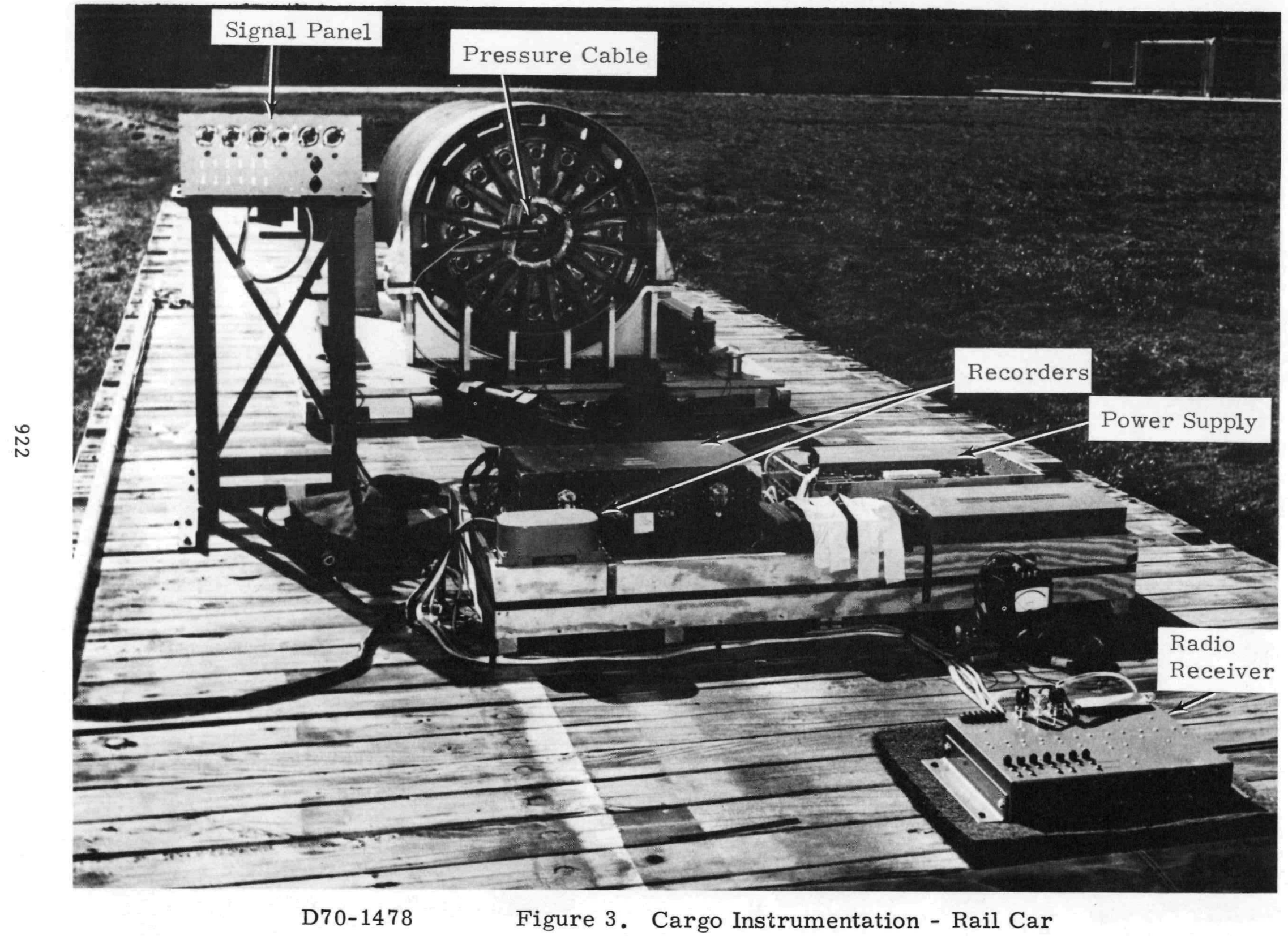




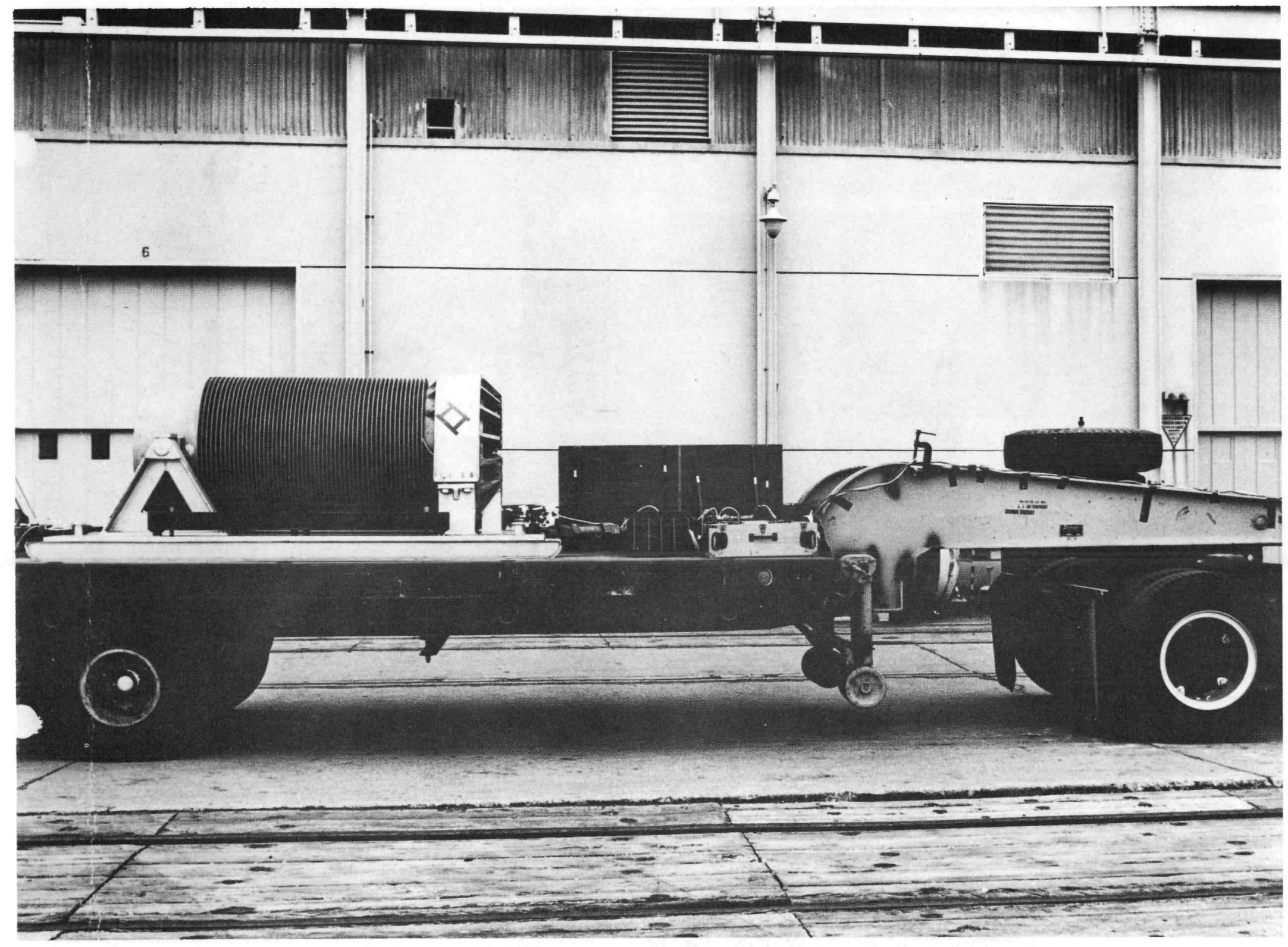



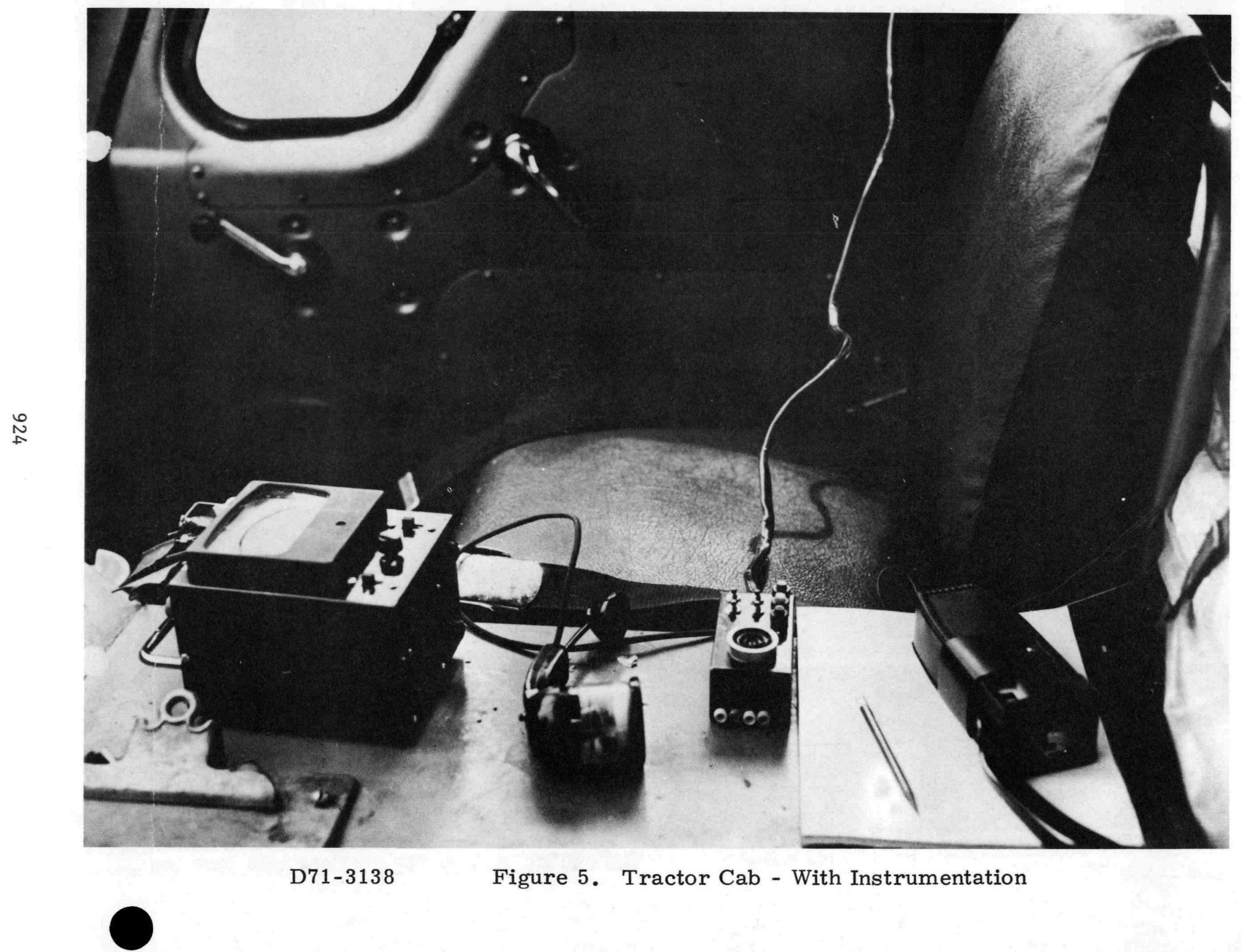


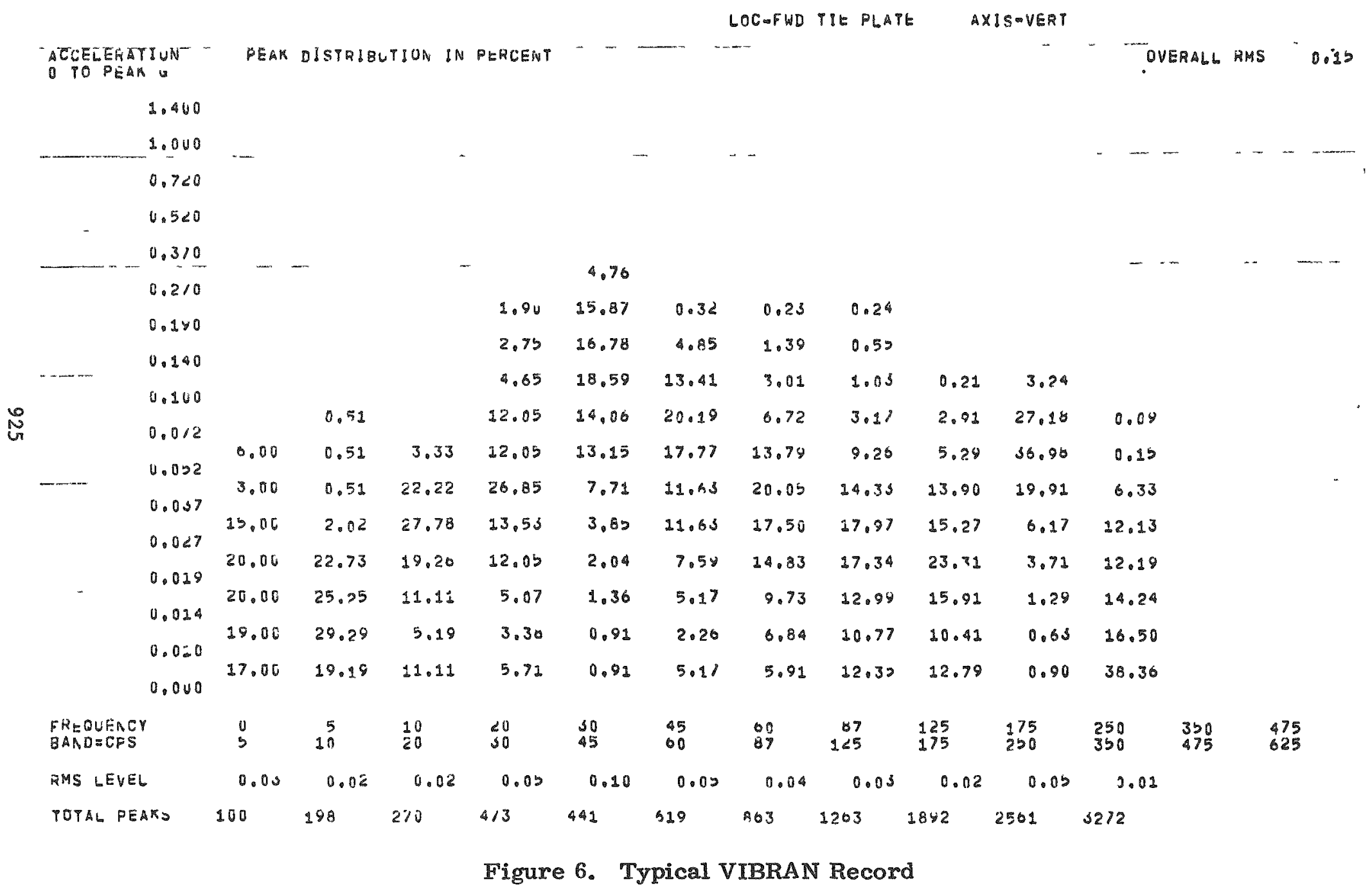




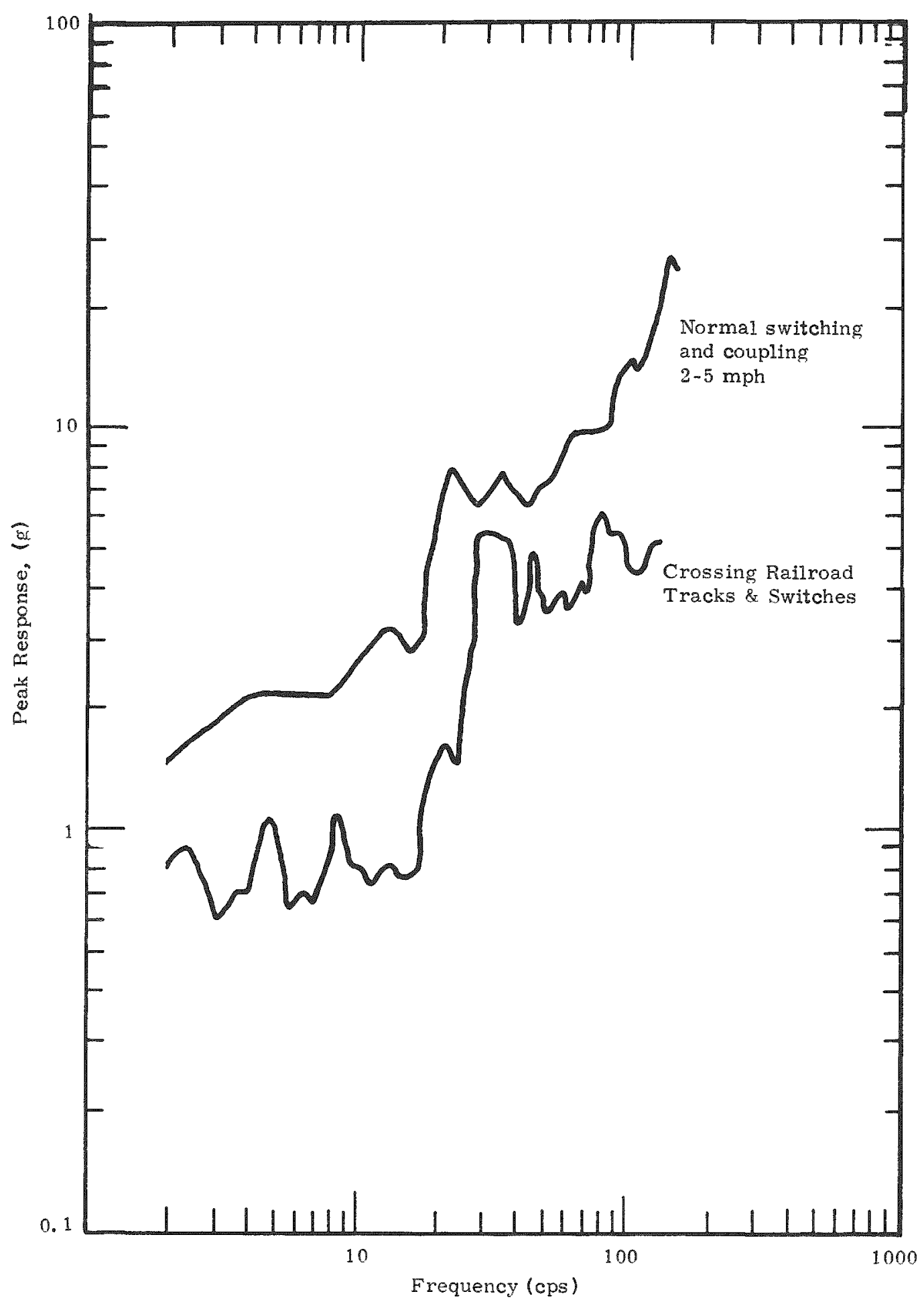

Figure 7. Shock Spectra Rail Envelope Comparison 


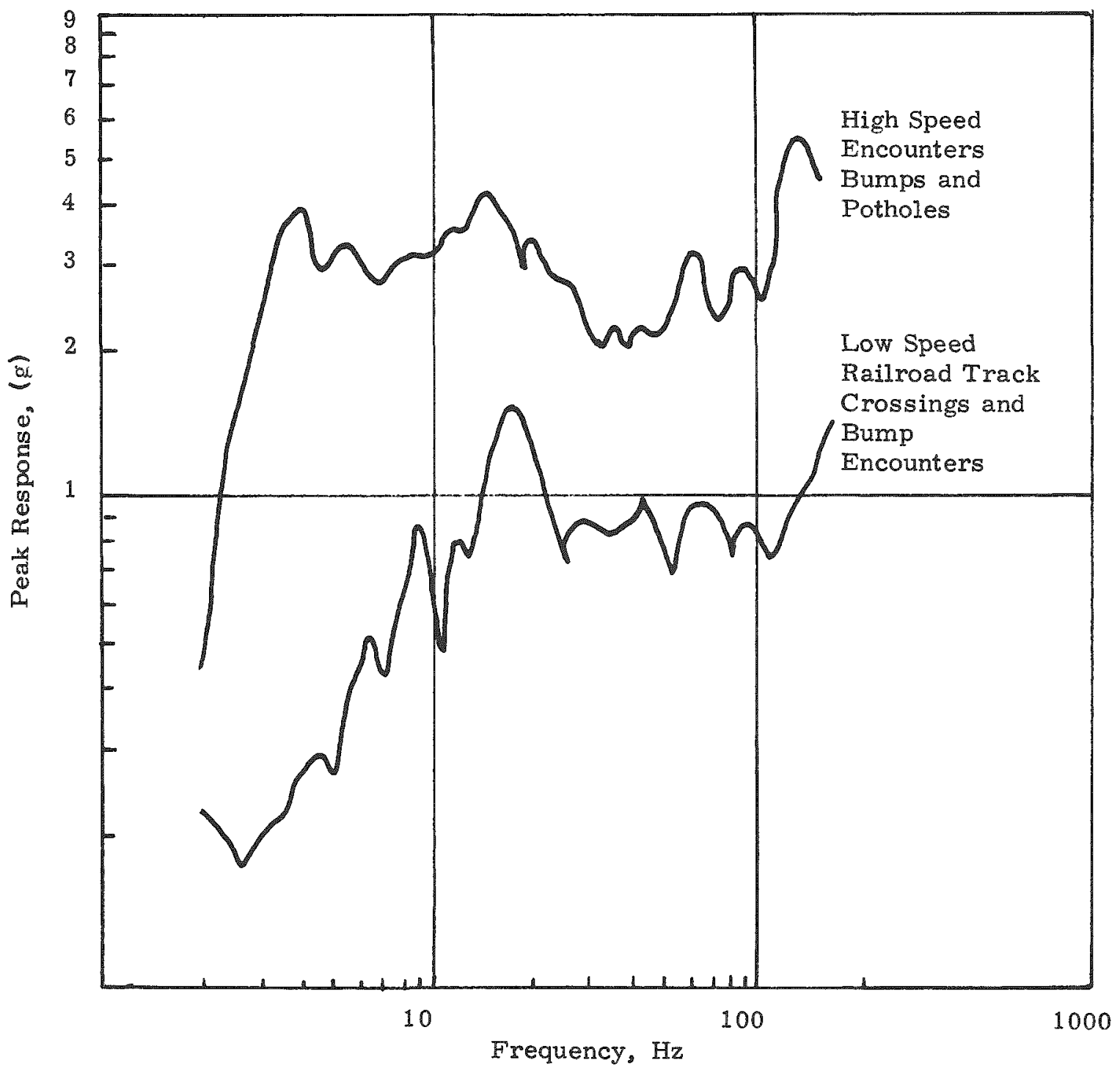

Figure 8. Shock Response Spectra Envelopes, Truck Transport Events, High and Low Encounter Speeds, All Three Axes 


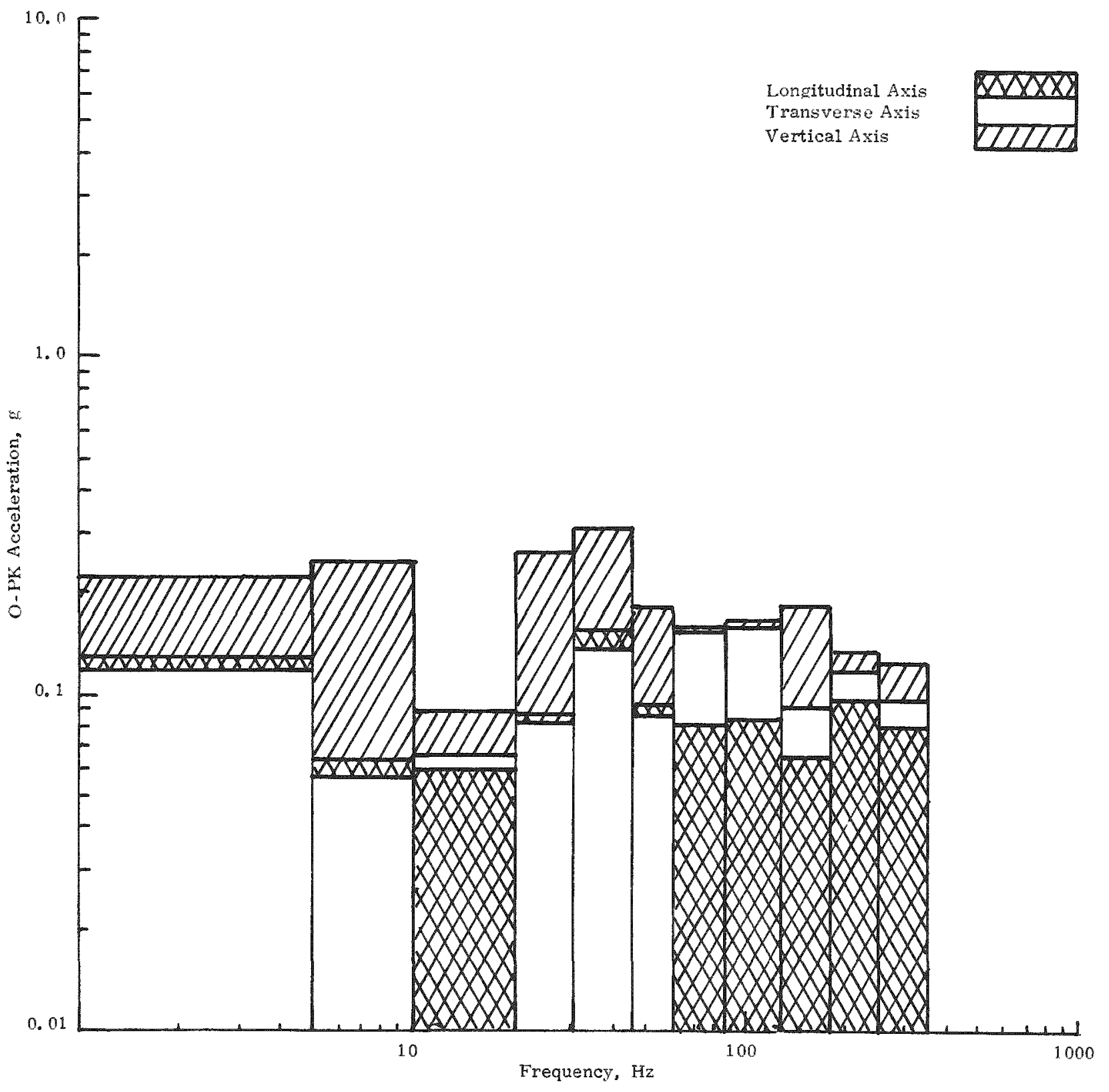

Figure 9. Rail Vibration Summary - 99 Percent Level 


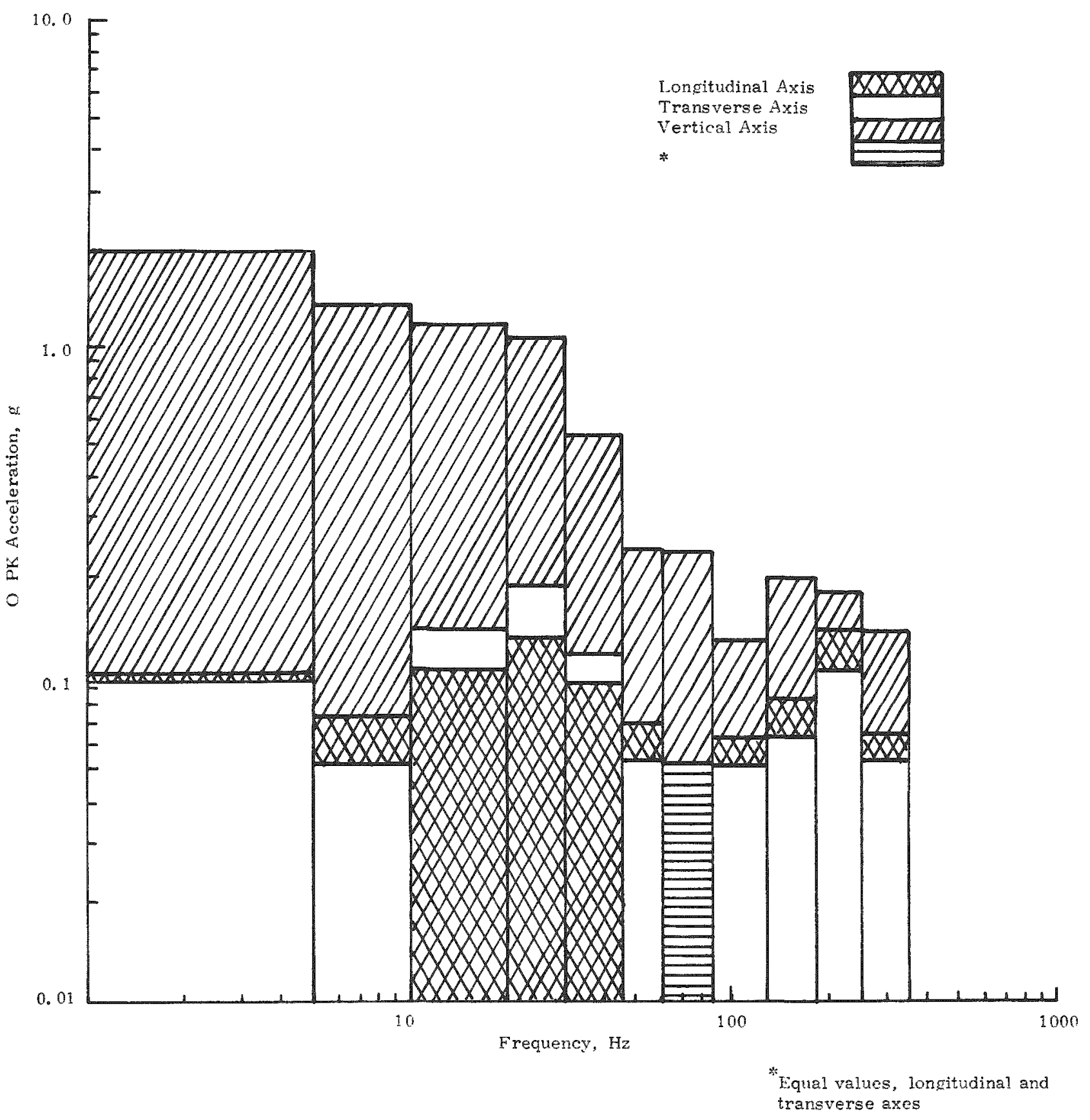

Figure 10. Truck Vibration Summary - 99 Percent Level 


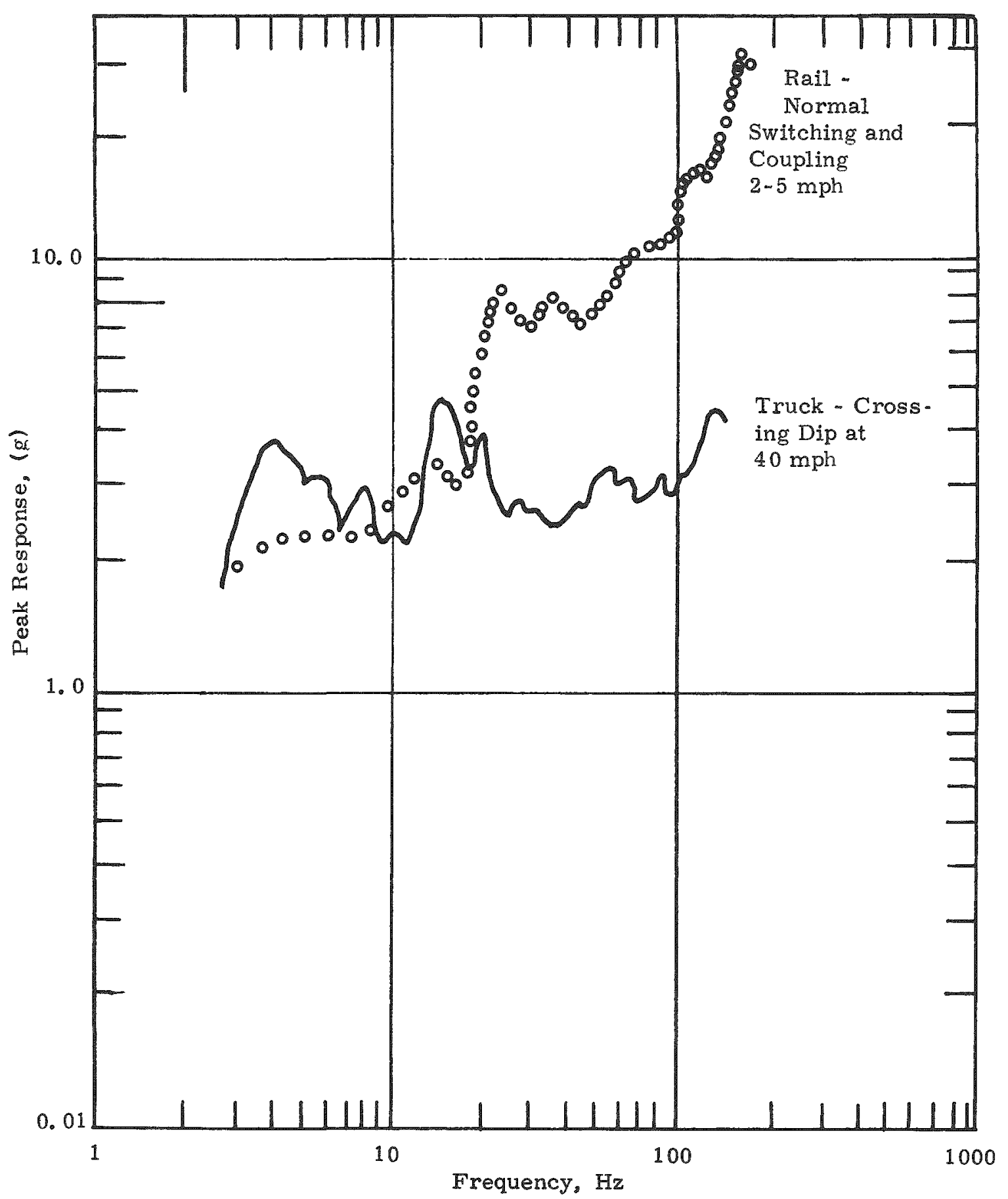

Figure 11. Shock Response Spectra Comparison Normal Transportation Events - Envelopes of Three Axes 


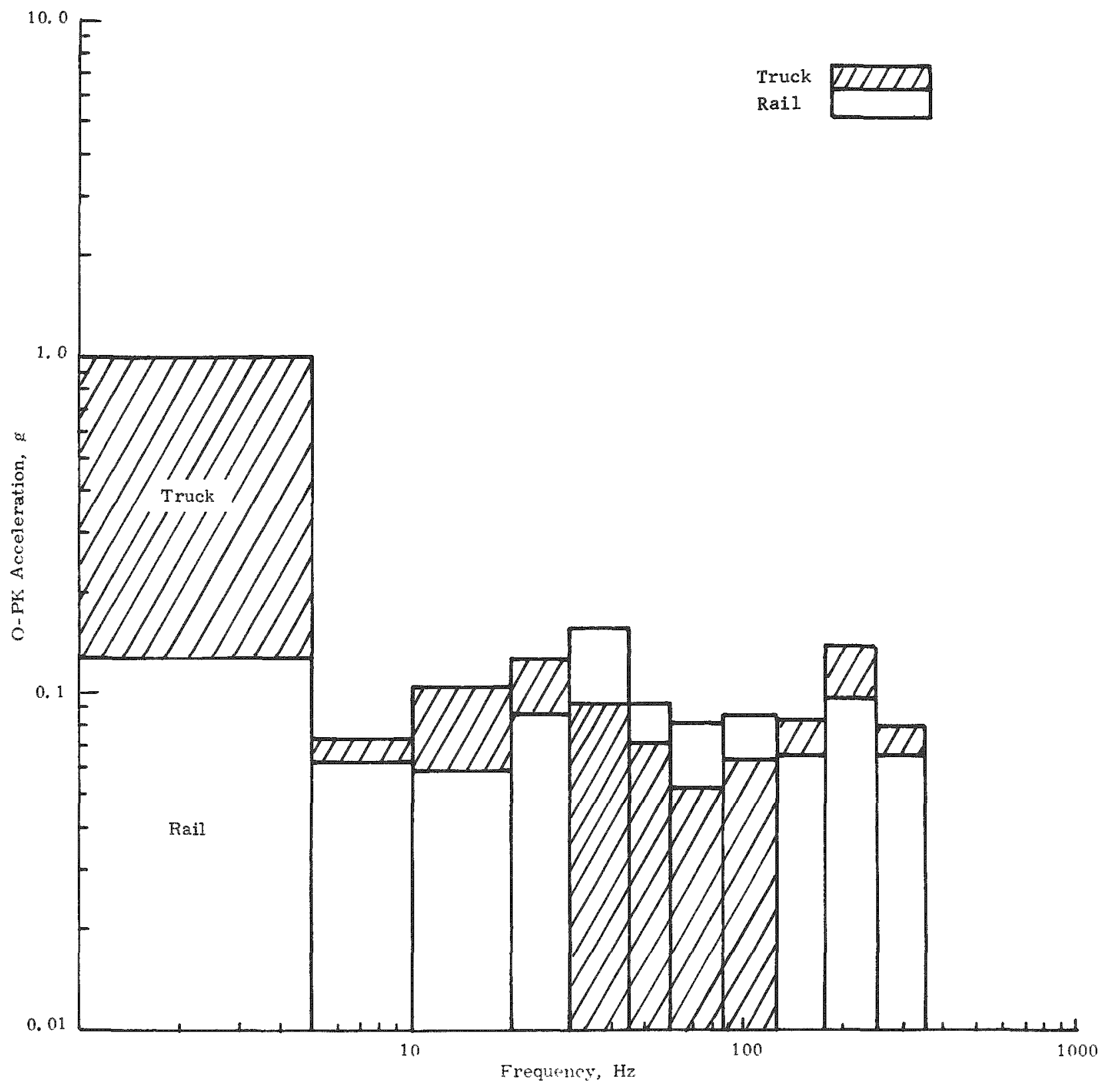

Figure 12. Truck-Rail Vibration Summary Longitudinal Axis 


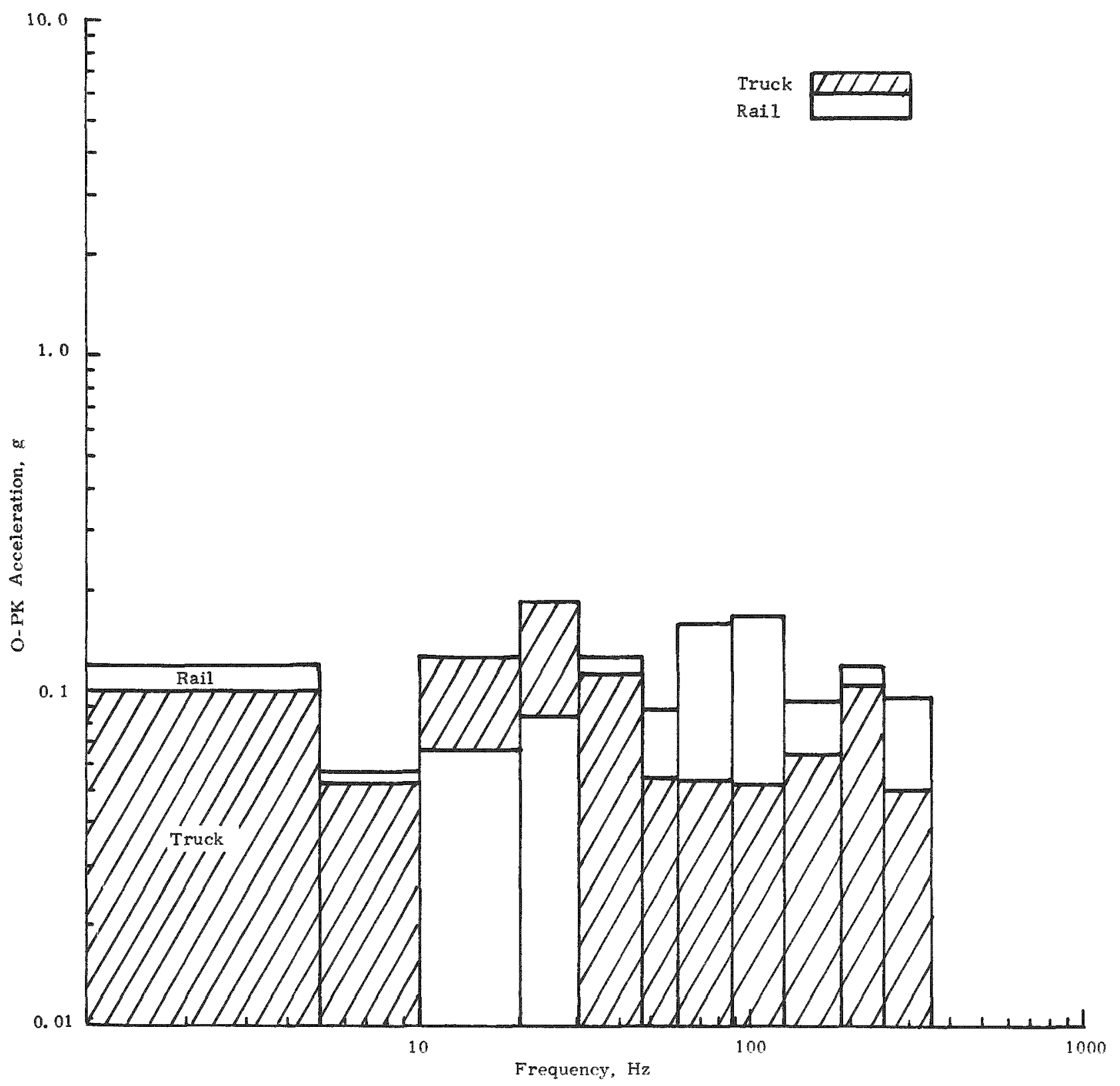

Figure 13. Truck Rail Vibration Summary Transverse Axis 


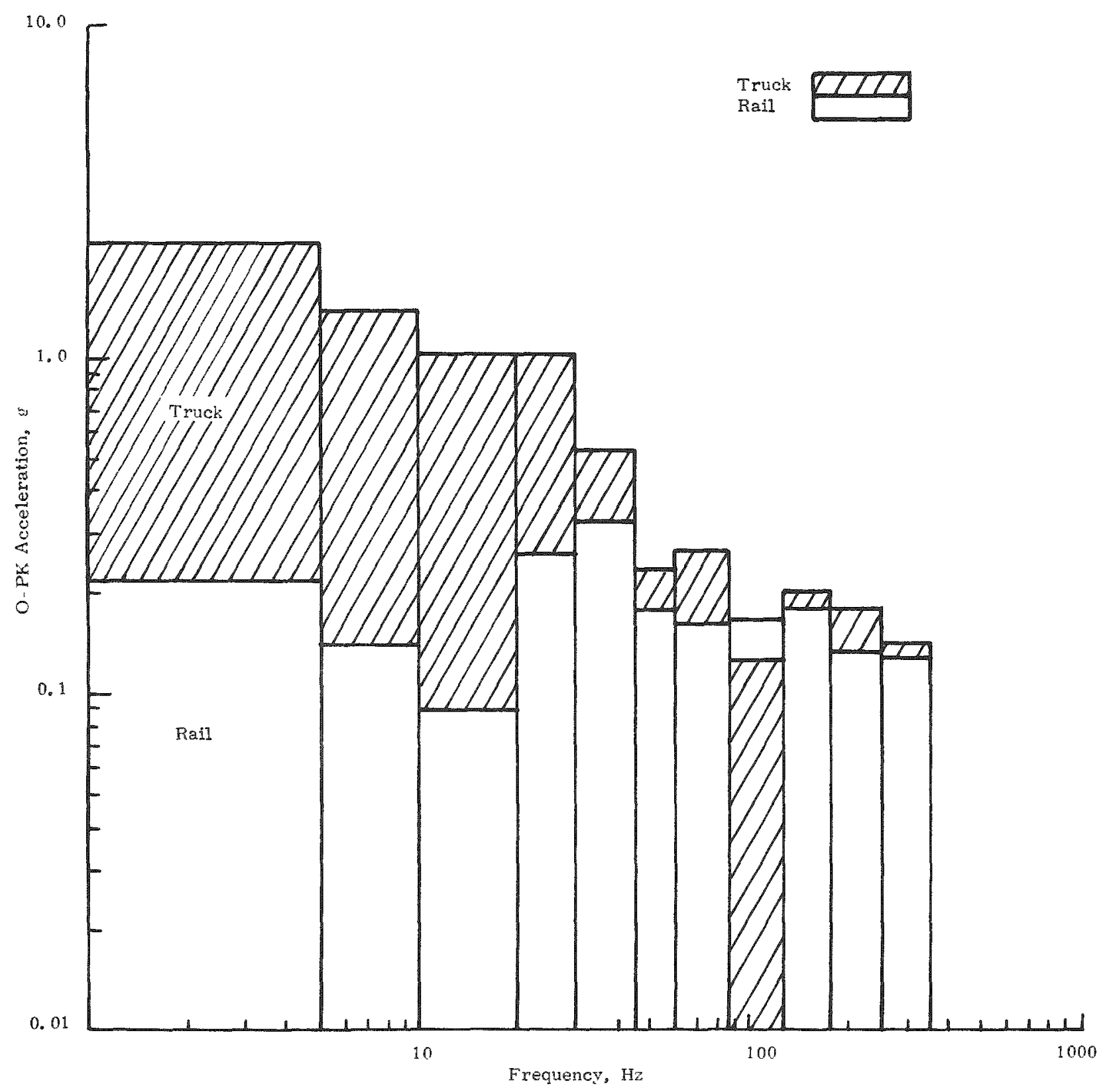

Figure 14. Truck-Rail Vibration Summary Vertical Axis 


\title{
UPGRADING OF PM-3A CASKS
}

\author{
R. A. Scaggs
}

\begin{abstract}
Four casks were fabricated nine years ago for shipment of spent PM-1 and PM-3A fuel cores from small power reactors at Sundance. Wyoming and McMurdo Sound, Antarctica. The casks have remained in service for the latter reactor. Compliance with present U.S.* and International Atomic Energy Agency regulations for shipment was considered doubtful because of possible failure of the closure and possible loss of molten lead under hypothetical accident conditions. Upgrading of two of these casks was undertaken at the request of the AEC. The casks were restored to useful service by extending the protective shroud. installing an insulating plate under the cask. modifying the tie-down devices and lifting trunnions, and modifying the cisk seal.

As part of the program to show compliance with shipping regulations, impact and leak tests were performed on a 500-1b, 1/4-scale test model. Calculated temperatures during the hypothetical fire indicated that the protective shroud will prevent melting of the lead shielding. A nuclear safety study showed that the shipment would comply as Fissile Class I. provided no water leaked into the casks. Leak tests on the model after the drop tests demonstrated the integrity of the seal.

After all modifications, the casks were hydrostatically tested at 30 psig and pneumatically leak tested at 20 psig. well above the maximum expected pressure 7 psig. Heat dissipation tests were then performed.

* Includes regulations from both the Department of Transportation and the Atomic Energy Commission.
\end{abstract}

\section{INTRODUCTION}

In 1962, four shipping casks were built and tested by the Martin Company for the purpose of shipping spent PM-1 and PM-3A fuel from Air Force and Naval reactor sites to reprocessing facilities in the United States. ${ }^{1}$ Later, the United States and the International Atomic Energy Agency (IAEA) regulations for shipping fissile material were revied. so it became necessary to review the cask design with respect to the newer requirements. Preliminary analysis indicated that modifications to the casks would be necessary for compliance with the regulations, and that suitable modifications were feasible provided a small reduction of heat dissipation capacity and a weight increase of perhaps 1000 pounds were acceptable. It was considered that without modification. there was significant probability that under hypothetical accident conditions the closure would leak and that weld failure would occur either from impact or from pressure of molten lead. The purpose of this paper is to discuss the modifications and tests that were made to bring the casks into compliance with the current U.S. and IAFA regulations. 
Spent PM-3.1 reactor cores are to be shipped dry from the power plant at McMurdo Sound. Antartia, to the reprocessing site in the United States. I he cask will be loaded underwater. lifted from the water, drained, and allowed to approach thermal equilibrium before sealing. I he fuel cores have the following characteristies:

Type 11 - enrichment 93'; cermet. stanless sted clad pin type. $31.0 \mathrm{~kg}$ (1-235: irradiated up to $2+$ MW. Yr: cooled 1 year. minimum: total weight 1000 pound.

Iype IV enrichment 9.6'i, stainless steel clad pin type. $57.3 \mathrm{~kg}$ U-235: irradiated up to $45 \mathrm{MW} \cdot \mathrm{Yr}$; cooled 1 year, minimum: total weight 3500 pounds.

Shipments in the cask. after modifications, were to constitute a large quantity of (iroup II

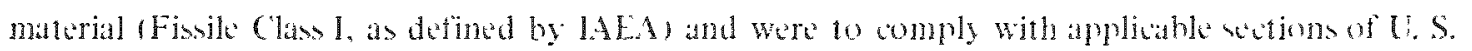
and IAEA regulations.

\section{DLSCRIPIION OF CASK BLFORI, MOIDIFICAIIONS}

The wask assembly consists of the following major components: a lead-shielded cask. 7-7/8-inch nominet thichnes. IFig. 11 into which the spent core is placed: a steel crash frame surrounding the cask to provide protection in the event of an accidental free fall: a shroul around the side: and an aluminum shipping pallet. The cavity walls consist of $1 / 4$-inch thich stainks stecl. Six stainless steel support blochs are welded to the base of the cavity to protide support for the spent core assembly. The outer cask walls consist of 1 -inch thick vainless sted to which are welded about 100 vertical 3 -inch-deep fins on approximately 1 -inch centers around the circumference of the cask for heat transfer purposes. The cask cover consists of $8-1 / 4$-inch thick lead encased in 1/4-inch thick stainless steel around the seals and bottom and 3/4-inch thick stainless steel on top. The crash frame over the cask cover is bolted to four H-beams located symmetrically around the cask circumference. Also bolted to the vertical H-beams is a 1-inch-thick shroud divided into four segments. The cask. crash frame, and shroud are mounted on a shipping pallet.

Some of the cask components were modified as discussed later. Originally, the cask. including its contents and pallet, weighed 35.500 pounds. Tie-down points located between pairs of extra heavy and enlarged fins permitted the cask to be secured both to its shipping pallet and the transport vehicle floor. A pair of trunnions facilitated handling. The cask, including the gasketed seal, was designed to withstand 60 psig. It was not vented directly to the atmosphere during normal transit: however, a relice valve on the cask was set at 30 psig. well above the maximum expected pressure. 


\section{CASK MODIFICATIONS}

With respect to the more recent shipping regulations, several suspected deficiencies axisted in the cask design which necessitated correction before compliance could be shown. At the time the casks were fabricated there was no requirement for maintaining fabrication records: consequently, weld inspection records were unavailable to provide assurance that the welds were of a quality that would withstand stresses generated during a 30 -foot drop or from the pressure of molten lead during the hypothetical fire. Failure of a weld would have permitted loss of at least a portion of the lead shielding, and it could not be shown that the radiation dose rate after such an incident would still be within regulatory requirements.

A second suspected deficiency was the inability to maintain a leaktight closure either during the hypothetical free fall because of forces on the lid or during the hypothetical fire because of excessive temperature of the neoprene O-ring.

To provide adequate assurance of compliance with regulations, the following modifications (Fig. 2 were made to two casks. The modifications added 1800 pounds to the original weight of each.

\section{Protection Against Fire}

The existing shroud was extended upward by 15 inches, an insulating plate was installed on the bottom of the cask, and openings around the shroud and crash frame were covered with louvers to protect the cask from direct thermal radiation in the hypothetical fire.

\section{Lid Fastening and Closure}

The number of lid bolts was doubled (from 12 to 24 ) to reduce the potential lid distortion during a 30-foot drop. The existing neoprene O-ring seal was replaced by a "Gaskoseal" [Parker Seal Co. trademark ] unit which accommodates more lateral motion between lid and body: a component part of this unit is a "Viton" fluoroelastomer [Du Pont trademark] seal which has a higher service temperature than does neoprene.

\section{Tie-down}

Brackets for attachment of wire rope were installed on the crash frame above the cask. The brackets are of sufficient size and number to meet the 2-5-10 g-fore requirements of the regulations (Fig. 3).

\section{Trunnions}

The existing 2-inch diameter trunnions were replaced with 3-inch diameter trunnions, reinforced to prevent serious damage to the inner shell of the cask in the event of a 30 -foot drop on a trunnion.

Stress analysis calculations were made on the lifting and tie-down devices after modification to show compliance with regulations. Stresses in the modified lifting trunnion due to three times the cask weight were found to be less than the yield strength. For the tie-down devices. no stress greater than yield would result from a static force with longitudinal, transverse, and vertical components of 10-g, 5-g. and 2-g. respectively. 


\title{
TESTING
}

\author{
30-Foot Drop Test
}

Regulations specify that the package must withstand a 30 -foot drop on an esentially unyielding surface without significant reduction in shiclding or excessive loss of its radioactive contents, and it must remain subcritical. In order to prevent melting and possible escape of lead, it was considered necessary that the protective thermal shroud, including the new estension discussed above. stay intact during impact. A nuclear criticality study of PM-3A cores II and IV in the cask indicated that Fissile Class I criteria are satisfied for both types of cores provided they are shipped dry and provided the cask shroud is in place. Consequently, a drop test was performed to show that the modified design met these criteria.

A 500-1b, 1 t-scale model of the cash was built for this purpose. The model Figs 4 and 5 was a replica of the actual cask exept that:

- Cooling fins on the cask shell and various louvers around the thermal shroud were deleted. there by subjecting the model to more severe damage than would otherwise have occurred.

- Trumnions and tiedown devices were deleted. Calculations indicated that impact upon a trunion would not puncture the outer shell.

- The shipping pallet was deleted. For the actual cask. the protrusion of the shipping pallet relative to the cask protest the cask from impact at its most vulnerable areas, i.e.. the eylindrical shroud plates and the hottom plate.

o Cask contents were simulated by a solid, cylindrical weight hat ing 1,32-inch clearancen radially and longitudinally.

- It was considered appropriate for leak testing purposes to use a full-scale cross section of the gatsket in the model.

- The upper shroud extension was a solid piece insteat of two plates separated by an air gatp.

- The shroud was fabricated from lour pieces instead of eight. The greater weight and rigidity of the shroud arrangement for the model were considered to be conservative, in that they woukd tend to make the model more susceptible to failure.

The initial drop on the top comer of the crusl trame resulted in negligible damage and the cover remained sealed. To obtain maximum impact energy, the next drop was at an impact angle such that the center of gravity of the package was directly above the impat point on the bottom plate. Portions of the bottom plate and the bottom flange of the cask were permanently deformed. Several bottom-plate attachment bolts were broken, but the bottom plate remained in place: thus. the package survived the drop in a manner which satisfied the regulations.

I wo drop tests on the side of the cash showed that further modifications were necessary to keep the thermal shroud and bottom plate intact. The shroud was then reinforced with wire rope and flexible clip plates and the diameter of the bottom plate was reduced. In the second of these side drops the shroud remained intact but the bottom plate came off due to failure of the attachment bolts; therefore, for the actual casks the ratio of bolt strength to plate strength was increased by more than 12 times. Based upon a stress analysis, it was concluded that the modified bottom plate would remain attached to the cask after being subjected to the impact of a 30-foot drop. Upon completion of the drop tests, immersion of the cask model in water and pressurization 
with air to 30 psig for 30 minutes showed that the seals had not failed upon impact. It was concluded that no water would have entered the real cask.

\section{Thermal Analyses}

The casks had been fabricated about eight years before the present regulations came into effect. It was not considered feasible to demonstrate that weld falure and loss of lead would not occur from impact or from axpansion of lead upon melting. Many of the modificitions mentioned above were made to shade the cask from direct thermal radiation (and thus prevent melting of lead in the firel while still permitting air circulation and removal of heat in normal transport.

Demonstration of compliance with requirements relating to loss of shielding, loss of coolunt. and escape of radioactive material under hypothetical fire conditions was based on calculations which show that: (1) the lead remains well below its melting point, (2) the lid closure does not reach the maximum acceptable operating temperature for the "Viton" seal, and $(3)$ the maximum pressure will be well under the leak-test pressure.

To determine the maximum temperatures in the cask during the hypothetical themal aceident, a thermal analysis was performed by Battelle Memorial Institute by means of the THT-D heat transfer code. It was assumed that:

- The cask conten ts produce decay heat of $2.5 \mathrm{kw}$.

- Before the fire the cask system is at a steady state corresponding to ambient air of $100^{\circ} \mathrm{F}$, with normal circulation of air and some chimney effect in the annular space between the cask wall and the external shroud.

o During the 30-minute fire all heat input is radiant heat to the exposed external surface, with no chimney effect by with convective as well as radiant heat transer between the shroud and the cask wall.

o After the fire cooling takes place by normal processes of radiation, convection, and conduction. with chimney effect and with $100^{\circ} \mathrm{F}$ ambient air. The effect of the absence of chimney effect during the cooling period is also discussed.)

Some approximations and simplifications were incorporated in the mathematical model to permit computer analysis with a reasonable number of nodes, and to accommodate certain restrictions of the code. The maximum calculated temperature for any point in the lead during or after the fire is $341^{\circ} \mathrm{F}$, occurring at the bottom outside corner of the lead region. The average lead temperature is in the range of 220 to $240^{\circ} \mathrm{F}$ at the end of the fire, and reaches a maximum of about $300^{\circ} \mathrm{F}$ one hour after the fire. The melting point of lead is $621^{\circ} \mathrm{F}$. The maximum temperature of the "Gaskoseal" assembly is about $300^{\circ} \mathrm{F}$ which is well below the recommended maximum continuous temperature of $400^{\circ} \mathrm{F}$ for "Viton."

Although the regulations require accounting for only radiant heat input, chimney effect could be important in an actual fire when the cask is surrounded by a thermal radiation shield. In this case, as an added safety feature, intumescent paint (swells with heating) was added to the bottom louvers of the shroud to substantially eliminate chimney effect during and after the fire. 
Heat dissipation tests were performed on both shrouded casks using dummy spent fuel loads (2.5 kw heat input) to show how the modifications changed the heat dissipation characteristics of the casks. Thermocouples measured the temperature drop across the cask wall as thermal equilibrium was established. These results, aside from the primary purpose of assuring that the cask would dissipate the required amount of heat during transport, provided a basis for slight adjustment of the previous computer calculations of temperatures both in normal transport and during the hypothetical fire. No significant difference exists between the two casks, and the maximum temperature difference between their cavity surfaces and ambient air was $88^{\circ} \mathrm{F}$ for an internal heat load of $2.5 \mathrm{kw}$, assuming no external heat source. The $28^{\circ} \mathrm{F}$ excess over the temperature estimated in the computer study was concluded to be not significant, and was attributed partly to air-flow restrictions of the cask modifications and to thermal resistance at the lead-steel interfaces.

Based on results of the calculations described above and the heat dissipation tests, it was concluded that exposure of the cask to the hypothetical fire produces no results which violate the applicable regulations.

\section{Leak Tevting}

After all modifications were made. the casks were hydrostatically tested at 30 psig and pneumatically leak tested at 20 psig, well above the maximum expected pressure of 7 psig during the hypothetical thermal accident. The sensitivity of the leak test was considered to be about $1 X$ $10^{-4} \mathrm{~atm}$ cessec.

\section{DISPOSI7ION}

Test results were assembled in a Safety Summary Report ${ }^{2}$ which was submitted as part of the application for a shipping license. and the licensed cask were returned to the Naval Facilities Engineering Command for use.

\section{REFERENCES}

1. W. P. Haass (Ed.s. Hazards Summary Lvaluation - Spent Fuel Shipping Cask for PM-1 and PM-3A Nuclear Power Plants. The Martin Company, Nuclear Division, Baltimore, Md., MND-M-1856 (May 1961).

2. J. W. Langhtar and R. A. Scaggs, Safety Summary Report - PM-3A-M Cask, F. I. du Pont de Nemours \& Co., DPSPL $71-124-3$ (June 1971). 


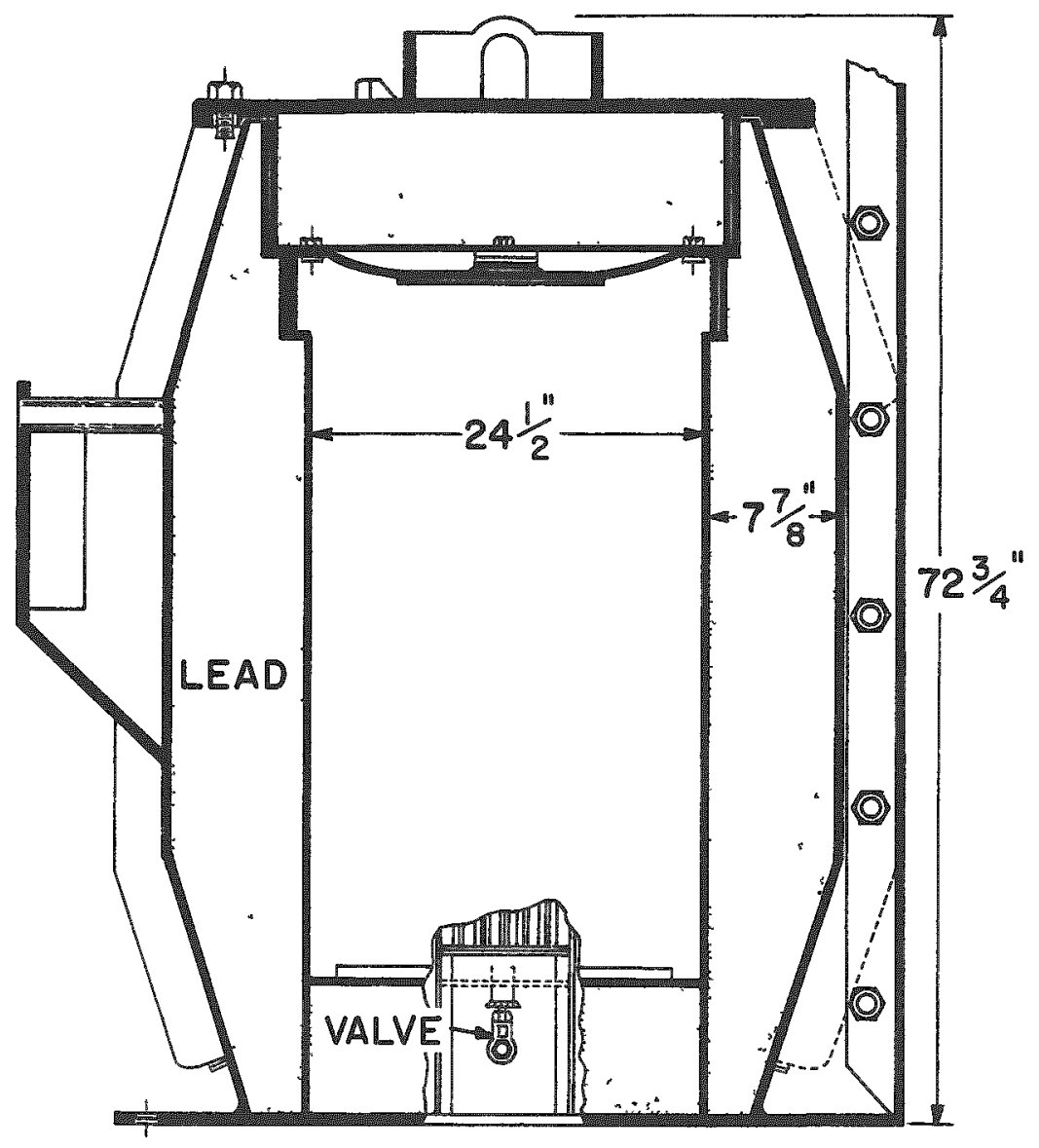

FIGURE 1. PM.3A CASK BEFORE MODIFICATIONS. (Nof shown crosh frame, thermal shroud, shipping pallet.) 


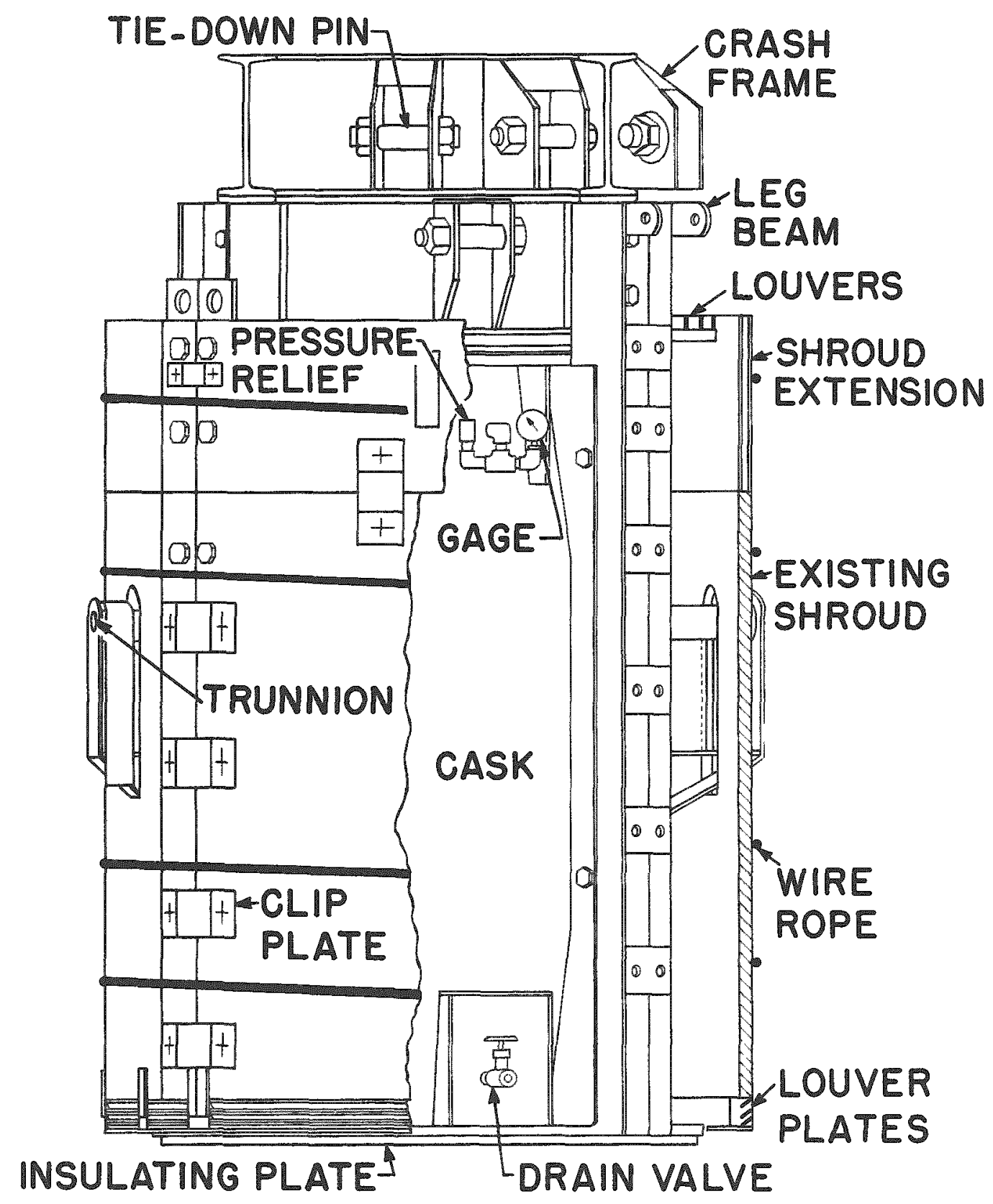

FIGURE 2. PM-3A CASK ASSEMBLY AFTER MODIFICATIONS 


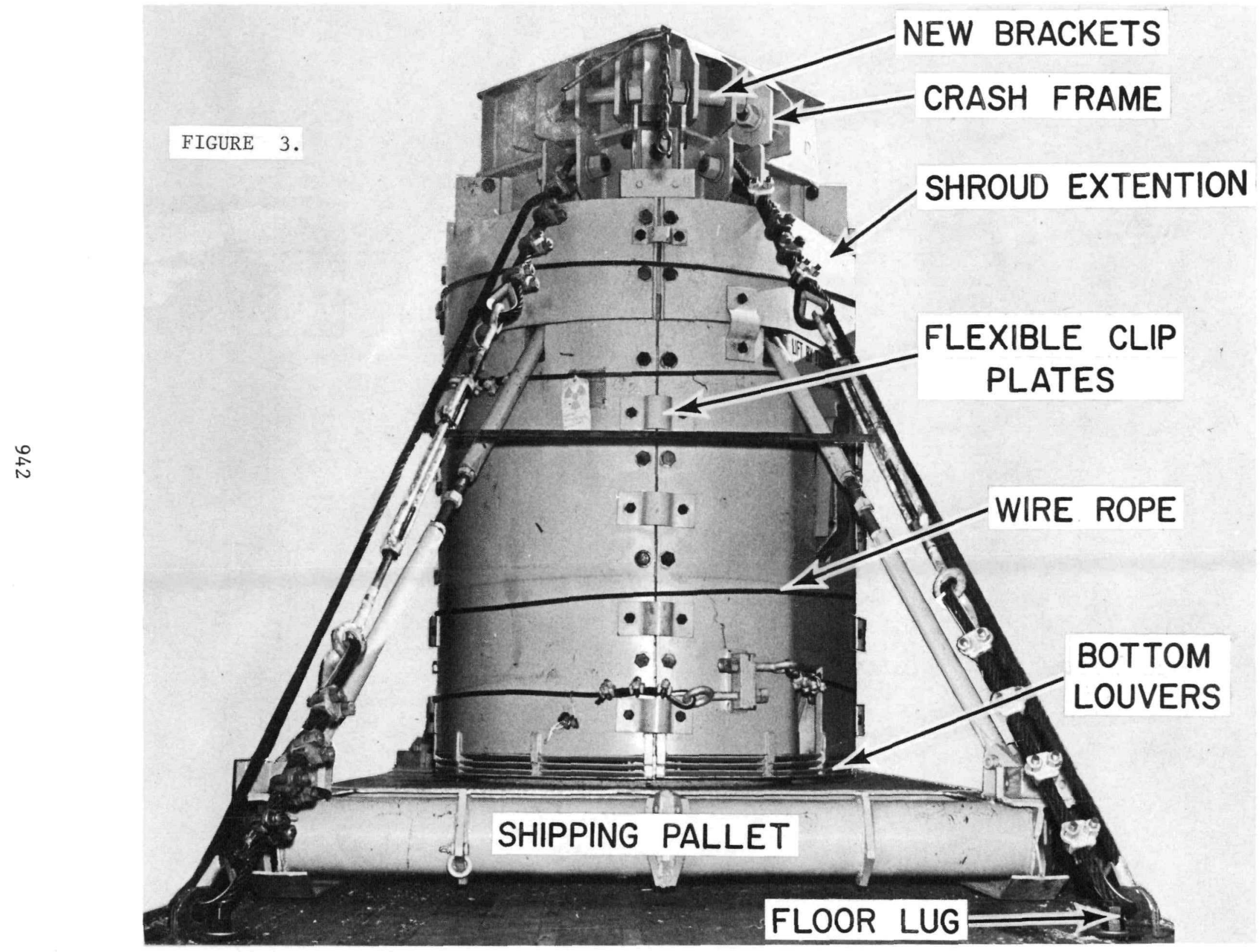



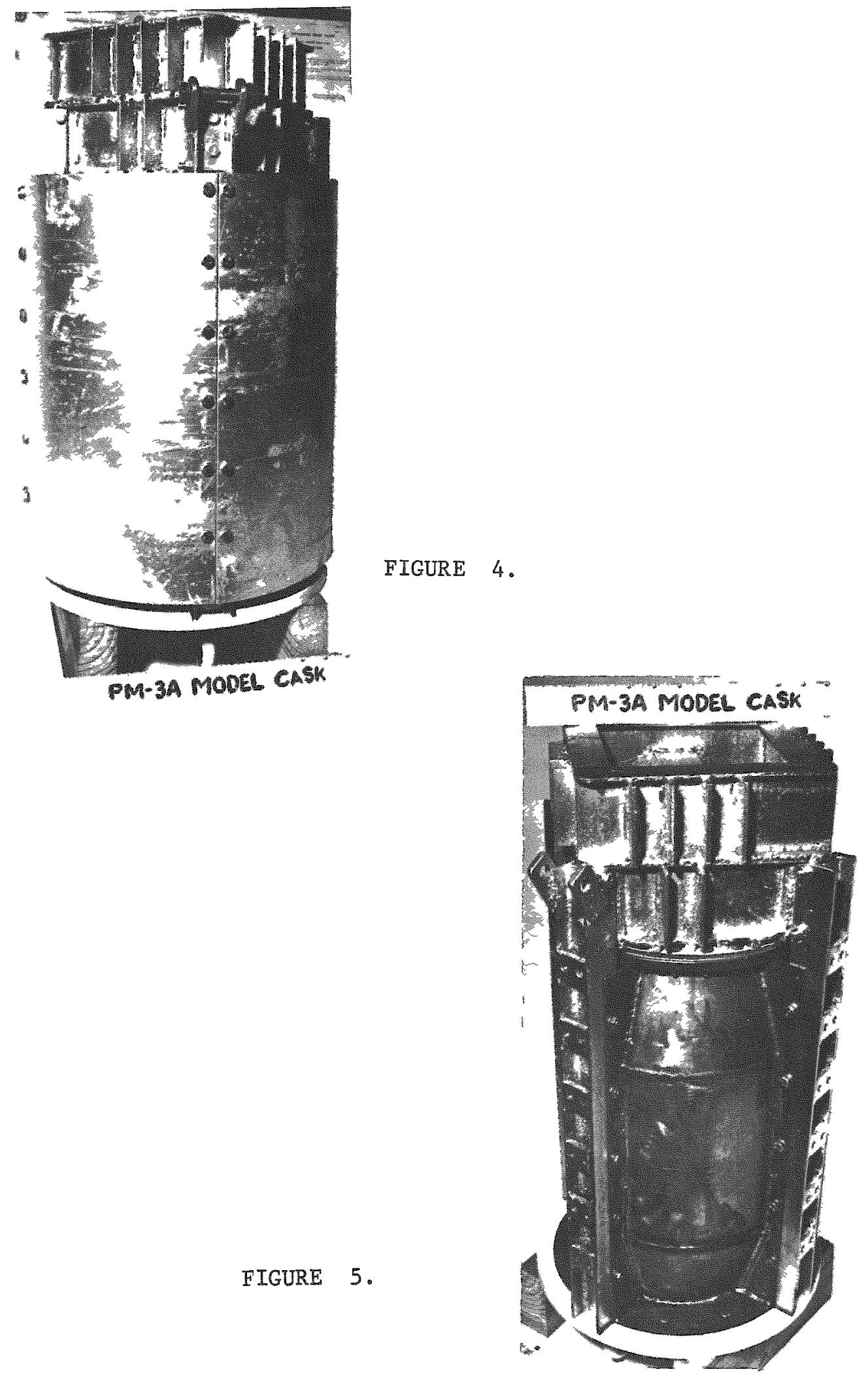
FUTURE TRENDS IN AUTOMATED FREIGHT HANDLING SYSTEMS

J. C. Wolff

This paper was not available at the time of printing. It has subsequently been issued as BNWL-SA-3906, available from NTIS, 5285 Port Royal Road, Springfield, Virginia 22151. 


\title{
QUALITY CONTROL OF SHIPPING CASK FABRICATION
}

\author{
Allen Short
}

\begin{abstract}
ABSTRACF
Vitro Hanford Engineering Services recently redesioned and inspected the modification of a cask (FAPC-1C-1) for shipping cesium-137. Safety requirements involving structural and containment integrity were understandably high. To achieve this conformance to stringent safety criteria, a carefully devised and administered quality-control program was prepared and implemented.

Because of the complex structural configuration of the cask, a detailed fabrication plan was prepared to insure that each comoonent was correctly installed in the proper sequence. This fabrication plan provided the framework for the ensuing quality-control program. Every requirement for confomance to codes, specifications, and drawings was carefully listed for each step in the preparation of every component and for the subsequent assembly of components to complete the fabrication. Thus, a "control" document evolved that was completely comprehensive and chronological in arrangement.

An adequate force of carefully instructed and experienced inspectors maintained constant surveillance over every facet of fabrication and assembly.
\end{abstract}

Accidents involving shipoing containers or casks filled with radioactive material are certainly to be avoided, especially situations where the containment integrity of casks are breached. Hapoily, breaching of such containers has not occurred in the US.

Stringent safety factors are incorporated into shinoing containers to positively insure their integrity if exposed to the violent forces of a transporta.tion accident. One effective and direct method of exercising quality control over container fabrication to assure safety in case of such an accident is the subject of this paper. 
Hanford Engineering Services (HES) recently accepted the responsibility for the design of an insert to be used in conjunction with an existing isotopes shipping cask. The new insert was to be used for cesium-137 shipment. The insert as positioned in the cask is shown in Figures 1 and 2 .

Seven drawings were required for the detail design of the insert; it consisted of 229 parts and was basically fabricated of AISI Tyne $304 \mathrm{I}$ stainless steel. The predominant assembly method was inert-gas, shielded tungsten are welding. Removable covers and blind flanges were held in place by threaded members. Safe shielding of the highly radioactive cesium-137 was achieved using 5192 lbs of poured lead.

Required quality levels for fabrication had been established in the cask insert design drawings and referenced specifications. Determining the verification of highest fabrication quality levels become the concern of HES inspection personnel.

During design of the insert (See Figure 3), it became apparent that a combined quality control and assembly sequence program was imperative. A system of quality control "checks" arranged in assembly sequence plus 100 percent inspection surveillance was settled on as the most effective approach.

The contracting organization, for whom the cask insert was fabricated, required a final document at the completion of the job attesting to the complete job conformance. A "check-list" type of quality-control document filled this requirement.

The fabricating contractor elected to work on the insert on a 24 -hour per day basis to neet extremely tight completion schedules. Several inspectors were thus required to maintain the degree of surveillance that was considered necessary. The use of more than one inspector introduced the necessity of standardizing the inspection and quality control. It also required that there be an uninterrupted transition at shift changes, and that each inspector establish and support his own individual responsibility.

The objectives of the inspection procedure were to:

- Provide an inspection instrument that would insure the attainment of the highest quality levels in the completed fabrication.

- Imphasize through high specificity of detail the detection and prevention of defects and deviations as soon as possible in the fabrication process, thus minimizing corrective efforts. 
- Provide pernarent documentation of the hish level of quality control exercised during the fabrication of the shirrin cask insert.

A study of the fabrication snecification from the perspective of the cask insert resulted in the arrangement of a "pre-favrication" check list. It was mainly a brief outine form of the srecification reauirements that recuired constant observance.

The specification requirements for the cask insert were not uncomonly severe. There were no unusually difficult fabrication problems anticipated, and nordestructive testing was linited to dye penetrant examination of the initial root weld pass. AIl other inspection was visual. It was strongly feit that with visual examination being the predominant inspection immlement to be used that a check list should be witten in enough detail that every edrantage of such inspection could be exnloited.

As part of the design package, an assembly-sequence document (HWh-8417) was provided. It described en orderly sequence for assembling the components. This "assembly sequence" served as the foundation upon which the check-Iists of the quality-control procedure were structured. Also, a "pre-eabrication" check list was developed (See Attachments A-I and 2). This list is basically a brief outline form of specifications.

A thorough study of the cask insert desion was a prerequisite to startino the check list. Irext a drawing was selected remesenting the assemblr of a segment of the insert. A reference to the Assembly sequence indicated the first part for which an individual checis list should be prepared. An entirely comprehensive evaluation was then made of every possible activity that might be involved in the accentance, preparation, treatment, and integration into a larger component of that one narticular part. Those that were applicable were listed in the proper order and in the same detail that were to later mark its union with another part.

Some representative steps are shown in Attachment 3 . Eighty-one such steps were included in the quality-control procedure. Some of them contained as many as 33 items.

When all the inspection requirements for one nart vere listed, the Assembly Bequence was consulted for the next nart to be considered. Then, the entire process was repeated until a check list had been develoned for all the parts; and all the parts had been integrated into the comnleted insert. There were some instances where the check lists added additional steps to those listed 
in the assembly sequence where it was felt necessary. In a few isolated cases, there were design errors that were detected as a result of the infinite detail involved in creating the check lists. In addition to the check lists, a drilling plan was created which located, dimensioned, and identified all the holes to be drilled in the upper, $1-1 / 2$ in.-thick circular plate. It was felt that centralizing all the drilling requirements was justified by the resulting simplification.

When the check lists were completed, they were immediately sent to the principal individuals in the purchasing organization for their review and approval. In a few cases, there were revisions and corrections that were sugrested and made. As soon as the check lists were approved, it was then possibie to consider the beginning of fabrication.

Several meetings were arranged between the inspection personnel and representatives of the fabricator. Discussions were held regarding the extent of documentation the fabricator was expected to provide and the best methods of handling it.

Welding procedures that had previously been qualified were selected to represent welding that would be done on all types of joint geometries involved in the fabrication. Those procedures were examined by the inspection personnel and. If found acceptable, were retained to become a pert of a nermanent file. Specification requirements allowed the optional use of three weldine processes, but virtually all the welding was done with the gas tungsten are (GIs) process.

Some weldors who were scheduled to work on the cask insert had been qualified previously. Their qualification records were submitted to the inspectors for review. Other weldors were tested at the time of fabrication and their records submitted for review.

Material certifications for all new materials were carefully checked, the specific material identified with the correct material certifications, and the documents filed. Each material segment was examined to verify that its identity in relation to material certification was maintained. Material preparation was monitored carefully to assure the use of proper equipment such as surface grinders that had not been previously used on carbon steel. Cleanliness was emphasized, and machined and threaded parts received protection as soon as possible after preparation. The exposed edges of stainless steel, when cut by either the flux-injection method or plasma are, were carefuly ground back to expose clean base metal. Prepared weld joints were carefully checked for 
conformance to the appropriate welding procedures and protective measures provided until the part was ready for fabrication.

The fabricator personnel had been given copies of the quality-control procedure for their use if they elected to use it as a guideline. Because the procedure was more specifically detailed than the assembly sequence (HWS-8417), it proved helpful as a fabrication aid. On a few occasions, it was found advisable to deviate slightly from the assembly sequence and chronology of the quality-control procedure. However, both documents were flexible enough to allow the changes to be properly noted without impairing their effectiveness. Changes were reviewed and aporoved.

Fabrication and assembly continued without interruption (three shifts each day, five days each week) with constant inspection surveillance exercised on all shifts. The fabricator had scheduled the work so that, when problems were encountered, the craftsmen's efforts could be shifted to other areas without lost time. The use of the quality-control procedure greatly simnlified the surveillance and documentation of such work interruptions. The transfer of inspection activities from one area to another, or from one inspector to another, was performed effortlessly and without loss of continuity or application. With fabricator craftsmen and inspectors virtually working from the same document, their efforts were concurrent and harmonious.

The few problems mentioned above that were encountered were quickly referred to the project engineer for resolution. His solutions were quickly conveyed back to the fabricator and inspector. The chenges were documented in the quality-control procedure and the required adjustments made in the check lists. Daily visits by the inspection supervisor verified the entry of the changes and their correctness. Changes were noted on the drewings for future "asbuilting"; these created only a minor problem, there being only eleven changes in the entire insert.

The resin-containment annulus of the insert was tested for containment integrity by pressurizing to 3 psig after the introduction into the annulus of a halogen gas mixture. A halogen detector (See Attachment $C$ ), sensitive to I part halogen gas in 250,000 , was used to detect the presence of any leaks. None were found. The thermowells and cooling coils were pressurized with air and tested for leaks by painting all potential leak areas with liquid soap. IVo leaks were detected. All the abovementioned tests were noted in the quality-control procedure in the appropriate places for permanent documentation. Testirg of the insert and cask for radioactive shielding capabilities had been assigned previously to another organization. 
Throughout the extire program, fabrication and inspection continued smoothly with few interruptions. The nature of the zuality-control procedure reauired that fabrication, inspection, and documentation remain concurrent. Nany advantages were realized as a result. There were no forgotten or overlooked items to require work retrogressions for installation. There were no frantic "last minute" recapitulations to develop a "punch-list" of neglected items. When the assembly was finished, the job was comleted in its entirety with all documentation intact and in good order. There were no "loose ends."

The final document stating that "inspection of the fabrication of the HAPO-IC-I shipping cask was done in strict accordance with the subject fuality control procedure or as noted therein," was signed by the three particinating inspectors and the supervisor (See Attachment D).

In summation, this guality-control procedure:

- Outlines the inspection activities and creates a coherent and sequential structure for the entire irspection effort.

- Provides a completely and comprehensively detailed check-off list that eliminates forgotten and overlooked items.

- Simplifies the temination and resumption of insrection activities and the transfer of responsibility from one insnector to another.

- Serves as a final check for drawing accuracy and eliminates delays and work retrogressions caused by drawing errors.

- Minimizes office record keeping time for the inspector and allows maximum time on the job site.

- Eliminates the uncertainty of the "punch-list" system.

- Simplifies documentation responsibilities.

The shipping cask described here continues to be routinely used for transporting cesium-137 across country by commercial carriers. 


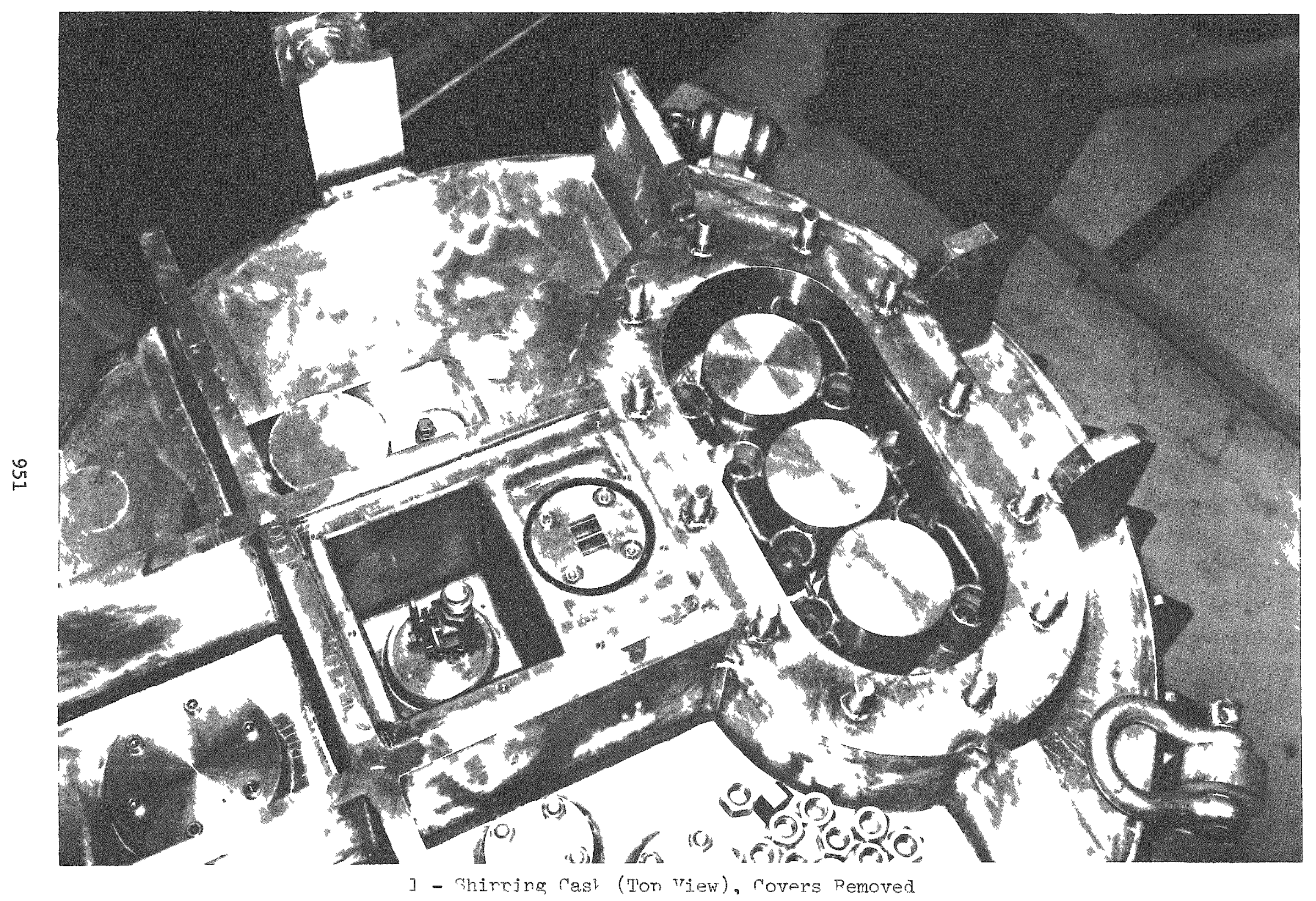




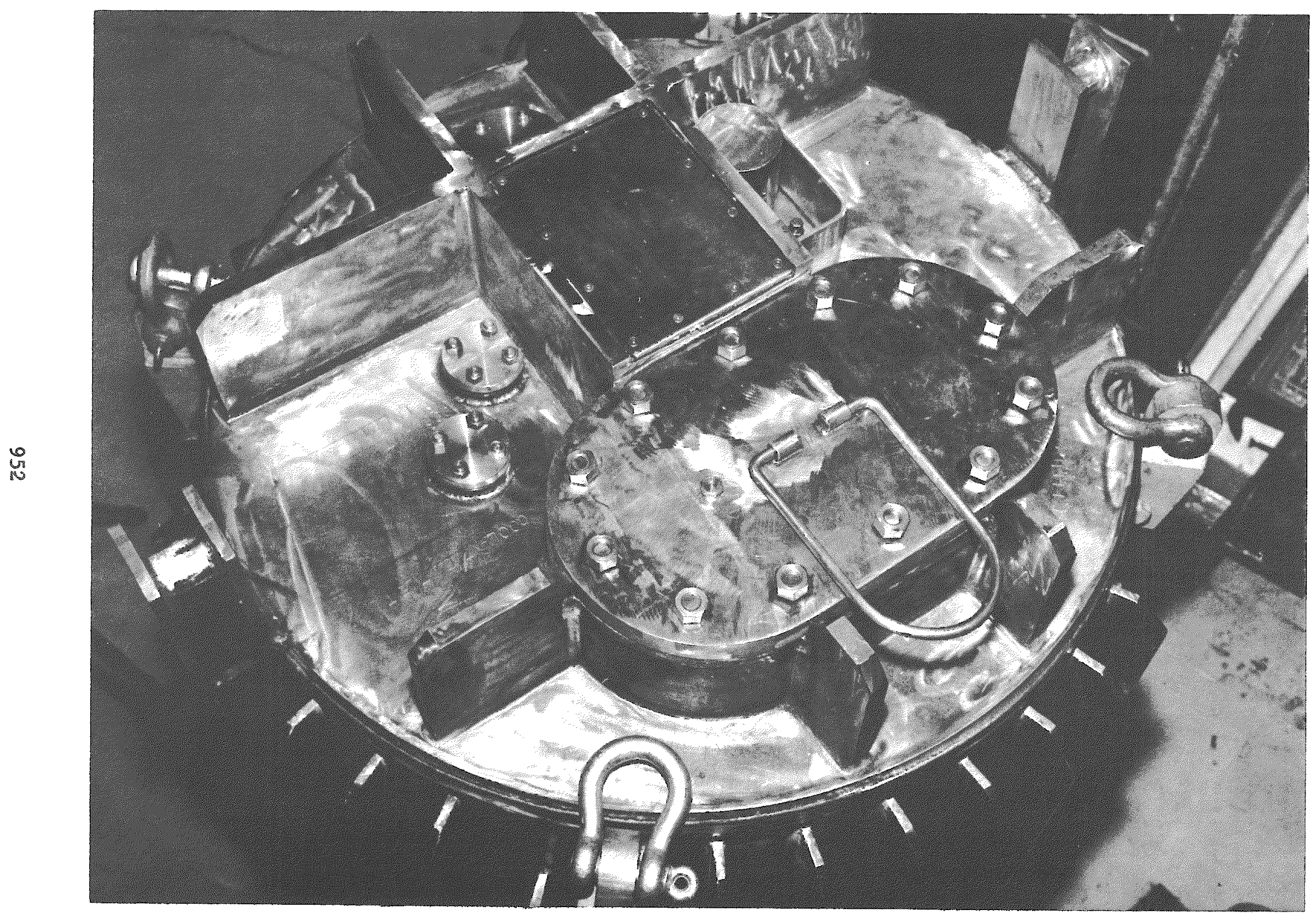

2 - Shipping Cask (Top View), Covers in Place 


\title{
IIST OF ATTACHMENTS
}

\author{
A - Pre-Fabrication Check List \\ $B$ - Check List for Drewing H-2-34553 \\ C - Halogen Testing of HAPO-IC-I Shipping Cask \\ D - Quality Control Procedure for Fabrication of HAPO-IC-I \\ Shipping Cask
}


I. Weld procedure qualifications

A. Each weld joint of different geometry requires a separate procedure qualification (reference HWS-8820, sec. 6.0).

B. All procedures must be approved before production welding is initiated.

II. Weldor performance qualifications

A. Performance qualifications of all weldors working on this project shall be submitted to the Title III inspector.

III. Weld filler metal

A. Must conform to HWS-8067-A, except, no corrosion requirements (ref. letter, Hammond/Kirkpatrick, June 22, 1970).

B. Must be certified to ASTM A371-62m.

C. TIG welding filler rod to be identified per HWS-8067-S.

D. CMA welding wire to be 0.70 to 0.90 silicon.

IV. Tungsten electrodes

A. Must conform to ASTM-B-297 Classification E.W. Th 2.

V. Shielding gas
A. Welding grade $-99.99 \%$ pure
B. Argon dew point - minus $60 \mathrm{~F}$
Mixed gases dew point - minus 50F

VI. Grinding wheels

A. Control to be rigidly exercised to insure use of grinding wheels that are new or have not been used previously on carbon steel.

VII. Wire brushes

A. Control to be rigidly exercised to insure use of only stainless steel brushes never previously used on materials other than stainless steel.

VII. Attachments

A. All temporary attachments, clamps, wedges, slips, welded to or mechanically fastened in contact with stainless steel components of the cask, are to be stainless steel.

IX. Cleanliness

A. Base metal in and near weld area to be clean.

B. Weld filler metal to be kept clean.

C. AII pipes and interior surfaces to be cleaned internally before assembly.

D. AII pipe ends to be kept covered at a.11 times. 
SHIPPIING CASK

HAPO $-\mathrm{IC}-1$

W.0. \#CE-0597

X. Machined surfaces

A. All threaded and machined surfaces must be carefully protected from damage at all times.

B. Bolt and dowel holes must be kept covered at all times to prevent entry of any extraneous material.

XI. Are scars

A. Striking bars are to be provided for GIA process in lieu of arc decay devices.

B. Accidental are scars must be prevented.

XII. Residue from dye penetrant testing must be completely removed prior to welding. 


\section{(1) Weld Pt. 15 to Pt. 3}

(a) Verify approved welding procedure for this joint.

(b) Verify weldor performance qualification for this joint.

(c) Verify material identification.

(d) Verify that Pt. 15 is ${ }^{3}$ " long radius, sched. 80.

(e) Verify cleanliness of Pt. 15 and area of attachment to Pt. 3.

(f) Verify purge capabilities for tack welding.

(g) Check tack welds for oxidation and cracks.

(h) Check upper face of Pt. 15 and verify that it is square with longitudinal axis of Pt. 3.

(i) Verify that joint geometry conforms to applicable weld procedure.

(j) Dye check root pass per HWS-8811.

(k) Check inner surface of root pass and verify complete penetration.

(I) Check during and after completion of welding for:

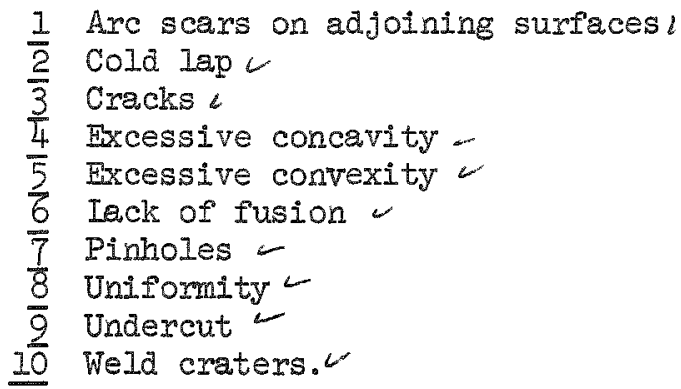

Arc scars on adjoining surfaces !

Cola lap $c$

Cracks \&

Excessive concavity -

Excessive convexity -

Iack of fusion -

Pinholes -

8 Uniformity

10 Weld craters.c
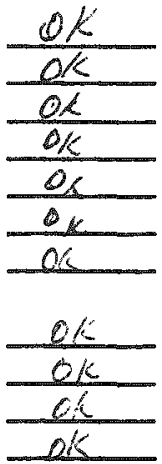

(2) Install Pts. 17 and 10 into Pt. 3.

(a) Check Pt. 17 for signs of physical damage.

(b) Verify that Pts. 10 have been prepared correctly to match pitch of coil at $60^{\circ}$ intervals without distortion.

(c) If coil is installed from bottom check carefully that deflection of outlet tube does not result in flattening, buckling, or crimping.

(d) If coil is installed from top, check carefully that screwing past Pt. 15 does not result in scretching, gouging, bending, kinking, or depressing any portion of the coil.

(e) State which method was used and rill in the appropriate space.

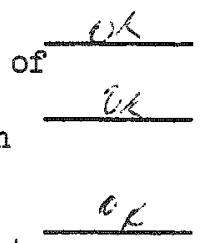

(f) Check to see that coil (Pt. IT) is placed in final position as Pts. 10 are inserted.

(g) Check coil for any damage from step (f).

(h) As Pts. 10 are placed in final position verify that coils (Pt. 17) are not deflected from required dimensions.

(i) Verify that the lower ends of Pts. 10 are flush with the lower edge of Pt. 3 .

(j) Verify that welding Pts. 10 to Pt. 3 is according to approved procedure and drawing.

(k) Check tack welds for cracks.

(1) Dye check root pass per HWS-8811.

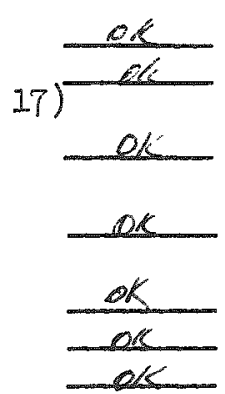


HAPO IC- 1

W. 0 . \#CE-0597
H-2-34553

sheet \#1

(m) Checi final welds for:

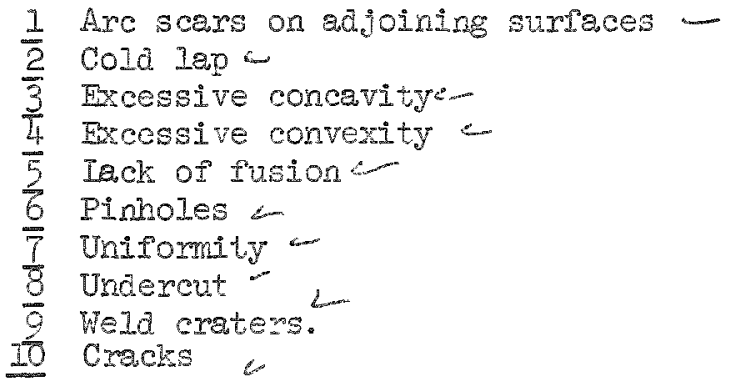

(3) Assemble lowem portion of outlet tube below Rt. I5 (Det. V) wela outle:

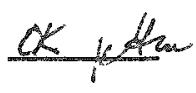
tube into Pt. 3 .

(a) Vexiry approved veld procedure for this jo: $n^{2}$.

(b) Verisy weluor perrommee qualification ror thin is st.

(c) Verify material identisicasion.

(a) Verify I" sched. 60 oipe and rittings.

(e) Verify that two $90^{\circ}$ clbows (Pt. I, have been trimmed to provide required angles and dimensions.

(e) Verify all dimensions and angles as noted on ref. bwg.

(g) Checl cleanliness of 311 components.

(h) Check purge capabilities for teck welding.

(i) Verify that joint geometry confoms to applicable welo procedure.

(j) Check tack welds rom oxilation and cracls.

(k) Dye check root pass per IWS-881].

(1) Check Juring anc anter weloing for:

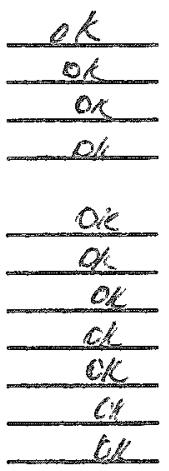

1 Are scars on adjoinirg anraces 2

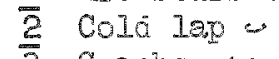

$\overline{3}$ Crecins

I. Excessive crown 6

5 Excessive widho

6 Taci of fusion

$\frac{7}{6}$ Pinholes

8 Uniformity

9 Undercut 2

10 Weld erators.c

(m) Check insertion of ourlet ibe through Pt. 3 and remify thet there is no interference betwen out let tube and innor coils.

(n) Check weld area fir gleanliness.

(o) Checis tack welds fon rreckn-

(p) Dye heok root pess pen ItwS-281:.

(d) check pinal wold ror:

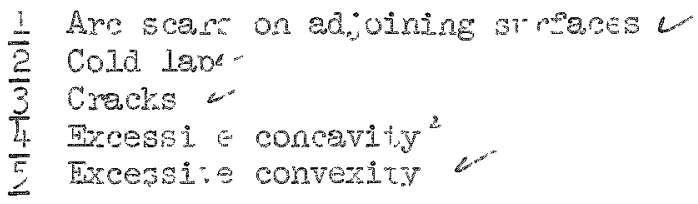


HAPO IC- 1

W. 0 . 1 CE $=0597$
$\mathrm{II}-2-34553$

sheet \#I

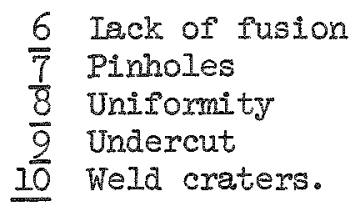

(4) Weld inner shell bottom plate (Pt. II) to Pt. 3.

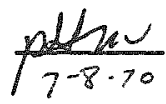

(a) Verify that joint geometry conforms to applicable weld procedure.

(b) Verify approved weld procedure for this joints.

(c) Verify weldor perfomance qualification for this joint.

(d) Verify material identification.

(e) Verify purging capabilities for inner surface of root pass.

(f) Verify cleanliness of weld areas.

(g) Check tack velds for cracks and oxidation.

(h) Because of inaccessibility of root side of this weld, it is

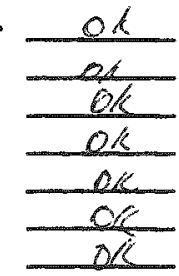
required that the inspector monitor the welaing process in its entirety.

(i) Dye check root pass per HWS 8811.

(j) Note number of weld passes visually monitored during welding process and any remarks.

Ist pass

2nd pass

$3 r d$ pass

4 th pass

5 th pass

6th pass

(k) Check between weld passes and after completion of weld for:
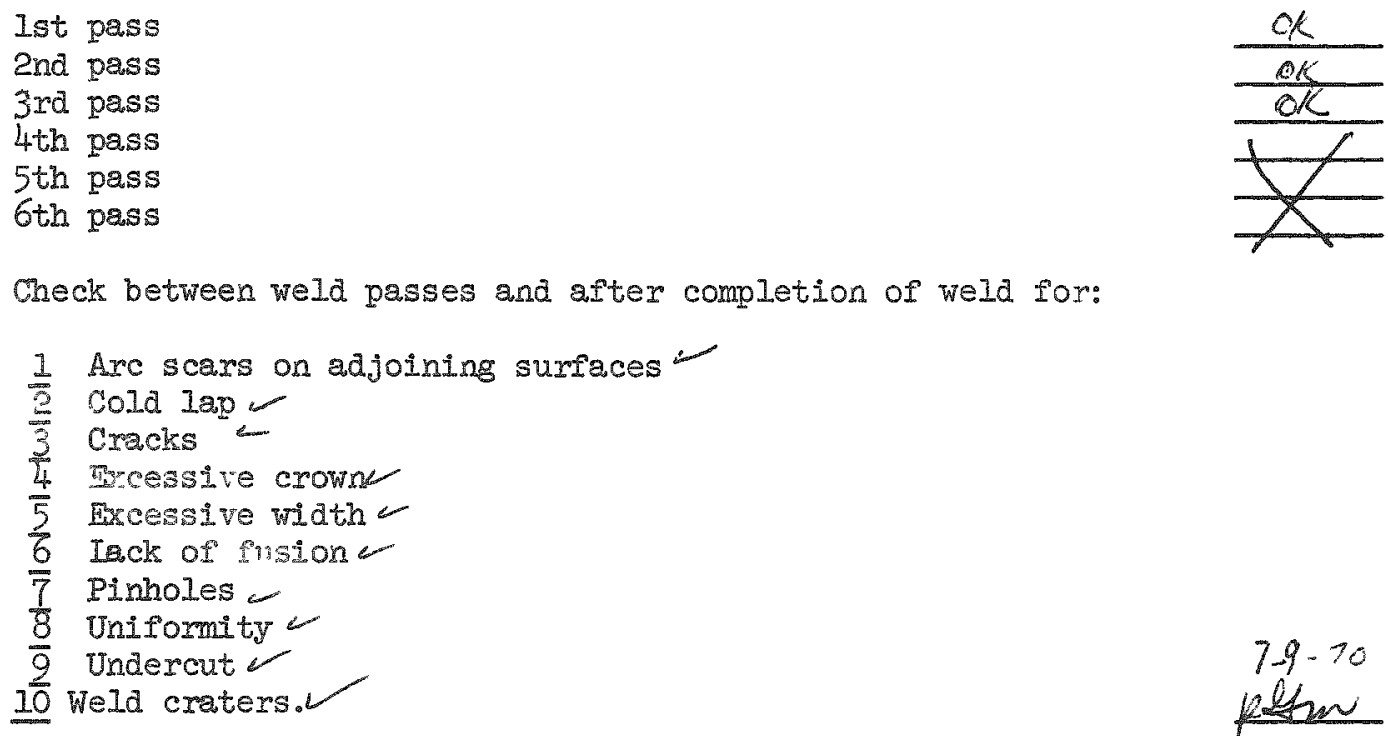

(1) Verify that weld was ground flush with surface of adjoining plate. WeLp Flust-NOT Ground.

(5) Fabricate lower distribution ring (Det. IV) and insert through Pt. 9 (1ower screen).

(a) Verify approved weld procedure for this joint.

(b) Verify weldor performance qualification for this joint.

(c) Verify material identification.

(d) Verify $1 / 2^{\prime \prime}$ Sch. 80 pipe and fittings.

(e) Verify that bending of pipe to required radius did not cause flattening, wrinkling, buckling, or any other physical damage.

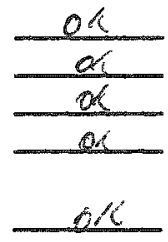


(f) Verify correct diameter for ring.

(8) Verify cleanliness of weld areas.

(h) Check purge capabilities for tack welding.

(i) Verify that joint geometry conforms to applicable weld procedure.

(j) Check tack welds for oxidation and cracks.

(k) Dye check root pass per HWS-8811.

(1) Check during and after welding for:
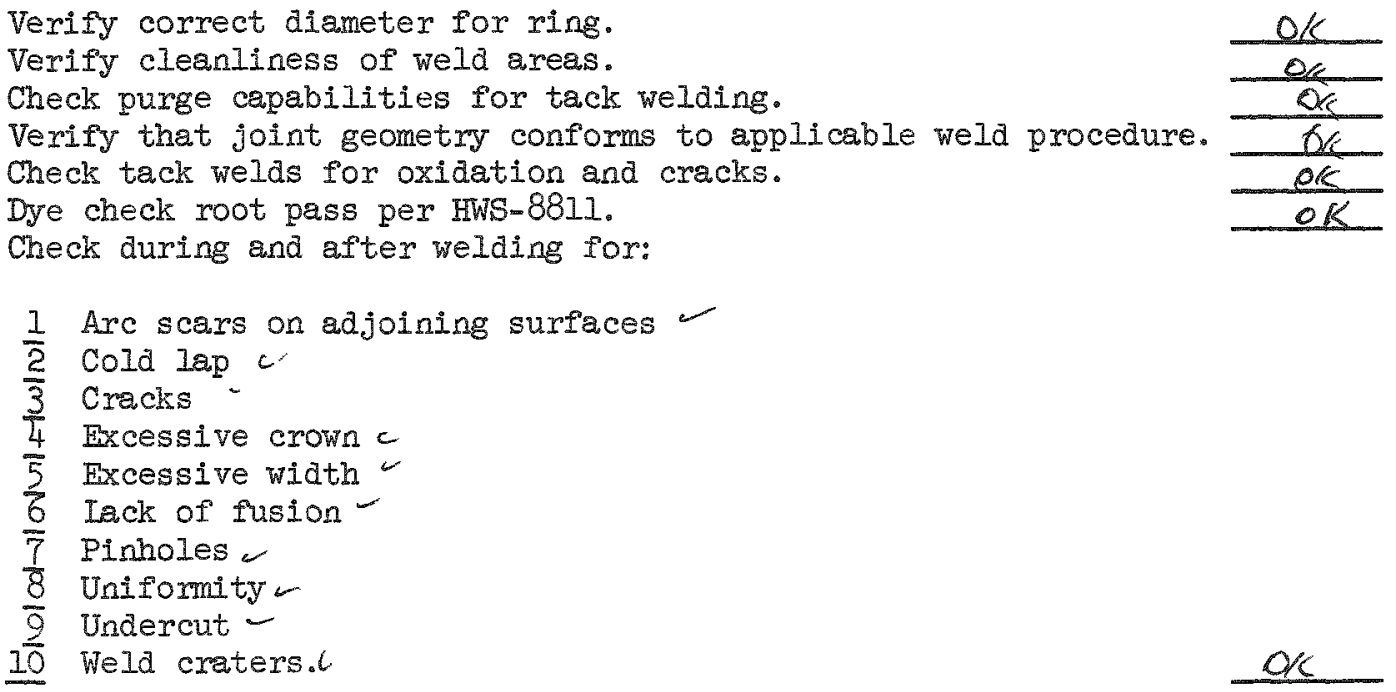

(m) Verify that layout for drilling holes is correct (see sec. C-C.)

(n) Verify that holes are .062 diameter, countersunk to remove burrs.

(o) Verify that all extraneous matter has been removed from interior of pipe after drilling, and that pipe interior has been cleaned per HWS-8820, sec. 13.0.

(p) Cover end of pipe riser from coil and insert through screen.
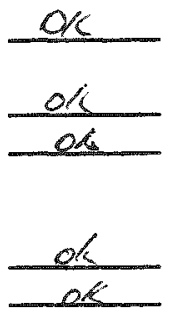

(6) Weld elbow (Pt. 14) to protruding end of outlet tube (Detail V), and weld lower distribution ring to elbow.

(a) Verify approved weld procedure for this joint.

(b) Verify weldor performance qualification for this joint.

(c) Verify material identification.

(d) Verify $1 / 2^{\prime \prime} 90^{\circ}$ elbow, sch. 80.

(e) Check cleanliness of weld areas.

(f) Check purge capabilities for tack welaing.

(g) Verify that joint geometry conforms to applicable weld procedure.

(h) Check tack welds for oxidation and cracks.

(i) Dye check root pass per HWS-88II.

(j) Check during and after welding for:

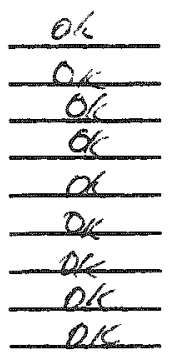

\footnotetext{
1 Arc scars on aajjoining surfaces 2

늘 Cold lap

Cracks 2

Excessive crown.

5 Excessive width -

6 Iack of fusion

$\overline{7}$ Pinholes

8 Uniformity w

9 Undercut

IO Weld craters.
} 
HAPO IC-1

W.0. \#CE-0597
$\mathrm{H}-2-34553$

Sheet \#1

(7) Weld screen part 9 to inner shell part 3 and weld to distributor ring riser.

(a) Verify approved welding procedure for this joint.

(b) Verify weldor performance qualification for this joint.

(c) Check fit, both shells, before proceeding.

(d) Verify cleanliness of weld area.

(e) Check tack weIds for oxidation and cracks.

(f) Check screen for level and location. Ascertain that screen is $90^{\circ}$ to shell surface and that 50 mesh screen is face up.

(g) Dye check root pass per HWS-8811.

(h) Check during and after completion of welds for:
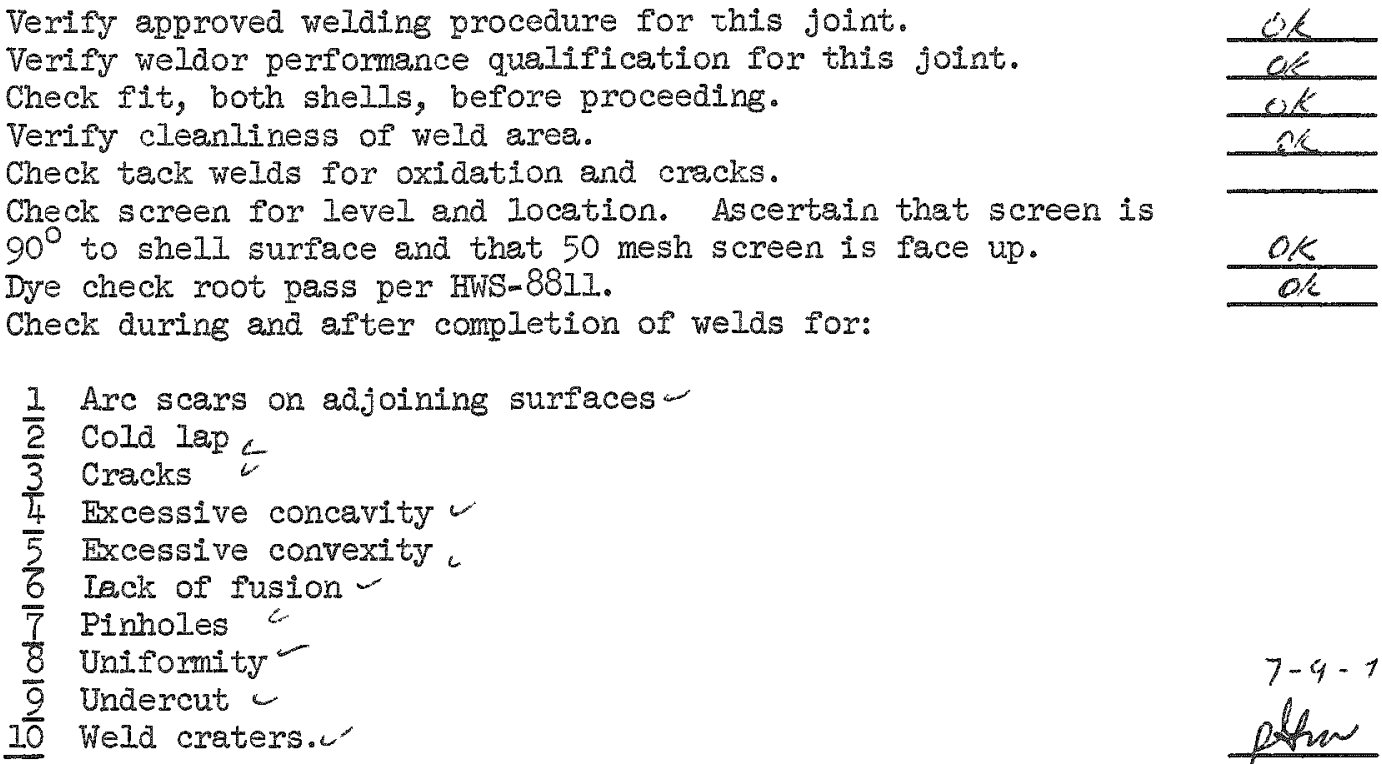

(8) Weld part 5 (outer shell) to part 9.

(a) Verify 1/8" minimum clearance between Pts. 11 and 24.

(b) Verify approved welding procedure for this joint.

(c) Verify weldor performance qualification for this joint.

(d) Verify cleanliness of weld area.

(e) Check tack welds for oxidation and cracks.

(f) Check screen location, even fit, proper location in outer shell, and that outer shell is properly located to inner shell on marked axis.

(g) Dye check root pass per HWS-8811.

(h) Check during and after completion of welds for:
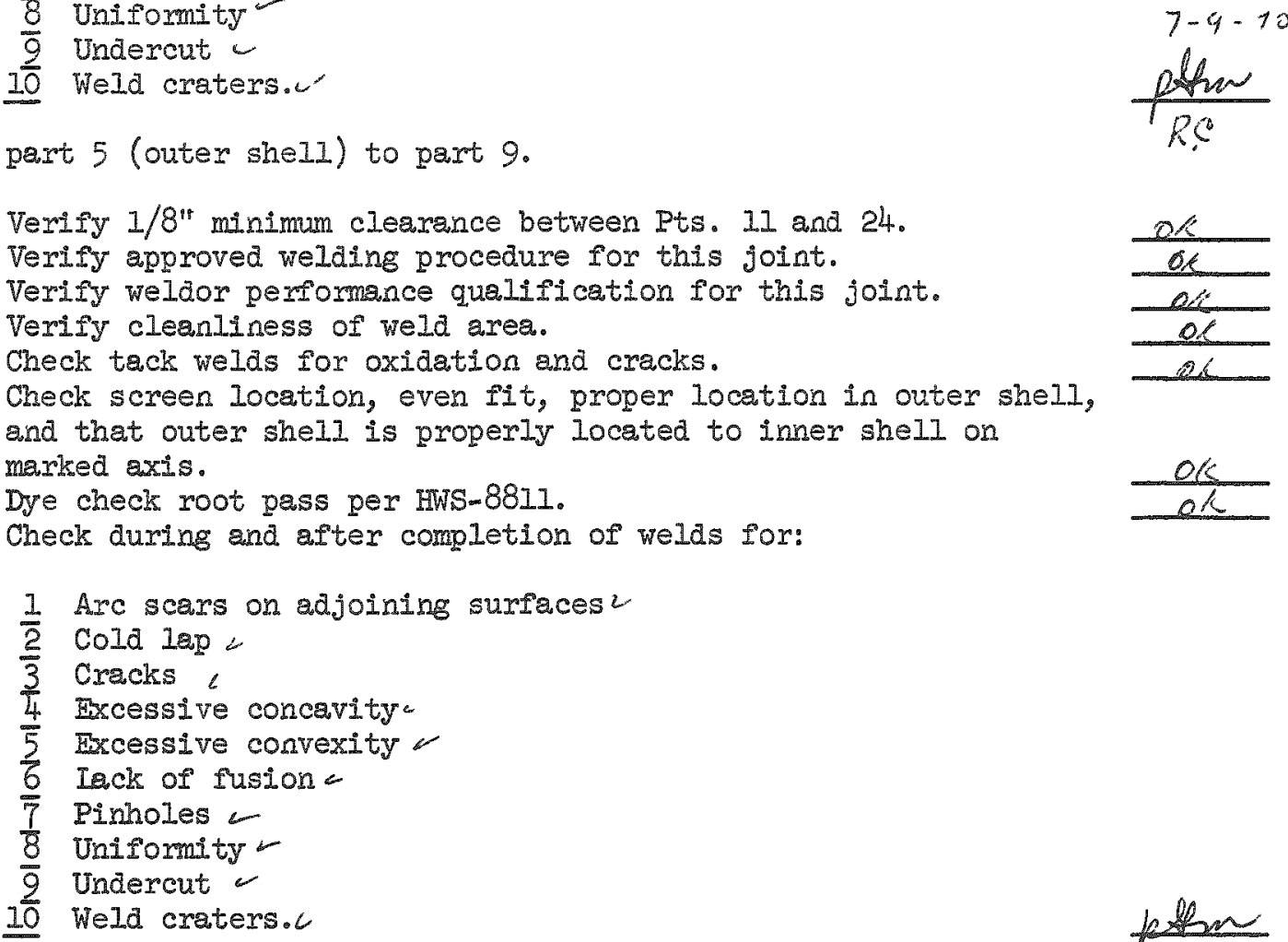

(9) Weld part 8 (upper screen) to inner shell (part 3) and outer shell (part 5).

(a) Verify approved welding procedure for this joint.

(b) Verify weldor performance qualification for this joint.

(c) Verify cleanliness of weld area.

(d) Check screen flatness, 50 mesh side down and properly located with outer lower angle base $1-3 / 16^{\prime \prime}$ below top of outer she11.
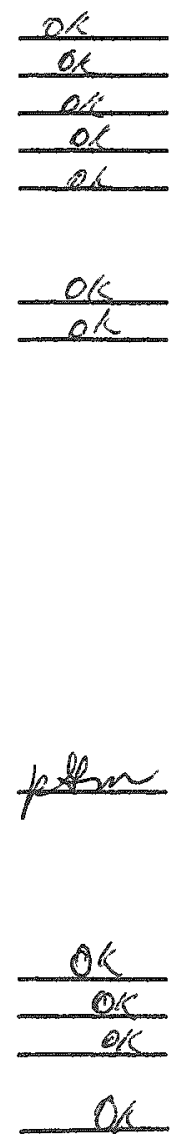
(e) Check tack welds for oxidation and cracks.

(f) Check sufficient room available for $1 / 2^{\prime \prime} \mathrm{sch} .80$ pipe between screen and bottom of top ring (.84".)

(g) Dye check root pass per HWS-8811.

(h) Check during and after welding for:
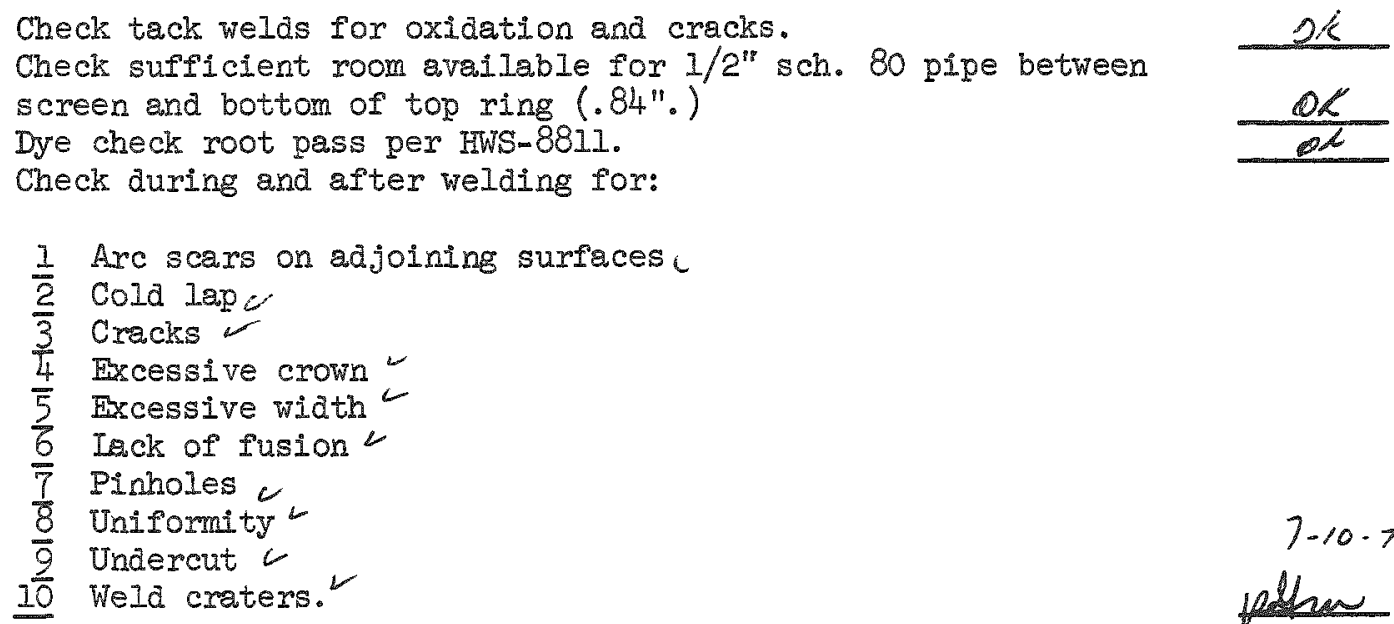

(10) Wela upper distribution ring (part 21) to part 2 (top ring.)

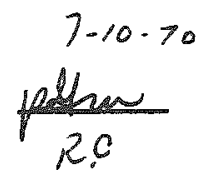
(a) Verify approved welding procedure for this joint.
(b) Verify weldor qualification for this joint.
(c) Verify material identification.
(d) Verify cleanliness of weld area.
(e) Check tack welds for oxidation and cracks.
(f) Check position and that ring is concentric.
(g) Dye check root pass per HWS-8811.
(h) Check during and after welding for:
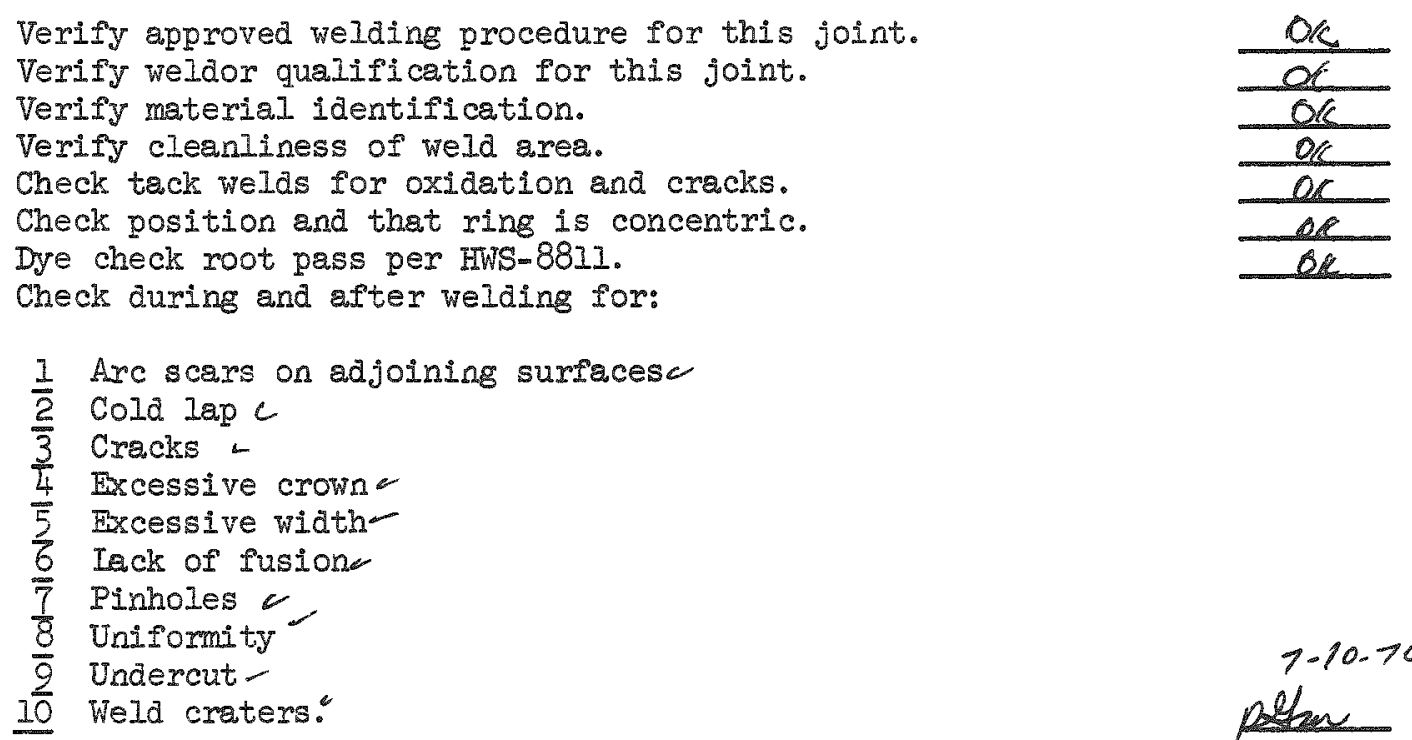

(1I) Weld top ring (part 2) to part 3 and 5 (inner and outer shell.)

(a) Verify approved welding procedure for these joints.

(b) Verify weldor performance qualification tor this joints.

(c) Check joints for proper joint preparation and fit-up cleanliness.

(d) Check tack welds for oxidation and cracks.

(e) Dye check root weld per HWS-8811.

(i) Check during and after weld for:

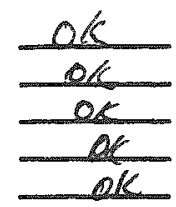

1 Arc scars on adjoining surfaces $\sim$

$\frac{1}{3}$ Cold lap
$\frac{4}{4}$ Eracks
$\frac{5}{6}$ Excessive crown
$\frac{6}{2}$ Iack of fusion 
HAPO IC-I

W. O. \#CE 0597
$\mathrm{H}-2-34553$

Sheet \#1 $\begin{aligned} \frac{7}{8} & \text { Pinholes } \\ \frac{9}{9} & \text { Undermity } \\ 10 & \text { Weld craters. }\end{aligned}$

(12) Weld spider (parts 25 and 28) to top ring (2) and support bracket (10).

(a) Verify approved weld procedure for this joint.

(b) Verify weldor performance qualification for this joint.

(c) Verify material identification.

(d) Check cleanliness of areas to be welded.

(e) Check tack welds for oxidation and cracks.

(f) Check geometry; verify spider and support brackets (10) are in correct position.

(g) Dye check root pass per HWS-8811.

(h) Check during and after welding for:
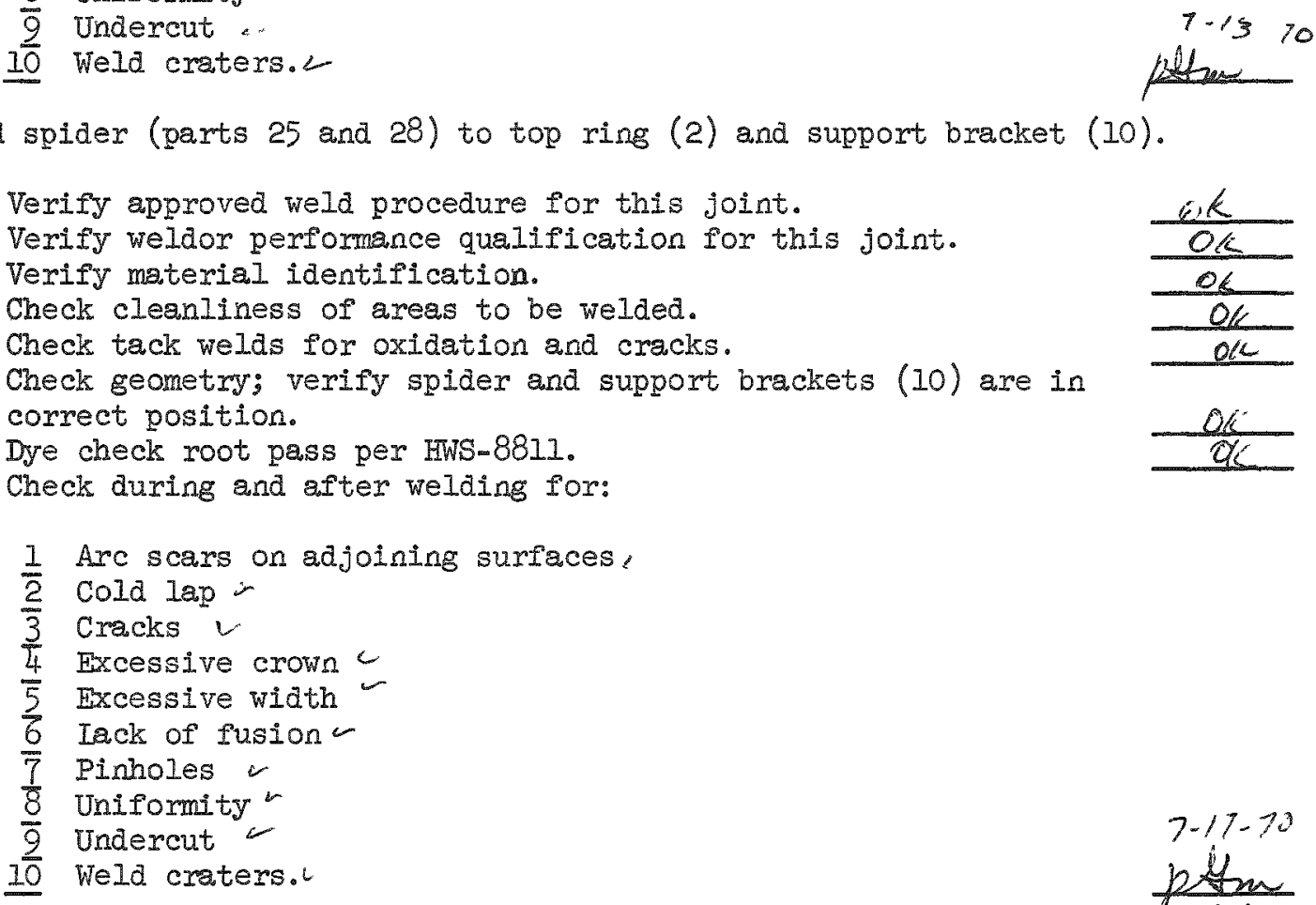

(13) Weld bottom plate (part 24) to outer shell (part 5).

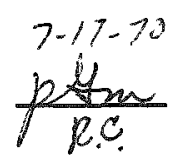

(a) Verify approved weld procedure for this joint.

(b) Verify weldor performance qualification for this joint.

(c) Verify bottom plate material identification.

(d) Verify cleanliness of area of attachment.

(e) Verify purge capabilities for tack welding.

(f) Check tack welds for oxidation and cracks.

(g) Dye check root pass per HWS-8811.

(h) Check during and after welding for:
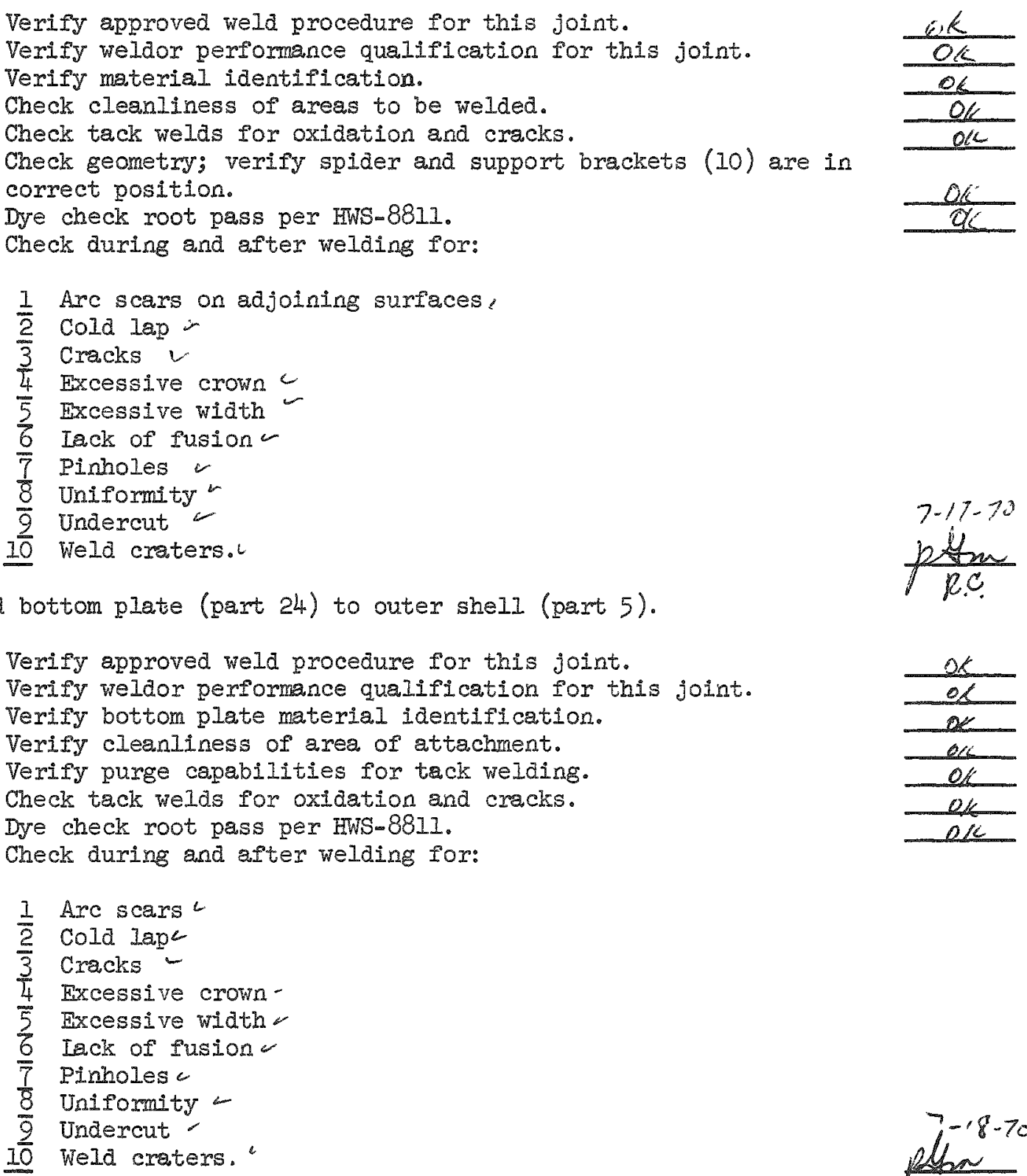
SHTPPING CASK

HAPO IC- 1

W.0. \#CE-0597
$\mathrm{H}-2-34553$

Sheet \#1

(14) Fabricate resin inlet tube (Detail I) and install.

(a) Verify approved weld procedure for this fabrication.

(b) Verify weldor performance qualification for this fabrication.

(c) Verify material identification: Pipe is I" $^{\prime \prime}$ sched. 80.

(d) Check cleanliness of Pts. 6 areas of attachment.

(e) Verify purge capabilities for tack welding.

(f) Check tack welds for oxidation and cracks.

(g) Check geometry of Detail I and tube being fabricated agree.

(h) Dye check root pass per HWS-88II.

(1) Check during and after completion of welaing for:
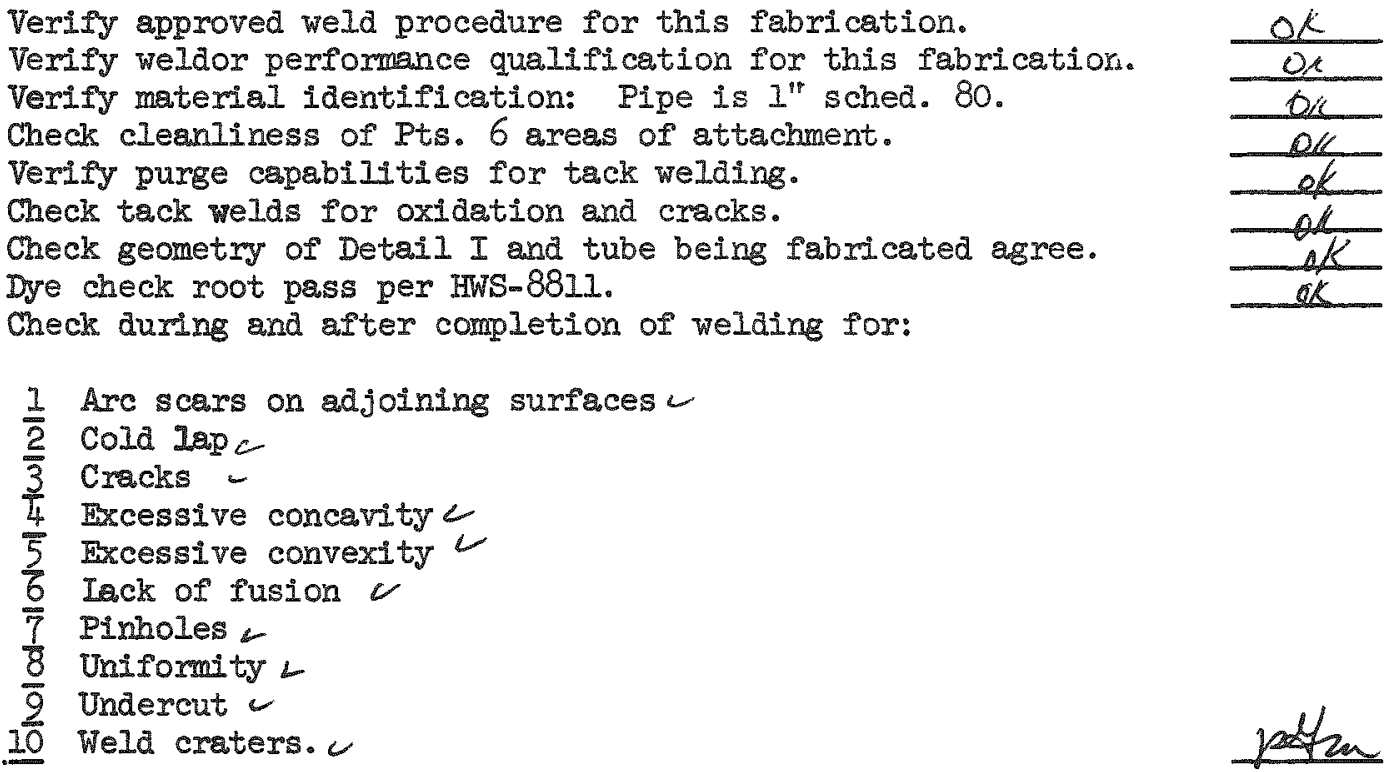

(15) Fabricate upper portion of outlet tube (Detail V) and weld to lower portion (installed in step 3).

(a) Verlfy approved welding procedure for these joints.

(b) Verify weldor performance qualification for these joints.

(c) Verify material identification.

(a) Verify that material is sched. 80 and elbows I", Iong radius.

(e) Verify cleanliness of parts to be joined.

(f) Verify purge capabilities for tack welding.

(8) Check tack welds for oxidation and cracks.

(h) Verify geometry of Detall $V$ and fabrication of tubing agree.

(i) Dye check root pass per HWS -881 .

(j) Check during and after completion of welding for:

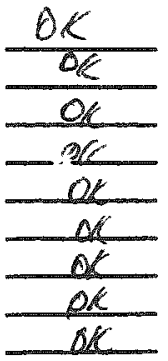

I Arc scars on adjoining surfaces $V$

$\frac{2}{3}$ Cola lap C

Excessive concavity

Dxcessive convexity

Iack of fusion 2

Pinholes $c$

Uniformity 5

Undercut -

10 Weld craters. $L$ 
HAPO IC- 1

W. 0 . $H C E-0597$
$\mathrm{H}-2-34553$

Sheet \#I

(16) Fabricate inlet tubing Detail III, position and weld to upper distributing ring.

(a) Verify approved welding procedure for these joints.

(b) Verify weldor performance qualification for these joints.

(c) Verify material identification.

(d) Verify that material is $1 / 4^{\prime \prime}$ and $1^{\text {"Seh. }} 80$ pipe.

(e) Verify cleanliness of joints to be welded.

(f) Verify purge capabilities for tack welding.

(g) Check geometxy of Detail III; verify it corresponds with tubing.

(h) Dye check pass per HWS-8811.

(i) Check during and after completion of welding for:
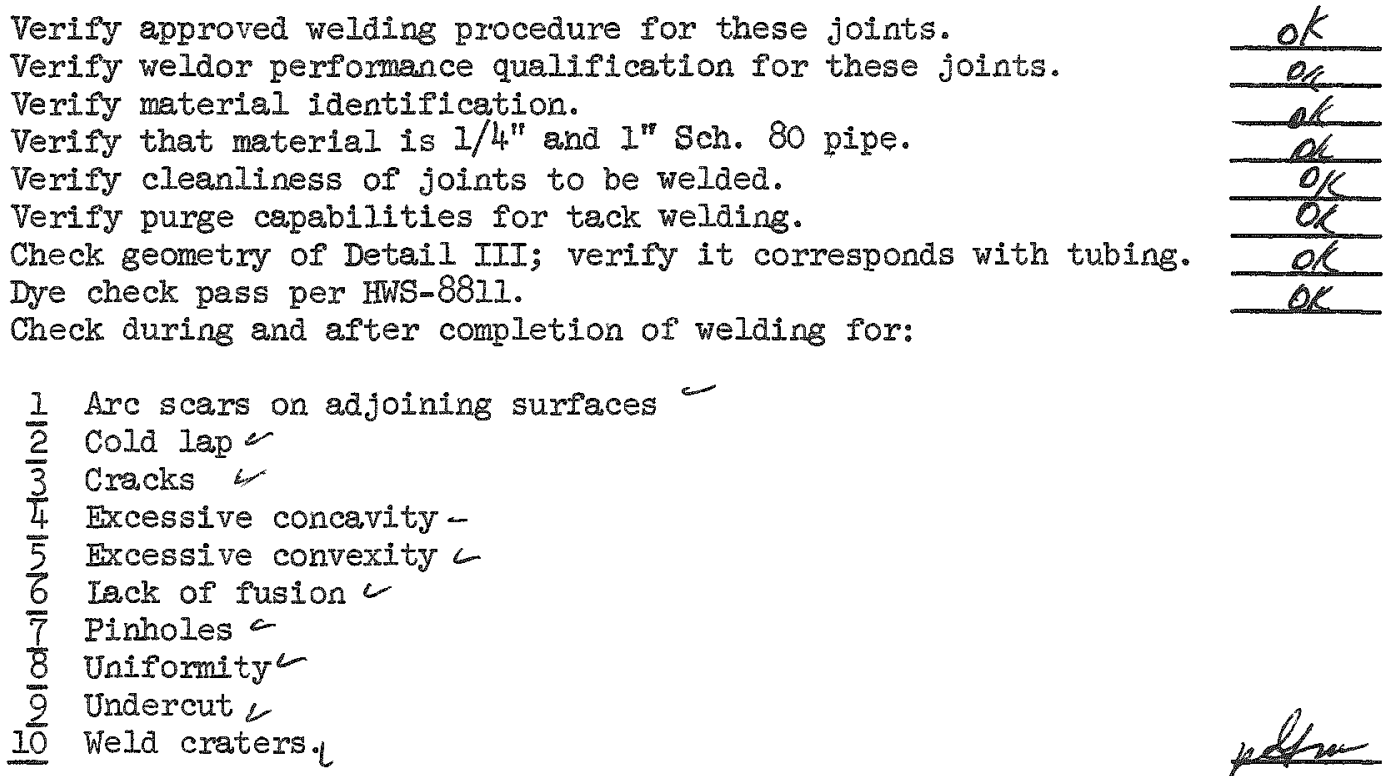

(17) Weld themocouple (13) well into top ring (2).

(a) Verify approved welding procedure for this joint.

(b) Verify weldor performance qualification for this joints.

(c) Verify cleanliness of parts to be joined.

(d) Check tack welds, if used, for oxidation and cracks.

(e) Dye check root pass per HWS-8811.

(f) Check during and after completion of welding for:
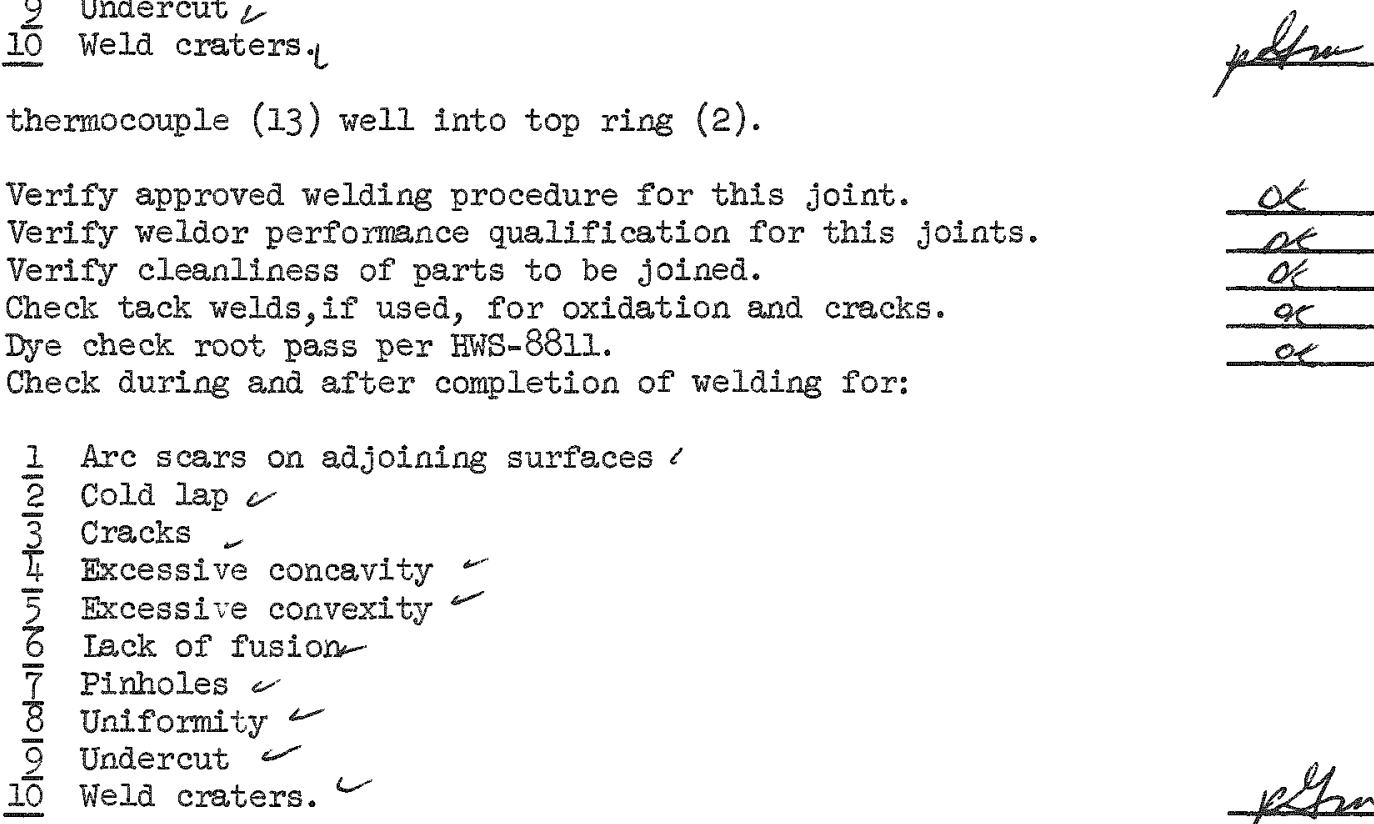

(18) Install outer cooling coil and weld upper tube into position.

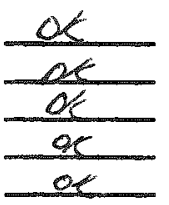

(a) Verify approved welding procedure for these joints.

(b) Verify weldor performance qualifications for these joints.

(c) Verify cleanliness of all parts to be joined.

(d) Coil spacers (\#23) installed. Welds checked for:

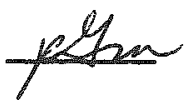

$\frac{1}{2}$ Oxidation
$\frac{2}{3}$ Scacks on adjoining surfaces
$\frac{3}{4}$ Lack of fusion
$\frac{5}{2}$ Pinholes 


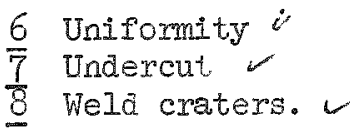

Sheet \#].

(e) Coil is installed evenly, with equidistant spacing throughout.

(f) Verify area to be welded is clean.

(g) Coil length abore top ring (2) checked to ascertain required length.

(h) Checir tacks on top ring to tubing for oxidation and cracks.

(i) Dye check root pass per HWS 8811 .

(j) Check during and after completion of welding for:
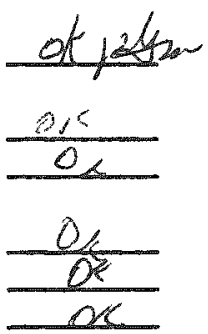

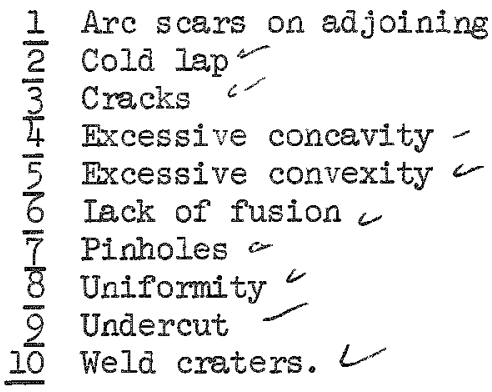

(19) Form portion of coil maxked "at assy" and weld inner and outer portions

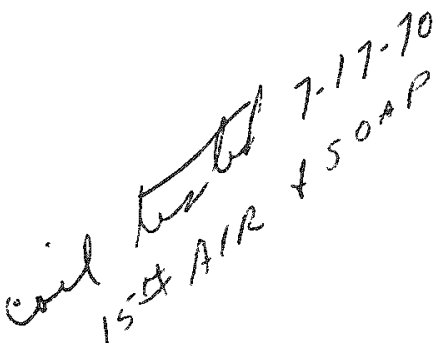
together.

(a) Verify approved welding procedure for these joints.

(b) Verify weldor performance qualification for these joints.

(c) Verify cleanliness of all parts to be joined.

(a) Verify coils are properly aligned, spacing is proper.

(e) Check forming of tubing that bends are free of lattening, buckling, or crimping; that formed tube 17 terminates $10-5 / 8^{n}$ above the upper plate and is positioned as per assembly plan.

(f) Check purge capabilities for tack welding.

(g) Check tack welds for oxidation and cracks.

(h) Dye check root pass per HWS-8811.

(i) Check during and after completion of weleding for:
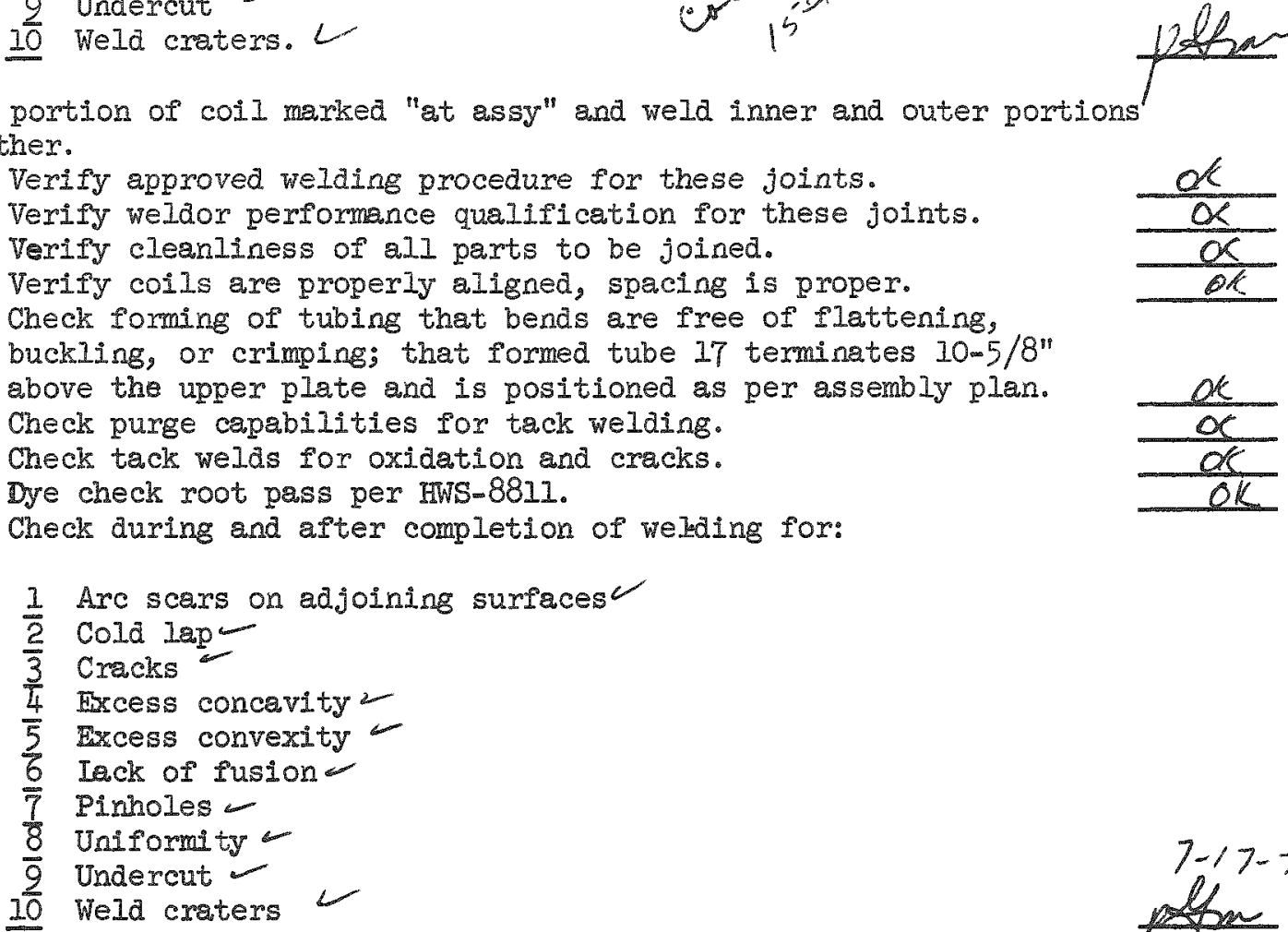
(20) Weld coil support studs (\#7) to outer shell (\#5).
(a) Verify approved welding procedure and method for this operation.
(b) Verify weldor performance qualification for this method.
(c) Verify material identification of suppors
(d) Verif 14 long.
(e) Check coil spacing satisfactory, check layout for points to be welded to see that they are clean and properly prepared.
(f) Check welds for: Used

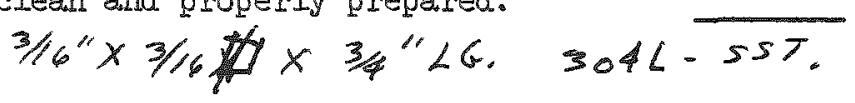

$\frac{1}{2}$ Iacessing of fusion ok
$\frac{2}{3}$ Spates
$\frac{3}{4}$ Undercut. or

(g) Verify that all studs are fair and true to plate surface.

(21) Thermocouple well (H12) and collar (\#18), weld in cover (\#2).

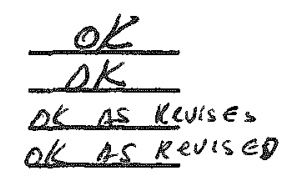

(a) Verify approved welding procedure for these joints.

(b) Verify weldor performance qualification for these joints.

(c) Verify material identification.

(d) Verify that tube is $1 / 4$ O.D. X.065 wall, bent per dwg. H-2-34553, sheet $2 / 2$, Detail VII, and $5 / 8^{\prime}$ O.D.X $5 / 16$ I.D.X $1 / 8^{\prime \prime}$

$\alpha<R-0$.

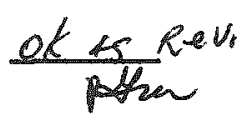

(e) Check tack welds for oxidation and cracks.

(f) Verify geometry of tube is per assembly plan and elevation.

(g) Dye check root pass per HWS-8811.

(h) Check during and after completion of welding for:
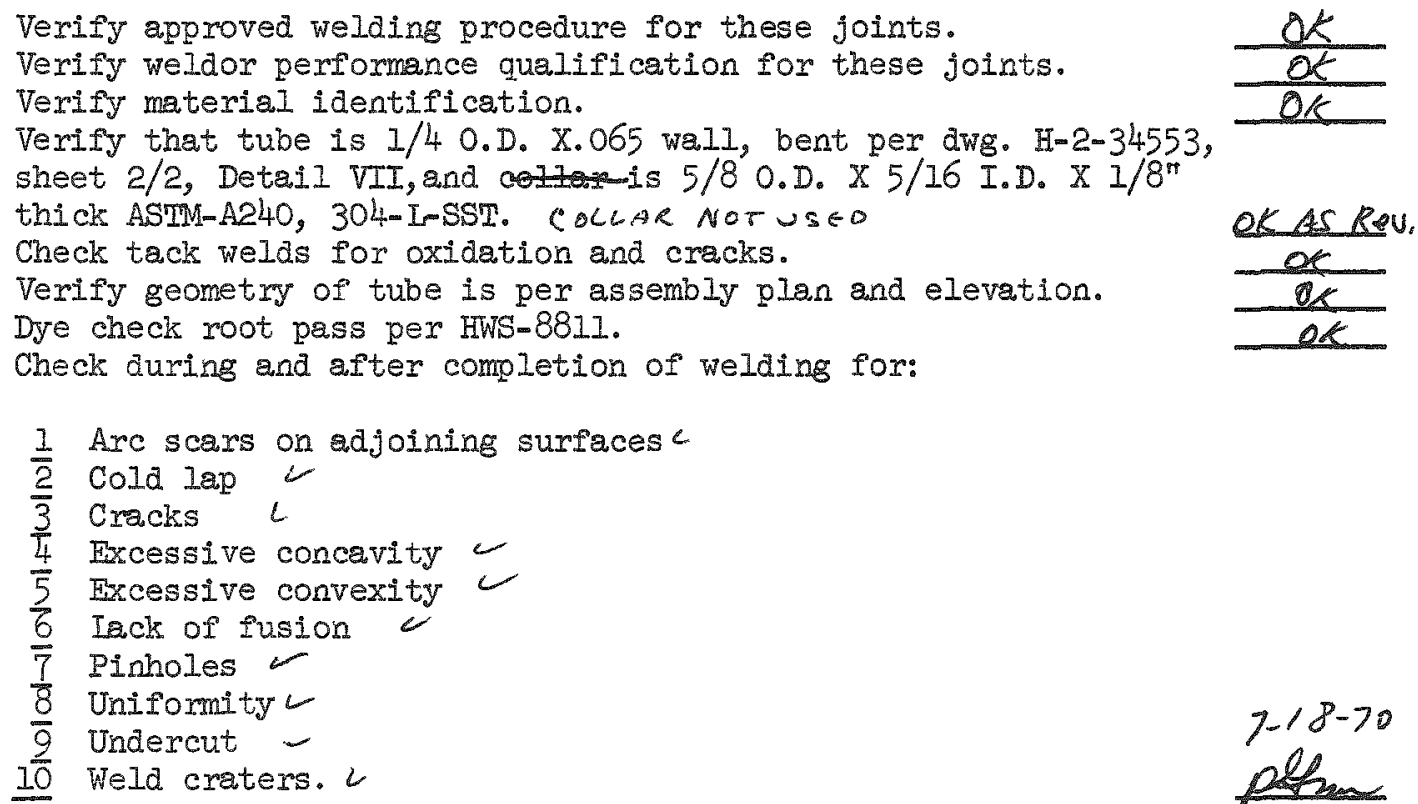

(22) Weld cask filler top (\#19) to top ring (\#2).

(a) Verify approved welding procedure for the se joints.

(b) Verify weldor perfomance qualification for these joints.

(c) Verify material identification part 19.

(d) Verify location part 19 to part 2 per plan and mpture disk requirements.

(e) Check fit up and cleanliness at weld joint.

(f) Check tack welds for oxidation and cracks.

(g) Dye check root pass per HWS-8811

(h) Check during and after completion of the weld for:

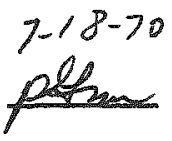


(h) 1 Arc scars on adjoining surfaces

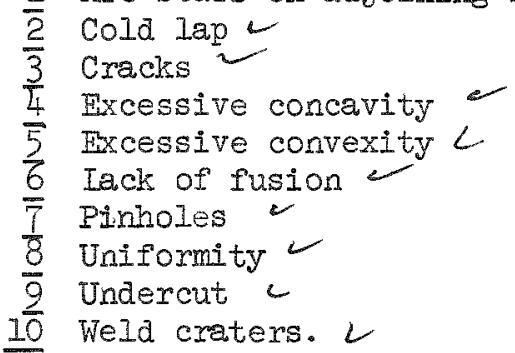

$$
\frac{O K}{R S D}
$$




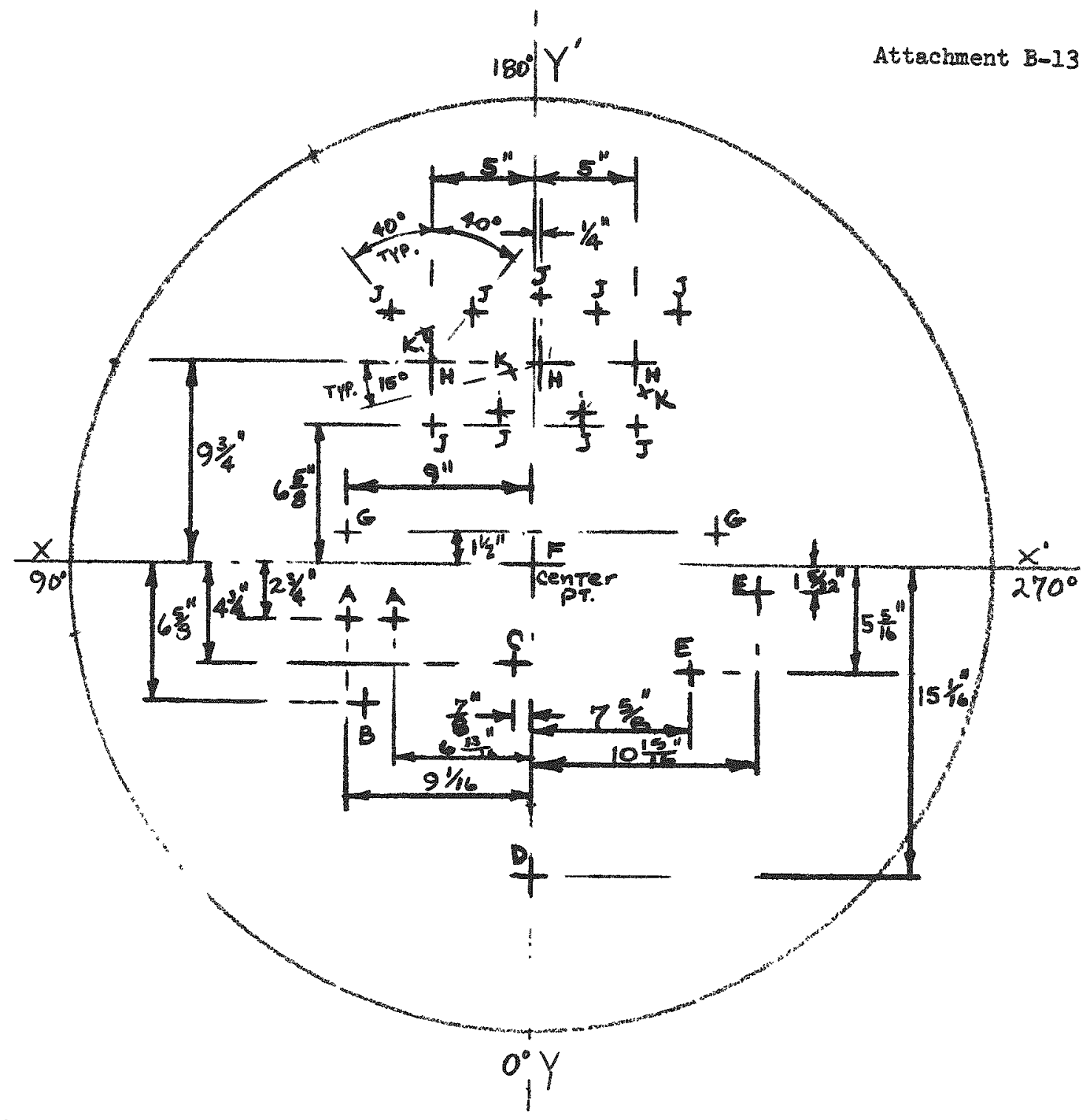

NOTES

1. HOLES "A" ARE .2RI DIA. FOR THERMOCOUPLE.

2. "B" IS 1.315"FOR I" PIPE. VERIFY O.D. PIECE OF PIDE

to be used pridir to drilline.

3. "C" IS.572 DIA. THRU $13 / 16$ " C $C$ " $\mathrm{CK}$.

4. "D" 3/16 DIA HOLE

5. "E" IS FOR $2 \Omega 17 / 32$ IN. HOLES, COOLANT INLET AND OUTLET.

6. "F" ON CENTERPOINT 2.375" DIA. HOLE FOR NOM. $z^{\prime \prime}$ PIPE a VERIFY O.D. OF PIPE TO bE USED PRIOR TO ORILLING.

7. "G" ARE sPRUE EVENT holes, $z$ "DIA. THE 1/2" FROM THE $x-x^{\prime}$ AXIS is APPRoXIMATE.

9. "H" is a 1 1/32" dia. hole thru larger flange CUTS \& C'SK. BE SEETION "D-D" DWG. H-2-345.9. 
10. "I" REPRESENTS 9 STUD HOLES, ORILL L 4 AND TAP 3/4-10 UNC-2B. BETEL BELOW FOR LOCATING HOLES.

HI. "K" REPRESENTS S DOWEL" HOLE: DRILL

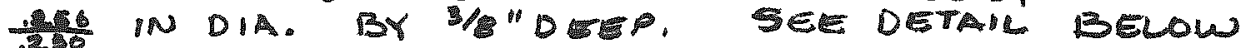
-25R LOCATING.

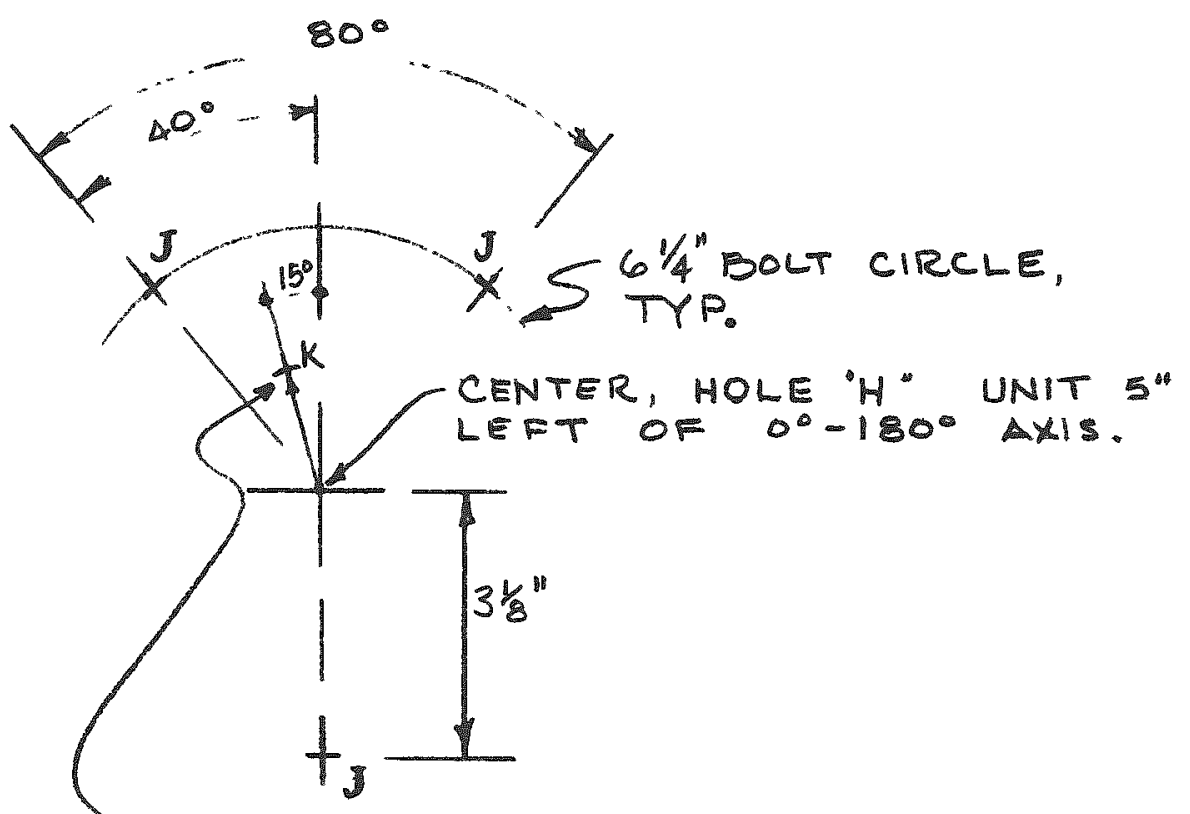

"HOLE "K" DOWEL ON 1/2"

"H" CONNECTION LEFT OF Y-Y" AXIS AS SHOWN ABOVE IS COUNTER CLOCKWISE, ID0'AXIS: OR CONN. 1/A" RIGHT OF Y.Y'AXIS, DOWEL $R=1 K^{\prime \prime}$ I5० COUNTER CLOULWISE FRUA

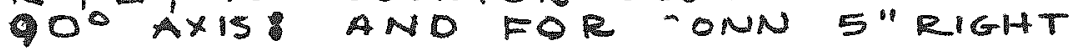
OF Y-Y AXIS, DOWE- IS I5० COUNTER. CLOCKWISE OF OO AXIS 
July 23, 1970

Halogen Testing of HAPO-IC-1 Shipping Cask

Testing of the resin-containment annulus of the subject shipping cask was accomplished as follows:

All openings to the annulus were closed except the resin pipe. A halogen family gas miture was then introduced into the vessel through that pipe, and the pipe closed and the internal atmosphere pressurized. All weld areas involved in resin containment were checked for leaks.

The detector was checked for sensitivity before and after testing the vessel, and was found to be operating properly at all times.

Cas used: Methylene Chloride/Ethylene Dichloride Mixture

Pressure: 3 psig

Results: No leaks

Equipment: General Electric - Type H-2 Halogen Detector

General Electric - Halogen Ieak Detector Control Unit Model - 5797934c1

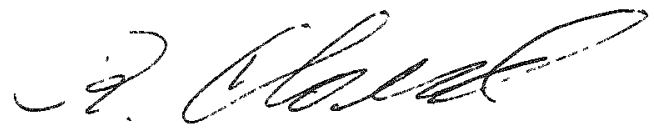




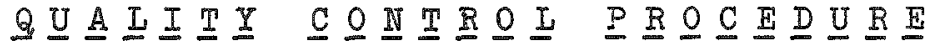

FOR

FABRICATION

OF

HAPO-IC-I

SHIPPING CASK

Inspection of the fabrication of the HAPO-IC-I

Shipping Cask was done in strict accordance

with the abovemoted Quality Control Procedure,

or as noted within.

Shipped from J. A. Jones: shops 8-5-70.

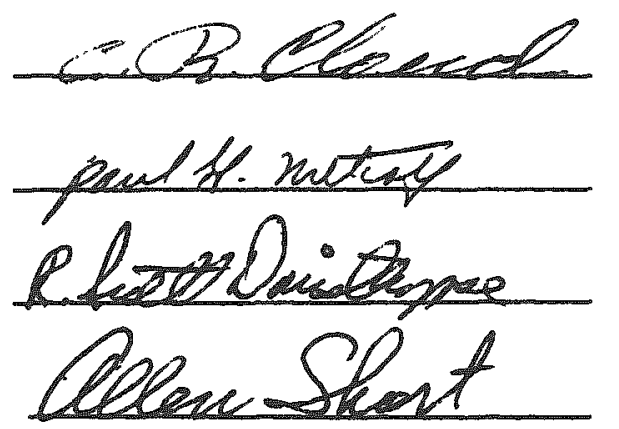

Inspector/Vitro/HES

Inspector/Vitro/HES

Inspector/Vitro/HES

Supervisor/Vitro/HES

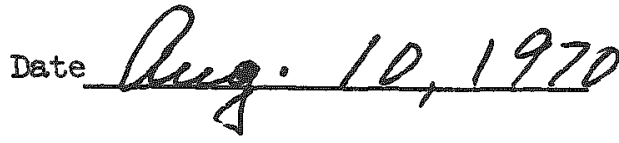




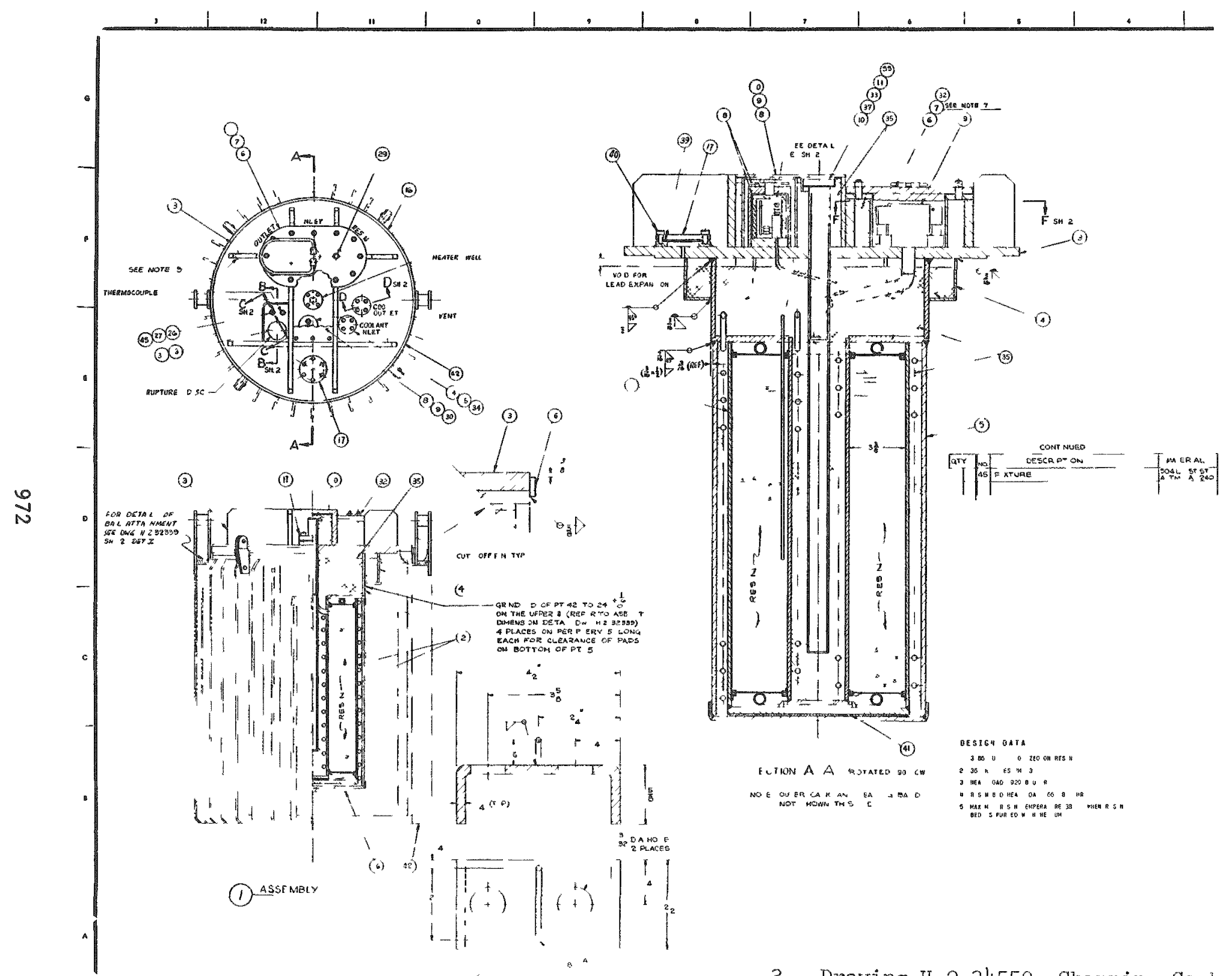

3 - Drawing H-2-34550, Shlnping Cask HAPn-1C-1 
DESIGN, FABRICATION, AND PERFORMANCE TESTING OF MODEL 160 SHIPPING CASK

\section{M. Kershner}

This paper was not available at the time of printing. It has subsequently been issued as BNWL-SA-3906, available from NTIS, 5285 Port Royal Road, Springfield, Virginia 22151. 
* URANIUM CASK FOR SHIPMENT OF FORT ST. VRAIN ETGR SPENT EUEL

C. R. Davis

The Fort St. Vrain fuel shipping cask was the first uranium-shielded containment vessel to be licensed by the USAEC for commercial transport operations. The uranium shield is fabricated of cast cylinders encased in stainless steel. The use of uranium permits the highest possible ratio of HTGR spent fuel element weight to cask weight for legal-weight truck transportation. This report presents the significant design features and engineering analyses used to satisfy the federal regulations for normal transportation and for hypothetical accident conditions.

\section{INTRODUCTION}

The Fort St. Vrain fuel shipping cask FSV-1 is designed for shipping six spent fuel elements at one time from the Fort St. Vrain high-temperature gascooled reactor (HTGR) to a nuclear fuel reprocessing plant. ${ }^{1}$ The spent fuel elements are hexagonal graphite blocks containing fissile material (primarily U-233 and U-235) and fertile material (primarily thorium) (Fig. 1). The cask may also be used for the handling and transportation of radioactive reprocessed fuel.

The FSV-1 shipping cask was designed to satisfy the following general requirements:

1. All regulations of federal and state government agencies.

2. Dry loading and unloading of HTGR fuel elements by remotely operated machinery.

3. Maximum ratio of spent fuel weight to gross shipping weight limited by highway restrictions of 73,280 lb gross vehicle weight for legalweight truck transportation.

FSV-I SHIPPING CASK DESIGN

The FSV-1 cask employs cast depleted uranium cylinders for primary shielding in order to obtain the minimum size and shipping weight for the six HTGR fuel 

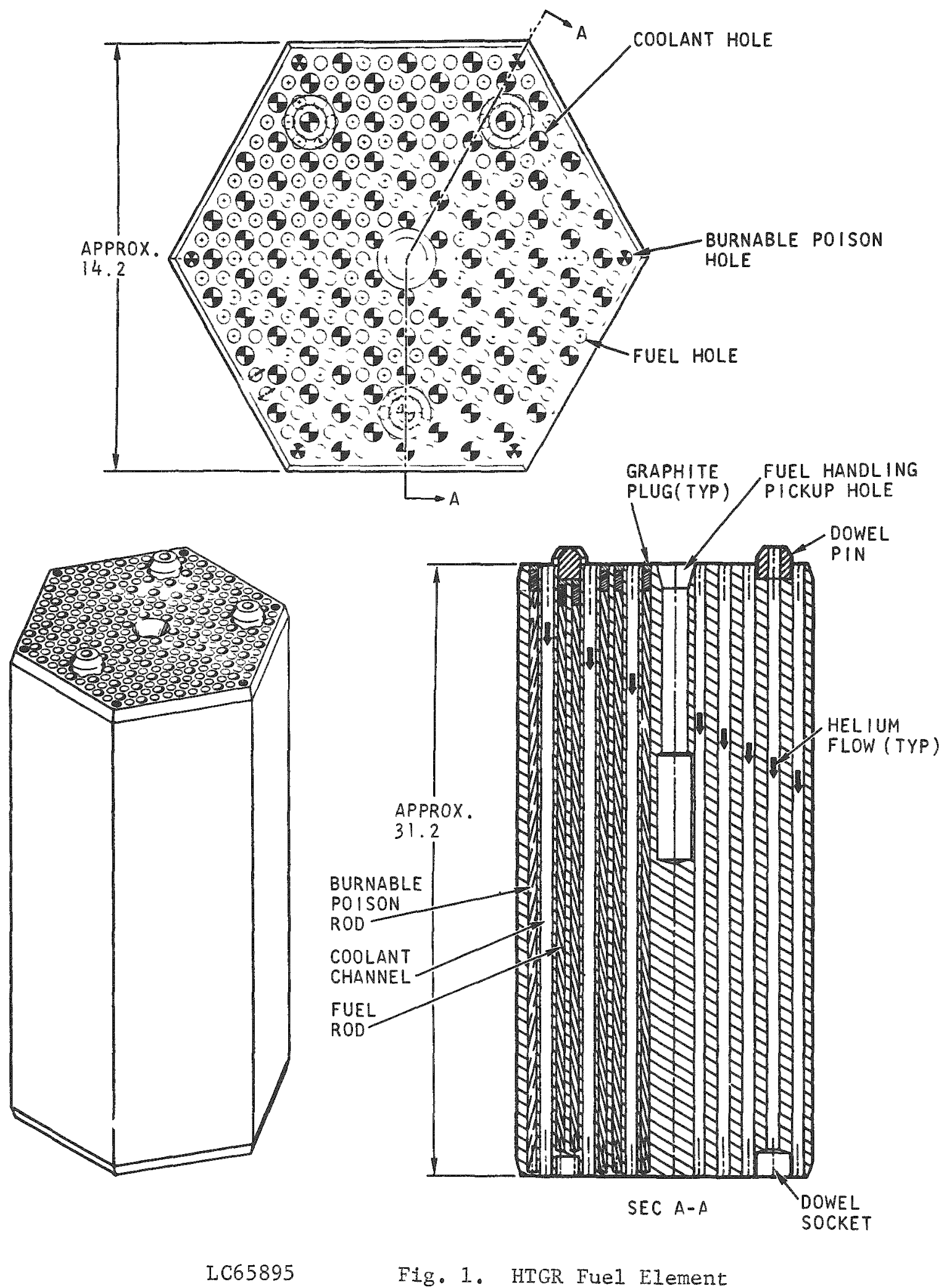
elements being transported. The unloaded weight of the FSV-1 has been calculated to be 43,000 1b. An equivalent weight cask made of lead shielding would carry only four HTGR fuel elements, and a cask of solid steel would transport only three*.

A basic design philosophy of the FSV-1 cask is that of "double containment." The six fuel elements are packaged in a spent fuel shipping container of stainless steel, which is sealed with a bolt-on lid containing both elastomer and metal 0-rings. This container fits snuggly in the shipping cask, which is sealed by a cover that also contains elastomer and metal 0-rings (Fig. 2). Structural and heat transfer analyses indicate that there is no release of radioactive gas or particulates from the fuel shipping container during or after any of the hypothetical accidents described in Appendix B of 10-CFR-71.

The Fort St. Vrain shipping cask is a long, cylindrical vessel with a cavity 17-3/4 in. in diameter by 192-1/2 in. Iong and an outer body diameter of 28 in. The head diameter is $31 \mathrm{in}$. and the overall cask length is $208 \mathrm{in.}$ (Fig. 3). The fuel shipping container cavity is $16-5 / 8$ in. in diameter by $187-5 / 8$ in. long, and the container body is $1 / 2 \mathrm{in.} \mathrm{thick.} \mathrm{The} \mathrm{cask} \mathrm{cover} \mathrm{includes} \mathrm{a} \mathrm{depleted}$ uranium disk $16 \mathrm{in.}$. In diameter by 2-1/4 in. thick for shielding, and the cask bottom if 9-in.-thick solid stainless steel. Located in the bottom of the cask is a tube connection for helium, used in testing the seals, and a removable center plug (Fig. 4). The plug is removed for decontamination of the cask and for transfer of a fuel shipping container from the cask through the wall into the Gulf General Atomic (GGA) hot cell.

\section{Shielding}

Dose rates for gama radiation were calculated for several points along the body and at the ends of the FSV-1 cask surface. Since the cask will be transported by a "sole use" vehicle with a barrier enclosing the cask on all sides, dose rates were also calculated at distances $6 \mathrm{ft}$ from the barrier and at the rear outer surface of the truck cab.

Radiation sources for fuel that had decayed for 100 days were used as input for the calculations and are listed in $\mathrm{Table} 1$. The source represents the highest fission product inventory a fuel element will have accumulated after schedule burnup in the equilibrium core. The activity was assumed to be uniformly

*By reducing the annual number of spent fuel shipments by one-third or one-half, the greater cost of depleted uranium (over lead or steel) is recovered in 2 to 3 years by reduced freight costs. 


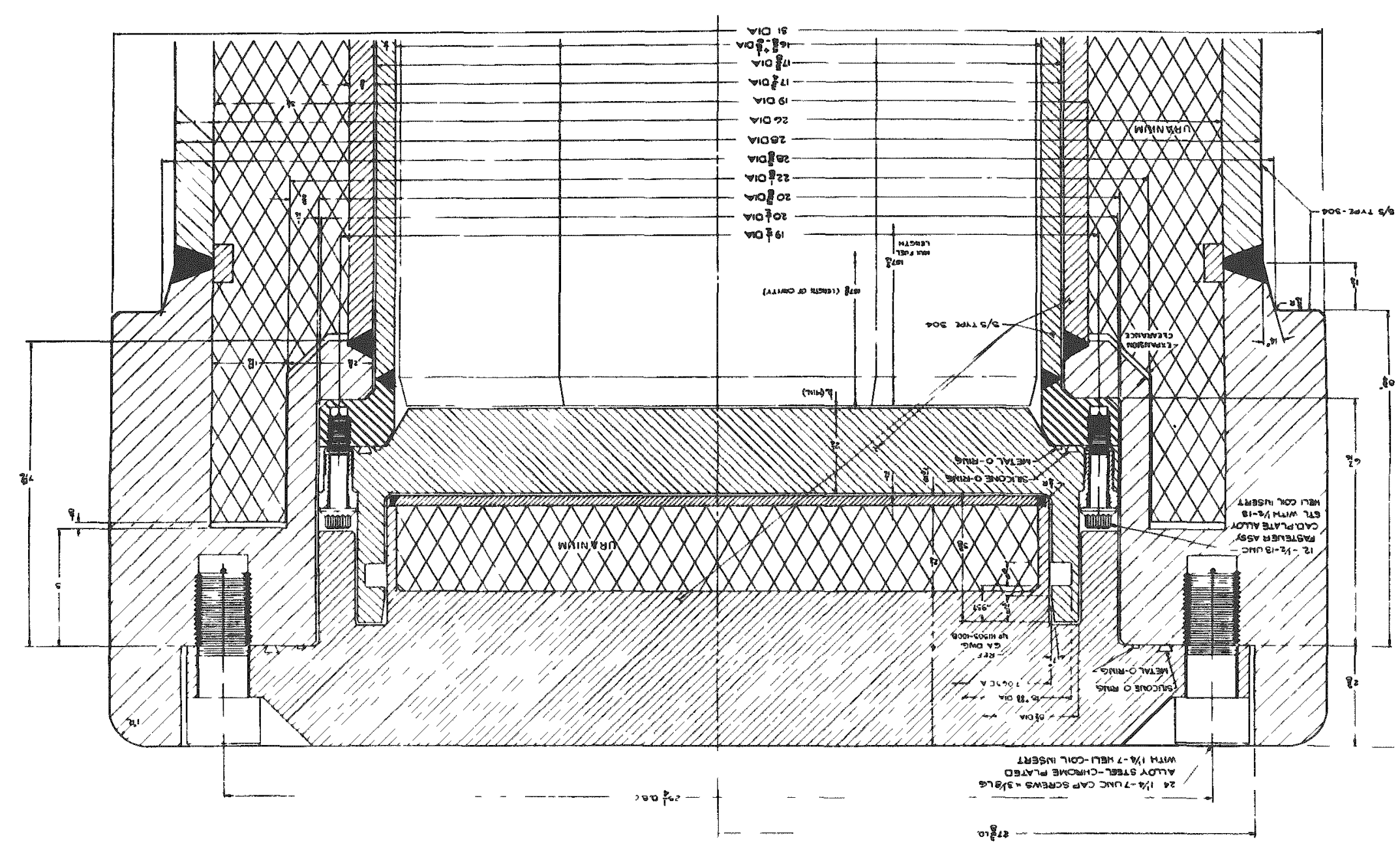




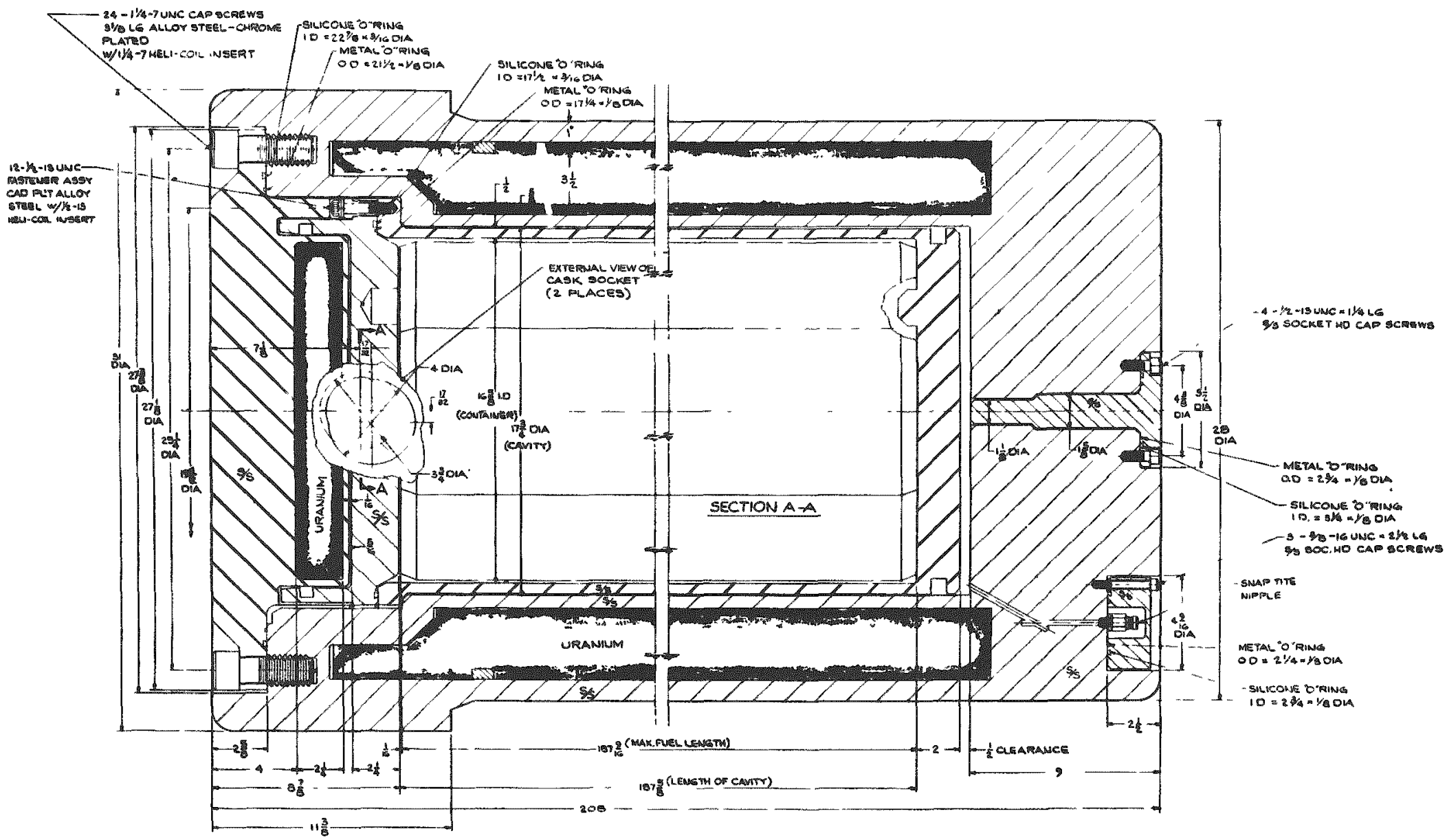




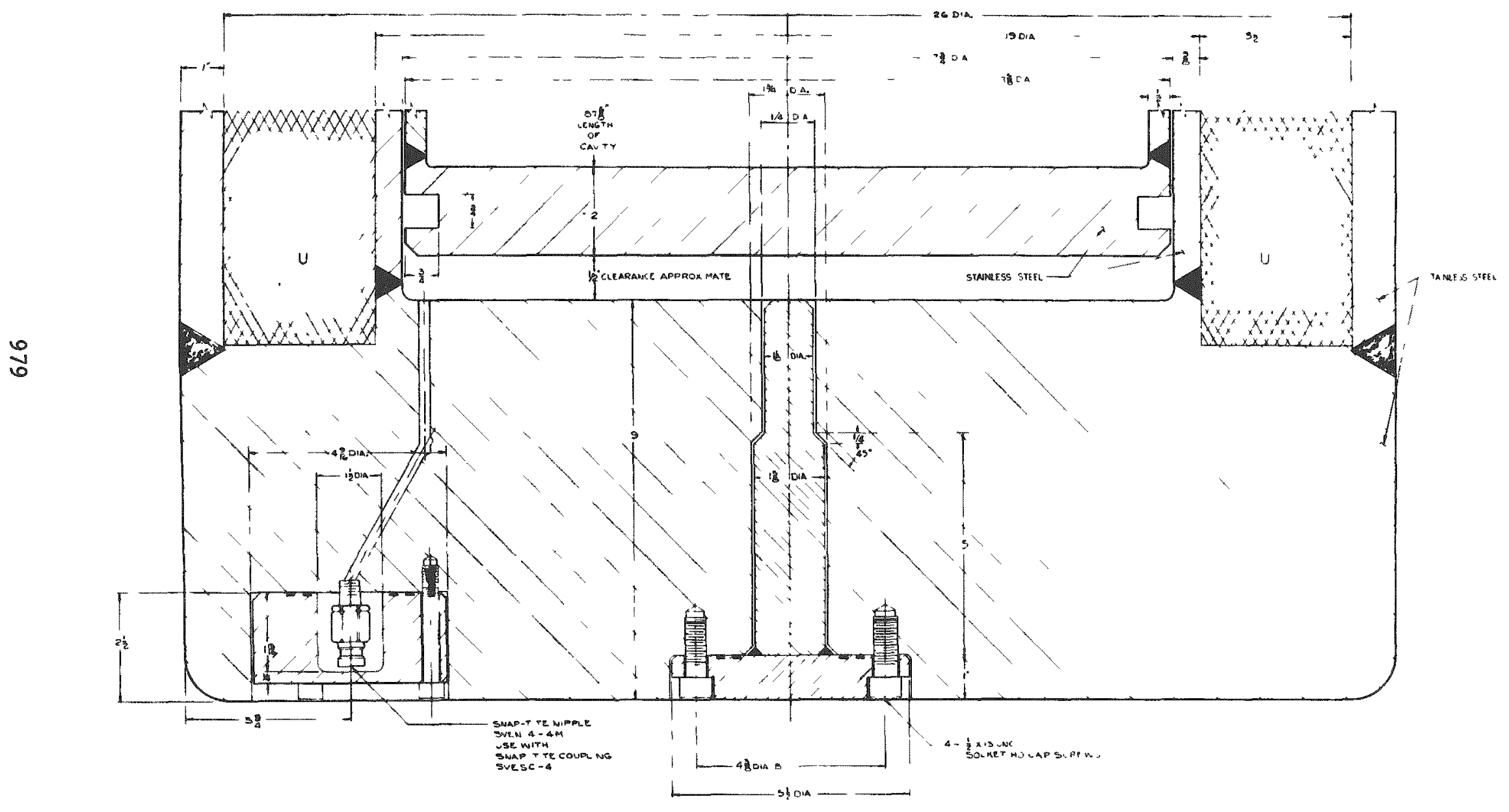


Table 1. Source Data for One HTGR Fuel Element From Fort St. Vrain Equilibrium Core with 100-Day Decay Storage

\begin{tabular}{ll}
\hline Isotope & Curies \\
$\mathrm{Y}-91$ & $1.19(+4)$ \\
$\mathrm{Zr}-95$ & $1.36(+4)$ \\
$\mathrm{Nb}-95 \mathrm{~m}$ & $2.7(+2)$ \\
$\mathrm{Nb}-95$ & $1.36(+4)$ \\
$\mathrm{Ru}-103$ & $2.7(+3)$ \\
$\mathrm{Rh}-106$ & $1.60(+3)$ \\
$\mathrm{Ba}-137 \mathrm{~m}$ & $2.08(+3)$ \\
$\mathrm{Ba}-140$ & $1.86(+2)$ \\
$\mathrm{La}-140$ & $1.86(+2)$ \\
$\mathrm{Ce}-144$ & $2.52(+4)$ \\
$\mathrm{Pr}-144$ & $2.52(+4)$ \\
\hline
\end{tabular}


distributed in each fuel element. The Gulf General Atomic (GGA) PATH code was used to calculate dose rates, which were then adjusted for buildup factors in a laminated shield.

It should be noted that the transplutonium isotopes $\mathrm{Cm}-242$ and $\mathrm{Cm}-244$, which are present in LWR spent fuel, ${ }^{2}$ are not listed in Table 1 since they are almost nonexistent in HTGR fuel; therefore, neutron shielding is not required for the FSV-1 shipping cask. For a nominal shield thickness of $3-1 / 2 \mathrm{in}$. of depleted uranium plus 2-1/8 in. of stainless steel, dose rates of 6 to $7 \mathrm{mr} / \mathrm{hr}$ were calculated 6 ft from the barrier that surrounds the cask during transport. The dose rate on the rear outside of the truck cab was less than $2 \mathrm{mr} / \mathrm{hr}$.

Heat Transfer Analysis

Owing to residual isotope activity, there is a continuing "after-heat" (which decays with time) in the HTGR fuel elements being shipped in the FSV-1 cask. This heat generation is predictable and has been calculated to be 2,322 Btu/hr per fuel element at 100 days decay time. Of this heat generation, $88 \%$ is realized within the fuel element and the remaining $12 \%$ is generated within the first inch of the surrounding shielding.

Steady-state and thermal analyses were conducted on thermal models of each end of the cask. The models extended far enough down the length of the cask to eliminate any end effects. 3 No unexpected results were obtained from the analysis of the relatively simple cask bottom; temperatures of the cask head are summarized in Table 2. The following three conditions were used to define the ambient conditions for the analyses:

1. Maximum temperature day. This condition assumes an ambient temperature of $130^{\circ} \mathrm{F}$ around all parts of the cask. Solar heating has a daily average effective intensity of $96 \mathrm{Btu} / \mathrm{hr}-\mathrm{ft}^{2}$, excluding the effect of the personnel shield. Fuel heat generation simulating 100 and 200 days from reactor shutdown was used.

2. Minimum temperature day. This condition is for a $-40^{\circ} \mathrm{F}$ ambient condition with no solar heating. Fuel heating of 100 days was used for comparison with Case 1 .

3. Fire accldent. The fire accident assumes a $1475^{\circ} \mathrm{F}$ fire completely surrounding the cask. A high surface heat of $300 \mathrm{Btu} / \mathrm{hr}-\mathrm{ft} \mathrm{L}^{2}-{ }^{\circ} \mathrm{F}$ was set to simulate the worst possible condition of hot, blowing gases; this condition lasts for 30 minutes, after which the cask is returned to the condition of Case 1 , the $130^{\circ} \mathrm{F}$ day. 
Table 2. Sumnary of the Thermal Analysis

\begin{tabular}{|c|c|c|c|c|c|c|}
\hline & \multicolumn{6}{|c|}{ Temperatures $\left({ }^{\circ} \mathrm{F}\right)$} \\
\hline & \multicolumn{3}{|c|}{$130^{\circ}$ Ambient } & \multicolumn{2}{|c|}{$-40^{\circ}$ Anbient } & \multirow{2}{*}{$\begin{array}{l}\text { Fire Acci- } \\
\text { dent Max }\end{array}$} \\
\hline & \multicolumn{2}{|c|}{ 100-Day Heat } & \multirow{2}{*}{$\frac{200-\text { Day Heat }}{\text { Max Gaps }}$} & \multicolumn{2}{|c|}{ 100-Day Heat } & \\
\hline & Max Gaps & Min fraps & & Max Gap & Min Gap & Min Gap \\
\hline Case seal & 141 & 137 & 133 & -14 & -15 & 1220 \\
\hline Container seal & 155 & 146 & 137 & 3 & 0 & 655 \\
\hline Fuel surface, max & 278 & 266 & 200 & 153 & 143 & 284 \\
\hline Fue1 centerline, max & 284 & 272 & 203 & 160 & 149 & 291 \\
\hline Container wa11, max & 174 & 159 & 147 & 28 & 14 & 502 \\
\hline Cask inner 1 iner, max & 161 & 149 & 141 & 13 & 2 & 715 \\
\hline Shielding, center & 152 & 146 & 137 & 3 & 0 & 829 \\
\hline Cask outer she11, max & 146 & 144 & 134 & -4 & -3 & 1397 \\
\hline
\end{tabular}


Temperatures were calculated by a nominal finite-difference method using GGA digital computer code RAT (acronym for radial-axial temperatures). RAT is applicable to calculating transient temperatures in a two-dimensional network of points. It may also be used to obtain steady-state solutions by extending a transient calculation to the point where time dependence of results becomes negligible. The network is specified by establishing two sets of grid lines parallel to the coordinate axis in one of the following three sustems: orthogonal $(X-Y)$, cylindrical $(R-Z)$, or circular $(R-\theta)$.

Because of manufacturing tolerances, it is very unlikely that all parts of the fuel container and cask would ever be manufactured with all-maximum or allminimum gaps. Nevertheless, thermal analyses were made using both extreme cases to lllustrate the maximum range of temperatures that might be encountered. The centerline fuel temperature was calculated to increases from $272^{\circ} \mathrm{F}$ for minimum gaps to $284^{\circ} \mathrm{F}$ for maximum gaps, while the outer cask surface was the same, $145^{\circ} \mathrm{F}$, for the $130^{\circ} \mathrm{F}$ ambient day.

In the thermal analyses, the minimum and maximum radial dimensions of the fuel container and cask components (inner liner, uranium shield, and outer she11) were used with appropriate coefficients of thermal expansion; thus, the correct gaps were recalculated as the cask changed in temperature. The net effect of this process was to decrease the gap sizes under normal conditions when the container and inner liner are both hotter than the outer shell. In the fire accident, however, the outer shell and shield will expand away from the inner liner, increasing the resistance of the gaps and retarding the heat flow into the fuel.

\section{Structural Details}

The use of uranium as a shielding material in place of lead in the design of the FSV-1 casks provided the opportunity for overall weight savings. In contrast to lead, it was possible to benefit from the structural strength of the uranium by correctly evaluating its energy-absorbing ability. Uranium does not permit the bulk slump and gross deformation common to lead-filled casks on the standard 30-ft free-fall drop test; however, there is definite absorption by a uranium-filled cask of comparatively large percentages of the kinetic energy generated.

Conventional stress analysis procedures are largely related to maximum developed stress levels in a static structure. The specification of a simple helght-of-drop condition requires, therefore, some acceptable computational 
conversion relating dynamic data to maximum stress values. It is neither necessary nor justifiable to engage in sophisticated approaches to impact analysis based on wave phenomena, especially for the relatively low velocity of 44 $\mathrm{ft} / \mathrm{sec}$ involved. A simple and most satisfactory conversion formula given by authorities Goldsmith ${ }^{4}$ and Cristescu ${ }^{5}$ relates maximum stress to impact velocity and the compressive stress-strain curve of the material:

$$
\rho v^{2}=\varepsilon_{1}\left(p_{1}-p_{y}\right)
$$

where $\quad \rho=\frac{1 \mathrm{~b} / \mathrm{in}^{3}}{386}$,

$v^{2}=(44 \mathrm{ft} / \mathrm{sec} \times 12)^{2}=278,784(\mathrm{in} . / \mathrm{sec})^{2}$,

$\varepsilon_{1}=$ maximum strain corresponding to $\mathrm{P}_{1}$,

$p_{1}=$ initial, and maximum, stress corresponding to moment of impact, and

$p_{y}=$ static compressive yield point (by 0.002 in./in. strain method).

Knowing the compressive stress-strain curve, it is a simple matter to find a point whose $\varepsilon_{1}$ and $p_{1}$ values satisfy the equation. Tensile curves are not satisfactory data, as they frequently differ from compression curves, especially for uranium.

Values of $p_{1}$ (maximum compressive stress) are calculated to be 90,000 psi for uranium ${ }^{6}$ and 53,800 psi for Type 302 stainless steel. ${ }^{4}$ It is notable that these are not ultimate compressive stresses, indicating that, at the velocity of impact involved, the full value of the kinetic energy per cubic inch of completely displaced material has not been reached. The phenomenon of impact is thus more like a finite time plastic deformation of a relatively large volume of material suffering only partial compression.

The stress values given above, being in the plastic zone, are distinctly greater than the static yield properties of the two materials. The obvious result is the development of correspondingly higher " $g$ " values to be applied in the static stress analysis of the structures. This basis for analysis is used for the FSV-1 cask and is genuinely conservative.

Plastic deformation is presumed to cease when the peak stress in compression is developed. This allows acceptable configuration distortion calculations of corner impacts. In this respect, the reduced distortion associated with greater maximum stress is of benefit in preventing gross warpage of the vital sealing surfaces of the spent full container and shipping cask. 
Structurally, the use of uranium provides a material which, unlike lead, not only supports itself but is also able to add strength and rigidity to the inner liner and outer shell of the cask.

$$
\text { Criticality }
$$

The criticality evaluation used the following assumptions:

1. The fuel elements contain the most reactive fresh fuel composition anticipated for fuel shipment, i.e., about $1.4 \mathrm{~kg}$ of $93.5 \%$ enriched uranium and $11.3 \mathrm{~kg}$ of thorium per element, or a maximum of $8.4 \mathrm{~kg}$ of uranium and $68 \mathrm{~kg}$ of thorium in the spent fuel container. The total amounts of all materials present in a fuel element as well as the homogenized atom densities (over a fuel element) are summarized in Table 3.

2. The presence of burnable poison or other neutron absorbing material, other than U-235, U-238, thorium, silicon, and graphite, is neglected.

3. The fuel is at room temperature.

4. All fission products are neglected.

These assumptions are all conservative. In general, spent fuel elements will contain considerably less fissile material. Also, all other fresh fuel element types are less reactive due to their lower uranium content and/or higher thorium content.

Two geometrical models were used to evaluate the criticality situation for the shipping cask. ${ }^{6}$ The one-dimensional model assumes an infinitely long cylinder. This model is adequate as long as it can be assumed that the fuel is well contained within the fuel elements.

A two-dimensional geometry model was used for the maximum criticality situation due to accident conditions, which include block breakage, internal flooding, and an accumulation of fuel particles at the bottom of the cask.

\section{Fabrication}

A1I steel materials for the spent fuel container and FSV-1 cask were purchased to commercial specifications such as ASTM, ASME, AISI, etc. Chemical and/or physical test reports were provided for the materials of all critical. parts. Welding was performed in accordance with Section IX of the ASME Code. Detailed manufacturing procedures were prepared, outlining step-by-step 
sequences for 211 fabrication, machining, and assembly operations. Inspection points were integrated into these procedures to provide $100 \%$ in-process and final inspection. 1

Table 3. Most Reactive Fuel Element Material Contents

\begin{tabular}{lcc}
\hline & $\begin{array}{c}\text { Total Anount } \\
(\mathrm{kg})\end{array}$ & $\begin{array}{c}\text { Homogenized } \\
\text { Atom Density } \\
\text { (atoms } / \mathrm{b}-\mathrm{cm})\end{array}$ \\
\cline { 2 - 3 } Th-232 & 11.25 & \\
$\mathrm{U}-235$ & 1.31 & $3.76 \times 10^{-5}$ \\
$\mathrm{U}-238$ & 0.081 & $2.22 \times 10^{-6}$ \\
Silicon & 4.63 & $1.12 \times 10^{-3}$ \\
Carbon & 111.30 & $6.27 \times 10^{-2}$ \\
\hline
\end{tabular}

Five uranium cylinders about $40 \mathrm{in.}$ long were welded together by a proprietary method developed by the National Lead Company (NLC) to obtain a one-piece shield. The shield was inspected for integrity by gamma probing. The uranium cylinder was then sprayed completely with copper to prevent corrosion and uranium-steel eutectic formation, after which the uranium shield was assembled over the cask inner liner.

The cask inner liner was welded to the cask base prior to assembling the uranium shield cylinder in place. After the uranium cylinder was fitted to the inner liner, the outer shell was placed in position and welded to the cask base. Last to be assembled was the cask head, which was first welded to the inner liner and then to the outer she11. All gaps and voids between the steel parts and the uranium were evacuated and backfilled with helium before completion of the final welding. After weldino, final machining of the cask head was accomplished to provide proper fitting of the cask cover.

A11 fabrication of the FSV-1 cask and containers was accomplished in accordance with the ASME Code, Section III, Class B vessels. The manufacture of the cask was followed by in-process inspections performed by personnel of the GGA Quality Assurance Department. In addition, an authorized code inspector performed all the inspections required by Article 15 of the ASME Code. Copies of material certifications, dimensional records, inspection reports, nondestructive test reports, and the manufacturers' process sheets, with the code inspector's concurrence indicated at appropriate checkpoints, have been maintained and are available for future reviews. 
Prior to delivery of the spent fuel container and shipping cask, a checkout test of the seals was accomplished by pressurizing the cask cavity with helium to 50 psig and then holding this pressure without decay for $24 \mathrm{hr}$. Shielding integrity was checked by a gamma probe and scan over 100\% of the cask surface, and heat transfer was checked by dissipating known quantities of electrical energy inside the fuel container and monitoring the surface terperatures of the casl: inner liner and outer shell by thermocouples.

SLMLARY

The fort St. Vrain fuel shipping cask satisfies all requirements of the USAEC and the T. S. Department of Iransportation. Because depleced uranium is used for shielding, the cask can transport the naximum possible number of HTGR fuel elements by legal-weight truck. The cask is designed for dry loading by remotely operated machinery at the Fort St. Vrain reactor.

The FSV-1 casl design employs the basic philosophy of double containment, with the imer spent fuel container providing the primary contaiment by the use of buth elastomer and metal o-ring seals. In case of a fire accident, the uranium shield does not melt, and the shield and steel inner Liner and outer shell expand in such a way as to allow a minimum temperature rise of the fuel elements. While the energy absorption of uranium is not as great as lead, it does not deform as does lead when subjected to impact. In addition, its strength in compression is much greater than that of stainless steel. All materials used in the fabrication of the FSV-1 cask were closely controlled and tested to current commercial specifications. The manufacture was followed by in-process inspections performed by an ASME Code inspector, by GGA Quality Assurance inspectors, and by NLC Quality Control persone1.

\section{ACKROTLEDG.MLI}

The author wishes to express his appreciation to "lessrs. h. C. Finch, R. F. Hinz, and U. A. Simon of Gulf General Atomic, and to Mr. Harold A. Backus of National Lead Company for their contributions and assistance in the preparation of this paper. This work was supported by the L. S. Atomic Energy Comission under contract $\mathrm{AT}(04-3)-633$. 


\section{REFERENCES}

1. C. R. Davis et al. (GGA) and D. C. Cocciolone et al. (NLC), "Final Design Report for Fort St. Vrain Fuel Shipping Cask," GADR-55, April 17, 1969.\%

2. H. S. Bailey, R.N. Evatt, C.P. Ruiz, and G. L. Gyorey, "Neutron Shielding Problems in High Burnup Thermal Reactor Fuel Shipping," Transactions, 1969 Winter Meeting, American Nuclear Society, pp. 448-9.

3. C. R. Davis et al. (GGA) and H. A. Backus et al. (NLC), "Final Design Report for Fort St. Vrain Fuel Shipping Cask, Supplement A," GADR-55, November $15,1969 . \%$

4. W. Goldsmith, Impact, Edward Arnold, Ltd, London, 1960.

5. N. Cristescu, Dynamic Plasticity, Interscience, New York, 1968.

6. C. R. Davis et al. (GGA) and H. A. Backus et al. (NLC), "Final Design Report for Fort St. Vrain Fuel Shipping Cask, Supplement B," GADR-55, November 15, $1969 . \%$

*These documents supported the application for AEC License for the Fort St. Vrain fuel shipping cask. They are on file in the AEC Public Information Center, 1717 H Street N.W., Washington, D.C., under Docket No. 70-1165. 
SHIPPING CASKS FOR SPENT FUEL WITH HIGH BURN-UP

F. Schmiedel

R. Dietrich

This paper was not available at the time of printing. It has subsequently been issued as BNWL-SA-3906, available from NTIS, 5285 Port Royal Road, Springfield, Virginia 22151. 


\title{
* "GENERAL DESCRIPTION OF EXPLCTED SIZE AND CAPABILITY OF 1100 MWE REACTOR SPENT FUEL SHTPPING CASKS \\ J.P. Malone
}

\begin{abstract}
A general consideration of the design parameters for 1100 MWe reactor spent fuel shipping casks permits reasonable estimates to be made of the expected size and capabilities of future spent fuel casks for 1100 WWe reactors.

The allowable weight of the cask, the required length, and the shielding thickness are factors used to detemine the expected cavity diameter. The cavity diameter and the heat transfer requirements are then employed to estimate the spent fuel capacity of the cask.
\end{abstract}

\section{INTRODUCTION}

Three modes of transportation are commonly associated with the shipment of spent fuel from nuclear reactors. They are truck, rail, and water. Iruck transportation is feasiule at all reactors while rail and/or water transportation are not always available. Fon this reason motor fruight has become the most common metrod of spent fuel transpontation. It is for this reason, also, that the electric utilities show more than a passing interest in the ability of motor freight to fulfill the spent fuel shipping requirements of the 1100 MWe Iight water reactors in an economical manner. The purpose of this presentation is to provide a general description of the expected size and capability of 1100 MWe reactor spent fuel shipping casks for highway use. 
By considering the design parameters, the expected size and capability of the future spent fuel casks for servicing the 1100 MWe reactors can be deduced. The first parameter to be considered is the weight. A practical limit of gross vehicle weight for road transportation is about 95,000 pounds. The weight of the tractortrailer combination must be subtracted from the gross vehicle weight in order to determine the allowable weight of the cask and its contents. Tractor-trailer combinations weighing 20,000 pounds can be expected to be available. This is a substantial improvement over the 30-35,000 pound tractor-trailer combinations formerly required to transport a large payload. This weight reduction is largely the result of employing lightweight-highstrength materials in the construction of the trailer thereby reducing its weight to the 7,000 pound range. The 95,000 pound limit less 20,000 pounds for the tractor-trailer leaves 75,000 pounds for the cask and its contents.

Since the weight of the cask and its contents has been established the length and shielding thickness parameters may be examined in order to determine the maximum permissible cask dimensions. The heat transfer requirements of the cask must be kept in mind and will be considered in a subsequent section. The cask length will be established first.

The 1100 MWe boiling water reactor fuel is typically 171 inches long while the pressureized water reactor fuel is 166 inches in overall length. About 6 inches of cavity length are required for a shock absorber to prevent damage to the fuel during transport. Considering the boiling water reactor fuel, a cask intended for both BWR and PWR fuel should have a cavity length of approximately 177 inches.

\section{Shielding Thickness}

The next design parameter is the shielding thickness required to reduce the dose rate to an acceptable level. For estimation purposes the shielding thickness may be considered to be insensitive to number of elements in the cavity, that is, essentially a constant. In reality the required shield thickness will change 
only slightly as the number of elements in the cavity changes. The thickness of lead required to reduce the dose rate from one assembly to an acceptable level will not double if it is desired to shield two assemblies. Perhaps an additional 1/2 inch of lead may be required in order to accomplish this. Preliminary calculations using the SDC code ${ }^{l}$ were performed in order to determine the approximate thickness of lead equivalent shielding with a 1 inch inner steel shell which is necessary to reduce the gamma radiation dose rate to an acceptable level for transportation. The PHOEBE code ${ }^{2}$ was used to obtain the gamma ray source strength used in the SDC calculations. An approximate operating history of a typical 1100 MWe reactor and a 150 day cooling off period were used in the PHOEBE calculation of the gamma ray source strength. The results of the calculations indicate that about $81 / 2$ to $91 / 2$ inches of lead equivalent shielding are required with a 1 inch inner steel shell to reduce the gamma ray dose rate to about 5 $\mathrm{mr} / \mathrm{hr}$ at 8 feet from the side of the cask.

Unlike prior generation reactors the radiation dose from the 1100 MWe spent fuel is due to both neutrons and gamma rays. The significant neutron activity in 1100 MWe reactor spent fuel will be the result of the presence of transuranium elements heretofore unencountered in spent light water reactor fuel. Certain isotopes of these elements present neutron shielding problems that were not present in spent fuel from prior generation light water reactors. 3 The presence of isotopes of curium is the result of attaining the high fuel exposures (burnup) that are the goal of the 1100 MWe reactors. The formation of one atom of ${ }^{242} \mathrm{~cm}$ requires four neutron captures, while ${ }^{244} \mathrm{Cm}$ requires six neutron captures. Therefore, the concentrations of these isotopes will depend, roughly on the fuel exposure to the 4 th and 6 th power until the concentrations approach equilibrium. 4 These isotopes produce neutrons by spontaneous fission and $(\alpha, N)$ reactions with the oxygen in the $\mathrm{UO}_{2}$ fuel.

As indicated above, the $81 / 2$ to $91 / 2$ inches of lead equivalent shielding will reduce the gamma ray dose rate to about 5 $\mathrm{mr} / \mathrm{hr}$ at 8 feet from the side of the cask. The balance of the allowable $10 \mathrm{mr} / \mathrm{hr}$ dose rate will be due to neutron activity. Calculations have shown that for initial cycle, $\mathrm{UO}_{2}$, 1100 MWe reactor fuel no special neutron shielding, such as a water gap in 
the lead, will be required. 5 The above considerations indicate that the expected shielding configuration should be about a $I$ inch steel inner shell, 9 inches of lead and a 1 I/2 inch thick steel outer shell.

Cask Diameter.--Knowing the weight of the cask and its contents, the length of the cask, and establishing the shield thickness then fixes the diameter of the cask cavity. A 23 inch diameter cavity is determined from this approach. This cavity size can accommodate 3 PWR assemblies or 7 BWR assemblies.

\section{Heat Removal}

Unlike the shielding thickness, the heat removal problem is compounded in direct proportion to the number of spent fuel assemblies in the cavity. The goal with respect to heat transfer is to remove the decay heat so that the temperatures of the fuel and the cask are maintained at a reasonable level. The decay heat load from 3 PWR assemblies is about $33 \mathrm{KW}$ while 7 BWR assemblies have a decay heat load of about $2 \mathrm{lKW}$. The use of aluminum fins on the outer surface of the cask seems attractive from a weight saving point of view. Aluminum fins could permit the dissipation of the decay heat without assistance from a forced cooling system. Current methods employed in joining dissimilar metals (such as aluminum and steel) result in strong joints with excellent heat transfer characteristics.

\section{SUMMARY}

Based on the above development, the casks used for highway transportation of 1100 MWe light water reactor spent fuel can be expected to be about 16 feet in overall length, weigh approximately 70,000 pounds, have a 23 inch cavity diameter and an outside diameter of about 5 feet including the fins. Such a cask could physically accommodate 3 PWR assemblies or 7 BWR assemblies and dissipate the corresponding decay heat after reasonable cooling time without the need for forced cooling. 


\section{REFERENCES}

1. E.D. Arnold, B.F. Maskewitz, SDC, A Shielding-Design Calculation Code For Fuel-Handling Facilities, ORNL-3041 (March, 1966).

2. E.D. Annold, PHOEBE - A Code For Calculating Beta and Gamma Activity and Spectra For 235 Fission Products, ORNL-3931 (July, 1966).

3. J.D. Rollins, R.E. Best, "Neutron Shielding Problems Associated With the Shipment of High-Burnup LWR Fuel", Transactions of the American Nuclear Society, volume 12, no. 2, Nov. 1969.

4. H.S. Bailey, et.al., "Neutron Shielding Problems in High Burnup Thermal Reactor Fuel Shipping", Transactions of the American Nuclear Society, volume 12, no. 2, Nov. 1969.

5. E.D. Annold, H.F. Soard, "Neutron Shielding Requirements for LMFBR and LWR Fuel Shipping Casks", Transactions of the American Nuclear Society, volume 13, no. 1, June-July, 1970. 
Henri BRUEL

Camille BOCHARD

ABSTRACT

The cost of the ruel cycle and especially of the irradiated fuels transportation, deserves of the specialists attention, taking into account the large number of power stations being presently erected.

However, the IWR fuels characteristics entail new technical problems concerning the thermal evacuation and the neutron shielding of the casks.

This article summarizes the solutions praised by the ROBATEL SLPI Company, casks designers and manufacturers, to solve these problems while stressing the economical and safety aspects.

\section{INTRODUCPION}

For several years the Nuclear Equipment Department of the ROBATEL SLPI Co. has been devoted itself to study and to manufacture shielded packagings for radioactive materials. In this purpose, our "Research and Development Group" has perfected new techniques enabling to follow the evolution of the Répulations on Radioactive materials transportation, on one hand, and to meet the nev problems set by the power reactors irradiated fuels elements transportation, on an industrial scale, on the other hand.

The first uncommon solution we have been using since 1964 for manufacm turing type $B$ casks consisted in incorporating between the lead shielding and the outer shell, a thin layer of an insulator, based on hydrous calcium sulfate. (U. S. Patent $\mathbb{N}^{0} 3.466 .662$ ). With this technique, now called "Thermal switch" technique, we designed and built a lot of casks in perfect conformity with the mechanical and thermal norms on irradiated fuel elements transportation, as they have been carried on till now. To-day, 175 casks using this technique have already been manufactured in our workshops, the heaviest ones weighing 50 tons (used for Chinon and Saint-Laurent-des-Eaux E D F Power plants fuels) and releasing a $15 \mathrm{~kW}$ power. As a matter of fact, the hydrous calciurn sulfate "thermal switch" secures a heat transfer of about $1,700 \mathrm{~W} / \mathrm{sq} . \mathrm{m}$ (540 BNu/h sq.ft) 
1 - Present problem data

The economical considerations in connection with the power reactors development tend to impose a reduction of the dead times, that are storing and fuel transportation. This principle raises two new difficulties in solving the package problem:

- The increasing of irradiated fuel elements reaidual power, following to the combustion rates increase and to short cooling time,

- The necessity of including, in addition to the classical protection against gamma rays, a neutron shielding, most often made of materials which are bad conductors of heat.

These conflicting problems have entailed to develop new perfectings, enabling to keep the packages at the highest level of safety.

The point was to design packages using materials which could in the whole serve the following fonctions :

- protection against gamma rays,

- protection against neutronic rays,

- dissipation of the thermal power emitted by the irradiated fuel elements,

- protection against the effects of the reglementary drop-tests,

- protection against the effects of the reglementary fire-tests.

We have also been guided towards the chosen materials by considerations less important, but not negligible, since they involve the economical aspects :

- weight of the package,

- easy use, i. e. manufacturing cost.

As a matter of fact, it stands to reason that a too important increase of the packages cost, consequently of the transportation cost, reduces as much the advantage to get relatively short cooling times.

\section{2 - Garma shielding}

The materials mare often used to make gamma protection are steel, lead or depleted uranium. We thought over these three possibilities, our workshops having the experience of making protections with these three metals.

From the economical point of view, the wo main criteria are the naterial price eterworking it and setting, and the total weight of the package 


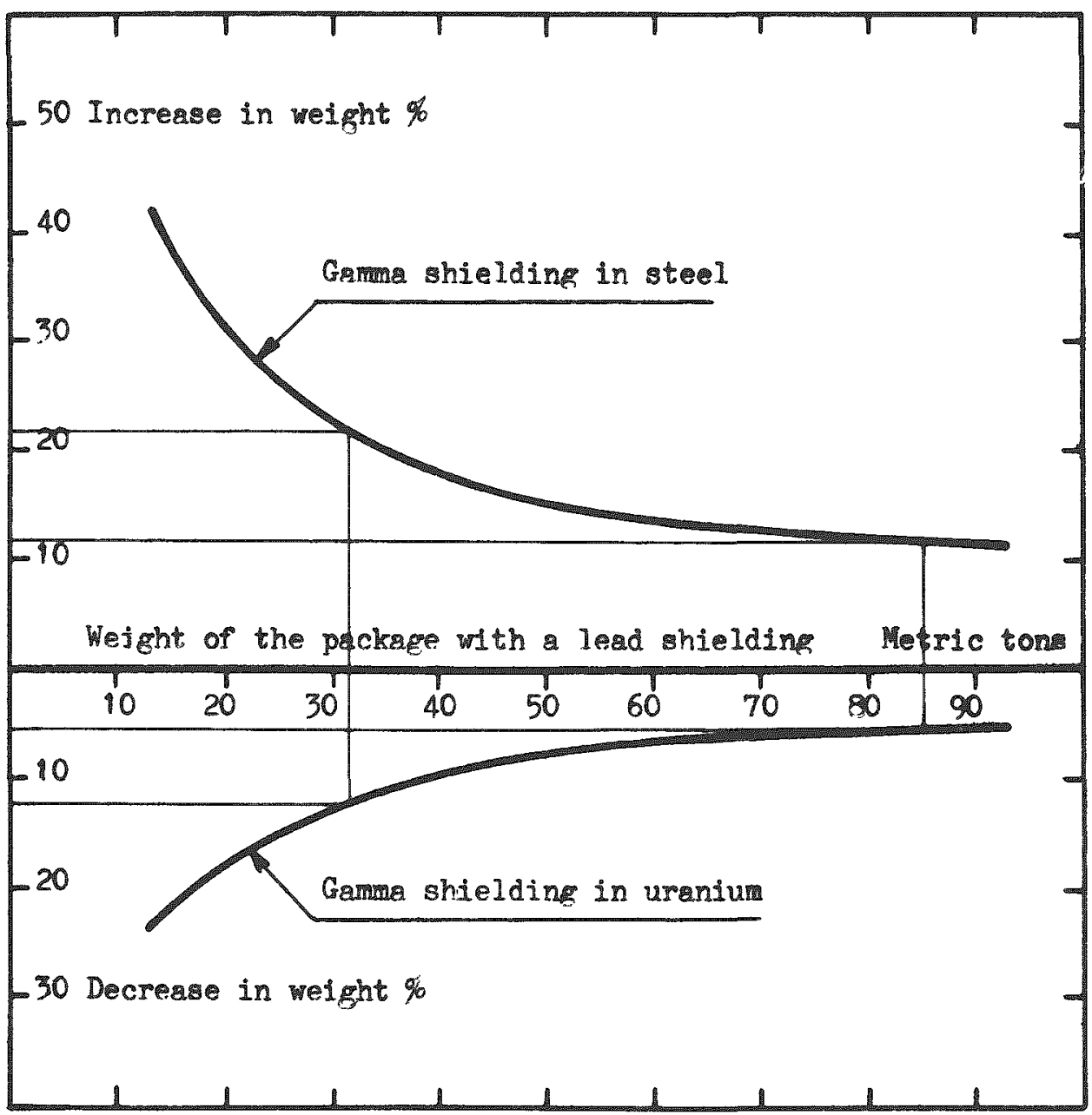

Fig. 1 - Relative fluctuations of the weight of a LWR package, according to the type of the farma protection chosen. 
during transportation. As an example, the curves of Fig. 1 show the fluctuations of the LWR packgge weight, according to the gamma protection chosen, in relation to the corresponding package weight with a lead gamma protection. The given values correspond to gamna protections equivalent to $200 \mathrm{~mm}$ of lead, for gama rays of 2 MeV.

It is to note that the percentage of weight increase is obviously more important as the package is small. Also for a 32 tons package carried by road, uranium enables to reduce the weight by $12 \%$ compared with lead and, on the reverse, a steel package is $22 \%$ heavier compared with a lead package.

For heavy packages carried by railways that we designed ( 85 tons) there are not so many differences, for uranium enables to decrease the weight only by $6 \%$, and steel increasing it by $12 \%$.

Those figures compared to the three protection types real costs have led us to choose lead. As a matter of fact, uranium high cost and its difficult processing are far from balancing the advantages of weight it gives; on the reverse, the noticeable loss in weight due to steel is not balanced by a sensible manufacturing cost decrease.

\section{3 - Neutron shielding}

3. 1. Material. - - In 1967, together with the French Commission to the Atomic Inergy (C.E.A.), we perfected a material absorbing neutrons (U.S. Patent Pending No 716 330) mainly composed of polyethylene, boron and hydrous calcium sulfate.

This material, particularly well adapted for the cask problem, shows the following advantages:

- neutron efficiency equivalent to that of massive polyethylene.

- easy processing enabling to fit the most complicated forms, hence a very interesting price.

- swelling when setting and good mechanical holding, which secures the gamma shielding a perfect conservation with respect to the steel resisting structures.

- interesting thermal insulation in case of an accidental fire.

The reglementary drop and fire tests periormed on a small gamma neutrons model have shown that the neutron absorbing compound was burnt only on $10 \mathrm{~mm}$ thick and that the temperature of the lead shielding did not exceed $104^{\circ} \mathrm{C}\left(214^{\circ} \mathrm{F}\right)$. 
3-2. Heat transfer. - - So as to get the minimu dead weight, this light material absorbing neutrons has been placed outside the gamma shielding. But as its good insulating properties did not enable to dissipate satisfactorily the heat spread by the fuel elements, we have placed good conductor metal structures inside this neutron absorbing protection.

Forms ans spots have been judiciously chosen, which enables us to reach apparent thermal conduction coefficients for the whole protection around $36 \mathrm{kcal} / \mathrm{h}$ m ${ }^{\circ} \mathrm{C}(24 \mathrm{BTV} / \mathrm{he} \mathrm{sq.ft.}(\mathrm{F} / \mathrm{ft}))$.

\section{4 - Thermen switch}

Regarding the protection against fire, we keep on using our thermal smiteh technique, which shows many advantages. The aims of such a process are, let us remind of it:

a) To make the transfer of heat towards outside easier, by placing between the gamma shielding and the outer steel shell, a product securing an excellent contact between these two parts (avoiding the gir gaps) and presenting a good conduction coefficient.

b) In case of fire, to block the heat penetration towards the inside of the package, in order to avoid a too important rise in temperature.

c) After the fire, to ensure the evacuation of the heat spread by the transported products, and therefore the material must keep an acceptable coefficient of conduction after accident.

These purposes, apperently incompatible, are reached with our new "thermal switch" made from alumina (U.S. Patent Pending No 59037 ). We call it "high flux thermal switch", as it allows a heat transfer of about $4,500 \mathrm{~W} / \mathrm{sq} \cdot \mathrm{m}$ $(9,430 \mathrm{BTU} / \mathrm{hr} \cdot 3 \mathrm{q} \cdot \mathrm{st})$.

The "high flux thermal switch" is essentially composed of alumina trihydrate and hydrated iron oxides; it is in a dry state, but yet contains a large quantity of water under combined form (conduction coefficient around 2,5 $\mathrm{kcal} / \mathrm{h} \mathrm{m}$ oC $: 1.7 \mathrm{BTU} / \mathrm{hr}$. sq.ft. $(9 \mathrm{~F} / \mathrm{ft}))$. The releasing temperatures being relatively high, this thermal switch may be used under normal conditions at a temperature of $160^{\circ} \mathrm{C}\left(320^{\circ} \mathrm{F}\right)$.

The swelling occuring when the raterial hardens ensures an excellent contact between the various shieldings.

In case of fire, the water contained in the material steams off through safety outlets, what limitates the rise in temperature. Even when it is free from its water, this material keep perfect mechanical holding and a conduction coef- 


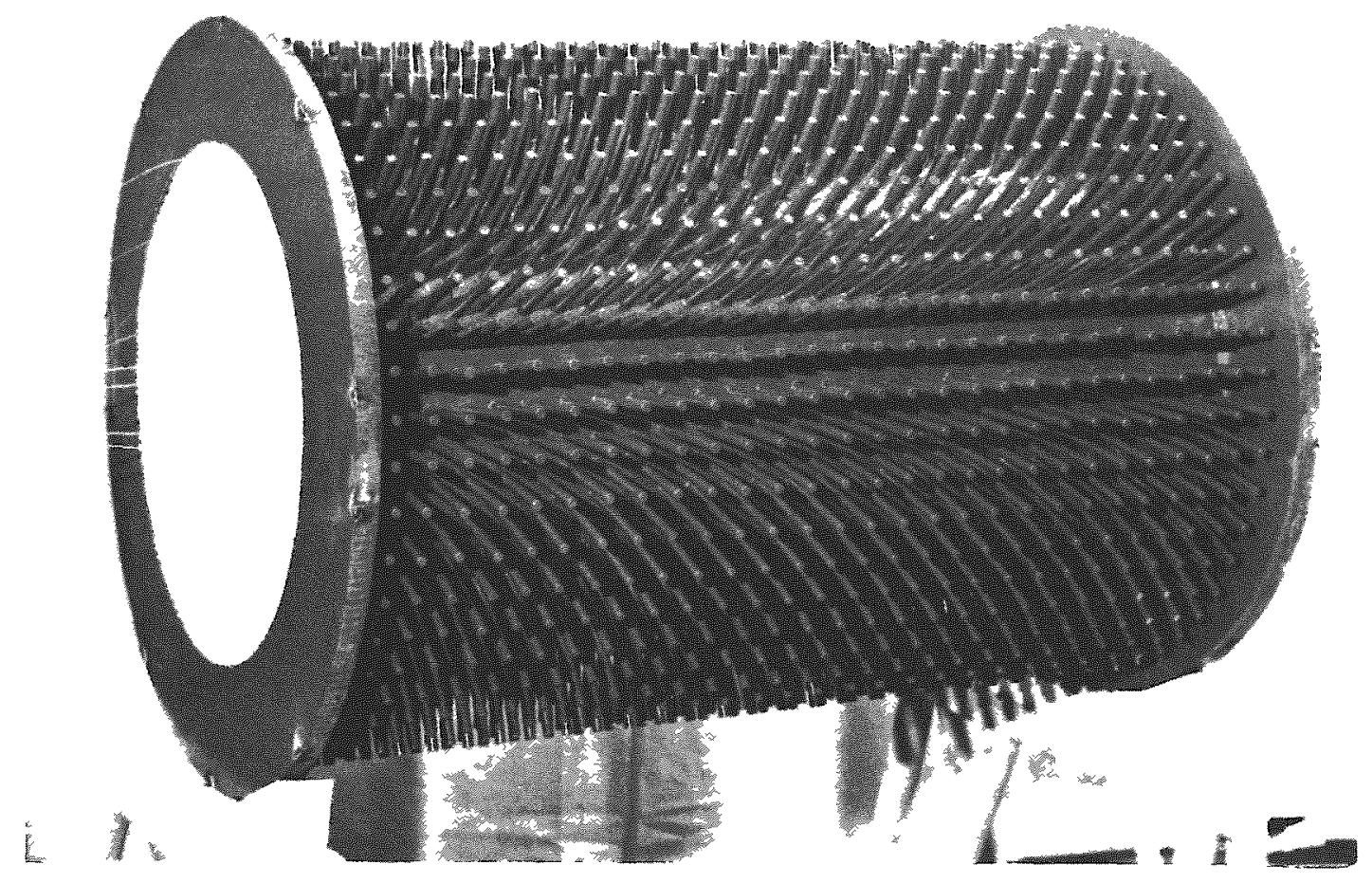

- Test in natursl convection -

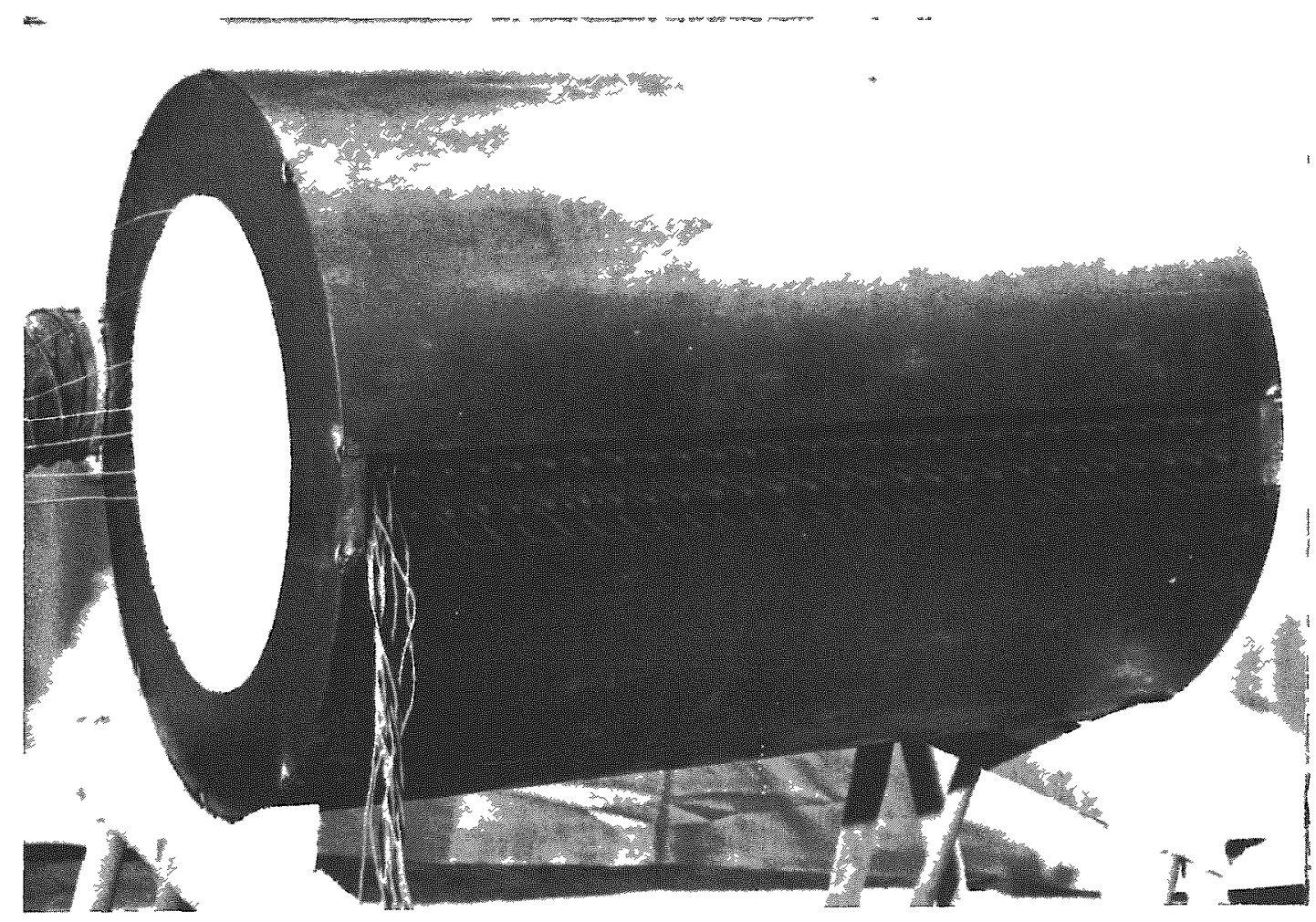

- Test in forced convection -

FIIS. 2 - THERMAL MODEL 
ricient high enough to ensure the heat transfer, after the fire, under normal safety conditions. This conduction coefficient is about $1.5 \mathrm{kcal} / \mathrm{h} \mathrm{m} \mathrm{m}^{\circ} \mathrm{C}$ ( $1 \mathrm{BTU} / \mathrm{hr} . \mathrm{sq} . \mathrm{ft}$. $(\mathrm{og} / \mathrm{ft}))$.

\section{5 - Forced cooling and ejectable envelope}

Most of the forced cooling systems are doubtful owing to their vulnerability in case of accirent. We think that this situation increases heavily the cost of the fuel cycle because it would be necessary either to increase the cooling time of the fuel elements, or to cut down their quantities per package, and, therefore, the ratio effective logd/total transported load.

That is the reason why we have designed a forced cooling system which facilitates the handings and the transportation of lerge packages spreading an important thermal power, while grentinf the transportations safety under any circumstances.

This system called "ejectable envelope" (U.S. Patent Pending) is composed of :

a) a fan driven either by an electric motor, or by an autonomous unit with, in any case, the usual means to prevent eventual break-down (reserve motor, sound or light giving signals),

b) an envelope covering the package, under which the air is blown by the fan, in order to increase the efficiency of the cooling elements such as fins or preferably studs.

In case the air circulation is stopped, whatever the cause may be, and supposing that $a 11$ the safety devices of the ventilation unit did not work, the removable envelope is ejected and the package is cooled down by natural convection in the open air, without infringing the package conformity with the reglementary tests.

Thus, this forced cooling system allows - under normal conditions to dispose of a relatively cold package that facilitates the handing and reduces the two followine dead times:

- The time for reachine thermal equilibrium before shipment of the package,

- The required cooling time before immersing the package into the pool for unloading.

6 - Test model

On Fig. 2 is shown the photograph of a model used for thermel tests which enabled us to check the velues defined during the preliminery tests and also the calculation assumptions leading us to design the real packapes. 


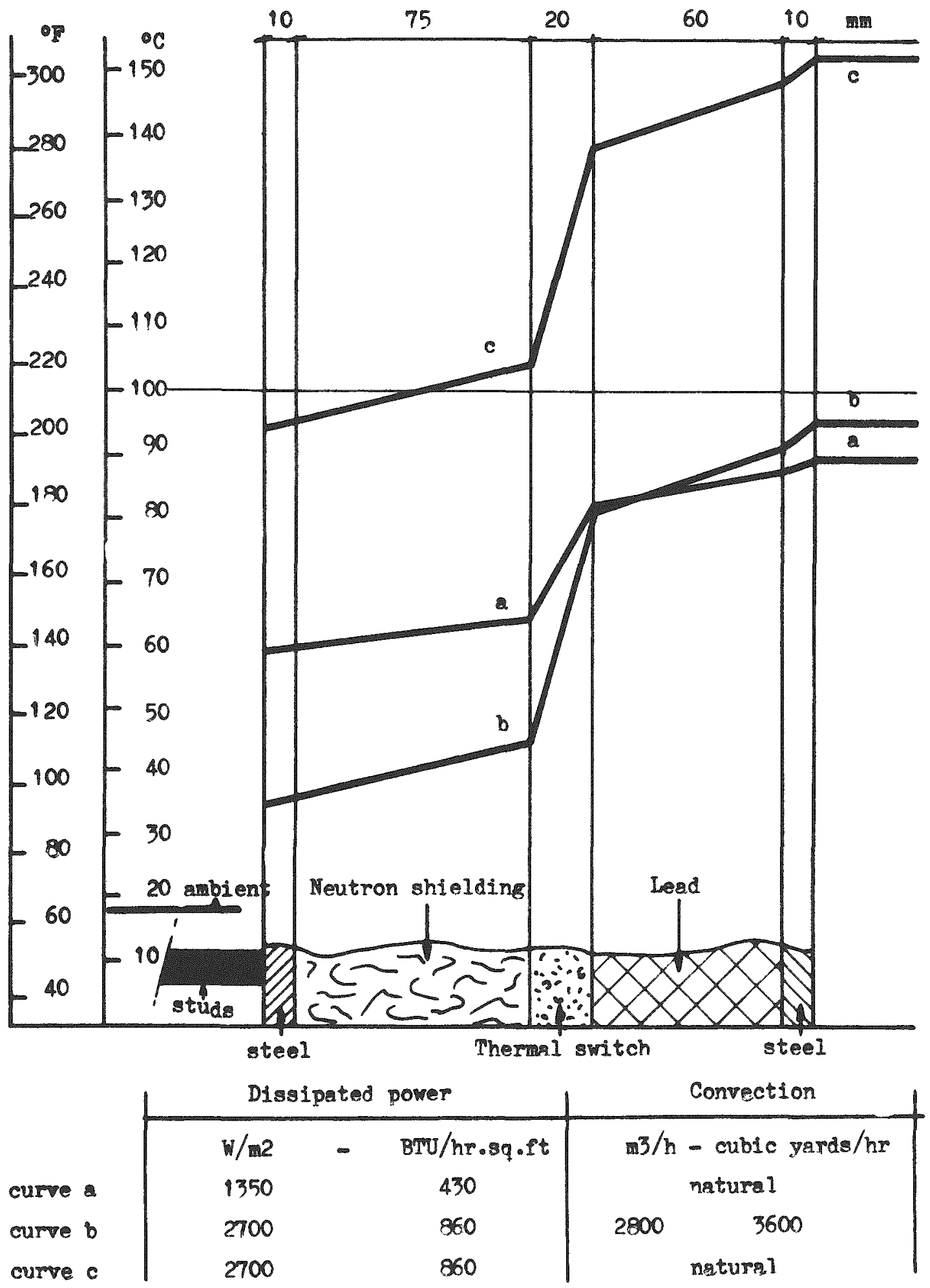

Fig. 3 - Repartition of the terperature in the thermal model. 
This model represents a package section and includes an inner cavity, a gamm lead shielding, the high flux thermal switch, a nentron shielding, and, on the outer shell, 1,460 cooling studs $10 \mathrm{~mm}$ in diameter, $900 \mathrm{~mm}$ long.

As a matter of fact, we have prefered studs to fins for the three following: reasons :

a) the use of studs allows a weight reduction of $30 \%$ with respect to the weight of the fins for the same cooling efficiency,

b) far better efficiency by forced ventilation,

c) possibility to ensure the proper cooling of the package, whatever its position may be, horizontal or vertical.

The secord photograph of Fig. 2 shows the model equipped with its cooling envelope, the air being blown at one end and discherged when hot at the other end.

The thermal tests results are given by curves on Figure 3 .

\section{THE NEW GENEKATION OF PACKAGES}

Most of the economical studies desline with irradiated fuels transportation prove the advantage of using large casks for reducing shipping and handlings costs (for instance, the article published by "Nuclear News" on July 1970 and written by $C$. W. Sinith and $w_{\circ}$. B. Bigge).

This is true for fast reactors as well as for light water kesctors (see economical studies made by $M$. M. LABKCUSEE, French Atomic Energy Commission).

We only give hereunder two renresentative figures :

- a package of 32 tons cortains about $900 \mathrm{~kg}$ of uranium,

- a package of 85 tons contains about $4,100 \mathrm{~kg}$ of uranium.

These fifures show that the performances of the larger package are superior by $70 \%$ to those of 32 tons package. To this advantage are to be added the lower tariffs and the better administrative facilities for railway transportation with respect to overweight truck shipment.

That is the reason why we have designed, by application of the above described techniques, a 85 tons package which will permit the transportation of fuel elements under economic conditions.

The dimensions of this package are the following:

- internal diameter : 1,100 $\mathrm{mm}$

- internal height : 4,550 ma 


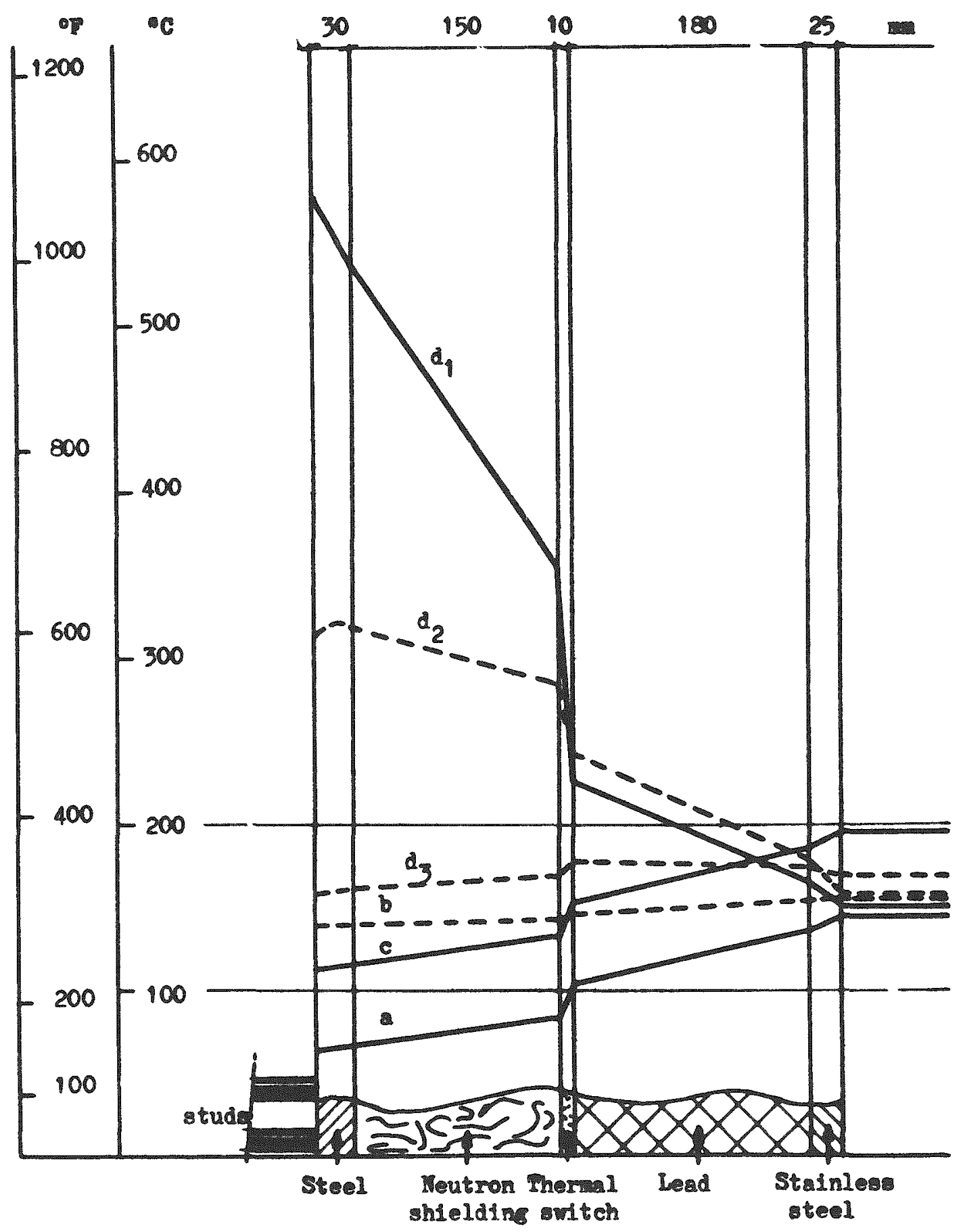

Pig. - Repartition of the temperature in 85 tons package of 100 itw. 


$$
\begin{aligned}
& \text { - over-ail diameter }: 2,300 \mathrm{~mm} \\
& \text { - over-all lnneht }: 5,800 \mathrm{~mm}
\end{aligned}
$$

The thermal orincipal characteristics of such a backage, for a surrounding temperature of $380 \mathrm{C}(100 \mathrm{~F})$, are :

- Cenacity

- a PWK Alements or $20 \mathrm{BWT}$ elements

- weight of transported uranium : 4,400 kg

- total power : $100 \mathrm{kw}$

- Ventilation : $20,000 \mathrm{~m} 3 / \mathrm{h} \quad(26,000$ cubic $\mathrm{yards} / \mathrm{hr})$

- Peckage outer shell temperature: $64^{\circ} \mathrm{C}\left(147^{\circ} \mathrm{F}\right)$

- Inner temperature : $146^{\circ} \mathrm{C}\left(295^{\circ} \mathrm{F}\right)$

- Kelative pressure : 3.5 kars ( 50 o.s.i. $)$

On Fig. 4, we have summarized the tenperatures distribution in the thickness of the various meterials comosing the package in the following cases:

a) curve (a) shows the equilibrium temberatures under normal conditions, i. e. with forced cooling.

b) in case the forced ventilation is stonped, the temperature of the packree outer shell oromressively rises up and reaches, after two hours, the removable envelone efection temperature $\left(140^{\circ} \mathrm{C}\right)\left(284^{\circ} \mathrm{F}\right)$ : then, the inner temperature is $157^{\circ} \mathrm{C}\left(315^{\circ} \mathrm{F}\right.$ ) (curve b).

c) after efection, the temperatures aim towards equilibrium temperatures by natural cooling (curve $c$ ). Unoer these conditions, the package outer shell is at $114^{\circ} \mathrm{C}\left(237^{\circ} \mathrm{F}\right)$, the insulator maximum temperature is $154^{\circ} \mathrm{C}\left(310^{\circ} \mathrm{F}\right)$, the inner temperature $196^{\circ} \mathrm{C}\left(335^{\circ} \mathrm{F}\right)$ and the steam pressure about 15 bars ( 213 p.s.i.).

d) Under the conditions of the reglementary fire, the temperatures evolution has been calculated by the graphical method of Binder and Schmidt.

We have taken an absorotion coefficient equal to 1 to take into account the studs beine, what procticaliy anounts to double the thermal flux penetreting into the package, compared with the regular prescriotions.

Curves $\left(d_{1}\right),\left(d_{2}\right)$ and $\left(d_{3}\right)$ respectively show the temperatures reached inside the package 30 minutes after the starting of the fire (extinction), then 8 minutes and, at last, 30 minutes after extinction of the fire. It can be seen that the inner temperature does not rise above the equilibrium temperature by natural cooling, i. e. $1960 \mathrm{C}\left(385^{\circ} \mathrm{F}\right)$. 
Our purnose was to demonstrate that, thanks to the shove ciascrimod 70 in tions, the package users and carriers vili find, in the nesp future, porfectiv adapted packages, which will lead to more economical fuel crole.

This is possibls thanks to the improvements browht to the packase materials performences, for, oniv a few years ago, the technical solutione allowing the conception of larse crpacitv nackasings did not appear clesrly at all.

It is also to be noted thet these characteristics are not ohtained to the detriment of safety, which remained our min womy all alone our researcines.

In our newly erected plant of GENAS, near LYONS (France), we have moreover provided for installations, testing pool and lifting capecities up to 120 tons. Which enable us, not only to menufmoture the nackages desiened hr our Enfineerine Department, but also to test them carefuliv before deliverv under close to normal operation. 


\title{
AN LMFBR FUEL SHIPPING CASK CONCEPT AND OBSERVATIONS PERTAINING TO HAZARD SURVIVAL POTENTIAL*
}

\author{
A. R. Irvine and L. B. Shappert \\ Oak Ridge National Laboratory \\ Oak Ridge, Tennessee
}

\begin{abstract}
Shipment of irradiated fuel from liquid-metal-cooled fast breeder reactors (LMFBR) is expected to be accomplished after a short decay period. The existence of gross amounts of dispersible radioiodine and radioactive rare gases at short decay times makes the ability of the shipping cask to survive accidental hazards a matter of prime concern.

The favored design for an LMFBR fuel shipping cask employs steel for both gamma radiation shielding and the cask structure. Heat is transported within the sealed fuel cavity by thermal convection in a sodium bath that surrounds multiple fuel subassemblies. Cask seals are designed to minimize the probability of damage due to impact, and to be capable of leak-free performance at elevated temperature and pressure. The fuel subassemblies are supported within the fuel cavity by means of a rotatable magazine such that they can be placed in and removed from the cask through a relarively few small ports. Cask temperature under normal conditions is maintained, by a special cooling system, at a moderate level in order to optimize cask material strength and ductility, as well as to increase the quantity of heat required to elevate the cask temperature to the maximum permissible level. Upon loss of secondary cooling, the cask remperature would rise to a sufficient level to dissipate the decay heat to the armosphere. Additional protection against damage due to impact is provided by an array of energy-absorbing buffers located in the vicinity of the seals and at other strategic points.
\end{abstract}

Results of impact tests with various scale model casks, heat transport experiments with liquid coolants, and calculations of thermal transients indicate that a rail shipping system which can resist credible impact and fire hazards can be designed and constructed at reasonable cost.

* Research sponsored by the U. S. Atomic Energy Commission under contract with the Union Carbide Corporation. 


\section{INTRODUCTION}

Shipment of spent fuel from liquid-metal-cooled fast breeder reactors (LMFBR's) to central reprocessing plants at relatively short times after removal from the reactor will be economically desirable when processes have been developed to accommodate short-cooled fuel, a substantial number of LMFBR's are in operation, and plutonium is not in oversupply. Development work is proceeding with some success on processes to accommodate short-decay fuels, and a successful demonstration of a large-scale LMFBR can be expected to bring about the latter two conditions.

LMFBR spent fuel at short decay periods will contain gross amounts of radioiodine and radioactive rare gases in a dispersible form. Therefore, the container in which these materials are shipped must be such that the probability of dispersal of these materials is minimal under both normal and accident conditions. This paper is concerned with the potential for hazard survival of a cask designed specifically for LMFBR fuel transport by rail. The hazards of greatest concern are impact and fire.

\section{CASK CONCEPT}

A concept of a cask for LMFBR fuel shipment is shown in Fig. 1. The principal features are as follows:

1. Steel structure and gamma shielding.

2. Small seals las compared to cask diameter) isolated from cask structure.

3. Fuel supported by a rugged structure to maintain its position under impact conditions.

4. Liquid primary coolant plus a volume-expansion system that will limit rate of deceleration (and hydrostatic pressure) of coolant.

5. Energy absorbers placed around vulnerable parts to reduce probability of damage.

6. Auxiliary cooling system for maintaining normal temperature of cask at relatively low temperature.

7. Thermal shields for reduction of heat uptake during a fire. 


\section{ORNL OWG 71-3840R1}

FUEL SUB-ASSEMBLY -

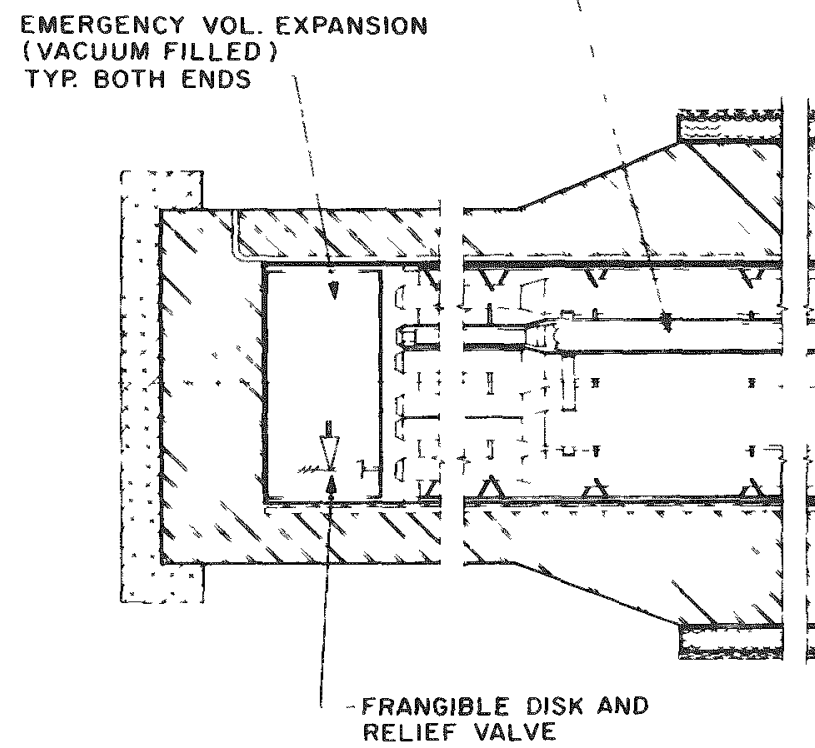

INSULATED WATER FILLED CONTAINER (TYP ALL OVER)

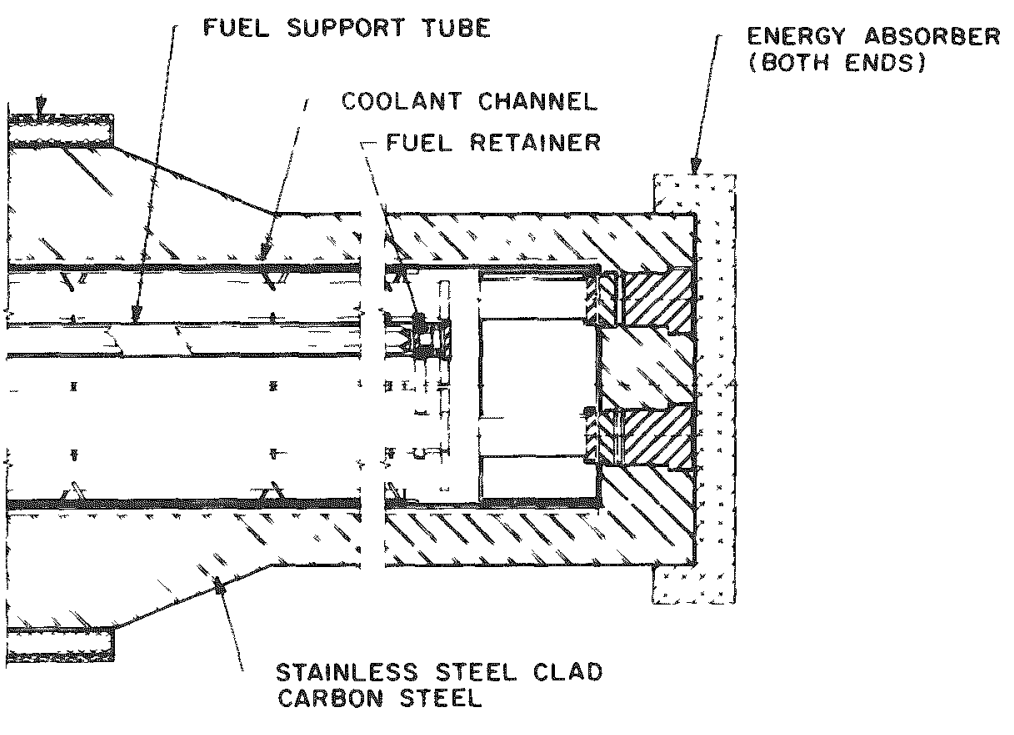

Fig. 1. An LMFBR Shipping Cask Concept. 


\section{HAZARD SURVIVAL POTENTIAL}

Impact tests have been made with models of a cask similar to that described in Fig. 1. These have shown no substantial damage to containment capability of the models when subjected to a $30-\mathrm{ft}$ free-fall impact against an unyielding surface. ${ }^{2}$

A total of 17 different model casks of five different scales were tested. All except one of these model casks were unprotected by any form of energy absorber. Four of the units were equipped with seals which were mechanically isolated from the cask structure. The damage to the unprotected cask structures was of a superficial nature, with no perceptible change in the dimensions of the fuel cavity. Of the four units equipped with seals, the initial negligible seal leak rates were increased somewhat after the impact tests. However, there was no indication of damage to the sealing surface. Each of these four units was impacted several times; in one case the unit was impacted twice on the same point. In no instance did unacceptable damage occur.

Tests were made with an energy absorber which demonstrated the capacity of a properly designed energy absorber to almost completely prevent cask structure deformation. A 1/8-scale model cask was dropped nine times, with various sized tube-in-tube energy absorbers attached to the impacting surface, without causing any deformation of the cask structure beyond rounding of a sharp edge.

Only cask models having relatively small diameter seals have been tested. Seals of full cask diameter, in addition to being more difficult to seal to a minimal leak rate, would be expected to be more difficult to protect from impact damage. To permit use of smalldiameter seals, the fuel support system must be capable of motion to render a number of fuel receptacles accessible to one opening. This fuel support system must be designed to hold each subassembly securely and to prevent their being more closely assembled. Further, the support system must be open enough to allow relatively free circulation of coolant for uniform temperature distribution throughout the cask fuel cavity. No device for this purpose has been designed, constructed, or tested, but no reason is immediately apparent to indicate that the requirements cannot be met.

A liquid coolant, in particular sodium, has been demonstrated to be exceedingly effective in distributing heat throughout the cask fuel cavity. However, free space must be provided within the fuel cavity to allow expansion of liquid coolant when temperature increases. This expansion space can also serve to minimize hydrostatic pressures developed when the cask is decelerated. An unbuffered steel cask striking an unyielding object flat 
on an end would come to rest in about $1 \mathrm{in.} \mathrm{A} \mathrm{properly} \mathrm{designed} \mathrm{expansion} \mathrm{space} \mathrm{could}$ increase this stopping distance for the liquid coolant by a factor of $>10$, thus reducing the hydrostatic pressure to easily manageable proportions. Although this pressure will be of short duration, the seal and cask structure will be capable of withstanding such pressure continuously.

As all fires are of finite duration, low rates of rise in cask temperature due to exposure to fire are desirable to increase the probability that the fire will be extinguished before a damaging condition is reached. Using an auxiliary cooling system to maintain the cask at temperatures only moderately above ambient will be beneficial in this respect as well as in making cask handling easier at the reprocessing site. Use of steel shielding, instead of lead or uranium, will increase the heat capacity of the cask as a result of borh increased mass and the approximately fourfold greater heat capacity of iron over lead and uranium. Figure 2 shows calculated temperatures ${ }^{3}$ for casks shielded with uranium and steel when exposed to $30-\mathrm{min}$ and 4 -hr fires. The higher heat capacity of steel can be seen to be a definite advantage in a longer fire. Other means may be employed to either increase the cask heat capacity or reduce its uptake of heat from a fire, or both. The cask neutron shield might be water that would boil away to absorb much heat. Also, insulation conceivably could be placed around the cask, which would remove itself when the temperature of the cask reaches the maximum acceptable level. Figure 3 shows the calculated change in temperature of a steel-shielded cask ${ }^{3}$ when it is insulated in such a way that the heat uptake from a fire is decreased to 10\% of the "normal" amount. The temperature of this cask can be seen to be at acceptable levels even after $10 \mathrm{hr}$ of exposure to a $1475^{\circ}$ fire.

\section{CONCLUSIONS}

The question of hazard survival is ultimately related to the magnitude of the hazard. Very heavy casks capable of surviving a 30-ft free-fall impact against an unyielding surface would appear to have a high probability of surviving any impact that might occur in the course of surface transport. Speeds are encountered in surface transport in excess of that attained in a $30-\mathrm{ft}$ free fall, but surfaces which are unyielding to a 50-ton-ormore object are very scarce indeed. A maximum credible duration and intensity for a fire is more difficult to estimate. As has been observed on many occasions, some finite amount of time is required to respond to an emergency. However, it appears that the inherent capability of a steel-shielded cask may, without assistance, provide sufficient time for 
ORNL DWG 70-10986RI
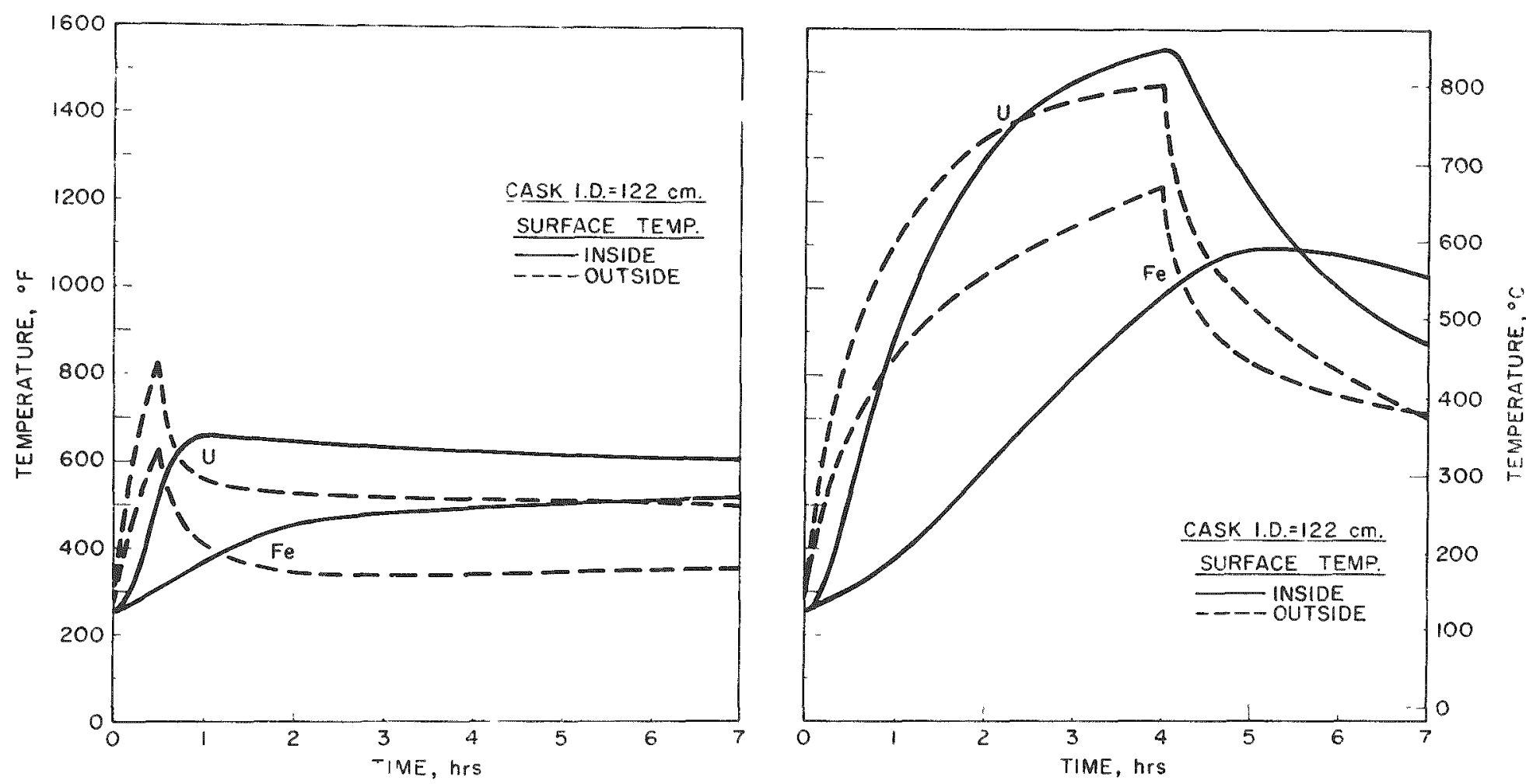

Fig. 2. Temperature Transients for Uranium - and Iron-Shielded Casks Exposed to 30-min and 4-hr Fires. Cask 1D, 48 in. Internal heat generation, $50,000 \mathrm{Bru} / \mathrm{hr}-\mathrm{ft}$ cask length. 
ORNL DWG $71-3830$

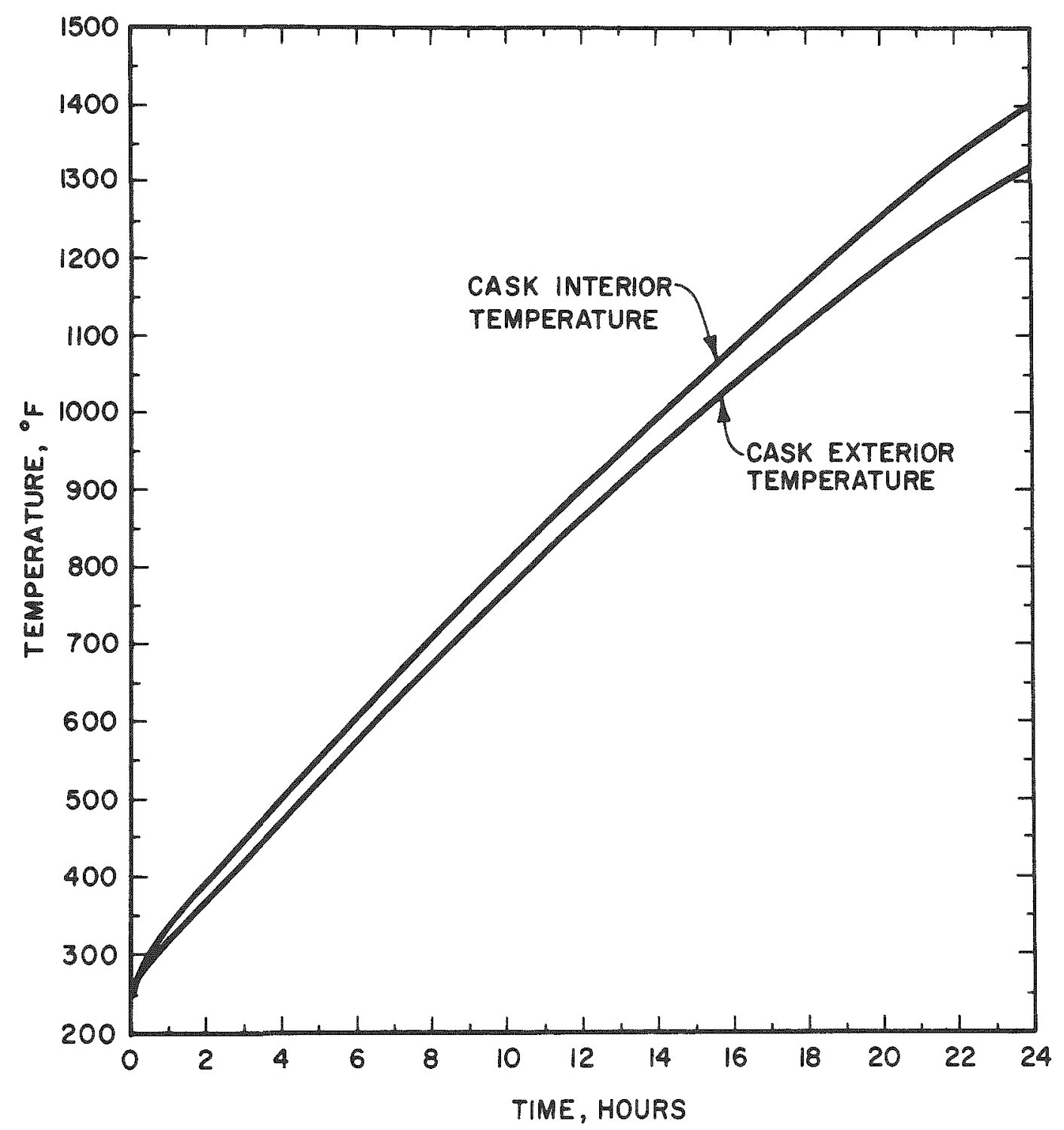

Fig. 3. Temperature Transient for an Iron-Shielded Cask Exposed to $1475^{\circ} \mathrm{F}$ Fire While Insulated to Limit Heat Uptake from Fire to $10 \%$ of the Normal Amount. Cask ID, 48 in.; cask OD, 84 in.; internal heat generation, 50,000 Btu/hr-ft cask length. 
response. The addition of other devices to retard the temperature rise of a cask exposed to fire can allow even longer times to gain control over an accidental fire. It is concluded that adequate protection against containment failure due to impact and fire can be provided for a rail shipment of short-decayed LMFBR fuel when the development work now in progress is completed.

\section{REFERENCES}

1. W. E. Unger, R. L. Cox, W. S. Groenier, A. R. Irvine, and C. D. Watson, "The Adaptation of Present Nuclear Fuel Reprocessing Technology for the Reprocessing of LMFBR Fuels," Paper $67 c$, presented at AlChE Sixty-Third Annual Meeting, Chicago, Illinois, November 29 - December 3, 1970.

2. D. E. Ferguson and Staff, Chem. Technol. Div. Ann. Progr. Rept. for Period Ending March 31, 1971, ORNL-4682 (July 1971).

3. R. L. Cox, ORNL, personal communication, 1971. 


\section{AIR CUSHION SUPPORT FOR HIGHWAY TRANSPORT OF HEAVY LOADS}

W. H. Trask

ABSTRACT

Air cushion technology is defined and related to applications in highway hauling. Equipment design requirements are discussed. Load spreading as a highway "preserving" technique is introduced with consideration for bridge capacities. The technology and economics of cushion support applied to spent fuel hauling are briefly considered. The possible effects of cushion vehicles on highway regulations are predicted. And, finally, the role of highway commissions in developing cushion support technology is suggested.

\section{INTRODUCTION}

\section{Air Cushion Technology}

Air Cushion Technology may be defined as that branch of motion engineering devoted to the support of gravity and inertial loads with low pressure air (less than 10 psig) acting over significantly large areas. A typical air cushion device, whether it be a seagoing hovercraft, warehouse pallet mover, or highway vehicle, employs a low pressure, high flow air source such as a centrifugal fan to pressurize a plenum chamber formed between the load and ground. Air flow is restricted to reasonable levels by the ground-chamber interface, usually an air gap of controlled dimension. The load floats slightly above the ground on a cushion of air making it quite mobile. Very large loads can be supported at pressures of a few pounds per square inch.

Air cushion technology began with waterborne craft as a means for 
side-stepping hydrodynamic hull resistance at high speeds. Large ships of conventional design are essentially limited to speeds under 50 knots by the rapid growth of power requirements beyond this limit. Speeds of 70 knots, however, are readily obtainable when a craft rides on air several inches above the water. This fact forms the basis for the British-developed SRN4, a hovercraft with a normal operating weight of 165 tons (50 ton payload) and capable of speeds up to 77 knots. This craft absorbs 13,600 horsepower at a cruise speed of 70 knots with about 40 percent of this power going for vertical lift. Cushion pressure is $50 \mathrm{lbs} / \mathrm{sq}$ Et. ${ }^{1}$

Ignoring the substantial cost of development, this vehicle is proving economically feasible in channel ferry usage. ${ }^{2}$ other designs, such as a 100-ton naval craft under developnent in this country, will ride a "captured air bubble" at speeds in excess of 92 mph. Bubble pressures between 95 and 110 psf are anticipated. Two versions of this craft to be tested during the fall of 1971 will develop between 12,000 and 13,000 horsepower. ${ }^{3}$

The British have also pioneered the use of very high cushion pressures, up to 5 psig and beyond, for transporting heavy electrical transformers over marginal roadways and bridges. One transporter with a "cushion lift" cpacity of 100 tons has been successfully operated. 4 Air cushion pallets and dollies are now commonplace. ${ }^{5}$ French-built high speed trains run along a single inverted "T" concrete "rail" supported by $1 / 2$ " thick cusions of air. Amphibious trucks and boats of various designs use the air cushion principle. ${ }^{6}$ oil drilling platforms weighing 100 tons and more will employ air cushion support for mobility during exploratory drilling in arctic 
regions. 7

As air cushion technology continues to develop, the economics becomes more attractive. Proper equipment design and shrewd applications engineering are today putting air cushion hardware on a money-making basis. Continuing developments in materials and fabrication techniques will see a significant increase over the next five years in dry land applications of air cushion support systems.

\section{Application to Land Vehicles}

Technology is ready now to produce air cushion support systems for land transportation equipment, particularly as applied to highway vehicles. Many hauling situations are amenable to air cushion support. Movement of construction machinery, power plant components, spent nuclear fuel, steel and other bulk materials could be accomplished with less wear and tear on. highway, structures with air cushion transporters.

The initial applications should come in highly specialized situations where large expensive loads must be moved by highway. Short skirts attached to lowboy txailers will be able to cushion 50 to $60 \%$ of the gross load at 2-3 psig. In some instances vehicles will be massive and move slowly, from 5-10 mph. Low speed movement is very compatible with cushion support. other vehicles, transporting nuclear fuel casks, for instance, will move at highway speeds of 45-55 mph and demand much more of the skirt/seal system. As sealing systems are perfected, cushion support will be applicable to conventional trailers with three to four feet of ground clearance. Packaged cushion systems will eventually be available to fit almost all vehicle sizes and applications. Road seal technology will improve, keeping power plant 
requirements small. User experience fed back to suppliers will spur applications and improvements in hardware and materials.

\section{EQUIPMENI REQUIREMENTS}

Four basic hardware "units" are required to apply air cushion technology to highway transporters. These are:

- Skirts

- Road Sea1

- Blowers

- Control Systems

Skirts

This element forms the cushion chamber sidewalls which, together with the load itself and ground, constitute a semi-pressure tight plenum of air. Skirts function as a pressure barrier and as a suspension system. Skirting a highway trailer would require tailoring the design and materials to the specialized dynamics and pressure requirements of these vehicles. For example, a standard 40-ton lowboy trailer could be equipped to contain 2 psi of air pressure between the trailer well and ground. The skirt should be rigid enough to support the internal pressure while maintaining the resiliency needed to maintain contact with the roadway as the trailer undergoes vertical motion.

Since the lower periphery of the skirt which contacts the road presents a particular problem it has thus been separated out and designated as the "Road Seal." 


\section{Road Sea1}

Approximately the lower three inches of skirt length are designated as the "road seal." This element will be detachable from the skirt because it will undergo wearout. A good pressure seal between skirt and road is necessary to keep air flow requirements from becoming excessive. For example, a standard 40-ton lowboy with skirts pressurized at 2 psi will support 58,000 1bs on air. Total air flow allowable through the skirt-road seal periphery of 66 feet may be calculated assuming the on-board blower power is limited to 100 horsepower. A maximun leakage rate of $105 \mathrm{CFM} / \mathrm{ineal}$ foot of road seal results. This is the maximum leakage rate that can occur under dynamic conditions if the cushion pressure is to be held at 2 psi. A minimum service lifetime for the detachable road seal may also be estimated by considering a typical hauling situation. At $45 \mathrm{mph}$ a large tractor-trailer combination might cover 400 miles during a 12-hour driving day. Total or partial seal replacement after a single such day would probably be required from initially available seal materials. Changeout would of necessity be simplified so that the driver could replace the entire seal in less than one hour.

\section{Blower}

This unit, including a power source, supplies air pressure to the support cushion. A $100 \mathrm{hp}$, diesel-powered package delivering $7000 \mathrm{CFM}$ of air at 2 psig would weigh approximately $3500 \mathrm{lbs}$ and require about $30 \mathrm{sq}$ ft of area for mounting. Several fans are available comercially that would be suitable. A belt drive would be used to allow optimization of available space and engine RPM. Blower and engine would be shock mounted to isolate 
the equipment from road vibration. A blower intake silencer would be required to suppress noise. The blower-engine combination can be considered essentially state-of-the-art requiring only minor modifications to insure its roadability.

\section{Control systems}

These systems would function to maintain a near constant cushion pressure over the support area during perturbations induced by road-vehicle interactions. Such systems would require feedback control for effective dynamic regulations. The state-of-the-art in this area is not well defined and would be a major part of any development program. The problem is aggravated by limitations on the air volumes that can be contained beneath a lowboy trailer.

Practical control of cushion pressure could be accomplished using a combination of several different hardware systems. Partitioning of the cushion volume, automatic flow control, accumulator systems and plenum venting devices are some possible approaches. Overall cushion pressure, as measured near the cavity centerline, for example, could be the regulatory signal governing inlet air flow from the main fan. Excess fan air, about 20 percent, would be vented during normal cushion operation but could, if required, be diverted partially or totally into the cushion area.

\section{LOAD SPREADTNG AND HIGHWAY STRENGTH}

The effect of air cushion load spreading on highway systems can be subdivided for clarity into the effect on 1) pavement structure and 2) on bridge structures. 


\section{Pavement}

Intuitively at least, load spreading should have a beneficial effect on highway durability. Among the many stresses highways must withstand, including freezing and thawing, ground motion and thermal expansion, are those imposed directly by vehicular traffic. Truck tixes inflated with 75-85 psi of air pressure load the highway surface accordingly. Multiple tires and tandem azle arrangements tend toward load distribution but usually do not include a significant reduction in tire pressure. Except for special hauling situations such as those requiring the one time movement of hundreds of tons, simply adding additional axles and wheels is impractical economically and to some extent technologically. Load distribution between axies is difficult to maintain. Most states have limited permissible gross loadings regardless of how many axles are used to subdivide the load, at least for repetitive haulings where highway lifetime becomes a factor. The use of trailers with 20,30 or even 40 wheels even if permitted would be expensive terms of tire maintenance alone.

Air cushion load spreading, for example, can support a 60,000 lb load over an area of $300 \mathrm{sq}$ ft at a 2 psi ground pressure. This is the approximate area contained beneath the well section of a 50-ton lowboy trailer. It is obvious at least that the highway degradation factor associated with a uniform 2 psi loading is significantly less than that associated with even the multiple pad loadings at $75-85$ psi produced by tandem axle trailers.

\section{Bridges}

Overstressing of bridge structures and overpasses is a source of major concern to state highway commissions. Where overstressing is requested on a 
repetitive basis, highway comissions find it difficult to justify the issuance of permits. At least one industry at present requires the repetitive shipment of overweight loads by highway. Spent nuclear fuel is hauled on a daily basis from power-producing reactors to special reprocessing plants. Very heavy containers are required, Iimiting payload fractions to less than three percent. Cushion support of such excess tonnage, while of significant benefit to states in protecting highway systems, would be of minimal value in the bridge crossing situation. Cushion support does distribute the load and reduces dynamic transients. But basically, bridges and overpasses used by haulers in moving spent nuclear fuel, for example, will require upgrading to the point where repetitive crossings at the maximum expected gross loadings will be feasible. The cost of bridge refurbishment where necessary should be assumed by the primary user. In the nuclear fuel case this would be the utility company owning or operating the generating stations. Ways in which such expenses may be written off or even balanced out involve use by the utilities of pavement-saving cushion support equipment in return for major concessions from the highway comissions regarding maximum allowable gross, divisible loads, and permissible hauling times.

\section{CUSHION APPLICATION TO HAULING SPENT NUCLEAR FUEL}

Cask Weight

Second generation spent fuel elements will require a cask weighing up to 80,000 lbs for highway shipment to the reprocessor. This will result in a gross vehicle weight of $115,000 \mathrm{lbs}$. The 80,000 lb cask will carry two PWR units or four BWR units for a total payload of slightly under 2,000 1bs. A cask weighing 130,000 Ibs would carry four PWR or eight BWR units with a 
payload of nearly 4,000 $\mathrm{lbs}^{8}$ This jump is highly significant in the economic context of spent fuel transport. However, the $180,000 \mathrm{Ib}$ vehicle gross required to haul such a cask is, under current considerations, unacceptable. If cushion support were employed to bear $80,000 \mathrm{lbs}$ of the total gross at 2.5 psig ground pressure, axle loadings would be correspondingly reduced to below the $17,0001 \mathrm{~b}$ level for a six axle unit. Significantly, the payload fraction of the 65-ton cask is 50 percent greater than for the 40-ton cask. More important, however, is the fact that air cushion support, once initiated by nuclear fuel haulers, would soon be ready for use in other transport situations which are currently overstressing highways in terms of axle loads. The widespread application of cushion support particularly during the spring thaw season could materially reduce highway surface degradation per ton mile of travel and thus enhance highway lifetime. The total economic payoff would benefit utilities, truckers and highway systems alike. In return for substantial increases in the maximum gross loading permitted on a repetitive basis, utilities could 1) refurbish bridges used for spent fuel hauling and 2) underwrite the expense, together with transport companies, of developing operational air cushion trailers. Highway commissions could stimulate this development by easing time of day and divisible load restrictions now in effect, using as their justification the road saving effect of widespread cushion transportation.

\section{EFFECT ON HIGHWAY HAUL ING REGULATIONS}

\section{Gross Loads}

As mentioned above, utilities, truckers and fuel reprocessors would all like to see highway commissions permit higher gross loads on a repetitive 
basis. Air cushion support allows increasing gross weights with no increase in axle loadings. As an example, a vehicle grossing 200,000 lbs supports $100,000 \mathrm{lbs}$ on air at 3 psig over an area measuring $8^{\prime} \times 40^{\prime}$. The axle supported "gross" is 100,000 lbs which divided among six axles gives approximately 17,000 lbs per axle. Axle loadings are seen as the significant factor in highway wearout unless of course argument can be made for the effect of 3 psig loadings, regardless of what the total gross may be.

\section{Divisible Loads}

Many states require that overweight loads, if divisible, be subdivided down to the smallest, single, non-divisible element. This regulation discriminates against spent fuel hauling while serving no useful purpose. Its modification would, however, represent a very major concession to one hauler by highway commissions and would, if made, require strong justification. As mentioned before, utilities, in funding the refurbishment of state and federal bridge crossings and in actively promoting the application of air cushion support, would be providing states with a reasonable and very significant justification for major regulatory concessions.

\section{Repetitive Hauling}

Repetitive hauling on a 24 -hour basis will be needed by nuclear reprocessors to do their job economically. Repetitive hauling in the context of spent fuel movement means, of course, a closely controlled, highly supervised operation which occurs on a routine basis. Safety is the key consideration followed closely by control and enforcement. Highway comissions may not feel that such a concession could be properly supervised. 
Radioactive materials, however, under transit are the subject of much concern to several agencies heavily charged with responsibility in this area. Utilities themselves along with the transporter could bear a larger share of the burden by nature of their involvement in bridge reconstruction and their investment in air cushion support equipment. With a heavy financial interest in the successful outcome of round-the-clock repetitive hauling, utilities and transporters alike could be expected to provide the selfregulation and control necessary to insure that transport was done in a safe and orderly manner at all times. Ttilities, in particular, would become partners with the states by this involvenent in preserving critical highway routings and in demonstrating the advantages of air cushion support.

\section{ROLE OF STATE HIGHWAY COMMISSIONS}

The basic function of highway commissions is to preserve and protect the state's investment in highways while providing erual access to the system for al1 segments of commerce desiring to use highway transportation. Highway vehicular traffic as a complex systems problem demands stringent regulation for two basic reasons: First, the rights of each user must be protected from infringement by others; and second, regulation is required to optimize highway availability and thus maximize the movement of goods to and from the marketplace. Obviously, allowing permissible gross loadings to increase significantly would benefit many segments of the hauling industry including firms hauling spent nuclear fuel. Such benefits would be short lived indeed if carefully chosen routes were disrupted by repeated overloadings. Whereas tires, bearings and even entire vehicles may easily be replaced when worn out, highways are, in today's econony, essentially irreplaceable. Blectric 
utilities, in forecasting 30 and 40 year service lifetimes for power reactors, must also consider the lifetimes of roads over which spent fuel from those reactors will move. Preservation of highways is fully as requisite to the function of utilities as to the states themselves. Because utilities stand to realize a significant economic gain from permitted increases in gross weight limits, it is utilities who should lead out in preserving the integrity of existing highway systems. Utilities can do this in two ways, given proper incentive by highways commissions. They can 1) renovate bridges and 2) underwrite air cushion hardware development. Concessions should favor the use of air cushion transportation as a road saving device. Taxation could also be levied in such a manner as to encourage investments by truckers in air cushion load spreading equipment. Axle weights should be re-emphasized while gross loadings are de-emphasized. Where bridges are involved, the cost for retrofit to handle increased gross weights should be assigned to the user. Highway comissions represented by AASHO should play a commanding role in providing the proper inducements for haulers to use air cushion hauling equipment. Centered around the air cushion principle and its application will be found a blend of participation by users and regulators alike. The rapid dispersal of air cushion technology throughout the heavy hauling industry will mean less dollars for road repairs and more profit for transportation companies and a11 those served by the trucking industry. 


\section{REFERENCES}

1. T. Ford, Hovering Craft \& Hydrofoil, 6(6) (March 1967)

2. L. Boddington, Hovering Craft \& Hydrofoil, 8(7) (April 1969)

3. J. L. Decker, J.Astronaut. \& Aeronaut., 8(6) (June 1970)

4. T. Ford, Hovering Craft \& Hydrofoil, I(10) (July 1968)

5. Anon., Design News, 25 (21), p. 62 (Oct. 1970)

6. Various authors, Hovering Craft \&: Hydrofoil, 10(1) (Oct. 1970)

7. L. Sheffer, Ocean Oi1, Week1y Report 5(16) (Jan. 18, 1971)

8. C. Wesley Smith, Proceedings, SINB Conference-Transportation of Nuclear Spent Fuels, (Feb. 1970) p. 63 


\title{
COMPUTER MOVIES FOR SIMULATION \\ OF MECHANTCAL TESTS
}

L. H. Baker

B. J. Donham

W. S. Gregory

E. K. Tucker

\begin{abstract}
Evaluation of results produced by digital computers need not be a tedious process of number evaluation. By means of the basic models used in simulating the effects of the 30-ft fall and the fire test of shielded shipping containers, conm puters can be progranned to produce a visual record of the results of the calculation in the form of geonetric inages. Viewed in rapid succession these inages form a motion picture of the modeled process.

A number of different schemes may be employed to depict the nunerous variables involved. Whenever possible one should present the various phenomena with generally accepted representations. Color, for example, may be used to represent temperature, while shape changes may be directly represented by a corresponding geometric presentation.
\end{abstract}

Along with the many benefits brought about by the speed and versatility of the digital computer there exist some inevitable disadvantages due to the very element of speed. Whereas the engineer using longhand calculations aided by nechanical calculators and slide rules can grind out a few well-thought-out solum tions to some design problem in a work day, he can utilize a digital computer and in a similar time period produce literally thousands of potential problen solutions resulting from the variation of important parameters.

problems involving optimum solutions often may be handled by the conputer itse1f, but some classes of problems, e.g., time history calculations, must be examined by the engineer at many points in time. He is thus faced with the problem of examining many numbers and analyzing many data in order to evaluate the overall results obtained from the solution.

These data are generally far too valuable an analysis tool to give up in favor of fewer longhand calculations, so the best solution of this dilemma will 
be obtained if one has a better method of result scanning. Progranming ingenuity can provide valuable assistance in presenting numerical data, but the simplest and most understandable form of presentation is motion pictures.

Motion pictures, as certain computer graphics are called when time is one of the plotted variables, can be prepared by the computer to show the interrelationship among the various phenomena as calculated by the programmed digital conputer. One of the simplest and best undexstood forms of animation occurs when one must display time as one of the several variables. This occurs, for example, when shielded shipping containers are avaluated for the mechanical tests of the 30-ft drop and the fire test. The results of these two tests are made to order for presentation in a computer movie.

It is of prime importance to any form of presentation of results that the results be calculated through the use of models that accurately represent the interrelationship of the important variables under consideration. For this reason the models used for the generation of the data shown in the movies will be covered in sone detail.

The dynamic analysis model is a simple undamped, close-coupled, multi-mass scalar spring system which may have non-linear coupling characteristics. Figure 1 is a typical model showing a technique for simulating a cylindrical container oriented to impact in an end-on configuration.

Spring characteristics for the mass coupling must be decermined for each segment of the container. In general the strength of lead has been shown ${ }^{1}$ to be reas onably well predicted by the equations shown in Fig. 1. Contact areas may be calculated by considering that horizontal planes within the container remain horizontal and that the individual finite volumes remain unchanged. Fins prom viding significant impact protection may be represented by introducing a force displacement variable comparable to the action of a fin when subjected to large axial strains ${ }^{2}$.

Corner drops may be modeled in much the same manner. Figure 2 shows a sketch of the possible configuration resulting from making the container into a series of discrete masses. Some error is introduced by the fact that all of the mass lumps do not have their center of gravity located along that of the total container. This effectively introduces a rotational component to each mass. Neglecting such coiponents should introduce only a minor error, provided the container is not of unusually large diameter. Elementary masses of the corner drop do not have the traditional cylindrical shape of the preceding model. This, however, should not cause any significant problens since the established equations of strength are independent of cross-sectional shape. There are some considexations of shape that must be included because the element volume must be 
While the ability of any rodel to accurately predict the behavior of the prototype is unquestionably the ultinate goal, it is for this report not the final objective. Although these models and the solution technique are believed to yield excellent results, wany other techniques have been used to represent similar systems quite successfully. The objective here is to show the results obtained fror one such technique in a unique and easily understandable namer. Solutions from this : ethod of analysis consist of arrays of times and corresponding rass positions. Display and evaluation of these solutions will be covered in the latter portion of this report.

Heat transfer models have likewise becom very popular and quite numerous in the past few years, but they, like the dynamic analys is techniques, are difficult and time consuming to analyze without some thoughtful presentation of results.

Results presentad in this report have been obtained from a suitably reliable three-diwensional finite eleient heat transfer code that calculates spatial and transient effects of the standard hypothetical 30-minute-duration fire acting upon a lead-shielded shipping container. One unique feature of the presentation is the ability of the analysis to consider a change of state of said lead to molten or its replace ent by air if the molten lead is assumed to escape through a breach in the steel jacket. Edges, corners, and fin effects ray be readily modeled because of the versatility of the three-dimensional analysis.

The computational model used in the heat transfer code assumes that a cross section of the specific configuration (body) of interest is divided into a system of small cells. Figure 4 shows one-quarter of the cylinder nodeled in this analysis. There are 2600 cells in this nodel, describing three different materials. Although finned surfaces can be modeled, it was assumed for this report that the outside surface of the cylinder was a smooth steel jacket.

The size, orientation, material composition, and modes of heat transfer for each individual cell and interrelationships between cells are prescribed in the program by a general heat balance equation.

$$
\dot{2} \text { stored }=\dot{2} \text { cond }+\dot{2} \text { conv }+\dot{2} \mathrm{rad}+\dot{2} \text { gen }
$$

The conduction equation is

$$
i \text { cond }=\frac{\left(T_{i}-T_{j}\right)}{R_{i-j}}
$$

where

$j$ cond $=$ conductive heat exchange between cells $i$ and $j, b t u / h x$,

$\mathrm{T}_{i}=$ temperature of cell $\mathrm{i},{ }^{\circ} \mathrm{R}$,

$T_{j}=$ temperature of cell $j,{ }^{\circ}$,

$R_{i-j}=$ thermal conduction resistance, ${ }^{\circ} \mathrm{R}-\mathrm{btu} / \mathrm{hr}$. 


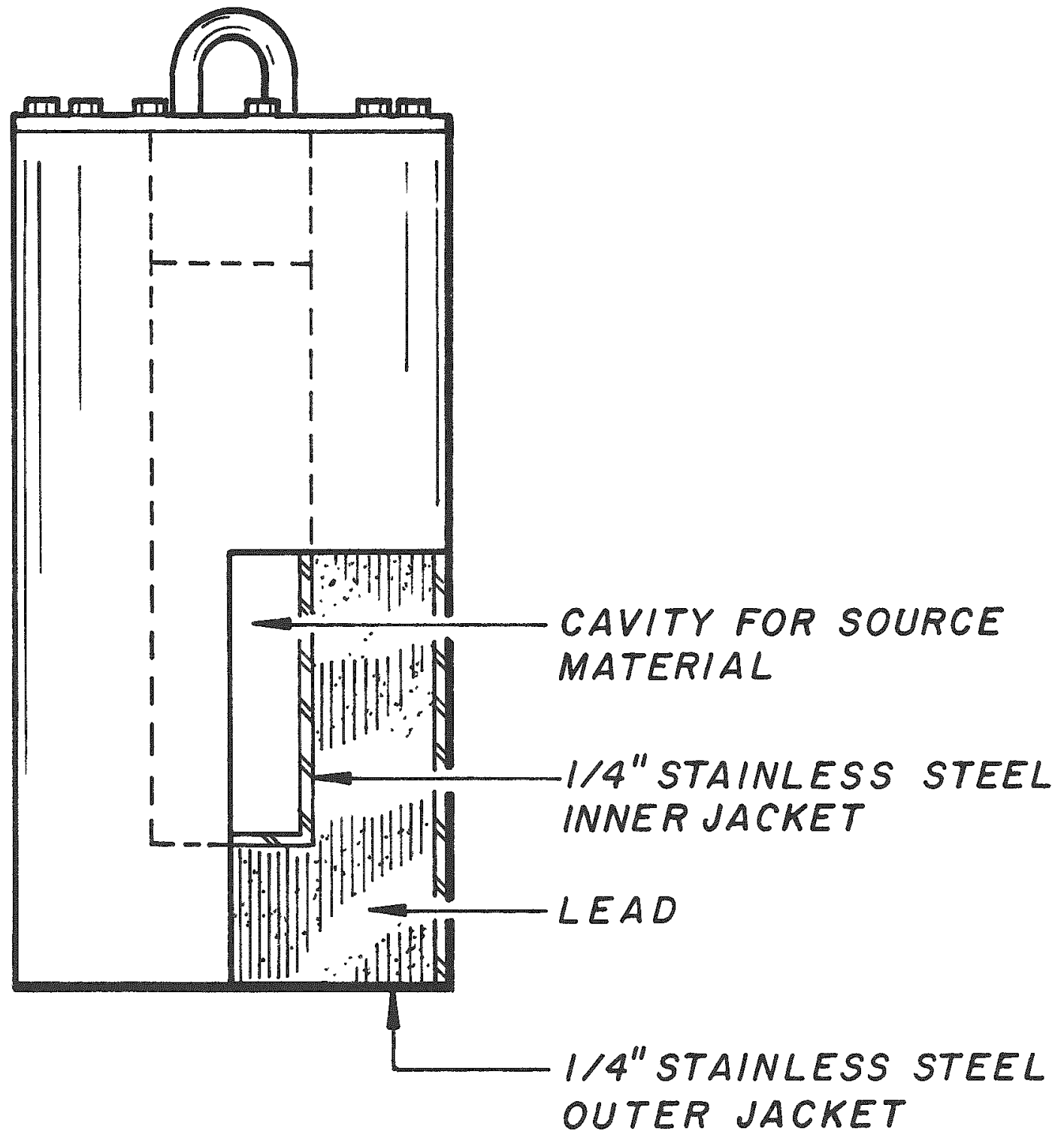

Fig. 4. Heat Transfer Model Container. 
The radiation received on the outside of the container can be expressed as follows

$$
\dot{Q} \mathrm{rad}=\sigma_{\mathrm{sb}} \Delta \mathrm{Bb} \mathrm{A}_{i}\left[\left(\mathrm{~T}_{\mathrm{f}}^{4}\right)\left(E_{f}\right)-\mathrm{T}_{i}^{4}\right]
$$

where

$$
\begin{aligned}
& \hat{r a d}=\text { radiation heat exchange between outside cell } i \text { and the flame temper- } \\
& \quad \text { ature, btu/hr, } \\
& \pi_{s b}=\text { Stefan-Boltzman constant }=0.1714 \times 10^{-8}, \text { btu/hr-ft }{ }^{2}-R^{4}, \\
& A b s=\text { absorbance of the cask }=0.8, \\
& A_{i}=\text { area of cell } i, f t^{2}, \\
& T_{f}=\text { flame temperature of the standard fire }=1935^{\circ} \mathrm{R}, \\
& E_{f}=\text { flame emissivity }=0.9 .
\end{aligned}
$$

The internal radiation exchange, calculated if a loss of lead is assumed, can be expressed as

where

$$
\dot{Q} \operatorname{rad}=\sigma_{s b} A_{i} F_{i-j}\left(T_{i}^{4}-T_{j}^{4}\right)
$$

$$
F_{i-j}=\text { view factor. }
$$

The radioactive source in the shipping container may impart heat to the materials surrounding the radioactive source. This heat generation term may be expressed as

where

$$
\dot{2} \operatorname{gen}=V_{i} \text { ? gen } i
$$

i gen = generation of heat within cell i, btu/hr,

$Q$ gen $=$ strength of the source of generation in cell $i, b t u / h r-f t^{3}$,

$v_{i}=$ volume of cell i, $\mathrm{ft}^{3}$.

Free and/or forced convection can also occur on the outside of the container and also internally if air or a liquid coolant is present. The general form for convective heat transfer between cells is

where

$$
\dot{p} \text { conv }=h_{i-j} A_{i-j}\left(T_{i}-T_{j}\right)
$$

Q conv = convective heat exchange, btu/hr,

$h_{i-j}=$ convective heat-transfer coefficient, btu/hr-ft ${ }^{2}-{ }^{0}$.

Combining the appropriate modes of heat transfer for each cell allows one to write an energy balance equation for a cell as

$$
\begin{gathered}
{\left[T_{i}(t+\Delta t)-T_{i}(t)\right] c_{i}=} \\
\Delta t: i \operatorname{cond}(i, j)+\dot{i} \operatorname{conv}(i, j)+\dot{p} \operatorname{rad}(i, j)+\dot{Q} \operatorname{gen}(i, j)]
\end{gathered}
$$

where

$$
\begin{aligned}
& C_{i}=\text { heat capacity of cell } i, b t u / \rho^{\circ}, \\
& t=\text { time interval, hr, }
\end{aligned}
$$


$T_{i}(t+\Delta t)=$ temperature of cell i after time interval $\Delta t,{ }^{\circ} R_{\text {. }}$ The above equation can be used to solve for the future temperature of ce11 i after time $\Delta t$. Many techniques are available for solving a set of simultaneous temperature equations for each ce11. The extrapolated Liebmann technique $4,5,6$ was used to obtain the results presented here.

Once again as in the case of the dynamic analysis model the accuracy of simulation of the prototype was not evaluated since the major objective was to develop and present movie methods of data evaluation.

Data presentation by computer movies is not a theoretically difficult task. Neither is it a trivial task when one considers the requirement of machine and programing effort. Since this effort is at neither extreme it is probably a medium of data presentation that will assume great importance in the future. It indeed enjoys a high level of utilization at the Los Alamos Scientific Laboratory, where film use approaches 350 miles per year.

Motion pictures are produced by the computer as a result of causing a sequence of images to be plotted on a cathode ray tube and then photographed, sometimes through a color filter, upon the appropriate size film. The instructions necessary to cause the desired image to appear on the cathode ray tube are prepared by the computer programer. Details of the plotting instructions may vary somewhat from one computer installation to another but they are usually rather simple to use.

Displaying the data from the two basically different calculations previously described may best be done if we attempt to display a series of pictures which look as nearly as possible like the actual prototype test. In the case of the dynamic analysis this is an easily obtainable goal. One needs merely to draw a graphical representation of the container, at regular time intervals, based on the data obtained from the calculations.

A11 elementary masses used in the dynamic analysis are considered to be right circular cylinders whose volumes are equal to that of a hypothetical mass cut from the cylinder by two planes parallel to the assumed unyielding surface. If these masses are suall enough the cylindrical representation will very closely resemble the geometry one wishes to project. Accepting the small exror of lateral motion caused by using the cylindrical model one can then draw the cylinders for each time step for which height calculations are made. Figure 5 shows a typical example of how the results of these cylinders may be shown. Note that further refinements can be made to the display by smoothing the intersection between hypothetical cylinders as in Figure $5 \mathrm{~d}$. Also, it must be borne in mind that one has great flexibility in displaying the lateral notion. Exaggerated lateral deformation may be plotted because this display is for visual effect only 


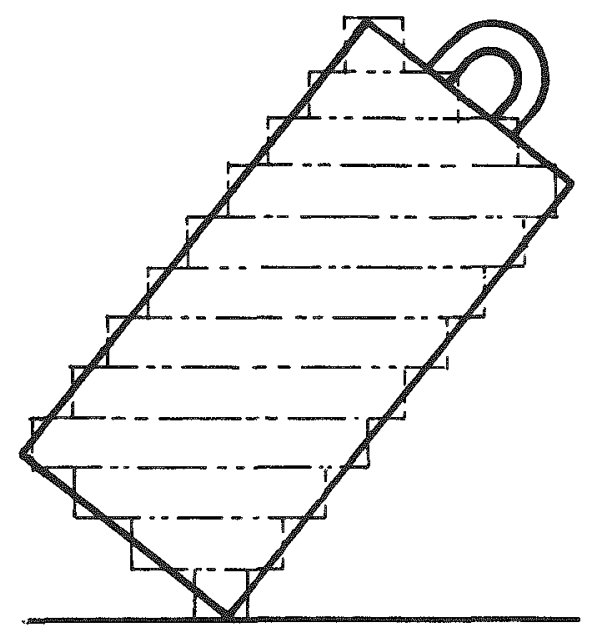

$T=000 . \mu$ SEC.

CALCULATIONAL MODEL (a.)

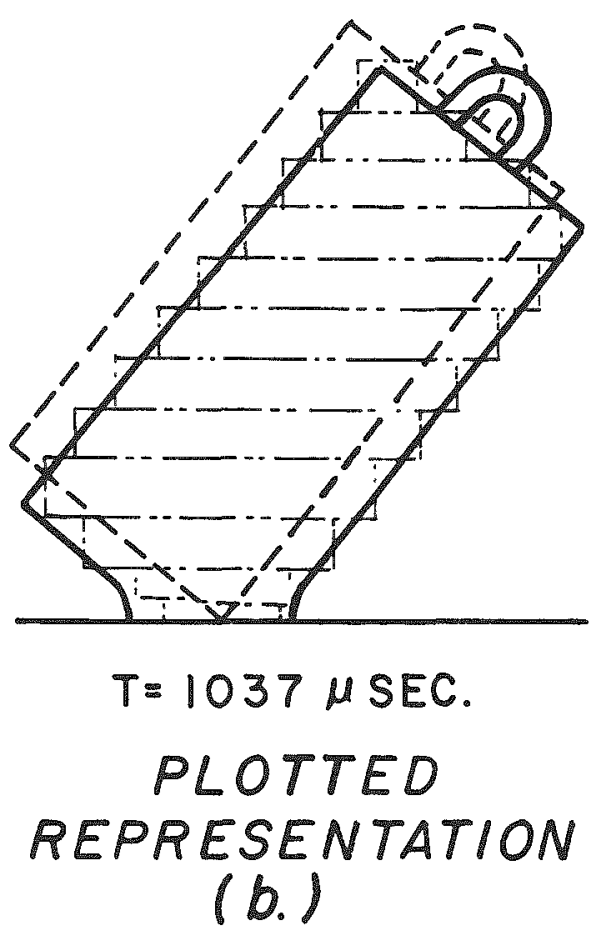

(b.)

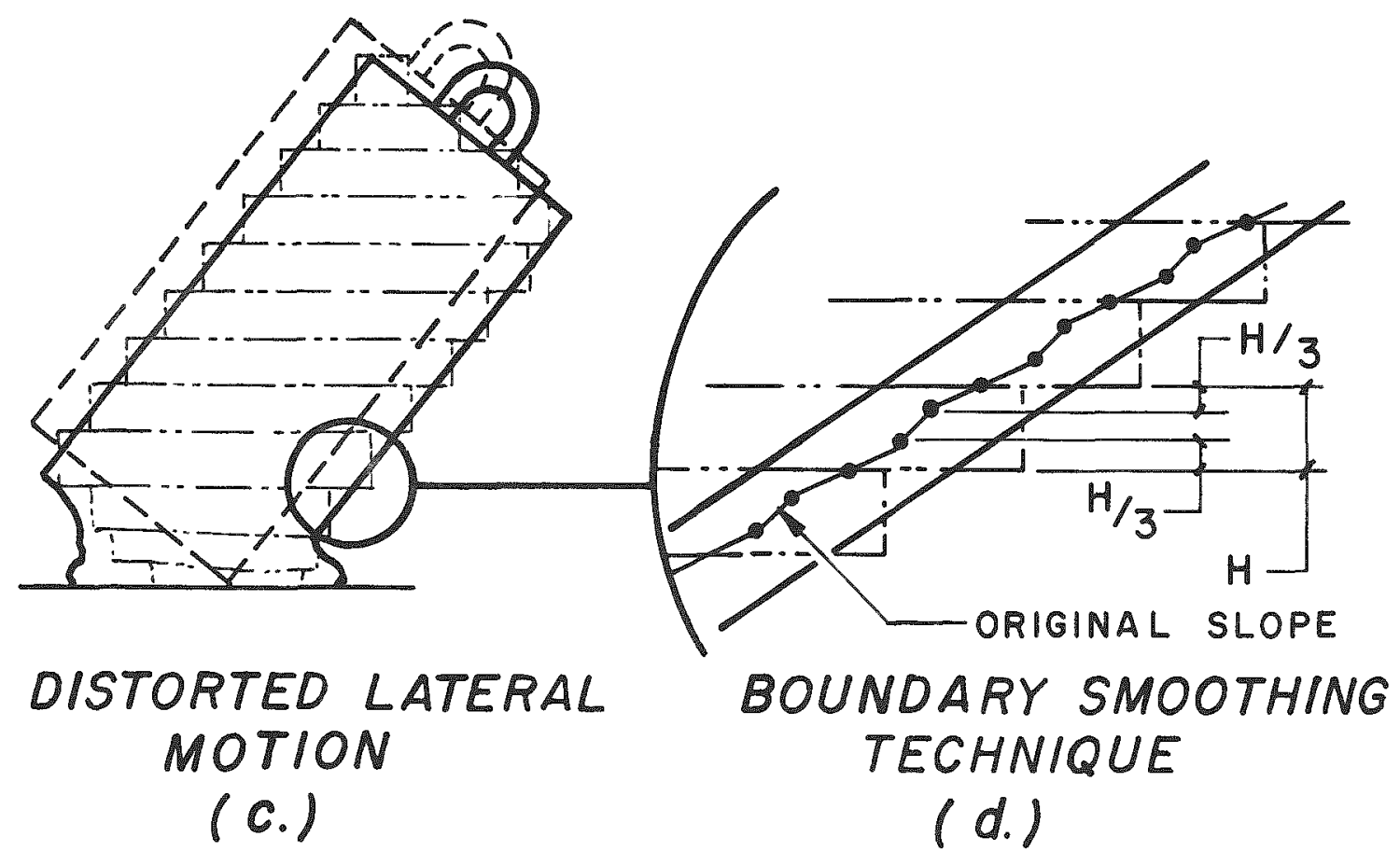

Fig. 5. Typical Results from Computer Plotted Graph for Dynamic Model Display. 
and does not affect the basic accuracy of the calculated vertical displacenent. Figure $5 \mathrm{c}$ shows the results of such a distorted plot. Although the distortion shown gives a somewhat unrealistic view of the results it does give a closer look at the actual distortion pattern.

Color film, responsive to colors ranging from red to blue, may be used to improve the overall appearance of computer motion pictures, but it would be nearsighted of the user to make this the sole reason for use of color film. Although this black and white publication cannot show how colors are used to clarify the plotted image, the original container configuration may be shown in a contrasting color to the final deformed shape.

Displaying a geometrical model is a very straightforward process and is a natural method of presenting a geometrical time dependent phenomenon, but one is faced with a different problem when one wishes to show the simulated results of a 30-minute fire test. Logically a temperature phenomenon may be represented by a color phenomenon, while prototype spacial coordinates or geometry may still be represented by a geometric pattern for the model display. Time relationships should be proportional to movie viewing time but need not be on the same scale.

In this temperature display, color film plays a very important role in projecting information, although other techniques such as isothermal lines or a subgeometrical representation may be used when color is not available. Figure 6 shows the basic display capabilities of the computer. Isothermal lines have been substituted for color for the purpose of this report.

Time required for the production of a complete set of simulations such as those described in this report would be a few man-hours while the computer time and film costs would probably run two or three times that amount. This reprew sents a total cost which cannot even be compared to the costs in labor and material required to conduct full scale tests. If sufficient data are available to prove the constants assumed for the mathematical models used, a remarkable saving may be realized while valuable and easily understood results are obtained. Unquestionably a thousand pictures shown as a movie will be worth a thousand-thousand numbers. 

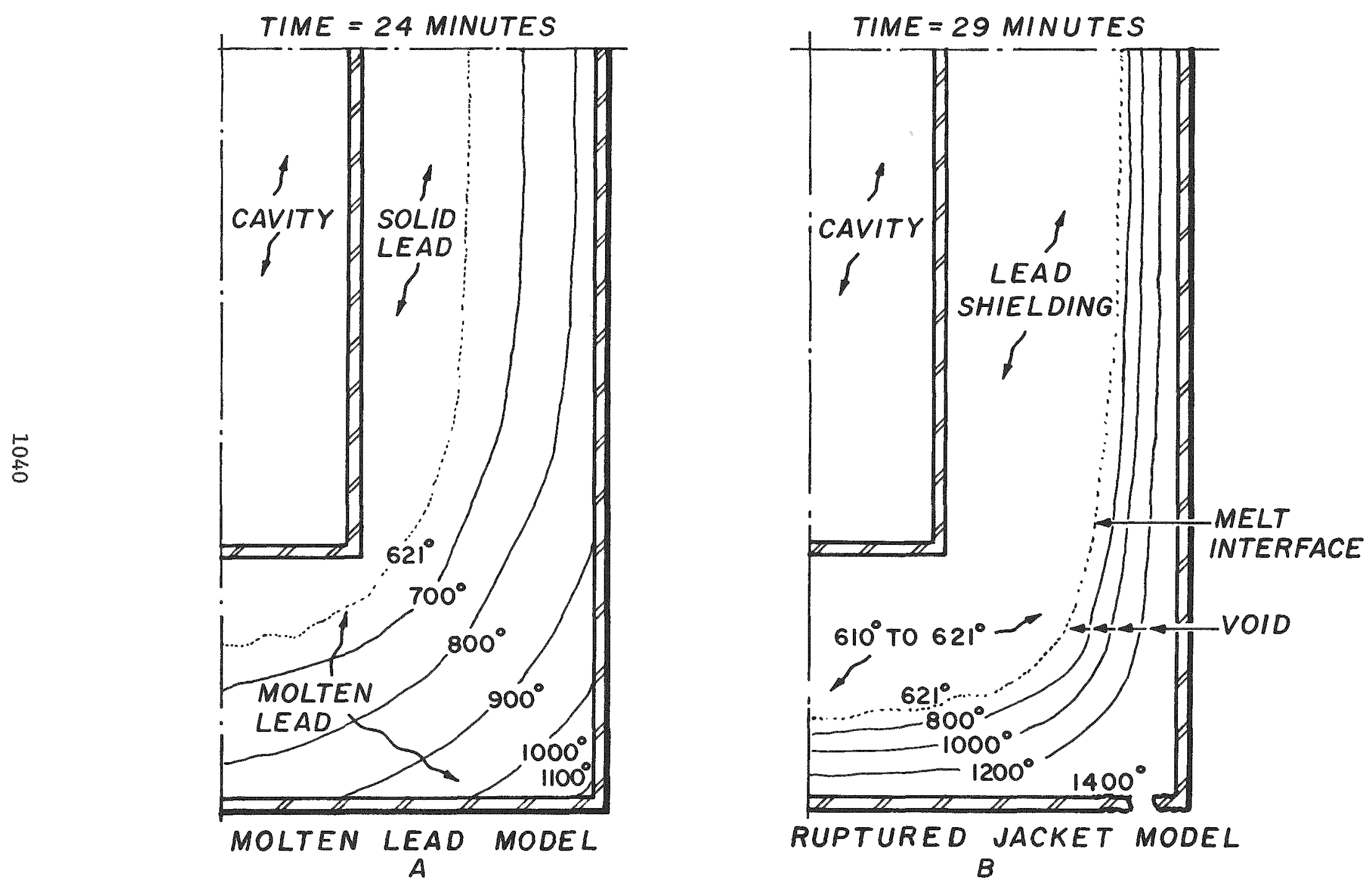

Fig. 6. Typical Results from Computer Plotted Graph for Temperature Display. 
1. B. J. Donham, A Mathematical Model for Prediction of Maximum Damage to Shielded Shipping Containers, Presented at IAEA International Seminar on Test Requirements for Packaging for the Transport of Radioactive Materials, Vienna, Austria, February 8-12, 1971.

2. F. C. Davis, Structural Analys is of Shipping Casks, Vo1. 9, Energy Absorption Capabilities of Plastically Deformed struts Under Specified Impact Loading Conditions, Oak Ridge National Laboratory, ORNL-TM-1312, Vol. 9.

3. N. M. Newmark, A Method of Computation for Structural Dynamics, Proceedings of the American Society of Civi1 Engineers, Vo1. 85, EM3 (July 1959).

4. R. F. Thomas and M.D.J. MacRoberts, RATH Thermal Analysis Programs, LA-3264-MS, Los Alamos Scientific Laboratory, Los Alamos, New Mexico (1965).

5. M. N. Ozisik, Boundary Value Problems of Heat Conduction, International Textbook Company, p. 407 (1968).

6. B. T. Chao and A. M. Clausing, Numerical Methods in Heat Transfer, Advanced Heat Transfer, p. 189 (1969). 
THE FOLLOWING PAPERS WERE NOT PRESENTED AT THE SYMPOSIUM 


\begin{abstract}
in.
1 HEAT TRANSFER ANAIYSIS OF A CESIUM- 137 SHIPPTNG CASK

G. R. Bray

J. J. Darby

C. E. Gruh 1

ABSTRACT

Shipment of cesium-137 from Richiend, Washington, to oak Ridge, Tennessee, required the design of a new shipping cask. Design factors were based on the structural integrity of the cask and the maximum volume of product that could be contained per unit of product heat generated under varying conditions.

Conventional calculations were used in the cask's design, and then a computer program was developed to confirm them. In addition, steddy-state temperatures were taken with various cask loadings.
\end{abstract}

\title{
INTRODUCTION
}

The fission product cesium-137 is one of the valuable (commercial and experimental) by-product isotopes produced in Hanford's plutonium-production reactors. This radioactive product must be shipped from Hanford to Dak Ridge in special. containers designed to exacting standards: regulations of both the Department of Transportation and the $A E C$ influenced this design.

Atlantic Richfield Hanford Company (ARHCO) requested that Vitro Hanford Engineering Services perform the necessary cask design. It entailed the design of a special insert for an existing cask's (HAPO-1B-3) outer shell (Figure l). The cask's new insert (HAPO-IC-1) is shown in Figure 2.

The IC-I cask was designed to contain $3.86 \mathrm{ft}^{3}$ of Zeolon 900 Resin* to absorb, by ion exchange, a 361 kilocurie lodding of cesium-137 (Figure 3). The $\mathrm{k}$ factor (thermal conductivity) for the Zeolon Resin was given as $0.13 \mathrm{Btu} / \mathrm{hr} / \mathrm{ft}^{2} / \mathrm{F}$ by

* T. H. Nortón Co. a Trade Name 
the manufacturer. The potential heat loading was set at 5.920 Btu/hr by ARHCO Maximum allowable resin temperature was determined to be $382 \mathrm{~F}$ with the resin bed being purged with helium.

\section{CALCULATIONS}

Calculations were first made using General Electric Design Datal to arrive at temperatures of various surfaces throughout the cask, and then the ORNL-MM-2410 formula ${ }^{2}$ was apolied to determine the cask's outer temperature.

The maximum allowable center-Iine temperature taken through a crossmsection of the annulus was the determining factor for the annulus dimensions. An ambient temperature of $130 \mathrm{~F}$ and a maximum resin bed temperature of $382 \mathrm{~F}$ established a. $\Delta T$ of $252 \mathrm{E}$.

Using the ORNL formula (Eq. 1), calculations were performed to determine the minimum $\Delta T$ between the cask surface and still air that would dissipate the heat load $(5,920 \mathrm{Btu} / \mathrm{hr})$ given in the criteria. The third trial indicated that 35 F difference would suffice, i.e., a cask surface terperature of 165 I. These calculations did not encompass solar loading since the cask is enclosed in a buffering structure during trensport (see Figure 4 ).

Q Total $=h_{c} A_{c}(T s-T 2)+0.173 \overline{F_{12}} \operatorname{Ar}\left[\left(\frac{T s+460}{100}\right)^{4}-\left(\frac{T a 460}{4}\right)^{4}\right]$

where

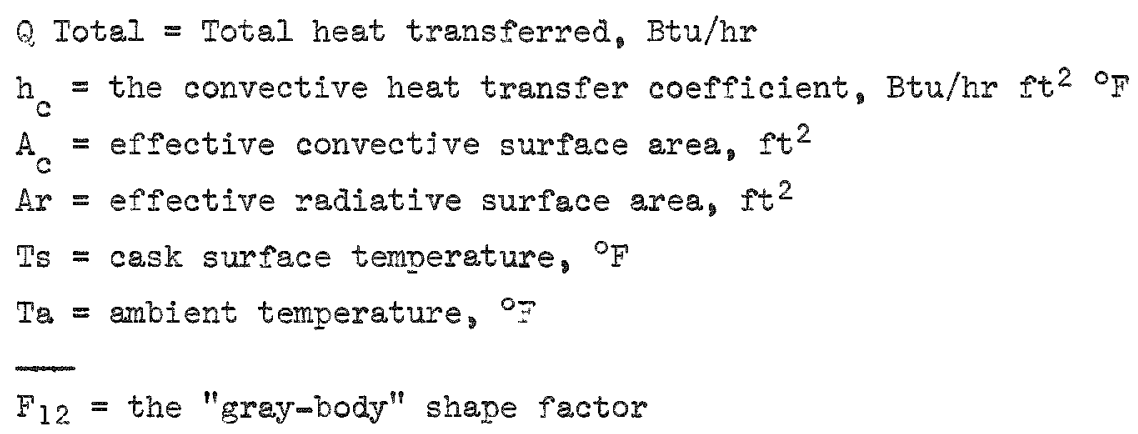

The Design Data formula (Sect. $6502.4, p 11)^{l}$ is used to determine temperatures at the extreme point in location from the temperature given. 
For a hollow cylinder of several layers

$$
t_{\max }=t_{s}+\frac{g}{2 \pi c}\left[\frac{10 g e^{\frac{r b}{r a}}}{k_{a}}+\frac{10 g e^{\frac{r c}{r b}}}{k_{b}}+\cdots\right]
$$

in which

$$
\begin{aligned}
& t_{\max }=\text { temperature at point in resin bed, }{ }^{\circ} \mathrm{C} \\
& t_{s}=\text { input at inner surface, }{ }^{\circ} \mathrm{C} \\
& q=\text { heat flow, watts } \\
& c=\text { linear dimension, inches } \\
& r_{a, b}, c=\text { radic of varying layers, inches } \\
& \mathrm{k}=\text { thermal conductivity, } \frac{\text { watts/sa in. }}{\text { deg } \mathrm{C} / \mathrm{in} .}
\end{aligned}
$$

Fhis calculation gave a temperature at the surfaces resin bed of 175 E. Further calculations using GE Design Datal were made to approximate the maximum temnerature of the resin bed itself.

$$
t_{\max }=\frac{q^{m}}{4 k}\left[r_{2}^{2}-x_{n}^{2}-x_{n}^{2} \log e \frac{r_{2}^{2}}{r_{n}^{2}}\right]
$$

in which

$$
\begin{aligned}
& q^{m}=\text { heat generation per unit volume, watt/cu in. } \\
& k=\text { thermal conductivity, watts/sq in. } \\
& r_{2}=\text { outside radius of cylinder, inches } \\
& r_{1}=\text { inside radius of cylinder, inches } \\
& r_{n}=\left\{\begin{array}{l}
\text { if there is no outward heat flow, } r_{n}=r_{2} \\
\text { if there is no inward heat flow, } r_{n}=r_{1}
\end{array}\right.
\end{aligned}
$$

For these calculations $r_{n}$ was taken to equal $r$.

Computed temperature of the resin bed by formula Eq. (3) was $360 \mathrm{~F}$, a temperature below that given by the criteria as maximum. 
While the cask was being fabricated, a computer model program was run by Mechanics Research Inc., ${ }^{3}$ of Tacoma, Washington.

The computer program showed a maximum resin bed temperature of $279.5 \mathrm{~F}$ under summer steady state conditions indicating that a larger volume space for cesium could safely have been designed into the cask.

\section{STEADY-STATE TESTS}

Tests made by the customer in October 1970 to determine actual steady state temperatures were made in a test cell under the following conditions:

\begin{tabular}{|c|c|c|c|c|c|c|}
\hline \multirow{2}{*}{$\begin{array}{c}\text { Pressure (ab) } \\
\text { (inches Hg) }\end{array}$} & \multirow[b]{2}{*}{ Gas } & \multirow[b]{2}{*}{ Resin Bed } & \multicolumn{3}{|c|}{ Temperature, $F$} & \multirow[b]{2}{*}{$\mathrm{CeII}$} \\
\hline & & & $\mathrm{Pb}$ & TOP & Side & \\
\hline 18 & Air & 335 & 126 & 93 & 111 & 70 \\
\hline 28 & $\mathrm{He}$ & 293 & 125 & 93 & 109 & 73 \\
\hline
\end{tabular}

These measurements were taken with the cask in the 212-B cell at Hanford's 200 East Area. The cask was exposed to approximately 4600 scfm ventilation air down over and past its top. All temperatures were taken with ironmconstantan thermocouples which demonstrated \pm I $F$ accuracy in an ice bath. The estimated isotropic heat load in the cask was $6720 \mathrm{Btu} / \mathrm{hr}$. This value should be within $\pm 5 \%$ 。

The increased heat loading was the result of achieving a cesium loading in excess of that given in the criteria, 430 kilocuries vs. 361 kilocuries. Comparing these test results to the original manual computations indicates that the formulae are accurate and conservative.

The detailed heat transfer analysis produced on the computer showed a higher heat transfer rate (loss) than was evidenced in the loading test, considering the amount of cooling air passing over the cask. There should be some discrepancy because of the difference in value assigned to the resin themal conductivity ( 0.13 from criteria vs. 0.25 from computer references). 
The steady-state temperatures were assumed to be in effect at the time of design accident. Considering the 48-hour buried condition with no external heat loss, calculations were made to detemine the length of time for cask material temperature equalization (heat sink characteristics) and then the temperature that would result at the end of the period ( 48 hours). Calculations indicated a total average temperature of $351 \mathrm{~F}$. The computer results show a resin bed temperature of $341 \mathrm{~F}$.

References:

I. General Electric Design Data (Section G502.4). October 1963.

2. Irradiated Fuel Shipping Cask Design Guide, ORIL-MM-2410.

3. Report C2399, ARHCO Contract SA-125. Mechanics Research, Inc., Tacoma, Washington. 


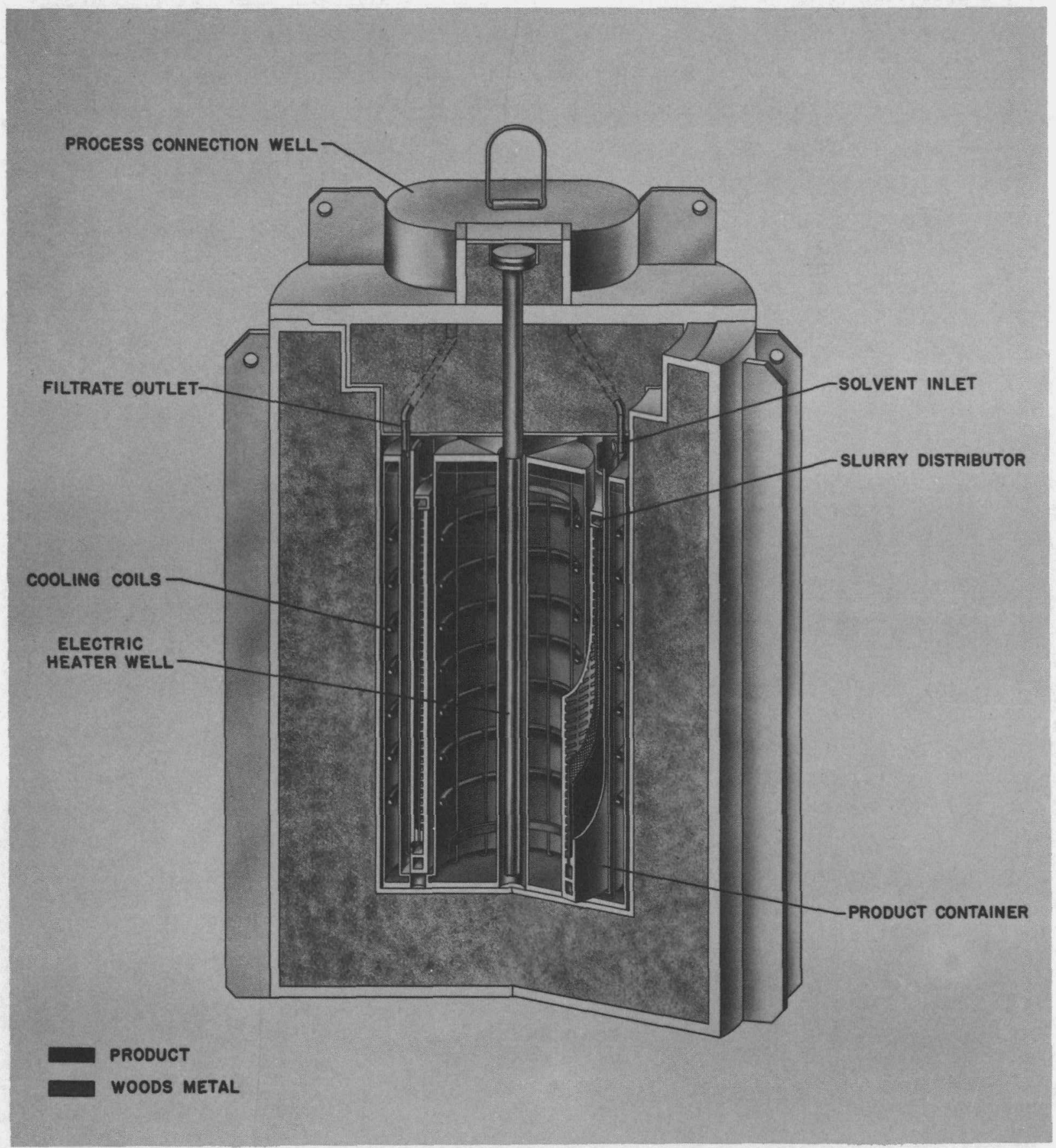

Figure 1. HAPO-1B-3 Cask 

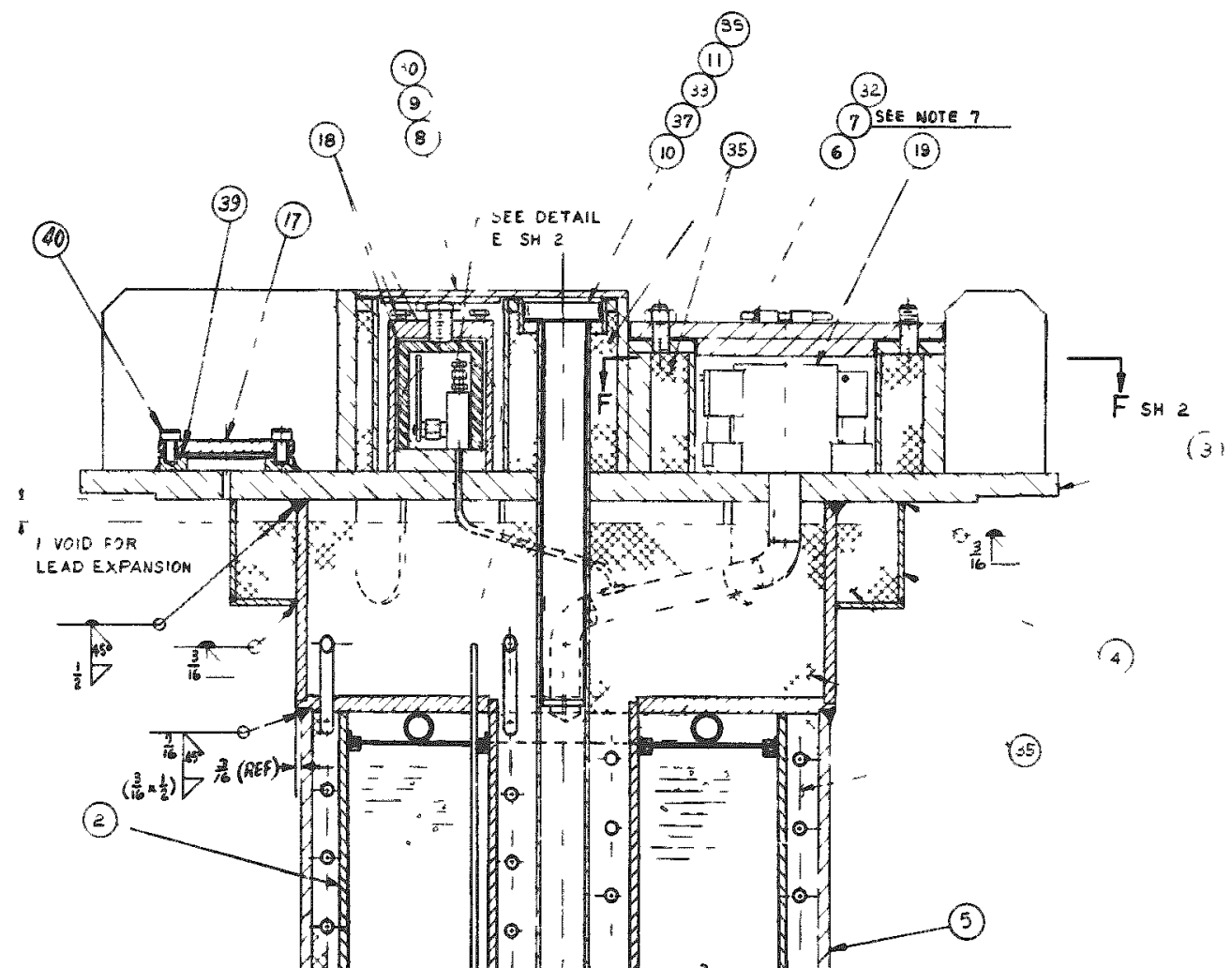


\section{C-1 ZEOLITE BED LOADING CYCLE}

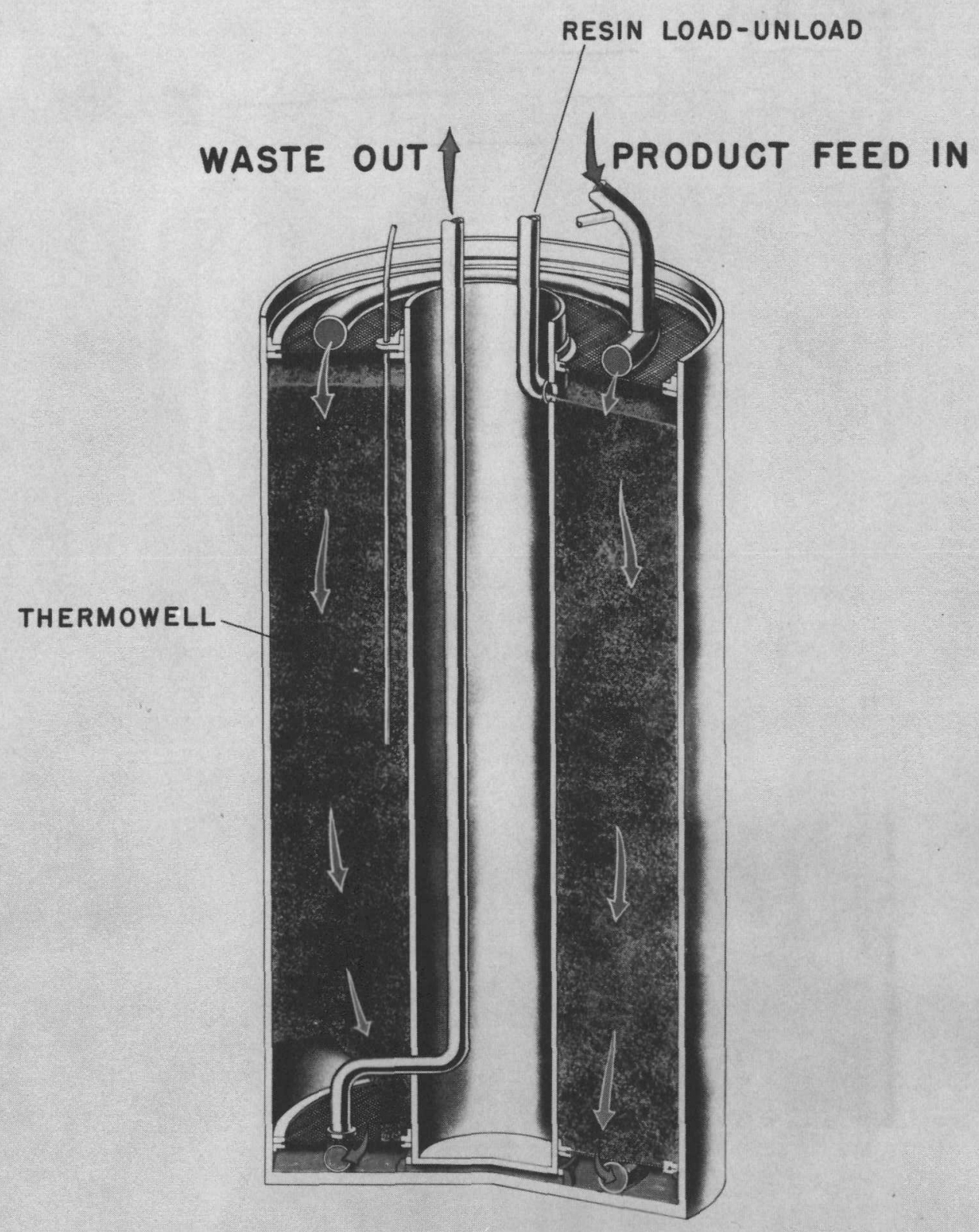

Figure 3. Cask Insert Resin Bed 


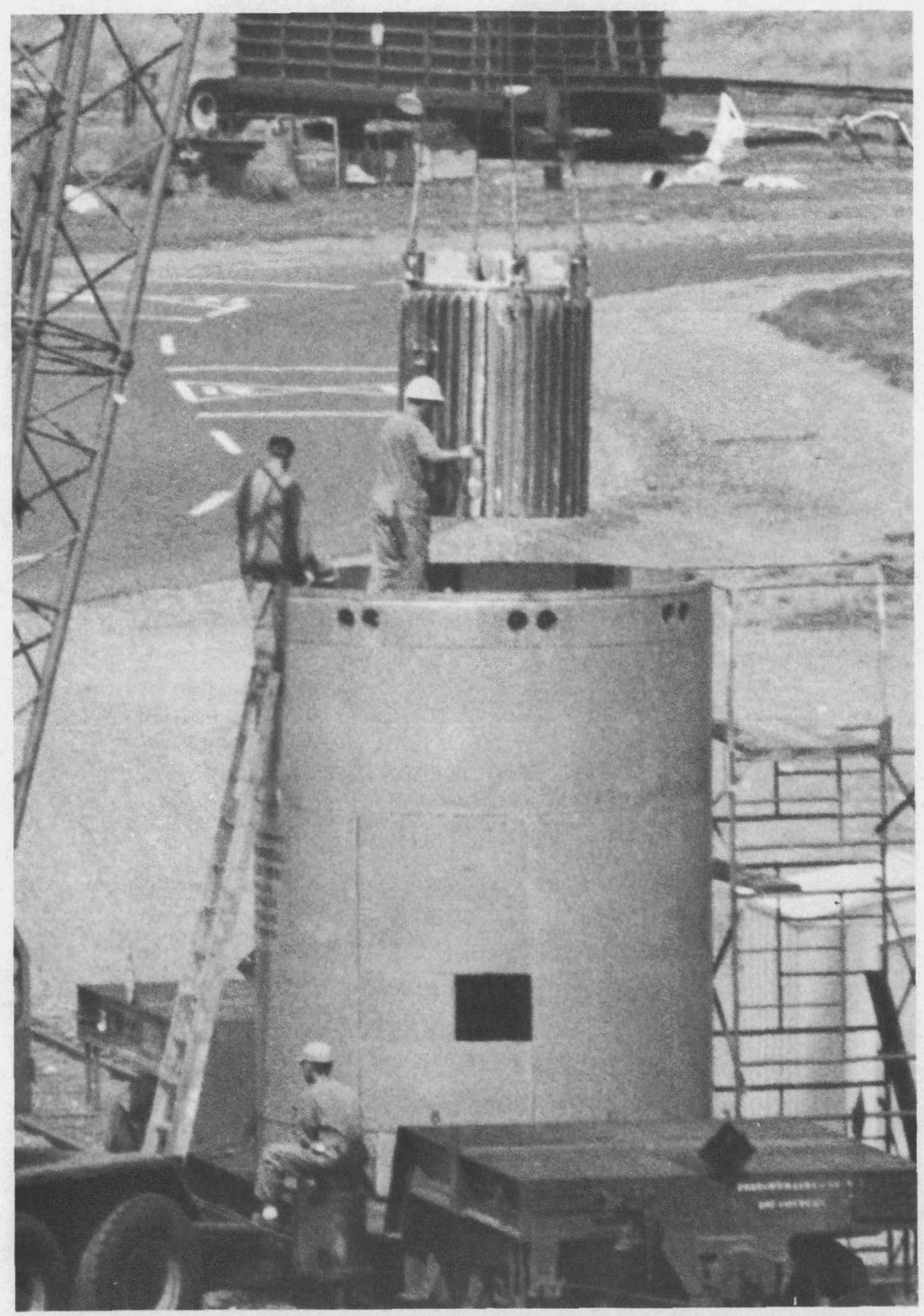

Figure 4. Lowering Cask into Buffering Structure 


\section{A STUDY OF THE EFFECT OF IMPACT AND OF THE USE OF A TOROIDAL SHELL AS AN ENERGY ABSORBER ON A CYLINDRICAL CONTAINER OF LEAD AND STEEL}

I. R. Shobe

B. R. Dewey

\section{ABSTRACT}

Test specimens of 0.167 scale model of a full size container were dropped from $30 \mathrm{ft}$ to determine their behavior during impact, their behavior during rebound, and the nature of the deformed regions. The severe damage experienced by the cylindrical specimen casks and the limited ability to absorb energy without failure lead to the development of a steel toroidal shell attached in such a way as to give maximum protection in corner impact. An approximate analysis of the energy absorption of such a shell and experimental verification shows that the stress state in the toroidal shell increases the shell's energy absorption by orders of magnitude over simple rings. A drop test with a toroidal shell attached to a scale cask substantiated the efficacy of this approach - a 14-1b model she11 completely protected a 233-1b model cask. This represents a sma1l percentage increase in weight for a major increase in protection against impact.

\section{INTRODUCTION}

Increasing use of radioactive materials makes it imperative that safer methods of transporting such materials be developed. In view of the catastrophic results of structural failures of containers, all possible accident conditions must be anticipated. AEC standards 1ist hypothetical accident conditions: (1) free drop, (2) puncture, (3) thermal, and (4) water immersion. This investigation examined the free drop accident condition -- a free drop through 30 feet onto a flat essentially unyielding horizontal surface striking the surface in a position for which maximum damage is expected. The position for which 
maximum damage is expected in a cylindrical container is that of impact on a corner. This accident condition was studied experimentally and a method for designing a necessary energy absorption device external to the container was formulated.

It is to be emphasized that the free drop condition which causes the maximum damage is one where the corner of the container strikes the unyielding surface with the mass center of the container directly above the corner. When the container is so oriented as it strikes the unyielding surface, it is hypothesized that all of the kinetic energy of the container is dissipated as plastic deformation of one spot on the corner. On the other hand, when a container falls such that the mass center is not above the corner that strikes the horizontal surface, some of the kinetic energy of translation is converted to kinetic energy of rotation. Thus several spots on the container ultimately impact with the horizontal surface and the plastic deformation is not confined to one location.

\section{MODEI CASK-DESIGN I}

The first specimen fabricated was a 0.167 scale model of a full size container designed by Shadid in an analytical study of the effect of impact on cylindrical containers of lead and steel construction. The design of the full size container made economical use of materials and funds; and, consistent with good engineering practice, all details were kept as simple as possible. The design featured welded construction of carbon steel plate; the fasteners were also of carbon steel.

All details were maintained as accurately as possible in the scale model, and resulted in a model whose length and diameter were 14 in. and 7 in., respectively. With simulated contents it weighed $1551 \mathrm{~b}$. The carbon steel components of this model cask are shown in Figure 1. During the development of this model by Welch", it became apparent that certain compromises, particularly with regard to welding, sealing, and fasteners, would have to be made in its design.

To overcome the difficulties involved in welding the thin materials in the model, the flange assemblies were machined from solid pieces of thick sheet steel. This eliminated all welds with the exception of those of the outer and inner shelis to the flange assemblies, and was felt to give a model whose behavior would be quite similar to that of the full size container.

Metal gaskets were selected for sealing because of their greater likelihood of satisfying the hypothetical thermal accident condition. The design of the full size container indicated a soft aluminum gasket having a thickness 


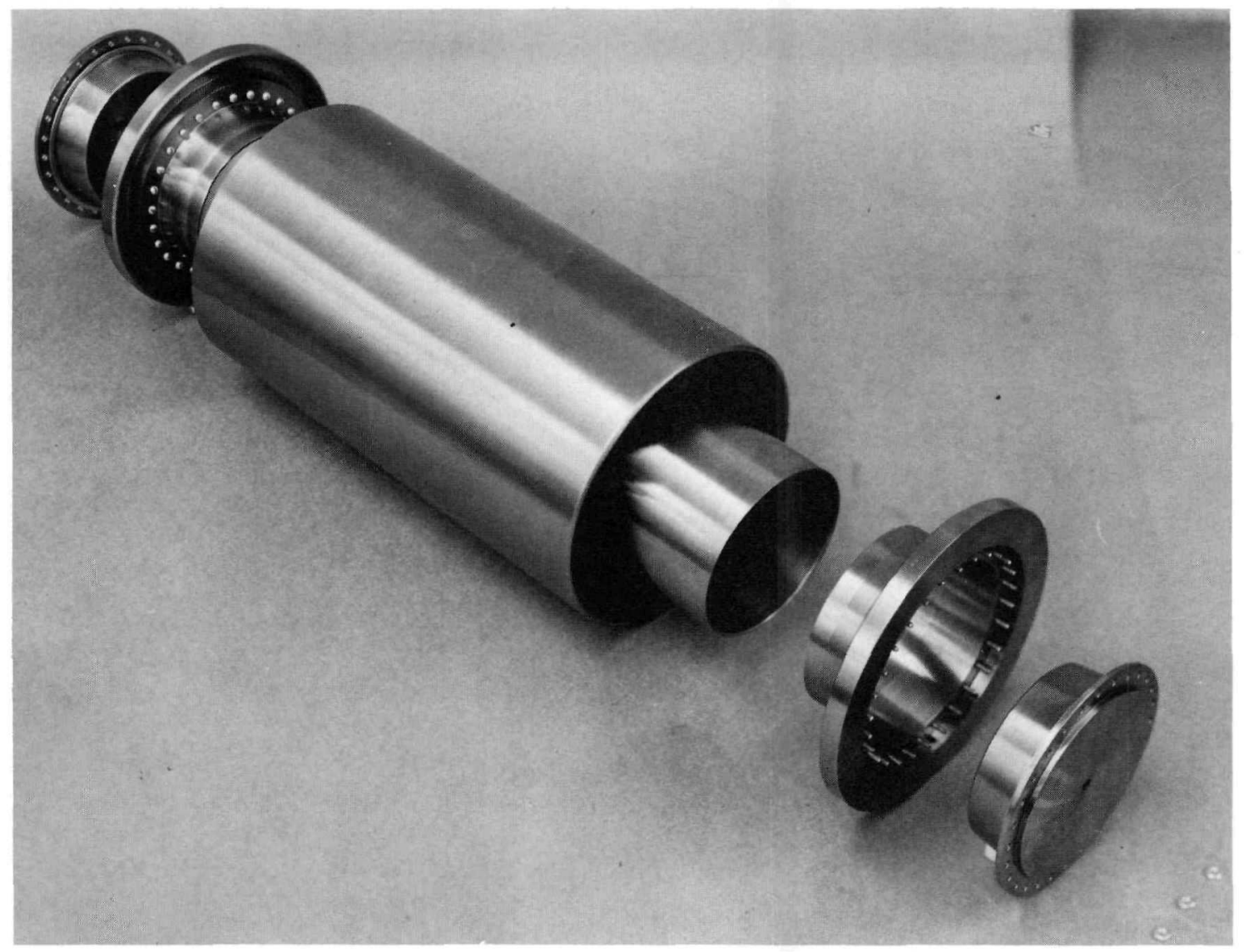

Fig. 1. Liner, Jacket, Flanges, and Closures of Model Cask I.

of 0.125 in. Application of a scale factor of 0.167 resulted in a thickness which presented formidable fabrication problems. A thickness of 0.050 in. was therefore specified, but on attempting to seal and pressurize the model, it was found that pressure could not be maintained. The fibrous gasket then substituted functioned properly and maintained a pressure of 50 psi. Subsequent examination of the gasket faying surfaces revealed that they were as much as 0.020 in. out of plane. Machining the faying surfaces at the end of the container opposite the end impacted to within 0.001 in. of plane permitted the soft aluminum gasket to function properly.

Scaled versions of the full size $0.750 \mathrm{in}$. diameter with 10 threads per inch fasteners were not commercially available in carbon steel. As a consequence, concessions were made in both material properties and size of the fasteners.

Six tests utilized this specimen. Initially the specimen was instrumented with electrical strain gages and an accelerometer, but the data obtained therefrom were not satisfactory. High speed motion pictures were made of all tests. 
During the first drop from $9 \mathrm{ft} .5 \mathrm{in}$. onto a corner, the specimen sustained damage indicating that the full scale container would not be satisfactory: The seal and fasteners failed, and pressure was lost. The five subsequent tests, even though the model was modified, served to indicate that this design concept was not acceptable. Thus it became apparent that additional work would be required to develop a cylindrical container which would safely withstand impact.

\section{MODEL CASK-DESIGN II}

Because of the severe damage ${ }^{2}$ experienced by the cylindrical specimen described above, it appeared that it would be appropriate either (1) to separate the sealing function from the radioactive shielding function, or (2) to provide a device whose sole function is to absorb the kinetic energy of impact without transmitting high impact loads to the shielding and sealing regions of a container. Adopting the first course of action led to the development of a two closure cask (1) in which the outer closure was designed to absorb most of the energy and the inner closure was expected to maintain the seal. The carbon steel components of this model cask are shown in Figure 2.

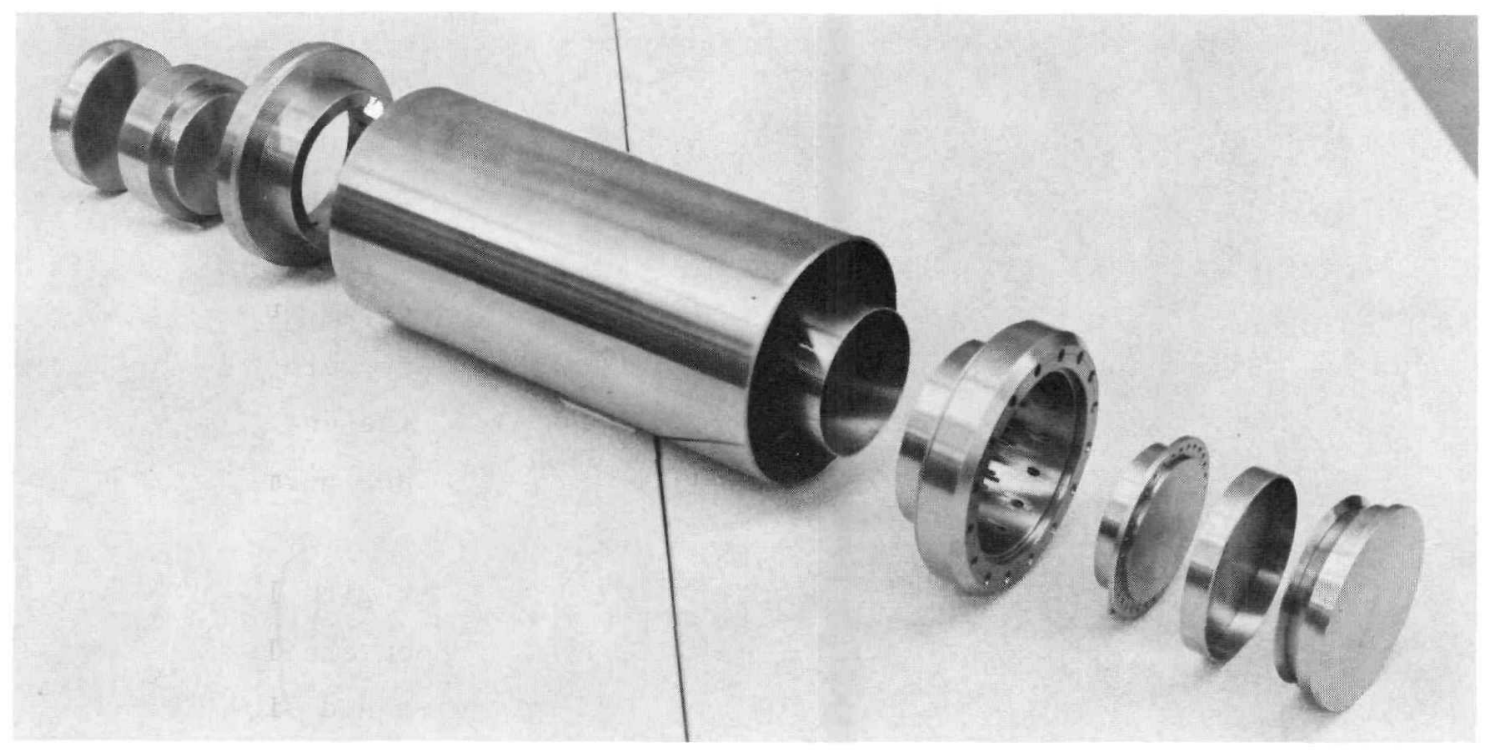

Fig. 2. Liner, Jacket, Flanges, and Closures of Mode1 Cask II. 
Subsequent testing of this model by dropping it 30 feet resulted in a loss of the seal. Because it was felt to offer more promise of success, the merits of an external energy absorption device were investigated and consideration of a design change wherein a greater clearance might have been provided between the two closures was discontinued.

AR EXTERNAL ENERGY ABSORBER-THE TOROIDAL SHELL

It seems clear that some sort of external energy absorber must be provided to protect such casks in the event of an accident in shipment. Such an energy absorber should be economical, should require no special maintenance, and should effectively protect the cask from impact in all possible directions, but needs only to be a one-time device. A hollow toroidal steel shell fastened on the ends of the shipping container is such an energy absorbing device. Since this sort of external energy absorber need only be attached to casks during shipment, and since only a small fraction of the total number of casks in the country will be in transit at any one time, this sort of concept certainly seems to be more economical than any one which would involve designing new containers and declaring the old ones obsolete. The utilization of the plastic deformation of ductile steel is one of the most efficient means of energy absorption. The geometry of the torold offers ease in manufacturing, fairly efficient utilization of the material in absorbing energy, protection from all directions with the maximum protection where it is needed most, and suitability for rational design.

In analyzing the energy absorption in a toroidal shell, it is necessary to deal with large deformations in the plastic range; and, as a consequence, the elastic contributions to strain energy are negligible. A biaxial state of stress is assumed in the deformed shells, whereby the two principal directions used give the "ring" contribution and the "dilatation" contribution to the strain energy absorbed. In Fig. 3, these principal directions are denoted I and II respectively; the strain energy due to stresses in the third principal direction (III) is negligible.

For I and II as principal directions, the energy absorption $U$ can be symbolically indicated as

$$
U=\int_{V} c_{I} \varepsilon_{I} d V+\int_{V} \sigma_{I I} \varepsilon_{I I} d V
$$

where $V$ is the material volume and $\sigma$ and $\varepsilon$ are stress and strain. 


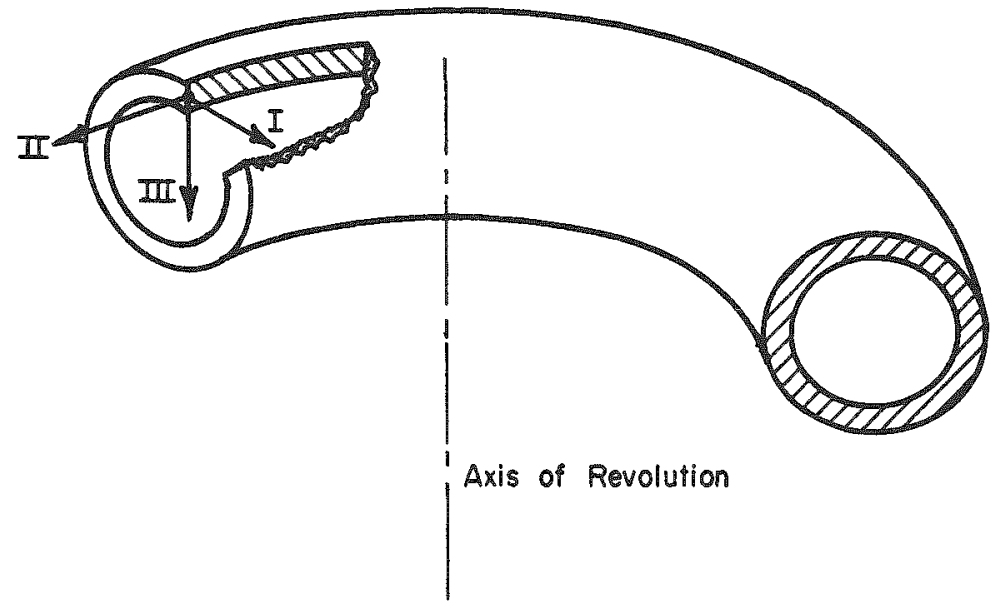

Fig. 3. Orientation of Axes

Energy Absorption in Ring

With reference to the cross sectional ring element of Figure 4, the shaded areas denote regions where the material has become fully plastic. For simplicity ${ }_{I}$ of Eq. (1) is assumed constant and equal to the yield stress "ys. At points $A$ and $C$ in the ring, it is assumed that a plastic hinge is formed whereby the energy absorbed in each plastic hinge $\mathrm{r}_{\mathrm{A}}$ is given by

$$
\mathrm{U}_{\mathrm{A}}=\mathrm{M}_{\mathrm{p}} d,
$$

where the $M_{p}$ is the fully-plastic bending moment. A refined expression for $U_{A}$ has been developed by Estep ${ }^{2}$ which considers the extent of a plastic zone at A and shows the simpler Eq. (2) underestimates the actual energy absorption.

In the flattened region at the top of the toroid, it may be shown ${ }^{2}$ from the geometry of deflection that the energy absorbed is

$$
\tau_{B}=\frac{1}{2} y_{y s} t^{2} \frac{L}{r}=2 M_{p} \frac{L}{r}=M_{p} ;
$$

since the inextensibility of the ring center line gives $2 L=r:$. Hence by Eqs. (2) and (3), the total energy absorbed in the entire ring is

$$
\tau_{I}=4 M_{p} t .
$$




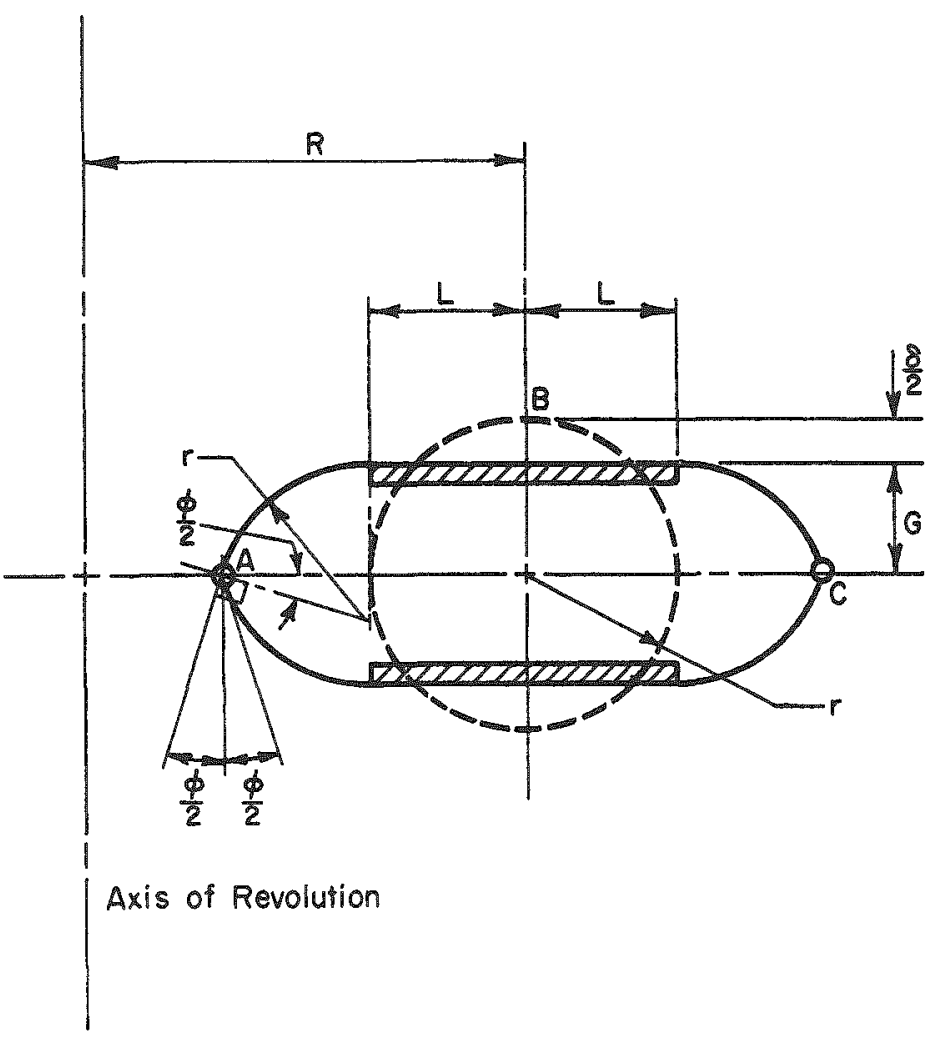

Fig. 4. Ring Element of Idealized Deformed Toroid

The angle $\&$ is related to the deflection $\delta$ of the ring, as shown in Fig. 4 by

$$
\delta=2 r \sin (t / 2)
$$

The fully plastic bending moment $M_{p}$ for non-strain-hardening materials is given ${ }^{4}$ by

$$
M_{p}=\sigma_{y s} t^{2} / 4
$$

Hence, the energy absorbed by the ring follows from Eqs. (4), (5), and (6), and is

$$
U_{I}=4 \pi R t^{2} \sigma_{y s} \sin ^{-1}(\varepsilon / 2 r)
$$

Static and dynamic tests performed by Estep ${ }^{3}$ on mild steel rings from $2 \mathrm{in.}$ to $8 \mathrm{in}$. in nominal diameter and with various wall thicknesses indicate that the energy absorption predicted by Eq. (7) is about $20 \%$ too low. One cause of this under-estimation is neglect of strain hardening. Estep's more refined analysis of strain energy in the plastic hinge (regions $A$ and $C$ of Fig. 4) is not presented here because of space limitations. Furthermore, these 
tests showed that essentially the same energy is absorbed by the rings in the static tests as is absorbed in a test where a weight is dropped on a ring from $30 \mathrm{ft}$. Hence, for toroidal shell calculations, the energy $U_{I}$ as given in Eq. (7) is increased by a factor of 1.2 .

Energy Absorption by Dilatation

The strain energy contribution of "dilatation" (direction IT of Fig. 3) is 2 to 5 times that of the "ring" energy. This effect may be visualized by reference to Fig. 4. Before deformation (dotted outline), point $\mathrm{C}$ is at a distance $(R+r)$ from the axis of revolution. After deformation (solid outline), point $C$ is somewhat further from the axis. Hence the circumference of the circle of radius $(R+r)$ has been extended or "dilatated."

Rhoades ${ }^{5}$ et al have developed a numerical procedure for computing this dilatation strain energy. Basically, the deformed cross section is assumed symmetric; one quarter of the cross section is divided into n elemental segments. The strain energy of each elemental segment is formulated in terms of deformation, and the contributions of the $n$ segments are summed. The result of sumation for $4 \mathrm{n}$ segments is of the form

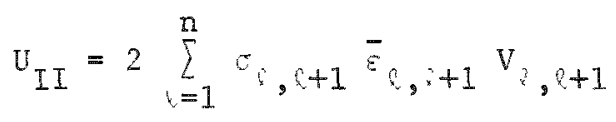

where the interested reader should consult the reference (5) for details on the computation of the terms within the summation of Eq. (8).

The total energy absorbed by the toroidal shell is the sum $1.2\left(U_{I}+U_{I I}\right)$ from Eqs. (7) and (8), with the 1.2 correction factor previously mentioned. Static tests run on toroidal shells show that such predictions are within a range of $-29 \%$ to $16 \%$ in error for a wide range of deflections and shell sizes.

In the case that a toroidal shell is not symmetrically deformed, a correction procedure has been developed". A "worst case" for non-symmetric loading is taken as that orientation where the load is applied by two horizontal surfaces acting as show on the torus of Fig. 5(a). The energy absorbed is a minimum where $\psi=\frac{\pi}{2}$ (Fig. $5(\mathrm{a})$ ) and a maximum when $:=0$, the case of symmetric loading previously developed. When: takes on intermediate values, linear interpolation is used. The minimum energy absorption is related to the maximum energy absorption $\left(U_{I}+U_{I I}\right)$ by

$$
U^{\min }=U_{I} \frac{2 x}{\pi} \int_{0}^{X} \cos \left(\frac{x^{\pi}}{2 x}\right) d x+U_{I I} \frac{2 X}{\pi}
$$



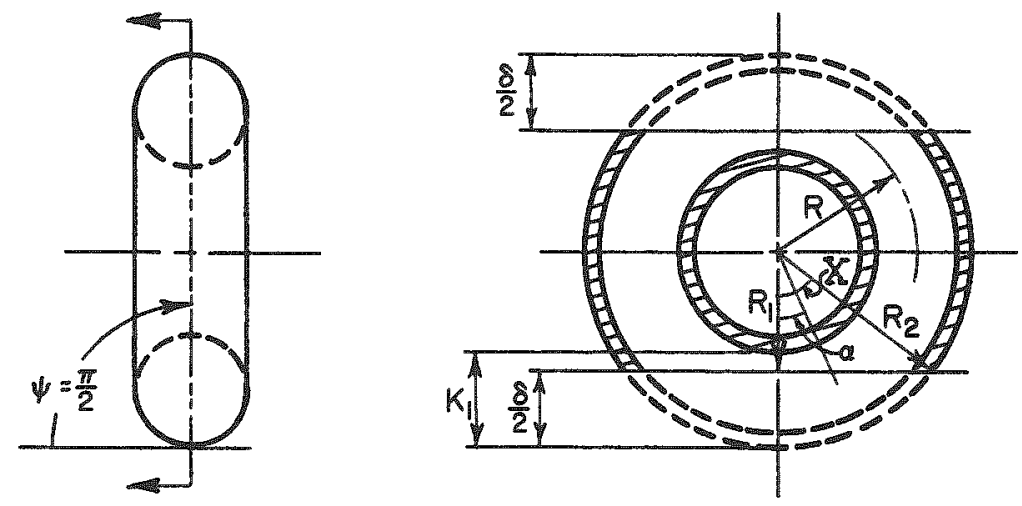

Fig. 5. Geometric Model for Correction Procedure

where the notations are defined in Fig. 5(b). Tests performed by Rhoades ${ }^{5}$ show the correction procedure predicts energy absorptions with a range of $-19 \%$ to $+29 \%$.

Proof Test of Mode1 Cask with Toroidal Shell

On the basis of the foregoing theory, a steel torus welded from four ells of $3 \mathrm{in.}$ long radius, light wall pipe was fitted to the untested end of the model cask-design II. Theoretically, this torus, symmetrically loaded should absorb more than $12,000 \mathrm{ft}-1 \mathrm{~b}$ of energy which is the sum of $2000 \mathrm{ft}-1 \mathrm{~b}$ "ring" energy and 10,000 ft-1b "dialation" energy. With a comer drop, the theoretical energy was about $5800 \mathrm{ft}-1 \mathrm{~b}$. Experimental data indicated these calculated values were $18 \%$ too 1ow. For the $233-1 \mathrm{~b}$ model cask that was dropped from $30 \mathrm{ft}$, about $7000 \mathrm{ft}-1 \mathrm{~b}$ needed to be absorbed. Hence, it appeared that the toroidal shell was capable of absorbing nearly all the required energy. This assembly was allowed to fall freely from a height of $31 \mathrm{ft}$. 6 in. with the mass center directly above the point of impact, as shown in Fig. 6. High speed motion pictures of the event indicate that virtually all of the kinetic energy was absorbed by the torus.

The photograph, Fig. 7, shows that the left-hand end of the cask, the end which was impacted on toroidal shell, is virtually undamaged. The righthand end shows the damage sustained in a similar drop without the toroidal shell protection. The kinetic energy of the assembly was sacrifically absorbed by the toroidal she1l, shown in Fig. 8. It is noted that the shell could have absorbed more energy than it did here, and the inherent energy absorption of the cask itself provides an extra factor of safety. 

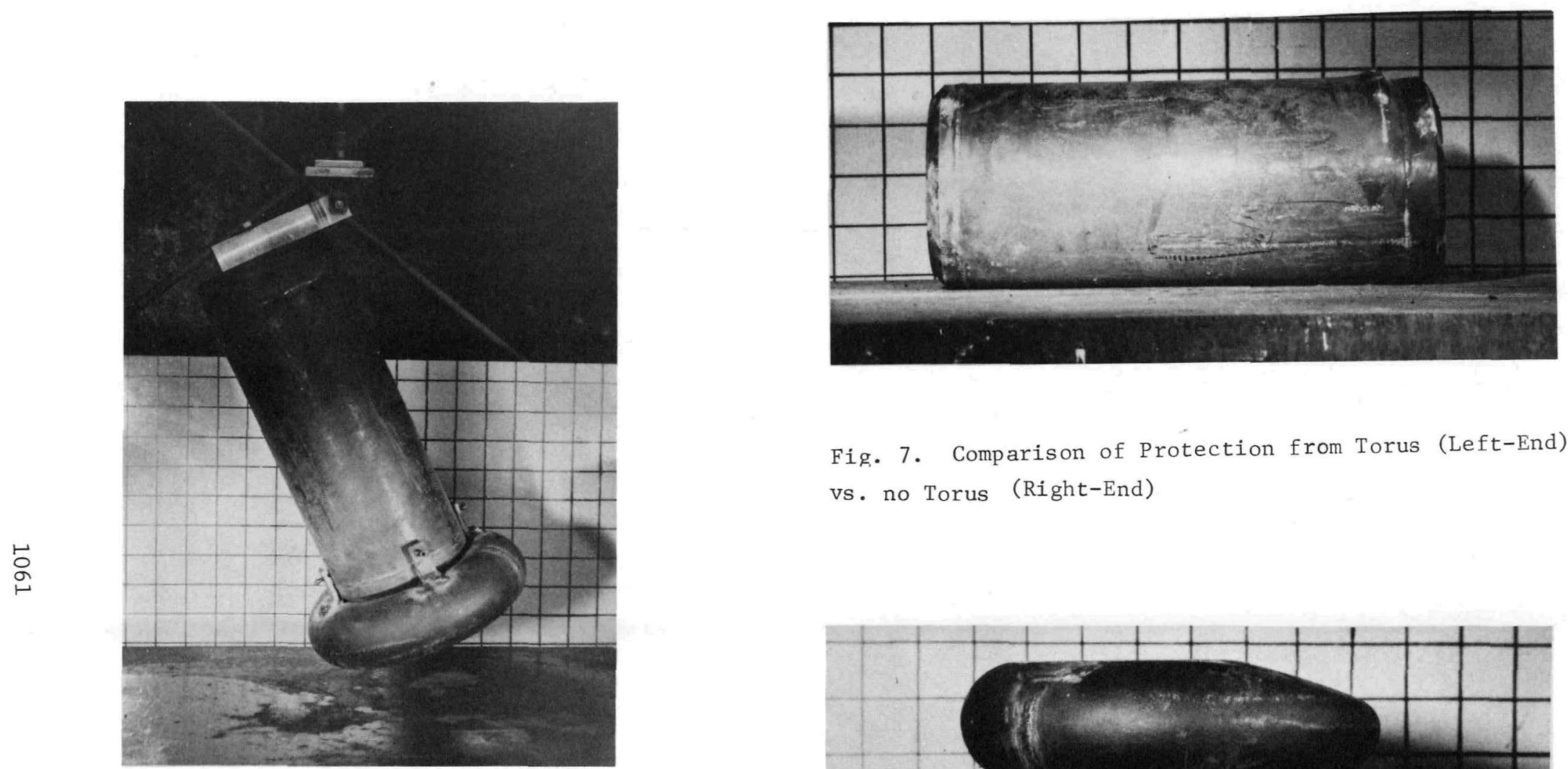

Fig. 7. Comparison of Protection from Torus (Left-End) vs. no Torus (Right-End)

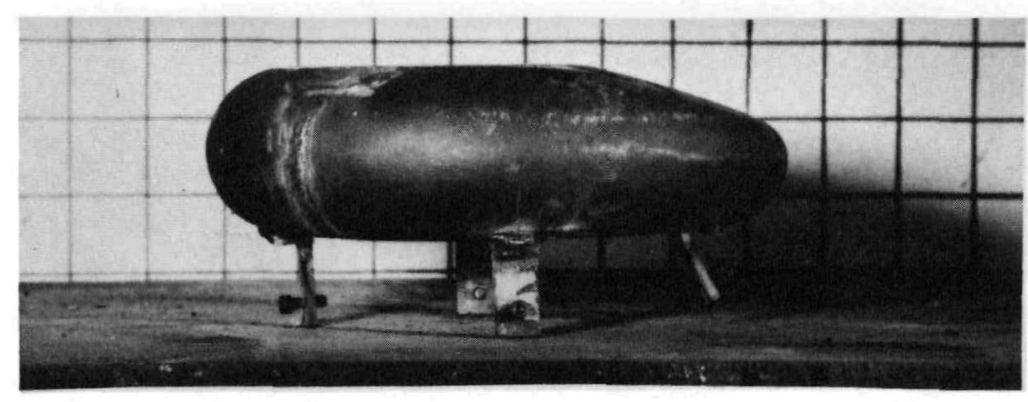

Fig. 6. Drop Configuration with Torus Attached

Fig. 8. Deformed Torus from Free-Drop Test 
The University of Tennessee tests on model casks show that failure of unsupported end closures is inevitable for the "worse-case" $30 \mathrm{ft}$. free drop-where the mass center is directly above the point of impact. All other orientations of drop simply produce less damage.

To protect against closure failure, the add-on toroidal shel1 is an efficient sacrificial energy absorber. An approximate analysis to estimate the energy-absorbing capability aids in the selection of the appropriate size torus for specific applications.

\section{ACKNOWLEDGEMENT}

This paper is based on the Master's thesis research done in the Department of Engineering Mechanics, Iniversity of Tennessee, Knoxville, by C.T. Welch, F. E. Shadid, A. Estep, and G. L. Rhoades, Jr.; this work is gratefully acknowledged. Also, the major portion of the work was supported by the Oak Ridge Jational Laboratory through contract.

\section{REFERENCES}

1. F. E. Shadid, Analytical Investigation of Procedures Proposed for the Design of a Shipping Cask for Radioactive Materials, Unpublished Master's Thesis, University of Tennessee, Knoxville, Dec., 1967.

2. C. T. Welch, An Experimental Investigation of the Effect of Impact on a Cylindrical Container of Lead and Steel Construction, Unpublished Master's Thesis, University of Tennessee, Knoxville, Dec., 1967.

3. A. Estep, L. R. Shobe, and B. R. Dewey, Energy Absorption Parameters in Stee1 Rings, University of Tennessee, Knoxville, Report EM 69-1, Mar., 1969.

4. S. P. Timoshenko, Strength of Materials, Part II, Advanced Theory and Problems, Third Ed., Van Nostrand, 1956.

5. G. L. Rhoades, Jr., B. R. Dewey, and L. R. Shobe, Energy Absorption in Toroidal Shells Undergoing Large Deformations, University of Tennessee, Knoxville, Report EM 70-1, Jan., 1970. 